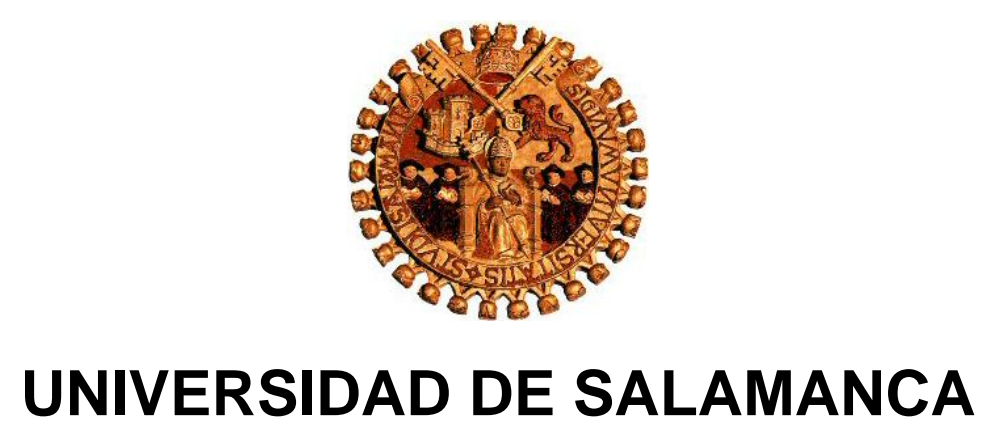

FACULTAD DE FILOLOGÍA

DEPARTAMENTO DE LENGUA ESPAÑOLA

\title{
LOS MARCADORES DEL DISCURSO Y LA FORMACIÓN DE PROFESORES DE ESPAÑOL EN EL NORDESTE BRASILEÑO
}

TESIS DOCTORAL

AUTORA: MARIA TRINIDAD PACHERREZ VELASCO

DIRECTOR: JUAN FELIPE GARCÍA SANTOS

Salamanca

2016 


\section{AGRADECIMIENTOS}

A mi familia.

A mis padres, Elías y Reneé, presentes siempre en mi vida.

A mi esposo, Luis, por su apoyo incondicional.

Por su presencia en mi ausencia.

Por su generosidad y paciencia.

A mis hijos, mi mayor fuente de inspiración.

Por tu confianza, Tony.

Por tu entrega, Lu.

Por tu infinita inocencia, Diego

A la familia leonesa/española.

Por darme un lugar en su seno.

Por su presencia y cariño. 
La fuerza del amor a la profesión, al conocimiento y a la vida me ha inducido a este camino de investigación que, aparentemente largo, me ha permitido dar dosis de entrega y presencia a las varias facetas de mi vida personal y profesional. Convencimiento, plena resistencia, perseverancia y mucha presencia divina han permitido salvar cada uno de los obstáculos encontrados en el trayecto, el verdadero sentido llega, justo por todo ello. Esta tesis ha sido posible gracias al apoyo y confianza que muchas personas han depositado en mí, por eso agradezco, además de a nuestro Padre Celestial:

A los hombres de mi vida: mi padre, mi esposo, mis tres hijos $\mathrm{y}$, por supuesto a mi madre. Ellos, con su amor infinito, ilusión y fuerza, me han inducido a crecer y buscar vencer, privándose en muchos momentos de mi presencia en sus vidas.

A mis directores, Don Juan Felipe García Santos y Don Julio Borrego Nieto, que durante estos años me han prodigado su atención, proximidad, honestidad y sabiduría. iQué orgullo! Gracias por haberme dado el privilegio de trabajar bajo su dirección y haberme guiado con sincero interés y profesionalismo, gracias por haberme prodigado su confianza y haberme dado libertad a la hora de realizar este trabajo, gracias por creer en mí, gracias por su inmensurable calidad humana y por supuesto, profesional.

A Doña Marina Maquieira, de la Universidad de León, por su incondicional apoyo aun cuando no se lo solicitara. Al personal docente e investigador de la Facultad de Filología de la Unileón por estar siempre a disposición. A la Administración de la Biblioteca Universitaria "San Isidoro" por adjudicarme un despacho de investigación en donde pasaba largas y largas horas, asimismo al personal de la biblioteca, que siempre atento me echó una mano incondicional cuando necesité ayuda e informaciones.

A Don Belchior de Oliveira Rocha y a Don José Yvan Pereira Leite, magnífico rector y vicerrector de investigación, respectivamente, del Instituto Federal de Rio Grande do Norte (IFRN), por el apoyo recibido sin el cual quizás no habría alcanzado esta meta. Gracias por haber merecido su confianza. 
A la comunidad académica del campus central del IFRN: colegas de área, colegas en general y colaboradores de mi ambiente laboral que directa y/o indirectamente hayan tenido, los mejores actos y deseos para que pueda llegar hasta aquí.

A todos mis alumnos y ex-alumnos, sin excepción alguna, que se constituyen el verdadero factor motivador de estos estudios, por quienes haría mucho más para garantizarles un aporte significativo en su formación docente.

A la familia Fernández González de León que me ha prodigado siempre su calor hogareño, en especial a Laura, Ana y Nuria. Mi tributo a Villapadierna, pueblo especial que me acogía cálidamente y con su paz, me daba paz, gracias Conchi y Teodorino, sois especiales.

A todos los amigos conquistados en España, en especial a los compañeros de estudios doctorales, a las Supernenas y Supernene, compis de piso 'presencial y a distancia' que me brindaron su incondicional apoyo y cariño; gracias a ellos todo ha sido acogida, con muchas alegrías, planes, también responsabilidades, gracias por el bienestar y tranquilidad ofrecido durante mi estancia en España.

A mi hermana brasileña, Veriña, persona que vive en mi corazón y forma parte de mi vida, de nuestra vida, desde siempre, representas el selecto grupo de personas al que no le importa cuán lejos estemos o cuánto tiempo pase, siempre seremos los mismos. Eso es maravilloso. 
Lo dicho, no es todo lo comunicado.

H. Paul Grice (1975) 
ÍNDICE GENERAL

LISTA DE SIGLAS, ABREVIATURAS Y SIGNOS EMPLEADOS ................. 12

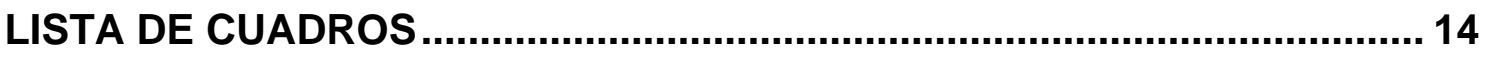

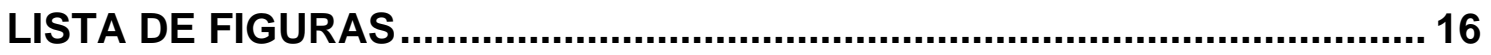

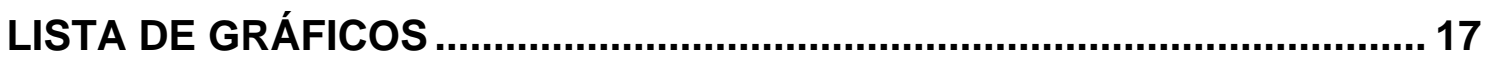

LISTA DE TABLAS

INTRODUCCIÓN

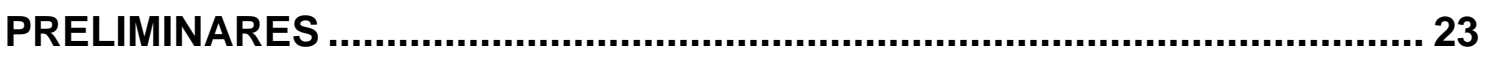

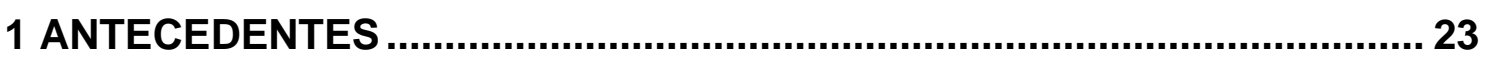

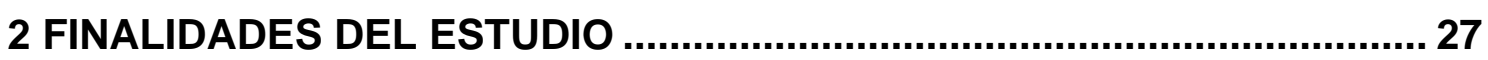

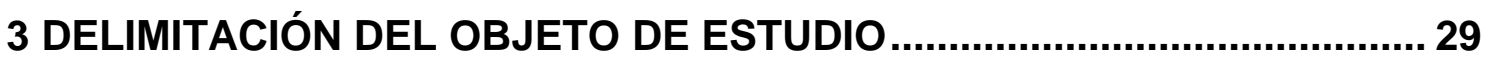

3.1 LA FORMACIÓN DEL PROFESORADO DE ESPAÑOL COMO LENGUA

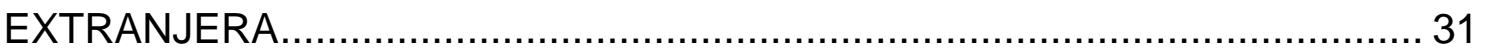

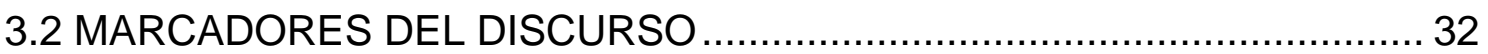

3.2.1 Conceptos clave y respaldo teórico ................................................... 33

3.3 ENSEÑANZA Y APRENDIZAJE DE LENGUAS EXTRANJERAS (ELE) ... 34

3.3.1 Conceptos clave y respaldo teórico ................................................ 35

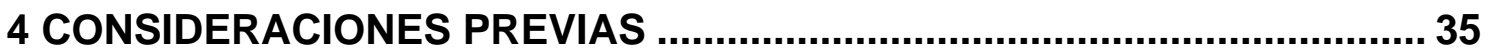

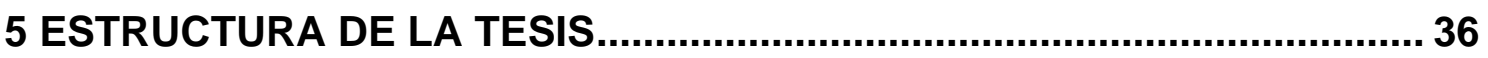

CAPÍTULO I - ESTADO DE LA CUESTIÓN................................................. 40

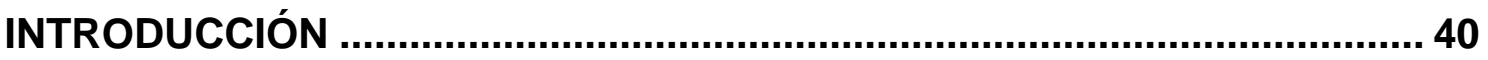

1 LA FORMACIÓN DEL PROFESORADO DE LENGUA EXTRANJERA (EN

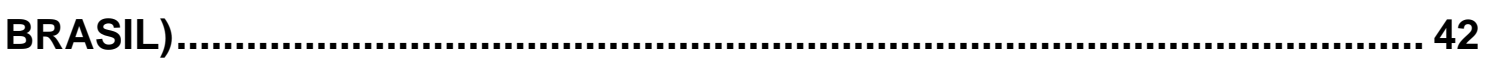

1.1 LA FORMACIÓN DEL PROFESORADO DE ESPAÑOL COMO LENGUA

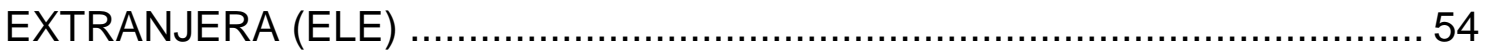

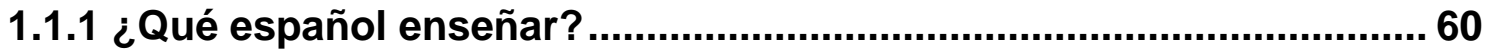

1.1.2 ¿Entrenar o formar un profesor de ele? ……..................................... 64

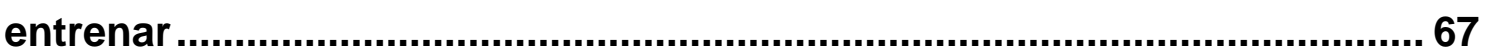

1.1.3 Programas de estímulo a la formación y labor del docente de ELE. 69 1.1.4 El marco común europeo de referencia para las lenguas (MCER) y la formación del profesorado de ELE............................................................ 73

1.2 EL PLAN DE ESTUDIOS DE GRADO EN ELE.................................. 74 
1.2.1 Caracterización general del plan de estudios de grado en ELE de las IES de RN.

1.2.2 Las asignaturas obligatorias en el plan de estudios de grado en ELE

1.2.3 Las asignaturas específicas de formación del plan de estudios de grado en ELE ........................................................................................ 82

1.3 LOS PROFESORES DE FUTUROS PROFESORES DE ELE .................. 97

1.3.1 La calidad y los mitos en la enseñanza de grado en ELE.................. 99

1.4 LOS PROFESORES DE ELE EN LA EDUCACIÓN BÁSICA Y PÚBLICA101

1.5 SOBRE ENSEÑANZA SUPERIOR .............................................. 103

1.5.1 Terminología lingüística de grado .............................................. 104

1.5.2 Equivalencia de estudios Brasil - España..................................... 108

2 LOS MARCADORES DEL DISCURSO (MD) EN LA FORMACIÓN DEL PROFESORADO DE LENGUA EXTRANJERA .......................................... 109

2.1 LOS MARCADORES DEL DISCURSO EN EL PLAN DE ESTUDIOS DEL

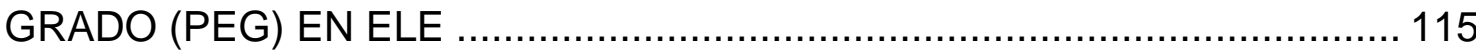

2.2 LAS ASIGNATURAS DE LENGUA ESPAÑOLA Y LOS MARCADORES

DEL DISCURSO (MD)

2.3 LOS MARCADORES DEL DISCURSO EN LA ORALIDAD DEL

PROFESORADO DE GRADO EN ELE. 124

2.4 LOS MARCADORES DEL DISCURSO Y EL ESTUDIANTE DE GRADO DE ELE

3 ENSEÑANZA DE LENGUA EXTRANJERA EN BRASIL 130

3.1 RETROSPECTIVA SOBRE LA ENSEÑANZA DE LENGUA EXTRANJERA EN BRASIL 130

3.2 LAS LENGUAS EXTRANJERAS EN EL CONTEXTO NACIONAL 133 3.3 LA ENSEÑANZA BÁSICA Y OBLIGATORIA EN BRASIL EN CONTRASTE CON OTRAS NACIONES 138 CONCLUSIONES 142

CAPÍTULO II - (MARCADORES DEL) DISCURSO, COMUNICACIÓN, ENSEÑANZA Y APRENDIZAJE: CUESTIONES TEÓRICAS....................... 144 INTRODUCCIÓN ...................................................................................... 144

1 LOS MARCADORES DEL DISCURSO (MD): BASES TEÓRICAS ........... 145 


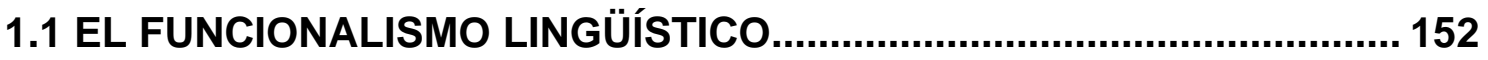

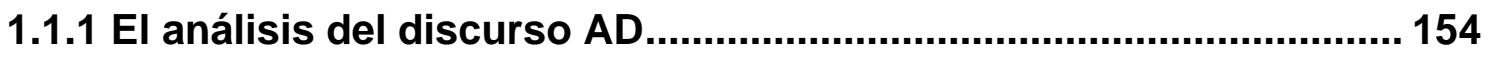

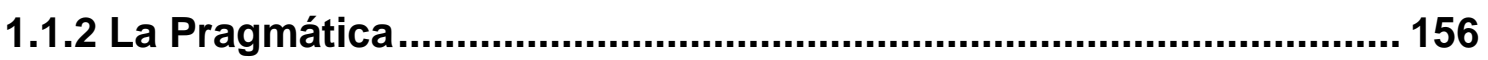

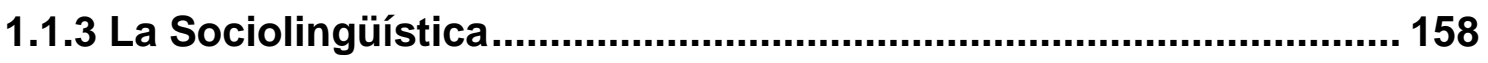

1.1.4 La lingüística aplicada a la enseñanza de ELE................................. 159

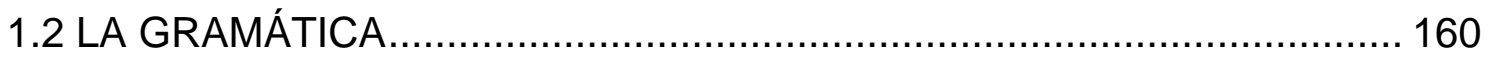

1.2.1 La Gramática: tradicional / prescriptiva/normativa, descriptiva y

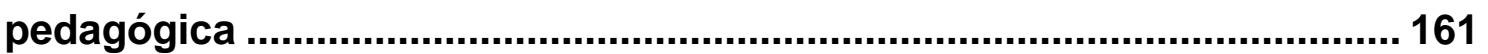

1.2.2 La gramática en la lengua materna (Portugués de Brasil)............... 165

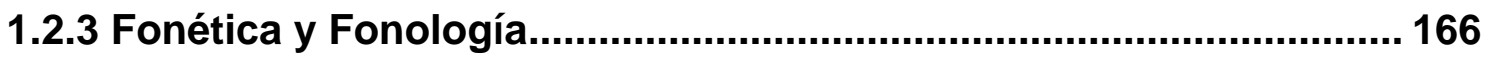

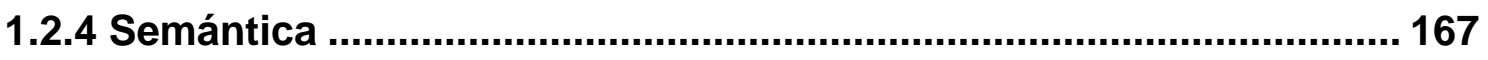

1.3 FORMALISMO Y FUNCIONALISMO: PUGNA, INTERSECCIÓN O SUMA .. 168

1.3.1 Una pica a favor del formalismo lingüístico .................................... 170 2 LAS TEORÍAS DEL APRENDIZAJE Y ENSEÑANZA DE UNA LENGUA

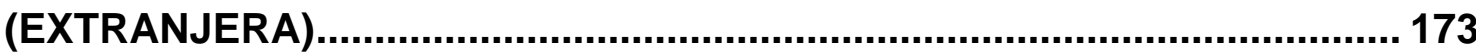

2.1 SOBRE LENGUAJE, LENGUAS Y COMUNICACIÓN ............................ 174

2.2 ¿ADQUISICIÓN O APRENDIZAJE DE UNA LENGUA? ......................... 177

2.3 METODOLOGÍAS DE ENSEÑANZA Y APRENDIZAJE DE ESPAÑOL

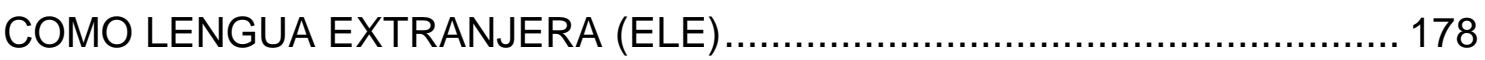

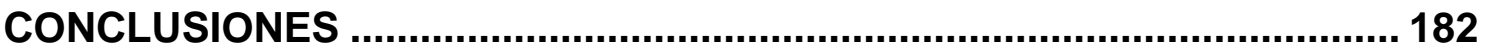

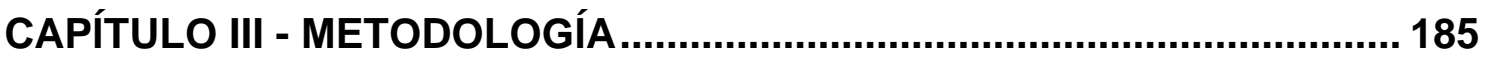

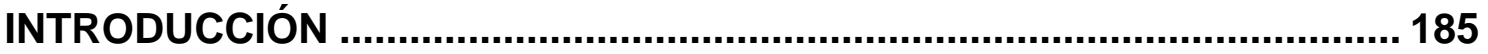

1 UN ESTUDIO DE CORPUS: OBJETOS DE ESTUDIO PARA UNA

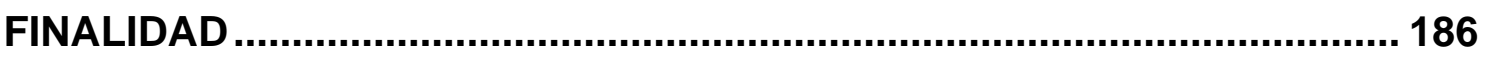

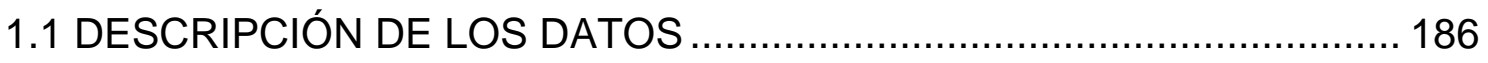

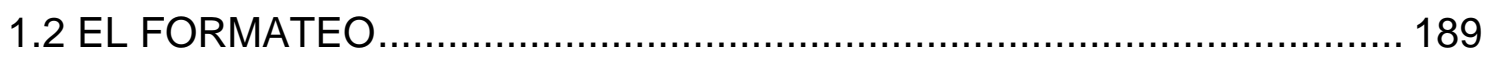

1.3 DESCRIPCIÓN DE LOS PARÁMETROS DE ANÁLISIS, PREGUNTAS DE INVESTIGACIÓN Y ANÁLISIS EMPÍRICO ............................................... 190

2 ENSEÑANZA Y APRENDIZAJE DE LENGUA EXTRANJERA (LE) EN LA

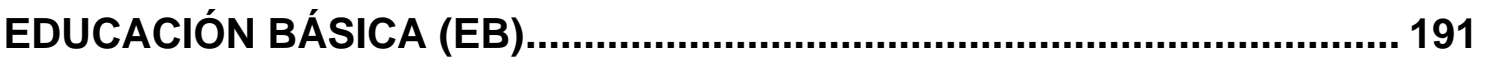

2.1 ENCUESTA 1- PREGUNTAS 1, 2, 3, 5 Y 6: OPINIÓN DEL CIUDADANO COMÚN Y DEL QUE ESTUDIA UNA LE. CONTRASTE. ............................. 192 
2.1.1 Descripción de los datos, instrumento de investigación y formateo 193

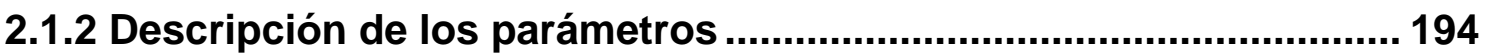

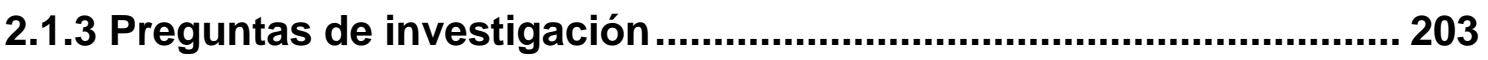

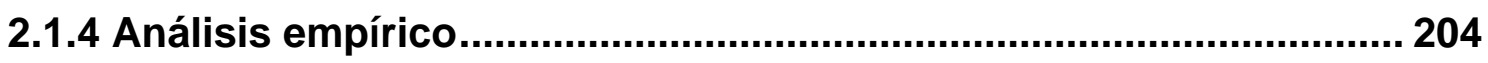

3 LOS MARCADORES DEL DISCURSO EN (LOS ESTUDIOS DE) ELE .... 207

3.1 LOS MD EN LA PRODUCCIÓN ESCRITA EN ELE EN LA EDUCACIÓN BÁSICA 207

3.1.1 Descripción de los datos, instrumento de investigación y formateo 208

3.1.2 Descripción de los parámetros de análisis...................................... 208

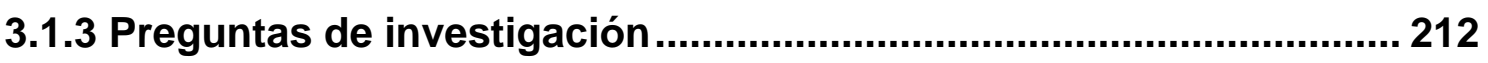

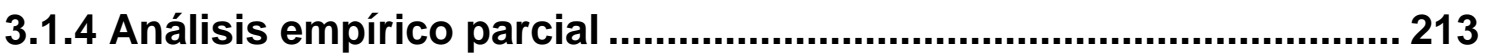

3.2 LOS MD Y LOS ESTUDIANTES DE GRADO EN ELE ………............... 213

3.2.1 Encuesta a estudiantes de grado en ELE ........................................ 214

3.2.1.1 Descripción de los datos, instrumento de investigación y formateo ... 215

3.2.1.2 Descripción de los parámetros de análisis ...................................... 216

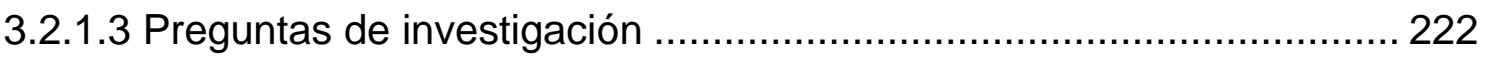

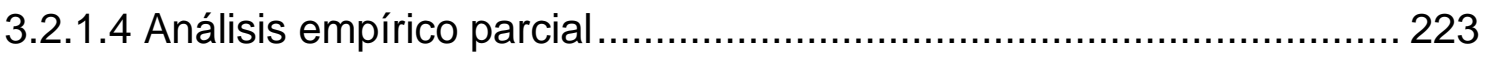

3.2.2 Los MD en la producción escrita de los estudiantes de grado en ELE 224

3.2.2.1 Descripción de los datos, instrumento de investigación y formateo ... 224

3.2.2.2 Descripción de los parámetros de análisis ....................................... 225

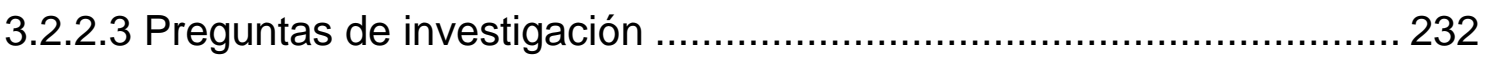

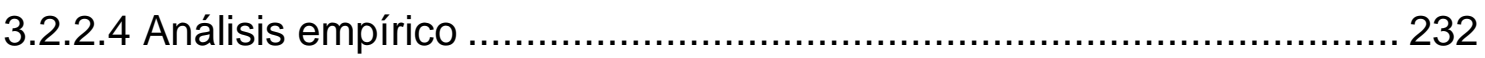

3.3 LOS MD Y EL DOCENTE DE GRADO EN ELE (PRODUCCIÓN ORAL Y

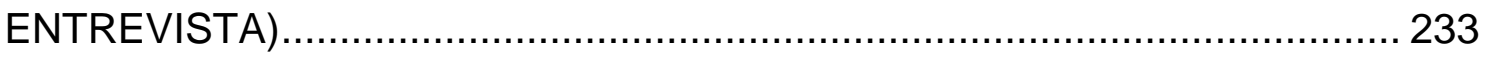

3.3.1 Producción oral de los docentes de grado en ELE.......................... 234

3.3.1.1 Descripción de los datos, instrumento de investigación y formateo ... 234

3.3.1.2 Descripción de los parámetros de análisis ....................................... 235

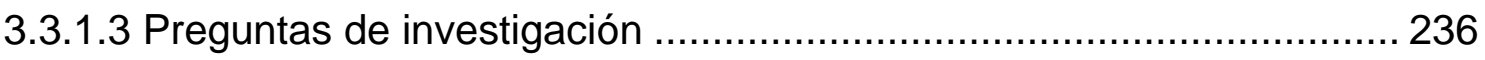

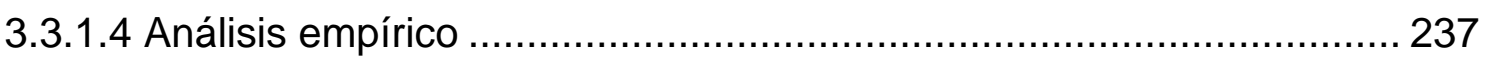

3.3.2 Entrevista a docentes de grado en ELE ........................................ 237 
3.3.2.1 Descripción de los datos, instrumento de investigación y formateo ... 238

3.3.2.2 Descripción de los parámetros de análisis .................................... 240

3.3.2.3 Preguntas de investigación e hipótesis ..................................... 242

3.3.2.4 Análisis empírico .......................................................... 243

4 LA FORMACIÓN DEL PROFESORADO DE ELE ................................... 243

4.1 EL PERFIL DE LOS DOCENTES DE GRADO ................................ 245

4.1.1 Descripción de los datos, instrumento de investigación y formateo

4.1.2 Descripción de los parámetros de análisis..................................... 247

4.1.3 Preguntas de investigación......................................................... 251

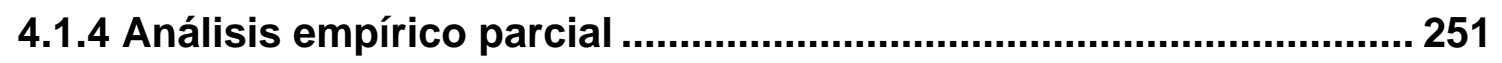

4.2 EL POSICIONAMIENTO DE LOS DOCENTES DE GRADO RESPECTO AL FORMALISMO Y FUNCIONALISMO EN LA ENSEÑANZA DE GRADO ....... 251

4.2.1 La recogida de datos, instrumento de investigación y formateo.... 252

4.2.2 Descripción de los parámetros de análisis................................... 253

4.2.3 Preguntas de investigación e hipótesis ....................................... 254

4.2.4 Análisis empírico........................................................................... 254

4.3 EL PLAN DE ESTUDIO DE GRADO (PEG) EN ELE, LOS PROGRAMAS

DE ASIGNATURAS ESPECÍFICAS Y EL CONTENIDO PROGRAMÁTICO MD. 255

4.3.1 El plan de estudio de las IES y las asignaturas funcionalistas:

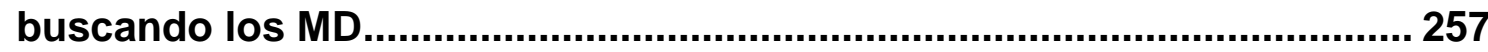

4.3.1.1 Descripción de los datos, instrumentos de investigación y formateo . 257

4.3.1.2 Descripción de los parámetros de análisis .................................. 260

4.3.1.3 Preguntas de investigación e hipótesis ........................................ 264

4.3.1.4 Análisis empírico ............................................................. 264

4.3.2 La distribución de asignaturas según el PEG de las IES, una

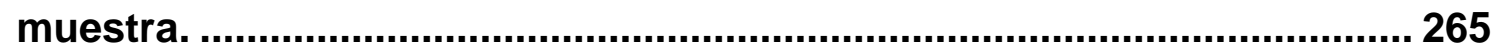

4.3.2.1 Descripción de los datos, instrumento de investigación y formateo ... 265

4.3.2.2 Parámetros de análisis .............................................................. 266

4.3.2.3 Preguntas de investigación ................................................ 268

4.3.2.4 Análisis empírico ........................................................... 269

4.3.3 El Trabajo de fin de curso en el Plan de estudio de grado en ELE. 271 
4.3.3.1 Descripción de los datos, instrumento de investigación y formateo ... 271

4.3.3.2 Parámetros de análisis ..................................................... 272

4.3.3.3 Preguntas de investigación e hipótesis .................................... 273

4.3.3.4 Análisis empírico ................................................................ 273

4.4 EL ABANDONO DE LA CARRERA DE ELE .................................. 274

4.4.1 Descripción de los datos, instrumento de investigación y formateo 275

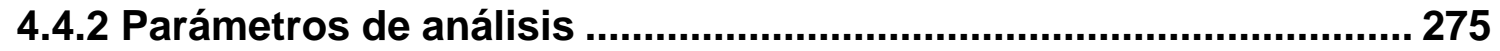

4.4.3 Preguntas de investigación ......................................................... 281

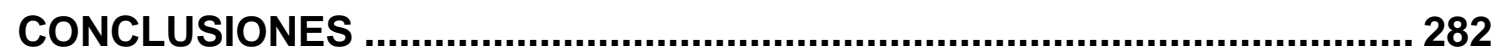

CONCLUSIONES GENERALES ................................................................ 288

CONCLUSIONES GENERALES ...................................................... 289

BIBLIOGRAFÍA ................................................................................... 295

APÉNDICES ..................................................................................... 306

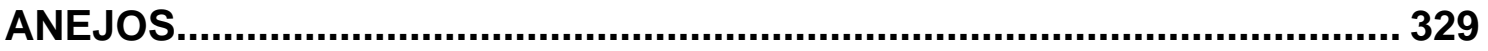




\section{LISTA DE SIGLAS, ABREVIATURAS Y SIGNOS EMPLEADOS}

AD Análisis del discurso

CAB Convenio Andrés Bello

CAPES: $\quad$ Coordenação de Aperfeiçoamento de Pessoal de Nível Superior

CNPq Conselho Nacional de Desenvolvimento Científico e Tecnológico

CONAES Comissão Nacional de Avaliação da Educação

DCOE Diccionario de conectores y operadores del español

DPDE Diccionario de partículas discursivas del español

EAdeLE Enseñanza y aprendizaje de lengua extranjera

ECTS European Credit Transfer System (Sistema de Créditos Europeo)

ED Educación Básica

EEES Espacio Europeo de Educación Superior

ELE Español como lengua extranjera

G1, G2 Grupo 1, Grupo 2

GDLE Gramática descriptiva de la lengua española

IES Institución de enseñanza superior

INEP Instituto Nacional de Estudos e Pesquisas Educacionais

INF Informante

L1 Lengua primera / Primera lengua

L2 Lengua segunda / Segunda lengua

LDB Lei de Diretrizes e Bases da Educação Nacional

LE Lengua extranjera

LM Lengua materna

LRU Ley de reforma universitaria

LT Lingüística del texto

MCER Marco común europeo de referencia

MD Marcador del discurso

MEC-Brasil Ministério da Educação e do Desporto do Brasil

NGLE Nueva gramática de la lengua española

PDI Planos de Desenvolvimento Institucional

PEG Plan de estudios de grado

PNE Plano Nacional de Educação

PNLD Programa Nacional do Livro Didático 
RAE Real Academia Española

SESU Secretaria de Ensino Superior do Ministério da Educação

SINAES Sistema Nacional de Avaliação Institucional da Educação Superior 


\section{LISTA DE CUADROS}

Cuadro 1 - Enseñanza de lengua extranjera en la educación básica...............44 44

Cuadro 2 - Contraste del significado entre formar y entrenar......................67 67

Cuadro 3 - Caracterización de la oferta de grado en ELE en RN....................78

Cuadro 4 - Identificación de las asignaturas de ELE ................................ 83

Cuadro 5 - Contraste de oferta de asignaturas del $1^{\circ}$ semestre ....................83

Cuadro 6 - Contraste de oferta de asignaturas del $2^{\circ}$ semestre.................... 85

Cuadro 7 - Contraste de oferta de asignaturas del $3^{\circ}$ semestre ................... 87

Cuadro 8 - Contraste de oferta de asignaturas del $4^{\circ}$ semestre.................... 88

Cuadro 9 - Contraste de oferta de asignaturas del $5^{\circ}$ semestre.................... 89

Cuadro 10 - Contraste de oferta de asignaturas del $6^{\circ}$ semestre................... 91

Cuadro 11 - Contraste de oferta de asignaturas del $7^{\circ}$ semestre.................. 93

Cuadro 12 - Contraste de oferta de asignaturas del $8^{\circ}$ semestre.................... 94

Cuadro 13 - Contraste de oferta de asignaturas del $9^{\circ}$ semestre................... 96

Cuadro 14 - Terminología de grado español - portugués ............................. 105

Cuadro 15 - Equivalencia de estudios Brasil - España................................ 109

Cuadro 16 - Oferta de asignaturas de perspectiva funcional en PEG de IES

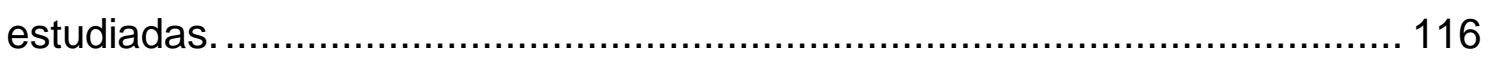

Cuadro 17 - La asignatura Lengua española y los Marcadores - IES-1 ....... 119

Cuadro 18 - La asignatura Lengua española y los Marcadores - IES-2 ........ 120

Cuadro 19 - La asignatura Lengua española y los Marcadores - IES-3 ......... 123

Cuadro 20 - Leyenda elementos aplicados en transcripción ortográfica ........ 125

Cuadro 21 - Clasificación de los marcadores del discurso ......................... 148

Cuadro 22 - Sobre la variedad disciplinar y el estudio de los MD ................. 149

Cuadro 23 - Detalle de los grupos de informantes ................................. 189

Cuadro 24 - Detalle de los informantes ........................................... 190

Cuadro 25 - Detalle de los textos analizados ...................................... 190

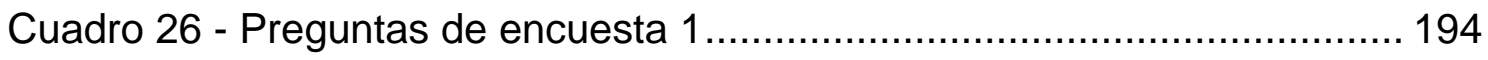

Cuadro 27 - Textos seleccionados de estudiantes EB (1) ......................... 209

Cuadro 28 - Textos seleccionados de estudiantes EB (2) ........................ 211

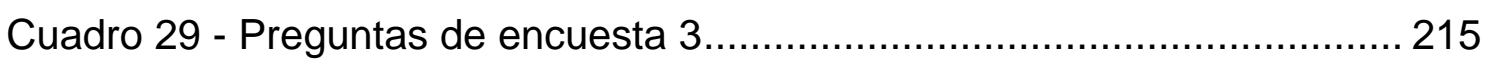

Cuadro 30 - Respuestas pregunta 6 de encuesta 3 sobre MD .................... 219 
Cuadro 31 - Respuestas pregunta 9 de encuesta 3 sobre MD

Cuadro 32 - Preguntas y respuestas entrevista a docentes de grado en ELE238 Cuadro 33 - Titulación del profesorado de grado en IES- Asignaturas de ELE.

Cuadro 34 - Tiempo de servicio de los docentes de RN

Cuadro 35 - Situación laboral del profesorado, nativo /no nativo en IES con actuación en asignaturas de ELE.

Cuadro 36 - Docentes de grado respecto al formalismo y funcionalismo 252

Cuadro 37 - Modificaciones al Plan de estudios de grado - IES estudiadas .. 258

Cuadro 38 - Oferta de asignaturas de perspectiva funcional en PEG de IES estudiadas

Cuadro 39 - Asignaturas obligatorias funcionalistas de las IES 259

Cuadro 40 - El trabajo de fin de curso en el grado en ELE 


\section{LISTA DE FIGURAS}

Figura 1 - Ciclo del objeto de investigación. ............................................... 21

Figura 2 - Formación de calidad para la sociedad.................................... 26

Figura 3 - Elementos fundamentales en la formación de profesores. .............. 45

Figura 4 - Principio, medio y fin del aprendizaje de LE .............................6 62

Figura 5 - Flujo de preguntas sobre aprendizaje y enseñanza de ELE ............64

Figura 6 - Página 132 del Plan de estudios de la IES-2. ..............................6 66

Figura 7 - Página 10-11 del Plan de estudios de la IES-3........................... 67

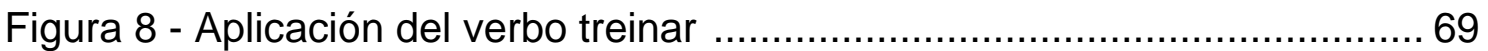

Figura 9 - Programa de la asignatura Análisis del discurso IES-2 ................ 117

Figura 10 - Video-clase sobre marcadores del discurso .......................... 124

Figura 11 - Transcripción de audio INF-PROF-2 .................................... 125

Figura 12 - Texto original iNF-EST-2 ................. Erro! Indicador não definido.

Figura 13 - Transcripción de audio INF-EST-2 ...................................... 128

Figura 14 - Teorías del funcionalismo .................................................. 152

Figura 15 - Formalismo vs funcionalismo ............................................. 168

Figura 16 - El ciclo del aprendizaje de lengua extranjera ......................... 244 


\section{LISTA DE GRÁFICOS}

Gráfico 1 - Para un plan de estudios de grado....................................... 75

Gráfico 2 - Distribución de asignaturas de Plan de estudios de IES ................80 80

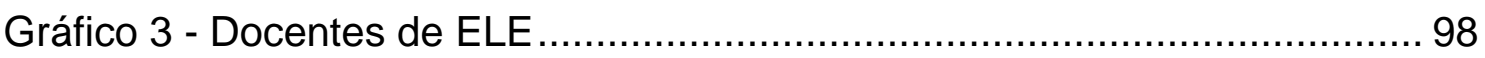

Gráfico 4 - Fuente: Datos de encuesta PIBID (2013) .............................. 102

Gráfico 5 - Lenguaje, funcionalismo y formalismo................................. 169

Gráfico 6 - Respuestas a la pregunta 1 de la encuesta 1 ............................ 195

Gráfico 7 - Respuestas a la pregunta 2 de la encuesta 1 ............................ 196

Gráfico 8 - Respuestas a la pregunta 3 de la encuesta 1 .......................... 197

Gráfico 9 - Respuestas a la pregunta 5 de la encuesta 1 ........................ 198

Gráfico 10 - Respuestas a la pregunta 6 de la encuesta 1 ........................ 202

Gráfico 11 - Respuestas a 1, 2 y 3, alternativa a) .................................... 205

Gráfico 12 - Contraste de respuesta $1^{\text {a }}$ entre el G1 y el G2 ........................ 206

Gráfico 13 - Respuestas pregunta 3 de encuesta 3 sobre MD..................... 217

Gráfico 14 - Respuestas pregunta 4 de encuesta 3 sobre MD .................... 218

Gráfico 15 - Respuestas pregunta 7 de encuesta 3 sobre MD.................... 220

Gráfico 16 - Respuestas pregunta 8 de encuesta 3 sobre MD .................... 220

Gráfico 17 - Formalistas y funcionalistas.......................................... 255

Gráfico 18 - Asignaturas específicas IES-1 ....................................... 266

Gráfico 19 - Asignaturas específicas IES-2 ............................................... 267

Gráfico 20 - Asignaturas específicas IES-3 ........................................... 267

Gráfico 21 - Asignaturas específicas IES-3. Actual ..................................... 268

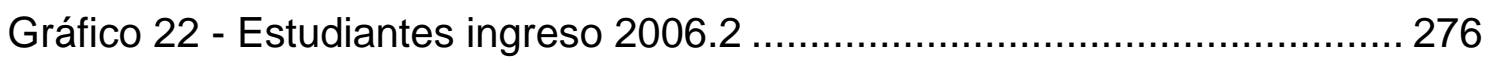

Gráfico 23 - Estudiantes ingreso 2007.2 ........................................ 277

Gráfico 24 - Estudiantes ingreso 2008.2 ........................................ 277

Gráfico 25 - Estudiantes ingreso 2009.2 ......................................... 278

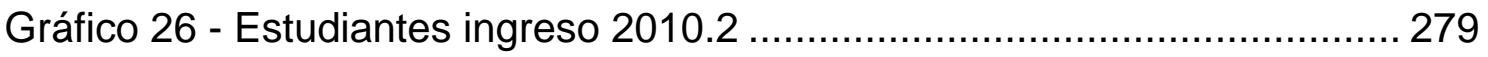

Gráfico 27 - Estudiantes ingreso 2011.2 ............................................ 279

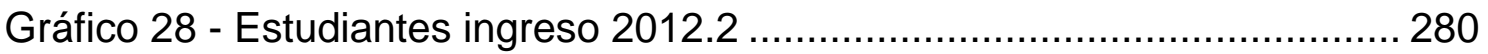

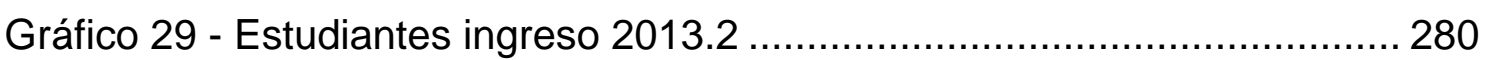

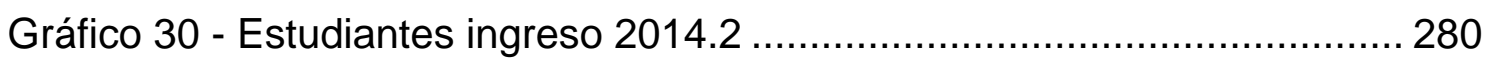




\section{LISTA DE TABLAS}

Tabla 1 - Brasil en el contexto del IDH mundial........................................ 42

Tabla 2 - Equivalencias de estudios primarios y secundarios ..................... 140 
El lenguaje es, antes que nada, oral.

Tusón, J. (1995)

\section{INTRODUCCIÓN}

Se nota que una de las características más presentes y crecientes en la actuación de un profesor de lengua extranjera es justamente la innovación al ejercer su práctica docente, apostando en nuevas metodologías, renovándolas creativamente a través de diferentes actividades, buscando transmitir el conocimiento lingüístico de forma natural, huyendo de la memorización léxica, de la esclavitud gramatical y de la monotonía en la clase de lengua extranjera. Todo esto suena muy bien, no obstante, es de absoluta relevancia la valoración del conocimiento y dominio lingüístico que estos profesores tengan de la lengua que enseñan para que su trabajo docente sea consciente y eficiente, no solo creativo.

Para que toda la fuerza innovadora y creativa de un profesor de lengua extranjera ${ }^{1}$ surta el debido efecto en el aula, en este caso, específicamente de español como lengua extranjera ${ }^{2}$, es indispensable que este contenga habilidades y competencias discursivas y específicas, lingüísticas y extralingüísticas, competencias que vayan mucho más allá del conocimiento formal de la lengua: nos referimos al conocimiento y dominio del discurso (oral y escrito), aquel que encadena el pensamiento y da cuenta de las intenciones y actitudes de los hablantes. El profesor de lengua (extranjera) debe ser capaz de establecer conexión a través de elementos como los marcadores del discurso ${ }^{3}$ que al ser recodificadores de múltiples funciones dialogales, crean, recrean y transforman la conversación y por ende el discurso, sea este oral o escrito (BOYERO,2002).

\footnotetext{
${ }^{1}$ LE de ahora en adelante.

2 ELE de ahora en adelante.

${ }^{3} \mathrm{MD}$ de ahora en adelante.
} 
Al entender que un profesor en general, y el de lengua extranjera también, debe saber establecer y expresar las relaciones existentes no solo entre oraciones, sino entre enunciados y otros aspectos del contexto de la enunciación ligados al discurso, esta investigación surge para indagar sobre la existencia y aplicación de los MD, partículas de invalorable importancia en el acervo lingüístico discursivo y en la práctica docente del profesor de ELE.

Sabemos que el conocimiento amplio o el poco dominio de estas partículas discursivas en el uso vivo y espontáneo de la lengua que se enseña puede representar un perfil docente de LE, que influirá en el resultado del aprendizaje de ELE en la escuela básica y pública en el nordeste brasileño, región que implementó más tardíamente la oferta obligatoria prevista en ley ${ }^{4}$.

Este estudio surge eminentemente de nuestra preocupación por la calidad del aprendizaje de ELE tanto para los estudiantes de grado a lo largo de su formación y desempeño en el trabajo docente que realizará, como para la sociedad que recibe su educación primaria y secundaria en instituciones públicas, para quienes aprender una segunda lengua puede significar mejores oportunidades laborales y estímulo a la formación continuada de sus saberes.

En Brasil, un ciudadano común tiene derecho a educación pública y además obligatoria hasta concluir la enseñanza secundaria ${ }^{5}$, y una de las asignaturas del plan de estudios nacional, en la actualidad, es 'lengua extranjera', bien inglés, bien español. Regularmente, es a lo largo de un promedio de 7 años que los estudiantes cursan una lengua extranjera en la educación básica (estudios primarios y secundarios) y, a priori, este largo periodo hace suponer que se logrará un nivel razonable de ELE para efectos de comunicación como está establecido en los parámetros curriculares nacionales $^{6}$ del Ministerio brasileño de Educación. Gran ilusión, pues aparentemente, no se viene consiguiendo mucho al tratarse de la lengua inglesa y ya va habiendo muestras de que el futuro para la lengua española no

4 Trataremos más ampliamente de este punto en el siguiente capítulo.

5 Para una mejor comprensión, en el capítulo uno presentamos un cuadro de equivalencia de educación básica.

${ }^{6}$ PCN de ahora en adelante 
será tan diferente, al menos en esta región del país. Es justo eso lo que se persigue como objetivo principal en este trabajo.

Indagamos en esta tesis: (1) el nivel de conocimiento y aplicación de los marcadores del discurso en la práctica oral y escrita del profesor de grado en cursos de Licenciatura/Letras ELE de la región nordeste del país, con atención especial en el estado de Rio Grande do Norte; (2) el posicionamiento de los docentes formadores del profesorado de ELE sobre el conocimiento y dominio de lengua española que los estudiantes de grado deben cultivar y alcanzar antes de iniciar su actividad docente; (3) las razones que influyen en la calidad de los resultados de la enseñanza de ELE a ciudadanos brasileños a lo largo de su educación básica y pública.

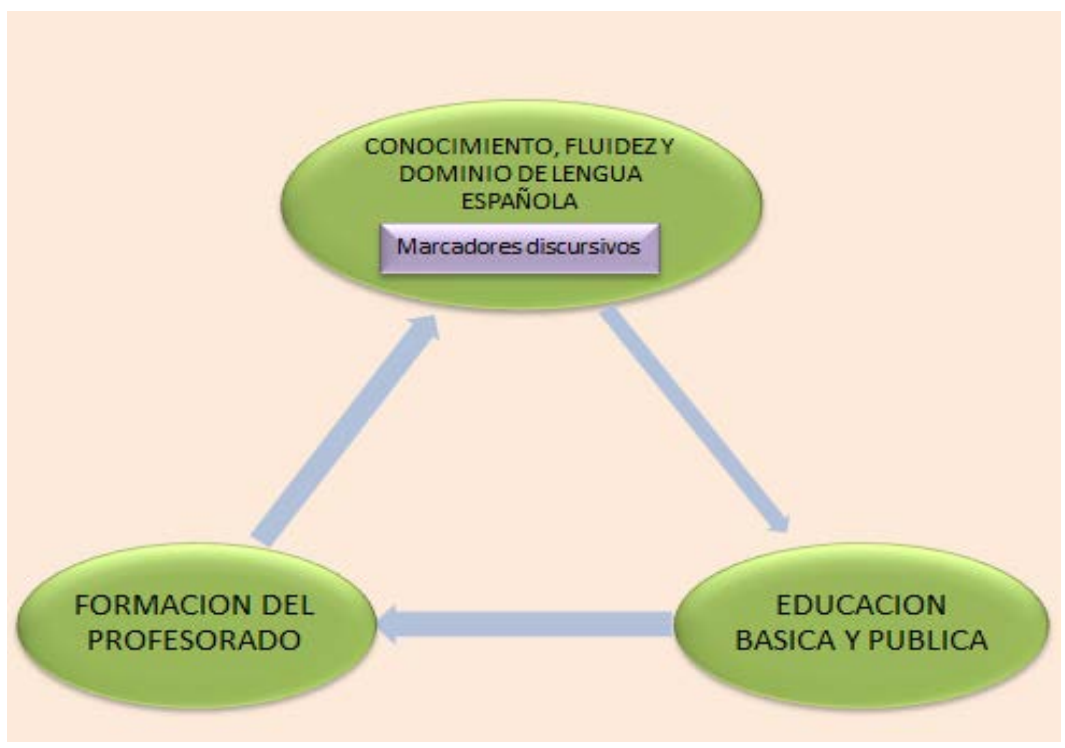

Figura 1 Ciclo del objeto de investigación. (Del Autor)

Este trabajo está estructurado en 2 partes principales: (1) Estado de la cuestión - relatamos en grandes y puntuales rasgos la situación actual con relación a los temas de enseñanza y aprendizaje de ELE en la educación básica brasileña, la formación del profesorado y la incidencia de los MD en ambos procesos, así como también tejemos comentarios que forman parte del marco teórico en el que se abordan las principales teorías del aprendizaje y su influencia en el desarrollo del proceso de enseñanza y aprendizaje de una lengua extranjera, así como el respaldo teórico de los MD, sin detenernos profundamente, intentando una exposición clara, simple y sobre todo objetiva, 
para que este trabajo pueda ser leído por los distintos públicos que puedan involucrarse directa o indirectamente con esta investigación. (2) Estudio empírico - presentamos documentos, fruto de métodos de investigación que reportan datos importantes sobre los temas que investigamos. Se echa mano de investigación bibliográfica de cuño estadístico para la recogida de datos, se aplican encuestas y entrevistas a sujetos directamente involucrados, y también se presentan recortes de documentos redactados en los que se localiza el dato investigado. En el análisis empírico presentamos cualitativamente los resultados obtenidos filtrando las informaciones que se juzguen pertinentes al objetivo de esta tesis. Y finalmente presentamos en las conclusiones los aspectos polémicos, los susceptibles de solución desde nuestro humilde punto de vista y las inquietudes de este investigador que pueden convertirse en tema de nuevas investigaciones. 


\section{PRELIMINARES}

En este capítulo de introducción se presentan los principales antecedentes sobre la incidencia que los marcadores del discurso pueden tener o no en la formación de profesores de español como lengua extranjera en Brasil, que a su vez repercute en la calidad del proceso de enseñanza y aprendizaje de esta lengua en la educación primaria y secundaria pública en Brasil (\&1), se expone la finalidad que se persigue en este estudio (\&2), se trazan los principales marcos teóricos (\&3) y se formula la delimitación del objeto de estudio (\&4). Se ha considerado pertinente exponer también las posibles limitaciones que esta, como toda investigación, suele tener (\&5) y por fin, se presenta la estructura detallada de este trabajo (\&6).

\section{ANTECEDENTES}

Construir un discurso articulado que permita fluidez en la comunicación es uno de los objetivos más importantes al aprender una lengua extranjera y al tratarse de lengua española para los brasileños, luso-hablantes, también es un objetivo razonablemente alcanzable. Sin duda, son varios los aspectos que pasan a tallar para lograr un nivel de comunicación aceptable, son aspectos de orden léxico, fonético, semántico, morfológico, sintáctico y aproximaciones culturales los que directa y/o indirectamente intervienen. No obstante, esos conocimientos no son suficientes, a pesar de ser imprescindibles.

La gramática tradicional ${ }^{7}$ es necesaria, pero no suficiente a la hora de la comunicación; la gramática describe, identifica, estandariza de acuerdo con un patrón de lengua, contribuye a la producción de oraciones, pero oraciones 'sueltas'. Este paradigma formal del lenguaje no se contrapone claramente a la articulación del discurso, sea este hablado o escrito, más bien se alía. Esta importancia no se discute, el conocimiento de la gramática tradicional en la formación de un profesor de LE es, a este humilde parecer, esencial, pero

\footnotetext{
${ }^{7}$ La prescriptiva o normativa, la que normaliza el uso de la lengua en situaciones formales.
} 
desde luego, no basta. Para articular el discurso, encadenar el raciocinio e interaccionar de forma adecuada y lógica, se unen los aspectos formales y los aspectos funcionales del lenguaje; si uno de los dos falla, la comunicación en lengua extranjera, se realiza defectuosa en su cabal comprensión.

La asignatura de ELE en el plan nacional de estudios en Brasil para la educación primaria y secundaria ${ }^{8}$, incluso desde antes de la promulgación de la ley que la ha convertido en oferta obligatoria ${ }^{9}$, viene generando una serie de transformaciones y evoluciones de carácter conceptual, metodológico, estratégico y de contenido que incide preponderantemente tanto en la formación del profesorado, como en el resultado de su actuación en el proceso de enseñanza y aprendizaje de ELE en la educación básica, sin dejar fuera de la criba analítica el trabajo y perfil profesional de los profesores de enseñanza superior.

Aparentemente, al indagar sobre el resultado del estudio de lengua extranjera en la educación básica, se origina una opinión generalizada respecto a que el aprovechamiento de este estudio no ha sido fructífero ni de gran aporte en la formación integral de un ciudadano, señalando diversas causas para justificar este resultado, independientemente de la lengua que se trate, principalmente de las lenguas inglesa y española, las 'oficiales' en el plan de estudios de la educación básica nacional.

Con la inclusión obligatoria del español en el plan nacional de estudios, en un país como Brasil, surge la preocupación del futuro y destino de este 'nuevo' conocimiento lingüístico, necesario en una realidad globalizada, que con tantas tecnologías permite un intercambio oral y escrito, en tiempo real, el mismo que se ve truncado por los alcances casi nulos de comunicación en lengua extranjera que la educación básica proporciona al ciudadano y que además ya cuenta con antecedentes históricos del comprometedor resultado del aprendizaje de la lengua inglesa.

\footnotetext{
${ }^{8}$ Para efectos de este trabajo, recibirá la denominación de educación básica.

${ }^{9}$ Se trata de la Ley 11.161 del 05 de agosto de 2005 que se refiere a la obligatoriedad de oferta de lengua española como lengua extranjera en la enseñanza, inicialmente secundaria en Brasil.
} 
Aprender satisfactoriamente una lengua extranjera a lo largo de la educación secundaria y parcialmente en la educación primaria, en Brasil, es una realidad que no se cristaliza como debería ser, o sea, no se logra un conocimiento suficiente con el que se sea capaz de establecer una comunicación en lengua extranjera, al menos, en un nivel B1 del Marco común europeo de referencia ${ }^{10}$; lejos de esta expectativa, más bien se cataloga como una asignatura 'faz de conta'11 porque es obligatoria y no alcanza sus objetivos, que según los Parâmetros Curriculares Nacionais del Ministerio de Educación de Brasil $^{12}$ (PCNs, 1998), para la enseñanza básica, deberían permitir vivencias y experiencias de comunicación humana a través del uso de una lengua extranjera, de modo que pueda expresarse o comunicarse y ver el mundo, reconociendo los bienes culturales de la humanidad construidos en otras partes, construir una conciencia lingüística y crítica de la lengua que aprende. Además de "utilizar la lengua extranjera como medio de acceso al mundo del trabajo y de los estudios avanzados, utilizando otras habilidades comunicativas que le permitan actuar en diversas situaciones".

En la actualidad, a un estudiante de educación secundaria pública de último año de estudios no le supone un dominio ni siquiera instrumental de una lengua extranjera, conoce muy poco, no consigue comunicarse y la mayoría se plantea la necesidad de ir a una escuela de idiomas para empezar todo 'de nuevo', cuando durante 7 años, de media, ha tenido la asignatura de LE entre las obligatorias de su plan de estudios. Lo más común es que estos estudiantes conozcan cierto vocabulario limitado y algunos pocos verbos, pero construir ideas completas, con cohesión y coherentes resulta una seria dificultad.

El estudiante de grado en ELE, futuro docente, que pueda acceder a una formación superior en la que no solo aprenda a ser profesor (saberes pedagógicos) sino que también adquiera el conocimiento de su formación

\footnotetext{
${ }^{10}$ MCER de ahora en adelante.

11 'faz de conta', en lengua portuguesa y en ese contexto, es como decir, en español, que algo se hace por cumplir, pero de hecho no para aprender.

12 Se trata de un documento nacional emitido y consolidado por el Ministerio de Educación y Cultura de Brasil, cuya redacción ha sido encargada a un equipo de reconocidos educadores. El carácter de este documento es referencial, busca dar orientación, auxilio y recomendaciones en el quehacer educativo nacional.
} 
específica, lengua española, se verá identificado, satisfecho y, sin duda, estimulado a realizar un trabajo cada vez mejor en el cotidiano de la educación básica.

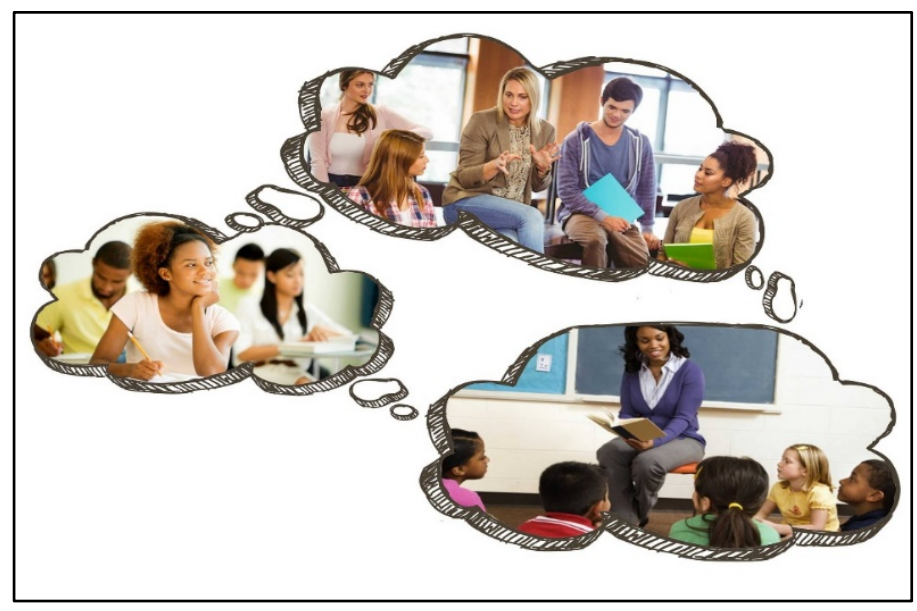

Figura 2 Formación de calidad para la sociedad (Creada por el autor)

A todo esto, hablar de competencias y habilidades para la comunicación supone generar discurso, sea este oral o escrito; supone dar los alcances de sentido y unidad estructural a lo que se quiere comunicar evitando la fragmentación en la enunciación y, por ende, en la comprensión, y es justo esta una de las más fuertes carencias y deficiencias percibidas a la hora de poner en acción los conocimientos de lengua española para comunicarse. En el día a día académico se constata la dificultad e incluso el desconocimiento de cómo aplicar partículas discursivas como los marcadores del discurso (MD). Estas unidades lingüísticas superiores a la oración son condición necesaria para la comunicación adecuada en cualquier comunidad, y en la enseñanza de ELE parece no estar entre una de las metas que el profesor deba lograr y, al no estudiarlo en la enseñanza de grado, tampoco la sabrá aplicar en su práctica docente a los estudiantes de educación básica y pública. Buscamos saber el porqué.

Cabe aclarar que aunque esta investigación pueda contribuir al menos a una reflexión para la enseñanza y preparación docente de distintas lenguas extranjeras en Brasil, este estudio se centra específicamente en la situación del 
español como lengua extranjera, ocupándose de aspectos que no abarcan a otras lenguas.

\section{FINALIDADES DEL ESTUDIO}

Esta investigación pretende someter a estudio la relación causa-efecto que los marcadores del discurso (MD) tienen sobre la formación del profesorado de español como lengua extranjera (ELE) y a su vez analizar los factores que inciden directa e indirectamente en el resultado del proceso de enseñanza y aprendizaje de ELE en la educación básica y pública del nordeste brasileño. Se pretende investigar, desde un planteamiento teórico, descriptivo y didáctico, la valoración y aplicación de estas partículas discursivas en el proceso de formación del profesorado de ELE y la repercusión de estos en su actuación docente.

La comunicación eficiente es aquella que articula mensaje y texto precedente relacionando unidades superiores a la oración, papel que desempeñan los MD otorgando fluidez y unidad al discurso oral y/o escrito; a este respecto se juzga importante conocer cómo se aprende el uso de los MD en la formación del profesorado de ELE, y de qué forma estas partículas contribuyen a la calidad del trabajo docente del profesor de ELE en la educación básica.

Reconocer la relación que existe entre el papel que los MD juegan en la fluidez y dominio del profesor de grado y su actuación en la formación del nuevo profesorado, puede convertirse en sinónimo de guía que lleve a mejorar la calidad y buena formación de estos profesionales, con resultados que ayuden a lograr el principal objetivo del Ministerio de Educación y Cultura de Brasil $^{13}$ que es, principalmente, el de "vivir experiencias de comunicación humana a través del uso de una lengua extranjera", y además, traducirse en un

\footnotetext{
${ }^{13}$ MEC-Brasil de ahora en adelante.
} 
estímulo positivo a la continuidad del estudio de español como lengua extranjera o segunda lengua/Lengua 2 (L2) ${ }^{14}$,

Así mismo, se pretende que a partir de investigaciones como esta se construya una realidad diferente para el resultado del proceso de enseñanza y aprendizaje de ELE, superando la expectativa de meramente cumplir con la obligatoriedad, situación que, sin duda, perjudica la calidad de los profesores de grado y el resultado en el aprendizaje de LE en la educación básica y pública. En este trabajo buscamos que no ocurra con ELE lo que en la actualidad se evidencia en el estudio de la lengua inglesa ${ }^{15}$ en la escuela básica y pública.

A continuación se presentan los fines específicos que se persiguen:

(1) Pretendemos centrarnos en la investigación del proceso de formación del profesorado de ELE en el nordeste brasileño, partiendo de una retrospectiva e indagando la legislación actual, el perfil y actuación del docente de grado, el plan de estudios del grado en ELE; contenidos programáticos de las asignaturas de cuño específico, el perfil del estudiante de grado, su permanencia en el curso, perfil del egresado de grado en ELE y su proyección y expectativas respecto al mercado de

\footnotetext{
14 En determinadas situaciones podemos referirnos a la segunda lengua o L2 y a la lengua extranjera como si se tratara de una misma realidad, no obstante, hay un factor preponderante que las distingue $y$ es el hecho de que el hablante esté o no en la comunidad donde se habla esa lengua. Pongo como ejemplo el caso de alguien que nace en México, pero desde los 12 años vive en Brasil. Su lengua materna sería el español, su segunda lengua, el portugués y si hablara o aprendiera otra lengua más, esa sería la lengua extranjera (Muñoz, 2002), Santos Gargallo (1999).

15 Encuestas y estudios diversos, muestran que durante la enseñanza básica no hay suficiencia en el aprendizaje de inglés, se juzga que la razón es el foco en la gramática en vez de ser en la oralidad. El resultado que se obtiene de los 7 años de clases de lengua inglesa, suele ser incipiente y hasta cierto punto, motivo de desánimo y trauma para los estudiantes calificándolo como 'algo muy difícil de aprender' y sobre todo en la escuela. De ahí que las escuelas especializadas de idiomas pasaron a tener un papel relevante en la formación del ciudadano brasileño para complementar esa habilidad. De esto se habla en las Orientaciones Curriculares para la enseñanza secundaria y se presenta un estado de la situación generalizada y en esta dirección. A eso se hace referencia cuando se habla de la lengua española en la educación básica. El siguiente texto revela un discurso muy común en Brasil:

"Narrativa 1: Meu primeiro contato com a língua inglesa foi na 6a série do ensino fundamental. Estava super ansiosa para aprender algo em inglês, e aprendi: aprendi gramática, tradução, algumas normas gramaticais, etc. Mas o que mais me interessava não foi bem trabalhado: a conversação (pronúncia, entonação) e trabalho com textos. Foi assim até o 3ㅇano do magistério" (Orientações curriculares para o ensino médio - Volume 1. 2006: 119, disponible en http://portal.mec.gov.br/seb/arquivos/pdf/book_volume_01_internet.pdf
} 
trabajo. Este trabajo prestará especial atención al estado de Rio Grande do Norte.

(2) Analizar y ponderar la actitud del docente de grado de asignaturas específicas de ELE con relación al conocimiento, fluidez y uso en el aula de la lengua extranjera, especificidad del curso de grado.

(3) Analizar y ponderar la actitud y solvencia lingüística del docente de asignaturas específicas de formación con relación al conocimiento y uso de los marcadores del discurso como elementos de crucial valor en la calidad del discurso oral y escrito del docente de ELE.

(4) Averiguar las dificultades para aprender español en los cursos de grado de IES en el nordeste brasileño, en concreto, el tema de los MD, investigando las metodologías, recursos y estrategias que son usadas para enseñar a articular el discurso haciendo uso de los MD

(5) Delimitar y percatarse del esencial papel que los MD juegan en el proceso de formación de los nuevos profesores de ELE como elementos de gran valía para la fluidez y dominio tanto oral como escrito de la lengua, lo que va a generar importante diferencia a la hora de su actuación como profesor en la enseñanza básica y pública de ELE.

(6) Por fin, presentar a la comunidad académica y científica la preocupación sobre el futuro de la enseñanza de la lengua española en un país lusohablante como Brasil, de forma que repercuta y lleve a reflexionar sobre la calidad de la formación del profesorado de ELE y, por ende, en la enseñanza y aprendizaje en la educación básica y pública. ${ }^{16}$

\section{DELIMITACIÓN DEL OBJETO DE ESTUDIO}

La finalidad primordial de esta investigación es estudiar aspectos que determinen una formación de excelencia que puedan significar una mejoría en

\footnotetext{
16 Hasta no hace mucho tiempo, la lengua inglesa gozaba de absoluta prioridad y por eso hacía y continúa formando parte del plan de estudios de la educación básica en Brasil, no obstante, concluir la secundaria sin haber alcanzado siquiera un nivel A1 en lengua inglesa es un hecho común. Es justo esta situación la que se busca evitar para la lengua española.
} 
la calidad del profesor de ELE en el nordeste brasileño en lo que respecta a su discurso, sea este oral o escrito y, además, relacionado directamente con el conocimiento y aplicación de los marcadores del discurso como elementos que proporcionan ilación, sentido y vínculo entre textos.

Que en la formación de los profesores de ELE se cuente con fluidez, conexión de ideas y dominio para expresar el pensamiento con el lenguaje que aplica en el aula, a priori, implica que los estudiantes de las escuelas públicas de primaria y secundaria tengan la oportunidad y la posibilidad de aprender a comunicarse con el mundo, en español, con propiedad y aún en su adolescencia, proporcionándoles amplitud y acceso a informaciones que pueden traducirse en estímulo para profundizar en sus estudios o incluso merecer un mercado de trabajo más atractivo.

Por otro lado, este trabajo también tiene como meta llamar la atención sobre el falso credo que se va afirmando en la mayoría de los países de que en la enseñanza básica, por lo general, no es posible aprender una lengua extranjera. Pensamos que si nos fijamos bien en el cómo se está realizando la enseñanza de ELE en un país como Brasil, acciones de refuerzo para los aspectos positivos y de observación y paulatina retirada para otros, pueden dar al niño o joven aprendiz la oportunidad de ver el mundo diferente tan solo por el conocimiento y posibilidad de comunicarse en español.

Para todos los efectos, el 'portuñol ${ }^{17}$ ', debe ser opción, transición, pero no regla, más aún en la escuela básica y sobre todo pública, esta palabra que ya empieza a oírse bastante se justifica en el fenómeno de la transparencia ${ }^{18}$ del español para el brasileño, cuestión que por lo general termina estancándolo en la interlengua ${ }^{19}$, de donde no consigue salir tan fácilmente. La 'transparencia de la lengua española para el brasileño puede ser un gran aliado o un gran

\footnotetext{
17 Se dice del español o portugués mal hablados por portugueses, brasileños y españoles que mezclan el vocabulario y la sintaxis española y portuguesa para entenderse. [En línea] http://www.trazegnies.arrakis.es/indexdi2.html

18 Al tratarse de dos lenguas neolatinas, se dice que la lengua española es 'transparente' para el brasileño porque sin haber tenido estudios cree que consigue comprender un poco de español al haber tanto parecido en la grafía o incluso en el sonido entre ambas lenguas.

${ }^{19}$ Sistema estructural independiente tanto de la LENGUA MATERNA como de la LENGUA META, que el aprendiz produce en el proceso de APRENDIZAJE de la lengua meta. (PALACIOS M., I., 2007) (Subrayado del autor)
} 
enemigo, según la postura, conocimiento y orientación que venga de los que están actuando en la formación de la enseñanza de grado de ELE, en la expectativa también de que estos no sean practicantes del tal 'portuñol'.

Ponderar y analizar diversos aspectos y factores capaces de interferir en el proceso de enseñanza y aprendizaje de ELE y por ende en el resultado, implica dimensionar sus dificultades, limitaciones y posibilidades. Conocerlas conducirá a la búsqueda de soluciones, así como a la reflexión favoreciendo las distintas partes del engranaje de aprendizaje de ELE: ajustes en el proceso de formación de profesores en relación a la articulación de su discurso aplicando los MD y mejores resultados en la educación primaria y secundaria por lo que respecta al aprendizaje de ELE. Sabido es que el dominio oral y escrito del profesor de ELE tiene sustancial poder para propiciar habilidades de comunicación al estudiante de primaria y secundaria, dependiendo de si ejerce con responsabilidad, compromiso y calidad su práctica docente en la enseñanza de ELE.

\subsection{LA FORMACIÓN DEL PROFESORADO DE ESPAÑOL COMO LENGUA EXTRANJERA}

Contextualizaremos históricamente la formación del profesorado de lengua extranjera y a continuación el de profesores de ELE con la finalidad de localizar esta enseñanza de grado en la realidad actual brasileña con atención especial al estado de Rio Grande do Norte, uno de los estados que implementó la ley del español ${ }^{20}$ más tardíamente. También indagaremos respecto de su legislación y de los programas gubernamentales que apoyan la enseñanza de grado de ELE. En cuanto a los docentes de enseñanza superior, se investigará su perfil profesional, su parecer sobre el objetivo lingüístico del profesor de ELE y su práctica en torno a este parecer emitido a través de entrevista o encuesta.

Del curso de grado se investigará la duración, el plan de estudios, el contenido programático de las asignaturas de perfil específico de formación, la estadística de ingreso, permanencia y culminación de carrera, así como la

\footnotetext{
${ }^{20}$ Ley del español, Ley Federal № 11.161 del 05/08/2005 dice de la oferta obligatoria de la asignatura lengua española en la enseñanza secundaria en todas las escuelas brasileñas.
} 
inserción de estos nuevos profesores en el mercado de trabajo, buscando delimitar cuándo y cómo se aprende a articular el discurso haciendo uso de los MD, así como saber de la aplicación de estas partículas en su actuación docente en la enseñanza básica y pública.

Del estudiante de grado de ELE se investigará su expectativa con relación a la profesión docente de ELE, su proyección, su aspiración en relación al mercado de trabajo en esta área profesional. También es de interés relevante el perfil del estudiante cuando ingresa y cuando egresa al respecto de su conocimiento lingüístico de ELE, específicamente, no por considerarlo más importante que los otros conocimientos (el pedagógico, el cultural, etcétera), sino porque el objeto principal de esta investigación es respecto del dominio y fluidez que alcance en su discurso oral y escrito de la lengua que enseñará.

Buscamos saber si el profesor de ELE ha profundizado los contenidos que supone el dominio de los conocimientos básicos, primero durante sus estudios y luego durante la formación continuada e investigación, si es que la ha tenido. Estos conocimientos abarcan los planos fónico, formal, de significado y de los usos del lenguaje.

\subsection{MARCADORES DEL DISCURSO}

Tener noción clara, conocimiento y facilidad de aplicación de los marcadores del discurso en la oralidad evidencia fluidez y dominio de la lengua extranjera, cuestión que se intentará verificar en qué momento y circunstancia durante la enseñanza de grado ocurre.

La clasificación que tendremos en cuenta de los marcadores del discurso para guiar este estudio será la propuesta por Portolés (1998) y Martín Zorraquino y Portolés (1999) debido a su mayor difusión y aceptación en la comunidad de lingüistas reconocidos en este ámbito. No obstante, se contempla la posibilidad de referirse a alguna otra clasificación a modo de contraste y si es necesario. 


\subsubsection{Conceptos clave y respaldo teórico}

En este trabajo no buscamos investigar las teorías de la Pragmática, de la Semántica o del Análisis del Discurso, sino que más bien nos proponemos apoyarnos en esas bases teóricas del lenguaje para explicar la importancia de la existencia y aplicación de los marcadores del discurso en la articulación de ideas llevadas al discurso oral o escrito del que un docente de ELE necesita apropiarse durante su formación y aplicar en su actuación en pro de una enseñanza y un aprendizaje eficiente de ELE.

Pretendemos partir de conceptos como el de lenguaje, lengua, habla, significado, gramática, contexto, comunicación, inferencia, discurso y afines, para presentar, analizar y concluir el papel que los MD juegan en la formación del profesorado de ELE en el nordeste brasileño.

¿De la semántica a la pragmática? O ¿de la pragmática a la semántica? ¿La gramática del texto?, ¿El Análisis del discurso? Cómo se evalúan estos saberes en el campo de la formación del profesorado de ELE en el nordeste brasileño es lo que pretendemos investigar. Este conocimiento y reflexión parece ser el principal conflicto que aún circunda el pensamiento y práctica del profesorado de grado de ELE en las instituciones de enseñanza superior en el nordeste brasileño. Se parte de esta discusión para llegar a la esencia de la gramática pedagógica ${ }^{21}$, cuyo objeto de estudio es el uso de los enunciados lingüísticos dentro de contextos concretos de comunicación que, para todos los efectos, permite la comunicación eficaz. Desde luego, eso no significa afirmar que la descripción formal ${ }^{22}$ de la lengua no sea un aporte indefectiblemente necesario para el logro de la fluidez y dominio de una lengua extranjera, en este caso ELE.

Reconocer la organización del lenguaje por encima de la oración o la frase y, en consecuencia, estudiar unidades lingüísticas mayores en el uso en contextos sociales o, concretamente, con la interacción o diálogos entre los

21 Concepto de gramática propuesto por Celce-Murcia y Larsen-Freeman (1999, p.5-6) para la enseñanza de lenguas extranjeras en la que se debía lidiar con la forma (estructura), el significado (sentido) y el uso (aspecto pragmático) para que la enseñanza de una LE sea bien conducida. En el capítulo II, se abordará este tema de forma amplia y contextualizada.

22 Plano formal del lenguaje: fonética, fonología, morfología, sintaxis, lexicología y semántica 
hablantes, es como Stubb (1983) describe el concepto del Análisis del Discurso. Pretendemos en este estudio, a partir de este tipo de análisis, justificar la importancia de la gramática del texto que incluye partículas discursivas capaces de establecer articulación y otorgar sentido, incluso a un discurso y no solo al sintagma, unidad máxima de la sintaxis, entendida también en el formalismo ${ }^{23}$ como la unidad máxima del lenguaje.

Cabe mencionar uno de los retos más importantes que se plantea la Pragmática, probar que la comunicación humana es un proceso inferencial y que, tal y como han puesto de manifiesto los investigadores Sperber y Wilson (SPERBER y WILSON, 1994) a través de la formulación de la Teoría de la Relevancia, solo codificamos la parte más relevante de lo que queremos decir y si así fuera se debería reparar en la parte del significado que es posible recuperar, tema que amerita una necesaria reflexión.

\subsection{ENSEÑANZA Y APRENDIZAJE DE LENGUAS EXTRANJERAS (ELE)}

En este campo delimitamos dos claros objetos de estudio sobre los que investigamos el proceso de enseñanza y aprendizaje de español como lengua extranjera, a saber: (1) el profesorado de enseñanza de grado con relación a su práctica docente y (2) el estudiante de grado con relación a su aprendizaje para tornarse un profesor de ELE y el perfil resultante de esa formación para su actuación docente en la enseñanza de ELE en la educación pública y básica. Se pretende identificar en ambos objetos de estudio el nivel de incidencia de los marcadores del discurso y verificar el parecer sobre la relevancia de estas partículas como elementos de articulación a nivel de discurso conducentes a la fluidez y dominio del conocimiento lingüístico de ELE, capaz de generar soltura a la hora de actuar en la docencia.

\footnotetext{
23 En este estudio el concepto de formalismo se contrapone al de funcionalismo, tema que será más ampliamente abordado en el capítulo II.
} 


\subsubsection{Conceptos clave y respaldo teórico}

Nuestro punto de partida se localiza en los conceptos de enseñanza, aprendizaje, lengua materna, lengua extranjera, profesor nativo, profesor no nativo, metodologías de enseñanza, entre otros que contribuirán a trazar el perfil de enseñanza y aprendizaje que existe en la formación del profesorado de ELE y la conciencia lingüística respecto de la importancia de la articulación del discurso a través de partículas discursivas, de la comunicación fluida que a su vez repercutirá en su acción docente en la educación básica y pública del nordestino ${ }^{24}$.

\section{CONSIDERACIONES PREVIAS}

Consideramos importante y necesario presentar de antemano aclaraciones y explicaciones inherentes a nuestro estudio, antes de sumergirnos en esta investigación, a saber: la jerarquía en la composición de nuestro objeto de estudio, la dinámica de presentación de esta investigación, así como lo evidente y hasta tradicional, las limitaciones que se pueden presentar en el desarrollo de una investigación.

Al tratarse de marcadores del discurso, formación de profesorado de LEELE e implícita y consecuentemente de la calidad de la enseñanza básica y, a priori, pública en el nordeste brasileño, ha habido interminables horas de reflexión, planificación y replanificación de la trayectoria que se ha querido dar a esta investigación intentando dar una lógica que no desmerezca la relevancia de cada uno de los tres puntos de estudio que se secuencian casi en un círculo cerrado, o sea, es como si el principio, el medio, y el fin del ciclo de la enseñanza de ELE pudiera estar en la educación básica del ciudadano común al que se busca convertir en un profesional de éxito, preparado para comunicarse con el mundo, en ELE. Establecer esa jerarquía en la composición de nuestro objeto de estudio ha sido difícil y en este trabajo se ha partido de la formación del profesorado de LE, con atención en ELE.

\footnotetext{
${ }^{24}$ Se refiere a las personas brasileñas nacidas en la región nordeste de Brasil.
} 
Como consecuencia de lo antes dicho, la dinámica de esta investigación genera la presentación del corpus en su diversidad de datos, así como su respectivo análisis en esa misma secuencia. Primero presentamos el corpus sobre la enseñanza y aprendizaje de lenguas desde la perspectiva del ciudadano común que ha estudiado o aún está estudiando una LE en la escuela pública de primaria y/o secundaria para llegar a la presentación y análisis del corpus sobre la incidencia del conocimiento y uso de los marcadores del discurso y finalmente sobre aspectos de formación del profesorado de ELE.

Como es bien sabido, no siempre se logra todo lo que se anhela y al investigar fenómenos complejos como el propuesto en este trabajo, las dificultades y las limitaciones se presentan irremediablemente; no obstante, el ánimo no ha decaído y estamos seguros de que, al menos, se propiciará un punto de partida para nuevas o más amplias y profundas reflexiones e investigaciones en este campo de la enseñanza y aprendizaje de una lengua extranjera, en este caso, lengua española en la sociedad brasileña.

Así, se trata de un trabajo de carácter mixto que trae un contorno histórico-teórico a partir del cual se busca respaldar conceptos inherentes a aspectos generales que inciden en el tema, tanto del aprendizaje de una lengua extranjera, la lengua en sí en su forma y función, así como en el de la formación de profesores, habiendo buscado para ello suficiencia y respaldo en estudiosos de estas áreas del conocimiento.

\section{ESTRUCTURA DE LA TESIS}

Esta investigación se estructura en dos partes. La primera engloba los capítulos Preliminares, I y II de nuestro estudio y presenta las bases teóricas centradas en la descripción y verificación del conocimiento e incidencia de los marcadores del discurso en la formación del profesorado de ELE. En la segunda parte está el capítulo III en el que se aborda el estudio empírico, el análisis de datos y las conclusiones generales respectivas de este estudio .

En el capítulo Preliminares se presentan antecedentes, finalidades, consideraciones previas y una breve descripción del objeto de estudio y lo que 
supone su soporte teórico en el ámbito de la enseñanza y aprendizaje de una lengua extranjera.

En el capítulo I, se expone descriptivamente el estado de la cuestión, de modo general con respecto al actual proceso de formación de profesores de lengua extranjera en el nordeste brasileño, con atención especial al estado de Rio Grande do Norte, relevando la incidencia del papel que los marcadores del discurso juegan en la formación de profesores de ELE en el plan de estudio de grado en ELE. Además, presentamos un contexto histórico sobre la enseñanza de lengua extranjera en Brasil y su contexto actual en el país. A modo de situar la educación brasileña en el contexto internacional, traemos un contraste con sistemas educacionales de otros países hispanoamericanos.

En el capítulo II se busca establecer relación e incidencia sobre el papel preponderante que los marcadores del discurso pueden suponer en la formación de un luso hablante, futuro profesor de ELE en una región brasileña como la del nordeste. Se hace una contextualización de las teorías del discurso en relación a los MD y a la relevancia de estos conceptos en la formación del profesorado de lengua extranjera en general y española, en especial. Se abarcan los presupuestos teóricos sobre procesos de enseñanza y aprendizaje, formación superior para enseñanza de lenguas y marcadores del discurso como elementos de alto poder en la comunicación.

Se presentarán conceptos inherentes al tema como lengua, lenguaje, enseñanza de lengua materna y extranjera, métodos, estrategias y posicionamientos, planteando contrastes entre la teoría y la práctica que nos lleven a reflexionar, el qué, el cómo, el para qué aprender, tanto durante la formación del profesorado, papel de alumno, como también durante la enseñanza básica en donde su papel es el de profesor.

Aún este capítulo se pretende establecer relación entre las teorías del aprendizaje y enseñanza de lengua extranjera, la actuación docente propiamente dicha y el resultado final de aprendizaje de ELE en la escuela básica y pública, pasando revista en la relevancia e incidencia de los MD en el resultado que suponga una herramienta de comunicación satisfactoria, la lengua española. 
En el capítulo III se inicia la presentación del estudio empírico. Las herramientas metodológicas empleadas para realizar esta investigación son descritas en este capítulo, a saber: encuestas, entrevistas, transcripciones de grabaciones y audiciones, relatos individuales, producción didáctica y documentos oficiales. Mixta y diversa es la fuente de datos que conforma nuestro corpus y su respectiva configuración, la misma que al someterse a los parámetros analíticos, generará la formulación de las preguntas de investigación e hipótesis que pretenden dar respuesta al respecto de la formación del profesorado y su conocimiento de los MD como elementos que contribuyen a la fluidez oral y escrita en la actuación docente que se realiza en la educación básica y pública.

Partir de datos reales nos permitirá analizar empíricamente el panorama del proceso de enseñanza y aprendizaje de una lengua extranjera en general y de ELE en particular, la experiencia como estudiante de grado, como profesor de grado y el conocimiento respecto de los marcadores del discurso. En esta investigación se aprecia un aspecto macro de la realidad brasileña, pero se delimita una aproximación al nordeste del país con énfasis en el estado de Rio Grande del norte de donde procede buena parte de las informaciones del día a día académico.

Para finalizar, se recogen las conclusiones generales logradas, fruto del análisis realizado, así como también se vislumbran nuevas posibilidades para futuras investigaciones. 
PRIMERA PARTE

PRESUPUESTOS TEÓRICOS SOBRE LOS MARCADORES DEL DISCURSO Y LA FORMACIÓN DEL PROFESORADO DE LENGUA EXTRANJERA 


\section{CAPÍTULO I - ESTADO DE LA CUESTIÓN}

El Progreso es la realización de utopías

Oscar Wilde

\section{INTRODUCCIÓN}

En este primer capítulo presentamos la situación actual en que se encuentran las partes que conforman nuestro objeto de estudio: la formación de profesores de español como lengua extranjera y la incidencia de los marcadores del discurso en la formación de profesores y en la enseñanza y aprendizaje de ELE en la educación básica y pública brasileña.

Tener noción de lo que significa Brasil, un país de proporciones casi continentales y de matices increíbles, resulta para los propios nativos una inmensidad de información que sin duda se tornaría relevante para tejer una visión macro de su realidad y necesidades al hablar de formación de profesorado de lengua extranjera, y además lengua extranjera española en el ámbito público y en la enseñanza básica ${ }^{25}$ y superior.

Es evidente que se trata de algo, incluso utópico, el lograr una visión macro que permita señalar de modo general los aciertos y las fallas al hablar de enseñanza de español como lengua extranjera (ELE), formación del profesorado de ELE, y aún más de un aspecto considerado relevante para la fluidez de esta lengua, como lo es el peso y significado de las partículas discursivas llamadas marcadores del discurso (MD) como responsables de la ilación del discurso que se desea comunicar. No obstante, este es un desafío que no se pretende enfrentar, pues el presente trabajo, nacido de inquietudes surgidas a lo largo de la actividad docente, pretende tomar referencias nacionales, pero centrar la investigación en la región nordeste del país, con énfasis en el estado de Rio Grande do Norte, con miras a optimizar la

\footnotetext{
25 La enseñanza básica comprende de la educación infantil (4 años de edad) a la educación secundaria (17 años).
} 
formación de nuevos profesores de español anhelando el consecuente beneficio en el resultado que se logre en la enseñanza básica y pública.

Cuestiones como la de reconocer históricamente el resultado del aprendizaje de la lengua inglesa como herramienta de comunicación en la educación básica y pública; la de detectarse que empieza a pasar algo semejante con la lengua española ${ }^{26}$; la de creer que falta a buena parte del profesorado de grado de ELE, dominio y fluidez en la lengua que enseña, limitándose a un repase de informaciones y contenidos desconectados y muchas veces en lengua portuguesa 27 ; la de creer que el uso y aplicación de los marcadores del discurso (MD) no es significativo para los formadores de profesores de ELE en Brasil, lo que conlleva a un efecto en cadena con la consecuente repercusión en el resultado de ELE en la educación básica, configuran obstáculos que se deben investigar para que la inserción de la lengua española como lengua extranjera en Brasil, tenga un curso adecuado y garantice un resultado eficiente que constituya un aporte al educando en la enseñanza básica.

Un aspecto que se torna relevante y que no es de extrañar, dadas las dimensiones de un país como Brasil, es que las realidades de base son diferentes según se trate de una región o de otra, de ahí que cabe evidenciar que la región nordeste fue clasificada en 2008, junto a la región norte, como las regiones "con menos español28", contrapuestas a las regiones sur y sudeste (MARTÍNEZ-CACHERO, 2008) aunque todo indica que en la actualidad se ha avanzado de varias maneras ${ }^{29}$, pero igual no lo suficiente y sobre todo, adecuadamente. Lo bueno es que al hablarse del ámbito educativo, las leyes, las políticas, los proyectos, las medidas y orientaciones curriculares, suelen ser las mismas, o al menos semejante, en todo el país, lo que se traduce en iguales oportunidades.

\footnotetext{
${ }^{26}$ Incluida en el plan de estudios de enseñanza básica, como de oferta obligatoria por las escuelas, a través de la ley 11.161 que está en vigor desde el año 2005.

27 Lengua materna en Brasil.

28 'Menos español' implicaba decir menos profesores, menos calidad, menos implementación en la educación pública, menos universidades formando profesores de ELE, entre otras desventajas para el fortalecimiento de esta lengua como lengua extranjera en Brasil.

${ }^{29}$ Se ampliará esta información en 1.1 del presente capítulo.
} 


\section{LA FORMACIÓN DEL PROFESORADO DE LENGUA EXTRANJERA (EN BRASIL)}

Hay mucho de qué hablar sobre formar profesores que enseñen lenguas extranjeras con ahínco y calidad en la educación básica, de modo que satisfaga las exigencias de comunicación que han devenido a través de eventos y fenómenos internacionales y mundiales y que han invadido el mundo con información y tecnología.

La calidad de vida y el desarrollo económico de una nación se sustentan en la sanidad, la educación y la renta de su población, mientras más larga vida, mejor nivel de escolaridad y mejores ingresos para llevar una vida decente, más alto $\mathrm{IDH}^{30}$ se marca y en esto, actualmente, Brasil se mantiene en el $79^{\circ}$ con el índice 0.744 , que revela una condición razonable de progreso y desarrollo.

\begin{tabular}{|c|l|c|}
\hline $\begin{array}{c}\text { Ranking } \\
\text { IDH Global }\end{array}$ & \multicolumn{1}{|c|}{ País } & IDH \\
\hline \multicolumn{3}{|c|}{ Muy alto desarrollo humano } \\
\hline 1 & Alemania & 0,944 \\
\hline 2 & Australia & 0,933 \\
\hline 3 & Suiza & 0,917 \\
\hline 27 & España & 0,869 \\
\hline 41 & Chile & 0,822 \\
\hline 44 & Cuba & 0,815 \\
\hline \multicolumn{3}{|c|}{ Alto Desarrollo Humano } \\
\hline 50 & Uruguay & 0,790 \\
\hline 65 & Panamá & 0,765 \\
\hline 71 & México & 0,756 \\
\hline 79 & Brasil & 0,744 \\
\hline 82 & Perú & 0,737 \\
\hline \multicolumn{3}{|c|}{ Medio Desarrollo Humano } \\
\hline 111 & Paraguay & 0,676 \\
\hline 112 & Bolivia & 0,667 \\
\hline \multicolumn{3}{|c|}{ Bajo Desarrollo } \\
\hline 173 & Etiopia & 0,435 \\
\hline 187 & Níger & 0,337 \\
\hline
\end{tabular}

Tabla 1 - Brasil en el contexto del IDH mundial.

Fuente: Informe de Desarrollo Humano 2014 [En línea] www.pnud.org.br.

30 Índice de desarrollo humano, indicador creado por el Programa de las Naciones Unidas para el Desarrollo (PNUD) cuya finalidad es determinar el nivel de desarrollo de los países del mundo. EI IDH varía entre 0 (ningún desarrollo y 1 (desarrollo total).

[En línea] http://www.pnud.org.br/atlas/ranking/Ranking-IDH-Global-2013.aspx 
A todo esto, la calidad en los procesos de enseñanza y aprendizaje en la educación, principalmente pública por tratarse de la mayoría de los brasileños, incide directamente en más y mejores oportunidades para el ciudadano, y nace ahí, por lo tanto, la preocupación por una formación idónea del profesorado, tanto desde el punto de vista pedagógico como del de conocimientos específicos; a lo largo del proceso de formación es cuando el docente reflexiona claramente sobre las posibilidades de construir o reconstruir una nación con mejores condiciones de vida.

El Estado brasileño es consciente de esta realidad, por eso busca estimular y colaborar con el desarrollo y cualificación docente de modo que quede garantizada una formación que responda eficientemente a la hora de la práctica docente, contribuyendo así a la mejoría del nivel educativo de la población brasileña desde sus primeros años escolares hasta su definición profesional y más allá.

Formar profesores de lengua extranjera competentes implica el dominio y conocimiento de diferentes áreas, obviamente incluido el saber pedagógico y el dominio de la lengua que se enseña, pues la clase de lengua extranjera al ser reflejo de lo que ocurre fuera de ella le exigirá al docente ese conocimiento del mundo, su reflexión y acción, y debe ser preparado para ello.

Por otro lado, vienen del Gobierno leyes, directrices, proyectos, convenios, y del mundo, tendencias, modas, etc., cuestiones que llegan impuestas para ponerse directamente en acción, pero aún así deben ser objeto de reflexión y parte en la formación del perfil del profesor, pues este deberá, críticamente, implementar la práctica, aunque muchas veces no esté de acuerdo con lo que se establezca. Peor aún ocurre cuando relaciones de poder político o económico intervienen en decisiones, como por ejemplo definir una $u$ otra lengua como obligatoria, definir, o incluso, otorgar a una lengua extranjera la multinacionalidad ${ }^{31}$, como lo fue en su momento la lengua inglesa.

Ante ese panorama, el profesor de esta década, de este siglo, no se puede formar igual a los anteriores, ni se puede adelantar a la formación de los futuros; lo que sí hay que hacer es prepararlos para lo que hoy se tiene, pues la

${ }^{31}$ Que pertenece a muchas naciones. 
realidad es otra. El profesor de LE del pasado tenía otras preocupaciones, otras formas de aprender a enseñar, tenía una lectura diferente, no era tan actor y gestor de la educación, y sí un seguidor obediente; positivamente eso ha cambiado, el profesor de hoy participa más, opina más, tiene autonomía en su clase, y eso está relativamente bien, cuando está bien centrado en los objetivos que deben ser alcanzados con su actuación docente en LE.

Según la legislación brasileña, los profesores de LE actúan en la educación básica, del $5^{\circ}$ al $9^{\circ}$ curso de enseñanza fundamental y del $1^{\circ}$ al $3^{\circ}$ curso de enseñanza media ${ }^{32}$, como lo vemos en el cuadro siguiente:

Cuadro 1 - Enseñanza de lengua extranjera en la educación básica.

\begin{tabular}{|c|c|c|c|c|c|}
\hline \multicolumn{2}{|c|}{$\begin{array}{l}\text { Denominación } \\
\text { oficial en Brasil }\end{array}$} & $\begin{array}{l}\text { Tiempo - } \\
\text { cursos }\end{array}$ & Edad & $\begin{array}{l}\text { Lengua } \\
\text { Extranjera }\end{array}$ & Responsabilidad \\
\hline \multirow{14}{*}{ 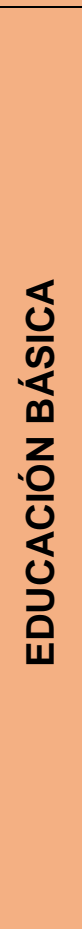 } & \multirow{2}{*}{$\begin{array}{l}\text { Educación } \\
\text { infantil }\end{array}$} & 4 años & $0-3$ & No & \multirow{2}{*}{$\begin{array}{l}\text { Gobierno } \\
\text { Municipal }\end{array}$} \\
\hline & & 2 años & $4-5$ & No & \\
\hline & \multirow{9}{*}{ 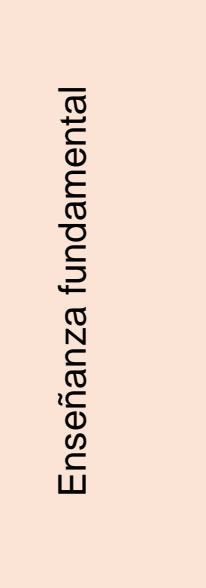 } & $1^{\circ}$ curso & 6 & No & \multirow{12}{*}{ 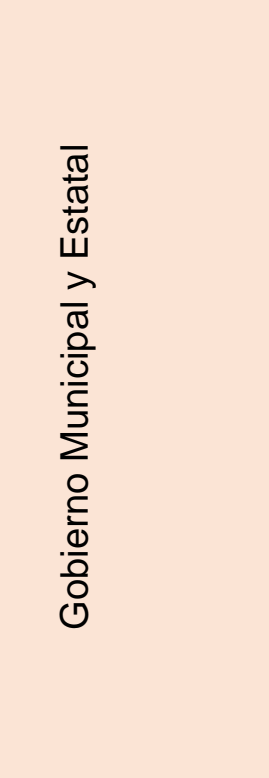 } \\
\hline & & $2^{\circ}$ curso & 7 & No & \\
\hline & & $3^{\circ}$ curso & 8 & No & \\
\hline & & $4^{\circ}$ curso & 9 & No & \\
\hline & & $5^{\circ}$ curso & 10 & Sí & \\
\hline & & $6^{\circ}$ curso & 11 & Sí & \\
\hline & & $7^{\circ}$ curso & 12 & Sí & \\
\hline & & $8^{\circ}$ curso & 13 & Sí & \\
\hline & & $9^{\circ}$ curso & 14 & Sí & \\
\hline & \multirow{3}{*}{$\begin{array}{l}\text { Enseñanza } \\
\text { Media }\end{array}$} & $1^{\circ}$ curso & 15 & Sí & \\
\hline & & $2^{\circ}$ curso & 16 & Sí & \\
\hline & & $3^{\circ}$ curso & 17 & Sí & \\
\hline
\end{tabular}

Al tratarse de un conocimiento semejante a cualquier otro de formación superior, debe quedar claro que la palabra 'entrenamiento' no tiene espacio en el abanico de posibilidades de reciclaje, cualificación o posgraduación de profesores de lengua extranjera, a no ser en circunstancias puntuales y de 
restricto espectro, pues los entrenamientos no le permiten al futuro profesor acceder a una fundamentación teórica ni a una reflexión que respalde su acción.

La figura 3 nos muestra lo mínimo a que se debe atener una formación superior: fundamentación, reflexión y experimentación. Y que además, el profesor en su actuación docente sea capaz de conseguir establecer un flujo de continuidad a partir de cualquiera de los puntos, sería esta la formación obligatoria y de base de un profesor de lengua extranjera en su conocimiento pedagógico, su saber lingüístico y conocimiento general y de mundo, que debería recibir.

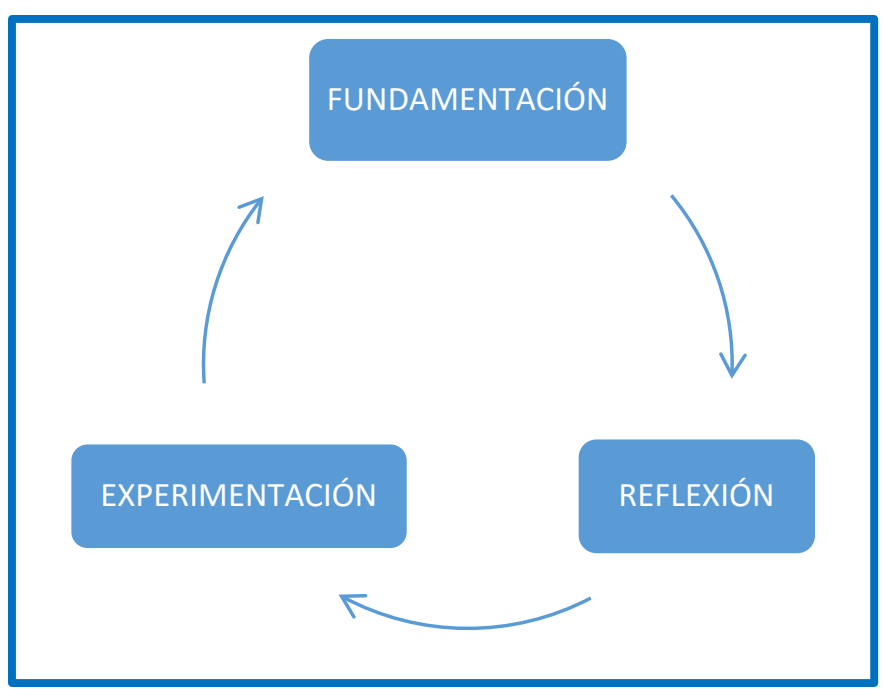

Figura 3 - Elementos fundamentales en la formación de profesores. (Creado por el autor)

La oferta de estudios superiores correspondiente a enseñanzas de Grado en Brasil es amplia y también está reglada por la Lei de Diretrizes e Bases da Educação Nacional ( $L B D)^{33}$, ley que deja claro que solo puede actuar en la enseñanza de LE quien esté legalmente graduado, situación que permite un estatus de seriedad académica a este conocimiento y garantiza una actuación docente respaldada por un estudio reglado, independiente de si se

\footnotetext{
33 Ley que rige la educación brasileña, fue promulgada el 20 de diciembre de 1996 y revisada recientemente (abril de 2013). Abarca toda la educación básica, desde infantil (ahora obligatoria para niños a partir de 04 años), enseñanza fundamental, media hasta la formación de profesores para la educación básica. También se encarga de otras modalidades de enseñanza como La educación especial, indígena y la enseñanza a distancia. [En línea] http://portal.mec.gov.br/arquivos/pdf/ldb.pdf
} 
trata de un nativo o no nativo. Esta ley se aplica a todos, sin excepción y además se determina en ella prácticamente todo lo que compete a la enseñanza básica y superior: contenidos, carga horaria, lengua extranjera, evaluación del aprovechamiento de estudios en colaboración con los sistemas de enseñanza, etc.

Con respecto a la formación del profesorado de LE, se procura en este trabajo estimular una reflexión profunda sobre este tema. PAIVA (1997) afirma que las instituciones de enseñanza superior (IES) en Brasil hasta ahora no han sido capaces de formar profesionales competentes en LE lo suficiente para las necesidades del estudiante que está a su espera en el colegio:

"CUÁL ES LA FORMACIÓN DEL PROFESOR DE LENGUA INGLESA? ¿Tal vez la mejor pregunta sería "Cuál es la de/formación del profesor de lengua inglesa?" - Examinamos programas de lengua inglesa de 07 facultades [...], y el resultado indica precariedad en la formación de nuestros profesores. [...]. (PAIVA, 1997) ${ }^{34}$

De eso se hablaba en 1997, cuando las IES que graduaban para la docencia era tarea exclusiva de las universidades, pero ahora estamos en 2015 y la tarea también está en manos de los Institutos Federales ${ }^{35}$, tradicionales instituciones de alta calidad en formación técnica que ajustaron su identidad educativa pública para el nuevo objetivo, situación que, en su momento, generó polémica en la comunidad académica universitaria. Las universidades se sintieron despojadas de una de sus responsabilidades: formar profesores para la educación básica, entre ellos los de LE, pero a día de hoy, parece que esta 'rivalidad' ya está superada.

Las propuestas para formar profesores fuera de la universidad, como por ejemplo en escuelas de idiomas o en instituciones extranjeras, en su momento fue algo muy cuestionado y causaba descontento porque se defendía fuertemente que la universidad sería la instancia ideal para la formación de

\footnotetext{
34 Texto original en portugués de Brasil: QUAL É A FORMAÇÃO DO PROFESSOR DE LÍNGUA INGLESA? Talvez a melhor pergunta seria "Qual é a de/formação do professor de língua inglesa?" - Examinamos programas de língua inglesa de 07 faculdades [...], e o resultado é indicativo da precariedade da formação de nossos professores. [...]. (PAIVA, 1997)

${ }^{35}$ Ampliaremos la información en el capítulo 1.
} 
profesores en general, a nuestro ver, nada más sensato y adecuado teniendo en cuenta que la profesión de profesor está en la base absoluta de la pirámide profesional del ciudadano en general en razón a su paso por la educación básica, lugar y momento en el que los profesores actúan llevando reflexión y conocimiento en busca de respuesta positiva en pro del progreso social y del desarrollo.

Pero retomando el tema de la calidad de la formación del profesor de LE, observamos que las dificultades prevalecen ${ }^{36}$; no obstante, cambios que se vienen implementando indican una buena reacción ante la difícil situación evidenciada en innúmeros testimonios de investigadores brasileños, profesores y estudiantes de grado, a través de artículos, libros, ponencias, conferencias, mesas de debate, etc., en congresos y diversos eventos académicos.

Un verdadero profesional de LE, docente reflexivo, competente, crítico y seguro es capaz de convencer a su alumno que conocer una LE puede cambiar para mejor su realidad, puede conseguirlo, incluso, en la primera clase, en el primer contacto, pero el desafío está en que esa llama se mantenga viva y conseguir que esa convicción forme parte de la personalidad de ese estudiante, sujeto en formación. ¿Cómo conseguir esto si los propios profesores ya empiezan a actuar sin tanta ilusión? Inclusive, aún durante su formación académica se les va opacando, porque esperan de la enseñanza de grado lo que no les llega.

Probablemente el tiempo y las condiciones a lo largo de los estudios superiores no sean suficientes, o quizás sea que las IES no están aún preparadas para formar adecuadamente al nuevo profesor, a este que necesita en simultáneo saber aprender y saber enseñar, saber realizar la lengua y saber enseñar a realizarla también. Hace pensar mucho si en verdad las IES realmente forman profesores o si el pasar por ellas no es sino el inicio del ser verdaderos profesores, esto parece mucho más sensato afirmar, y si es así, la enseñanza superior necesita reorientarse en toda su composición.

\footnotetext{
36 Presentaremos en 1.1 los problemas observados, pero en el escenario nordestino de educación superior para LE.
} 
Partiendo de que en educación nada está terminado, en formación de profesorado en general tampoco lo está, este posicionamiento está muy vivo y presente en los gestores de la educación brasileña y en el caso de LE, cuentan con la contribución de la colectividad de investigación quienes afirman que sin continuidad de estudios, actualización en la LE que enseñan y sin la creación de materiales didácticos adecuados no se puede esperar que los profesores de LE estén realmente preparados para ejercer la acción docente. A esto se cree prudente añadir que un mejor resultado depende definitivamente de determinar lo que debe hacerse en esa continuidad de estudios y actualizaciones, de dónde vendrían los indicadores y qué condicionamientos habría para realizarlos.

Se nota claramente que la enseñanza de LE, se admita o no, ha sido, es y seguirá siendo de alguna manera rehén de intereses tanto económicos, como también políticos que se constatan fácilmente a la hora de conocer la realidad de la enseñanza de una LE en la educación básica o superior. Como ejemplo, en el estado de Rio Grande do Norte, fue larga la espera para implementar la lengua española como opción de lengua extranjera en el entonces examen 'vestibular'37, sin existir claro impedimento para tal cosa. Son cuestiones de este tipo las que la legislación debería dejar bastante claro sobre qué criterios y procedimientos hacer valer cuando los que detentan el poder de definir no hicieran lo que se debe, sino lo que les conviene, a priori, sería la única forma de hacer realidad lo que respecto de LE esta LDB propone.

Citamos algunos de los aspectos señalados por CELANE en 2009 respecto a las dificultades hasta entonces detectadas sobre formación docente en LE:

(1) La doble licenciatura (portugués y una LE); no hay forma de abarcar tanta información en tan poco tiempo;

(2) Facultades sin profesores preparados, no investigan y dictan asignaturas basados en gramática;

(3) La desvalorización de la asignatura LE por la propia institución educativa;

\footnotetext{
${ }^{37}$ Selectividad de aprobación obligatoria para realizar estudios universitarios.
} 
(4) Los profesores de LE no tienen idea de la capacidad de inclusión que una LE tiene;

(5) Se continúa hablando portugués en el aula de LE por falta de dominio del idioma que se enseña;

(6) Es posible usar los dos idiomas, el materno y la LE, según sea estrictamente necesario, no es disculpa el temor a que los alumnos no entiendan;

(7) El profesor de LE no es capaz de hablar en la lengua que enseña, debería entender hablantes nativos, que al mismo tiempo no deben ser entendidos como modelo;

(8) El profesor de LE debe actuar como un investigador de su propia práctica.

(9) Un serio problema del profesor de LE es su soledad, no tiene con quien intercambiar experiencias en la escuela;

(10)Deberían tener perfeccionamiento lingüístico en primer lugar, luego un curso de extensión, grabación de clases y análisis de lo que funcionó o no, estudiar aspectos didácticos y preparar unidades didácticas.

De forma directa o indirecta, los puntos destacados por CELANE (2009) suenan familiares a la realidad que investigamos en este trabajo y podrían ser explicación al buen uso, o no, de marcadores del discurso en el dominio de lengua extranjera y por ende podría explicar también la ineficacia de buenos resultados en el aprendizaje de ELE en la educación básica y pública. De ahí que intentaremos contextualizarlos situándonos en la observación de la realidad de 2015 identificándolos con la formación de profesores en las instituciones de enseñanza superior (IES) que son objeto de nuestra investigación.

Los cursos de grado de este Estado serán denominados con las siglas IES-1, IES-2 e IES-3, sabiendo que son universidad federal, universidad estatal e instituto federal, respectivamente. 
Respecto a (1), la mayoría de las IES en el país han cambiado ya lo de doble titulación ${ }^{38}$ por licenciatura única, sea en portugués, inglés, español, francés, etc., lo que se perfila de gran expectativa en el resultado de la actuación de esos profesionales y de su acción docente sobre el estudiante de grado de ELE, pues se contará con un carácter mucho más específico de formación y con marcada identidad profesional. En el nordeste ${ }^{39}$, específicamente en Rio Grande do Norte, son tres las IES públicas que ofertan curso de licenciatura en LE y las tres ofertan Licenciatura en ELE en la actualidad, aunque dos de ellas, la IES-1 e IES-2, hasta 2011, presentaban el modelo de formación con titulación doble desde su primera oferta. La IES-3, no, desde su primera oferta solo formaba profesores de LE con la única titulación de Licenciados en Lengua Española. Es pertinente señalar que cambiar lo de doble titulación ha sido por orientación recibida por el MEC-Brasil ante los precarios resultados arrojados en los diferentes momentos de evaluación de cursos de grado, de docentes y de alumnado respecto de LE, sobre todo inglés.

Sobre (2) y en amplio panorama, podemos afirmar que hay mucho de esto, pero que también está sujeto a determinado relativismo. La IES-1 solo contrata doctores para el cuadro permanente de docentes y eso es una gran ventaja vista del punto de vista de la 'investigación', lo que no asegura profesores con fluidez y conocimiento de la LE que va a enseñar, y al mismo tiempo es un gran factor con poder de inercia para dar clases gramaticales que no van a ayudar mucho a la hora de formar nuevos profesores.

Las IES-2 e IES-3 contratan, al menos con grado en LE y en el proceso selectivo se valora la titulación, lo que no garantiza doctores para el cuadro permanente, pero sí docentes de grado en inicio de carrera, con ilusión de hacer un buen trabajo y de continuar la formación en posgrado, con poca fluidez en ELE. Sin embargo, en estos dos grupos de profesores, cuesta investigar y dedican su esfuerzo a las clases de LE. Se nota en estos profesores un sentimiento de súper valorización de su propio perfil, más allá de

\footnotetext{
${ }^{38}$ En Brasil se denomina 'graduação com dupla habilitação'.

${ }^{39}$ Se compone de los estados de Maranhão, Piauí, Ceará, Rio Grande do Norte, Paraíba, Pernambuco, Alagoas, Sergipe y Bahía.
} 
los intereses de las cuestiones académicas que favorezcan o no al alumnado en formación. Consideran como relevante, por ejemplo el tema de si el mejor profesor es el nativo o el no nativo, como si fuera la respuesta a una formación pedagógica y de especificidad altamente relevante.

Lo expuesto en (3) sí que es una realidad abrumadora, las escuelas públicas, sobre todo, presentan abiertamente este hecho, la asignatura de LE no es objeto de atención en intensidad y dimensión como lo sería matemáticas, por ejemplo, o cualquier otra. De ese punto devienen cuestiones como la escasa carga horaria que se destina a LE, la informalidad a la hora de definir el profesor de LE, el descuido de luchar por recursos y espacios que garanticen un mínimo de condiciones para la enseñanza de una LE. En definitiva, este sí es un verdadero problema que retrasa todas las iniciativas y esfuerzos que se puedan implementar para la enseñanza de una LE.

Y en la actualidad, para ELE es aún peor, porque, de alguna forma, el inglés sigue siendo la LE considerada como más importante si la comparamos con el español, tornándose ese el punto de partida para que no sea tan necesario que las clases de ELE sean dadas por un profesor de ELE, puede ser uno de portugués o de filosofía o de historia o de lo que fuere con tal que tenga algún conocimiento y pueda demostrarlo, ni sea necesario más que un horario de 45 minutos por semana cuando inglés tiene 90 (dos horarios) y para colmo, si hay profesor de ELE, este tiene que ver cómo se las arregla para completar su carga horaria mínima de 20 horas semanales, porque si es otro profesional el que da las clases de ELE, es este el que continúa. Todo ello fruto de la implementación de la ley del español, de lo tardío del inicio de la formación de profesores de ELE en este estado, uno de los últimos en hacerlo, y también de la subestimación de la lengua española por lo parecido que es el español al portugués, es fácil, qué más da, estudiarlo como Dios manda.

Lo que se afirma en (4), sí se constata en el quehacer diario académico: la postura, el mensaje, la actitud de un docente inspira y estimula, sin duda; puede cambiar la vida de muchos alumnos, sobre todo de aquellos que se subestiman por su origen, su raza, su condición social y económica. El profesor de grado tiene la posibilidad de propiciar todas las formas posibles de inclusión, 
mejorando la autoestima y de fondo con la enseñanza de la LE propiamente dicha, de ahí la gran relevancia del dominio y la fluidez de la LE que enseña.

Lo dicho en (5) por CELLANI (2009) es en general una práctica común que deturpa el objetivo mayor de la asignatura LE, es el mal que mutila la ilusión, el futuro, las expectativas; a nuestro entender, lo mismo que se trate de lengua inglesa o española, la fluidez y proximidad de la LE estimula positivamente el aprendizaje o suscita un sentimiento de desprecio y disgusto que en muchos se lleva consigo de por vida. El profesor de LE tiene obligación de saber la lengua que enseña y enseñar a través de ella en la medida de lo posible en alianza con la lengua materna (6), de hecho usarla cuando hace falta, y cuando no, pues cada una en su momento, pero saber que se tiene uno o dos horarios de 45 minutos cada semana, y no aprovecharlos al máximo aprendiendo y enseñando LE es de hecho condenar esta profesión a "hacer que se enseña ${ }^{40 "}$

Respecto de (7) hay una serie de situaciones que se suscitan a raíz de este primer planteamiento de CELANE (2009), y que a pesar de haber transcurrido 6 años, se mantienen y continúan suscitando situaciones de lo más diversas, a saber: el profesor de LE sigue sin ser capaz de hablar la lengua extranjera que enseña; el profesor de LE sigue sin dar sus clases en la LE que debe enseñar; el profesor de LE sigue sin entender a cabalidad a los hablantes nativos, aunque en ELE esto se da parcialmente; el profesor de LE no solo no sigue el modelo de hablar de los nativos de LE, lo que nos parece muy bien, sino que critica al profesor nativo de la LE cuando ejerce la profesión regladamente y lo peor está en que lejos de 'usarlo' como un elemento más para su mejora en LE, pierde tiempo en entenderlo como una amenaza a su práctica docente, pues se siente siempre en desventaja a la hora de hablar la lengua frente a un nativo de la LE.

Aunque, por observación y averiguación, no ocurren estas situaciones internas en otras IES, el tema de ser o no ser nativo de la LE que enseña y en el de quién es el mejor profesor, si el no nativo porque conoce todos los

\footnotetext{
${ }^{40}$ 27. tr. Simular, aparentar algo. Hace QUE estudia, QUE trabaja. Hacer QUE hacemos. [En línea] http://dle.rae.es/?w=hacer\&m=form\&o=h
} 
momentos por los que se pasa para llegar al dominio y la fluidez de la LE o si el nativo porque al aprenderla lo hace aproximándose lo más posible a la identidad de esa LE, pues resulta interesante esta discusión aunque a simple vista parezca irrelevante, y quizás lo sea de hecho al estar plenamente de acuerdo con CASSANY cuando dice que:

\footnotetext{
"Hay muchos maestros, de la misma manera que hay muchos médicos, electricistas o bomberos, por poner un ejemplo, que pronuncian mal uno o muchos sonidos, que tienen un lenguaje repleto de calcos léxicos o sintácticos de otra lengua, o que auto limitan su capacidad expresiva por miedo al error. En el caso de los maestros, podemos calificar estos hechos de mucho más graves, por sus implicaciones educativas" CASSANY (1994: 7)
}

A todo esto, para la realidad que este maravilloso país vive en sus macro y gigantescas dimensiones, se perfila como muy interesante tratar este tema para no dejarlo ir más lejos de lo que debe. Nuestra primera opinión es que el mejor profesor es aquel que alcanza sus objetivos y además inspira a sus pupilos a saber más. Otra cuestión que es interesante delimitar ante esta situación es la de cuál sería el perfil de ese profesor nativo del que se dice que es 'menos' bueno que el no nativo (más adelante abordaremos este tema nuevamente provistos del resultado de encuesta realizada para esta finalidad).

Lo de investigador (8) se cultiva y nace en la verdadera práctica de la enseñanza, superior o no, la búsqueda de más, de compartir y de hacer mejor; pero en buena parte es lo que se dice en (9): el profesor de LE vive en soledad, en cada escuela suele ser uno, a lo mucho dos, hay relatos que muestran que a la hora de escribir el plan de trabajo para el año escolar, este es dispensado porque no encaja en ninguno de los otros grupos, grupo de profesores de matemáticas, de portugués, de ciencias, de historia, de física, etc.

CELANE (2009) afirma que los profesores de LE deberían tener perfeccionamiento lingüístico y además dice que esto en primer lugar, por supuesto que sí, pero creemos que tendría que haber un modo de hacerlo permanentemente $y$ que fuera de responsabilidad de quien lo forma. El profesor de LE, como cualquier otro profesor, trabaja por lo general en dos o 
tres escuelas, con eso tiene que preparar estrategias y materiales, no dispone de tiempo durante el día en el periodo académico, y otra clara razón es la inversión financiera que necesita hacer para avanzar en el dominio y fluidez de la lengua que enseña y que, a nuestro entender, tendría que haber aprendido en un porcentaje bastante significativo durante los cuatro años de formación en la enseñanza de grado. Pensamos que uno de los mayores problemas está ahí, el círculo vicioso que ya existe: el profesor de grado que no tiene un dominio fluido y forma al profesor de educación básica y tampoco lo tiene y el alumno de educación básica que, tras 8 años de estudio de LE, tampoco sabe usarla ni instrumentalmente y el ciclo se repite, sucesivamente. Sin contar que existe el perfil de profesor de grado de LE que exonera de toda responsabilidad el proceso de formación docente en relación al conocimiento y fluidez de la lengua, y afirman que ese conocimiento se debe aprender en las escuelas especializadas de idiomas. Hay muchas incongruencias que explican los problemas que existen, pero llegar a un consenso de forma madura, responsable y sobre todo profesional es difícil. Si esas situaciones se viven en pequeños grupos de docentes de grado en un estado, no imaginamos la dimensión en todo el país.

\subsection{LA FORMACIÓN DEL PROFESORADO DE ESPAÑOL COMO LENGUA EXTRANJERA (ELE)}

La formación en nivel de graduación de profesores de lengua española en Brasil no ha sido nunca tan intensa como en los últimos 10 años y también hay que señalar que más en algunos Estados del país que en otros, y con intensidades muy diferentes.

Al institucionalizarse la enseñanza de español con carácter optativo en la educación básica formal, hace casi un siglo y por primera vez en el Colégio Pedro II, en Rio de Janeiro, se inicia un peregrinaje sufrido hasta conseguir llegar al estatus que se ha alcanzado hoy y, sobre todo, a contemplar esta lengua extranjera como un aliado necesario en la formación integral del individuo. 
Por razones lógicas de orden cultural, geográfico, estratégico, comercial, económico, social y por muchas otras, aprender lengua española para el brasileño se tornó un requisito de importante presencia en su formación integral, a pesar del difícil y arduo trayecto al no encontrar en los estudios de educación básica un cobijo adecuado para ello. En la actualidad, ya se ve con claridad la posibilidad de beneficios y oportunidades de desarrollo que el conocer una LE puede suponer para el individuo, y este convencimiento alcanza al ciudadano común, aunque observa pasivo su paso por la educación básica sin lograr un avance cualitativo de aprendizaje. Esto es lo preocupante.

Aunque el estudio de una lengua extranjera registre históricamente en Brasil una escasa valoración frente a las demás asignaturas escolares, cabe señalar que, desde siempre, la América hispana y lusófona ha tenido una relación estrecha y directa con lo extranjero, lo que hoy en día no hace más que confirmarse, y sumarse es lo que se intenta desde siempre, en especial desde 1930 con la creación del Ministerio de Educación y Cultura (MEC) cuya función hasta hoy es la de reglamentar, organizar y administrar la educación nacional.

Con el MEC en actuación, por primera vez se defiende la gratuidad, la autonomía y la descentralización de los procesos educativos y, por supuesto, se empieza a destacar el tema de la formación del profesorado en el entonces Instituto de Educação de Sao Paulo. Más tarde, en la Constitución de 1937 se dice:

\begin{abstract}
Artículo 15 - Es de única competencia de la Unión: [...]
IX - Establecer las bases y determinar los cuadros de la educación nacional, trazando las directrices que deben obedecer La formación física, intelectual y moral de la infancia y la juventud; [...]"41 (Traducción nuestra)
\end{abstract}

Aunque esta Constitución brasileña no explicita nada directamente respecto de la formación de profesores de lengua extranjera o de su enseñanza

\footnotetext{
41 Texto original en portugués: “Art. 15 - compete privativamente à União: [...]; IV - fixar as bases e determinar os quadros da educação nacional, traçando as diretrizes a que deve obedecer à formação física, intelectual mora da infância e da juventude; [...]" [En línea] http://www.planalto.gov.br/ccivil_03/Constituicao/Constituicao37.htm
} 
(pues sí lo hace de religión, educación física y orientación pre-vocacional) deducimos que este asunto se encuentra incluido en el artículo 128:

\section{"DE LA EDUCACIÓN Y DE LA CULTURA;}

Artículo 128 - El arte, la ciencia y la enseñanza son libres a la iniciativa individual y a la de asociaciones o personas colectivas públicas y particulares. Es deber del Estado contribuir, directa e indirectamente, para el estímulo y desarrollo de una y de otro, favoreciendo o fundando instituciones artísticas, científicas y de enseñanza" [... $]^{42}$ (Traducción nuestra).

Lo más importante en este momento de la educación brasileña es el llamamiento a los profesores a profesionalizarse para asumir de hecho la enseñanza primaria por ser obligatoria, y también la secundaria y superior, pues en esta ley se habla de "infancia y juventud". En este tiempo (1937), aún existía el molde del curso 'normal', creado en 1830, para preparar a los profesores de la escuela primaria, que además habilitaba administradores escolares para la misma finalidad. El tiempo de formación de profesores en el curso 'normal' era de 4 años.

A todo esto, es importante decir que el modelo escolar, a lo largo de todos los tiempos en Brasil, ha tenido siempre, si no origen, al menos mucha influencia europea para cuestiones de orden teórico; prueba de ello, en la actualidad y en el campo de ELE en Brasil, es la influencia del Marco común europeo de referencia ${ }^{43}$ con sus parámetros aplicados a la hora de delimitar las competencias y habilidades lingüísticas que según cada nivel de lengua extranjera se debe alcanzar. No obstante, y sobre el origen de la formación de profesores vemos una notoria implicación con diversos componentes que no se

\footnotetext{
42 Texto original en portugués: “DA EDUCAÇÃO E DA CULTURA; Art 128 - A arte, a ciência e o ensino são livres à iniciativa individual e a de associações ou pessoas coletivas públicas e particulares. - É dever do Estado contribuir, direta e indiretamente, para o estímulo e desenvolvimento de umas e de outro, favorecendo ou fundando instituições artísticas, científicas e de ensino" [En línea] http://www.planalto.gov.br/ccivil_03/Constituicao/Constituicao37.htm

${ }^{43}$ El Marco común europeo de referencia para las lenguas: aprendizaje, enseñanza, evaluación forma parte esencial del proyecto general de política lingüística del Consejo de Europa, que ha desarrollado un considerable y bien fundamentado esfuerzo por la unificación de directrices para el aprendizaje y la enseñanza de lenguas dentro del contexto europeo. [En línea] http://cvc.cervantes.es/ensenanza/biblioteca_ele/marco/cvc_mer.pdf
} 
visualizan en registros oficiales pero se evidencian en la investigación histórica, son aspectos y factores internos y externos que influyen directamente en las decisiones de cómo hacer la educación. Esa realidad no es diferente en la actual formación de profesores en general, pues de una u otra forma se siguen orientaciones de organismos internacionales que directa o indirectamente participan en su financiamiento o se siguen modelos que se aplican en otros países, lo que puede significar un perjuicio si no se observa la singularidad y diversidad de este pueblo brasileño.

Desde entonces, hasta hoy, en todos los estados brasileños hay por lo menos una Institución de Enseñanza Superior que oferta el curso de Licenciatura / Letras Lengua Española, sea esta una universidad pública o privada o un Instituto Federal ${ }^{44}$ que forma profesores. El Gobierno federal, preocupado por la calidad de la educación y por la formación de los docentes de la enseñanza básica establece por decreto ${ }^{45}$ el "Plano de Metas Compromisso Todos pela Educação"46, en el que se ampara la formación de los profesores exigida por la LDBEN, según consta en el artículo 62:

"La formación de docentes para actuar en la educación básica se hará en nivel superior, en curso de licenciatura, de graduación plena, en

\footnotetext{
${ }^{44}$ Los Institutos federales en Brasil, son instituciones públicas de educación que surgen en 1909 como Escola de aprendizes Artífices en las que se ofrecía curso primario de dibujo y talleres de trabajos manuales. Durante un siglo de historia, muchos cambios ocurrieron en su estructura, denominación, oferta de cursos, habiendo destaque para cursos en el campo de la industria, en 1942. Los cambios continuaron, en 1959 se convirtieron en una autarquía, que los transforma en instituciones federales. Actualmente, cada estado brasileño tiene al menos un campus y el de Rio Grande do Norte se denomina Instituto Federal de ciência, educação e tecnologia do Rio Grande do Norte (IFRN), habiendo pasado por las denominaciones Escola industrial Federal do Rio Grande do Norte (EIFRN), Escola Técnica federal do Rio Grande do Norte (ETFRN) y Centro Federal de educação tecnológica do Rio Grande do Norte, como también ha ocurrido para los demás estados del país. La nueva y actual institucionalización entró en vigor en 2008 y por opción, pasaron a ser instituciones pluri curriculares y multi campi de educación superior, básica y profesional, redefiniendo el sistema de enseñanza brasileño. Esta nueva identidad de los institutos federales reforzó su autonomía administrativa, patrimonial, financiera, didácticopedagógico y disciplinar imprimiendo equivalencia a la oferta universitaria en lo que respecta a las disposiciones que rigen la reglamentación, evaluación y supervisión de las instituciones y de los cursos de educación superior.

45 El Decreto $n^{\circ} 6.094$ establece en el país un régimen de colaboración entre todos los órganos federativos: la Unión, los Estados y los Municipios, en el que se insta una movilización social que priorice mejoras y calidad en la educación, además de asegurar formación en nivel de graduación a todos los profesores de la educación básica.

${ }^{46}$ En español: Plan de Metas Compromiso Todos por la Educación.
} 
universidades e institutos superiores de educación, admitida como formación mínima para el ejercicio del magisterio en la educación infantil y en las cuatro primeras series de enseñanza fundamental hasta la ofrecida en nivel" medio, en la modalidad Normal. (BRASIL, 2011, p.34) $)^{47}$ (Traducción nuestra).

La enseñanza de lengua extranjera en la educación básica formal en Brasil y más precisamente, la enseñanza de lengua española lleva ya casi un siglo: desde la incursión institucionalizada y electiva para los alumnos del Colégio Pedro II, en Rio de Janeiro, en 1919 hasta 2005 con la ley 11.161 que habla de la oferta obligatoria en la enseñanza básica, por supuesto con largos y varios periodos de ausencia en la educación básica y además muchos entrabes que no es prioritario tratar ahora en esta investigación, por lo que solo nos referiremos a ello si puntualmente fuera necesario.

El marco de la incursión formal de la lengua española en la educación básica brasileña está en la promulgación de la ley del español ${ }^{48}$, que determina la oferta obligatoria, en horario regular y de forma gradual en la educación secundaria y a partir del $6^{\circ}$ curso en la enseñanza fundamental, es así que se nota plenamente la necesidad de más, de muchos más profesores de español.

A partir de entonces, una serie de leyes, resoluciones, orientaciones curriculares nacionales, entre otros documentos emitidos por el gobierno federal han ido surgiendo en la educación superior brasileña, buscando reglar y normalizar la formación del profesorado de lengua española en el sistema de educación superior y a servicio del sistema educativo básico y sobre todo público.

Si aprender a aprender ya significa un amplio universo de teorías, enseñar a enseñar suscita también un vasto campo de estudio según las especialidades y/o especificidades de que se trate. En principio, se ratifica la comprensión de que cada individuo aprende de una forma diferente; no obstante, el auge de estos estudios no lleva más que algunas décadas; si cada

\footnotetext{
${ }^{47}$ Versión original: "A formação de docentes para atuar na educação básica far-se-á em nível superior, em curso de licenciatura, de graduação plena, em universidades e institutos superiores de educação, admitida, como formação mínima para o exercício do magistério na educação infantil e nas quatro primeiras séries do ensino fundamental, a oferecida em nível médio, na modalidade Normal. [...]

${ }^{48}$ Ley $n^{\circ} 11.161$ del 05 de agosto de 2005.
} 
uno aprende de forma diferente, por ende, deberá enseñarse de maneras diferentes, apropiándose del pensamiento, reflexión y construcción del conocimiento según su manera, organizándose según las herramientas cognitivas, estrategias, estilos y habilidades destinadas, según su criterio, a construir el conocimiento. A diferentes formas de aprender, le corresponden diferentes formas de enseñar que pueden generar aspectos facilitadores o dificultadores en la tarea del enseñar.

La enseñanza de grado en ELE, es joven, muy joven en este estado brasileño, solo este punto ya supone un indicador de fragilidad en la calidad del trabajo que se realiza para algunas IES, sobre todo las del norte y nordeste brasileño, como lo señaló en su momento MARTíNEZ-CAHERO:

\footnotetext{
"La región nordeste es el área más deprimida del país y, como suele ser habitual, las variables económicas tienen su reflejo en las estadísticas educativas generales y en las del español en particular. Hace una década solo se tenían noticias sobre la enseñanza del español en el estado de Bahía, donde hay una importante colonia española, y [...] (MARTíNEZ-CACHERO, 2008).
}

Pero lo que se tiene en contrapartida es el fuerte deseo de superar las dificultades y aprender, continuar aprendiendo para hacer mejor el trabajo que el profesorado de ELE tiene en manos y su propósito mayor es el de contribuir a la formación integral del ciudadano de estos tiempos de globalización, interrelación mundial, tecnología y comunicación en todo ello.

Las IES que ofertan este grado han surgido una a una, en tiempos diferentes, con fuerzas y fragilidades diferentes también. Cronológicamente, la IES-2 inició actividades académicas en grado de ELE en el año 2000 y su más fuerte dificultad ha sido exactamente componer el cuerpo docente para las asignaturas específicas del curso. La IES-3 fue la segunda, inició actividades en 2006 y a pesar de las dificultades que en aquel tiempo eran muy serias, al menos pudo contar con 3 profesores preparados para asumir las asignaturas específicas, dos de los cuales eran profesores y nativos de lengua española, además contaba con el apoyo del gobierno español a través de la Embajada de España. La IES-1 ha sido la tercera y última en el Estado de Rio Grande do 
Norte, inició sus actividades en 2009 cercada de mucha expectativa en la comunidad porque de alguna forma influía en la decisión del ciudadano de estudiar inglés o español para seguir estudios de grado. Las dificultades de esta IES-1 también se relacionaban con el cuerpo docente para asumir las asignaturas de cuño específico, aunque contaba con el respaldo de plantillas docentes de grado de otras lenguas extranjeras como inglés y francés.

\subsection{1 ¿Qué español enseñar?}

Esta discusión es antigua en suelo brasileño, antes de la promulgación de la ley del español en 2005, en las escuelas de idiomas que ofrecían el curso de español había lo de 'el español que se enseña aquí es el de España' o 'tenemos un profesor español' o 'los profesores son nativos'. Era tal el desconocimiento del brasileño sobre este tema que se llegaban a afirmar cosas como: 'español no se habla en Sudamérica, español es solo el de España" o entonces, 'español y castellano son cosas diferentes, el primero es de España, el mejor; el segundo es de Sudamérica, bueno...' y había personas que para elegir donde estudiarían, primero visitaban las escuelas de idiomas verificando qué profesores había y solían decir "solo quiero aprender el español de España y con profesor nativo'; en fin, era deprimente lo que pasaba, pero todo esto con el paso del tiempo se ha superado positivamente, aunque han ido llegando nuevos posicionamientos considerados de una u otra forma desfavorables, pero ya en otros ámbitos y que de alguna forma interfieren en el éxito de la tarea de aprender y/o enseñar lengua española.

Actualmente, ya se tiene claro que el español es una lengua hablada en muchas naciones y que esta obedece la forma de un único código, pero con particularidades o diríamos singularidades de orden léxico, fonético, pragmático que hace a cada una un dialecto. Sin embargo, tras la implementación de la ley del español buena parte de los profesores eran nativos de lengua española naturalizados brasileños y claro, cada uno tenía una identidad lingüística diferente, el argentino con el voseo, el chileno con su entonación particular, el colombiano con su velocidad de elocución, ambos con el ustedeo parcial, el 
español con el uso de [e] y algunos no, en fin, tantos más, tantas identidades tantas variantes.

Entonces, el bloque de profesores de español que inicia su actuación docente en los cursos de grado de ELE en Rio Grande do Norte, es mixta, compuesta de profesores no nativos (los nacidos en países hispanófonos) y nativos (profesores nacidos en Brasil). Al ser así, la labor docente en los cursos de grado de ELE presenta un panorama competitivo y al mismo tiempo singular para cada IES que oferta el curso, a saber: la IES-1, al ser la que inició la tarea de formar profesores más tarde, tuvo mejores oportunidades de formar su cuadro docente con relativa facilidad y además al requerir doctores consigue profesores con mejor titulación y entre ellos también nativos de ELE, lo que significa para los nativos buscar aproximarse lo más posible a la lengua extranjera que enseñan.

En la IES-2, la primera en ofertar grado en ELE, conforma su cuadro docente con mayoría de profesores nativos (de Brasil), lo que a los días de hoy aún le supone desventajas serias en la formación lingüística del alumnado de grado que termina la carrera sin un dominio al menos aceptable de ELE, dejando evidente la necesidad de complementar esos conocimientos fuera de la universidad, algo que pocos hacen en virtud de la necesidad de colocarse en el mercado de trabajo y organizar su vida personal y profesional. De esa forma, aunque organice su vida, difícilmente retoma los estudios de lengua española porque actuar en la educación básica y pública no le demanda esfuerzo y no tiene incentivo desde ningún punto de vista para invertir tiempo y dinero en ese complemento o, a veces, implemento de la lengua española que enseña.

El sistema educativo brasileño desde los gestores educacionales que están en el ministerio de educación y cultura hasta los directores de las escuelas de educación básica, respetando la jerarquía y autoridad, van teniendo discursos que se diferencian y se reflejan en el desánimo de la actuación del docente de ELE y por ende desánimo en el deseo de buscar proveerse del conocimiento y dominio de aquello que es su especificidad de actuación profesional. Esto con el paso del tiempo ya va traduciéndose a otros discursos que expondremos en el capítulo siguiente con más detalle y análisis, 
son cuestiones relacionados a justificativas que se van fortaleciendo para el hecho de no hacer falta mejorar el nivel de lengua española.

Como se ve, la discusión ya no va tanto en la sintonía de qué español enseñar sino del cuánto español hace falta saber para ser profesor de español con curso superior. En la IES-3, de inicio, se realizó un trabajo muy interesante en medio a una alianza fuerte de conocimientos y saberes que rindió muy buenos frutos, el equipo de profesores de asignaturas de cuño pedagógico y el de asignaturas de cuño específico se aliaron y el resultado de ese trabajo se torna visible al decir que varios de aquellos que fueron alumnos de grado, ahora conforman el cuadro de docentes de la IES1 e IES3. No obstante, aun así se presentan problemas serios de abandono, y sobre eso se buscan respuestas.

Por lo dicho, a día de hoy, se observa en el cotidiano de la educación, en lo que respecta a la enseñanza de LE y consecuentemente de ELE, que existe de hecho un círculo que empieza, se entrelaza y termina en el mismo punto: en la dependencia de una preparación adecuada de los profesores de ELE tanto pedagógica como lingüística y que, además, queda evidente la incidencia de compromiso de unos y otros. El punto de partida puede estar en las IES que forman el profesorado, en el perfil del nuevo profesor, o en el trabajo que este desarrolle en su actuación docente.

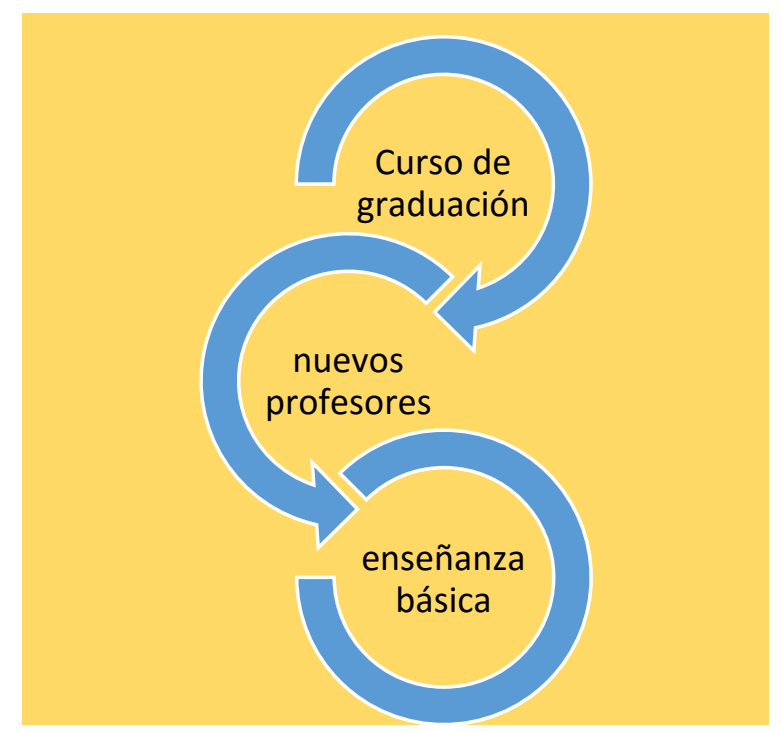

Figura 4 - Principio, medio y fin del aprendizaje de $L E$ (Creado por el autor) 
A nuestro humilde ver, la preocupación no debería estar en cuestiones como la de qué español enseñar, ni tampoco en si el mejor profesor es el no nativo (el nacido en país hispanófono) o el nativo (nacido en Brasil), lo que debe preocupar de hecho en este tema de formación de profesores de ELE, son cuestiones del tipo que aborda CELANE:

"A formação deficiente de professores em faculdades sem qualidade que se proliferam pelo país e a escassez de programas de Educação continuada bem organizados são apenas dois dos desafios enfrentados no ensino de Língua Estrangeira. Outra questão, somada a essas, torna o cenário ainda mais desafiador: a ausência de uma política clara - em nível nacional -, o que leva a disciplina a uma posição secundária dentro do currículo". (CELANE, 2009).

Para que la realidad de la enseñanza de ELE y del producto que genera este proceso que es el aprendizaje y dominio suficiente para una buena comunicación en ELE, hace falta enfocar estas 3 partes fundamentales: formación, a través del curso de graduación - estudiantes de grado, futuros profesores de ELE y enseñanza de ELE en las escuelas públicas, partes aparentemente desconectadas en la práctica y que al parecer no se plantean claramente el objetivo de estar unos bien preparados para enseñar ELE y otros bien atentos a la calidad de esa enseñanza en pro de un aprendizaje real de ELE para comunicarse razonablemente, propósito que plantea el MEC-Brasil para los ciudadanos brasileños durante sus estudios primarios y secundarios.

Algo falla y no se consigue explicar el qué ocurre o deja de ocurrir para que en la escuela de enseñanza básica no se consiga aprender una lengua extranjera con razonable fluidez oral y escrita y buen nivel de comprensión, o al menos, significativa, que permita "vivir experiencias de comunicación humana a través del uso de una lengua extranjera" en un nivel apreciable de comprensión y calidad. 
Hilvanar un discurso es darle conectividad, lógica, secuencia, armonía y sobre todo un sentido macro, todo eso tiene relación directa con el papel que los marcadores del discurso desempeñan en el acto de comunicarse y que, al parecer, brillan por su ausencia en la oralidad casi inexistente del alumnado de educación básica y también limitada de muchos profesores de grado nativos de Brasil.

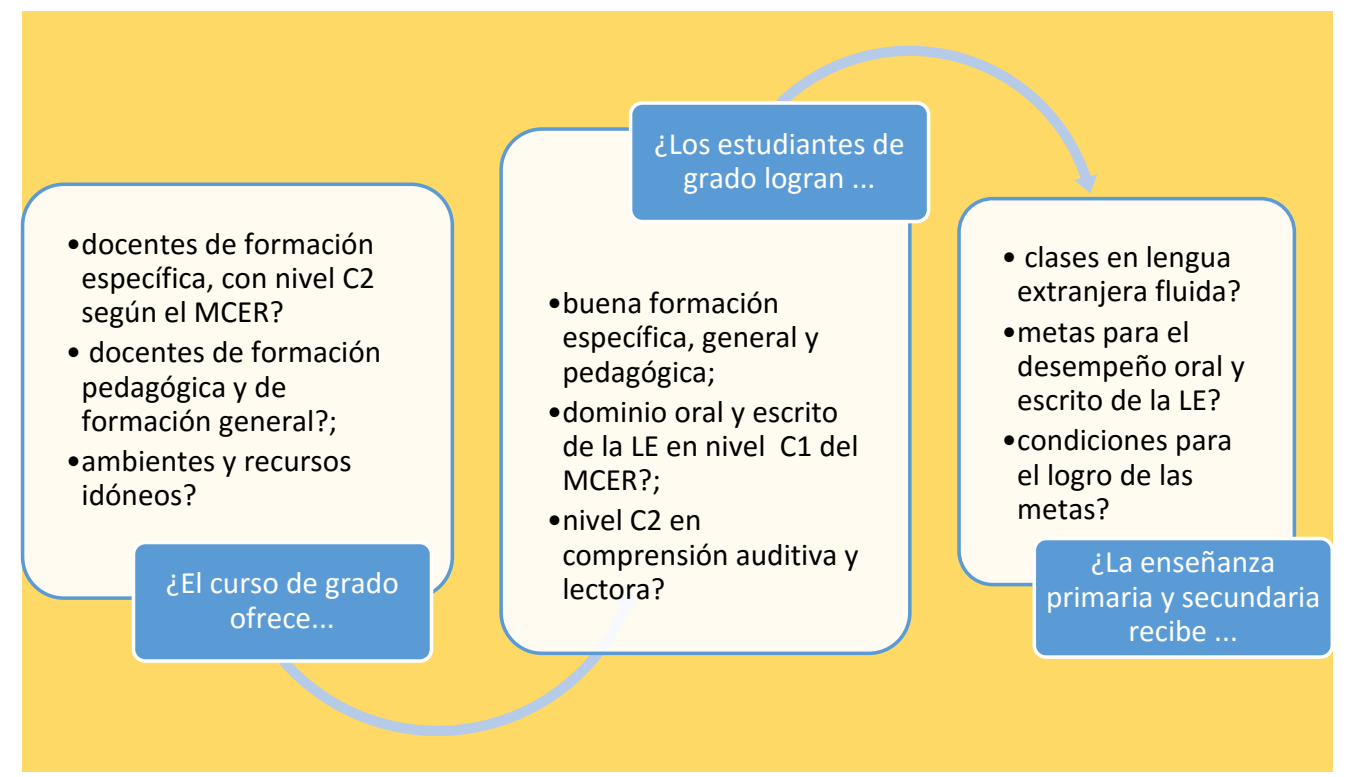

Figura 5 - Flujo de preguntas sobre aprendizaje y enseñanza de ELE (Creada por el autor)

\subsection{2 ¿Entrenar o formar un profesor de ele?}

Las instituciones de enseñanza superior tienen como finalidad formar el profesor de ELE, sin duda; no obstante, es muy común captar mensajes diferentes cuando se habla de entrenar como formar y viceversa. Es evidente que son cosas muy diferentes y probablemente sea este el punto de partida de necesaria aclaración para que prevalezca el entendimiento de que el profesor de ELE debe surgir de la enseñanza de grado y no de cortos cursos, como parece prevalecer hasta el día de hoy desde cuando hubo un programa de emergencia en este Estado para habilitar profesores de ELE con un 'entrenamiento o capacitación' de 120 horas: 
Para solucionar el problema la SEDUC ${ }^{49}$ optó por dar a finales de 2007 un curso de capacitación para profesores de otras materias [...] con objeto de que estos puedan asumir la disciplina de español en las escuelas. Estos docentes hicieron una capacitación de 120 horas, realizada en dieciséis fines de semana consecutivos. Siendo la Universidad del Estado de Rio Grande do Norte (UERN) la institución responsable de la formación de estos profesores en [...].

El resultado final fue que 279 profesores de portugués y/o inglés pasaron a estar capacitados para la enseñanza del español. MARTÍNEZ-CACHERO, 2008)

Esta medida de emergencia tomada por la SEDUC, hoy, provoca situaciones que perjudican el avance en el proceso de enseñanza de español en la escuela pública, los profesores de otras materias no ceden la enseñanza de español que se les adjudicó para los formados en español, aprobados en procesos selectivos para el desempeño formal de la función, pues los primeros se dicen también cualificados para la finalidad y a esto se suman cuestiones de antigüedad, jerarquía, etc. se imponen obstaculizando que los profesores FORMADOS en enseñanza de grado en ELE asuman la tarea para la que de hecho han sido preparados con el consecuente perjuicio para el aprendizaje de español en la escuela pública y básica.

El tema no es exactamente que estén cualificados o no, igual puedan estarlo en virtud de estudio y experiencia personal, pero no es una formación reglada y específica y, lo que sí, es que esta situación se refleja en otros ámbitos como en el ánimo de seguir la carrera de profesor de español por no haber plazas en el mercado de trabajo, se refleja en el ánimo y la entrega a perfeccionar competencias lingüísticas, para qué si los que están actuando como profesores solo tienen 120 horas de español, también afecta al ánimo y la ilusión de volcarse profesionalmente para lograr metas, es decir, todo contribuyendo a falta de calidad y por supuesto, resultados imprevisibles, ¿o previsibles?

Cabe añadir que la desvalorización de la enseñanza de español en la educación básica tiene, además, un estigma de 'menos' ante la lengua inglesa

\footnotetext{
${ }^{49}$ Secretaria de educación del estado de Rio Grande do Norte.
} 
que se manifiesta en los 50 minutos $^{50}$ semanales de clase para español contra los 100 para inglés y la justificación de esto no queda clara; aunque lo que no ofrece dudas es que esta situación no es exactamente porque falten profesores de español para dar las clases.

Es necesario comentar que es de sentido común esperar que alguien que cursó grado en Historia, sepa historia y si en Geografía, sepa geografía, en Matemáticas, pues matemáticas; de ahí surge la pregunta por qué el que cursa grado en ELE no conoce lo suficiente de ELE, y más al tenerlo como objetivo de ese grado:

O profissional de língua estrangeira trabalhará em instituições públicas e privadas de ensino,[...] Por conseguinte, poderá assumir as seguintes funções:

- de docente na rede pública e privada;

- de tradutor de textos;

- de revisor de textos.

- de assessor e consultor de empresas.

- de produtor e divulgador dos saberes científicos e tecnológicos no âmbito educativo, escrevendo e elaborando artigos, teses, livros, pareceres e aulas;

- de ferramenta social em programas de difusão da língua estrangeira nas escolas de ensino fundamental e médio, executando assim o aprendizado do idioma como instrumento de ascensão social. PPP, 2006 [En línea] https://goo.gl/WHmEEm

Se puede apreciar en los siguientes textos en las figuras 6 y 7 :

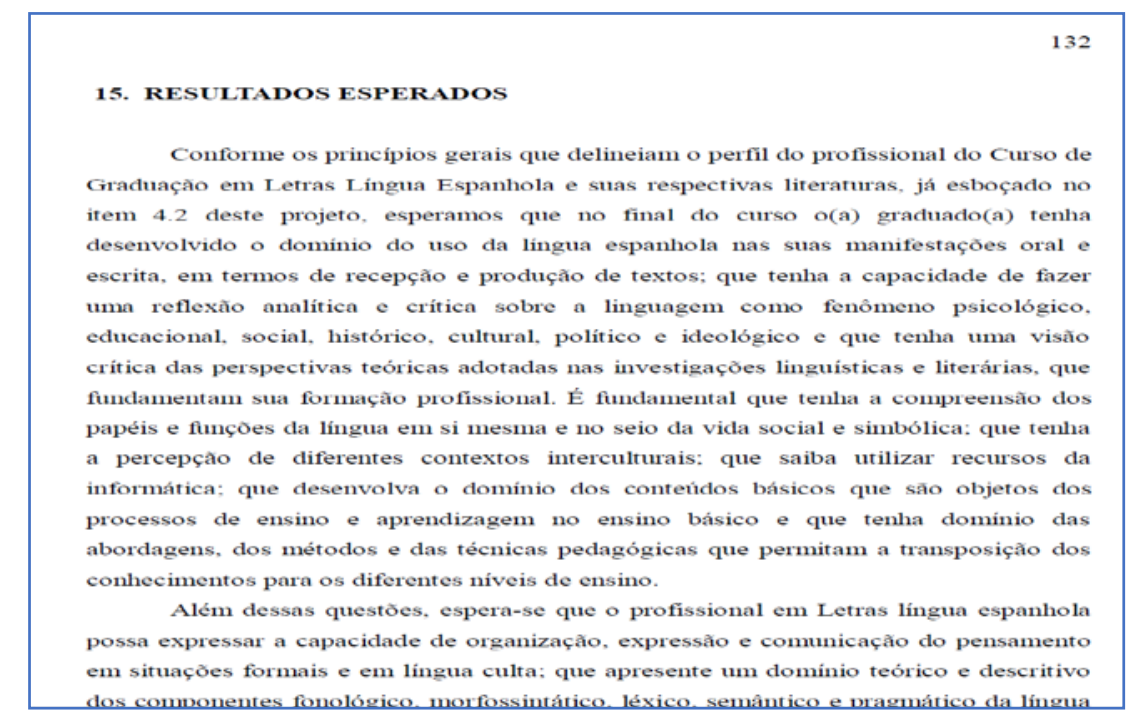

Figura 6 - Plan de estudios de la IES-2.

Fuente: Projeto P. Pedagógico do curso [En línea] http://goo.gl/jlJ9hY

50 Duración de la hora de clase en la educación brasileña. 


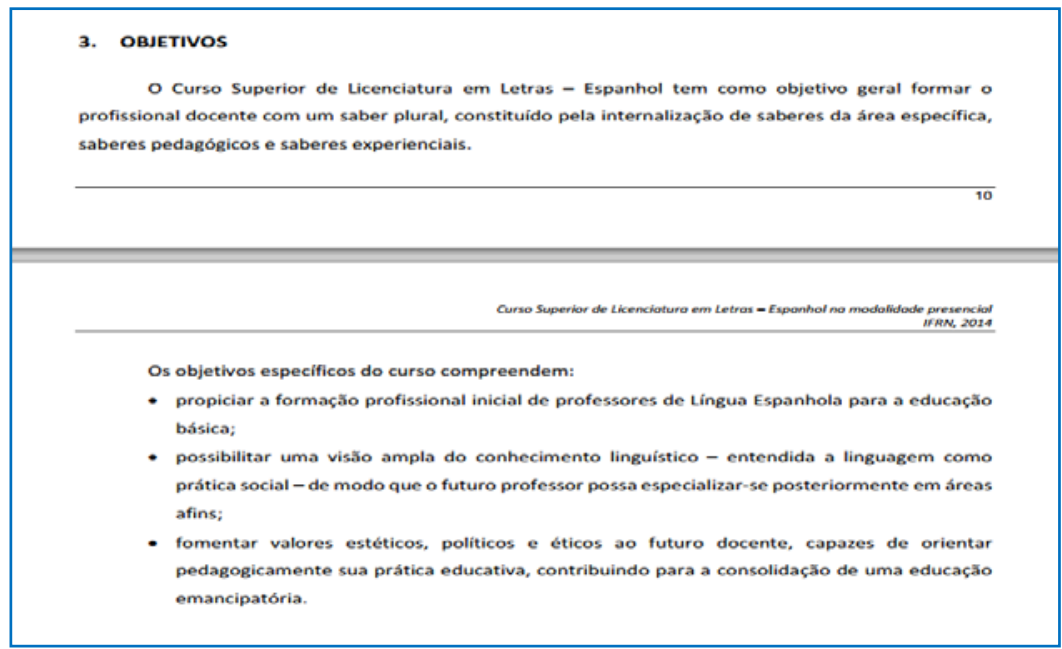

Figura 7 - Plan de estudios de la IES-3.

Fuente: Projeto Pedagógico Espanhol. [En línea] http://goo.gl/Qkx50B

Por lo expuesto, 'entrenar' en el sentido de 'capacitar' no es lo suficiente para que se establezca calidad en la enseñanza de ELE en Brasil, más bien sí 'formar' al profesor en instituciones con cursos de grado, pensamos que capacitar es el tipo de cualificación complementaria que podría y debería ser posterior al grado y además de flujo continuo. De esto se hablará más ampliamente en el capítulo III de este trabajo. Pero al respecto, no viene mal contrastar el significado de lo que es entrenar y formar en español y portugués para no caer en el vacío de la carga semántica cultural de cada lengua.

Cuadro 2 Contraste del significado entre formar y entrenar

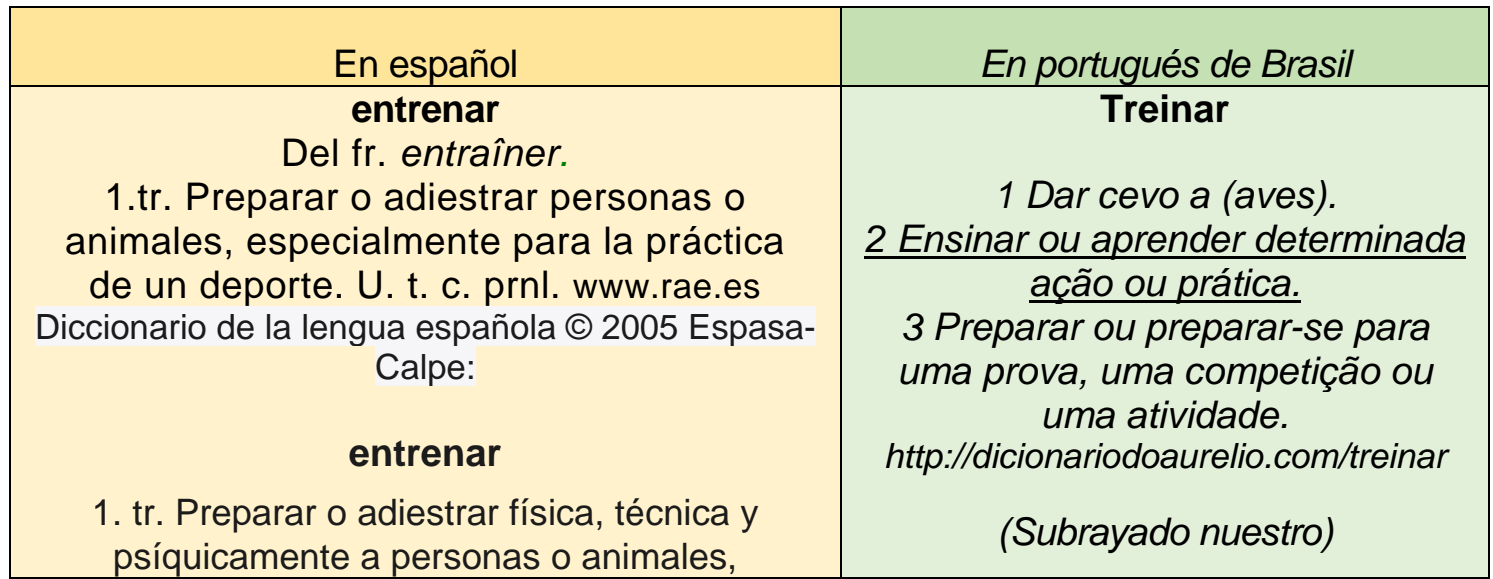


especialmente para mejorar el dominio de un deporte. También prnl. e intr.:

se entrenaban cinco días a la semana.

2. Adiestrar a alguien en el manejo de algo.

También prnl.: se entrenaba con el coche para

mejorar sus reflejos.

http://www.wordreference.com/definicion/entrenar formar

Del lat. formāre.

1. tr. Dar forma a algo.

2. tr. Juntar y congregar personas o cosas, uniéndolas entre sí para que hagan aquellas un cuerpo y estas un todo.

3. tr. Dicho de dos o más personas o cosas: Hacer o componer el todo del cual son partes.

4. tr. Preparar intelectual, moral o profesionalmente a una persona o a un grupo de personas.

5. tr. Mil. Poner en orden.

Formar el escuadrón.

6. tr. Méx. Preparar el formato de las páginas de un texto, hasta dejarlas listas para imprimir.

7. intr. Dicho de una persona:

Colocarse en una formación, cortejo, etc. 8. intr. [...].

9. prnl. Dicho de una persona: Adquirir preparación intelectual, moral o profesional. (subrayados nuestros) www.rae.es

\section{Formar}

1 Dar corpo ou forma a.

2 Constituir.

3 Organizar.

4 Fundar.

5 Conceber; imaginar. 6 Preparar. 7 Amoldar. 8 Instruir, educar. 9 Traçar.

10 Descrever, criar. 11 Alinhar.

12 Estabelecer. 13 Planear; promover a formatura de.

14 Entrar na forma, em linha. 15 Tomar forma.

16 Receber ensinamentos. 17 Doutorar-se.

http://dicionariodoaurelio.com/forma $r$

(subrayados nuestros)

(Creado por el autor)

Se deduce, a partir de lo presentado en el cuadro anterior:

$\checkmark$ No hay equivalencia semántica para el verbo 'entrenar' - 'treinar' en español y portugués;

$\checkmark$ En portugués, treinar equivale a 'capacitar' del español; por lo tanto, el sustantivo 'entrenamiento' no debe ser usado en el lugar de 'treinamento' de la lengua portuguesa, sino 'capacitación';

$\checkmark$ El verbo 'formar' sí tiene equivalencias semánticas, pero no hay registro de que su realización sea necesariamente en nivel superior.

Aclarado este punto, vale añadir que al formar profesores, el cúmulo de informaciones deja de ser solo eso, informaciones, sean estas léxicas, morfológicas, semánticas, sintácticas, pragmáticas, para convertirse en 
cuestiones con respaldo teórico que llevarán al profesor hacia una consciencia lingüística real. Para empezar, un profesor debe ser investigador de su propia práctica, y no mero repetidor de contenidos. Para que haya capacitaciones tendría que haber primero formación y desde siempre estudios e investigación, de esta forma el profesor establece relación y fusión entre la experiencia y la reflexión de su práctica, la misma que compartida tiende a aportar positivamente para sí y para los demás profesores.

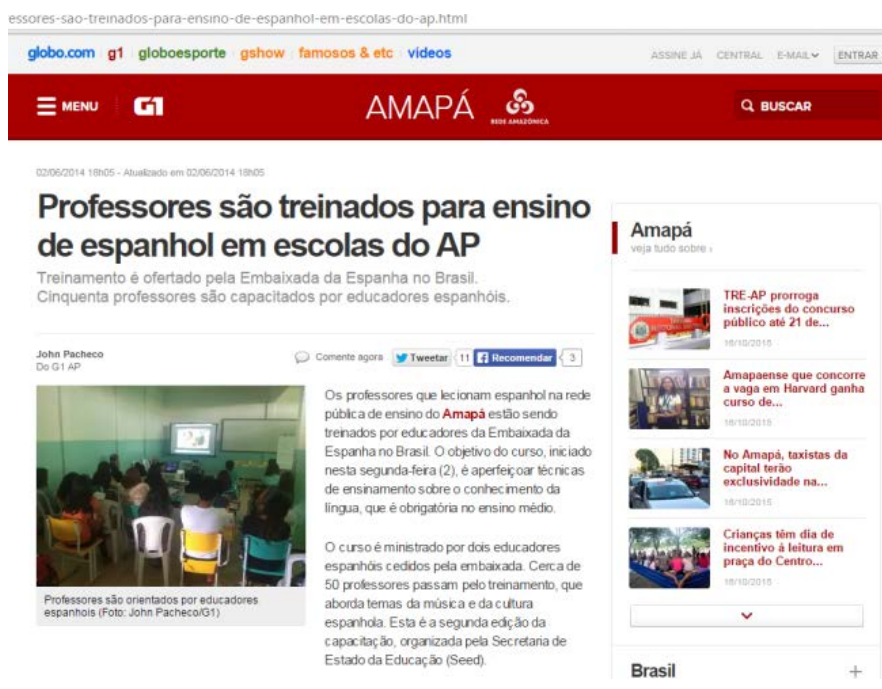

Figura 8 - Aplicación del verbo treinar Fuente: [En línea] http://goo.gl/rYJCHc

Para finalizar, en la figura superior, lo de "professores que são treinados para o ensino de espanhol..." ya queda claro que debe establecer equivalencia a español como "profesores son capacitados para la enseñanza de español", y no "entrenados".

\subsubsection{Programas de estímulo a la formación y labor del docente de ELE}

En 2009, el Ministerio de Educación y Cultura (MEC) publicó ${ }^{51}$ en su sitio de internet una lista de 26 programas destinados a la formación de profesores

\footnotetext{
51 [En línea] http://portal.mec.gov.br/component/content/article?id=15944
} 
de educación básica, programas estos que también benefician la formación del profresorado de ELE. De esa forma durante el curso de grado, los estudiantes de ELE van insertándose en los diversos y programas del gobierno federal que aportan interesantes experiencias a los alumnos de ELE.

De los 26 programas creados, citamos aquí aquellos que inciden relevantemente en el grado en ELE:

$\checkmark$ Programa de Formación Inicial y Continuada, Presencial y a Distancia, de Profesores para la Educación Básica (PARFOR) ${ }^{52}$

Creado para elevar el patrón de calidad de la formación del profesorado de la educación básica en territorio nacional. Su objetivo es ofrecer cursos de formación inicial de emergencia, según demandas indicadas en el foro estatal permanente de apoyo al profesor. Este programa está en aplicación en Rio Grande do Norte y las IES públicas participan plenamente.

\section{$\checkmark$ Programa Institucional de Beca de Iniciación a la Docencia (PIBID) ${ }^{53}$}

Programa al que la mayoría de los estudiantes aspira participar y como el nombre del programa ya dice, estos estudiantes se organizan bajo la orientación de un docente de grado para actuar en la enseñanza de español a modo de práctica profesional, perciben una beca mensual durante el periodo que están vinculados al programa. Objetivos: incentivar la formación docente en nivel superior para la educación básica elevando la calidad de las acciones académicas en los curso de grado; promover la integración entre la educación superior y la educación básica; insertar el alumnado de grado de ELE en el cotidiano de la escuela pública proporcionando la oportunidad de conocer la realidad y los problemas del proceso de enseñanza y aprendizaje;

\footnotetext{
52 Texto original en portugués: Programa de Formação Inicial e Continuada, Presencial e a Distância, de Professores para a Educação Básica (PARFOR)

53 Texto original en portugués: Programa Institucional de Bolsa de Iniciação à Docência (PIBID) Este programa del gobierno federal está dirigido a estudiantes de graduación pensando en el perfeccionamiento y valorización de la formación del profesorado de educación básica. Los estudiantes, bajo la orientación de un docente de grado y uno de escuela pública en actuación, desarrollan actividades didáctico-pedagógicas, promoviendo de esta forma su inserción en el cotidiano de la escuela pública. [En línea] http://www.capes.gov.br/educacao-basica/capespibid
} 
incentivar a los profesores en actividad de las escuelas públicas tornándolos protagonistas en el proceso de formación inicial para el magisterio; y dar la oportunidad de aliar la teoría a la práctica en acciones reales y que favorecen a la comunidad de la escuela pública como un todo. Este programa está en aplicación en Rio Grande do Norte y las IES públicas participan plenamente.

\section{$\checkmark$ Programa de Consolidación de las Licenciaturas (Pro docencia) ${ }^{54}$} Apoya financieramente proyectos institucionales que contribuyan a la innovación de los cursos de grado y a mejorar el proceso de enseñanza y aprendizaje de los futuros profesores y a la superación de problemas identificados en la evaluación de los cursos de licenciatura. Busca la integración entre la educación superior y la educación básica. Este programa también está en aplicación en Rio Grande do Norte y las IES públicas participan plenamente.

\section{$\checkmark$ Universidad Abierta de Brasil (UAB) ${ }^{55}$}

Oferta cursos de grado para la población con dificultades de acceso a la formación superior a través de la educación a distancia, mediado por tecnologías de información y comunicación. Su propósito es reducir la desigualdad de oferta de enseñanza de grado a las diferentes regiones del país. Actualmente, está en ejecución la enseñanza de grado en ELE con profesores formados dentro de este programa gubernamental.

\section{$\checkmark$ Portal del profesor ${ }^{56}$}

Ofrece a los educadores, en especial a los de educación básica, acceso rápido y funcional a un acervo variado de contenidos educativos multimedia y a enlaces y funcionalidades que subsidian la investigación y la interacción en la educación básica, profesional y modalidades.

$\checkmark$ PROYECTO GESTOR - Programa de posgrado en educación tecnológica - Formación de másteres para la red federal de educación profesional científica y tecnológica ${ }^{57}$

\footnotetext{
54 Texto original en portugués: Programa de Consolidação das Licenciaturas (Prodocência)

55 Texto original en portugués: Universidade Aberta do Brasil (UAB)

56 Texto original en portugués: Portal do Professor
} 
Programa desarrollado en sociedad con la Facultad de Educación de la Universidad de Brasilia y la Secretaria de Educación Profesional y Tecnológica. Su objetivo es elevar la titulación de los profesores de forma que las instituciones oferten cursos de posgrado y estimulen el desarrollo de la investigación y la innovación y contribuyan a la consolidación de los Institutos Federales de Educación, Ciencia y Tecnología.

$\checkmark$ Fondo de financiamiento al estudiante de enseñanza superior FIES

Financia prioritariamente cursos de graduación a estudiantes matriculados regularmente en instituciones privadas de enseñanza registradas en SINAES ${ }^{58}$ y con evaluación positiva. El objetivo de este programa es el de ampliar el acceso de estudiantes a la enseñanza de grado.

\section{$\checkmark$ Programa de apoyo a eventos en el país - PAEP 59}

Concede auxilio financiero a las comisiones organizadoras de eventos científicos y tecnológicos para la enseñanza de grado y básica.

$\checkmark$ Programa de cooperación internacional y becas en el Exterior ${ }^{60}$ Son acciones de apoyo, asistencia y actividades de cooperación. Su objetivo es complementar las acciones de los programas de posgrado en el país buscando una formación de alto nivel para docentes e investigadores.

\section{$\checkmark$ Programa Escuela de Altos Estudios}

Apoya visitas de corta duración a Brasil de profesores e investigadores de reconocido prestigio internacional para realizar cursos monográficos, de modo que estudiantes de grado y posgrado tengan la oportunidad de

\footnotetext{
57 Texto original en portugués: PROJETO GESTOR - Programa de Pós-Graduação em Educação Tecnológica / Formação de Mestres para a Rede Federal de Educação Profissional Científica e Tecnológica

${ }^{58}$ Texto original en portugués: Sistema Nacional de Avaliação da Educação Superior. Sistema nacional de evaluación de la educación superior (Traducción nuestra).

59 Texto original en portugués: Programa de Apoio a Eventos no País (PAEP)

60 Texto original en portugués: Programa de Cooperação Internacional e Bolsas no Exterior
} 
interaccionar. También tiene la finalidad de fortalecer, ampliar y cualificar los programas de posgrado stricto sensu de instituciones brasileñas.

En conclusión, la educación superior con la enseñanza de grado en ELE cuenta con un amplio y muy interesante respaldo por parte del gobierno federal. A priori, los estudiantes de grado tienen una fuerte estructura que acompaña su formación, entonces qué es lo que puede estar impidiendo el resultado esperado en la enseñanza de ELE en la educación básica.

\subsubsection{El marco común europeo de referencia para las lenguas (MCER) y la formación del profesorado de ELE}

El Marco común europeo de lenguas, resultado del consenso de especialistas europeos que delimitan una base común para la elaboración de programas, exámenes y evaluación aplicables a cualquier lengua, es uno de los parámetros de que echa mano el MEC-Brasil para delinear los objetivos del aprendizaje de lenguas extranjeras, en especial, de la lengua española, debido al hincapié que se hace a este respecto por el Instituto Cervantes ${ }^{61}$ :

Es de esperar que contribuya de modo importante a la mejor reflexión sobre los problemas que interesan a los profesionales de la enseñanza de lenguas $y$, de modo especial, a los de la lengua española ${ }^{62}$ CVC. (Subrayado nuestro)

Una cuestión que parece incongruente a partir del senso común es que estos parámetros sean aplicados en los programas del plan de estudios de la formación del profesorado de ELE y también en los de la educación básica y pública. A nuestro humilde parecer se hace necesario un análisis que conduzca a un redimensionamiento de las expectativas en relación al aprendizaje de

\footnotetext{
61 Institución pública, española, creada en 1991 para la promoción y la enseñanza de la lengua española y de las lenguas cooficiales y para la difusión de la cultura española e hispanoamericana. Está presente en 90 ciudades de 43 países en los cinco continentes. Tiene por finalidades: organizar cursos de lengua española y demás cooficiales; expedir certificación en nombre del MEC; actualizar métodos de enseñanza y formación de profesorado; apoyar la labor de los hispanistas; difundir la lengua española; entre otras.

62 [En línea] http://cvc.cervantes.es/ensenanza/biblioteca_ele/marco/
} 
lengua española en la educación básica, o en todo caso, un redimensionamiento de carga horaria para al menos aproximarse a las metas que el MEC propone.

Y por cierto, la vieja observación acerca del contrasentido con relación a que este documento, el MCRE, fue creado para una sociedad diferente y distante de la realidad brasileña en muchos sentidos:

El Ministerio de Educación, Cultura y Deporte se complace en poner a disposición de los profesionales de las lenguas modernas, en su versión en español, esta obra que, según todas las expectativas, marcará las líneas generales de la enseñanza y aprendizaje de lenguas en Europa durante los próximos años. JOSÉ LUIS CÁDIZ DELEITO Secretario General Técnico Ministerio de Educación, Cultura y Deporte. [En línea] http://goo.gl/ZFw2Dm (Subrayado nuestro)

EI MCER es un documento digno de toda la admiración y respeto, comporta dosis ideales de objetivos según cada nivel propuesto, no obstante, no se ajusta a la realidad actual de esta región y probablemente a la realidad de muchas otras regiones de Brasil, no de momento. En primer lugar haría falta que el profesorado alcanzara los objetivos propuestos en el plan de curso de grado para que luego la educación básica consiga lo propio, de otra forma, la situación no va a cambiar, la tendencia es a repetir la retrospectiva que se conoce sobre la enseñanza de lengua inglesa. No es lo que se quiere para el español.

\subsection{EL PLAN DE ESTUDIOS DE GRADO EN ELE}

Para hablar del plan de estudios de grado en Brasil, es necesario comprender a grandes rasgos como se da la creación de carreras en las IES en general. El punto de partida es el resultado de estudios sociológicos que señalan la necesidad de ofertar determinados cursos o carreras por demanda 
de la sociedad; enseguida, la IES nombra una comisión de docentes y educadores para elaborar el respectivo plan de estudios ${ }^{63}$ de ese curso.

El trabajo que esta comisión ${ }^{64}$ realiza, provisto de amplio conocimiento y ponderada reflexión, es el de delinear la trayectoria que se debe seguir para conquistar la conclusión de una carrera. En este documento se registran objetivos, justificativa de creación del curso, contenidos programáticos, metodología, recursos, estrategias, la manera de medir su efectividad, o sea, todo lo inherente para la realización adecuada de la formación.

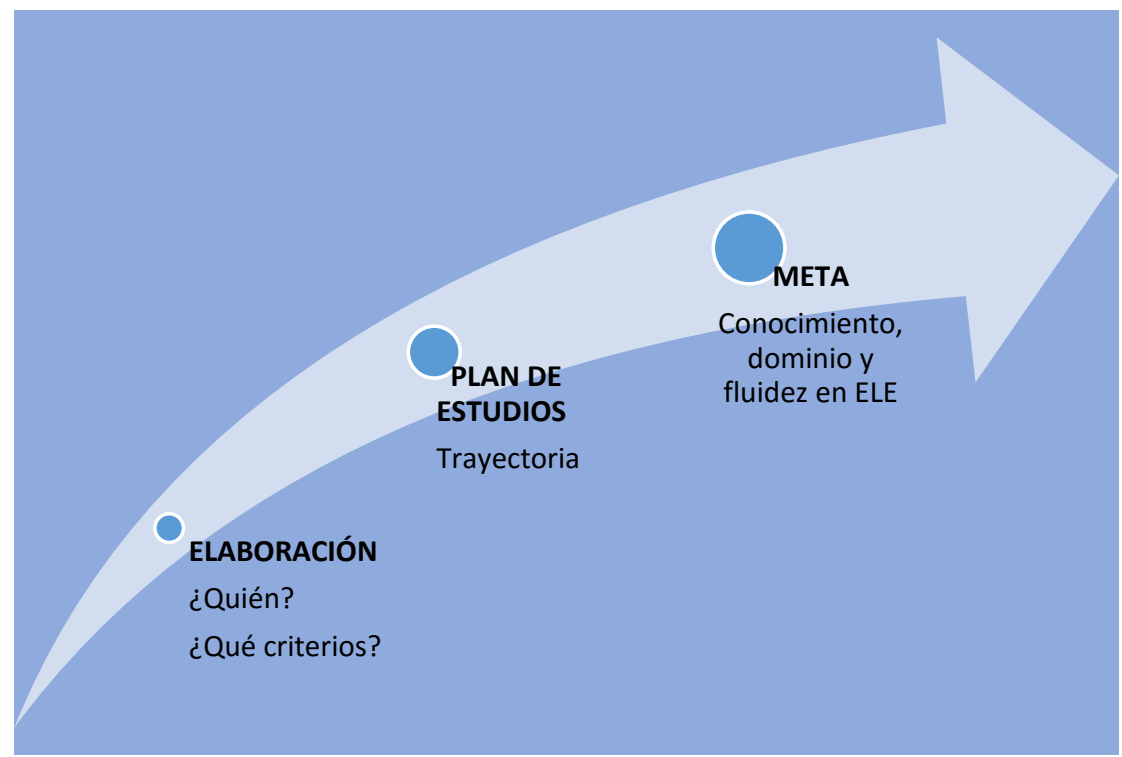

Gráfico 1 - Para un plan de estudios de grado.

(Creado por el autor)

Es importante comentar que elaborar un plan de estudios de grado es una tarea muy compleja que pondera factores de diversa índole y que además la identidad institucional del ofertante de la carrera cuenta mucho. En esa identidad hay una historia que se refleja a la hora de ejecutar un plan de estudios de grado que puede diferir de los procedimientos tradicionales para esta finalidad. La IES-3, por ejemplo, empieza a impartir cursos de grado acompañando políticas gubernamentales de acceso al nivel superior e interiorización del mismo, pero originalmente su campo de actuación estaba en

\footnotetext{
63 En el ámbito de la educación brasileña recibe el nombre de 'Projeto político-pedagógico do curso' ${ }^{64}$ Esta comisión es nombrada a través de documento oficial de la IES y se compone por docentes de amplio conocimiento específico de la oferta del curso, pedagogos y especialistas en educación superior.
} 
la enseñanza técnica. La IES-2 tiene en su historia, cambios drásticos que se reflejan de alguna forma en la vida académica actual. No obstante, el avance en el estado de Rio grande do Norte en lo que respecta a la educación superior va superándose.

Ya sobre el tema, un plan de estudios se refiere al aprendizaje que ha sido previsto y reglamentado por la IES, es el conjunto de actividades a ser realizadas por los estudiantes, más que por los docentes, tiene valor oficial y se atiene a la normativa nacional para la educación superior. En el capítulo siguiente ampliaremos el respaldo teórico respecto de la formulación de un plan de estudios de grado.

Pero, vale aclarar que en este apartado nos proponemos presentar la situación actual de la formación del profesorado en lo que respecta al plan de estudios. De esta forma, presentaremos aquí comentarios inherentes al plan de estudios en vigor en el año 2015 y, más adelante, en el capítulo II se hará un análisis detallado de las transformaciones y/o ajustes más sensibles ya realizados y que pueden explicar progreso o retroceso para lograr el objetivo de la fluidez y dominio de ELE y la contribución que los marcadores del discurso puedan dar en ello y en la formación del profesorado de ELE.

La denominación de la carrera docente de lengua española en Brasil obedece a una amplia gama de matices según cada IES, el plan de estudios presenta diferencias en carga horaria, distribución, conformación, denominación, contenido de los programas, y muchos otros aspectos:

Las denominaciones de los estudios son muy variadas, las más habituales son las siguientes:

- Espanhol

- Espanhol com respectiva Literatura

- Espanhol e Literatura da Língua Espanhola

- Espanhol Português e Respectivas Literaturas

- Letras - Espanhol

- Letras - Licenciatura Espanhol

- Letras - Língua Espanhola [...]

MARTÍNEZ-CACHERO LASECA, 2008: 103) 
Esta realidad, sin duda, también la vive el nordeste brasileño y las IES del estado de Rio Grande do Norte.

Al reflexionar sobre lo que pueda significar un obstáculo para una buena formación del profesorado de ELE, capaz de lograr un aprendizaje efectivo de lengua española en la enseñanza básica y pública, se pone la mirada en los varios factores que forman parte de ese proceso, pues al estar directamente involucrados, terminan, a priori, siendo los responsables de la calidad en ese aprendizaje. Uno de estos factores es el plan de estudios de grado en ELE.

Por eso, buscamos visualizar lo que a aprendizaje de ELE se refiere y se realiza a lo largo de un promedio de 4 años de estudio de grado y que, a priori, también delinearía el nivel de fluidez y dominio de la lengua española, herramienta principal para la actuación docente. Primero se presentará una caracterización objetiva del plan de estudios, para luego observar la distribución de los contenidos por bloque, las asignaturas de formación específica con relación a si están previstas para su realización en lengua española o no y la carga horaria destinada a cada una de las asignaturas, especialmente las de contenidos específicos de lengua española. Otros aspectos importantes de nuestra investigación relacionada con el plan de estudios, como por ejemplo, los marcadores del discurso en la formación de profesores, serán presentados, defendidos y discutidos en capítulos y secciones posteriores.

\subsubsection{Caracterización general del plan de estudios de grado en ELE de las IES de RN.}

En este momento, nos proponemos presentar objetivamente la caracterización del plan de curso en vigor de las IES del estado de Rio Grande do Norte (RN) para la enseñanza de grado en ELE, en el que se pretende observar datos concretos y globales de esa oferta.

Como ya hemos establecido, continuaremos refiriéndonos a IES-1, IES2 e IES-3 sabiendo que son instituciones de enseñanza superior de esfera federal, estatal e instituto federal, respectivamente. 
Cuadro 3 - Caracterización de la oferta de grado en ELE en RN.

\begin{tabular}{|c|c|c|c|}
\hline & IES-1 & IES-2 & IES-3 \\
\hline $\begin{array}{c}\text { Nombre actual del } \\
\text { curso de grado en } \\
\text { ELE }\end{array}$ & $\begin{array}{c}\text { Letras Licenciatura } \\
\text { Língua espanhola } \\
\text { e Literaturas } \\
\text { Presencial }\end{array}$ & $\begin{array}{l}\text { Letras Língua } \\
\text { Espanhola e suas } \\
\text { respectivas } \\
\text { Literaturas }\end{array}$ & $\begin{array}{c}\text { Licenciatura em } \\
\text { Letras Espanhol. } \\
\text { Modalidade } \\
\text { presencial }\end{array}$ \\
\hline Carga horaria total & 2.880 h (mínima) & $3.350 \mathrm{~h}$ & $3.614 \mathrm{~h}$ \\
\hline $\mathrm{N}^{\circ}$ de semestres & 9 (mínimo) & 8 & 8 \\
\hline Oferta en turno & Nocturno & $\begin{array}{l}\text { Matutino y } \\
\text { nocturno }\end{array}$ & $\begin{array}{l}\text { Matutino y } \\
\text { nocturno }\end{array}$ \\
\hline Duración de la clase & $50 \mathrm{~min}$ & $50 \mathrm{~min}$ & $45 \mathrm{~min}$ \\
\hline $\begin{array}{l}\text { Asignaturas } \\
\text { obligatorias }\end{array}$ & 2.580 & 2.730 & 2.220 \\
\hline Asignaturas electivas & 300 & 180 & 240 \\
\hline Práctica profesional & $400^{65}$ & $400^{*}$ & 800 \\
\hline $\begin{array}{c}\text { Actividades } \\
\text { académicas AACC }\end{array}$ & $200^{66}$ & $200^{*}$ & 200 \\
\hline $\begin{array}{c}\text { Seminarios curriculares } \\
\text { obligatorios }\end{array}$ &.-- &.-- & 154 \\
\hline
\end{tabular}

Como se puede apreciar en el cuadro anterior, la realidad actual de la oferta de grado en ELE presenta diferencias que según se miren, pueden significar notorias implicancias. En primer lugar comentamos la similitud que presentan la IES1 e IES2 en la denominación del grado evidenciando los contenidos literarios previstos en el plan de estudios, lo que no ocurre con la 


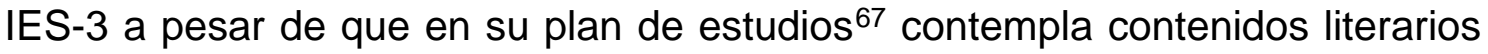
suficientes para tal.

Se aprecia considerable diferencia en la carga horaria total del curso, principalmente respecto de la IES-1, lo que no significa que realmente lo sea, pues la misma especifica que es el número mínimo de horas curriculares, o sea, el alumno de grado, aún tiene la posibilidad de ampliar su plan de curso de acuerdo a sus expectativas y necesidades matriculándose y aprobando asignaturas electivas del riquísimo acervo que oferta esta IES-1 ${ }^{68}$.

La duración de la clase en el grado suele ser de 45 o 50 min y si la oferta es diurna, se programan 6 clases, pero al ser nocturna, solo 4 horarios, eso explica la duración de 9 semestres que expone la IES1 ya que su oferta es solo nocturna. La IES 3 también tiene oferta nocturna, no obstante mantiene la oferta en 8 semestres contando con el soporte de la enseñanza a distancia, parcial.

En la IES-1 e IES-2, la práctica profesional o práctica supervisada tiene el papel de una asignatura obligatoria y consta en el plan de estudios como tal, lo que no ocurre en la IES-3. Las actividades académico-científico-culturales (AACC) tienen el mismo tratamiento generando registro académico propio.

\subsubsection{Las asignaturas obligatorias en el plan de estudios de grado en ELE}

En este primer momento, pretendemos mostrar la proporción que las asignaturas de formación específica del profesorado de ELE tienen en el conjunto de asignaturas obligatorias a lo largo de los estudios de grado. Para tal, se ha extraído del plan de estudios de cada IES esta información, se ha analizado y luego construido el gráfico 1.2 que se presenta a continuación. Objetivamente podemos ver la carga horaria de las asignaturas de carácter específico que un estudiante de esta carrera cursa para fortalecer la formación lingüística en ELE.

\footnotetext{
67 Ver anexo III - Documentos académicos IES-3.

68 Ver Anexo IB - Asignaturas electivas - Plan de estudios en vigor 2015 - IES-1.
} 


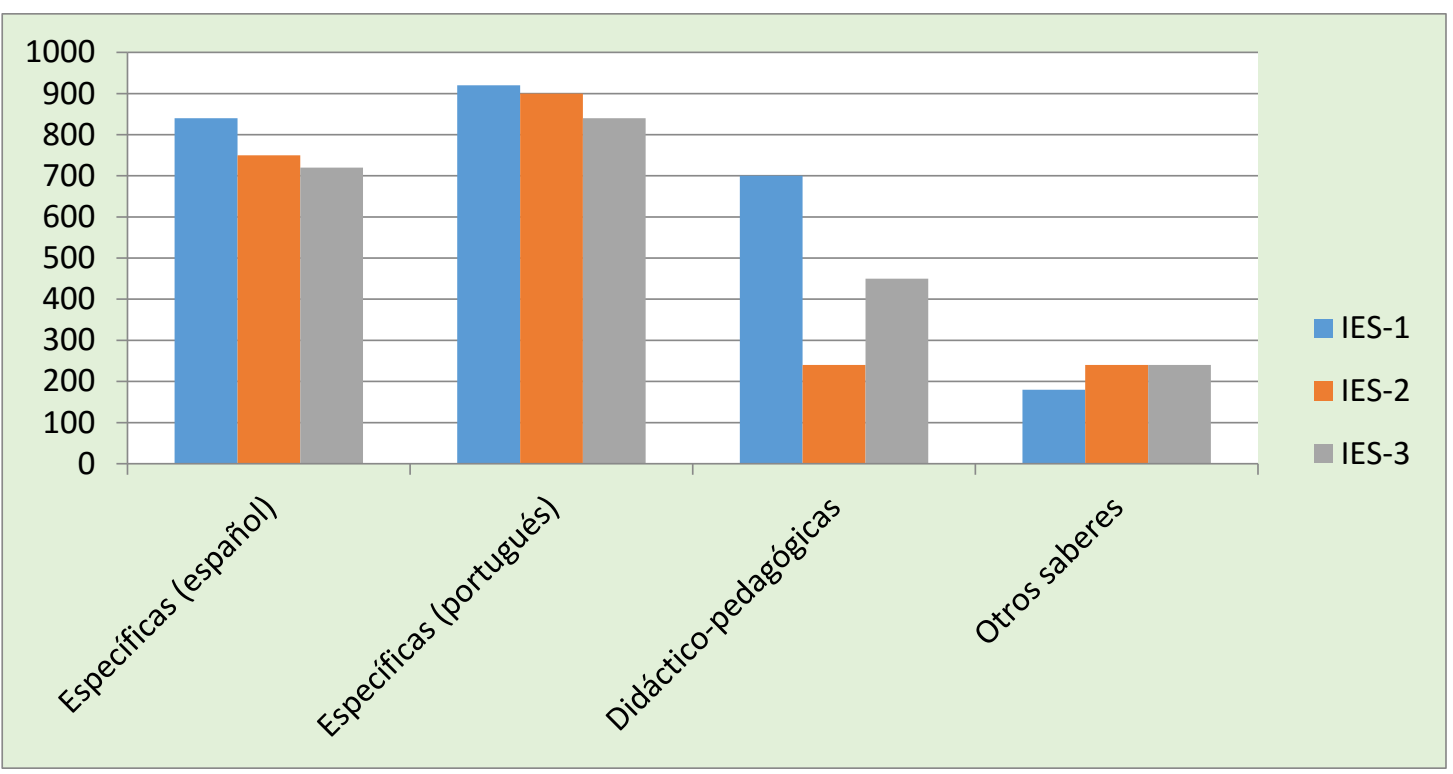

Gráfico 2 Distribución de asignaturas de Plan de estudios de IES

Fuente: [En línea] https://goo.gl/WHmEEm

[En línea] http://goo.gl/8rOs9K

[En línea] http://goo.gl/Qkx50B

Del gráfico anterior, aclaramos que:

$\checkmark$ Especificas (español) se refiere a toda aquella asignatura que se imparte en español, o al menos debe serlo debido a la especificidad del contenido de la misma;

$\checkmark$ Específicas (portugués) son asignaturas de formación lingüística que por lo general son impartidas en portugués;

$\checkmark$ Didáctico-pedagógicas son aquellas que siempre son impartidas en portugués, generalmente, por docentes pedagogos que atienden las demandas de casi todos los grados;

$\checkmark$ Otros saberes contempla asignaturas diversas de importante presencia en el plan de curso de grado como Lenguaje de señales, educación inclusiva, lengua portugués, entre otras. Por supuesto, son asignaturas impartidas en portugués.

La lectura inmediata que hacemos del gráfico anterior es que las asignaturas específicas del grado en ELE impartidas en lengua portuguesa son más numerosas que las impartidas en español, en las tres IES. A simple generalización esto no podría configurarse como un obstáculo para lograr 
fluidez y dominio de lengua si de hecho las asignaturas específicas (en español) fueran verdaderamente impartidas en español y además en un nivel C1 del MCER por parte del docente, como mínimo, porque de otra forma, más bien el efecto sería contrario al esperado en relación a la fluencia que se objetiva alcanzar en los proyectos de curso:

Conforme los principios generales que delinean el perfil del profesional del curso de grado en Letras Lengua Española y sus respectivas literaturas, ya esbozado en el ítem 4.2 de este proyecto, esperamos que al final del curso, el(la) graduado(a) haya desarrollado el dominio del uso de la lengua española en sus manifestaciones oral y escrita, en términos de recepción y producción de textos, que tenga la capacidad de hacer una reflexión analítica y crítica sobre el lenguaje como fenómeno psicológico, educacional, social, histórico, cultural, político e ideológico y que tenga una visión crítica de las perspectivas teóricas adoptadas en las investigaciones lingüísticas y literarias, que fundamentan su formación profesional. ${ }^{69}$ PROYECTO DE CURSO (UERN, 2014: 132) (Traducción nuestra) (Subrayado nuestro)

Desde este humilde punto de vista, y a raíz de la evaluación que se hace sobre el resultado de la enseñanza de ELE en las escuelas públicas de educación básica, no nos vale de mucho un buen plan de curso de grado en ELE, si no se cuenta con un profesorado de grado con dominio de contenido y también con fluidez y soltura en lengua española, ambos aspectos son en extremo de necesaria existencia para que se concrete una formación holística del nuevo profesor de ELE.

\footnotetext{
69 Texto original en portugués: Conforme os princípios gerais que delineiam o perfil do profissional do Curso de Graduação em Letras Língua Espanhola e suas respectivas literaturas, já esboçado no item 4.2 deste projeto, esperamos que no final do curso o(a)graduado(a)tenha desenvolvido o domínio do uso da língua espanhola nas suas manifestações oral e escrita, em termos de recepção e produção de textos; que tenha a capacidade de fazer uma reflexão analítica e crítica sobre a linguagem como fenômeno psicológico, educacional, social, histórico, cultural, político e ideológico e que tenha uma visão crítica das perspectivas teóricas adotadas nas investigações linguísticas e literárias, que fundamentam sua formação profissional. [...]
} 


\subsubsection{Las asignaturas específicas de formación del plan de estudios de grado en ELE}

La terminología empleada para cuestiones de orden académico difiere un poco entre el español y el portugués, pero no lo suficiente para recurrir a la traducción al español de la totalidad. En este trabajo y con relación a la denominación de las asignaturas en portugués, se intentará aplicar, cuando sea necesario, términos equivalentes que no dejen duda y reflejen de hecho la denominación original, pero, en primera instancia, se mantendrá el nombre original en portugués.

La finalidad de contrastar la oferta académica semestral de las IES que ofertan grado en ELE en este Estado es: (1) reparar la semejanza o desigualdad que pueda haber en la organización de las asignaturas específicas impartidas en español; (2) ponderar si la carga horaria es compatible, al fin del grado, con la posibilidad de lograr un nivel de fluidez y dominio de lengua española que respalde la formación específica del profesor de ELE; (3) verificar el grado de certeza respecto a que es el curso de grado en ELE el responsable de propiciar el aprendizaje de la lengua extranjera, objeto de la especificidad de ese grado y no delegar en el estudiante la tarea de hacerlo en escuelas de idiomas con la consecuente demanda de más tiempo y mayor inversión financiera. A no ser que la propia universidad proporcione la posibilidad de actualización, fortalecimiento o ampliación del aprendizaje de ELE realizado en el contexto del curso de grado en la forma de proyectos de extensión temporarios o de flujo continuo. A este propósito, las IES-1 e IES-2 ya tienen acciones de esta naturaleza en ejecución, pero la IES-3 a causa de limitaciones de personal docente, aún no.

A continuación, presentamos la organización en cuadros de cada semestre académico (sería lo equivalente a un cuatrimestre en el sistema educativo de grado en España), contemplando la oferta de asignaturas del plan de estudios de las tres IES que ofertan el grado en ELE en el Estado de Rio Grande do Norte, en Brasil con la finalidad de establecer un análisis más objetivo. Las informaciones sobre las asignaturas han sido coloreadas obedeciendo la agrupación establecida en el cuadro I.4: 
Cuadro 4 - Identificación de las asignaturas de ELE

\begin{tabular}{|c|c|c|c|}
\hline $\begin{array}{c}\text { Asignaturas } \\
\text { específicas de ELE } \\
\text { impartidas en } \\
\text { español. }\end{array}$ & $\begin{array}{c}\text { Asignaturas } \\
\text { específicas de ELE } \\
\text { impartidas en }\end{array}$ & $\begin{array}{c}\text { Asignaturas de } \\
\text { cuño didáctico } \\
\text { pedagógico. Todas }\end{array}$ & $\begin{array}{c}\text { Asignaturas de otros } \\
\text { saberes necesarias } \\
\text { portugués }\end{array}$ \\
& impartidas en & la formación \\
& & portugués & impartidas en \\
& & portugués \\
\hline
\end{tabular}

(Creación del autor)

Al observar el contraste de oferta de asignaturas del primer semestre académico del grado en ELE, se visualizan las siguientes coincidencias en las IES:

(1) Las tres imparten 300 horas de asignaturas;

(2) Las tres imparten al menos una asignatura de lengua española;

(3) Las tres imparten la asignatura Lingüística I, 60h;

(4) Las tres imparten contenidos de Língua portuguesa, 60h, a pesar de la diferencia en la denominación.

Cuadro 5 - Contraste de oferta de asignaturas del $1^{\circ}$ semestre

\begin{tabular}{|c|c|c|c|c|c|}
\hline \multicolumn{6}{|c|}{ ASIGNATURAS OBLIGATORIAS DEL $1^{\circ}$ SEMESTRE } \\
\hline \multicolumn{2}{|l|}{ IES-1 } & \multicolumn{2}{|l|}{ IES-2 } & \multicolumn{2}{|l|}{ IES-3 } \\
\hline Asignatura & $\mathrm{CH}$ & Asignatura & $\mathrm{CH}$ & Asignatura & $\mathrm{CH}$ \\
\hline $\begin{array}{c}\text { Expressão oral e } \\
\text { compreensão } \\
\text { auditiva em língua } \\
\text { espanhola I }\end{array}$ & $60 h$ & Produção textual & $60 h$ & Língua portuguesa & $60 h$ \\
\hline $\begin{array}{l}\text { Leitura e produção } \\
\text { escrita em língua } \\
\text { espanhola I }\end{array}$ & $60 h$ & $\begin{array}{c}\text { Língua brasileira } \\
\text { de sinais }\end{array}$ & $60 h$ & $\begin{array}{c}\text { Fundam. } \\
\text { históricos e } \\
\text { filosóficos da } \\
\text { educação }\end{array}$ & $60 h$ \\
\hline Língua latina I & $60 h$ & $\begin{array}{c}\text { Fundamentos de } \\
\text { Língua } \\
\text { Espanhola }\end{array}$ & $60 h$ & Língua espanhola I & $60 h$ \\
\hline Linguística I & $60 \mathrm{~h}$ & $\begin{array}{c}\text { Metodologia do } \\
\text { Trabalho } \\
\text { científico }\end{array}$ & $60 h$ & Linguística I & $60 h$ \\
\hline $\begin{array}{l}\text { Leitura e produção } \\
\text { de texto }\end{array}$ & $60 h$ & Linguística I & $60 h$ & $\begin{array}{l}\text { Fundamentos de } \\
\text { literatura ocidental }\end{array}$ & $60 h$ \\
\hline
\end{tabular}

Fuente: [En línea] https://goo.gl/WHmEEm

[En línea] http://goo.gl/8rOs9K

[En línea] http://goo.gl/Qkx50B 
Es satisfactorio notar que hay varios aspectos coincidentes, considerando que el plan de estudios de cada IES es elaborado aisladamente, no se comunican para esta finalidad, algo que a título de sugerencia, podría implementarse, uniendo de esta forma fuerzas para el logro de los objetivos de enseñanza en la educación básica.

A nuestro ver, es importante comentar y resaltar que tratándose de un grado en ELE, es justificable y muy acertado que la IES-1 imparta el $40 \%$ de las horas del primer semestre $(300$ h) clases de lengua española, principalmente por el hecho de que para acceder a los estudios de grado no es requisito el conocimiento de ELE en cualquier nivel y los alumnos recién llegados, en su mayoría solo saben lo que puedan haber aprendido en la educación básica, que por lo general es de nivel insatisfactorio.

La IES-2 e IES-3 imparten $80 \%$ de las 300 horas en asignaturas varias, pero solo $20 \%$ en una asignatura de lengua española. No conseguimos justificar desde ningún punto de vista las razones para esta distribución, teniendo en cuenta la especificidad del grado y todo lo más, antes expuesto. Se configura más bien como un curso con poco énfasis en la especificidad de ese grado, lo que puede desencadenar consecuencias varias, como asentar la creencia de que para ser profesor de ELE no hace tanta falta empezar luego a conocer mejor la lengua con la finalidad de dominarla y lograr fluidez suficiente durante la carrera y dentro de ella para que su futuro desempeño docente realmente esté completo.

La carga horaria media de asignaturas de lengua española en el grado en ELE, sin considerar las asignaturas de contenidos gramaticales específicos, tiene un promedio de 460 horas, a razón de 70 horas por semestre, solo asignaturas destinadas al aprendizaje de ELE. ¿Cómo es que no se puede lograr un aprendizaje razonable que se enriquecerá con las asignaturas de contenidos gramaticales, con la práctica profesional, con las actividades académico-científico-culturales y mucho más contemplado en el plan de estudios?

Un curso de lengua extranjera en una escuela de idiomas, por lo general tiene la duración de 3 años, son 6 semestres (cuatrimestres) y las clases se imparten a razón de dos encuentros por semana de 1 h30 de duración cada 
uno, no son públicas y además se debe comprar el material didáctico solicitado para el curso. La configuración de estos cursos de idiomas se parece demasiado a la configuración de la asignatura de lengua española en cualquier IES que oferta la enseñanza de grado en ELE.

Con relación al contraste de oferta de asignaturas del segundo semestre académico del grado en ELE, las IES coinciden nuevamente en:

(1) Las tres imparten un promedio de 300 horas de asignaturas;

(2) Las tres imparten la asignatura Linguística II, 60h;

(3) Las tres imparten contenidos de Língua portuguesa, 60h, a pesar de la diferencia en la denominación.

Cuadro 6 - Contraste de oferta de asignaturas del $2^{\circ}$ semestre

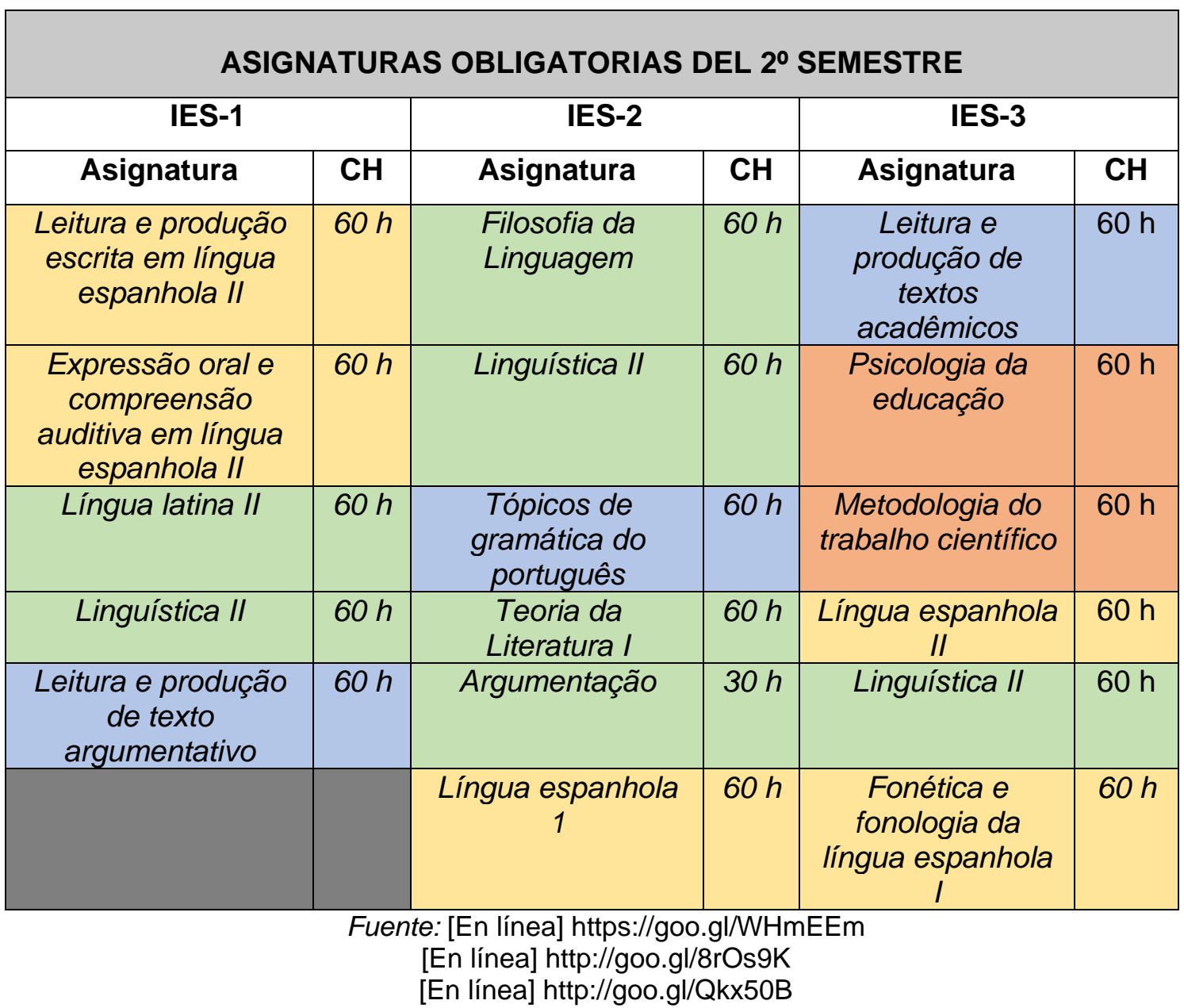

La IES-1 mantiene la identidad de la especificidad del grado en ELE con $40 \%$ de las horas del segundo semestre destinadas a clases de lengua 
española, algo parecido pasa con la IES-3 que presenta en este semestre una asignatura específica que debe ser presentada en español dada el carácter de la misma (Fonética y Fonología de la lengua española I), no obstante surge la preocupación de si el nivel de comprensión de lengua española sea suficiente para recibir este contenido específico que además es técnico, se comenta esto en virtud de la carga horaria de lengua española recibida en el primer semestre (60h), quizás mejor preparados estarían los estudiantes de la IES-1 que tienen 120 horas, en vez de 60 en la IES-3.

En contrapartida la IES-2, mantiene el $20 \%$ de la carga horaria del semestre y esta situación lleva a pensar que a lo largo de todo un año se ha visto tan poco de la lengua, especificidad de esa formación, que es probable que a este tiempo los estudiantes ya estén creyendo que para ser profesor de español no hace tanta falta la fluidez y el dominio de la lengua que supuestamente van a enseñar tras la culminación de sus estudios de grado.

Aunque es saludable comentar sobre los falsos pretendientes a profesores de ELE, que se presentan dispuestos a cursar el grado pensando y deseando ver solo lengua española, justo lo que no encontrarían tan bien hecho en las escuelas de idiomas en donde, a pesar de los profesores nativos que imparten las clases, el progreso no es tan significativo como el senso común de la mayoría de los estudiantes interesados espera o cree al tratarse de una escuela 'especializada'.

Al iniciar el tercer semestre, las tres IES presentan una carga horaria apreciable de asignaturas específicas en español, las tres tienen Fonética y fonología del español, asignatura que debe impartirse, por supuesto, en español y con todo el tiempo necesario para la asimilación de los contenidos que resultan bastante técnicos. 
Cuadro 7 - Contraste de oferta de asignaturas del $3^{\circ}$ semestre

\begin{tabular}{|l|l|l|l|l|l|}
\hline \multicolumn{5}{|c|}{ ASIGNATURAS OBLIGATORIAS DEL 30 SEMESTRE } \\
\hline \multicolumn{2}{|c|}{ IES-1 } & \multicolumn{2}{c|}{ IES-2 } & \multicolumn{2}{c|}{ IES-3 } \\
\hline Asignatura & CH & Asignatura & CH & Asignatura & CH \\
\hline $\begin{array}{l}\text { Fundamentos } \\
\text { sócio-filosóficos } \\
\text { da educação }\end{array}$ & $60 \mathrm{~h}$ & $\begin{array}{l}\text { Fonética e } \\
\text { fonologia I } \\
\text { (Espanhol) } \\
\text { Língua espanhola } \\
\text { II }\end{array}$ & $90 \mathrm{~h}$ & Didática & $90 \mathrm{~h}$ \\
\hline $\begin{array}{l}\text { Fonética e } \\
\text { fonologia da } \\
\text { língua espanhola I }\end{array}$ & $60 \mathrm{~h}$ & $\begin{array}{l}\text { Fundamentos } \\
\text { Sociopolíticos e } \\
\text { Econômicos da } \\
\text { Educação }\end{array}$ & $60 \mathrm{~h}$ \\
\hline $\begin{array}{l}\text { Lexicologia da } \\
\text { língua espanhola }\end{array}$ & $60 \mathrm{~h}$ & Sociolinguística & $90 \mathrm{~h}$ & $\begin{array}{l}\text { Língua espanhola } \\
\text { III }\end{array}$ & $60 \mathrm{~h}$ \\
\hline $\begin{array}{l}\text { Fundamentos da } \\
\text { Literatura } \\
\text { ocidental I }\end{array}$ & $60 \mathrm{~h}$ & $\begin{array}{l}\text { Psicologia da } \\
\text { educação }\end{array}$ & $90 \mathrm{~h}$ & $\begin{array}{l}\text { Fonética e } \\
\text { fonologia da } \\
\text { língua espanhola } \\
\text { II }\end{array}$ & $60 \mathrm{~h}$ \\
\hline Linguística III & $60 \mathrm{~h}$ & $\begin{array}{l}\text { Teoria da } \\
\text { Literatura II }\end{array}$ & $90 \mathrm{~h}$ & $\begin{array}{l}\text { Cultura } \\
\text { espanhola }\end{array}$ & $60 \mathrm{~h}$ \\
\hline
\end{tabular}

Fuente: [En línea] https://goo.gl/WHmEEm

[En línea] http://goo.gl/8rOs9K

[En línea] http://goo.gl/Qkx50B

Mientras la IES-1 imparte la asignatura de Lexicología de la lengua española, la IES-3 imparte Cultura española, ambas asignaturas de formación específica que desde luego deberían ser impartidas en español, cuestión que, a priori, sí ocurre, a juzgar por la afirmación del profesorado de grado cuando se les preguntó en encuesta si impartía sus clases en español cuando se trataba de asignaturas específicas.

La asignatura de lengua española II para la IES-2 con 90 horas y III para la IES-3 con $60 \mathrm{~h}$ ambas impartidas, por supuesto en español, totalizan solo en este tercer semestre ( $3^{\circ}$ cuadrimestre) 120,150 y 180 horas para cada IES, respectivamente de convivencia académica en español, lo que implica un importante aporte a la fluidez y dominio de la lengua española en el grado de ELE, pues serían doce horarios de 45 minutos para la IES-3, o sea, 9 horas de lengua española directa e indirectamente a cada semana a lo largo de este semestre, sin duda un aporte importante a la fluencia y dominio de ELE, si de hecho estas asignaturas fueran impartidas en español, sin dejar de evidenciar, por supuesto, que la formación pedagógica del futuro profesor va forjándose en paralelo a su competencia lingüística. 
Al analizar el cuadro de contraste de oferta de asignaturas para el cuarto semestre, observamos que la IES-1 no presenta asignatura de lengua española ni algo semejante en este periodo, pero sí dos componentes curriculares ${ }^{70}$ de contenido específico de la forma de la lengua, morfología y sintaxis, cada una con 60 horas, que deberían ser impartidas en español, obvio el porqué, inclusive a pesar de si la propuesta de esas asignaturas es de carácter contrastivo con relación a la lengua portuguesa.

La IES-2 imparte lengua española III, Lectura y producción de textos I (español) y Metodología I (español), el sentido común nos indica que las tres asignaturas son impartidas en español, lo que significa 210 horas de clase en lengua española, eso representa 14 horarios de clase de 45-50 minutos por semana, número bastante atractivo para la finalidad que investigamos: fluidez y dominio de lengua española en el profesorado de ELE.

Cuadro 8 - Contraste de oferta de asignaturas del $4^{\circ}$ semestre

\begin{tabular}{|c|c|c|c|c|c|}
\hline \multicolumn{6}{|c|}{ ASIGNATURAS OBLIGATORIAS DEL $4^{\circ}$ SEMESTRE } \\
\hline \multicolumn{2}{|l|}{ IES-1 } & \multicolumn{2}{|l|}{ IES-2 } & \multicolumn{2}{|l|}{ IES-3 } \\
\hline Asignatura & $\mathrm{CH}$ & Asignatura & $\mathrm{CH}$ & Asignatura & $\mathrm{CH}$ \\
\hline $\begin{array}{l}\text { Língua brasileira } \\
\text { de sinais LIBRAS }\end{array}$ & $60 h$ & $\begin{array}{l}\text { Língua espanhola } \\
\text { III }\end{array}$ & $60 \mathrm{~h}$ & $\begin{array}{l}\text { Organização e } \\
\text { gestão da } \\
\text { educação brasil. }\end{array}$ & $60 \mathrm{~h}$ \\
\hline $\begin{array}{l}\text { Fundamentos da } \\
\text { Psicologia } \\
\text { educacional }\end{array}$ & $60 h$ & $\begin{array}{l}\text { Leitura e } \\
\text { produção de } \\
\text { textos I } \\
\text { (espanhol) }\end{array}$ & $90 \mathrm{~h}$ & $\begin{array}{l}\text { Língua espanhola } \\
\text { IV }\end{array}$ & $60 \mathrm{~h}$ \\
\hline $\begin{array}{l}\text { Morfologia da } \\
\text { língua espanhola I }\end{array}$ & $60 h$ & $\begin{array}{l}\text { Literatura luso- } \\
\text { brasileira }\end{array}$ & $60 \mathrm{~h}$ & $\begin{array}{l}\text { Morfologia da } \\
\text { língua espanhola }\end{array}$ & $60 \mathrm{~h}$ \\
\hline $\begin{array}{l}\text { Sintaxe da língua } \\
\text { espanhola I }\end{array}$ & $60 h$ & $\begin{array}{l}\text { Metodologia I } \\
\text { (espanhol) }\end{array}$ & $60 h$ & $\begin{array}{l}\text { Teoria da } \\
\text { literatura I }\end{array}$ & $60 \mathrm{~h}$ \\
\hline $\begin{array}{l}\text { Teoria da } \\
\text { Literatura I }\end{array}$ & $60 h$ & Didática geral & $30 h$ & $\begin{array}{l}\text { Cultura hispano- } \\
\text { Americana }\end{array}$ & $60 \mathrm{~h}$ \\
\hline & & Psicolinguística & $\begin{array}{l}30 \\
\text { h/aula }\end{array}$ & & \\
\hline
\end{tabular}

${ }^{70}$ Lo mismo que asignatura de plan de estudios de grado. 
La IES-3 imparte las asignaturas de lengua española IV, Morfología del español y Cultura Hispanoamericana, totalizando 180 horas de clases en lengua española que equivale a 12 clases de 45-50 minutos, semanalmente, carga horaria muy apreciable que contribuye a la formación específica del profesorado de ELE en lo que también respecta a la fluidez y dominio de lengua española.

La oferta de asignaturas del quinto semestre se presenta relativamente homogénea en lo que respecta a la carga horaria impartida en español, la IES-1 y la IES-3 presentan 120 h, pero la IES-2, $180 \mathrm{~h}$. La IES1 y la IES-3 coinciden en la oferta de Sintaxis del español, pero la IES-2 y la IES-3 coinciden en la oferta de la asignatura de Lectura y producción de textos en ELE, pero con cargas horarias diferentes: la primera pone $90 \mathrm{~h}$ contra 60 de la segunda, y es que además la IES-2 oferta Lengua española IV también con 90 horas. Obviamente esta distribución de asignaturas y cargas horarias obedece a intereses de la IES que elabora el plan de curso y no hay ninguna interrelación entre las IES del Estado, lo que para muchas finalidades de movilidad, transferencias y demás sería de gran valía para la comunidad académica.

Cuadro 9 - Contraste de oferta de asignaturas del $5^{\circ}$ semestre

\begin{tabular}{|c|c|c|c|c|c|}
\hline \multicolumn{6}{|c|}{ ASIGNATURAS OBLIGATORIAS DEL $5^{\circ}$ SEMESTRE } \\
\hline \multicolumn{2}{|l|}{ IES-1 } & \multicolumn{2}{|l|}{ IES-2 } & \multicolumn{2}{|l|}{ IES-3 } \\
\hline Asignatura & $\mathrm{CH}$ & Asignatura & $\mathrm{CH}$ & Asignatura & $\mathrm{CH}$ \\
\hline $\begin{array}{l}\text { Sintaxe da língua } \\
\text { espanhola II }\end{array}$ & $60 h$ & Língua espanhola IV & $90 h$ & $\begin{array}{l}\text { Mídias } \\
\text { educacionais }\end{array}$ & $60 h$ \\
\hline $\begin{array}{l}\text { Historia da língua } \\
\text { espanhola }\end{array}$ & $60 h$ & $\begin{array}{l}\text { Literatura espanhola } \\
I\end{array}$ & $60 h$ & $\begin{array}{l}\text { Leitura e produção } \\
\text { de textos em ele }\end{array}$ & $60 h$ \\
\hline $\begin{array}{l}\text { Teoria da } \\
\text { literatura II }\end{array}$ & $60 \mathrm{~h}$ & $\begin{array}{l}\text { Leitura e Produção } \\
\text { de Textos II } \\
\text { (Espanhol) }\end{array}$ & $90 h$ & $\begin{array}{l}\text { Sintaxe da língua } \\
\text { espanhola }\end{array}$ & $60 h$ \\
\hline Didática III & $60 h$ & $\begin{array}{l}\text { Literatura hispano- } \\
\text { Americana I }\end{array}$ & $60 \mathrm{~h}$ & $\begin{array}{l}\text { Sociolinguística da } \\
\text { língua espanhola }\end{array}$ & $60 h$ \\
\hline & & $\begin{array}{l}\text { Estrutura e func. } \\
\text { Ensino básico }\end{array}$ & $60 \mathrm{~h}$ & $\begin{array}{l}\text { Teoria da literatura } \\
\text { II }\end{array}$ & $60 h$ \\
\hline & & & & $\begin{array}{l}\text { Literatura } \\
\text { espanhola I }\end{array}$ & $60 h$ \\
\hline
\end{tabular}

Fuente: [En línea] https://goo.gl/WHmEEm

[En línea] http://goo.gl/8rOs9K

[En línea] http://goo.gl/Qkx50B 
Lo que se observa y se quiere comentar aquí es que si todas las asignaturas de formación específica de ELE fueran impartidas en la lengua objeto de la especificidad de formación del profesorado de ELE, muy probablemente resolvería la falencia de la que sufren los profesores en su práctica docente: fluidez y dominio de la lengua que enseñan. Por experiencia, relato la facilidad con que los profesores de grado imparten sus clases prioritariamente en portugués, inclusive cuando se trata de asignaturas específicas. Por ejemplo, Historia de la lengua española, es una especial oportunidad de hacer relatos (estimular indirectamente la comprensión auditiva) y escuchar relatos (estimular la producción oral) de los estudiantes, en español, el profesor de grado debería tener el compromiso profesional de contribuir con su/s asignatura/s al fortalecimiento de la fluidez y dominio de la lengua objeto de ese grado.

Analizando la oferta de asignaturas del sexto semestre, se aprecia que la IES-1 presenta 120 horas de clase en dos asignaturas que tienen por objetivo dar a conocer la cultura de los países cuya lengua es la especificidad del grado que desean alcanzar profesionalmente, qué oportunidad mejor para hacerlo en español, serían 120h más de oportunidad para lograr fluidez y dominio en español, sin contar con las 100 horas de la práctica profesional (Estágio supervisionado de formação de professores 1) que pone español en paréntesis y si eso quiere decir que esas 100 horas de actividades académicas son en español, se aproxima mucho más la posibilidad de fluidez y dominio de lengua española. 
Cuadro 10 - Contraste de oferta de asignaturas del $6^{\circ}$ semestre

\begin{tabular}{|c|c|c|c|c|c|}
\hline \multicolumn{6}{|c|}{ ASIGNATURAS OBLIGATORIAS DEL $6^{\circ}$ SEMESTRE } \\
\hline \multicolumn{2}{|l|}{ IES-1 } & \multicolumn{2}{|l|}{ IES-2 } & \multicolumn{2}{|l|}{ IES-3 } \\
\hline Asignatura & $\mathrm{CH}$ & Asignatura & $\mathrm{CH}$ & Asignatura & $\mathrm{CH}$ \\
\hline $\begin{array}{l}\text { Organização da } \\
\text { educação brasileira }\end{array}$ & $60 h$ & $\begin{array}{l}\text { Língua } \\
\text { Espanhola V }\end{array}$ & $90 \mathrm{~h}$ & $\begin{array}{l}\text { Educação } \\
\text { inclusiva }\end{array}$ & $60 h$ \\
\hline Cultura Espanhola I & $60 h$ & $\begin{array}{l}\text { Prática de ensino } \\
\text { I (Espanhol) }\end{array}$ & $210 h$ & LIBRAS & $60 h$ \\
\hline $\begin{array}{l}\text { Cultura hispano- } \\
\text { Americana I }\end{array}$ & $60 h$ & $\begin{array}{l}\text { Análise do } \\
\text { discurso }\end{array}$ & $60 \mathrm{~h}$ & $\begin{array}{l}\text { Praticas orais e } \\
\text { auditivas em ELE }\end{array}$ & $60 h$ \\
\hline \multirow{3}{*}{$\begin{array}{l}\text { Estágio superv. de } \\
\text { formaçãoprofessores } \\
\text { I (Espanhol) }\end{array}$} & $100 \mathrm{~h}$ & $\begin{array}{l}\text { Literatura } \\
\text { Espanhola II }\end{array}$ & $60 \mathrm{~h}$ & Língua latina & $60 h$ \\
\hline & & $\begin{array}{l}\text { Literatura } \\
\text { Hispano- } \\
\text { Americana II }\end{array}$ & $60 \mathrm{~h}$ & $\begin{array}{l}\text { Literatura } \\
\text { espanhola II }\end{array}$ & $60 h$ \\
\hline & & & & $\begin{array}{l}\text { Teorias e } \\
\text { aquisição de } \\
\text { segundas línguas }\end{array}$ & $60 h$ \\
\hline
\end{tabular}

Fuente: [En línea] https://goo.gl/WHmEEm

[En línea] http://goo.gl/8rOs9K

[En línea] http://goo.gl/Qkx50B

La práctica profesional es un componente curricular obligatorio para todo curso de grado para docencia. Son 400 horas divididas en 4 bloques o en 2, según la visión de cada IES en las que se van superando etapas de aproximación a la realidad de la educación básica y, sobre todo, pública. La IES-1 ha dividido la práctica en 4 bloques, el primero corresponde al sexto semestre cuando el estudiante visita escuelas públicas que tengan oferta de la asignatura español, el objetivo es conocer la realidad de la escuela pública y elegir entre ellas aquella en donde realizara las etapas subsecuentes de su práctica profesional.

La IES-2 presenta 90h de lengua española y una práctica profesional en español de 210h, carga horaria total en el semestre bastante importante. La opción de la IES-2 ha sido dividir la práctica profesional en dos bloques de 210 horas, tiempo en que realiza las visitas a las escuelas públicas, elige aquella en la que va a realizar la observación, fase que consiste en presenciar la actuación docente del profesor titular de la escuela pública y tras esto escribe 
un informe en el que relata sus observaciones y teje sus reflexiones sobre la realidad observada.

La IES-3, respecto de la práctica profesional, no la contempla como asignatura, es un proceso que se da en paralelo a las asignaturas, es de realización obligatoria y es ejecutada en los moldes de la IES1, también a partir del sexto semestre.

Además, presenta una asignatura de lengua (prácticas orales y auditivas en ELE) de 60h y una asignatura de bases teóricas para la enseñanza de lenguas, son en suma 120 horas de lengua española a lo largo de este sexto semestre que dan su aporte a la fluidez y dominio de lengua de los futuros profesores de ELE para la educación básica.

Ya en el séptimo semestre, la oferta de asignaturas se direge más al ámbito de la literatura. Por lo general, son impartidas en español, o al menos esa es la propuesta de los cursos. La IES-1 oferta las asignaturas de Literatura española 2 y Literatura hispanoamericana 1, además oferta la fase de la práctica profesional en que se hace observación, asistir a las clases del profesor titular de la escuela pública para presentar un informe con las respectivas reflexiones.

Pasa algo semejante con la IES-2, pero en lo que se refiere a la práctica profesional, en este segundo bloque, el estudiante de grado elabora un plan de clases para la enseñanza primaria y otro para la secundaria, después se organiza todo de tal modo que el estudiante pueda actuar en ambos niveles de enseñanza básica siempre bajo la observación y orientación del docente titular de la escuela pública. Tras finalizar la aplicación, se debe redactar el informe total respectivo, supuestamente en lengua española, pero la realidad no es a cabalidad de esta manera, quizás si lo fuera tendríamos un profesorado mejor preparado que cambiaría los resultados de aprendizaje que conocemos en la actualidad pero no es lo que suele ocurrir, porque quien lee los informes son profesionales pedagogos que no tienen obligación de saber lengua española. 
Cuadro 11 Contraste de oferta de asignaturas del $7^{\circ}$ semestre

\begin{tabular}{|l|l|l|l|l|l|}
\hline \multicolumn{5}{|c|}{ ASIGNATURAS OBLIGATORIAS DEL 70 SEMESTRE } \\
\hline \multicolumn{1}{|c|}{ IES-1 } & \multicolumn{2}{c|}{ IES-2 } & \multicolumn{2}{c|}{ IES-3 } \\
\hline Asignatura & CH & Asignatura & CH & Asignatura & CH \\
\hline $\begin{array}{l}\text { Estágio } \\
\text { supervisionado de } \\
\text { formação de } \\
\text { professores } \\
\text { (Espanhol) }\end{array}$ & $100 \mathrm{~h}$ & $\begin{array}{l}\text { Língua espanhola } \\
\text { VI }\end{array}$ & $60 \mathrm{~h}$ & $\begin{array}{l}\text { Filologia } \\
\text { hispânica }\end{array}$ & $60 \mathrm{~h}$ \\
\hline $\begin{array}{l}\text { Literatura } \\
\text { espanhola I }\end{array}$ & $60 \mathrm{~h}$ & $\begin{array}{l}\text { Literatura } \\
\text { espanhola III }\end{array}$ & $30 \mathrm{~h}$ & $\begin{array}{l}\text { Literatura } \\
\text { hispano- } \\
\text { Americana I }\end{array}$ & $60 \mathrm{~h}$ \\
\hline $\begin{array}{l}\text { Literatura hispano- } \\
\text { Americana I }\end{array}$ & $60 \mathrm{~h}$ & $\begin{array}{l}\text { Literatura } \\
\text { Hispano- } \\
\text { Americana III }\end{array}$ & $30 \mathrm{~h}$ & $\begin{array}{l}\text { Metodologia de } \\
\text { ensino de ELE }\end{array}$ & $60 \mathrm{~h}$ \\
\hline & $\begin{array}{l}\text { Seminário de } \\
\text { monografia I } \\
\text { (Espanhol) }\end{array}$ & $120 \mathrm{~h}$ & & \\
\hline $\begin{array}{l}\text { Prática de ensino } \\
\text { II (Espanhol) }\end{array}$ & $210 \mathrm{~h}$ & & \\
\hline
\end{tabular}

Fuente: [En línea] https://goo.gl/WHmEEm

[En línea] http://goo.gl/8rOs9K

[En línea] http://goo.gl/Qkx50B

Aún sobre la oferta de las asignaturas del séptimo semestre, la IES-3 oferta una que lleva el nombre de Filología hispánica, 60h, cuestión que ha suscitado sorpresa al percibir que esta ha sido entendida como una asignatura de historia de la lengua, como lo expresa en el programa de la asignatura:

A história da língua espanhola, desde o latim até os dias de hoje, contemplando as mudanças internas do sistema linguístico ao longo desse período, especialmente do latim para o castelhano medieval e deste para o espanhol moderno, bem como as mudanças políticas e sociais que se desdobraram em consequências sobre a história da língua. PPC.2014. [En línea] http://goo.gl/Qkx50B

En fin, como esta singular forma de catalogar una asignatura, como es natural, otras habrá y de ser así, en su momento será presentado a modo de contribución. A continuación está la definición más básica del término filología que es suficiente para respaldar, de momento la observación realizada. 
filología

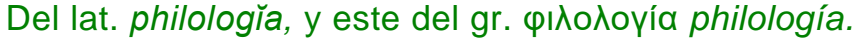

1. f. Ciencia que estudia una cultura tal como se manifiesta en su I engua y en su literatura, principalmente a través de los textos escritos. [En línea] www.rae.es

La oferta de las asignaturas del octavo y noveno semestre para la IES-1 es fuerte aún, pero para la IES-2 y sobre todo IES-3, no. Asignaturas de cuño literario en un total de 120 h, son ofertadas por IES-1, también la práctica profesional, $100 \mathrm{~h}$ en las que se desarrollará la acción docente en la enseñanza primaria bajo la orientación del docente titular de la escuela pública y una asignatura de $60 \mathrm{~h}$ importantísima y de base para la enseñanza de lenguas extranjeras que es la de Lingüística aplicada a la enseñanza de ELE, asignatura que a nuestro humilde ver debería ser ofertada en el primer tercio de la carrera.

La IES-2 oferta una asignatura de lengua inglesa de $60 \mathrm{~h}$. y no se entiende muy bien cuál es la razón de esta oferta, de carácter obligatorio casi al final de la carrera y sin continuidad.

Cuadro 12 - Contraste de oferta de asignaturas del $8^{\circ}$ semestre

\begin{tabular}{|c|c|c|c|c|c|}
\hline \multicolumn{6}{|c|}{ ASIGNATURAS OBLIGATORIAS DEL $8^{\circ}$ SEMESTRE } \\
\hline \multicolumn{2}{|l|}{ IES-1 } & \multicolumn{2}{|l|}{ IES-2 } & \multicolumn{2}{|c|}{ IES-3 } \\
\hline Asignatura & $\mathrm{CH}$ & Asignatura & $\mathrm{CH}$ & Asignatura & $\mathrm{CH}$ \\
\hline Literatura espanhola II & $60 \mathrm{~h}$ & $\begin{array}{l}\text { Seminário de } \\
\text { monografia } \\
\text { II(Espanhol) }\end{array}$ & $30 \mathrm{~h}$ & $\begin{array}{l}\text { Literatura } \\
\text { hispano- } \\
\text { Americana II }\end{array}$ & $30 \mathrm{~h}$ \\
\hline $\begin{array}{l}\text { Literatura hispano- } \\
\text { Americana II }\end{array}$ & $60 \mathrm{~h}$ & $\begin{array}{l}\text { Fundamentos } \\
\text { língua } \\
\text { inglesa }\end{array}$ & $60 \mathrm{~h}$ & & \\
\hline $\begin{array}{l}\text { Linguística aplicada ao } \\
\text { ensino de língua espanhola }\end{array}$ & $60 \mathrm{~h}$ & & & & \\
\hline $\begin{array}{l}\text { Estágio supervisionado de } \\
\text { formação de professores I } \\
\text {-Ensino fundamental } \\
\text { (Espanhol) }\end{array}$ & $100 \mathrm{~h}$ & & & & \\
\hline & $\begin{array}{l}\text { e: [En } \\
\text { [En lín } \\
\text { [En lín }\end{array}$ & $\begin{array}{l}\text { a] https://goo. } \\
\text { http://goo.gl/8 } \\
\text { http://goo.gl/Q }\end{array}$ & $\begin{array}{l}\mathrm{Hm} \\
9 \mathrm{~K} \\
\mathrm{OB}\end{array}$ & & \\
\hline
\end{tabular}


La IES-3 ya solo oferta una asignatura de $30 \mathrm{~h}$ de Literatura hispanoamericana II, pero en el plan de grado se constata que en este octavo semestre es cuando se redacta el texto final del trabajo de fin de curso que viene en construcción en paralelo con las asignaturas desde el sexto semestre, es en el octavo cuando este trabajo se presenta ante el tribunal académico.

En el noveno semestre ya solo la IES-1 tiene actividades académicas y oferta de asignaturas, como la de Traducción en lengua española I, que ciertamente se refiere a Traducción español / portugués, el perfil de esta asignatura es de relevante aporte en la formación del estudiante de grado de ELE porque le permite acceder a otras posibilidades profesionales a partir de esta inicial experimentación, como lo propone la IES-3 en su plan de estudios, pero no contempla otras posibilidades de especialización en áreas a fin como la de Traducción, por ejemplo:

\begin{abstract}
Os objetivos específicos do curso compreendem: - propiciar a formação profissional inicial de professores de Língua Espanhola para a educação básica; - possibilitar uma visão ampla do conhecimento linguístico entendida a linguagem como prática social - de modo que o futuro professor possa especializar-se posteriormente em áreas afins; • fomentar valores estéticos, políticos e éticos ao futuro docente, capazes de orientar pedagogicamente sua prática educativa, contribuindo para a consolidação de uma educação emancipatória. PPC, 2014 [En línea] http://goo.gl/Qkx50B (Subrayado nuestro)
\end{abstract}

Además, en términos prácticos y sobre fluidez y dominio de lengua española, traducir en este punto de la formación docente, ya no es más una cuestión de literalidad y sí de conjunto, resolver cuestiones de traducción implica encuadrarse al menos en un nivel B2 o C1 del MCER, es cuando docente de grado y estudiante pueden constatar logros, que el nuevo profesor de ELE es capaz de actuar con fluidez y dominio de la lengua objeto de su especificidad de formación. 
Cuadro 13 - Contraste de oferta de asignaturas del $9^{\circ}$ semestre

\begin{tabular}{|l|l|l|l|l|l|}
\hline \multicolumn{5}{|c|}{ ASIGNATURAS OBLIGATORIAS DEL 9 SEMESTRE } \\
\hline \multicolumn{1}{|c|}{ IES-1 } & CH & Asignatura & CH & Asignatura & CH \\
\hline Asignatura & $60 h$ & & & & \\
\hline $\begin{array}{l}\text { Tradução em língua } \\
\text { espanhola I }\end{array}$ & $200 h$ & & & & \\
\hline $\begin{array}{l}\text { Atividades acadêmico- } \\
\text { centífico-culturais }\end{array}$ & $100 h$ & & & & \\
\hline $\begin{array}{l}\text { Estágio supervisionado de } \\
\text { formação de professores - } \\
\text { Ensino médio (Espanhol) }\end{array}$ & & & & & \\
\hline
\end{tabular}

Fuente: [En línea] https://goo.gl/WHmEEm

[En línea] http://goo.gl/8rOs9K

[En línea] http://goo.gl/Qkx50B

Después de todo lo expuesto, afirmamos:

$\checkmark$ que el aprendizaje de ELE en nivel C1 o inclusive C2, es posible lograrlo a lo largo de la enseñanza de grado en ELE si se contara con fluidez y dominio de la lengua, la buena disposición y el convencimiento del profesorado para tal meta;

$\checkmark$ la carga horaria de disciplinas específicas de ELE del curso de grado es adecuada y suficiente para el logro de la fluencia y dominio de la lengua española para los futuros profesores de ELE, consecuentemente no es de necesaria implementación curso en paralelo en escuela de idiomas;

$\checkmark$ que las IES del estado de Rio Grande do Norte deberían socializar, discutir, promover reflexiones mutuamente y en conjunto por una oferta de enseñanza de grado robusta, homogénea y eficiente que beneficie sobre todo la enseñanza pública y básica;

$\checkmark$ que un plan de estudios de grado tiene extrema importancia para el éxito de la carrera que se oferta y que en virtud de ello, se debe actuar en la elaboración con tino profesional y no personal, con perspectiva desde la óptica del estudiantado y de la sociedad que aguarda esos aciertos y no del profesorado de grado no especialista;

$\checkmark$ el plan de estudios no puede dejar de contemplar asignaturas que contribuyan a despertar el deseo y posibilidad de insertarse en alguna 
otra área afín, como especialistas del lenguaje, revisión, elaboración de materiales didácticos, asesor lingüístico en ELE, traductor, lexicólogo, lexicógrafo, gramático, fonetista, etc., y por supuesto, profesor, más aún cuando el propio plan de estudios enuncia esta cuestión como uno de sus principales objetivos.

Al crear un plan de estudios de grado en ELE o cualquier otro, siempre habrá aspectos que mejorar, implementar, retirar, añadir de acuerdo a ánimos puramente profesionales, metas académicas, perspectivas, expectativas, si bien es verdad que cada docente de grado tiene su punto de vista, es importante, estar siempre dispuesto a oír, negociar, admitir, valorar el parecer según se beneficie sobre todo la calidad de los estudios para el futuro profesor que por ende beneficiará a la sociedad.

\subsection{LOS PROFESORES DE FUTUROS PROFESORES DE ELE}

La categoría profesor de enseñanza de grado de institución pública, en general goza de prestigio, estabilidad y sueldo razonable, además, es posible acceder a una de las plazas sin el requisito 'experiencia' pero a través de rigurosos procesos selectivos, cuyo objetivo es evaluar la competencia de los candidatos velando los principios de igualdad.

Por lo general, los profesores de grado actúan en el ámbito de la educación federal, en universidades federales, estatales e institutos federales. Son profesionales que para tomar posesión de su función tienen que haber superado una prueba escrita de conocimientos específicos tanto objetiva como discursiva, una prueba de desempeño que consiste en exponer una clase para un tribunal y la prueba de titulación en la que presenta toda documentación que compruebe estudios, experiencia, investigación, etc.

La calidad del profesor de grado es indiscutible, no obstante, en algunas situaciones, como la que se presentó por fuerza de la ley 11.161, profesores de lengua española fueron aprobados con criterios especiales, como el de no poseer titulación de 'doctor' para ingresar en ell cuerpo docente permanente de una IES, lo que a los días de hoy ya está superado en la IES-1 y, en la IES-2 e 
IES-3 se encuentra en proceso de superación. Las políticas gubernamentales apoyan de todas las maneras posibles los estudios de maestrías y doctorados en pro de una enseñanza de muy buena calidad que venga a beneficiar la sociedad como un todo.

En concreto, sobre los profesores de grado en ELE, lo que es de relevancia determinar en este trabajo es su conocimiento de lengua española medido en su fluidez y dominio oral y escrito, el mismo que pone en práctica a la hora de impartir las asignaturas específicas de su cargo, pues esta competencia se perfila como de especial importancia al tratarse de enseñanza de una lengua extranjera, español, en la formación de sujetos que serán profesores también tras concluir los estudios de grado. Se plantea la clara expectativa de que formarse profesor de lengua extranjera, español en este caso, y no transitar con fluidez y dominio de lengua en la acción docente para fines de efectiva comunicación, implica en un estancamiento de la verdadera función que le compete comprometiendo seriamente el poder de inclusión que existe en el acceso a este conocimiento y sobre todo al mundo de oportunidades que comunicarse en una lengua extranjera pone al alcance del sujeto desde su educación básica.

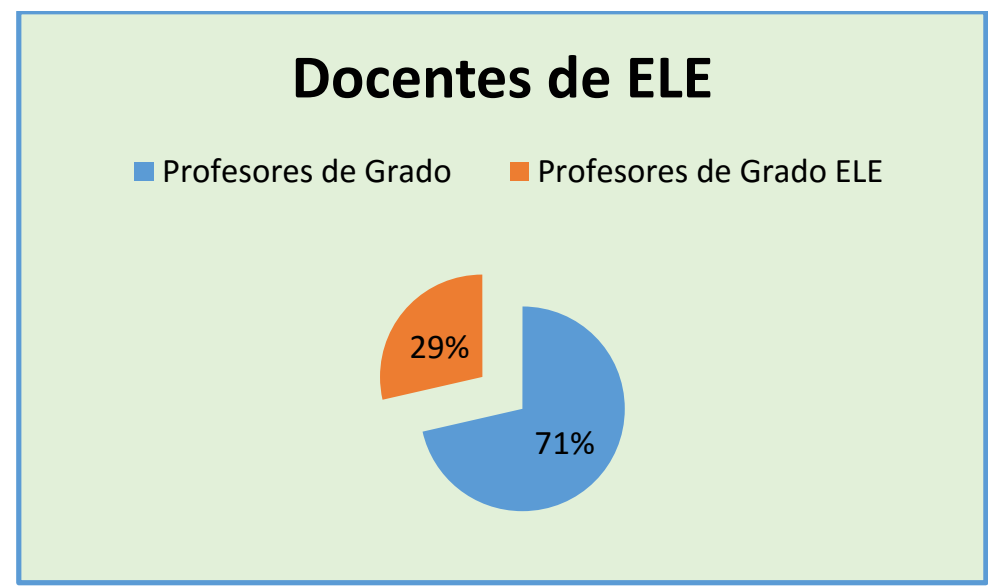

Gráfico 3 - Docentes de ELE

Fuente: [En línea] https://goo.gl/WHmEEm [En línea] http://goo.gl/8rOs9K [En línea] http://goo.gl/Qkx50B

En la enseñanza de grado en el estado de Rio Grande do Norte, en Brasil, actúan en la docencia de enseñanza superior en las tres IES contempladas en este trabajo, un promedio por IES de 16 a 18 profesores de 
los cuales 5 o 6 actúan impartiendo asignaturas específicas de ELE. Estos serían los profesionales que tendrían bajo su responsabilidad el aprendizaje de ELE del estudiantado de grado, pues su práctica académica es clave para el logro de la fluencia y dominio de la lengua objeto de sus estudios de grado.

No solo en el nordeste brasileño, sino en todo el país, ciudadanos de origen hispano, brasileños naturalizados, por tanto, brasileños y profesores actúan en la enseñanza de español, en la formación del profesorado de ELE. Así mismo se ve que en los últimos procesos selectivos, casi no se presentan más profesores no nativos brasileños, así, los nuevos aprobados van agregándose a los cuadros permanentes de los cursos de grado en ELE en las IES del estado y lo que se desea es que estos nuevos profesores brasileños valoricen la importancia de una fluidez y dominio de lengua española suficiente que sea motivo de inspiración a los estudiantes de ELE y estímulo para esforzarse en lograr un nivel interesante de comunicación.

En la encuesta realizada recientemente para esta investigación, los profesores de grado en ELE, contestaron que sí impartían todas sus clases en español en las IES investigadas.

\subsubsection{La calidad y los mitos en la enseñanza de grado en ELE}

Lo que vamos a escribir aquí es raro verlo en trabajos de esta naturaleza, pero son decires velados de realidades que hace falta analizar, aclarar, mejorar o definitivamente cambiar. Veamos algunos de ellos, agrupados (o separados) por docentes y estudiantes:

Mitos de algunos docentes de grado:

(1) El curso de grado no es para aprender la lengua, debe hacerlo acudiendo a una escuela de idiomas;

(2) Profesor de español en la educación básica está para despertar la conciencia de la existencia de otras culturas, de otros pueblos, nada más;

(3) Semántica no sirve para nada, no hace falta constar en el plan de estudios; 
(4) Fonética, tampoco sirve porque, no es para imitar como hablan los nativos, no tenemos obligación de hacerlo.

(5) Aprender gramática es una pérdida de tiempo, eso no sirve para nada;

(6) Voy a hablar en portugués para ir más rápido, hay mucho contenido;

(7) Enseñar lengua extranjera en escuela pública es en vano.

Mitos de los estudiantes de grado;

(1) Mi sueño es que todos los profesores den sus clases en español

(2) Quisiera que todos mis profesores fueran doctores

(3) Quisiera hablar bien español cuando termine el curso de grado

A priori, lo primero en que se piensa cuando un estudiante no aprende lo que debería en su ambiente escolar, es que está teniendo malos profesores, profesionales sin una buena estrategia de enseñanza, y más aún, sin formación específica suficiente para enfrentar la tarea de enseñar una lengua extranjera, en específico lengua española. Pero, es más inquietante no tener claro si estos nuevos profesores, graduados tras cuatro años de estudios, realmente fueron, o no, preparados para el desafío de insertar nuevas personas en el fascinante mundo de la comunicación en lengua extranjera.

QUEM É O PROFESSOR DE INGLÊS?

Comecemos pelo ideal. O professor de inglês deveria ter, além de consciência política, bom domínio do idioma (oral e escrito) e sólida formação pedagógica com aprofundamento em linguística aplicada. Em número reduzido, temos profissionais bem formados dentro do perfil ideal que acabamos de descrever. A boa formação é, muitas vezes, fruto apenas de esforço próprio, pois os cursos de licenciatura, em geral, ensinam sobre a língua e não aprofundam conhecimentos na área específica de aprendizagem de línqua estrangeira. (PAIVA, 1997: 9) (Subrayado nuestro).

Es obvio que no todos los problemas que comprometen la calidad del desempeño docente, la calidad de la fluidez y del dominio de lengua extranjera así como la calidad de la formación teórica y pedagógica está en el cuerpo docente de los estudios de grado, aspectos de otros niveles de jerarquía y de 
otros aspectos se confabulan para contribuir con el cuadro del profesor de lengua extranjera y la calidad de su trabajo, por ejemplo, es altamente desestimulante dar 50 minutos de clase por semana, cuando estudiantes y docente tardan al menos 10 minutos para acomodarse e iniciar la clase, y a nada ya tiene que terminar, de esta forma por mucho que se haga, no se consigue completar, es lamentable.

Pero, ante esta realidad, qué hemos hecho para revertirla, para tener el mismo derecho que la lengua inglesa, 100 minutos semanales, por qué inglés tiene el doble de tiempo por semana que español.

Se vive una realidad que no solo no agrada, sino que perjudica el conocimiento de la lengua española que puede significar inclusión, oportunidad, expectativas, perspectivas de un futuro mejor. Lo ideal sería que los 150 minutos, al menos se repartieran equitativamente entre inglés y español, 25 minutos más ya es un avance.

Los mitos de algunos docentes, están en consonancia con lo que PAIVA (1997) escribe sobre el mismo asunto y aquí sí está claro que la responsabilidad recae sobre "os cursos de licenciatura, em geral, ensinam sobre a língua e não aprofundam conhecimentos na área específica de aprendizagem de língua estrangeira", (subrayado nuestro) lugar exacto donde están nuestros marcadores del discurso, lugar donde está la fluencia y el dominio de la lengua que estos profesores deberían conocer bien.

\subsection{LOS PROFESORES DE ELE EN LA EDUCACIÓN BÁSICA Y PÚBLICA}

La educación básica y pública en Brasil es ofertada por las escuelas municipales para la enseñanza infantil y primaria y por las estatales para la enseñanza secundaria. Actualmente y por imposición de la famosa ley del español, la mayoría de las escuelas secundarias tiene un profesor de lengua española que es el que imparte las clases, este debe cumplir 20 horas semanales La carga horaria semanal de clases de español es de solo 50 minutos, tiempo demasiado corto para lograr avances significativos en todo sentido. 
Es importante resaltar que son pocas las escuelas estatales en cuyo proyecto pedagógico figura la asignatura de español como disciplina de oferta regular, no obstante es ofertada como si estuviera registrada. Es en este contexto que la labor docente se realiza, los profesores, por otro lado, tienen un perfil diferente entre sí, a saber:

$\checkmark$ Profesor con grado en ELE

$\checkmark$ Profesor con grado en otra área con capacitación en ELE

$\checkmark$ Profesor con grado en otra área y curso de idiomas

$\checkmark$ Profesor con grado en otra área con capacitación en ELE y curso de idiomas

$\checkmark$ Profesor con grado en otra área.

Gráfico 4 -Perfil de los profesores de la escuela pública.

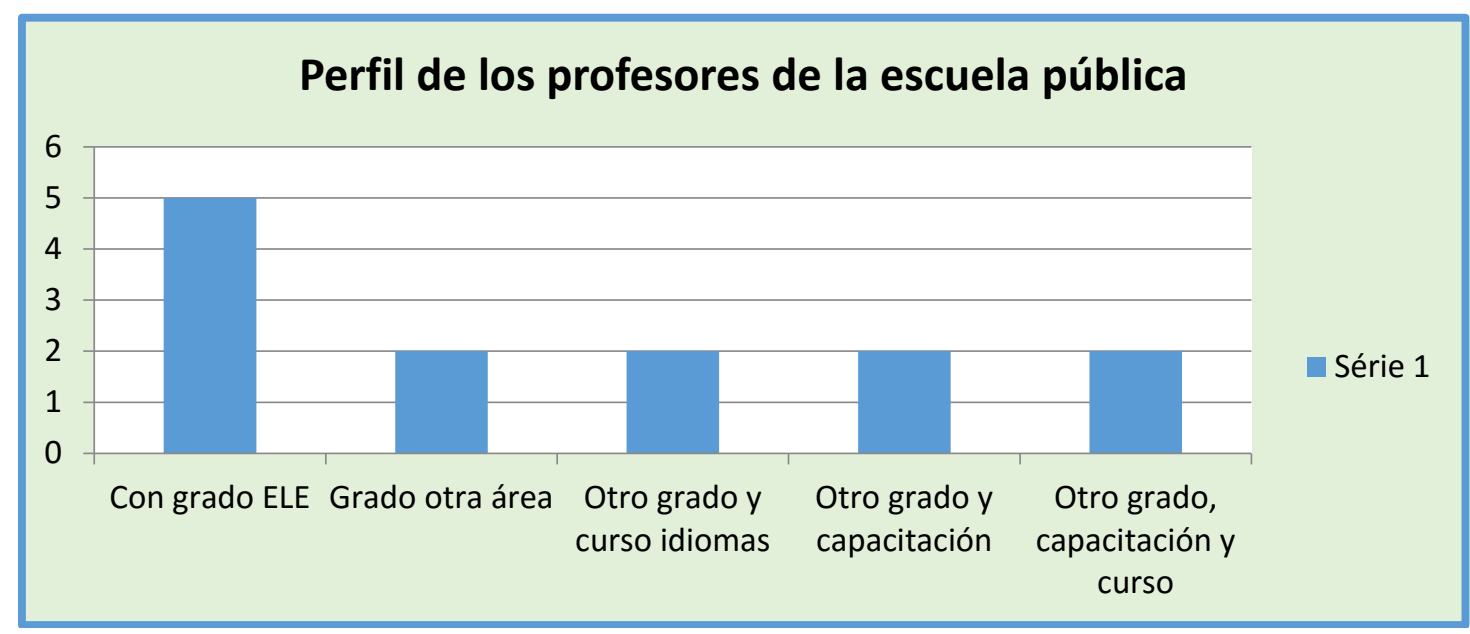

Fuente: Datos de encuesta PIBID (2013)

El gráfico anterior revela que de un universo de 13 profesores de enseñanza básica y pública, son 5 los que de hecho son aptos para ejercer la docencia en ELE, los demás son profesionales con grado en otras áreas como lengua inglesa, historia, filosofía e inclusive matemáticas que ejercen la función de profesor de español respaldados en un curso de capacitación de 120 horas o en un curso realizado en escuela de idiomas, o inclusive en ambos.

En este breve texto, se revela la difícil situación en que se desarrollo la tarea de enseñanza y aprendizaje de lengua española en la educación básica y 
pública en esta región y más puntualmente en el estado de Rio Grande do Norte, en Brasil.

\subsection{SOBRE ENSEÑANZA SUPERIOR}

En Brasil, como en cualquier lugar del mundo, el progreso de su sociedad se manifiesta a través del nivel en la educación de sus ciudadanos y su preparación para actuar como fuerza para sí y para su sociedad. La formación de profesores, elemento fundamental para avanzar en lo que a educación respecta, en su histórico revela que solo ha tomado riendas de su propio destino en las últimas décadas, porque antes, de una u otra forma siempre ha estado atada a influencias extranjeras.

Los primeros profesores brasileños recibieron una formación basada en los clásicos antiguos y volcada para patrones de la sociedad europea cristiana, esto alrededor de los años 1750. La formación, recibida en Portugal y luego en Brasil constituyó la primera y más fuerte influencia externa en la formación de profesores brasileños.

Desde entonces hasta llegar a las escuelas normales brasileñas que formaban a los profesores, pasaron unos 100 años y claro estaban hechas a modelo europeo, más precisamente, francés:

[...] embora não haja como negar o caráter transplantado de nossas instituições [...] a historiografia mais recente tem procurado mostrar também sua articulação com o contexto nacional e com algumas contradições internas de nossa sociedade (TANURI, 2000: 63).

En la República empezaba a manifestarse la influencia de principios positivistas. Las características y realidad del país no eran tomadas en cuenta en los proyectos nacionales, los profesores eran muy pocos y además de baja calificación.

La formación de profesores en la Posguerra consolidaba las ideas liberales y del Estado de derecho; fue cuando se definió como "derecho de todos y deber del Estado", pensamiento vigente hasta el día de hoy, debatiendo 
el derecho de construir un sistema nacional de enseñanza con gratuidad y a cargo del gobierno. Es en este tiempo cuando el brasileño, por primera vez en la historia de su educación piensa su política para la formación de sus profesores.

En suma, tras el origen del sistema de educación a imagen del europeo, se rescata como positivo que fue en donde se encontró respaldo teórico que orientó el conocimiento. El inicio de la formación del profesorado en Brasil siempre ha estado vinculado e influenciado por la presencia de organismos internacionales como el Banco Mundial y muchos otros como la UNESCO que hasta los días actuales continúan influyendo porque estos participan en su financiamiento.

\subsubsection{Terminología lingüística de grado}

A medida que se ha ido tejiendo este trabajo de investigación, hemos reflexionado sobre el cómo nombrar algo para que no haya lugar a cambio de significado o interpretación, sobre todo en lo que se refiere a cuestiones formales y legales entre las lenguas española y portuguesa de Brasil. Ante eso, incluimos este apartado para delimitar términos, a fin de estar seguros de que estamos hablando y entendiendo lo mismo.

A ese propósito, la afirmación de CABRÉ se configura como de absoluta pertinencia:

La terminología, como actividad inconsciente apareció en el momento en que alguien necesitó referirse a la realidad de un modo preciso y exacto. Como actividad consiente, surgió del interés de los científicos para ponerse de acuerdo en la fijación de los conceptos y denominaciones de sus respectivas ciencias, sobre todo, las ciencias naturales. (CABRÉ, 2004: 91)

Hemos elaborado el siguiente cuadro con tres informaciones:

1. Término en español.

2. Explicación del contenido

3. Término equivalente en portugués de Brasil. 
Cuadro 14 Terminología de grado español - portugués

\section{Término y explicación (en español) ${ }^{71}$}

\section{Acreditación (1)}

Reconocimiento y aprobación de las normas académicas de un centro docente por parte de un órgano exterior imparcial que goza de gran predicamento público

\section{Alumno - Estudiante (1)}

Niño matriculado en la enseñanza preescolar o primaria. A los jóvenes y adultos matriculados en niveles de enseñanza superiores se les designa a menudo con el término estudiantes"

\section{Aprovechamiento escolar $I$ académico}

Resultados obtenidos en pruebas o exámenes normalizados que miden los conocimientos o competencias en una materia específica. Esta expresión se utiliza a veces como indicación de la calidad de la educación en un sistema educativo, o para efectuar comparaciones entre varios centros docentes. (Añadido y subrayado nuestro)

\section{Discapacidad (1)}

Afección física o mental que puede ser temporal o permanente y que limita las posibilidades de una persona para participar en la vida comunitaria en condiciones de igualdad con las demás.

\section{Docente formado (1)}

Docente que ha recibido el mínimo de formación estructurada que se exige normalmente en un país dado para enseñar en un determinado nivel de enseñanza.

\section{Docentes o personal docente o cuerpo docente (1)}

Número de personas empleadas oficialmente a tiempo completo o parcial para orientar y dirigir el itinerario de aprendizaje de los alumnos y estudiantes, independientemente de sus calificaciones y del mecanismo de transmisión de los conocimientos (presencial y/o a distancia). Esta definición excluye al personal educativo que no desempeña funciones de enseñanza (por ejemplo, los directores o administradores de centro $=\mathrm{s}$ de enseñanza que no ejercen la docencia), así como a las personas que trabajan de forma esporádica o voluntaria en centros docentes. (Añadido y subrayado nuestro)

\section{Educación básica (1)}

Conjunto de actividades educativas realizadas en contextos diferentes (formal, no formal e informal) y destinadas a satisfacer las necesidades educativas básicas. Según la Clasificación Internacional Normalizada de la Educación (CINE), la educación básica abarca la enseñanza primaria(primera etapa de la educación básica) y el primer ciclo de la enseñanza secundaria
En portugués de Brasil

Revalidação de estudos

\section{discente}

Rendimento escolar / acadêmico IRA

\section{Docente - professor}

Docentes ou pessoal docente ou corpo docente
Educação básica: Ensino fundamental $1+$ Ensino Fundamental II + Ensino médio

71 (1) Del Glosario de UNESCO. [En línea] http://www.unesco.org/education/GMR/2007/es/glosario.pdf

(2) Referenciado a partir de nomenclatura dada en www.usal.es

(3) Referenciado a partir de www.rae.es 


\section{(segunda etapa)}

\section{Enseñanza obligatoria (1)}

Programas educativos a los que niños y adolescentes tienen la

\section{Ensino obrigatório} obligación de asistir a tenor de lo dispuesto en la legislación. Estos programas se suelen determinar por número de años o periodo de edad, o con arreglo a estos dos criterios a la vez

\begin{abstract}
Enseñanza superior (1)
Programas con un tenido educativo más adelantado que el de los niveles 3 y 4 de la CINE. El primer ciclo de la enseñanza superior (nivel 5 de la CINE) consta de dos niveles: el nivel $5^{a}$, cuyos programas son principalmente de carácter teórico y están destinados a proporcionar calificaciones suficientes para ser admitido a cursar programas de investigación avanzados o ejercer una profesión que requiere competencias elevadas; y el nivel 5B, cuyos programas tienen por regla general una orientación más práctica, técnica y/o profesional. El segundo ciclo de la enseñanza superior (nivel 6 de la CINE) comprende programas dedicados a estudios avanzados y trabajos de investigación originales que conducen a la obtención de un título de investigador altamente calificado.
\end{abstract}

\section{Enseñanza técnica y profesional. (1)}

Programas principalmente destinados a preparar directamente a los alumnos o estudiantes para desempeñar un oficio o profesión técnica de carácter específico (o para una categoría de profesiones o actividades técnicas). El estudiante que termina con éxito uno de estos programas consigue una calificación adecuada para entrar en el mercado de trabajo, que es reconocida por las autoridades competentes del país don la ha obtenido (Ministerio de Educación, asociaciones de empleadores, etc.).

Equidad (1)

El grado de justicia e imparcialidad del acceso a la educación y las posibilidades de educación ofrecidas a los niños y los adultos. Lograr la equidad supone reducir las disparidades basadas en el sexo, la pobreza, el lugar de residencia, la pertenencia étnica, la lengua y otras características.

\section{Grado (1)}

Etapa de la enseñanza que por regla general corresponde a un Ano-série año escolar completo

Enseñanza de grado (2)

Ensino técnico e
profissional

Igualdade - equidade

\section{Graduado (1)}

Persona que ha terminado con éxito el último año de un nivel o subnivel de educación. En algunos países la terminación de un nivel o subnivel exige haber superado con éxito un examen o una serie de exámenes, y en otros haber acumulado un número preceptivo de horas lectivas. Hay países en los que coexisten Ensino de graduação ambos sistemas.

\section{Lengua [o vector] de enseñanza (1)}

Lengua(s) utilizada(s) para la enseñanza y el aprendizaje en un Língua de ensino contexto de enseñanza formal o no formal 


\section{Lengua indígena (1)}

Lengua originaria de un territorio o comunidad particular que no ha Língua indígena sido importada. Véase Lengua materna y Lengua vernácula.

\section{Lengua materna (1) \\ Lengua principal hablada en el contexto domestico y adquirida Língua materna $L M$ como primera lengua. A veces se denomina "lengua del hogar"}

\section{Lengua nacional (1)}

Lengua hablada por una gran parte de la población de un país, que

Língua nacional - oficial puede ser proclamada o no lengua oficial, es lengua designada por

la ley para ser utilizada en la esfera pública.

Lengua vernácula (1)

Lengua hablada por la población de un país o región, que es Língua vernácula distinta de las lenguas oficiales o mundiales

Pedagogo (1)

Persona formada en técnicas de docencia. En las profesiones que guardan relación con la primera infancia, el pedagogo recurre a la teoría y la práctica de la pedagogía, centrándose en un planteamiento relacional y holístico. La distinción entre pedagogo y docente difiere según los países

\section{Primera infancia (1)}

Periodo de la vida de un niño que va desde el nacimiento hasta los Primeira infância ocho años de edad.

\section{Proporción alumnos/docente (PAD) (1)}

Promedio de alumnos por docente en un determinado nivel de

Proporção alunos/docentes enseñanza, calculado sobre la base del número de alumnos y $P A D$ profesores.

\section{Repetidores (1)}

Número de alumnos matriculados en el mismo grado o nivel que año escolar precedente, expresado en porcentaje del total de alumnos matriculados en ese grado o nivel.

\section{Sectores de estudios de la enseñanza superior (1)}

[..]Educación: formación de docentes y ciencias de la educación Humanidades y artes: Humanidades, religión y teología, bellas artes y artes aplicadas.[...]

\section{Tasa bruta de escolarización (TBE) (1)}

Número total de alumnos de a cualquier edad matriculados en un determinado nivel de enseñanza, expresado en porcentaje de la población del grupo en edad oficial de cursar ese nivel de enseñanza. En la enseñanza superior, la población es la que corresponde al grupo de edad de los cinco años que siguen a la edad de terminación de la enseñanza secundaria. La TBE puede ser superior al $100 \%$ debido a los ingresos tardíos y/o las repeticiones.

Tasa bruta de ingreso (TBI) (1)

Número total de los alumnos de cualquier edad matriculados por Taxa bruta de ingresso TBI primera vez en el primer grado de la enseñanza primaria, expresado en porcentaje de la población en edad oficial de ingresar en ese grado.

Tasa de deserción por grado (1)

Proporción de alumnos o estudiantes que abandonan un Taxa de deserção/evasão 
determinado grado de estudios en un año escolar determinado. Es la diferencia entre $100 \%$ y el total de las tasas de transición al curso siguiente y las tasas de repetición.

\begin{tabular}{lll|}
\hline $\begin{array}{l}\text { Tasa neta de asistencia (1) } \\
\text { Número de alumnos del grupo en edad oficial de cursar un } \\
\text { determinado nivel de enseñanza que asisten a la escuela, } \\
\text { expresado en porcentaje de la población total de3 ese grupo e } \\
\text { edad. }\end{array}$ & \\
\hline $\begin{array}{l}\text { Plan de estudios de grado (2) } \\
\text { Macro documento que describe todo lo concerniente a la oferta de }\end{array}$ & $\begin{array}{l}\text { Projeto pedagógico do do } \\
\text { un curso de grado o graduación en la enseñanza superior. }\end{array}$ & Disciplina \\
\hline $\begin{array}{l}\text { Asignatura (2) } \\
\text { Componente Del plan de estudios de grado }\end{array}$ & \\
\hline $\begin{array}{l}\text { Programa de curso (2) } \\
\text { Documento académico que para cada asignatura existe y en el que } \\
\text { consta datos de oferta, código de la asignatura, sumilla, objetivos } \\
\text { del curso, contenidos, recursos, metodología, criterios de } \\
\text { evaluación y bibliografía recomendada. }\end{array}$ & \\
\hline $\begin{array}{l}\text { Contenido programático (2) } \\
\text { Detalle de los temas a ser estudiados }\end{array}$ & Conteúdo programático \\
\hline $\begin{array}{l}\text { Resumen (2); Sumilla } \\
\text { Extracto del contenido del programa de un curso de la formación } \\
\text { académica }\end{array}$ & \\
\hline
\end{tabular}

(Creado por el autor)

\subsubsection{Equivalencia de estudios Brasil - España}

La educación en Brasil marca claramente tres macrogrupos, a saber: educación infantil, educación básica y educación superior, pero dentro de ellas hay subgrupos. Es semejante al sistema educativo español, aunque hay algunas diferencias: el español ofrece opciones de estudios que en Brasil no tenemos. Para conocimiento, se pueden apreciar las equivalencias en el cuadro I.15. 
Cuadro 15 - Equivalencia de estudios Brasil - España

\begin{tabular}{|c|c|}
\hline EDUCACIÓN SUPERIOR EN BRASIL & EDUCACION SUPERIOR EN ESPAÑA \\
\hline Educação infantil (até os 6 anos) & \\
\hline Educação Básica: & $\begin{array}{c}\text { Educación Primaria EGB } \\
\text { Fundamental I (5 anos) } \\
\text { Fundamental II (4 anos) } \\
\text { Ensino médio (3 anos) } \\
\text { unificado polivalente BUP } \\
\text { Bachillerato COU }\end{array}$ \\
\hline Cursos de Graduação-Licenciatura (4 & $\begin{array}{c}\text { Educación Secundaria ESO o Bachillerato } \\
\text { anolo formativo de Grado medio (CFGM-FPI) } \\
\text { Ciclo formativo de grado superior (CFGS- } \\
\text { FPII) }\end{array}$ \\
\hline Cursos de Engenharias (5 anos) & $\begin{array}{c}\text { Diplomatura (3 años) } \\
\text { Licenciatura - Grado (4 años) } \\
\text { Ingeniería } \\
\text { Ingeniería Superior (4 años) }\end{array}$ \\
\hline Mestrado (+ - 2 anos) & $\begin{array}{c}\text { Posgrado (de 30 a } 60 \text { créditos ECTS) } \\
\text { Máster Posgrado (de } 30 \text { a } 60 \text { créditos ECTS) }\end{array}$ \\
\hline Doutorado (+ - 4 anos) & Doctorado \\
\hline Pós doutorado (1 ano) & Postdoctorado \\
\hline
\end{tabular}

Fuente: [En línea] http://goo.gl/uJp9LV

\section{LOS MARCADORES DEL DISCURSO (MD) EN LA FORMACIÓN DEL PROFESORADO DE LENGUA EXTRANJERA}

Construir un discurso articulado que permita fluidez en la comunicación es uno de los objetivos más importantes al aprender una lengua extranjera. Sin duda, son varios los aspectos que hay que tener en cuenta para alcanzar un buen dominio: aspectos de orden léxico, fonético, semántico, morfológico, sintáctico, pragmático y de conciencia discursiva son los que directa 0 indirectamente intervienen. Esa articulación que da coherencia y cohesión a un discurso, generalmente, está en el buen conocimiento y aplicación de elementos de enlace extra oracional como los marcadores del discurso que son los responsables de conectar las relaciones semántico-pragmáticas entre las partes y de guiar las inferencias que se realizan en la comunicación: 
Los marcadores del discurso son unidades lingüísticas invariables, no ejercen una función sintáctica en el marco de la predicación oracional y poseen un cometido coincidente en el discurso: el de guiar, de acuerdo con sus distintas propiedades morfosintácticas, semánticas y pragmáticas, las inferencias que se realizan en la comunicación. (PORTOLÉS, 2001: 26)

Comunicar una simple y hasta corta idea o información en la que esté presente un MD, puede desencadenar inferencias que se transforman automáticamente en más información. Este es el punto de partida de la lingüística del texto, que se apoya en las bases de la pragmática y la sociolingüística, y que el análisis del discurso estudia, analiza y consagra, derrumbando el concepto de unidad mínima del lenguaje que se le otorgaba a la oración. Para muestra, vemos los ejemplos de PORTOLÉS, 2001:22)

(1) Ana es de Teruel y, por tanto, es habladora.

(2) Ana es de Teruel y, sin embargo, es habladora.

Lo dicho en (1) se compone de dos oraciones:

(1A) Ana es de Teruel

(1b) Ana es habladora

Dichas así, el significado se detiene en lo meramente dicho en cada oración, pero como está en (1), no solo se dice que Ana es de Teruel y que ella es habladora, se dice mucho más, o mejor, se infiere que todos en Teruel ${ }^{73}$ son habladores, o que los de Teruel tienen esa fama, por eso, ella también. No obstante, en (2) haber cambiado 'por tanto' por 'sin embargo', lo que comunica ya es otra cosa, además, contraria, se infiere que la gente de Teruel no es habladora, pero ella, por alguna razón, sí lo es, infiere que por alguna otra razón, Ana es habladora, lo que termina generando expectativas diversas a partir de esa inferencia.

\footnotetext{
73 Teruel es una ciudad española situada al sur de la Comunidad Autónoma de Aragón, es capital de la provincia con el mismo nombre. [En línea] http://goo.gl/eKG6OY
} 
Lo dicho hasta ahora sobre marcadores del discurso ya es de absoluta obviedad para muchos que ahora mismo estén leyendo este trabajo, pero, es pensando en estudiantes de los primeros periodos académicos que se repite tal cual la fuente para que no haya lugar a dudas. En este apartado nos proponemos presentar y analizar el estado de la cuestión con relación a los MD en el plan de estudios de grado en vigor, en las asignaturas específicas y de lengua española y comentaremos algunos discursos enfocando la presencia y el uso de los MD en cortos textos enunciados por involucrados en el proceso de enseñanza de grado y aprendizaje de ELE.

De esta forma, esta investigación se centra en evaluar la importancia que los marcadores del discurso tienen en la fluidez y dominio de la lengua española y en los fallos o aciertos de su enseñanza durante la formación de los futuros profesores brasileños de español como lengua extranjera por instituciones públicas de enseñanza superior (IES) del nordeste brasileño buscando objetivamente dónde, cuándo y cómo se enseñan los MD; se abordan aspectos teóricos que justifiquen y respalden la identidad de los marcadores del discurso en la oralidad de un individuo desde una óptica general buscando tejer un raciocinio de base que los configure como elementos de esencial conocimiento, dominio y fluidez de una lengua extranjera o segunda lengua.

Retomando el tema, el tipo de relación destacada en de Ana, Teruel y habladora (1) y (2) se da en toda lengua, pero por supuesto, se nota más clara facilidad en la lengua materna, al punto de siquiera percibirlo conscientemente. Al aprender una lengua extranjera, estas relaciones se tornan de emisión compleja, lo que no debería pasar y, si pasa, no se debería dejar avanzar. Esta dificultad se podría superar si en las clases impartidas a lo largo de los estudios de grado, las de cuño específico, sobre todo, explotaran estrategias diversas en un proceso de inmersión temporaria (durante las horas de clase) de convivencia en ELE, de esa forma, creemos posible que se pueda conquistar la fluidez y dominio de español como lengua extranjera, requisito indispensable para ejercer la docencia de ELE.

Es de importante mención y lo afirmamos con vehemencia, hace falta una buena conducción y buenos conductores para llegar a la meta de la fluidez y 
dominio de español en nuestro caso, y ahí ya estamos en el campo de los formadores de profesores que por varias y diversas razones toman un posicionamiento contradictorio en el desempeño de su función 'profesor de grado de ELE'. En algunos es corriente oír cosas como:

(1) 'la enseñanza de grado es para tornarlo profesor, lo de tener fluidez en la lengua debe buscarlo fuera, en una escuela de idiomas o con estudios autodidácticos';

(2) La semántica no sirve para nada, no debe ser siquiera más tratado ese contenido en el grado en ELE;

(3) No hay necesidad de preocuparse por cómo pronunciar en español, somos brasileños, pronunciamos como brasileños, la fonética no sirve para nada, tampoco debería dársele esa importancia;

(4) Gramática para nada, eso es cosa del pasado, tampoco sirve; es perder el tiempo; etc.

Y sobre el papel del docente de ELE en la escuela pública, se afirma con vehemencia:

(1) El objetivo de la asignatura español en la educación básica es el de concienciar a esos alumnos de los pueblos que existen, de las diversas culturas, no es para que aprendan a hablar español;

(2) Mientras exista oferta de inglés, español estará en desventaja, estará en un segundo plano, no hay forma de resolver eso;

(3) Históricamente, el resultado de la enseñanza de una lengua extranjera en la educación básica y sobre todo pública, es nulo, por qué sería diferente con español;

(4) Lengua extranjera en la escuela pública, tema que nunca será tomado en serio, no tiene peso frente a matemáticas, portugués, etc.;

(5) Par qué perder tiempo enseñando si es algo que no interesa, sino solo para la selectividad, examen ENEM y eso; etc.

Por estar insertados en este contexto y percibir el perjuicio que deviene de esas 'convicciones' para toda una sociedad, escribimos este trabajo. Y aunque aún no estemos en posesión de datos más apurados y específicos, afirmamos que: 
(1) Un profesor de grado en ELE debe tener fluidez y dominio de la lengua que dice de su especificidad profesional, si fuera como algunos lo piensan, un profesor de matemática, sería profesor de matemática sin saber suficiente matemática, algo definitivamente absurdo.

(2) Que la semántica sirva o no sirva no es la cuestión, la cuestión está en qué nivel de conocimiento teórico se detiene para conducir opiniones, muchos solo repiten, no reflexionan, y eso también afecta a los formadores que por 'moda' siguen raciocinios, cuestiones como las de: "el formalismo es cosa del pasado" ¿Cómo podría serlo? Abordaremos este tema de forma más amplia, más adelante.

(3) Fonética es del campo del funcionalismo y no del formalismo, en todo caso lo sería Fonología;

(4) Estos discursos son incoherentes al analizar los programas de las asignaturas específicas, las bibliografías básicas y complementar listan títulos y títulos de gramáticas y diccionarios y el contenido de los mismos parten de aspectos gramaticales.

La realidad de la enseñanza de lengua extranjera en la escuela básica y pública adolece de un histórico, eso es verdad, aunque no lo queramos admitir, y es una dolencia creo que no solo nacional, también afecta a otros países, esa dolencia hay que curarla, no puede mantenerse, el diagnóstico existe, hace falta el tratamiento:

(1) El contexto brasileño está desconectado cuando se trata de lengua extranjera y educación básica, ahora más con la inserción de español como asignatura obligatoria, los objetivos que se trazan para la LE son demasiado ambiciosos en las condiciones reales de ejecución, al caracterizarse esta situación, todo lo que no se pueda hacer y hasta no se quiera hacer, encuentra asilo en esa justificativa.

(2) (3) (4) Es consabido el mundo de intereses que está en juego en la decisión de una $u$ otra lengua en el sistema formal de educación brasileña, las dimensiones de este país lo convierten en el "fruto deseado", pero hasta qué punto es posible defender los intereses de los posibles beneficiarios, el niño, el joven, el hombre brasileño que paga el 
precio de acceder a una educación limitada por esos intereses. Es lastimoso admitir que si no se defiende el aprendizaje de calidad de lengua extranjera, español, terminaremos no teniendo ninguna y solo ir en el barco de lo que se "faz de conta"

(5)La lengua extranjera Sí INTERESA y mucho, ilusiona, hace soñar, hace que el individuo se esfuerce porque la puerta que busca para un futuro mejor puede estar allí, son los formadores, los que necesitan creer en ello, solo eso, ya bastaría.

Se preguntarán: ¿y dónde están los MD en todo lo dicho? A nuestro ver es simple: están en todo. Si no hay una comprensión estable y equilibrada de que los MD son los que llevaron a la reflexión de que el lenguaje no se restringe a la forma de la lengua y que más bien la colocan en un escenario mucho más amplio como es un discurso, pues habrá que conocerlos para saber aplicar y poco a poco ir internándonos en la esencia de su existencia.

Actualmente, se nota que elementos con este poder cohesivo suelen brillar por su ausencia en el desempeño oral de los involucrados en los estudios de grado en ELE, incluso, en el discurso de los propios docentes, por razones que se investigan en este trabajo, entre las que, grosso modo citamos algunas:

$\checkmark$ falta desarrollar ese conocimiento;

$\checkmark \quad$ no existen en la lengua materna, por eso no se aplican en la LE;

$\checkmark$ Existen, pero no se aplican en la lengua materna;

$\checkmark \quad$ No hay valorización positiva para estas partículas;

$\checkmark$ se les atribuye poca relevancia;

$\checkmark$ Hay dificultad para aplicarlos en la oralidad y escritura

$\checkmark$ la actitud esquiva de aplicarlos se debe a opinión y opción personal.

Lo mencionado es importante investigarlo al tratarse de la formación de nuevos profesores, pues la práctica como docente de grado y como docente de ELE en la educación básica, sin duda contribuye o no al aprendizaje y cultivo de una lengua extranjera rica y de fluidez oral con la que se sea capaz de comunicarse satisfactoriamente. La no articulación del discurso y su consecuente poder de inferencias contribuye o no, a la configuración del saber 
lingüístico como competencia o como dificultad para su solvencia en el uso de la lengua, sea para el ejercicio de la profesión o para el uso personal en cualquier situación comunicativa en ELE.

En este apartado pretendemos situar en la actualidad y objetivamente los MD en el proceso de formación del profesorado de lengua española: en el aprendizaje (plan de estudios y asignaturas específicas) y en el uso, señalando aspectos empíricos sobre el uso de los MD en el desarrollo y desempeño de la lengua a través del discurso oral de los involucrados en el proceso.

\subsection{LOS MARCADORES DEL DISCURSO EN EL PLAN DE ESTUDIOS DEL GRADO (PEG) EN ELE}

El plan de estudios, en vigor, de las IES tienen características semejantes, lo que no es extraño ya que su formulación sigue una normativa federal y adecuaciones de acuerdo con la región del país donde se hace la oferta; no obstante, también presentan aspectos particulares que deben ser objeto de análisis. A priori, verificaremos si entre las asignaturas que cada IES presenta en su plan de estudios actual están contempladas aquellas que tratan del funcionalismo de la lengua, dentro de las cuales podríamos localizar el tema de los marcadores del discurso, asignaturas a saber:

$\checkmark$ Pragmática;

$\checkmark$ Gramática del texto;

$\checkmark$ Análisis del discurso;

$\checkmark$ Lingüística aplicada a la enseñanza de LE o de ELE;

$\checkmark$ Sociolingüística;

$\checkmark$ Psicolingüística. 
Cuadro 16 - Oferta de asignaturas de perspectiva funcional en PEG de IES estudiadas

\begin{tabular}{|c|c|c|c|c|c|c|}
\hline \multirow[b]{2}{*}{ IES } & \multicolumn{6}{|c|}{ Asignaturas obligatorias } \\
\hline & 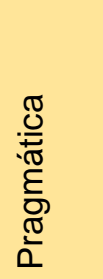 & 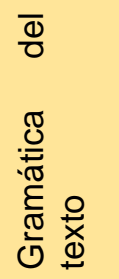 & 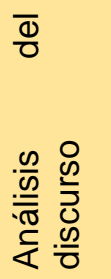 & 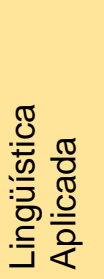 & 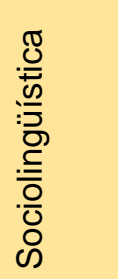 & 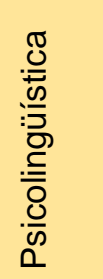 \\
\hline IES-1 & NO & NO & NO & sí & NO & NO \\
\hline IES-2 & NO & NO & sí & NO & NO & sí \\
\hline IES-3 & NO & NO & NO & NO & sí & NO \\
\hline
\end{tabular}

Fuente: [En línea] https://goo.gl/WHmEEm

[En línea] http://goo.gl/8rOs9K

[En línea] http://goo.gl/Qkx50B

De acuerdo con las informaciones recogidas en las respectivas coordinaciones de los cursos, la IES-1 e IES-2, se encuentran en proceso de reformulación del perfil del curso, en virtud de orientaciones del Ministerio de Educación y Cultura do Brasil, ambas instituciones tenían la oferta del curso de Letras con una composición de asignaturas base y otra con asignaturas específicas de la titulación a optarse:

Perfil do curso

O Curso de Letras é composto de cinco Licenciaturas: Língua Portuguesa e Literaturas; Língua Inglesa e Literaturas; Língua Francesa e Literaturas; Língua Espanhola e Literaturas \& Língua Brasileira de Sinais. O Curso forma professores nas quatro áreas acima citadas para atuar no ensino Fundamental e Médio. Além de docentes, os profissionais formados em Letras poderão atuar como tradutor e revisor de textos. [En línea] https://goo.gl/F3h4OB

Así mismo, en la IES-1 e IES-2, se constata que las asignaturas del funcionalismo forman parte del listado de asignaturas de libre elección o electivas y están enfocadas al curso de Letras lengua portuguesa. Estas asignaturas no fueron diseñadas para la formación en ELE, aunque los fundamentos sean los mismos, no se pueden apreciar para la finalidad que nos 
ocupa, la de encontrar formal y explícitamente contenidos sobre marcadores del discurso, para muestra presentamos la sumilla de una de ellas:

Figura 9 - Programa de la asignatura Análisis del discurso IES-2

\begin{tabular}{|c|c|c|c|}
\hline Código: 04021081 & \multirow{2}{*}{$\begin{array}{l}\text { Nome do Componente } \\
\text { Curricular: } \\
\text { Análise do Discurso }\end{array}$} & \multirow{2}{*}{$\begin{array}{l}\text { Grupo: } \\
\text { Disciplina }\end{array}$} & \multirow{2}{*}{$\begin{array}{l}\text { Carga } \\
\text { Horária/Crédito: } \\
\qquad 60 \mathrm{~h} / 04\end{array}$} \\
\hline & & & \\
\hline \multicolumn{2}{|l|}{ Aplicação: Teórica/Prática } & \multicolumn{2}{|c|}{ Avaliado por: Nota } \\
\hline \multicolumn{4}{|c|}{$\begin{array}{l}\text { EMENTA: Contexto epistemológico da Análise de Discurso de tradição francesa. Dispositivo } \\
\text { teórico-analíticos da Análise do Discurso. Análise de discursos institucionais e não-institucionai } \\
\text { (politico, midiático, religioso jurídico e do cotidiano). Relações saber/poder e produção de } \\
\text { subjetividades. }\end{array}$} \\
\hline \multicolumn{4}{|c|}{$\begin{array}{l}\text { Bibliografia básica } \\
\text { FERNANDES, C. A. Análise do Discurso: reflexões introdutórias. 2. ed. São Carlos: Claraluz, } \\
2007 . \\
\text { FOUCAULT, M. A Ordem do Discurso. São Paulo: Loyola, 1999. } \\
\text { ORLANDI, E. Análise de discurso: principios \& procedimentos. 3. ed. São Paulo: Pontes, } 2001 . \\
\text { Bibliografia complementar } \\
\text { COELHO, C. N. P. e CASTRO, V. J. (orgs). Comunicação e sociedade do espetáculo. São Paulo: } \\
\text { Paulus, } 2006 \text {. } \\
\text { COURTINE, J.-J.. Metamoforses do discurso político: derivas da fala pública. São Carlos: } \\
\text { Claraluz, 2006. } \\
\text { GREGOLIN, M. R. Pêcheux e Foucault na análise do discurso: diálogos e duelos. São Carlos: } \\
\text { Claraluz, 2005. } \\
\text { MILANEZ, N. e GASPAR, N. (Orgs.). A (des)ordem do discurso. São Paulo:Contexto, 2010. } \\
\text { SILVA, A. M. M. et. al. De memónia e de identidade: estudos interdisciplinares. Campina Grande: } \\
\text { EDUEPB, 2010. }\end{array}$} \\
\hline
\end{tabular}

Fuente: [En línea] http://goo.gl/8rOs9K

La asignatura de Sociolingüística es una oferta obligatoria de la IES-3, su contenido programático está dividido en dos unidades en las que son presentados conceptos de sociolingüística, variación, variedad y luego ya se pasa a hablar de cuestiones dialectales de España y América. Aparentemente es un programa diseñado para grado en ELE, no obstante, a priori, no es posible determinar si los MD en algún momento serán estudiados en el ámbito de esta asignatura, porque:

Linguagem e sociedade estão ligadas entre si de modo inquestionável. Mais do que isso, podemos afirmar que essa relação é a base da constituição do ser humano (ALKMIN, 2001, p. 21).

En el capítulo II 'marcadores del discurso' ampliaremos la investigación analizando el plan de estudios anterior o anteriores al actual, de forma que consigamos localizar o constatar la presencia o no, explícita sobre el tema de los MD en medio a cada realidad. Además, nos situaremos conceptualmente al respecto de las asignaturas del funcionalismo. 


\subsection{LAS ASIGNATURAS DE LENGUA ESPAÑOLA Y LOS MARCADORES DEL DISCURSO (MD)}

Nuestro interés ahora se vuelca sobre las asignaturas de lengua española, en las que juzgamos puedan haber sido explícitamente contemplados los MD, además nos fijaremos en la carga horaria prevista para el aprendizaje de lengua a lo largo de la formación docente buscando justificar la suficiencia de esta para lograr fluidez y dominio de ELE durante la formación de grado.

En general, las IES destinan una asignatura de lengua española para cada semestre, pero no es el caso de la IES-1. De los 9 semestres que conforman el grado, solo cuatro son los que contemplan asignaturas específicas en las que se va a desarrollar la competencia comunicativa, pero afortunadamente, aunque no explícito, todo indica que de alguna forma los MD están contemplados en el desarrollo de estas cuatro asignaturas, pues lo expone abiertamente cuando habla de marcas de enunciación, relaciones anafóricas y catafóricas, adecuación lingüístico-discursiva, actos y hechos de habla. Son 240 horas de clase de español que prometen un importante aporte a la fluidez y dominio de la lengua española.

A juzgar por el contenido del resumen de las asignaturas de ELE en la IES1, se evidencia el interés por la función y no por la estructura gramatical. Al leer el resumen es fácil imaginar que el profesor de grado llega al aula y escribe en la pizarra iTe invito a un café!, y a partir de ahí queda claro que lo que se va a aprender en esa clase es a 'invitar (a) algo' y con ello ya hay bastante para esa clase. Igual para la práctica escrita en la que lo formal se usará, de hecho, no solo se verá la estructura. La estructura del programa de las asignaturas de esta IES no detalla contenidos. 
Cuadro 17 - La asignatura Lengua española y los Marcadores - IES-1

\begin{tabular}{|c|c|c|}
\hline $\begin{array}{c}\text { Nombre de la } \\
\text { asignatura }\end{array}$ & $\mathrm{CH}$ & Resumen \\
\hline $\begin{array}{l}\text { Expressão oral e } \\
\text { compreensão } \\
\text { auditiva de língua } \\
\text { espanhola I }\end{array}$ & $60 \mathrm{~h}$ & $\begin{array}{l}\text { Interpretación del funcionamiento del sistema de } \\
\text { procedimientos de cohesión responsable del efecto de } \\
\text { coherencia en el funcionamiento de la lengua española } \\
\text { - nivel I. Marcas de enunciación: persona, espacio, } \\
\text { tiempo. Relaciones anafóricas y catafóricas - nivel I. } \\
\text { Procedimientos de determinación, indeterminación, } \\
\text { generalización - nivel I. Relaciones entre interlocutores } \\
\text { y adecuación lingüístico-discursiva -nivel I. Modos de } \\
\text { enunciación de contrastes y oposiciones -nivel I. } \\
\text { Pragmática del español hablado: actos de habla y } \\
\text { hechos de habla en español. }\end{array}$ \\
\hline $\begin{array}{lr}\text { Leitura } & e \\
\text { produção } & \text { escrita } \\
\text { em } & \text { língua } \\
\text { espanhola I }\end{array}$ & $60 \mathrm{~h}$ & $\begin{array}{l}\text { Perfeccionar La competencia comunicativa de La } \\
\text { escrita, en situaciones propuestas de comunicación real. } \\
\text { Realizar actividades específicas para dominar el sistema } \\
\text { lingüístico, en los contenidos funcionales, fonéticos, } \\
\text { morfo sintéticos y ortográficos, intentando una relación } \\
\text { efectiva de los materiales didácticos con los aspectos } \\
\text { fundamentales de la cultura, literatura del mundo } \\
\text { hispánico. }\end{array}$ \\
\hline $\begin{array}{l}\text { Expressão oral e } \\
\text { compreensão } \\
\text { auditiva Lengua } \\
\text { espanhola II }\end{array}$ & $60 \mathrm{~h}$ & $\begin{array}{l}\text { Interpretación del funcionamiento del sistema de } \\
\text { procedimientos de cohesión responsable del efecto de } \\
\text { coherencia en el funcionamiento de la lengua española } \\
\text { - nivel II. Marcas de enunciación: persona, espacio, } \\
\text { tiempo. Relaciones anafóricas y catafóricas - nivel II. } \\
\text { Procedimientos de determinación, indeterminación, } \\
\text { generalización - nivel II. Relaciones entre interlocutores } \\
\text { y adecuación lingüístico-discursiva -nivel II. Modos de } \\
\text { enunciación de contrastes y oposiciones -nivel II. } \\
\text { Prácticas de conversación y empleo de tópicos } \\
\text { pragmáticos. }\end{array}$ \\
\hline $\begin{array}{lr}\text { Leitura } & \text { e } \\
\text { produção escrita } \\
\text { em } \\
\text { espanhola II }\end{array}$ & $60 \mathrm{~h}$ & $\begin{array}{l}\text { Prácticas escritas sobre formación y posición de } \\
\text { palabras en español a través de textos escritos. Lectura } \\
\text { de textos literarios y no literarios; estrategias de lectura, } \\
\text { estudio de la naturaleza del texto y los mecanismos de } \\
\text { construcción del sentido. }\end{array}$ \\
\hline
\end{tabular}

Fuente: [En línea] https://goo.gl/WHmEEm (Subrayado nuestro)

En el cuadro 18 están las asignaturas de lengua española de la IES-2, que totalizan 540 horas de clase, un número bastante importante, diríamos que suficiente para lograr metas de fluidez y dominio de lengua. $Y$ es justo en este punto que cabe reflexionar sobre la relación tiempo - contenidos - objetivos. 
Cuadro 18 - La asignatura Lengua española y los Marcadores - IES-2

\begin{tabular}{|c|c|c|}
\hline $\begin{array}{l}\text { Nombre de la } \\
\text { asignatura }\end{array}$ & $\mathrm{CH}$ & Resumen \\
\hline $\begin{array}{l}\text { Fundamentos de } \\
\text { língua espanhola }\end{array}$ & $60 h$ & $\begin{array}{l}\text { Estudo das estruturas linguísticas básicas da língua } \\
\text { espanhola através de atividades que envolvam as } \\
\text { quatro habilidades linguísticas. }\end{array}$ \\
\hline Língua Espanhola I & $60 h$ & $\begin{array}{l}\text { Aprofundamento nos estudos da Língua Espanhola } \\
\text { em todas as habilidades linguísticas: audição, } \\
\text { conversação, leitura e produção de textos. }\end{array}$ \\
\hline Língua Espanhola II & $60 h$ & $\begin{array}{l}\text { Estudo da Língua Espanhola em nível pré- } \\
\text { intermediário, envolvendo as quatro habilidades } \\
\text { linguísticas. }\end{array}$ \\
\hline Língua Espanhola III & $60 h$ & $\begin{array}{l}\text { Expansão do estudo da língua espanhola em nível } \\
\text { pré-intermediário. Ênfase em atividades de audição } \\
\text { e conversação. }\end{array}$ \\
\hline $\begin{array}{l}\text { Leitura e produção } \\
\text { escrita em espanhol }\end{array}$ & $60 h$ & $\begin{array}{l}\text { Fundamentação teórica e prática da leitura e da } \\
\text { escrita através de estudos sobre gêneros textuais. }\end{array}$ \\
\hline $\begin{array}{l}\text { Língua Espanhola } \\
\text { IV }\end{array}$ & $60 h$ & $\begin{array}{l}\text { Estudo da língua espanhola em nível intermediário, } \\
\text { com ênfase em morfologia. }\end{array}$ \\
\hline $\begin{array}{l}\text { Leitura e produção } \\
\text { de texto em } \\
\text { espanhol II }\end{array}$ & $60 h$ & $\begin{array}{l}\text { Aprofundamento teórico e prático da leitura e da } \\
\text { escrita dos gêneros textuais estudados. Estudo da } \\
\text { redação oficial. }\end{array}$ \\
\hline Língua espanhola $V$ & $60 h$ & $\begin{array}{l}\text { Estudo da língua espanhola em nível pré-avançado, } \\
\text { com ênfase em sintaxe de período simples. }\end{array}$ \\
\hline Língua espanhola VI & $60 h$ & $\begin{array}{l}\text { Estudos de língua espanhola em nível avançado, } \\
\text { com ênfase em sintaxe do período composto. }\end{array}$ \\
\hline
\end{tabular}

Fuente: [En línea] http://goo.gl/8rOs9K (Subrayado nuestro)

La IES-2 presenta en el resumen de las asignaturas de lengua una descripción notoriamente volcada en el aspecto estructural de la lengua española, menciona 'estructuras lingüísticas, fundamentación teórica, géneros textuales, sintaxis, morfología', son todos términos que se relacionan con lo formal de una lengua, sin duda son aspectos que contribuyen al conocimiento, pero pueden no garantizar su fluidez y dominio. 
Cuando los estudiantes de grado inician los estudios de ELE, su primera motivación es el deseo de aprender a hablar la lengua que va a enseñar, y es este el principal factor que se debe preservar para lograr la meta de la fluidez y dominio, es el factor que el profesor formador debe apreciar. Porque claro está que sin motivación no se llega a nada, pero tampoco a tanto con programas de lengua española que enfocan prioritariamente el estudio de la gramática aunque esta sea aplicada en situaciones comunicativas forjadas, sin mencionar que se aprecia mucho hacerlo en portugués, lengua materna del profesor de lengua extranjera. Los profesores de lengua extranjera se 'mecanizan' necesitan un foco en el que haya un discurso preparado, que no demande improvisación, con eso se complica su clase preparada:

De una manera consciente o inconsciente, los maestros lo saben y el hecho de saberlo genera una gran inseguridad, inseguridad que combaten asiéndose a la norma, habitualmente ortográfica que, como mínimo, es explícita, tiene límites y, por tanto, es controlable, pero sin abordar, o haciéndolo con gran timidez, la lengua como vehículo de comunicación. (CASSANI, 1994: 14)

Son 540 horas de clase de las que no se puede prever el uso, dependerá de la visión del profesor una explotación sensata con menos gramática y más función, de modo que el estudiante pueda aproximarse más al aprendizaje de ELE en un nivel C1 o C2 del MCER. La estructura del programa de las asignaturas de la IES-2 no detalla contenidos.

Las horas de clases de lengua española deben ser para incentivar la comunicación y concienciar en el sentido de que comunicarse tiene dos direcciones, lo que comunicas y lo que interpretas sea de forma oral o escrita. De esta forma, clases más gramaticales que pragmáticas generarán un proceso de aprendizaje lento, recurriendo siempre a la 'estructura'; las asignaturas como morfología, sintaxis, fonología y otras darían las informaciones 'técnicas' y deberían estar en asignaturas específicas para absorber ese conocimiento, no podrían ser objetivo de una asignatura de lengua, en estas se tendría que enseñar el cómo producir comunicación en 
situaciones comunicativas reales, prioritariamente, teniendo en cuenta, gestos, actitudes, hechos de relaciones interpersonales.

En la IES-3, en general, pasa algo semejante a lo que ocurre en la IES2: a partir del resumen se interpreta que la clase tiende a desarrollarse a partir de un contenido gramatical y no funcional, pero en el programa de la asignatura presenta, con detalle, los contenidos de la siguiente forma:

UNIDAD III: ¡Y fue así!

- Hablar de acciones puntuales en el pasado

- Narrar experiencias o vivencias personales

- Contar historias, cuentos, fábulas, etc.

- Expresar necesidad y obligaciones

Contenidos lingüísticos: Pretérito Indefinido, marcadores temporales; verbos: necesitar, deber, tener que.

PPC-2014. En línea] http://goo.gl/Qkx50B

Esta información parece dejar claro que las 360 horas de enseñanza de lengua española se da prioritariamente con enfoque funcional y no gramatical. Además en su plan de estudios contempla asignaturas de Morfología y sintaxis encargadas de presentar el conocimiento formal de la lengua. 
Cuadro 19 -La asignatura Lengua española y los Marcadores - IES-3

\begin{tabular}{|l|l|l|}
\hline $\begin{array}{l}\text { Nombre de la } \\
\text { asignatura }\end{array}$ & CH & \multicolumn{1}{|c|}{ Resumen } \\
\hline $\begin{array}{l}\text { Língua } \\
\text { espanhola I }\end{array}$ & $60 \mathrm{~h}$ & $\begin{array}{l}\text { Introdução ao estudo da língua espanhola. Desenvolver } \\
\text { a competência comunicativa de nível básico, } \\
\text { compreender e utilizar expressões simples e cotidianas, } \\
\text { que consigam satisfazer necessidades básicas de } \\
\text { comunicação. Desenvolver simultaneamente as } \\
\text { habilidades de compreensão e produção oral e escrita. }\end{array}$ \\
\hline $\begin{array}{l}\text { Língua } \\
\text { espanhola II }\end{array}$ & $60 \mathrm{~h}$ & $\begin{array}{l}\text { Desenvolver a competência comunicativa através do } \\
\text { estudo de estruturas básicas que possibilitam trocas } \\
\text { comunicativas simples e diretas sobre assuntos } \\
\text { familiares e cotidianos. Desenvolver simultaneamente as } \\
\text { habilidades de compreensão e produção oral e escrita. }\end{array}$ \\
\hline $\begin{array}{l}\text { Língua } \\
\text { espanhola III }\end{array}$ & $60 \mathrm{~h}$ & $\begin{array}{l}\text { Desenvolver a competência comunicativa de nível } \\
\text { intermediário, compreender e produzir discursos simples } \\
\text { e coerentes sobre temas familiares ou de interesse } \\
\text { pessoal. Desenvolver simultaneamente as habilidades } \\
\text { de compreensão e produção oral e escrita. }\end{array}$ \\
\hline $\begin{array}{l}\text { Língua } \\
\text { espanhola IV }\end{array}$ & $60 \mathrm{~h}$ & $\begin{array}{l}\text { Compreender e produzir textos complexos sobre temas } \\
\text { variados. Desenvolver a competência comunicativa e as } \\
\text { habilidades de compreensão e produção oral e escrita. }\end{array}$ \\
\hline $\begin{array}{l}\text { Leitura } \\
\text { produção de } \\
\text { textos em E/LE }\end{array}$ & $60 \mathrm{~h}$ & $\begin{array}{l}\text { Fundamentação teórica e prática da leitura e da escrita } \\
\text { através de estudos sobre gêneros textuais. }\end{array}$ \\
\hline $\begin{array}{l}\text { Práticas orais e } \\
\text { auditivas em }\end{array}$ & $60 \mathrm{~h}$ & $\begin{array}{l}\text { Compreender e produzir textos orais em língua } \\
\text { espanhola. Desenvolver as habilidades de produção e } \\
\text { compreensão oral. }\end{array}$ \\
\hline
\end{tabular}

Fuente: [En línea] http://goo.gl/Qkx50B (Subrayado nuestro)

A todo esto, observamos que las IES en su mayoría definen en la práctica la metodología que tendrán las clases de lengua española; al no haber presentación de los contenidos registrada en los programas de las asignaturas, no es posible saber a ciencia cierta la metodología que se aplica para el aprendizaje de español en los estudios de grado en ELE.

Sobre registros del contenido MD en los programas hasta el momento no vemos nada en concreto, pero la IES-3 presenta la producción de una video clase dirigida a estudiantes de grado de ELE, material interesante para trabajar un contenido del que se admite no estar contemplado en materiales didácticos de aprendizaje de ELE para ninguno de los niveles de enseñanza: 
O tema "Los marcadores del discurso" em língua espanhola tem a tendência de perfilar-se como um dos conteúdos de especial peculiaridade e acentuada importância no processo de ensino/aprendizagem dos futuros professores desta língua, principalmente pela escassa ou quase nula apresentação ou abordagem deste tema de forma direta nos manuais didáticos. Daí que se torna este vídeo uma ferramenta de relevância extrema como complemento didático (Dato de investigación IES-3, 2010) (Subrayado nuestro).

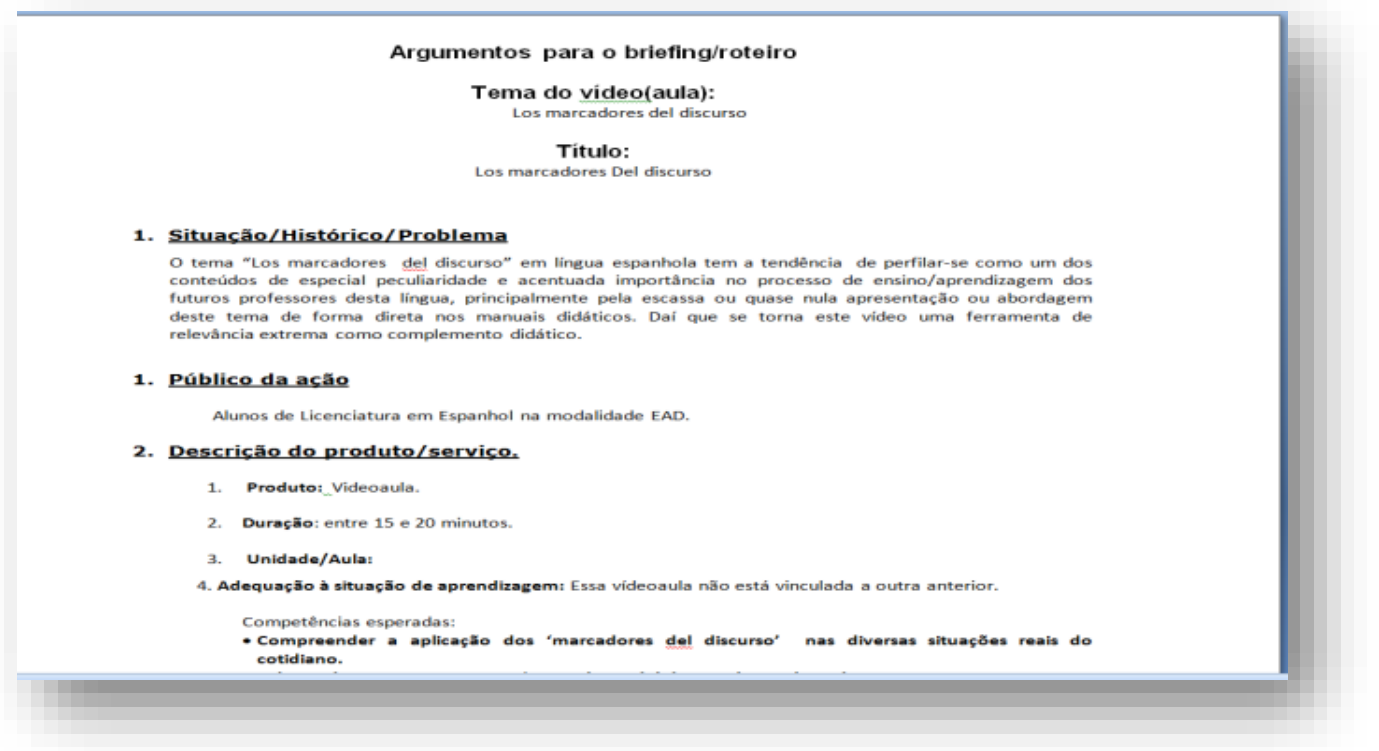

Figura 10 Video-clase sobre marcadores del discurso

\subsection{LOS MARCADORES DEL DISCURSO EN LA ORALIDAD DEL PROFESORADO DE GRADO EN ELE}

En algunos casos hemos grabado con el consentimiento de los involucrados y en otros los hemos podido asistir yendo a eventos públicos, clases o presentaciones de profesores de grado en ELE de las IES involucradas en este estudio. Han sido momentos académicos en los que se ha podido apreciar el desempeño oral de los profesores, en español. Nuestro objetivo ha sido el de reconocer en su oralidad o producción escrita, el uso de partículas discursivas del tipo marcadores del discurso.

Cada una de las IES de este Estado tiene una media 5 a 7 profesores de grado de área específica, entre los cuales hay alguno no nativo brasileño, a estos se les ha obviado por entender que el objeto del análisis ya tiene 
respuesta en su identidad de origen hispana. Para muestra generalizadora y de apreciación de uso de marcadores del discurso en la oralidad de un docente de grado de ELE, presentamos el relato de INF-PROF-2, docente cuyo nombre ha sido cambiado para proteger su identidad, el audio ha sido transcrito ortográficamente y el código aplicado está en el cuadro siguiente:

Cuadro 20 Leyenda elementos aplicados en transcripción ortográfica

\begin{tabular}{|l|c|}
\hline \multicolumn{1}{|c|}{ Elemento codificado } & Marca de codificación \\
\hline $\begin{array}{l}\text { Prolongamiento de vocal y consonante } \\
\text { (como s, } r \text { ) }\end{array}$ & :: puede aumentar para :.:.: o más \\
\hline Hipótesis de lo escuchado & (hipótesis) \\
\hline $\begin{array}{l}\text { Truncamiento (habiendo homografía, se } \\
\text { usa acento indicativo de tónica y/o timbre }\end{array}$ & $/$ \\
\hline Silabeo & - \\
\hline Cualquier pausa & $($ ) \\
\hline Interrogación & $?$ \\
\hline
\end{tabular}

Presentamos a continuación el discurso del INF-PROF-2:

Tiempo: $3 \min .54 \mathrm{seg}$.

Entrevistadora: INF-PROF-2

Entrevistada: Bueno yo voy a contar la historia de cómo::: llegue a ser profesora de español () Desde niña no me gustaba el inglés () Entonces empecé a estudiar el español y::: me enamoré y entonces estudié un cursos libres y después hice la facultad pero a mí no me gustaría ser profesora sino azafata pe-ro cuando empecé a dar clases de español porque era obliga/ obligatorio en la facultad me enamoré y entonces desde dos mil cinco que soy profesora de español () Intenté alguna::/ algunos concursos y:: trabajé en otra universidad y en Instituto estoy hace tres años () Pero para llegar aquí fue todo muy muy raro muy divertido porque:: no conocía la ciudad y en el día de la prueba de la prueba didáctica yo:: he perdido el::: no sé/ el canino me olvidé como era y salí por la lluvia hasta la clase () me perdí () No había comido no había dormido entonces estaba totalmente fatal () Pero al final todo funcionó correctamente y trabajo aquí y me gusta mucho () Ahora quiero seguir siendo profesora pero también quiero perfeccionarme más () estudiar () hago el doctorado ya y quiero vivir un tiempo en España porque realmente me gusta el español () Entonces () es eso () a ver ()

Figura 11 Transcripción de audio INF-PROF-2. (Datos de Investigación) 
Procederemos a realizar el análisis en el nivel discursivo de este texto transcrito:

$\checkmark$ Se trata de un texto oral recogido de producción espontánea;

$\checkmark$ De tipología situacional: entrevista, con intervención mínima del entrevistador y máxima del entrevistado;

$\checkmark$ La grabación fue efectuada en contexto natural;

$\checkmark$ Cumple el requisito de neutralidad y fidelidad, sin contemplar ningún tipo de interpretación.

En nuestra observación global del texto en relación al uso de marcadores discursivos anotamos que el INF-PROF-2 ha utilizado los marcadores: bueno, entonces (5), pero (3) porque (2), al final, a ver:

$\checkmark$ Bueno, es un marcador del discurso conversacional, operador de formulación (Portolés, 1998), de apertura y uno de los más utilizados en la conversación, hace parte de los marcadores metadiscursivos de control de mensaje (Briz, 1998).

$\checkmark$ entonces (5), conector consecutivo, usado tres veces seguidas por el informante docente y luego dos más, es un marcador que ha conectado informaciones en una misma intervención del hablante. El informante muy probablemente repita el uso de este conector porque desconozca otros similares (de ahí, así pues, luego, etc.) o por falta de práctica. El discurso del INF-PROF-2 se presenta limitado y no revela la riqueza de la lengua española.

$\checkmark$ pero (3), es un conector pragmático de oposición o restricción (Briz, 1998) que da cohesión al texto y guía la interpretación. Los conectores pragmáticos funcionan como enlaces de conexión enunciativa.

$\checkmark$ porque (2), (conjunción subordinante en el formalismo del lenguaje usado como conector para indicar relaciones causativas)

$\checkmark$ al final, marcador discursivo reformulador, recapitulativo, utilizado para introducir una conclusión de un miembro discursivo anterior.

$\checkmark$ a ver, marcador discursivo interactivo, normalmente usado para mantener el contacto, o para chequear seguimiento durante el turno, situación que no se ajusta al uso del INF-PROF-2. 
$\checkmark y$, conjunción coordinante considerada marcador discursivo, Portolés (1998), ha sido aplicada por el INF-PROF-2, once veces como un ordenador de continuidad, como una especie de mecanismo de ilación para no perder el hilo del discurso.

Como se puede apreciar, en el discurso del docente INF-PROF-2, se registra un nivel razonable de discurso, con el uso de un número medio de marcadores discursivos; no obstante, evitar la repetición incisiva de determinadas partículas podría dar más calidad a su discurso, articulándolo mejor con una riqueza más amplia de MD. Este nivel de uso de partículas discursivas sería 'deseable' para un usuario común de la lengua española, pero un docente necesitaría una formulación de discurso oral más robusta.

\subsection{LOS MARCADORES DEL DISCURSO Y EL ESTUDIANTE DE GRADO DE ELE}

Sin duda, diversos son los niveles de conocimiento de lengua española entre los estudiantes en las IES investigadas y, para evitar injusticias, se ha elegido la clase del último semestre académico, el octavo, para aplicar una actividad escrita sobre marcadores del discurso. Presentaremos ahora, una de once actividades que nos permitirá acceder a informaciones clave sobre el estado de la cuestión. Como se puede apreciar en el documento original, se solicita que el estudiante escriba un texto de libre elección en el que aplique marcadores discursivos listados en el recuadro superior de la actividad. La identificación del estudiante autor se ha ocultado para proteger su identidad. Hemos creído conveniente presentar el texto original producido a modo de ilustración y para una clara lectura se ha reescrito en: 


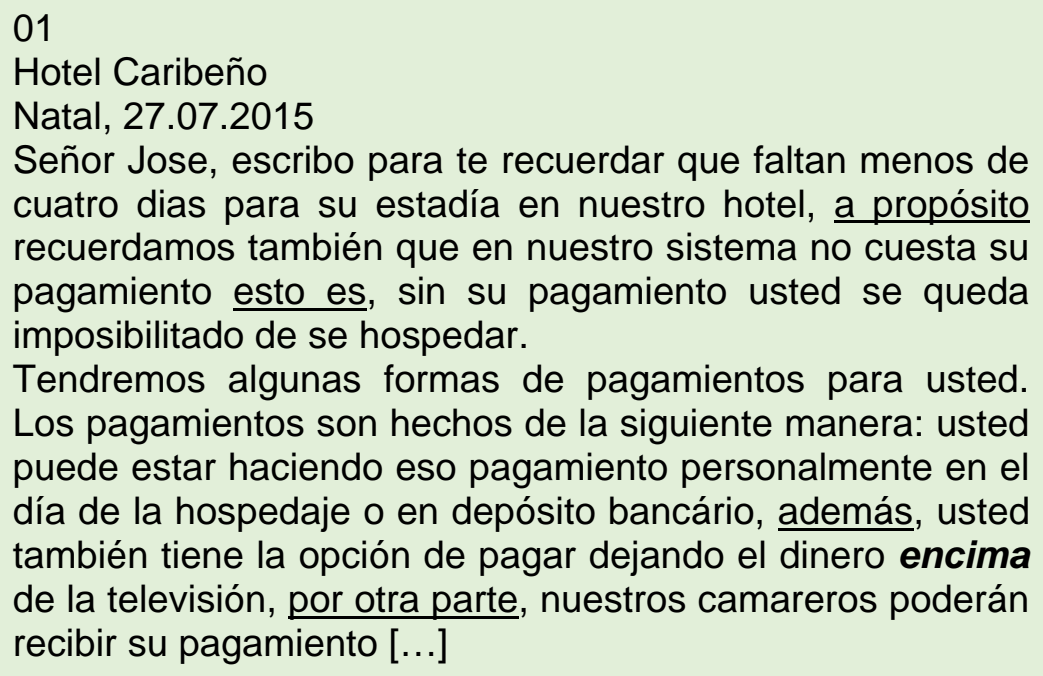

Figura 12 - Transcripción INF-EST-2

(Datos de investigación)

Procederemos a realizar el análisis en nivel discursivo de este texto escrito que surge de una producción espontánea en contexto natural, en aula, y nuestra observación global del texto es directamente en relación al uso de marcadores discursivos que el INF-EST-2 ha utilizado, que son: a propósito, esto es, además, por otra parte.

$\checkmark$ A propósito, es un marcador del discurso, clasificado como estructurador de la información, del tipo digresor, utilizado para organizar la información dentro del mismo texto, (Portolés, 1998);

$\checkmark$ Esto es, marcador discursivo del tipo reformulador explicativo, aplicado adecuadamente por el INF-EST-2;

$\checkmark$ Además, es un conector pragmático de adición que da cohesión al texto y guía la interpretación, en este contexto aplicado de forma coherente;

$\checkmark$ Por otra parte, marcador discursivo clasificado como un estructurador de información, del tipo ordenador, ha servido para organizar el lenguaje en una situación de doble posibilidad. El límite de coherencia en el uso de este marcador para la circunstancia se supone de frágil contundencia de corrección en su uso.

A pesar de que el comando de la actividad académica es: "1.PRODUCCIÓN DE TEXTO [...] APLICANDO LOS SIGUIENTES MARCADORES DEL DISCURSO" citando luego los marcadores, entre ellos 
"encima", el INF-EST-2 formula en su texto "dejando el dinero encima de la televisión", lo que deja ver el desconocimiento de esta palabra como un marcador discursivo.

Se ve que en el texto del estudiante INF-EST-2, se registra un nivel precario de discurso, tanto en lo formal de la lengua como en lo funcional, el uso de marcadores se presenta como resultado de un proceso de equivalencia, y/o traducción literal de los mismos. Un fenómeno interesante se percibe, el INF-EST-2 conoce la equivalencia de los marcadores, pero al mismo tiempo se nota que es demasiado tenue el conocimiento y dominio de la aplicación, para un estudiante de grado de ELE, futuro profesor al que le quedan alrededor de dos meses para estar en posesión de la titulación de profesor de ELE.

La situación media de los egresos de grado es parecida a la aquí relatada, salvo contadas excepciones; no obstante, hace falta reflexionar sobre las medidas que deben ser tomadas que podrían dar más calidad a la formación específica del profesor, pues de ello también depende la calidad de lengua que se multiplicará en la educación básica y pública.

A nuestro humilde ver, hace falta que la conciencia de estar formándose nuevo profesor se fortalezca y se ponga en práctica para que de hecho se puedan esperar verdaderos cambios. De modo general, este nivel de lengua en todo sentido (formal y funcional) podría 'atender' las expectativas y necesidades de un usuario común, pero definitivamente no el de quien al terminar los estudios de grado va en su actuación a seducir o a incentivar el rechazo a una lengua extranjera que puede significar para ese público inclusión y mejores oportunidades de vida. 


\section{ENSEÑANZA DE LENGUA EXTRANJERA EN BRASIL}

Los profesores expertos reflexionan continuamente acerca de cómo pueden enseñar aún mejor

J. BIGGS (1999: 25)

Plantearse, al día de hoy, una educación sin el conocimiento de una lengua extranjera es algo absolutamente atípico en el mundo que vivimos, cuando la tecnología y la información llega a, y de, casi todo el mundo, principalmente el occidental. Luego comunicarse en otra lengua no es solo un hecho diferencial en la formación consciente, sino una necesidad imperiosa.

En esta sección pretendemos presentar la situación actual de la enseñanza de lenguas extranjeras, en especial de español, en la educación básica y pública; se hace una breve retrospectiva intentando contextualizar este tema en la realidad brasileña; se establece un paralelo con la enseñanza básica en Sudamérica para saber si existe compatibilidad entre las políticas educativas brasileñas con las de otras naciones, inclusive con las del país europeo de quien aprendemos la lengua como vehículo de comunicación internacional.

\subsection{RETROSPECTIVA SOBRE LA ENSEÑANZA DE LENGUA EXTRANJERA EN BRASIL.}

Históricamente, la lengua portuguesa en América, más precisamente en territorio brasileño ha sido ya una lengua extranjera, pues en 1500, con la llegada de los portugueses, se inicia la enseñanza del portugués con el intuito de comunicarse con los pueblos indígenas, constituyéndose de esa forma, una lengua extranjera.

Durante 27 años, el Marquês de Pombal ${ }^{74}$ fue ministro de Portugal y en este tiempo su principal objetivo era solucionar las dificultades portuguesas con

\footnotetext{
${ }^{74}$ Sebastião José de Carvalho e Melo fue un diplomático que recibió el título de Marquês de Pombal por decreto del rey $D$ José I de Portugal. Ciudadano portugués a servicio de la corona portuguesa, fue el 
lo que procuró organizar la escuela de forma que sirviera a esos intereses. En este sentido y buscando debilitar el poder de la Iglesia Católica sobre la colonia, en 1758 prohíbe la enseñanza del tupí, lengua indígena e instituye el portugués como única lengua en Brasil. De esta forma, podemos afirmar que fue entonces, cuando oficialmente en Brasil se empieza a aprender una lengua que no es la natural o la materna y que el paso del tiempo la ha transformado en eso.

Otras lenguas estuvieron presentes en tierras brasileñas, la lengua francesa, por ejemplo, para la enseñanza a los miembros de la Corte Imperial. También fue el caso de la lengua inglesa que hizo parte, por primera vez, del plan de estudios de la educación pública y secundaria en 1837

Hasta 1857, aún había quien hablara el Tupí, por eso vino a la luz la obligación del uso de lengua portuguesa en Brasil. Un dato interesante es el de la prohibición también de la lengua de signos en Brasil, pues desde la fundación de la primera escuela para sordos, esta venía siendo enseñada, para luego ser prohibida en 1881.

Las lenguas extranjeras empiezan a tener presencia y son objeto de investigación en 1900 cuando se celebra el $1^{\circ}$ Congresso Internacional de Línguas Vivas, en el que se evidencia el método directo como el mejor para la enseñanza de lenguas. Es en 1919 cuando la lengua española es institucionalizada en Brasil como asignatura de libre elección para los estudiantes en el Colegio Pedro II con el primer profesor de español el Sr. Antenor Nascentes.

principal responsable por la expulsión de los jesuitas de Portugal y de las colonias. Ejerció el cargo de ministro en el periodo de 1750 a 1777. En sus planes estaba actualizar la situación de Portugal en relación a los demás países de Europa; impulsó la educación en Portugal, creo la ley que prohibía esclavizar a los indios, reformo la Universidad de Coímbra, el Ejército y la Marina, creó la Prensa Real y la Escuela de Comercio e impulsó el comercio de tal forma que se tornará Portugal, un país menos dependiente de Inglaterra. Todas sus acciones disgustaron a la nobleza y al clero porque estos sentían reducido su poder y privilegios, razón por la que ganó varios enemigos que tras la muerte del rey que lo eligió, D. María I, reina sucesora, lo condenó a exilio, acusado de corrupción. www.helb.org.br (Fecha: 03/05/2014) 
La reforma Capanema ${ }^{75}$, en 1942, marco principal de la enseñanza de lenguas en Brasil, trae la exclusión de la enseñanza de alemán y de italiano, permaneciendo el francés, el inglés, e incluyendo el español, pero esta última con una señal de 'menos' en su oferta, que quiera o no, se puede decir que persiste hasta los días de hoy: la visión de los gobernantes sobre la (ir)relevancia de esta lengua demostrada en la desventajosa asignación de carga horaria para su enseñanza .

La distribución de horas para el estudio de las lenguas modernas en el currículo era el siguiente: para la enseñanza de francés, trece horas; para inglés, 12 horas y para español, solo dos horas. De cualquier forma, al menos fue la oportunidad de acceder formalmente a esa enseñanza en el sistema de la educación brasileña.

Casi 20 años más tarde, fue publicada la primera Ley de Directrices y bases de la educación nacional (LDBEN) N4024, en la que la enseñanza de lenguas deja de tener carácter obligatorio, estableciendo, además, que las asignaturas obligatorias serían decisión del Consejo Federal de Educación, las complementares serían indicadas por los Consejos de Educación de los Estados y las de libre elección por los centros escolares. De hecho, estos cambios se tradujeron en limitado espacio y oportunidad para la enseñanza de español en el sistema nacional de educación.

Diez años después, con la LDBEN ${ }^{76}$ N05692, se mantiene lo previsto en la ley anterior para la enseñanza de lenguas extranjeras, lo que implicó en la exclusión de muchos estudiantes brasileños del estudio de una LE a lo largo de la educación básica y, por supuesto, la lengua española prácticamente desaparece del sistema educativo brasileño dando predominancia a la lengua inglesa en relación a la francesa.

Esta situación se mantuvo por mucho tiempo, pero poco a poco y a consecuencia de tratados comerciales y la globalización, se publica la LDBEN No 9394, en 1996 trayendo la obligatoriedad de oferta de la lengua extranjera

\footnotetext{
75 Denominación dada a la reforma ocurrida en el sistema educativo brasileño y realizada en 1942, en el gobierno de Getúlio Vargas, bajo la responsabilidad del entonces ministro de educación Gustavo Capanema.

${ }^{76}$ Ley de directrices y bases de La educación nacional.
} 
para la enseñanza fundamental ${ }^{77}$, a partir de la quinta serie y para la enseñanza media. Pero, en la ley también se expresa que la institución de enseñanza determinaría la lengua a ser ofertada, de acuerdo con sus posibilidades (BRASIL, 2011: 23).

Con esta ley (9394) realmente se avanzó, porque había ya la obligatoriedad de la enseñanza de una lengua extranjera, pero con respecto a la lengua española, no, porque fue prácticamente absoluta la opción de oferta de lengua inglesa por parte de las escuelas para cumplir la ley.

En la década de los 90, había tímida oferta y demanda del idioma español en las escuelas de idiomas, pero se acentuó con la expansión de las relaciones comerciales y la consecuente creación del Mercado común del Sur (MERCOSUR) del cual Brasil era miembro y tenía como lenguas oficiales el portugués y el español.

Fue así que se llega al año 2005 y se publica la ley federal no 11.161, ley del español que dispone la oferta obligatoria de lengua española, de inicio en la educación secundaria y luego a partir del $6^{\circ}$ año del fundamental, para todo el país. Esta ley tuvo amplísima repercusión en los países hispanos, sobre todo en Argentina y España.

En Brasil, en unos estados más que en otros, hubo reacciones inmediatas de implementación, pues ya venían preparándose para tal, en otros no, hasta pasado algún tiempo, este fue el caso del estado de Rio Grande do Norte.

\subsection{LAS LENGUAS EXTRANJERAS EN EL CONTEXTO NACIONAL}

Hasta cierto punto es relativamente fácil hablar sobre lo vivido, pues se trata de lo conocido, es más complejo describir el presente porque está en ejecución y los juicios pueden desequilibrarse, esto se parece mucho a lo que los profesores hacemos, preparar ahora para algo que los estudiantes van a vivir en el mañana. Al hablar de lengua extranjera en la educación entra a tallar un aspecto de mucha relevancia en un país como Brasil que aprecia un imitar

77 Enseñanza fundamental comprende de la 1a a la 8 o serie. 
exagerado de lo extranjero, dicen que violando su propia identidad, hasta qué punto realmente se trata de esto, hablando de lengua extranjera.

De otro lado, un país, el que sea, no vive más solo, forma parte de un mundo globalizado, que intervendrá drásticamente en su historia interna y en el quehacer ciudadano. En este apartado hablaremos de los periodos de ascensión y decaídas de la lengua extranjera hasta los días de hoy.

En tiempos del imperio en Brasil, la enseñanza de lenguas, las clásicas primero y luego las modernas, podemos decir que tuvo gran énfasis y que estas presentaban dos carencias, una era la metodología y otra la administración. La metodología aplicada a las lenguas muertas, era la misma que a las vivas: traducción de textos y análisis gramatical. En la administración, se detenía mucho poder pero poca visión y preparo para administrar el difícil ámbito de la enseñanza de lenguas, se registra el estudio de al menos cuatro lenguas en la enseñanza secundaria (CHAGAS, 1957).

En la Primera República (1892), continua una reducción de horas de clase de lengua extranjera iniciada ya en el Imperio, así como desaparecen varias para dar paso exclusivo a la enseñanza de inglés y alemán, debiendo elegir una solamente. Frecuentar las clases no era obligatorio, pero se realizaba una prueba de estudios con la que es accedía a estudios superiores, a lo que CHAGAS afirmó:

Si antes, no se estudiaban los idiomas considerados facultativos, a esta altura ya no se aprendían ni los obligatorios, simplemente porque al anacronismo de los métodos se aliaba la casi certeza de las aprobaciones gratuitas (CHAGAS, 1957: 89)

Lo dicho por CHAGAS nos parece tan familiar a lo que al día de hoy ocurre respecto a las lenguas extranjeras en la educación básica pública, que a pesar de ser obligatorias por ley nacional, no son objeto de una verdadera evaluación de su aprovechamiento durante su estudio. Parece que la historia se repite y seguro también nos va a pasar factura.

Pero lo de frecuencia libre se extinguió en la reforma de la educación de 1931 y sobre lenguas extranjeras los cambios estuvieron relacionados con la metodología en la enseñanza, se implementaba oficialmente el método 
'directo', aprender la lengua a través de la lengua, método que en Francia se aplicaba desde 1901, o sea 30 años antes, cómo demoramos tanto para hacer lo mismo.

Con el método 'directo' surge la figura del Profesor Carneiro Leão, o viceversa, quien según CHAGAS (1957: 92), implementó una reforma en la enseñanza de lengua extranjera magnífica y que no tuvo seguidores en la enseñanza secundaria de la educación brasileña. Carneiro Leão llevó adelante el método 'directo' y relató su experiencia en ' $O$ ensino das línguas vivas' (1935), algunos de los 33 los artículos escritos que merecen especial relevancia porque siguen en vigor en la enseñanza actual de lenguas:

La enseñanza de la lengua debe tener un carácter práctico y ser impartida en la propia lengua, adoptándose el método directo desde la primera clase.

$\checkmark$ El significado de las palabras debe ser transmitido no por la traducción, y sí por la ligación directa del objeto a su expresión, usándose para eso ilustraciones y objetos del mundo real.

Las nociones gramaticales deben ser deducidas por la propia observación y nunca presentadas bajo la forma teórica o abstracta de reglas. (CARNEIRO, 1935)

Estamos hablando del año 1935 y se registra hoy como algo que se realizó y que además fue de muy buena repercusión y de lo que se lamenta el que no haya habido seguidores con la misma fuerza, cuándo se perdió esa fuerza y se adormeció en el conformismo.

En aquel entonces ya había señales claras de enseñar basados en el funcionalismo de la lengua y en la alianza con el formalismo para la estructuración del código lingüístico: la gramática debe ser deducida..'.

Decir que 'la enseñanza de la lengua debe ser impartida en la propia lengua desde la primera clase', algo absolutamente sensato, mucho más al tratarse de lengua española para los brasileños, pero algo que 
lamentablemente muchos profesores no lo hacen en la escuela pública, cuál es el porqué.

En 1943, seguía recomendándose el uso del método directo y una enseñanza acentuadamente práctica, pero ampliando los objetivos educativos para la "capacidad de comprender tradiciones e ideales de otros pueblos, inculcando nociones de la propia unidad del espíritu humano", en otras palabras, el método directo muda de curso, de la practicidad al énfasis en lo escrito, se debía leer más, pero no era solo leer.

La orientación de leer más en ese entonces se entendió como 'solo se debe leer en vez de practicar la lengua', eso no se dijo en momento alguno, fue asumido como tal y así se implementaba la enseñanza de lengua extranjera en esa época. ¡Qué equivocación!

Las LDBEN de 1961, 1971 y 1996, significaron avances en los que respecta a lengua extranjera, sobre todo la de 1996, pero también supusieron retrasos y retrocesos, en ese trayecto, hubo muchos que no tuvieron acceso al estudio de una lengua extranjera a lo largo de su educación básica, hubo una significativa disminución de horas de clase de lengua extranjera, eso ya se vive hoy en la enseñanza de lengua española, por qué repetimos las historias.

Sobre metodología, el método directo dejó de ser el único, la enseñanza pasó a ser impartida bajo el principio del "pluralismo de ideas y de concepciones pedagógicas (Art. $3^{\circ}$, inciso III) y se incentiva la reorganización de los grupos de estudiantes según necesidad y conveniencia al aprendizaje también para la enseñanza de lenguas.

Tras la LDBEN de 1996 fueron publicados los Parámetros Curriculares Nacionales que no proponen ninguna metodología de enseñanza en especial, pero sugieren (se entendió como 'ordenan') un abordaje socio interaccionista, con énfasis en el desarrollo de la lectura, sugerencia que se justifica en la necesidad del alumno con relación a su lengua materna:

Por tanto, a leitura atende, por um lado, às necessidades da educação formal, e, por outro, é a habilidade que o aluno pode usar em seu próprio contexto social imediato. Além disso, a aprendizagem de leitura em LE pode ajudar o desenvolvimento integral do letramento do aluno. La leitura tem função primordial na escola e aprender a ler em LE pode 
colaborar no desempenho do aluno como leitor em sua LM

(Parâmetros Curriculares Nacionais para Línguas Estrangeiras-PCN)

A lo dicho en los PCN queda saber cómo, por ejemplo, la lectura en lengua inglesa podría contribuir al conocimiento de su lengua materna. Como si fuera poco absurdo, aún tenemos como justificativa de la orientación al énfasis a la lectura en la enseñanza de LE:

Deve-se considerar também o fato de que as condições na sala de aula da maioria das escolas brasileiras (carga horária reduzida, classes superlotadas, pouco domínio das habilidades orais por parte da maioria dos professores, material didático reduzido ao giz e livro didático, etc.) podem inviabilizar o ensino das quatro habilidades comunicativas. Assim, o foco na leitura pode ser justificado em termos da função social das LEs no país e também em termos dos objetivos realizáveis tendo em vista condições existentes. (Parâmetros Curriculares Nacionais para Línguas Estrangeiras-PCN) (Subrayado nuestro)

Las contradicciones evidenciadas en los PCN causaron muchas críticas. Ese documento estaba, en otras palabras, renunciando a las ventajas que una LE aporta a la formación integral del ser humano. Enumerar las condiciones de aprendizaje y admitirlas como justificativas para reducir o limitar la enseñanza de una LE era lo menos esperado en un documento de esta naturaleza. Fue el mayor absurdo en la historia de la administración y organización de la educación nacional en lo que se refiere a LE.

Comunicación, información y lengua son sinónimo de mudanza, el docente de LE media esos campos, pero de su calidad depende el desarrollo y el logro de metas en todo lo que interviene. Su mayor meta: el estudiante de educación básica y pública. 


\subsection{LA ENSEÑANZA BÁSICA Y OBLIGATORIA EN BRASIL EN CONTRASTE CON OTRAS NACIONES}

La educación en Brasil ha tenido un avance significativo en relación al acceso y permanencia de estudiantes en la enseñanza básica y pública, probablemente esto sea el resultado de cambios importantes con miras a la construcción de una ciudadanía comprometida y volcada al desarrollo y futuro del país. Uno de esos cambios fue el incremento de un año más de estudio en la enseñanza fundamental y obligatoria, resultado de indagaciones sobre el sentido que la educación podría tener para los niños y adolescentes.

Otra cuestión de sensible relevancia en la formación de un individuo fue la de establecer, inicialmente, la oferta obligatoria de la lengua española como lengua extranjera en el plan de estudios de secundaria ${ }^{78}$ y gradualmente en los estudios de primaria, a partir del $6^{\circ}$ año en todas las escuelas públicas del país. Cabe destacar que la oferta y estudio de la lengua extranjera inglés, hegemónica en su categoría, continuó y continúa en el plan de estudios, inclusive como única oferta aún en algunas escuelas públicas.

De esta forma, la enseñanza básica ${ }^{79}$ en Brasil se compone de 13 años, a saber: 1 de educación infantil, 9 de fundamental, (que se divide en 5 años de Fundamental I y 4 de Fundamental II) y 3 de enseñanza media. Para efectos de comparación con otras naciones en lo que respecta a la distribución de etapas en la educación básica, hemos construido la tabla I.1 con datos emitidos en el boletín del Convenio Andrés Bello ${ }^{80}$, los países elegidos han sido Chile, Colombia, Cuba, España y Venezuela.

\footnotetext{
78 Denominada en Brasil, ensino médio.

${ }^{79}$ En Brasil, se entiende por enseñanza básica, aquella que engloba la educación infantil, la enseñanza fundamental I y II, y la enseñanza media, o sea los 13 años previos al ingreso a estudios universitarios o a estudios técnicos de carácter profesional. Esta denominación no se ajusta a todos los países, pues para algunos, como Chile por ejemplo, denomina como básica solo a la educación primaria (fundamental I y II, En Brasil) y en contrapartida, Colombia incluye dos años de secundaria/media como educación básica. Por esta razón y para evitar equívocos o malas interpretaciones, al referirse al sistema educacional brasileño, será con la traducción literal de su denominación, de la siguiente manera: Educação infantil = Educación infantil; Ensino Fundamental I = Enseñanza Fundamental I; Ensino Fundamental II = Enseñanza Fundamental II; Ensino Médio = Enseñanza Media;

${ }^{80}$ Vea Tabla de equivalencias de la educación primaria o básica y media o secundaria de los países de MERCOSUR y del Convenio Andrés Bello (CAB)-Tabla de equivalencias con denominaciones de cursos y títulos,
} 
En el documento emitido por el $\mathrm{CAB}^{81}$ se puede apreciar que la mayoría de sus países miembros, al igual que en Brasil, también desarrollan la educación básica o fundamental o primaria y media o secundaria en 13 años, a excepción de Colombia, Perú y Venezuela que lo hacen en 12 años. Además, a partir de esas informaciones, resulta interesante visualizar que no por tener el mismo tiempo de duración de los estudios primarios y secundarios, haya la misma visión en la distribución de ese tiempo. Hay sistemas de educación, como el de Cuba y Colombia (ver Tabla I.1) que dentro del mismo periodo de 13 años, son destinados 3 y 2 años, respectivamente, o, a la preparación del estudiante para ingresar a estudios superiores o en todo caso, a prepararlos para el mercado de trabajo como técnicos en determinados oficios o profesiones, como es el caso de países como Venezuela y Colombia, por eso, se cree pertinente hacer algunas observaciones que permitirán trazar el perfil de los que estudian una lengua extranjera, cuándo lo inician y las necesidades y expectativas de aprendizaje tras la finalización de los estudios primarios y secundarios.

Se aprecia que hay tres tipos de distribución del tiempo dedicado a los estudios previos a la formación superior/universitaria: la primera es la educación básica primaria y secundaria volcada a la formación integral y base de un ciudadano, es el caso de países como Brasille2; la segunda, es la educación básica con un periodo, uno o dos años dedicados a la preparación universitaria, como lo hace Cuba y de cierto modo también España ${ }^{83}$, y el

81 El Convenio Andrés Bello (CAB) es una organización internacional intergubernamental cuya misión es la integración educativa, científico-tecnológica y cultural, cuyo propósito es el de favorecer el desarrollo integral de sus pueblos. Actualmente, los países miembros son: Bolivia, Colombia, Cuba, Chile, Educador, España, Panamá, Perú y Venezuela.

82 La ley federal 11.274, del 06 de febrero de 2006 instituye que la enseñanza fundamental en Brasil, sea realizada en nueve años, iniciándose a los seis años de edad la inclusión de los niños en la escuela. Con este cambio, pues hasta hace poco, eran 8 años para la Enseñanza Fundamental I (EFI), el MEC-Brasil busca asegurar a todos los niños un tiempo más largo de convivencia escolar, también favoreciendo más oportunidades de aprender, significando una posibilidad más amplia de alfabetización y acceso a los contenidos pertinentes a ese nivel. La ampliación de 8 para 9 años de la EFI (estudios primarios para otros países), empezó a ser discutida en Brasil en el año 2004, pero su implementación se inicio gradual y regionalmente a partir de 2005, previéndose que hasta 2010, estuviera implementada en todo el país, como en efecto ha sido.

83 En España no se puede acceder a estudios universitarios sin haber cursado los dos años de bachillerato, que además son cursados contemplando también materias en áreas determinadas como Artes (dos vías), Ciencias y Tecnologías y Humanidades y Ciencias Sociales. 
tercero es la educación que contempla dos o tres años para la preparación técnica en áreas profesionales que dan acceso al mercado de trabajo, como es el caso de Venezuela, país en el que durante cinco años se cursa el Liceo Bolivariano, durante el cual, además de las materias de base, se lleva "educación para el trabajo", materia en la que se opta por estudiar cursos de dibujo técnico, turismo, periodismo, manualidades, cocina, electricidad, arquitectura, comunicación social, fotografía, entre otros, con miras a la obtención del título de Bachiller o Técnico Medio con mención en la materia que haya optado.

Tabla 2 - Equivalencias de estudios primarios y secundarios

\begin{tabular}{|c|c|c|c|c|c|c|c|}
\hline 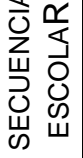 & 蟺 & BRASIL & VENEZUELA & CHILE & COLOMBIA & CUBA & ESPAÑA \\
\hline 1 & $0-5$ & $\begin{array}{l}\text { Educación } \\
\text { infantil / Pre } \\
\text { escolar }\end{array}$ & $\begin{array}{l}\text { Preescolar } \\
\text { Simoncito }\end{array}$ & Parvularia & $\begin{array}{c}\text { Grado de } \\
\text { Transición en el } \\
\text { nivel de } \\
\text { Educación Pre- } \\
\text { escolar*3 }\end{array}$ & $\begin{array}{c}\text { Grado pre- } \\
\text { escolar }\end{array}$ & Infantil \\
\hline 2 & 6 & $\begin{array}{c}1^{\circ} \text { año de } \\
\text { enseñanza } \\
\text { fundamental I } \\
(E F-I)\end{array}$ & $\begin{array}{l}1^{\circ} \text { de Escuela } \\
\text { Bolivariana } \\
\text { (EB) }\end{array}$ & $\begin{array}{c}1^{0} \text { de } \\
\text { Educación } \\
\text { Básica (EB) }\end{array}$ & $\begin{array}{c}1^{0} \text { grado de } \\
\text { Educación Básica } \\
\text { Primaria (GEBP) }\end{array}$ & $\begin{array}{l}1^{\circ} \text { grado de } \\
\text { Educación } \\
\text { Primaria } \\
\text { (GEP) }\end{array}$ & $\begin{array}{c}1^{0} \text { de } \\
\text { Educación } \\
\text { Primaria (EP) }\end{array}$ \\
\hline 3 & 7 & $2^{\circ}$ año de EF-I & $2^{\circ}$ de EB & $2^{\circ}$ de EB & $2^{\circ} \mathrm{GEBP}$ & $2^{\circ} \mathrm{GEP}$ & $2^{\circ}$ de EP \\
\hline 4 & 8 & $3^{\circ}$ año de EF-I & $3^{\circ}$ de $E B$ & $3^{\circ}$ de EB & $3^{\circ} \mathrm{GEBP}$ & $3^{\circ} \mathrm{GEP}$ & $3^{\circ}$ de EP \\
\hline 5 & 9 & $4^{\circ}$ año de EF-I & $4^{\circ}$ de EB & $4^{\circ}$ de $E B$ & $4^{\circ} \mathrm{GEBP}$ & $4^{\circ} \mathrm{GEP}$ & $4^{\circ}$ de EP \\
\hline 6 & 10 & $5^{\circ}$ año de EF-I & $5^{\circ}$ de $E B$ & $5^{\circ}$ de $E B$ & $5^{\circ} \mathrm{GEBP}$ & $5^{\circ} \mathrm{GEP}$ & $5^{\circ}$ de EP \\
\hline 7 & 11 & $\begin{array}{c}6^{\circ} \text { año de } \\
\text { enseñanza } \\
\text { fundamental II } \\
\text { (EF-II) }\end{array}$ & $6^{\circ}$ de $E B$ & $6^{\circ}$ de $E B$ & $\begin{array}{c}6^{0} \text { grado de } \\
\text { Educación Básica } \\
\text { Secundaria (GEBS) }\end{array}$ & $6^{\circ} \mathrm{GEP} * 2$ & $6^{\circ}$ de EP \\
\hline 8 & 12 & $7^{\circ}$ año de EF-II & $\begin{array}{c}1^{0} \text { Liceo } \\
\text { Bolivariano } \\
\text { (LB) }\end{array}$ & $7^{\circ}$ de EB & $7^{\circ} \mathrm{GEBS}$ & $\begin{array}{c}7^{0} \text { grado de } \\
\text { Secundaria } \\
\text { Básica (GSB) }\end{array}$ & $\begin{array}{c}1^{0} \text { de } \\
\text { Educación } \\
\text { Secundaria } \\
\text { Obligatoria } \\
\text { (ESO) }\end{array}$ \\
\hline 9 & 13 & $8^{\circ}$ año de EF-II & $2^{\circ}$ LB & $8^{\circ}$ de $E B$ & $8^{\circ} \mathrm{GEBS}$ & $8^{\circ} \mathrm{GSB}$ & $2^{\circ}$ de ESO \\
\hline 10 & 14 & $9^{\circ}$ año de EF-II & $3^{\circ} \mathrm{LB}$ & $\begin{array}{c}1^{\circ} \text { de } \\
\text { Educación } \\
\text { Media (EM) }\end{array}$ & $9^{\circ} \mathrm{GEBS}$ *2 & $9^{\circ} \mathrm{GSB}^{\star 2}$ & $3^{\circ}$ de ESO \\
\hline 11 & 15 & $\begin{array}{c}1^{0} \text { año de } \\
\text { Enseñanza } \\
\text { Media (EM) }\end{array}$ & $4^{\circ} \mathrm{LB}$ & $2^{\circ}$ de EM & $\begin{array}{c}10^{\circ} \text { grado de } \\
\text { Educación Media } \\
(\text { EM) }\end{array}$ & $\begin{array}{l}10^{\circ} \text { grado de } \\
\text { Preuniversitario } \\
\text { (GpreU) }\end{array}$ & $4^{\circ}$ de ESO *2 \\
\hline 12 & 16 & $2^{\circ}$ año de EM & $5^{\circ} \mathrm{LB}^{*}$ & $3^{\circ}$ de $E M$ & $\begin{array}{c}11^{\circ} \text { grado de } \\
\text { EM }^{*}\end{array}$ & $11^{\circ} \mathrm{GpreU}$ & $\begin{array}{c}1^{0} \text { de } \\
\text { Bachillerato }\end{array}$ \\
\hline
\end{tabular}




\begin{tabular}{|c|c|c|c|c|c|c|c|}
\hline 13 & 17 & $3^{\circ}$ año de EM & & $4^{\circ}$ de $E M^{*}$ & & $12^{\circ} \mathrm{GpreU}$ * & $\begin{array}{c}2^{\circ} \text { de } \\
\text { Bachillerato* }\end{array}$ \\
\hline \multicolumn{2}{|c|}{ NOTAS } & & $\begin{array}{l}\text { * Bachiller o } \\
\text { Técnico Medio } \\
\text { con mención } \\
\text { específica en } \\
\text { la especialidad }\end{array}$ & $\begin{array}{l}\text { *Licencia de } \\
\text { EM }\end{array}$ & $\begin{array}{l}\text { *Bachiller } \\
\text { Académico/Técni } \\
\text { co en la } \\
\text { especialidad } \\
\text { cursada } \\
\text { *2 Certificado } \\
\text { Término de } \\
\text { Educación Básica } \\
\text { *3 Solo es } \\
\text { obligatorio el } \\
\text { grado de } \\
\text { transición. }\end{array}$ & $\begin{array}{l}\text { *Título de } \\
\text { bachillerato } \\
{ }^{* 2} \text { Certificado } \\
\text { de egreso de } \\
6^{\circ}, 9^{\circ} \text { y } 12^{\circ}\end{array}$ & $\begin{array}{l}\text { *Bachiller con } \\
\text { mención de } \\
\text { modalidad } \\
{ }^{* 2} \text { Graduado } \\
\text { en ESO }\end{array}$ \\
\hline
\end{tabular}

Fuente: Datos publicados por el MEC-Brasil y el Convenio Andrés Bello. [En línea] http://www.convenioandresbello.org/tablas_equivalencias/pdf/Tabla_Mercosur.pdf.

Actualmente en Brasil se da la oferta de dos lenguas extranjeras, inglés y español, pero el estudiante obligatoriamente debe estudiar una, la que este opte. De momento, no se puede considerar como de igual situación la oferta de estas dos lenguas, porque el inglés es el que viene formando parte del plan de estudios oficial desde hace mucho y goza de una situación estable, situación que aún no se da para el español, pues se incorporó recientemente (en 2006) al plan de estudios de la enseñanza media, y de inicio como de oferta obligatoria por parte de los colegios y opcional para los alumnos, ellos tendrían que elegir una. Además habría un periodo de gradual implementación hasta llegar a ofertarla a partir del $6^{\circ}$ año de la enseñanza fundamental II, al tiempo en el que las IES titulaban nuevos profesores de ELE que pudieran asumir la tarea a nivel nacional y en todas las escuelas, al menos públicas.

El tema de elegir una de las dos lenguas de oferta obligatoria, durante buen tiempo, ha sido ficticio y ciertamente aún sigue siéndolo en algunas regiones del país. Esta situación venía ocurriendo debido a la falta de profesores de ELE para atender la demanda nacional (MARTÍNEZ-CACHERO, 2008).

Poco a poco, el Ministerio de Educación y sus políticas educativas han ido implementando cursos de grado en ELE, las instituciones de educación superior IES, tras 4 años de estudios formaba nuevos profesores de español para tomar acción en la enseñanza de ELE y formalizarla, ya que los pseudo profesores de ELE no tenían estudios de grado, o si lo tenían era en otras áreas y se sentían preparados para dar clases por haber realizado un curso de 
120 horas. De otro lado estaban los nativos de lengua española que ejercían la profesión sin estudios específicos de grado. Este fue un inicio inestable de enseñanza de ELE que ha podido influir o acarrear una desafortunada mediocridad en el logro de un futuro diferente en relación al dominio y fluidez oral y escrito de ELE a lo largo de la enseñanza fundamental y media del ciudadano brasileño.

\section{CONCLUSIONES}

El capítulo I presenta el estado de la cuestión sobre tres puntos considerados fundamentales en esta investigación: la formación de profesores de español como lengua extranjera; la incidencia de los marcadores del discurso en la formación de profesores, y la presencia de estos en la enseñanza y aprendizaje de ELE en la educación básica y pública brasileña

Sobre la formación del profesorado de grado en ELE, en el estado de Rio Grande do Norte-Brasil, se concluye que la iniciativa ha sido resultado, a priori, de la promulgación de la ley 11.161 que surge de acuerdos internacionales de comercio con países hispanos y también de la creciente globalización que con la contribución de la tecnología da acceso a información.

De las IES analizadas se concluye que hay incongruencia entre lo que el plan de curso dice sobre el perfil del profesor de grado en ELE y la realidad tras cuatro años de carrera y, sobre todo, sobre su actuación docente en la educación pública.

Los cursos de grado, en general, siguen la política de no privilegiar ninguna variedad lingüística en respeto a la identidad cultural de las naciones hispanohablantes, aunque el diseño del plan de estudio de grado en el amplio contenido intenta conocerlas desde varias ópticas de estudio.

La educación brasileña contempla las orientaciones del Marco común europeo para lenguas en la elaboración y diseño de las metas, niveles y procedimientos de enseñanza para la formación del profesorado, así como reconoce la institucionalización de las Academias de lengua de las naciones como un todo. MCER es aplicado como parámetro en el plan de estudios de 
grado y también en las orientaciones curriculares nacionales para la enseñanza básica, cómo podría ser esta aplicación sin una proporcionalidad y delimitación lógicas a los niveles y finalidades de enseñanza de LE.

Se concluye que la incidencia de los marcadores del discurso en la formación del profesorado de ELE no es puntualmente localizada en el plan de curso vigente de las tres IES del Estado de RN, después de haber evaluado asignaturas específicas de formación en ELE.

Se concluye a partir del análisis de audio transcrito que la fluidez y dominio de lengua en los docentes de grado en ELE es, en general, razonable, aunque el uso de marcadores del discurso podría tener un mejor desempeño, al tratarse de docentes de grado. Al analizar la muestra escrita de discurso de un estudiante, notamos que su desempeño en lengua no está en el nivel que se esperaría para un estudiante que está próximo a titularse.

Sobre la enseñanza de lengua extranjera, bibliográficamente constatamos que se enseña LE desde 1500, y todavía hoy seguimos teniendo dificultades que ya han formado parte de la historia de la enseñanza de lenguas extranjeras en Brasil. Al evaluar los reglamentos y normativas oficiales en el contexto nacional, se concluye que ha habido aciertos como el de la aplicación del método directo en su momento y fallos importantes como el de limitar la enseñanza de una lengua extranjera a la práctica de lectura en la enseñanza básica y publica, fortaleciendo indirectamente el formalismo puro de la lengua extranjera en contexto educativo. 


\title{
CAPÍTULO II - (MARCADORES DEL) DISCURSO, COMUNICACIÓN, ENSEÑANZA Y APRENDIZAJE: CUESTIONES TEÓRICAS
}

\author{
‘El discurso es también un fenómeno \\ práctico, social y cultural"
}

(VAN DIJK, 2000)

\section{INTRODUCCIÓN}

Dedicarse a la tarea de investigar la incidencia e importancia de los marcadores discursivos (MD) en la formación de grado en ELE obliga a que antes tratemos de las teorías del lenguaje bajo la perspectiva del análisis del discurso, la pragmática, la sociolingüística y otras disciplinas afines que estudian el uso de la lengua en situaciones concretas de comunicación, ya sean orales o escritas.

Aunque el objetivo previsto para esta investigación no es exactamente el ámbito teórico, como medio, pero sí como medio para comprender mejor el carácter y la incidencia de los MD en la formación del profesorado de grado en ELE, en este capítulo nos proponemos echar mano de conceptos claves y explicaciones teóricas que puedan favorecer la comprensión de fenómenos lingüísticos en el proceso de enseñanza y aprendizaje de ELE conducentes a la fluidez y dominio de español como lengua extranjera.

El buscar una formación de excelencia para aquellos que serán profesores de ELE en la educación básica implica entrar en la ponderación y el análisis de diversos aspectos y factores que intervienen e interfieren en el proceso tanto de enseñanza como de aprendizaje y por ende en el resultado, suponiendo posibilidades nuevas, que percibidas, influirán en la solución de problemas o dificultades actuales en relación al proceso de formación docente de ELE que, a su vez, tendrá eco irremediable en su poder de comunicación y en el momento de la práctica docente o enseñanza en la educación básica.

Este trabajo es fruto de inquietudes que a lo largo del ejercicio docente en los cursos de grado en Letras Lengua Española en el nordeste brasileño 
han ido surgiendo y al mismo tiempo tornándose una cuestión de responsabilidad ante la que se debe reaccionar haciendo los estudios, ponderaciones, conclusiones y sugerencias propias del caso, de forma que se pueda conseguir un avance cualitativo en la formación del profesorado brasileño de lengua española.

Hemos partido de la observación del desempeño oral y escrito de los estudiantes de grado para tomar la decisión de investigar la razón de los resultados de aprendizaje de ELE en lo que respecta a fluidez y dominio de la lengua, a lo largo de su formación, reflexionando sobre los posibles entrabes que intermedian ese resultado y las consecuencias que este supone.

\section{LOS MARCADORES DEL DISCURSO (MD): BASES TEÓRICAS}

Cada día que pasa, se ve más claro que para codificar y/o descodificar un código lingüístico (una lengua), no basta conocer ese código ${ }^{84}$, no es del todo como lo decía Saussure:

La lengua es un sistema, y un sistema puramente formal. (Saussure 1985: vi)

Hace falta mucho más, aunque esta contribución al estudio del lenguaje haya sido de especial relevancia y un hito en la historia lingüística. Grice (1985) ${ }^{85}$ afirma que lo que se codifica y/o descodifica no es todo lo que se comunica y como él muchos otros estudiosos comparten este pensamiento, y así lo demuestran en sus escritos, a ese respecto, veamos este ejemplo:

(1) Luis: Me duele mucho la espalda.

(2) Ana: Pues hay que cambiar la silla.

\footnotetext{
${ }^{84}$ Ferdinand de Saussure en su 'Cours de linguistique générale' (1916) no se refería a la lengua como 'estructura', forma como el prusiano W.von Humbolt la entendía, sino, 'sistema' (1985)

${ }^{85}$ En Portolés (1998: 14)
} 
Parecen dos asertivas sin relación, que no tienen ninguna coherencia ni cohesión entre sí, a priori no se detectaría ninguna lógica, sin embargo, sí que la hay, y además, otras informaciones que no han sido dichas, explicitadas, son comprendidas o mejor dicho, inferidas, como por ejemplo: que Luis trabaja o estudia sentado; que ha pasado o pasa mucho tiempo sentado; que la razón de su dolor de espalda es la silla que no debe ser la adecuada, además podemos inferir que ya se sabía que esa silla en la que se sentaba Luis pudiera estar averiada o inadecuada como para estar sentado en ella durante mucho tiempo; todo lo dicho antes es comunicado, pero no está codificado, ni tampoco hubo descodificación para tener acceso a esas informaciones, buena parte de esa información ha sido inferida lógicamente para un determinado contexto, y que además, la palabra 'pues' matiza, marca muchas de esas informaciones, tal como lo dice PORTOLÉS:

'La simple descodificación no es suficiente, pues la comunicación humana es esencialmente una comunicación inferencial' (PORTOLÉS, 1998: 15)

En el capítulo I recogimos la definición que Portolés (1998) le otorga a los marcados del discurso, veamos ahora la de Briz (1998:167)

Una clase funcional, como puede notarse, heterogénea, que engloba categorías gramaticales distintas, aunque con un papel similar: encadenar las unidades de habla y asegurar la transición de determinadas secuencias del texto (hablado), colaborando así en el mantenimiento del hilo discursivo y la tensión comunicativa.

A todo esto, cuestiones como la de 'una comunicación inferencial' en Portolés, y palabras como 'pues', marcador que hila el discurso de Briz, surge la preocupación de cómo despertar y cultivar esta habilidad en los nuevos profesores de español a lo largo de su formación para que, a su vez, en su práctica docente, pongan en marcha un proceso de enseñanza y aprendizaje de la lengua española consciente y eficaz, al punto de tornar significativo el tiempo de estudio de LE en las escuelas de educación básica (primaria y 
secundaria) en Brasil y la acción docente que se aprende en los cursos de grado en letras en las universidades brasileñas, especialmente en las del nordeste.

En el año 2000, PORTOLÉS en su libro Marcadores del discurso, comentaba la proliferación y publicación, en diversas lenguas, de investigaciones sobre las unidades del tipo por tanto, en suma, en fin, las mismas que en las gramáticas tradicionales eran solo enumeradas en aquel tiempo, sin saber que serían las responsables de toda una revolución en el estudio del lenguaje.

Eran justo los marcadores del discurso los que consolidaban la lingüística del texto, a partir de ellos se afianzaba la teoría pragmática, se pasaba a analizar el discurso y no la oración, derrumbando la teoría de que esta era la unidad mínima del lenguaje y creando con esto serias dificultades hasta hoy no superadas por la gramática tradicional. (PORTOLÉS, 1998).

Visto está que los MD condicionan la interpretación del mensaje y también la direccionan, cómo pueden tener tanta fuerza, este fenómeno se torna fundamental para entender mejor el funcionamiento del lenguaje en las diversas situaciones de comunicación humana, de ahí su relevancia absoluta y el poder que se encierra en ellos.

Los MD pertenecen a una clase heterogénea no identificable, no hay forma de ponerlos en una categoría gramatical única: son adverbios, conjunciones, interjecciones, etc. En lo que sí coinciden es en que funcionalmente conectan diversos elementos que van de sintagma a sintagma, oración a oración, párrafo a párrafo, de párrafo a discurso, en fin, su actuación es ilimitada cuan ilimitado es el pensamiento humano que a través del lenguaje se exterioriza.

Una de las principales características de los MD es su presencia, entre signos de puntuación, aislados del texto; es que no pertenecen a él, sino al enunciado completo, se pueden localizarse en diferentes posiciones (Pues, toma; Toma, pues), su significado no es conceptual, sino procedimental, guían la interpretación del texto en el que están, agregan un significado subjetivo.

Al no pertenecer a ninguna categoría y a todas, los MD actúan como enlaces supra oracionales que otorgan cohesión textual y favorecen la 
interpretación de los enunciados. Morfológicamente se consagran por ser unidades lingüísticas invariables.

\section{Clasificación}

El afán de poder ofrecer una clasificación unánime de MD viene siendo infructuoso, pero destaca una para el idioma español que es la de Portolés y Zorraquino (1999) fundamentada en la función discursiva atribuida a los MD.

En el cuadro siguiente se recoge la clasificación de los marcadores del discurso:

Cuadro 21 - Clasificación de los marcadores del discurso

\begin{tabular}{|c|c|c|}
\hline \multirow{3}{*}{ 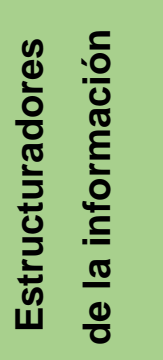 } & Comentadores & pues, pues bien, así las cosas, etc. \\
\hline & Ordenadores & $\begin{array}{c}\text { en primer lugarlen segundo lugar/; por } \\
\text { una parte/por otra parte; de un lado/de } \\
\text { otro lado, etc. }\end{array}$ \\
\hline & Digresores & $\begin{array}{c}\text { por cierto, a todo esto, a propósito, } \\
\text { etc. }\end{array}$ \\
\hline \multirow{3}{*}{ 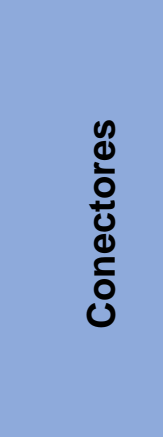 } & conectores aditivos & además, encima, aparte, incluso, etc. \\
\hline & conectores consecutivos & $\begin{array}{c}\text { por tanto, por consiguiente, por ende, } \\
\text { en consecuencia, de ahí, entonces, } \\
\text { pues, así, así pues, etc. }\end{array}$ \\
\hline & $\begin{array}{l}\text { conectores contra - } \\
\text { argumentativos }\end{array}$ & $\begin{array}{c}\text { en cambio, por el contrario, por contra, } \\
\text { antes bien, sin embargo, no obstante, } \\
\text { con todo, etc. }\end{array}$ \\
\hline \multirow{4}{*}{$\begin{array}{l}\text { d } \\
\frac{0}{0} \\
\frac{0}{0} \\
\frac{\pi}{5} \\
\frac{5}{0} \\
\frac{0}{0} \\
\widetilde{d}\end{array}$} & Reformuladores explicativos & o sea, es decir, esto es, a saber, etc. \\
\hline & $\begin{array}{l}\text { Reformuladores de } \\
\text { rectificación }\end{array}$ & mejor dicho, mejor aún, más bien, etc. \\
\hline & $\begin{array}{c}\text { reformuladores } \\
\text { de distanciamiento }\end{array}$ & $\begin{array}{l}\text { en cualquier caso, en todo caso, de } \\
\text { todos modos, etc. }\end{array}$ \\
\hline & reformuladores recapitulativos & $\begin{array}{l}\text { en suma, en conclusión, en definitiva, } \\
\text { en fin, al fin y al cabo, etc. }\end{array}$ \\
\hline \multirow{2}{*}{ 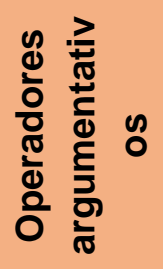 } & $\begin{array}{l}\text { operadores de refuerzo } \\
\text { argumentativo }\end{array}$ & $\begin{array}{c}\text { en realidad, en el fondo, de hecho, } \\
\text { etc. }\end{array}$ \\
\hline & operadoresde concreción & por ejemplo, en particular, etc. \\
\hline
\end{tabular}




\begin{tabular}{|c|c|c|}
\hline \multirow{4}{*}{ 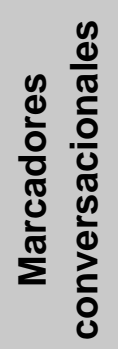 } & de modalidad epistémica & claro, desde luego, por lo visto, etc. \\
\hline & de modalidad deóntica & bueno, bien, vale, etc. \\
\hline & Enfocadores de la alteridad & hombre, mira, oye, etc. \\
\hline & $\begin{array}{l}\text { metadiscursivos } \\
\text { conversacionales }\end{array}$ & bueno, eh, este, etc. \\
\hline
\end{tabular}

Fuente: [Martín Zorraquino, María Antonia / Portolés Lázaro, José: "Los marcadores del discurso". En: Bosque, Ignacio / Demonte, Violeta (eds.): Gramática descriptiva de la lengua española. Madrid: Real Academia Española / Espasa Calpe. 1999, § 63.1.2, § 63.1.3.1 y §

63.1.6]

En el entorno regional de este país, Brasil, los estudios directamente relacionados con este tema no son perceptibles como lo son en el ámbito nacional y en el mundo hispánico. Tan evidente es, que en el plan de estudios de grado en ELE de IES a los que se ha tenido acceso no se registra explícitamente el estudio de los marcadores del discurso.

A modo de información, presentamos el cuadro 22 de GONZÁLEZ $(2013)^{86}$ que organiza los principales enfoques disciplinares en torno a la existencia de los MD:

Cuadro 22 - Sobre la variedad disciplinar y el estudio de los MD.

\begin{tabular}{|c|c|c|c|c|c|}
\hline \multicolumn{6}{|c|}{ VARIEDAD DISCIPLINAR EN EL ESTUDIO DE LOS MD } \\
\hline Disciplina & $\begin{array}{l}\text { Lógica del } \\
\text { texto }\end{array}$ & $\begin{array}{c}\text { Teoría } \\
\text { Argumentación }\end{array}$ & $\begin{array}{l}\text { Análisis del } \\
\text { discurso }\end{array}$ & $\begin{array}{c}\text { Teoría de la } \\
\text { Relevancia }\end{array}$ & $\begin{array}{c}\text { Teoría de } \\
\text { Gramaticalización }\end{array}$ \\
\hline Teóricos & $\begin{array}{l}\text { Van Dijk y } \\
\text { Hasan }\end{array}$ & $\begin{array}{l}\text { Ascombre } \\
\text { Ducrot }\end{array}$ & $\begin{array}{l}\text { Roulet } \\
\text { Rossari }\end{array}$ & $\begin{array}{ll}\text { Sperber } & \text { y } \\
\text { Wilson } & \\
\text { Blakemore } & \end{array}$ & $\begin{array}{l}\text { Hopper } \\
\text { Traugott } \\
\text { Dasher }\end{array}$ \\
\hline Ámbito & $\begin{array}{l}\text { Gramática } \\
\text { textual }\end{array}$ & $\begin{array}{l}\text { Semántico- } \\
\text { pragmático }\end{array}$ & $\begin{array}{l}\text { Pragmático } \\
\text { conversacional }\end{array}$ & $\begin{array}{l}\text { Pragmático } \\
\text { cognitivo }\end{array}$ & Cognitivo \\
\hline $\begin{array}{l}\text { Foco de } \\
\text { atención }\end{array}$ & $\begin{array}{l}\text { Cohesión } \\
\text { del texto }\end{array}$ & $\begin{array}{l}\text { Relaciones y } \\
\text { estructuras } \\
\text { argumentativas }\end{array}$ & El habla & $\begin{array}{l}\text { La } \\
\text { comunicación e } \\
\text { interpretación de } \\
\text { enunciados }\end{array}$ & $\begin{array}{l}\text { Evolución } \\
\text { histórica } \\
\text { Layering y } \\
\text { bleeching }\end{array}$ \\
\hline
\end{tabular}

(Adaptado de GONZÁLEZ, 2013: 89)

86 Para más amplia información y contextualización del estudio de los MD, recomendamos la descripción que GONZÁLEZ, EVA (2013) realiza en su tesis intitulada 'Uso y función de los marcadores del discurso en el discurso argumentativo oral: desde la tertulia hacia el debate político televisivo' León, 2013. 


\section{¿Es lo mismo un conector que un MD que una conjunción?}

Definitivamente no, para Portolés y Zorraquino (1999) los conectores son un subgrupo de los MD, pero para otros estudiosos, la denominación marcadores del discurso se refiere a los marcadores conversacionales (eh, bien, pues, vale, etc.). Sobre las conjunciones, resulta difícil marcar límites, pero el alcance de estas es a la oración, mientras que los conectores enlazan párrafos.

Conceptualizar unánimemente en el campo de la investigación es sin duda todo un proceso que lleva años y años, más aún cuando se trata de nuevos fenómenos, en nuestro caso, lingüísticos como los MD que sabemos, no gozan de tanta antigüedad 'descubierta' pero sí de riqueza de investigaciones, nomenclaturas y clasificaciones. A este respecto, hasta el día de hoy, parece que el consenso que va siendo admitido sobre su denominación y clasificación por la fuerza del uso, de la producción científica y de las publicaciones es el propuesto por Portolés y Zorraquino (1999).

A todo esto, resulta curioso encontrar conceptualización de los MD en el contexto del formalismo, sin hacer ninguna alusión al funcionalismo, cuna en la que nacieron y a la cual 'pertenece' el marcador discursivo.

\section{Conteúdos a serem apresentados} Inicio:

Cuando nos comunicamos, relacionamos enunciados intentando que las personas nos comprendan. Muchas veces conectamos lo que decimos en el momento con algo que hemos dicho anteriormente, expresamos opiniones, concordamos o no con lo que nos dicen.

Para esto, para expresar nuestras intenciones comunicativas, utilizamos elementos lingüísticos que facilitan la cohesión textual. Son los llamados Marcadores del discurso.

Este nombre "marcadores del discurso" viene del hecho que son unidades que marcan límites en el discurso, según nos dicen Sinclair y Coulthard (1975). Además de este nombre, podemos también encontrarlos denominados como "enlaces extraoracionales", "conectores argumentativos" etc. 
Y ¿qué son los marcadores? Los marcadores son unidades lingüísticas clasificadas en las gramáticas tradicionales como conjunciones, locuciones adverbiales, adverbios, frases preposicionales, formas verbales e interjecciones.

Son ejemplos de marcadores: Bueno, pero, pues, en primer lugar... (Datos de investigación. IES-3, 2011) (Subrayado nuestro).

El límite entre conectores, conjunciones y marcadores discursivos parece ir aclarándose cada vez más; no obstante, aún resulta difícil distinguirlos en determinados casos. Por ejemplo, las conjunciones ' $y$ ' / 'o', que, de hecho, son lo que son en el campo del formalismo dentro de lo prescriptivo de la morfología en su categorización gramatical: conjunciones. Pero cuando 'y' marca continuidad de discurso o cuando 'o' justifica o argumenta, su actuación ya no es la de conjunción aditiva y conjunción disyuntiva, en absoluto, son nada más ni nada menos que marcas de enlace del macro discurso y no de una oración.

\section{Notemos la diferencia:}

Necesito comprar libros y cuadernos

(Conjunción aditiva, clasificación morfológica, campo del formalismo)

Ana: Se me ha estropeado el coche

Juan: ¿Y ahora?

En “¿Y ahora?" marca la continuidad del discurso anterior, que además es reacción a lo dicho en un intercambio de acto comunicativo y aunque no lo fuera. En este caso es un MD, campo del funcionalismo de la lengua.

Aún sobre clasificación, los marcadores conversacionales, que no dejan de ser discursivos, son de lógico reconocimiento, y además, con la definición de Boyero hay una clara especificación:

Así, hemos definido al marcador conversacional, como un fenómeno lingüístico interactivo, con entonación independiente, funcionamiento en cadena, con modalidad de imperación, que da cuenta de las intenciones y actitudes de los hablantes, incidiendo cada uno de ellos sobre el contenido de lo enunciado. (BOYERO, 2002: 18) 
Desde nuestro punto de vista, un marcador conversacional tendría que estar insertado en una conversación en la que habría interlocutores en interacción, los mismos que darían a estos elementos vacíos, aparentemente, de contenido, frecuentemente monosilábicos, funcionamiento y valor en la comunicación (Portolés y Zorraquino,1999).

\subsection{EL FUNCIONALISMO LINGÜÍSTICO}

'El texto no es una unidad de la gramática como la sílaba, la oración o el sintagma nominal, sino de la intención de los hablantes. Por ello, la coherencia no es un criterio de buena formación comparable a la gramaticalidad sintáctica' (PORTOLÉS, 1998)

El término funcionalismo, referido al ámbito lingüístico, dice de las corrientes que parten del principio teórico de que toda lengua tiene como su mayor propósito la comunicación y que de él debe partir todo y cualquier estudio de lengua que se realice.

En el anejo 7 y 7A presentamos el cuadro de CORRAL (2010: 22) en el que se describe resumidamente la terminología, los autores y las teorías del ámbito funcionalista, inclusive en España, información muy útil para todas las finalidades.

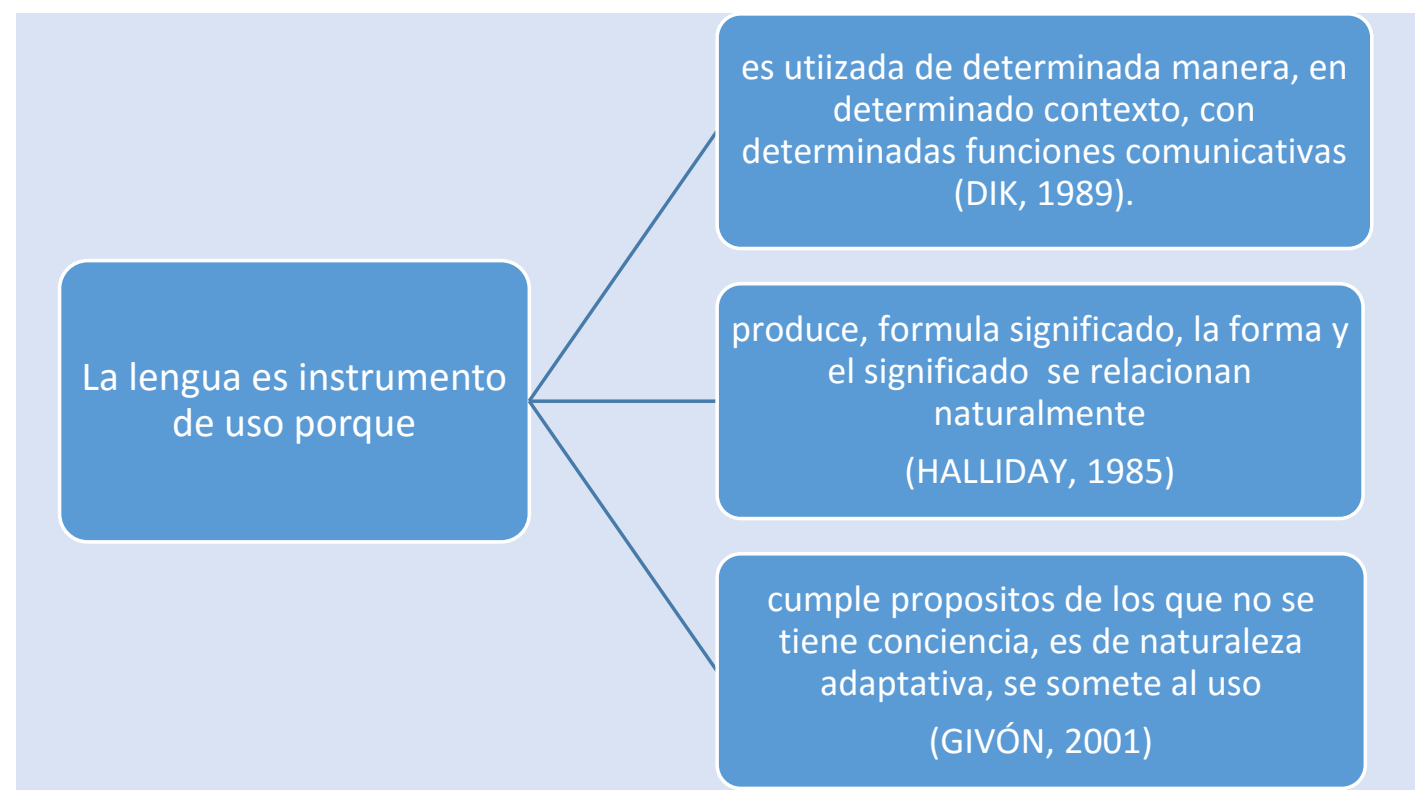

Figura 13 - Teorías del funcionalismo

Adaptado y traducido al español de http://goo.gl/QPAUTj 
El funcionalismo surge como respuesta a la gramática generativa transformacional, contradiciéndole todos sus puntos de vista teóricos referidos al lenguaje, tiene como objeto de estudio el entender cómo se comunican los usuarios de una determinada lengua, analizando no solo formas estructurales, gramaticales, sino también lo que constituyen las situaciones comunicativas: los participantes, el contexto discursivo, la situación etc.

Los funcionalistas sostienen que toda situación comunicativa motivada determina las estructuras gramaticales y las explica, el cómo explicar esas funciones es en donde las corrientes funcionalistas divergen. La convergencia teórica está en considerar a la lingüística como el estudio de las funciones que están en elementos, clases y mecanismos que actúan en la lengua, pues la intención explicativa es sustancial, además del valor descriptivo. Los funcionalistas afirman que la lengua es, sobre todo, el medio que posibilita la comunicación.

En la lingüística funcional se encuentra explicación a la forma de locuciones, textos o discursos a partir de principios diversos como el de menor esfuerzo, la economía de medios expresivos, la doble articulación de las unidades lingüísticas y la iconicidad como reflejo de lo simbolizado en la representación verbal o como la pintura que puede hacer el lenguaje de la realidad. Se imprime importancia a que una lengua se interprete como sistema de significados acompañados por formas que expresan el sentido de las palabras.

El funcionalismo es incompatible con las reglas gramaticales y critica el innatismo de N. Chomsky, analiza la importancia de la interpretación de los textos y se aplica al uso del lenguaje en su contexto y en la interpretación del sistema fonológico (ROBÁU, 2013)

Para los funcionalistas, el contexto tiene relevantes consecuencias en el uso de la lengua y el uso de un elemento puede variar en función de la situación contextual en la que se aplique, se busca encontrar explicaciones al modo como los hablantes utilizan la lengua. En ese sentido, el análisis funcional se asemeja al de la competencia comunicativa de los hablantes, de su destreza en la codificación y decodificación de mensajes. 
Según el funcionalismo, la competencia comunicativa tiene tres aspectos: (1) la importancia del código verbal y no verbal, así como de las variantes a utilizar; (2) el cómo interaccionar para lograr comunicación efectiva contemplando reglas y expresiones; y (3) el conocimiento cultural, valores, creencias y conceptos.

En efecto, para comunicarse es indispensable el conocimiento del código y sus matices, sin código, no hay comunicación y sin el código no habría cómo acceder a la realidad cultural en su total dimensión.

\subsubsection{El análisis del discurso AD}

Así se le llama al conjunto de disciplinas cuyo objeto de estudio es el uso lingüístico de modo contextualizado, es la ciencia interdisciplinaria que tiene como objeto de estudio el uso que los hablantes hacen de la lengua en situaciones concretas, o sea, el discurso en sí. Todo y cualquier enunciado, oral o escrito puede ser objeto de estudio para el AD. Según la óptica del análisis del discurso, la unidad mínima de análisis es el enunciado, y no el sintagma oracional como lo apuntado en el ámbito de la sintaxis.

Los primeros estudios se centran en el análisis de la conversación, realizado sobre producciones escritas a las que se les denomina texto. EI AD entonces se centra en producciones orales y su constitución es resultado del encuentro de corrientes diversas, como la antropología, la sociología, la psicología, entre otras cuyo interés es el discurso y otras más antiguas según reconozcan el planteamiento de la relación entre discurso y hablante-oradoraudiencia $^{87}$. El AD engloba, al parecer, disciplinas como la etnografía de la comunicación, el análisis de la conversación, la pragmática, la teoría de la enunciación y la lingüística textual.

En el ámbito del aprendizaje de lenguas y en razón de que:

El discurso es parte de la vida social y a la vez un instrumento que crea la vida social (CASAMIGLIA, 1999: 15)

\footnotetext{
${ }^{87}$ [En línea] http://goo.gl/siiMJa
} 
El $A D$ ha generado una visión diferente de cómo enseñar lengua influyendo en las metodologías y la redacción de las unidades didácticas refiriéndose a enunciados, enunciación, textos, usos en contexto, entre otros aspectos; asimismo, el aprendizaje se ha volcado en la contextualización y el uso en concreto de la lengua que se aprende. Su objeto fundamental es describir la importancia que el texto hablado o escrito tiene en la comprensión de la vida social.

El material lingüístico se pone pues al servicio de la construcción de la vida social, de forma variada y compleja, en combinación con otros factores como los gestos, en el discurso oral, o los elementos iconográficos en la escritura; los elementos cognitivos, sociales y lingüísticos se articulan en la formación del discurso. (CASAMIGLIA, 199: 16-17)

La evidencia de que la lengua tiene vida, y por eso no puede estar sometida a un código estático, pone de manifiesto también que ella nos hace seres sociales:

Las lenguas viven en el discurso y a través de él. Y el discurso -los discursosnos convierten en seres sociales y nos caracterizan como tales (CASAMIGLIA, 1999: 17)

De otro lado, la lengua en sus dos más fuertes vehículos de comunicación, la oralidad y la escritura, al ser viva y al hacernos seres sociales, necesita indefectiblemente de un código que establezca signos de comunicación inequívoca en situaciones formales:

Los enunciados se combinan entre sí para formar textos, orales o escritos. El texto, así, está constituido por elementos verbales combinados que forman una unidad comunicativa, intencional y completa. (CASAMIGLIA, 1999: 17)

Los elementos verbales también son signos que se combinan para realizar la intención comunicativa. 


\subsubsection{La Pragmática}

La pragmática se concibe para dar cuenta de la diferencia entre lo dicho y lo interpretado, ejemplo: "Vamos a comer"; respuesta: "Estoy retrasado en el trabajo". De esta forma dejamos claro que la pragmática se encarga de estudiar la palabra directamente usada en acto de comunicación que se caracteriza por tener una intención y está restringido a las circunstancias en que se produce la comunicación de esa palabra. Como bien lo dice Reyes (2003: 9) palabras como yo, este, allá, mañana, solo significan algo si están en determinado contexto.

El estudio del lenguaje no es nada nuevo, [...], pero la pragmática es el primer intento de hacer, dentro de la lingüística, una teoría del significado de las palabras en su relación con hablantes y contextos. (REYES, 2003:8)

"Significado del hablante", nos lo explica REYES (2003), debemos entender que solo tiene significado como constituyente de un enunciado que el hablante quiere comunicar explícita e implícitamente. Lo implícito es la interpretación de este significado, resultado de la descodificación y también del proceso inferencial, se infiere lo que se nos quiere comunicar, porque no todo es explícito.

Relación entre los signos y sus intérpretes. Comienza en 1970 (Morris, 1938 apud Portoles, 1998)

La pragmática estudia la porción de significado que no es convencional o gramatical, es decir, lo que no está codificado por reglas, justo aquello que no se estudia desde un punto de vista puramente gramatical, estudia más bien los factores extralingüísticos que determinan el uso de la lengua por ejemplo: la situación, el conocimiento del mundo, el contexto verbal, la intención, el destinatario, el emisor, es decir, todo lo que interviene en el discurso.

Pragmáticamente, los deícticos en general, no se pueden estudiar sin un contexto por la simple razón de que estos establecen conexiones entre lo 
que se enuncia y el contexto. Estas partículas se localizan en el límite entre la semántica y la pragmática. Para muchos lingüistas, la pragmática empieza con los deícticos y otros elementos similares, que forman parte de la gramática de una lengua, pero no son independientes del contexto. A partir del momento en que, para asignar significado a expresiones lingüísticas, debemos recurrir al contexto, estamos haciendo pragmática. (REYES, 2003).

Supone un desafío para la Pragmática tener en cuenta que la comunicación humana es un proceso inferencial y que, tal y como han puesto de manifiesto los investigadores Sperber y Wilson (SPERBER y WILSON, 1994) a través de la formulación de su teoría ${ }^{88}$, solo se codifica la parte más relevante de lo que se quiere decir. Si tenemos en cuenta la propuesta de estos autores, es de obligada reflexión decidir también qué parte del significado es posible recuperar realmente.

La relación que une pragmática y marcadores del discurso es de génesis para la primera, pues fueron los marcadores del discurso su primer objeto de investigación, el gran instigador de campos nuevos de investigación:

[...] los llamados marcadores del discurso fueron el primer campo de investigación pragmática, ya que constituía un terreno casi yermo en la gramática. Su estudio nos abrió las puertas para entender cómo fluía el discurso y desde ahí para descubrir [...] (FUENTES RODRIGUEZ, 2010: 689).

De esta forma, el campo de la Pragmática a día de hoy sigue siendo amplio y continúa en la discusión de si debe ser disciplina o subdisciplina dentro de la lingüística, si es una lingüística alternativa o una ciencia especial, distinta de la lingüística (REYES, 2003: 23)

\footnotetext{
88 La Teoría de la Relevancia dice que la comunicación humana se consigue por la conjunción de la ostensión y la inferencia en la búsqueda de la relevancia, concepto comparativo que deriva de la relación entre el supuesto que proporciona el emisor y un contexto que reconstruye el destinatario.
} 


\subsubsection{La Sociolingüística}

Se comprenderá mejor [...] En efecto, ¿cómo se puede pensar una lingüística funcional que no sea sociolingüística? Todos los fundadores del funcionalismo han subrayado el carácter social del lenguaje y lo hay concebido como una institución social. (CLAIRIS, CH., 1996: 71)

En efecto, un funcionalismo sin sociolingüística, claro que no. Son factores como sexo, origen étnico, edad, clase social, o tipo de educación, derivados de diversas situaciones de aplicación, el objeto de análisis de la sociolingüística, rama de la lingüística que estudia la relación del lenguaje con la sociedad.

En 1952 es cuando aparece por primera vez el término sociolingüística, y es en 1964 con las reuniones que se realizaron con investigadores lingüistas, sociólogos y antropólogos, cuando se inició una actividad incesante. Según W. Labov, de ninguna manera la lengua se podría separar de su realización, presenta y defiende el concepto de competencia sociolingüística a la que definió como el todo formado por el nivel interno de la lengua (competencia, el externo (actuación) y los factores sociales.

La sociolingüística empírica es la que se encarga de recoger datos y por eso la responsable del desarrollo actual de la disciplina, también está la sociolingüística teórica que lleva a cabo las reflexiones sobre los datos recogidos. Investiga en tres campos: en el campo de la sociolingüística cuantitativa urbana o variacionismo, en el campo de la sociología del lenguaje y el de la Etnografía de la comunicación.

Los desacuerdos entre lingüistas es bastante acentuado sobre la delimitación del objeto de estudio de la sociolingüística a lo que han propuesto que se puede incluir el estudio de la comunicación interpersonal hasta el estudio de la planificación lingüística, la elección de la lengua en comunidades bilingües o plurilingües.

En el campo del aprendizaje de lenguas han sido muchas y muy buenas las relaciones establecidas a partir del principio de que el contexto social es el 
factor más influyente en ese proceso y propone que el tema de la variación lingüística debe estar presente en la enseñanza de una lengua.

Asimismo, el MCER señala que los estudiantes de una lengua extranjera deben ampliar sus conocimientos y destrezas necesarios para poder utilizar la lengua en su dimensión social, desarrollando su competencia sociolingüística.

\subsubsection{La lingüística aplicada a la enseñanza de ELE}

El estudio de los marcadores del discurso va ocupando espacio importante en el estudio de la lengua, sin duda, y al traerlos para el ámbito de la enseñanza de español como lengua extranjera se presenta un campo abierto e intenso que hace falta examinarlo con mucho cuidado. A priori, las primeras observaciones que podemos hacer en este campo es que la equivalencia semántico-pragmática de los MD entre español y portugués de Brasil es un terreno altamente resbaladizo, por las siguientes razones:

1 Notamos que en la oralidad hay poco uso de MD, pero en la descripción hay muchos más que en español, por ejemplo;

2 Notamos que en la oralidad y en la escritura se usan siempre los mismos marcadores, o sea que hay unos que solo se usan en situaciones especiales, por no decir raramente especiales, como el 'malgrado', que nosotros mismos no lo hemos escuchado hasta ahora en nuestro entorno nordestino;

3 Notamos que construir un paralelo gramatical, literal entre los marcadores discursivos en español y portugués es una tarea ardua, de ahí que pensar en traducción literal no es para nada bueno.

Son muchos los aspectos que se deben tener en cuenta a la hora de enseñar una lengua extranjera, a saber: no traducir, lo que quiere decir usar otros recursos, inclusive la lengua materna del aprendiente ${ }^{89}$; no usar la gramática o en todo caso asumir situaciones comunicativas para lograr el

\footnotetext{
${ }^{89}$ Aunque pensemos que lo ideal es no tener que depender de la lengua materna para enseñar español a los brasileños, a causa de la transparencia y la comprensión que se alcanza, es saludable contemplar la posibilidad en el último de los casos.
} 
objetivo de aprendizaje; a todo eso, y ante el ejemplo que tenemos, como llevaríamos los marcadores del discurso del español a un brasileño, futuro profesor de español. Veamos la equivalencia:

\begin{tabular}{|l|l|}
\hline (1) En portugués & $\begin{array}{l}\text { Você não faz os deveres, não ajeita seu quarto, não ajuda } \\
\text { em nada, e ainda por cima me pede o dinheiro que não } \\
\text { tenho? }\end{array}$ \\
\hline (2) En español & $\begin{array}{l}\text { ¿No haces las tareas, no arreglas tu habitación, no ayudas } \\
\text { a nada, y encima, me pides dinero cuando no lo tengo! }\end{array}$ \\
\hline
\end{tabular}

En portugués, la palabra 'encima' existe, pero equivale a 'sobre' en español; necesita la preposición 'por', en español no, ninguna preposición; solo la composición 'por cima' no equivale a 'encima' del español; en portugués necesita las palabras 'e ainda' (y aún) para que diga 'y encima' del español.

'encima' en español es un conector aditivo (Portolés, 1999) cuya equivalencia en portugués es la suma de 3 palabras 'ainda por cima', de otra forma no valdría lo que en español, no sirve 'por cima', e por cima, ainda cima, etc.

En español tenemos el adverbio de lugar 'encima' también como lo tiene el portugués, entonces la tendencia termina concretando el error, este tipo de situaciones de aprendizaje son relativamente frecuentes en la clase de ELE en Brasil. Es en la oralidad que va a lograrse dominar este tipo de situaciones de aprendizaje, funcionalmente, pero al tener profesores que no ponen en uso partículas como estas, entonces, cuándo se realizará el aprendizaje.

\subsection{LA GRAMÁTICA}

La lengua, como materia primera del discurso, ofrece a quienes la usan una serie de opciones (fonéticas, gráficas, morfosintácticas y léxicas) de entre las cuales hay que elegir en el momento de (inter)actuar discursivamente. (CASAMIGLIA, 1999:15) 
Se la define a la Gramática como la ciencia cuyo objeto de estudio es la lengua en sus componentes y combinaciones. Este es uno de muchos conceptos que existen de gramática, y es que además los hay para todos los gustos, desde los más neutros como el citado antes, hasta los más prejuiciosos como el de "arte de dominar una lengua de modo correcto desde el habla hasta la escritura", pero ahora mismo no pretendemos ocuparnos de este tipo de apreciación, más bien el de localizarla en el ámbito del formalismo.

Los niveles de la gramática han sido objeto de discrepancia a la hora de delimitarlos, pues unos entienden que gramática es tratar exclusivamente del nivel sintáctico-morfológico de la lengua, no obstante, otros, la mayoría de los teóricos de este ámbito contemplan: el fonético-fonológico porque reglas gramaticales surgen del sonido de la lengua, el sintáctico-morfológico por la combinatoria y relación de las palabras así como su categorización y el léxicosemántico por el significado que se atribuye a las palabras.

\subsubsection{La Gramática: tradicional / prescriptiva/normativa, descriptiva y pedagógica}

La principal diferencia entre las dos primeras es que la tradicional no contempla contextos extralingüísticos, su límite es la oración no pudiendo a partir de ella estudiar coherencia, intención, situación, entre otros, pues no analiza el texto, no aborda las relaciones supra oracionales.

Con el estructuralismo en lingüística (1920-1930), el fenómeno de prescribir fue superado por el de describir; más tarde (1960), Noam Chomsky con la teoría generativo-transformacional revolucionó conceptos a causa de un nuevo elemento: la gramaticalidad o aceptabilidad de la lengua, lo que significó una postura contraria a la teoría estructuralista, pero en común ambas se oponían a la rigidez de la gramática prescriptiva.

Al no presentar variedades lingüísticas, la gramática prescriptiva da por única, correcta y verdadera una lengua ficticia, la literaria, mientras que la descriptiva presenta la riqueza de las variedades lingüísticas, por eso heterogénea. La tradicional/prescriptiva siempre pretende ser homogénea, una lengua formal: 
La lengua patrón, por ejemplo, aunque sea una entre las muchas variedades de un idioma, es siempre la más prestigiosa, porque actúa como modelo, como norma, como ideal lingüístico de una comunidad. (CUNHA, 1985: 3) $)^{90}$

La gramática tradicional es normativa, su metodología se plantea enseñar la lengua con reglas y excepciones y lo que no esté señalado por ella, es incorrecto, ya la descriptiva analiza las características de la lengua sin emitir juicio. Aunque reconozca la sociolingüística y la variación de sus dialectos, la gramática tradicional no los acepta, no ve a la lengua como un ente vivo, en evolución, se mantiene enfatizando la forma, situación que desde cierto punto de vista resulta importante reevaluar, pues al servir fielmente a la lengua escrita, más que a la oral, la gramática tradicional o prescriptiva debería tener su espacio de uso e investigación garantizado, que si no, la confusión continuaría instalada como hasta ahora, en la práctica hay una gigante contradicción entre lo que se dice de la gramática y lo que de hecho ocurre en las aulas de lengua, sea esta materna o extranjera.

De hecho, creemos que unas reglas gramaticales mientras relativas y no absolutas son útiles en el aprendizaje de una lengua extranjera y sin duda para la lengua materna. Las reglas deben ir acorde con la agilidad y las transformaciones que indefectiblemente ocurren en toda lengua y que suele ser consecuencia de fenómenos sociales, culturales, económicos, inclusive políticos.

Ante lo dicho, parece obvio que al tratarse de aprender una lengua extranjera, puntualmente español, lengua que se habla en más de 20 países, y si de gramática se trata, se deberá empezar por conocer aquella que permita acceder a un español con el que ese aprendiente de ELE pueda transitar sin restricciones por el mundo hispano, sin que en un primer acercamiento a la lengua extranjera, tenga que enterarse por ejemplo que colectivo, autobús,

\footnotetext{
90 Texto original en portugués: A língua padrão, por exemplo, embora seja uma entre as muitas variedades de um idioma, é sempre a mais prestigiosa, porque atua como modelo, como norma, como ideal linguístico de uma comunidade. (CUNHA, 1985: 3)
} 
ómnibus, guagua, etc. se dice en Perú, España, Chile, y Cuba respectivamente, que le bastara saber que diciendo autobús u ómnibus, ya sería entendido y capaz de resolver bien una situación comunicativa.

Que la lengua está antes de la gramática, es absolutamente correcto y en esa lógica, entonces, solo se podría estudiar gramática cuando ya se hubiera desarrollado habilidades comunicativas en esa lengua, si esta realidad fuera para el nativo respecto de su lengua materna, no se podría alfabetizar a los niños a los 6 años, sino mucho más tarde y esto no estaría en consonancia con el sistema de educación que vigora en la mayoría de los países.

La gramática no solo es necesaria como es indispensable según sus finalidades y en determinados ámbitos del lenguaje, como por ejemplo en el aprendizaje de segundas lenguas o lenguas extranjeras y en ese sentido, las diferencias son marcadamente presentes, no es lo mismo enseñar una lengua para fines de mera comunicación que para formar profesores.

La enseñanza de gramática debe ajustarse a la función a que se destina en el ámbito y objetivos para que se aplique. En un curso de grado en enseñanza de ELE en un país cuya lengua oficial no es español y pretende formar profesores de otra lengua a sus nativos, estos no deberían tener la gramática por opción, sino por formación, por responsabilidad profesional.

\footnotetext{
¿Qué gramática? Recordemos que este segundo aspecto hace referencia a la existencia de diferencias objetivas $-\mathrm{y}$ por lo demás archiconocidas - de nivel o de etapas en la adquisición de las segundas lenguas. Este hecho se concreta, en la práctica más cotidiana, en la distribución de los materiales, la organización concreta de cursos, o en fin, en la expedición de títulos que tratan de medir el grado de dominio de un idioma, en los tres niveles clásicos que, con distintas denominaciones, responden a los conceptos de iniciación o básico, intermedio y superior (GARCÍA SANTOS, 1994: 71)
}

La gramática descriptiva, como su propio nombre lo dice, es aquella que describe y registra una determinada variedad de la lengua en determinado momento de su existencia, por tanto su abordaje es sincrónico, su estudio 
abarca la estructura y el funcionamiento; su aplicación en la enseñanza de ELE, la verdad, pensamos que es para estudios más profundos.

Por lo dicho, la gramática descriptiva es importante, es enriquecedora, es acompañante fiel de lo vivo de la lengua, pero hay que plantearse hasta qué punto es lo que debemos enseñar en nuestra clase de ELE y en qué momento, para servir a qué finalidades.

La gramática comparada en un caso de estos sería incluso conveniente; no obstante tendría que ser predecible el conocimiento de la gramática de su lengua nativa para que funcione, y en caso de que no, pues valerse de esta fase de aprendizaje lingüístico para actualizar los conocimientos de gramática de su lengua nativa, aunque tornaría el proceso más denso y desviaría el objetivo 'aprender lengua extranjera', aunque, qué mejor reaprender, a deambular en la oquedad de la información necesaria para ser un profesor apto al desempeño docente con calidad y compromiso.

Habiéndonos referido a la gramática prescriptiva y a la descriptiva, nos queda la gramática pedagógica, de la que podemos decir que tras tanta polémica, aciertos y fallos en los abordajes a ser aplicados en la enseñanza de lengua, parece estar acorde con lo que hace falta para lograr el éxito, sobre todo en el ámbito de la enseñanza de lengua extranjera.

EI "PIE CHART", propuesta de CELCE-MURCIA E LARSEN-FREEMAN (1991) para la enseñanza de lenguas extranjeras contempla la forma, el sentido/significado y el uso de la lengua, en conjunto, nada más sensato. Ante los extremos formulados teóricamente y llevados también a la práctica, a nuestro humilde ver, erróneamente, la propuesta de la gramática pedagógica se perfila como apropiada para lograr los objetivos de aprendizaje y las orientaciones para la enseñanza.

Lo que no puede ocurrir es permanecer como está, condenando radicalmente el formalismo, e implícitamente los estudios que lo componen porque estudia la lengua sin considerar las circunstancias en las que esta es usada. Si bien es verdad que la lengua solo se realiza en contexto, cuál sería el código con el que se comunicaría, ese código está en el formalismo, ¿no?

Este tema necesita una reflexión mucho más amplia, a nuestro ver, el avance de los estudios en el ámbito del funcionalismo son loables y de extrema 
relevancia, no obstante esta 'rivalidad' creada, lejos de traer beneficio al cultivo y aprendizaje de lengua, más bien ha significado un retroceso en la práctica, No recuerdo haber visto ningún parecer respecto a que NO se debe enseñar gramática en la clase de lengua, pero lo que se viene haciendo y defendiendo "inocentemente" incluso, es justo esto.

La dosis de gramática, por supuesto, está sujeta a reacomodación buscando equilibrio entre lo adecuado ( $\mathrm{y}$ no lo correcto), tanto en la oralidad como en la escritura.

\subsubsection{La gramática en la lengua materna (Portugués de Brasil)}

Al contextualizarnos, en un país, Brasil, en un estado, Rio Grande do Norte, una lengua, portugués, un contexto de aprendizaje, lengua portuguesa en la enseñanza básica, presentamos una realidad que resulta interesante analizar al tratarse de gramática en este ámbito.

(1) Una profesora de portugués, pregunta: ¿Finalmente, debemos o no utilizar la gramática en la enseñanza de lengua portuguesa? ${ }^{91}$

(2) "La enseñanza de la lengua fue desviada hacia la enseñanza de la teoría gramatical". (GERALDI, 1987: 21) ${ }^{92}$

(3) Bueno, si la función de la escuela es la enseñanza de la lengua patrón (estándar), no es con la teoría gramatical con lo que alcanzará su objetivo $^{93}$.

Este tipo de planteamientos aún forma parte del día a día del docente de lengua portuguesa en Brasil y es el retrato de la confusión que existe. Gramática, no; pragmática sí. Perfecto, ¿pero los profesores brasileños cuando terminan la carrera tienen las ideas claras sobre ese tema? Ya es tiempo de admitir que la existencia de uno no perjudica ni entorpece la existencia del otro,

\footnotetext{
91 [En línea] http://www.filologia.org.br/viiicnlf/anais/caderno09-14.html

92 "O ensino da língua foi desviado para o ensino da teoria gramatical". (GERALDI, 1987: 21)

93 Ora, se a função da escola é o ensino da língua padrão, não é com teoria gramatical que ela concretizará seu objetivo.
} 
que la gramática no es el foco: es complemento para un desempeño lingüístico que en el día a día del brasileño es exigido, y para muestra un botón: para acceder a estudios universitarios, hace falta superar la selectividad que tras un filtro de preguntas objetivas exige una redacción; para superar la carrera, se exige una monografía en el área de formación, y así en los sucesivos o paralelos pasos que vamos dando a lo largo de la vida.

Creemos que es en la alianza y no en la separación o afrontamiento que se superarían muchos problemas de orden lingüístico que se relacionan directamente con la vivencia del ciudadano de esta y de cualquier sociedad, se insiste en el equívoco de separar o afrontar el formalismo y el funcionalismo, la verdad es que no hay como separarlos, ambos son y están en la lengua, eso hace falta entender, aceptar, ponderar y sobre todo ilustrar a quien no lo ve y que se pare ya de preconceptos que solo traen perjuicio.

\subsubsection{Fonética y Fonología}

Son ramas de la lingüística que tienen por objeto de estudio los sonidos de una lengua, pero la fonología desde el punto de vista de su función en el sistema de la comunicación lingüística y la Fonética desde el punto de vista de la realización en sí, desde su constitución acústica y de su percepción. Fonética y Fonología son dos asignaturas diferentes, aunque básicamente relacionadas y sobre todo condicionadas, sin conocer Fonología de la lengua no puedes describir su fonética.

Ambas forman parte de la gramática porque ciertas reglas gramaticales se realizan a partir del sonido de la lengua, ayudan a delimitar lo que se entiende como agramatical:

La gramática (en la que incluyo fonología, morfosintaxis y semántica) es la disciplina lingüística que estudia las estructuras convencionales de sonidos, combinaciones de monemas y significados (REYES, 2003: 14)

No obstante, cada vez está más claro, tal como lo ve REYES, (2003) que Fonética, al ser un conocimiento de realización viva de sonido, no forme 
parte de la gramática como está generalizado. Fonética es acción y realización de sonido, ya no se puede decir lo mismo de Fonología.

Estos conocimientos de absoluta relevancia en el aprendizaje de una lengua, no por hacerlos llegar al estudiante de ELE de la educación básica, sino, más bien para que siendo del conocimiento del profesor, este pueda contribuir efectivamente a una producción oral más próxima de la lengua meta.

\subsubsection{Semántica}

La Semántica estudia el significado sentido o interpretación de los signos lingüísticos como símbolos, palabras, expresiones o representaciones formales y sus combinaciones. Los medios de expresión suponen una correspondencia entre las expresiones y determinadas situaciones o cosas, ya sean del mundo material o abstracto, o sea, la realidad y los pensamientos pueden ser descritos a través de las expresiones analizadas por la semántica.

La semántica puede ser estudiada desde diferentes puntos de vista como el de la semántica lingüística que se encarga de estudiar la codificación del significado en el contexto de las expresiones lingüísticas y a su vez se subdivide en semántica estructural y semántica léxica o desde la semánticapragmática en la que la completitud se realiza, y otros muchos enfoques que no ahondaremos pero que no por eso son menos importantes.

El valor de los conocimientos semánticos se manifiesta plenamente en la riqueza y facilidad con que los aprendientes se expresan. Hace falta conocer el significado, tanto formal como pragmático, en el desempeño de la labor docente de ELE y, visto desde este punto de vista, es un conocimiento que no puede ser omitido del plan de estudios de un futuro profesor de lengua.

Lo importante es siempre avanzar, ampliar la visión formalista, de ahí la relevancia impar de la semántica-pragmática; omitir este conocimiento es sinónimo de la poca valoración que se otorgue al significado de las palabras, al sentido que estas puedan albergar en determinados contextos. 


\subsection{FORMALISMO Y FUNCIONALISMO: PUGNA, INTERSECCIÓN O SUMA}

Con el surgimiento de nuevas explicaciones para el fenómeno del lenguaje, lo que durante mucho tiempo reinó fue el formalismo que reglaba el código lingüístico de donde partía el conocimiento para que las personas se comunicaran. Lo que se observa con bastante frecuencia es un exacerbado discurso que coloca al formalismo en un escenario de inutilidad, inclusive absoluto, El formalismo y el funcionalismo son presentados como corrientes que inicialmente son contrapuestas o son incompatibles para una misma dirección, la dirección del aprendizaje o adquisición de una lengua, sobre todo si es extranjera. Parece que se exagera, si bien es verdad que el formalismo por sí solo no completa ni explica la comunicación con toda la riqueza que esta encierra, es de fundamental respaldo para que haya unidad en la comunicación, al tratarse de una lengua que no solo se habla en una nación, ni dos.

La figura 15 muestra esas direcciones y en cualquiera de las dos, la relación entre formalismo y funcionalismo es de pugna o imposibilidad de juntarse para atender un mismo fin, la unidad de la lengua, en este caso, español.

Figura 14 - Formalismo vs funcionalismo
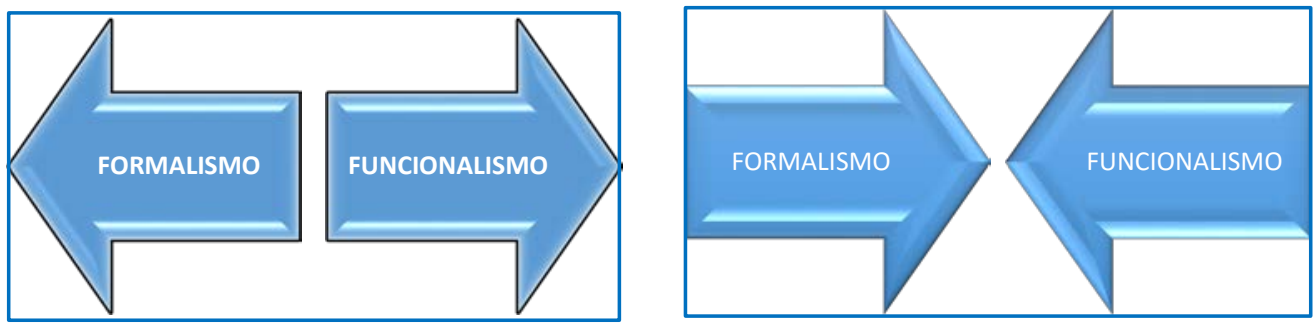

(Creación del autor)

De esa forma, creemos que la incompatibilidad de bases y perspectivas teóricas entre formalismo y funcionalismo creó la inferencia de que la gramática estaba prohibida, y que conocimientos como Fonética, Fonología y Semántica contemplados en el formalismo no servían más a los intereses de la lengua, a los seguidores del discurso de los investigadores les faltó reflexión propia a 
partir de su actuación docente y de los resultados que de esta emanan. Cada teoría es resultado de estudios, en diferentes tiempos y con la finalidad de explicar el lenguaje, no se trató de una competencia por ver cuál explica mejor, tanto una como otra en su momento explicó su razón de ser, pero todo y, sobre todo lengua, evoluciona, conceptos, perspectivas, finalidades. $Y$ en eso de finalidades, el formalismo no podría ser puesto en el escenario de la inutilidad porque si hay algo que no deja que la unidad de la lengua española se desintegre, ese es el formalismo.

El aparato lingüístico formal es necesario para quien aprende una lengua extranjera, de otra forma le será muy demorado e inconsistente aprenderla, sobre todo simulando situaciones reales de comunicación en la clase de lengua extranjera.

Parece que se olvidara que si existe comunicación es porque esta se da a partir de un código, que al tratarse de la formación de profesorado no nativo de lengua española para la enseñanza de ELE, necesita todo lo que significa conocimiento formal de la lengua, pues es, nos atreveríamos a decir, obligación conocerla, cómo no, cómo ser profesor de ELE sin ello, Es evidente que a la hora de enseñarlo ese no debe ser el foco ni el objetivo, sí de repente la opción y dicho sea de paso, la más pensada.

A todo eso, en el gráfico 5, expresamos el cómo vemos que el formalismo debe ser contemplado en el macro sistema de la comunicación.

Gráfico 5 Lenguaje, funcionalismo y formalismo

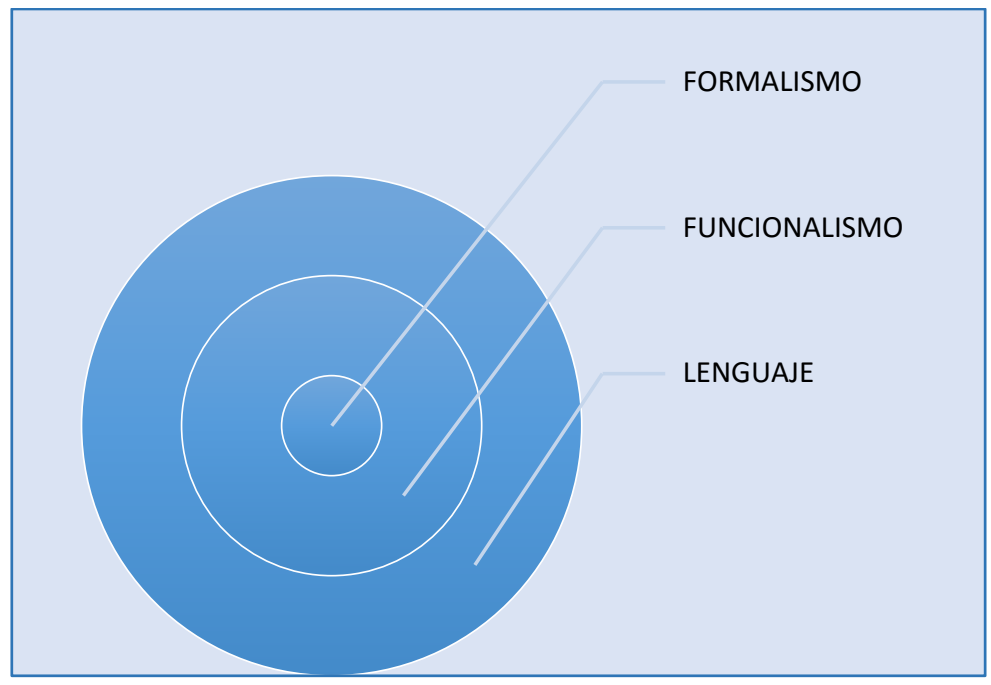

(Creación del autor) 
Y aún ponemos de manifiesto nuestra FUERTE simpatía para la propuesta de CELCE-MURCIA E LARSEN-FREEMAN (1991) con el PIE CHART en su gramática pedagógica con su fórmula:

\section{FORM + MEANING + USE}

\section{FORMA + SIGNIFICADO + USO}

\subsubsection{Una pica a favor del formalismo lingüístico}

En el contexto del quehacer diario académico de enseñanza de grado en ELE, se constata la desvalorización de las asignaturas del formalismo de la lengua y lo más curioso es que no son exactamente los docentes de esas asignaturas y sí los de asignaturas del bloque funcionalista, además de los de lengua materna. Es exagerado el ánimo que se refleja en el discurso sobre el tema. Es que claro, al leer cuestiones como:

La gramática prescriptiva establece normas a seguir. Está relacionada a lo "cierto y errado", a una forma que no reflexiona el código lingüístico, al final es una ley a ser obedecida. TRAVAGLIA, 2001: 30)

Cómo se caracterizaría una lengua si no hubiera una tal gramática que la estableciera como un código con el que te entiendan y tú entiendas. Cada individuo inventaría el suyo y de nada tendríamos muchas y muchas formas de decir las cosas, de escribirlas, de representarlas. Probablemente tampoco tendríamos lengua escrita:

La gramática tradicional se dedica exclusivamente a la lengua escrita y pasa a dejar de lado la lengua hablada. Entonces, detiene las normas del buen uso, la variedad culta, patrón. Desprecia la oralidad y otras 
variedades de la lengua. Por eso, surgen los preconceptos lingüísticos (TRIVAGLIA, 2001: 228) (subrayado nuestro)

La gramática es importante para la lengua escrita (y para la oral) y por ello debe ser valorada, el prejuicio lingüístico que hay con el tema de la gramática está haciendo daño a muchos segmentos de la educación, empezando por la formación de profesores, sean estos de lengua materna y más, mucho más aún, si son de lengua extranjera. Lo importante es definir el tipo de gramática:

¿Qué gramática? Yo diría sencillamente que gramática para extranjeros, lo que significa, en un sentido muy general pero radical, que no se debe perder de vista en ningún momento que el objetivo no es describir una lengua, sino dotar al hablante extranjero de un instrumento de comunicación. Este principio básico se podría concretar en los siguientes términos, en los que resumimos los puntos esenciales a que hemos aludido: 1) La gramática está presente de manera necesaria en todos los niveles, pero en cada uno habrá que colocarla en su sitio. 2) Las cuestiones gramaticales podrán ser obviadas hasta donde se pueda o se considere oportuno, pero conviene tener en cuenta que, con independencia de la noción de nivel, hay funciones comunicativas que, por su complejidad gramatical, será difícil afrontarlas desde otra perspectiva. (GARCÍA SANTOS, 1994: 71)

A cada finalidad, su camino. Hablemos de la lengua portuguesa de Brasil. Un brasileño que nace, vive, respira su lengua en el día a día, para profesionalizarse, tiene que saber leer, escribir y expresar su pensamiento de todas las maneras, el código formal empieza a aprenderlo por ley, en la escuela cuando va a alfabetizarse; el código funcional está indirectamente en todo, absolutamente todo, él está en la fuente misma de ese conocimiento. ¿Necesita el formalismo lingüístico para avanzar por la vida? Por supuesto que sí, pero en determinado momento de ella, el formalismo ya queda en un segundo plano, porque ya lo absorbió, no es más tan necesario. Esta es otra realidad. Pero, ¿necesitó el formalismo lingüístico para realizar el funcionalismo? Por supuesto que sí. 
Un brasileño debe aprender una lengua extranjera, tiene 11 o 12 años, cursa el sexto año de educación primaria, ¿cómo debe el profesor de lengua intervenir en ese aprendizaje? Con óptica preponderantemente funcionalista, por supuesto, y el formalismo estaría en un segundo plano, porque sino, ¿cómo se enteraría que 'año' se escribe con 'eñe', si este grafema no hace parte del código formal que le hizo falta aprender para estar en el sexto año de primaria? ¿Cómo se enteraría que debe pronunciar [ano]?

Un brasileño que quiere ser profesor de español como lengua extranjera, es un estudiante de grado que para poder conocer el código, tiene que saber leer en la lengua meta, al saber leer tiene que recurrir a manuales didácticos para reforzar o ampliar lo que ve en la clase y cuando lo ve, porque es frustrante practicar en situaciones comunicativas forjadas, interactuar repitiendo lo que se debe decir, para poner algo en práctica, primero hay que saber al menos lo que se quiere decir y cómo lo va a decir, en este contexto especialmente diferente, el formalismo tiene su espacio garantizado, porque el brasileño que estudia la lengua española para ser profesor, al dejar la sala de clase tiene que aprender más de forma que le permita avanzar solo, y solo, va a ver la lengua desde el formalismo, también.

Sin contradecir en absoluto que el funcionalismo de la lengua es de hecho fundamental para comunicar y comunicación, un sujeto que aprende una lengua extranjera para ser profesor de esa lengua que aprende, tiene, a nuestro humilde ver, que saber gramática, semántica, fonética y fonología, esos conocimientos son de base necesaria a su formación docente, además las otras asignaturas.

Es de incalculable valor delimitar lo que se escribe respecto a temas como este de la gramática tradicional, porque los públicos son diferentes, consecuentemente las finalidades. Si se tratara de enseñanza a estudiantes de educación básica en la escuela pública o privada o incluso en las escuelas de idiomas, el papel de ese público es otro, es el de usuario, para estos si no hace tanta falta el tema de la gramática, ellos no van a ser profesores de nadie, si ni siquiera van a ser usuarios de la lengua, y en este caso, sí que estudiar la gramática tradicional solo tiene un fin, escribir con el código formal, pero igual necesita estudiarla en algún momento, sea de forma directa o indirecta. 


\title{
2 LAS TEORÍAS DEL APRENDIZAJE Y ENSEÑANZA DE UNA LENGUA (EXTRANJERA)
}

\author{
En otras palabras, el lenguaje es algo más que una retahíla \\ interminable de palabras que se enredan en estructuras \\ identificables. \\ Carlos Lomas, (2007)
}

Desde temprana edad y aún desprovista de cualquier influencia, 'aprender una lengua extranjera' ha significado el deseo de hacerlo como lo hacen los nativos y, si no, al menos, de la forma que más se aproximara. Escuchar hablar con fluidez al profesor de lengua extranjera ha supuesto un estímulo especial que ha despertado el deseo de practicar más para dominarlo mejor y, por lo general, ha coincidido con el perfil de un profesor que ha sabido ‘enseñar' mejor ese código.

De la misma forma, pero en sentido contrario, ha ocurrido al percibir que el profesor no domina la lengua que enseña; el desánimo por un lado, y la falta de 'respeto' a su trabajo e inclusive a sus exigencias, por el otro, se ha hecho presente, sobre todo cuando este ha recurrido a su lengua materna, justificando su actitud con la afirmación de que así, avanzaría más rápido los contenidos del día y principalmente, cuando ha dicho que en la lengua materna, todo queda más claro para el alumno, que es como este comprende y aprende mejor, esto no vale para todos los momentos, obvio es.

Lo antes relatado no es diferente para muchas otras personas y en diferentes épocas, lo lamentable es tener que admitir que son pocos y cada vez más raros los profesores que tienen como su mayor estímulo profesional dos cosas: una, que su fluidez vaya a mayores cada vez más y la otra, que la lengua que enseña realmente sea aprendida con la finalidad de comunicarse con fluidez; pero, cada uno hace lo que 'puede' dentro de lo que 'sabe' y cree que es suficiente o pertinente. Surge aquí la primera de las inquietudes. 
En esta sección pretendemos presentar las teorías de la enseñanza de lenguas extranjeras, en especial de español, se revisan conceptos inherentes a lengua, lenguaje, enseñanza de lengua materna y extranjera, métodos, estrategias y posicionamientos, planteando contrastes teoría-práctica que nos lleven a reflexionar sobre el qué, el cómo, el para qué aprender, tanto durante la formación de profesores (papel de alumno) como también durante la enseñanza básica (papel de profesor), tratando de ver en paralelo los aspectos que pueden conducir a mejores resultados tanto en el aprendizaje como en la enseñanza.

A todo esto, dominar una lengua extranjera, hablarla y escribirla con fluidez, no es tan simple tarea, lograr esta meta significa contemplar los muchos factores que se confabulan a favor o en contra de ello. Para hilar el pensamiento y concretarlo en palabras, sean estas orales o escritas, evidenciadas o no, se requiere el conocimiento formal y funcional y aún no es lo suficiente, hasta podría decirse que es solo el comienzo y más al tratarse de aprender una lengua extranjera que parece que se parece ${ }^{94}$

\subsection{SOBRE LENGUAJE, LENGUAS Y COMUNICACIÓN}

La realidad del mundo, hoy por hoy, es una cuestión de comunicación, de ahí que se hable de lenguaje como ese algo que nos torna humanos en un contexto 'mundo', donde vivimos nuestras ideas, pensamientos, sentires, costumbres, o sea, nuestra cultura, ella está impregnada en la facultad del lenguaje. Universalmente, el lenguaje es la facultad a través de la cual expresamos lo propio y lo general, es nuestro vehículo de vida a lo largo y ancho de las 6000 lenguas existentes ${ }^{95}$ en el mundo. Además, la lengua es el instrumento de comunicación a través del cual se intercambian modos de ver el mundo, de organizarse, de pensar y de vivir ${ }^{96}$.

\footnotetext{
94 Es histórico en Brasil, pensar que hablar español es fácil, y que no hace falta estudiarlo porque es casi igual al portugués.

95 Tussón J. (2009: 29)

${ }^{96}$ Cassany, Luna y Sanz (2008).
} 
Notoriamente complejo es entender el lenguaje a partir de una única teoría o interpretación. Leemos, ponderamos y nos posicionamos parcial o totalmente a favor o en contra de las más diversas teorías del lenguaje, claro y evidente es, que ninguna de ellas explica a satisfacción lo que es el lenguaje, son abordados enfoques y perspectivas diferentes privilegiando intereses, métodos de análisis e investigación o bases históricas. Lo importante de esto es que cada una de ellas siempre aporta algo a más, algo que puede significar un camino que llegue a explicar imparcialmente aspectos del lenguaje aún no conocidos. De esta forma, en general, se conceptúa al lenguaje como:

Conjunto de sonidos articulados con que el hombre manifiesta lo que piensa y siente.

Manera de expresarse. Lenguaje culto, grosero, sencillo, técnico, forense, vulgar.

Estilo y modo de hablar y escribir de cada persona en particular.

Uso del habla o facultad de hablar.

Conjunto de señales que dan a entender algo.

Conjunto de signos y reglas que permite la comunicación con una computadora (en informática)

[En línea] del.rae.es

Adrede, hemos expuesto aquí el significado del término lenguaje que está en el Diccionario de la lengua española, el más simple y directo posible, y la verdad, es consonante a las más actuales teorías.

Al ser parte de la vida del ser humano, el lenguaje no podría ser visto ni estudiado como algo inerte y sí como algo que está vivo, que se nutre en el tiempo, en el contexto y que se va transformando en sus individuales formas de comunicarse: las lenguas. Lenguaje, lengua y comunicación, contenidos en sí, indisociables:

La sociedad y la cultura es un universo simbólico que ofrece a disposición de los individuos un patrimonio de conocimiento. Las sociedades producen sus propias interpretaciones y representaciones de los eventos, sus propias teorías y explicaciones [...] Mediante el lenguaje, la sociedad se expresa, se comunica y transmite todo el bagaje de la cultura que con ese mismo lenguaje crea (RÁBADE, 1995). 
El lenguaje se manifiesta y presenta de muchas y diversas formas en las comunidades que existen en el mundo, cada una de esas formas es una lengua que también es llamada código con el que se puede acceder a una comunicación entre personas. Que una comunidad conozca un determinado código permite la comunicación.

Visto así, aprender lenguas presenta un enfoque favorecedor y enriquecedor, cualquiera sea la que se aprenda debe valorizar su comunidad, variaciones, cultura y sobre todo identidad, aprender una lengua, no solo es conocer el código lingüístico, sin duda, es poner en acción el binomio lenguaje e identidad.

Es evidente que una lengua no ha surgido de la nada, que no ha estado, ni está sola, que ha llegado por diversas razones: históricas, sociales, económicas, geográficas, etc. y que así mismo si alguna se extingue, tampoco se va sola, se va llevándose consigo muchos otros aspectos que ciertamente afectarán de diversas maneras, positivas o negativas, a otras lenguas. Por ejemplo qué pasaría con la lengua de la informática, de los internautas ${ }^{97}$ si la tecnología dejara de existir, algunos términos como email, pasarían al olvido y otros como ratón ${ }^{98}$ y virus ${ }^{99}$ dejarían de ser homógrafos u homófonos porque nadie necesitaría uno en su cotidiano. De esta forma, al hablar de lengua, se puede afirmar que es en la diversidad, en la utilidad viva cuando se fortalece, se enriquece o desaparece.

Si existiera solo una lengua y por ende una sola cultura, sin antecedentes ni expectativas futuras, sin el aporte de otras culturas, sería pensar en esto como una condena al concepto de cultura, que al fin de cuentas no es sino lo mismo que identidad de un grupo de un pueblo visto desde fuera por otras, eso sin contemplar que toda cultura no deja de ser blanco de las más

\footnotetext{
97 Entendida como una 'lengua de especialidad' que acoge el lenguaje utilizado por profesionales, especialistas e inclusive usuarios para comunicar información de cuño específico de un área. Las lenguas de especialidad contienen un léxico que es de dos tipos: (1) léxico técnico: términos de carácter unívoco, no tienen otros significados y (2) léxico semitécnico: (Alcaraz 2000:15)

98 Ratón, componente informático y también roedor.

${ }^{99}$ Virus, en el ámbito de la informática es lo que puede afectar un sistema operacional causando daños importantes, también es lo que puede afectar un sistema inmunológico causando graves daños en el campo de la medicina.
} 
variadas influencias y una lengua siempre estará provista de aportes y aportes provenientes de contactos con otras lenguas, de otras culturas, todas con su forma de lenguaje.

Así, se coincide con la afirmación de Tusón (2009) en que ninguna cultura, con su lengua, ha estado absolutamente sola en el mundo, por muy escondida que viva o haya vivido, ciertamente influencias de otras tribus, de pueblos antiguos habrán dejado sus marcas, sus huellas:

"no existe en la tierra ninguna raza pura, ninguna cultura completamente aislada, ninguna lengua que no contenga préstamos, recientes o antiquísimos"; [...] "raza pura [...] una pura irrealidad. (TUSÓN, 2009: 29)

\section{2 ¿ADQUISICIÓN O APRENDIZAJE DE UNA LENGUA?}

A partir de la experiencia, se ha observado que respecto a una lengua, cabe contemplar factores de incidencia terminológica, pues es común encontrar textos y discursos, inclusive en el nivel superior, que no hacen distinción al referirse a términos como 'adquirir' o 'aprender' una lengua, para referirse al proceso a través del cual se alcanza el dominio de una, sea esta materna (LM) / lengua 1 (L1) o lengua extranjera (LE) / lengua 2 (L2).

Para conseguir comunicarse en otra lengua, se presentan dos conceptos bastante pertinentes APRENDIZAJE - ADQUISICIÓN que para Chomsky (1986), Ellis (1994) y Pinker (1994) pueden tener la misma interpretación al ser difícil delimitar lo que sería un proceso inconsciente y un proceso consciente por parte del aprendiz, sin embargo, para Krashen (1981) sí existe esa clara distinción

Así, es importante interiorizar que adquirir una lengua es el resultado del accionamiento de mecanismos naturales del individuo en su medio, (Krashen, 1982). Es parecido a lo que ocurre a todos los individuos con relación a su primera lengua, se realiza involuntariamente, es incontrolable e inconsciente, o sea ocurre de modo natural. En la enseñanza de lenguas, el enseñante propicia o proporciona al aprendiente situaciones comunicativas 
para que este pueda participar en ellas y de este modo, adquirirla de forma inexplícita (Krashen, 1982).

Aprender una lengua es seguir el proceso basado en el estudio de los aspectos formales de la lengua, es lo opuesto al proceso de adquisición. El aprendizaje es voluntario, consciente, el aprendiente reconoce la necesidad de saber y busca satisfacerlo.

\subsection{METODOLOGÍAS DE ENSEÑANZA Y APRENDIZAJE DE ESPAÑOL COMO LENGUA EXTRANJERA (ELE)}

Como se ha comentado antes, los primeros profesores de ELE en Brasil, tras la promulgación de la ley del español ${ }^{100}$ han sido, en buen número, profesores nativos, unos con formación superior específica para la docencia, y otros no.

Al tratarse de un profesor nativo (brasileño) de español con el propósito de enseñarla como una lengua extranjera, evidentemente, se han levantado desventajas que pueden haberse traducido a dificultades en comprender y conducir el proceso de enseñanza/aprendizaje de ELE, por saber que no es lo mismo enseñar lengua materna que enseñar lengua extranjera, por muy parecidas que aparentemente estas sean.

A modo de ilustración, presentamos una síntesis de los métodos de aprendizaje de lenguas extranjeras que de alguna forma han tenido encuadramiento en el formalismo lingüístico y más recientemente, en el funcionalismo.

Método tradicional: Fue aplicado en la enseñanza del griego y del latín, en el siglo XVI. El objetivo era conocer muy bien la gramática normativa y la traducción literal. Se trabajaba con textos, ejercicios de traducción. Las reglas gramaticales y el vocabulario eran memorizados por fuerza del uso y de cotidianos dictados.

Método Directo: De 1930 a 1940 fue oficial en Brasil. O ensino de línguas vivas es el título del libro publicado en 1935 por el principal seguidor de este método, 
Antônio Carneiro Leão. Se proponía a que el estudiante pensara en la lengua meta sin traducirla, más bien experimentándola directamente. Se hacían muchos ejercicios de conversación basados en el modelo pregunta-respuesta. La lengua materna no debería usarse y para entenderse se aceptaban gestos, imágenes, simulaciones. El aprendizaje seguiría la secuencia de oír y hablar, leer y escribir. Actividades con textos para comprensión de lectura y aprendizaje de gramática.

Método audio lingual: Es el método influenciado por el behaviorismo de Skinner y de Saussure, surge en 1950. El propósito de este método era que el aprendizaje de la lengua sea de forma natural y para ello se echaba mano de audios, repetición, memorización y ejercicios orales de palabras y frases hechas.

Método socio interaccionista: Surgió en 1970 basado en el pensamiento de Lev Vygotsky, también se le llama método socio cultural. No apoya a ningún otro método en especial. Busca que se aprenda la lengua en contextos que esta sea realmente utilizada. Para tal fin, se crean situaciones reales de uso de la lengua extranjera con actividades que necesiten comunicación entre personas, la diversidad de géneros textuales y orales y la reflexión sobre estos.

Es lamentable admitir, pero aun hay profesores de lengua extranjera en la escuela pública del nordeste brasileño que aplican el método tradicional en su enseñanza, los antiguos profesores y sobre todo de inglés, porque los de español, con pocas excepciones son docentes de reciente grado, lo que implica decir que está más actualizado en relación a metodologías de enseñanza. Es durante la formación de grado del profesorado el momento clave para propiciar verdaderas transformaciones de forma que nuevas y más eficientes metodologías vengan a implementarse en la enseñanza de ELE.

De acuerdo con encuestas aplicadas, se recogen informaciones interesantes como la de que las universidades no valoran la fluidez en el idioma de especificidad de formación y esto se debe, a su vez, porque los profesores de grado no dominan las habilidades esenciales para La enseñanza de la lengua.

Para aprender una lengua se despliega una serie de estrategias que bien pensadas y aplicadas pueden propiciar el dominio y fluidez de una lengua 
dentro de un proceso que quizás pueda demorar un poco más, si se contrasta con el proceso de adquisición, el cual suele transcurrir de forma natural, con el uso o en la inmersión lingüística, por ejemplo.

Como en Brasil, en muchos otros países se vive una realidad algo parecida cuando se habla del desempeño escolar en general, estudiantes que no son capaces de comprender un texto, que van cada vez más limitando su capacidad de expresar coherentemente sus ideas, que van convirtiéndose en personas monosilábicas al tiempo que van creando su propio modo de comunicarse con los de su edad o círculo. ¿Y dónde queda la lengua materna, la social, aquella con la que se comunicará la vida entera? ¿Será este el punto de partida del relativo fracaso al aprender una lengua extranjera? El comentario de CASSANI se hace muy familiar a la realidad que se vive en Brasil:

\begin{abstract}
El aumento del analfabetismo funcional, es decir, la ineptitud que presentan alumnos escolarizados normalmente para resolver cuestiones elementales relacionadas con la lengua escrita, la estrecha relación entre dificultades de lenguaje y fracaso escolar, y la observación directa de jóvenes y adolescentes incapaces de salir airosos de situaciones cotidianas que implican una cierta elaboración intelectual, tiene que obligarnos a pensar que hay algo en la escuela que no funciona como debería hacerlo (CASSANI, 1994: 11).
\end{abstract}

Es evidente que estamos hablando de situaciones diferentes, sin duda, lengua materna y lengua extranjera, pero de alguna forma están conectadas y tienen intersección como causa del resultado de no avanzar significativamente a la hora de aprender una lengua extranjera ${ }^{101}$ en la enseñanza básica. Además es relevante considerar que en la medida que se avanza en el tiempo, resulta cada vez más difícil "enseñar" y más difícil "aprender" (CASSANI, 1994)

La Ley de Directrices y Bases (LDB) 9.394 de diciembre de $1996^{102}$ que respecto a la enseñanza dice en su TíTULO II:

\footnotetext{
101 LE de ahora en adelante.

102 Redacción original en lengua portuguesa de Brasil y
} 
Artículo $2^{\circ}$ - La educación [...], tiene por finalidad el pleno desarrollo del educando, su preparación para el ejercicio de la ciudadanía y su cualificación para el trabajo.

A todo esto, saber una lengua extranjera en un nivel B1 del MCER, en un país como Brasil, significa una gama de oportunidades en su vida personal y laboral.

El desarrollo de la enseñanza y del aprendizaje es un proceso único (VYGOTSKY, 1896), el profesor es un mediador del aprendizaje, busca diferentes posibilidades de implementar principios y es flexible al análisis que pueda hacer en relación a la realidad en que sus alumnos están insertados.

El profesor necesita conocer y dominar el contexto de sus pupilos, de su comunidad, el contexto mundial y el suyo propio por medio de principios básicos de enseñanza y aprendizaje que no tienen que estar atados a la metodología.

Evidentemente, en la enseñanza de lenguas extranjeras no existe el método ideal, incluso porque el éxito del objetivo depende del ánimo y meta personal de querer aprender un idioma, de querer enseñarlo y ambas acciones con un sólida preparación y entrega. Motivación es esencial en toda iniciativa.

Saber lo que los estudiantes, en este caso, de grado, esperan de la clase de ELE y lo que se propone dar, es esencial para que los acuerdos y los ajustes de aprendizaje se formalicen y haya una convivencia académica de alto provecho lingüístico. El uso de la lengua materna puede ayudar, de vez en cuando, ir poco a poco perdiéndole miedo al silencio y consolidar la fluidez y dominio de ELE.

PERO, antes de eso, es indispensable que quien está en el papel de docente de grado, sea realmente un docente de grado en ELE, capaz de demostrar que está ahí por el carácter de su formación general y principalmente por la específica. 


\section{CONCLUSIONES}

El conocimiento teórico cuando no forma parte de la conciencia de un profesional de cualquier área y, sobre todo, de la educación supone a nuestro ver un vacío que condena su trabajo y el resultado de este a un bamboleo de ondas que no podrá controlar y menos equilibrarse en él sin provocar perjuicios, principalmente a quien confía en su formación, esta es la primera conclusión a que llegamos y creemos que esta realidad debe ser corregida.

Tras haber pasado revista a conceptos básicos y haber situado estos en el ámbito de nuestro estudio, concluimos que el aporte de la corriente funcionalista es de absoluta relevancia y pertinencia también para la enseñanza de lenguas extranjeras, y que los marcadores discursivos son pieza clave en la comunicación como un todo aportando enlace, inferencias, fluidez y dominio de la lengua.

Concluimos que la pragmática, el análisis del discurso, la sociolingüística, la psicolingüística, la lingüística aplicada a la enseñanza de lenguas tienen un rol importante; es a través de ellas que se consigue 'palpar' lo impalpable. Son sus explicaciones las que van a aportar sentido a lo que muchas veces se presenta (en algún material actualizado) y solo se podrá aplicar en las clases de ELE si los profesores lo entienden.

De otro lado y a propósito de metodologías de enseñanza de lenguas, concluimos que la contribución del formalismo es de necesaria consideración a la hora de enseñar; que el exilio lingüístico en el que está sumergido tiene que acabar, como tiene que acabar la interpretación errónea de que con el funcionalismo es inconcebible cultivar el conocimiento formal de una lengua.

Asimismo, concluimos que la sociedad que no procesa la investigación a favor de sus metas, corre serio riesgo de ir haciendo cosas porque de repente se ponen de moda. Concluimos que ser profesor tiene implícita una ilusión que lleva a tomar decisiones y que también las promueve; con esto, lo que queremos concluir es que NO es el método lo que va a permitir alcanzar logros, ellos solo van a contribuir; es el profesor de lengua el que con su sensibilidad y preparación profesional encontrará los mejores caminos, mezclando 
metodologías, atendiendo teorías distintas y, sobre todo, siendo capaz de lograr metas. 


\section{SEGUNDA PARTE}

ESTUDIO EMPÍRICO 


\section{CAPÍTULO III - METODOLOGÍA}

Los límites de mi lenguaje, son los límites de mi mundo. Ludwig Wittgenstein

\section{INTRODUCCIÓN}

Buscar caminos para comprobar y hacer notar aspectos que pueden contribuir positivamente en la formación del profesorado de ELE, con la consecuente mejora en la calidad de la enseñanza y aprendizaje en la educación básica y pública brasileña, a priori, es sinónimo de un peregrinaje duro que a medio camino puede perfilarse como infructuoso por no poder derrumbar verdaderos convencimientos de que esa realidad puede cambiar.

No obstante, se alienta la realización de este estudio, en la certeza de que el resultado pueda señalar lo adecuado y lo deficiente del proceso de formación del profesorado de ELE, conllevando a la necesidad de tomar iniciativas y acciones concretas para la superación de esas dificultades.

En esta parte de la investigación presentamos la descripción y los procesos de elaboración y recogida del corpus con que se ha trabajado, también la metodología aplicada. Inicialmente, se organiza en tres bloques el ámbito en el que se investiga, a saber:

(1) Enseñanza y aprendizaje de ELE en la educación básica;

(2) Formación del profesorado de ELE;

(3) Marcadores del discurso y su incidencia en (1) y (2).

Enseguida y dentro de cada uno de los bloques antes mencionados, describimos las características de los datos, su recogida y los instrumentos que han sido utilizados para ello. Además, presentamos detalles sobre procedimientos de transcripción aplicada en datos cuando la recogida de estos haya sido a través de grabaciones de audio o videos.

Tras presentar los procedimientos de formateo, exponemos las bases y criterios de análisis y mensuración en los que fundamentamos este estudio 
empírico y desde donde partimos para formular las interrogantes de investigación e hipótesis.

Se considera pertinente comentar que a pesar de tratarse de una investigación que está en el campo de la experiencia del investigador, no dejaría de encuadrarse en el ámbito exploratorio ya que tras la fase de análisis del corpus cabe la posibilidad de delinear caminos para futuras investigaciones en el tema de enseñanza y aprendizaje de español como lengua extranjera y el papel que los MD juegan en ese proceso. Además, toma carácter de investigación explicativa, porque persigue la delimitación de los porqués del deficitario nivel de aprendizaje de ELE en la educación básica pública y la influencia que la presencia o ausencia de los MD pueda tener en ese resultado, se busca conocer para actuar, o sea, se tiene interés de aplicar acciones a partir de los resultados sobre la realidad existente, en pro de una formación de calidad del profesorado que se refleje en el aprendizaje efectivo de lengua extranjera en las escuelas de educación básica y pública brasileña.

\section{UN ESTUDIO DE CORPUS: Objetos de estudio para una finalidad}

Este trabajo se fundamenta en un análisis cuantitativo y cualitativo de datos e informaciones en ámbitos que se conectan directa e indefectiblemente, e incluso, se interceptan, a saber: la formación del profesorado de ELE, la enseñanza y aprendizaje de ELE en la enseñanza básica y pública brasileña y el rol de los MD en ambos procesos.

\subsection{DESCRIPCIÓN DE LOS DATOS}

Los datos de este corpus están compuestos por informaciones de distintas fuentes y tipos; de esta forma, los presentaremos según el ámbito en el que juegan un papel importante como elemento de análisis.

Datos sobre la enseñanza de lengua extranjera y de ELE 
Se compone de cuatro encuestas: 1) aplicada al ciudadano común que estudia o ha estudiado LE en su educación básica; 2) aplicada al estudiante de ELE en general; 3) aplicada al estudiante de grado de la carrera de ELE; 4) aplicada a docentes de grado de cursos de grado en ELE.

Sobre los MD en la formación de profesores y en la enseñanza de ELE en la educación básica y pública.

Este corpus se compone de actividad escrita sin ningún condicionamiento relacionado a MD en la redacción a estudiantes de educación básica; actividad escrita sobre MD aplicada a estudiantes de grado en ELE; transcripción de audio de docentes; entrevista sobre MD direccionada a docentes de grado en ELE; recorte de documentos producidos por estudiantes de grado, cuyo foco de acción se limita a la visualización del uso y conocimiento de los MD.

$>$ Datos sobre la formación de profesores de ELE

El corpus está constituido por datos estadísticos sobre el perfil del docente de grado, encuesta docente sobre formalismo y funcionalismo, el plan de estudios, las asignaturas específicas y los correspondientes contenidos programáticos respecto a la presencia del tema MD y datos estadísticos de ingreso, egreso y abandono de carrera.

La recogida de los datos, los instrumentos de investigación y aún el formateo serán reinformados de acuerdo con la presentación del corpus para una comprensión adecuada.

La encuesta, una de las técnicas utilizadas, es fundamentalmente, cuantitativa; no obstante, también ofrece la posibilidad de medición cualitativa según el tipo de pregunta que se formule, si abierta o cerrada. En nuestro caso, las encuestas aplicadas se han formulado con preguntas del tipo cerrado buscando cuantificar datos de los informantes, pero al mismo tiempo se ha dado la oportunidad de expresar opinión con sus propias palabras cuando no constara en las alternativas el pensamiento del informante. 
Las encuestas realizadas tienden a ser descriptivas porque buscan reflejar realidades, punto de partida para el análisis cualitativo con miras a respaldar o derrumbar las hipótesis sobre formación de profesorado, MD y enseñanza y aprendizaje de ELE en la educación básica y pública del nordeste brasileño

Otro instrumento aplicado es la entrevista, realizada con o sin grabación en la que: (1) se verificará el uso de MD en la oralidad; (2) se analizará el discurso objetivamente con respecto al nivel de encadenamiento de ideas y (3) se apreciará el parecer del informante sobre lo que de alguna forma tenga a decir sobre el sistema educacional y el aprendizaje de ELE.

De esta forma, parte del corpus utilizado en esta investigación está compuesto de fragmentos de exposición oral que necesitan transformarse en herramienta de estudio para posterior análisis, por esta razón ha sido necesario transcribirlas ortográficamente. Consideramos pertinente añadir que de ser necesario, en algunos fragmentos se describirá el momento precedente a la grabación, o comentar lo expresado por el informante tras la finalización de su audio, todo esto con la finalidad de complementar el análisis respectivo.

En el anexo VII, se registra el conjunto de pautas que han sido aplicadas en la transcripción de los audios y videos utilizados como fuente de análisis para efectos de esta investigación.

Cada tipo de informante ha generado un grupo de estudio que ha sido identificado por la letra G seguido de número correlativo. De esta forma, en el cuadro 23 detallamos estos grupos; en el 24 detallamos la codificación de los informantes y en el 25 la codificación de los textos que serán objeto de análisis en este estudio. 
Cuadro 23 Detalle de los grupos de informantes

\begin{tabular}{|c|c|c|}
\hline$\frac{8}{2}$ & Descripción & $\begin{array}{c}\mathbf{N}^{\circ} \text { de } \\
\text { informantes }\end{array}$ \\
\hline G1 & $\begin{array}{l}\text { INF-LE - Grupo de informantes constituido por } \\
\text { ciudadanos comunes encuestados sobre parecer } \\
\text { de su experiencia en la enseñanza básica. }\end{array}$ & 244 \\
\hline G2 & $\begin{array}{l}\text { INF-ELE - Grupo de informantes constituido por } \\
\text { estudiantes de lengua española en general. }\end{array}$ & 171 \\
\hline G4 & $\begin{array}{l}\text { INF-EST-8-ELE - Grupo de informantes constituido } \\
\text { por estudiantes del último semestre de graduación } \\
\text { de Letras lengua española. }\end{array}$ & 17 \\
\hline G5 & $\begin{array}{l}\text { INF-PR-ELE - Grupo de informantes constituido } \\
\text { por profesorado de lengua extranjera. }\end{array}$ & 22 \\
\hline
\end{tabular}

(Creado por el autor)

Se ha aplicado tanto a ciudadanos comunes como a profesores y futuros profesores de lengua extranjera, español en específico que ya hayan estudiado una lengua extranjera durante su primaria y/o secundaria.

También forman parte del corpus analizado la producción oral y escrita del profesorado de grado, de estudiantes de los primeros y últimos semestres de carrera en la que se pueda observar la presencia y aplicación de MD como elementos de vital importancia para la cohesión y coherencia del discurso.

\subsection{EL FORMATEO}

Al tener un corpus con más de un tipo de informantes, se ha implementado un sistema de referencia lógico que facilite la deducción y el consiguiente reconocimiento de los mismos en esta investigación. Lo presentamos en el cuadro 24. 
Cuadro 24 Detalle de los informantes

\begin{tabular}{|c|l|}
\hline \multicolumn{2}{|c|}{ INFORMANTE + TIPO DE INFORMANTE + NÚMERACIÓN } \\
\hline INF-LE-000 & Informante - que estudia o ha estudiado lengua extranjera; \\
\hline INF-ELE-000 & Informante - estudiante de ELE \\
\hline INF-EST-8-ELE-00 & $\begin{array}{l}\text { Grupo de informantes constituido por estudiantes del último semestre de } \\
\text { grado en ELE }\end{array}$ \\
\hline INF-PROF-000 & Informante - docente de grado en ELE de IES \\
\hline
\end{tabular}

(Creado por el autor)

De igual forma, para una clara identificación de los datos presentados en transcripción ortográfica, imagen o figura, siendo producción textual, aunque recorte del documento original, obedecen a una codificación como instrumento de investigación y de análisis. En el cuadro 25 presentamos esta información.

Cuadro 25 Detalle de los textos analizados

\begin{tabular}{|c|c|c|}
\hline TEXTO & + & DE QUÉ INFORMANTE $\quad+\quad$ NUMERACIÓN \\
\hline TX-INF-ELE-EB-00 & & $\begin{array}{l}\text { Texto - del informante estudiante de enseñanza básica } \\
\text { Español como lengua extranjera; }\end{array}$ \\
\hline TX-INF-EST-8-ELE-00 & & $\begin{array}{l}\text { Grupo de informantes constituido por estudiantes de último } \\
\text { semestre de grado en ELE }\end{array}$ \\
\hline TX-INF-PROF-00 & & Texto - del informante docente de grado en ELE de IES \\
\hline
\end{tabular}

(Creado por el autor)

\subsection{DESCRIPCIÓN DE LOS PARÁMETROS DE ANÁLISIS, PREGUNTAS DE INVESTIGACIÓN Y ANÁLISIS EMPÍRICO}

El parámetro principal de análisis es el que responde a los objetivos de este trabajo de investigación que, en suma, explicarían las razones por las que los estudiantes de las escuelas públicas no logran un aprendizaje de ELE sustancial, a lo largo de +/- 8 años de estudio de la asignatura lengua extranjera, en general, y en especial español, actualmente de oferta obligatoria según las leyes de la educación brasileña, considerando la incidencia de los 
marcadores del discurso como elementos de importante conocimiento en el logro del aprendizaje de ELE

Consideramos como parámetros paralelos y complementarios a este estudio la fluidez, dominio y conocimiento de la lengua en la acción docente durante la formación del profesorado y el resultado de la aplicación del plan de estudios de la carrera.

Preocupados por presentar este estudio de forma sincronizada con la metodología científica, pretendemos realizar el análisis empírico al final de cada etapa metodológica investigativa previa formulación de las respectivas preguntas de investigación.

Ante lo expuesto, procedemos a la presentación de los objetos parciales de investigación.

\section{ENSEÑANZA Y APRENDIZAJE DE LENGUA EXTRANJERA (LE) EN LA EDUCACIÓN BÁSICA (EB)}

Lo que se observa en el día a día de la educación del nordeste brasileño, en lo que respecta a la enseñanza de LE y consecuentemente de ELE, es que existe un círculo que empieza, se entrelaza y termina en la aparente dependencia de una preparación adecuada de los profesores de ELE y que, además, muestra incidencia de responsabilidad. El punto de partida parece estar en la enseñanza de grado, responsables de la formación del profesorado, en el perfil del nuevo profesor, y en el trabajo que este tenga condiciones de desarrollar en su actuación docente en la educación básica y pública.

El Gobierno con relación a la educación, como en muchos lugares del mundo, tiene los mejores ánimos de ir subiendo peldaños de progreso que beneficie a la población y esa realidad no es diferente en Brasil, no obstante, en el engranaje que se ejecuta la educación, hay participantes con limitaciones de todo orden que al no ver los claros beneficios indirectos que el saber comunicarse en una lengua extranjera puede generar, simplemente no reacciona y con eso se instala un cotidiano inerte en el que no se procura 
actuar para dar razón de ser y existencia a saberes esenciales, como el de lengua extranjera en la enseñanza pública.

La realidad que está instalada en la escuela pública sobre lengua extranjera se traduce en aparente desvalorización de este conocimiento si se reconoce la situación en la que se encuentra en sus diferentes dimensiones. Para situar los hechos, se investigan aspectos relacionados con el plan de estudios, la postura de todos los participantes en este proceso, llegando al propio sujeto receptor de este conocimiento, el alumno de educación básica de escuela pública.

Por lo general, el ciudadano brasileño que estudia en escuela pública forma parte de la sociedad cuya situación económica es limitada y ante esta realidad el acceso al conocimiento y dominio de una lengua extranjera lo tiene en esa fase de su educación básica y que evidentemente si no surte algún efecto, puede cerrarle las puertas al mercado laboral, o incluso puede truncar aspiraciones y expectativas de formación profesional formal. Es a partir de esta comprensión que el nivel de importancia del efectivo aprendizaje de lengua extranjera en la educación básica se eleva para la sociedad brasileña, implicando un increíble poder de inclusión y una sociedad más justa.

Por lo dicho, en esta etapa inicial de investigación empírica hemos buscado conocer lo que el ciudadano tiene a decir de su experiencia de estudio de lengua extranjera desde su experiencia personal.

\subsection{ENCUESTA 1- PREGUNTAS 1, 2, 3, 5 Y 6: OPINIÓN DEL CIUDADANO COMÚN Y DEL QUE ESTUDIA UNA LE. CONTRASTE.}

Con las preguntas 1,2, 3, 5 y 6 de la encuesta $1^{103}$, queremos saber el parecer y la impresión de ciudadanos brasileños respecto al perfil del profesor de lengua extranjera en la enseñanza básica en general, contrastando aquellos que estudian o han estudiado por currículum obligatorio y los que lo hacen por razones personales, profesionales, etc.

\footnotetext{
${ }^{103}$ Formulario en el anexo VIA.
} 


\subsubsection{Descripción de los datos, instrumento de investigación y formateo}

Redactada en lengua española y portuguesa, la encuesta $1^{104}$ está dirigida al ciudadano común, identificado como INF-LE ${ }^{105}$ de ahora en adelante y que constituye el grupo 1 (G1) de informantes, que es el que ha sido abordado en ambientes públicos como bancos, tiendas, centros comerciales, academias e incluso en las calles, en horario comercial brasileño ${ }^{106}$. Y, por otra parte, al ciudadano que estudia español como lengua extranjera, identificado como INF-ELE, pertenecientes al grupo 2 (G2) de informantes, que ha sido encuestado en universidades, institutos, escuelas de idiomas y similares.

El G1 responde la encuesta sin ningún condicionamiento más que el de haber estudiado lengua extranjera en su educación básica. Y el G2, que además de haber estudiado LE en su educación básica, es estudiante de español para fines de formación profesional, perfil profesional o algún otro objetivo específico.

A todo esto, en el cuadro 26 presentamos las preguntas 1, 2, 3, 5 y 6 y a medida que se teja la descripción de los parámetros de análisis se generará el respectivo gráfico en el que se muestra el resultado de la encuesta.

\footnotetext{
104 La encuesta 1 tiene dos versiones, una en portugués y la otra en español. La razón de esta formulación tiene explicación en el tipo de informante (INF) para quien estaba dirigida. ${ }^{105}$ Ver detalle en Cuadro 24.

${ }^{106}$ El horario llamado comercial en Brasil oscila, no obstante se encuadra por lo general entre las $8 \mathrm{~h}$ y las $18 \mathrm{~h}$.
} 
Cuadro 26 Preguntas de encuesta 1

\begin{tabular}{|l|l|c|}
\hline $\mathbf{N}^{\mathbf{0}}$ & \multicolumn{1}{|c|}{ PREGUNTAS DE ENCUESTA 1 } & GRÁFICO \\
\hline $\mathbf{1}$ & $\begin{array}{l}\text { ¿Considera Ud. que un profesor de lengua extranjera de primaria } \\
\text { y/o secundaria debe conocer y dominar fluidamente la lengua } \\
\text { que enseña? }\end{array}$ & 6 \\
\hline $\mathbf{2}$ & $\begin{array}{l}\text { ¿Considera Ud. que un profesor de lengua extranjera de primaria } \\
\text { y/o secundaria debe dar sus clases en la lengua que enseña? }\end{array}$ & 7 \\
\hline $\mathbf{3}$ & $\begin{array}{l}\text { ¿Considera Ud. que los profesores de LE de primaria y/o } \\
\text { secundaria, generalmente, conocen y dominan fluidamente la } \\
\text { lengua que enseñan? }\end{array}$ & 8 \\
\hline $\mathbf{5}$ & $\begin{array}{l}\text { ¿A Ud. le gustaba tener clases de lengua extranjera, cuando } \\
\text { estudiaba primaria y/o secundaria? }\end{array}$ & 9 \\
\hline $\mathbf{6}$ & $\begin{array}{l}\text { Como padre/madre de familia, ¿qué le parecería que su hijo } \\
\text { aprendiera a hablar la LE que se enseña en la escuela primaria } \\
\text { y/o secundaria? }\end{array}$ & 10 \\
\hline
\end{tabular}

(Datos de investigación)

\subsubsection{Descripción de los parámetros}

El resultado de la encuesta a la pregunta 1 es mostrado en el gráfico 6, en el que 432 brasileños exponen su parecer con respecto a la fluidez y dominio que un profesor de lengua extranjera debe tener o no para ejercer su profesión de profesor. Son 415 los que afirman categóricamente su expectativa a favor del conocimiento, dominio y fluidez que un profesor de LE debe tener, habiendo elegido la alternativa a) Sí, sin duda, lo que se configura como mayoría representativa del pensamiento de la sociedad respecto al profesor de lengua extranjera.

Del total de respuestas, tenemos 244 informantes que solo han estudiado lengua extranjera en su educación básica y 171 que actualmente estudian español como lengua extranjera en diversas modalidades, en la enseñanza básica, en academias especializadas, en proyectos del Gobierno Federal, en cursos de extensión universitaria, en cursos de grado en ELE, etc. Aclaramos que en virtud del objeto de la pregunta no ha sido prioridad nuestra 
clasificar a los informantes bajo ningún criterio que no haya sido el solo hecho de estudiar español como lengua extranjera.

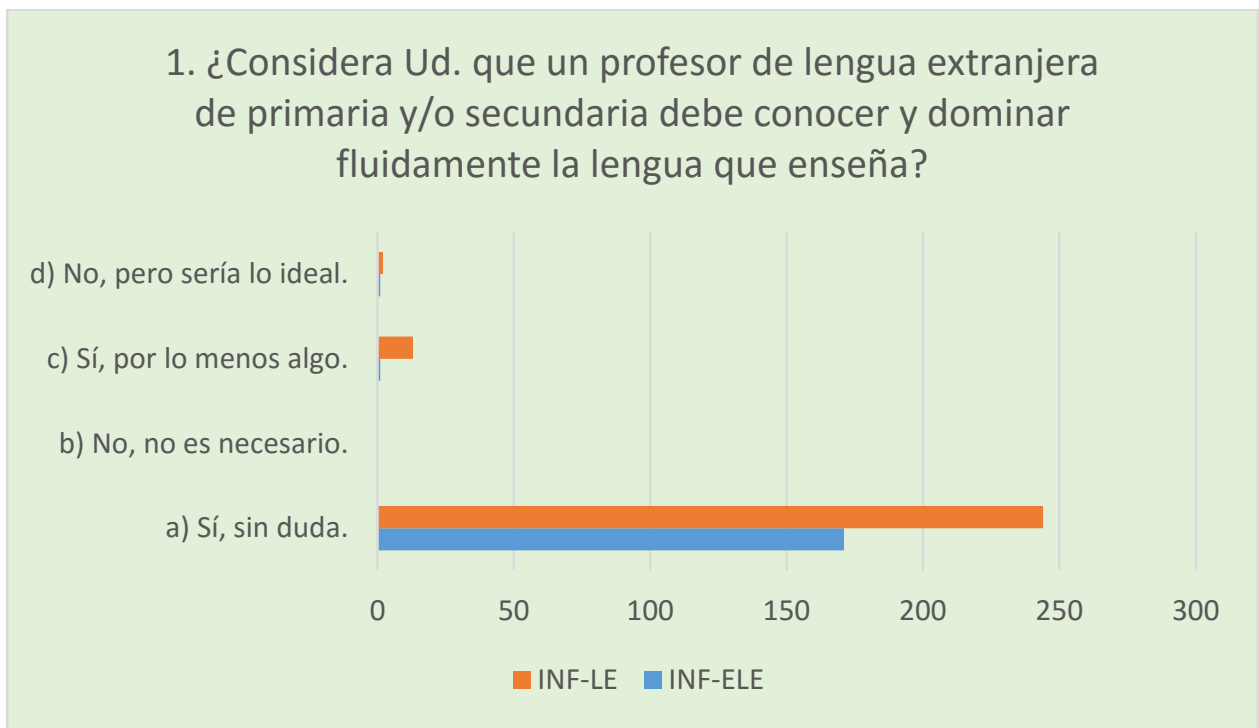

Gráfico 6 - Respuestas a la pregunta 1 de la encuesta 1 (Datos de investigación)

Llamamos la atención sobre el bajo número de informantes, 15, que han elegido la respuesta 'c' 'Sí, por lo menos algo', a los que no incomoda que el profesor de LE no tenga fluidez ni dominio de la lengua que enseña, o diríamos a los que les es, hasta cierto punto, indiferente. Este dato puede tener muchas explicaciones, puede ser que esta situación se deba al bajo interés por aprender la lengua, al bajo nivel económico del estudiante o a situación individual en el curso (en ocasiones, cuando el estudiante es becario, este se abstiene de reclamar, por temor a perder la beca o el curso) o inclusive a la cuestión de estudiar una lengua extranjera obligado por la familia.

Aparentemente, no sería importante comentar la respuesta de los 2 únicos informantes que eligieron la respuesta ' $d$ ' 'No, pero sería lo ideal', lo que se está diciendo es 'No considero que el profesor de LE deba conocer y dominar fluidamente la lengua que enseña, pero eso sería lo ideal'. Esta afirmación, a priori, sería una contradicción, pero yendo un poco más allá, es como leer: ESO DEBERÍA SER, pero [...]. La continuidad de aseveración es indescifrable 
Sobre todo, es de absoluta relevancia hacer notar que de 432 informantes, no hubo uno que eligiera la respuesta ' $b$ ' 'No, no es necesario'. Eso quiere decir sin lugar a dudas que, definitivamente, la opinión de todos los informantes es que el profesor de LE debe conocer y dominar fluidamente la lengua que enseña.

En el gráfico 7 presentamos el resultado de la encuesta a la pregunta 2. Se desea saber si el profesor de LE de educación básica (primaria y secundaria) debe dar sus clases en la lengua que enseña y, según vemos, 94 informantes del G1 han elegido la respuesta 'a' 'sí, sin duda' el profesor debe dar su clase en la lengua que enseña, también lo dicen 62 informantes del G2.

Del G1, 10 informantes han elegido la opción 'b' 'No, no es necesario', dicen que el profesor de LE no debe dar sus clases en la lengua que enseña, lo mismo 8 informantes del G2. La alternativa 'c' 'Sí, por lo menos algo' ha sido por la que más informantes han optado, 149 del G1 han dicho que el profesor de LE debe dar por lo menos algo de su clase en la lengua que enseña, mientras que del G2, 92 informantes, este dato es un tanto contradictorio con relación a las respuestas de la pregunta 1.

Además, 6 de los informantes del G1 han tomado la alternativa 'd' 'No, pero sería lo ideal' y 19 del G2 también la han escogido, estos informantes dicen el profesor de LE no debe dar sus clases en la lengua que enseña, pero que lo haga sería lo ideal.

Gráfico 7 Respuestas a la pregunta 2 de la encuesta 1

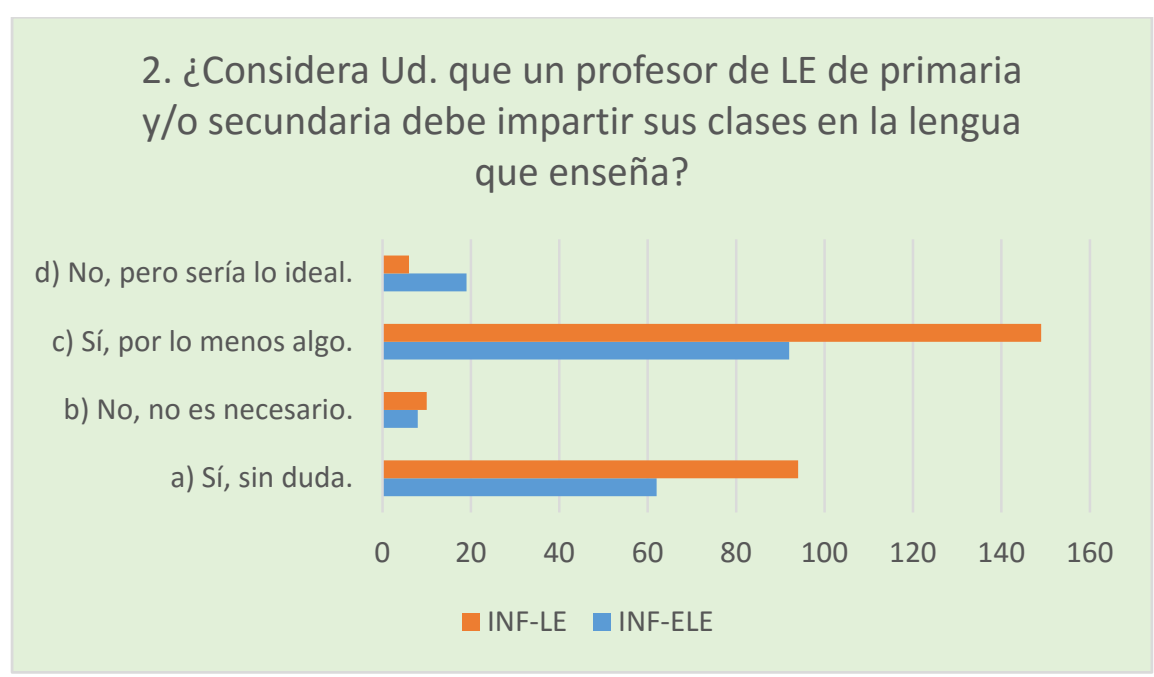

(Datos de investigación) 
En el gráfico 8 presentamos el resultado de la encuesta a la pregunta 3 que indaga sobre la opinión inmediata de ambos grupos, G1 y G2 de si en general creen que el profesorado de LE conoce y domina fluidamente la lengua que enseñan. Esta pregunta fue formulada con la intención de saber lo que está en la opinión general de las personas que estudian idiomas o se interesan especialmente por estos.

Fueron 43 informantes del G1 los que eligieron la alternativa 'a' 'Sí, sin duda', pero solo 11 del G2 dijeron que sí, que indudablemente, los profesores de LE conocen y dominan fluidamente la lengua que enseñan (solo por el hecho de ser profesores de LE).

Para la alternativa ' $b$ ' 'No, la mayoría, no', 61 informantes del G1 dijeron que la mayoría de los profesores de LE no conocían ni dominaban fluidamente la lengua que enseñaban y del G2 solo 28 dijeron lo mismo, una marcada diferencia.

Gráfico 8 Respuestas a la pregunta 3 de la encuesta 1

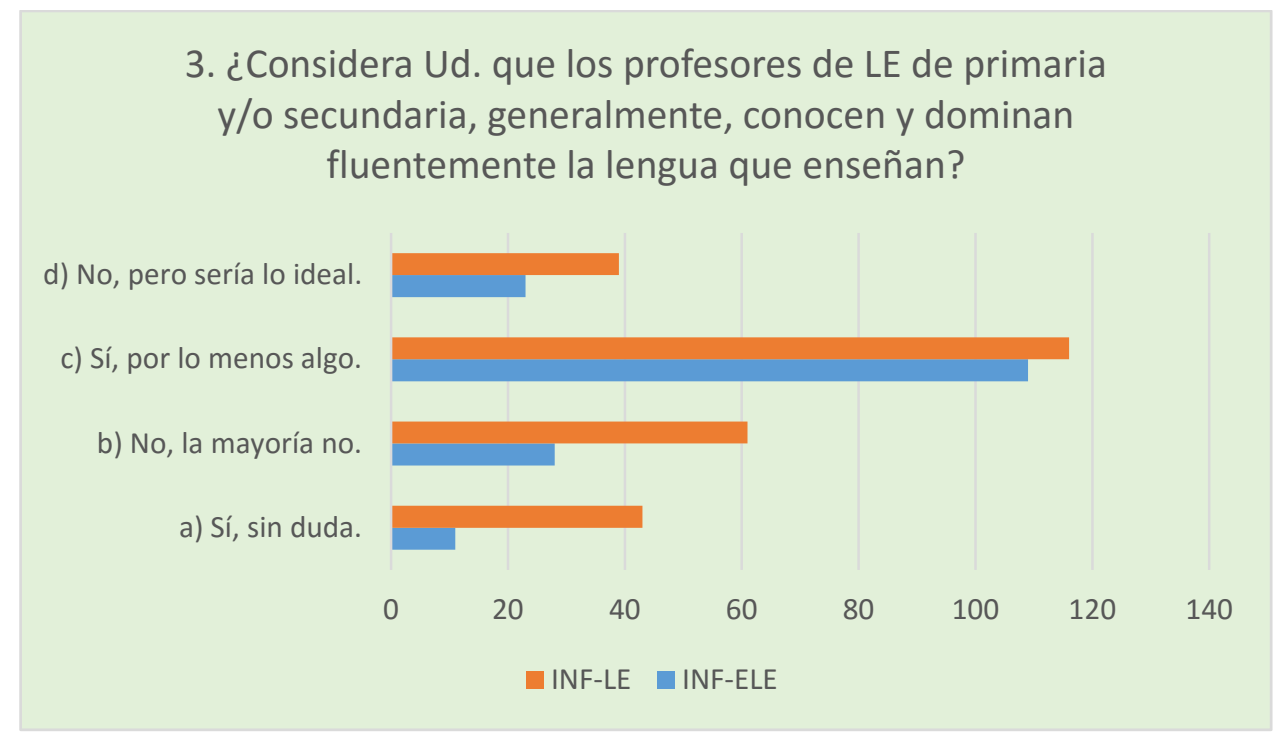

(Datos de investigación)

Del G1 fueron 116 informantes los que optaron por la alternativa 'c' 'Sí, por lo menos algo', o sea que creían que los profesores de LE, conocían y dominaban por lo menos algo de la lengua que enseñaban y del G2, 109 informantes dijeron lo mismo. 
La alternativa ' $d$ ' 'No, pero sería lo ideal', fue la elegida de 39 informantes del G1, también 23 del G2, estos informantes dijeron que no creían que los profesores de LE conocieran o dominaran fluidamente la lengua que enseñaban, pero que a su ver, lo ideal sería que sí.

En el gráfico 9 presentamos el resultado de la encuesta a la pregunta 5 que indaga si al informante le gustaba tener clases de LE en la EB. Esta pregunta es aplicada en la encuesta con la intención de conocer el grado de ilusión y placer que el informante espera encontrar en el aprendizaje de una LE en la educación básica.

En esta pregunta 5 han sido 6 las alternativas, de las cuales solo debería elegirse solo una. Haremos la descripción contrastando el G1 y el G2. De esta forma, han sido 113 informantes del G1 los que han dicho que sí les gusta o gustaba tener clases de $L E$ en la EB, respuesta 'a', siendo este el más alto número de respuestas para esta encuesta, mientras que del G2 solo 70 informaron lo mismo.

Del G1, para la respuesta 'b' 'Al principio sí, pero después no', 53 informantes en contraste con los 42 del G2. Para la alternativa 'c' 'No, para nada', o sea para nada apreciaban tener clases de LE en la EB, 23 informantes del G1 lo afirmaron, mientras que 3 del G2, resultado que refleja que lo que se ofrecía en el EB no estimulaba el deseo de aprender una LE.

Gráfico 9 Respuestas a la pregunta 5 de la encuesta 1

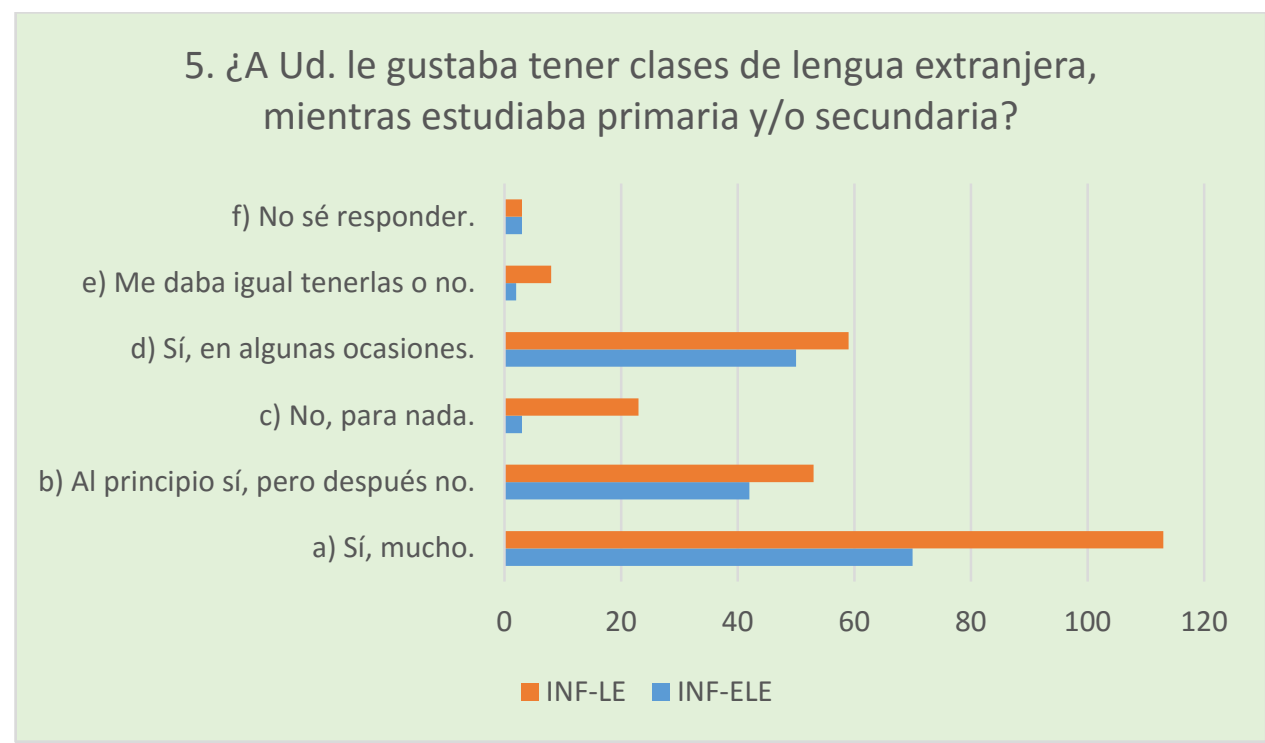

(Datos de investigación) 
La alternativa 'd' 'Sí, en algunas ocasiones' me gusta o gustaba tener clases de LE, del G1 fueron 59 informantes contra 50 del G2, esta respuesta puede ser consecuencia de muchas situaciones, entre ellas que en las ocasiones en que sí les gustó, la clase de LE fue estimuladora, el objetivo de captar la atención y colaboración de los aprendientes se consiguió.

Del G1 fueron 8 los informantes de la alternativa 'e' 'Me da o daba igual tenerla o no', mientras solo 2 informantes del G2 lo admitieron. En este grupo es posible que se encuentren los aprendientes condicionados u obligados, estos que frecuentan la clase LE por calificación o nota.

Los 3 informantes del G1 y los 3 del G2 que eligieron la alternativa 'f' 'No sé responder' evidencian indiferencia absoluta respecto de la clase de LE.

La pregunta 5 de esta encuesta también presenta una respuesta abierta en la que se solicita del informante que explique el porqué de la alternativa elegida. Todos los pareceres de los que atendieron este pedido se recogieron en dos planillas, la primera es de los informantes del G1 que respondieron en portugués, lo que fue versado a español y los del G2 que fue directamente respondido en español, ambos componen el anexo VIB. Estas declaraciones se perfilan como interesantes porque explica puntualmente mucho de las respuestas de ese informante sobre una realidad que no es virtual ni asumida, se trata de la propia realidad, aquella en la que estamos insertados todos y muchas veces pasivos permanecemos ante la problemática de la LE en la enseñanza básica.

Verifiquemos algunas respuestas de los informantes del G1 y G2 a la pregunta, ¿Por qué eligió la alternativa que respondía la pregunta 5? Añadida a las respuestas 1, 2, 3 y 5 :

EI INF-LE-010 dijo:

- Sí, sin duda el profesor de LE debe conocer y dominar la lengua que enseña;

- Sí, por lo menos algo el profesor de LE debe dar de clase en LE;

- Sí, por lo menos algo conoce el profesor de la LE que enseña;

- Sí, en algunas ocasiones me gustaban las clases de LE La respuesta abierta a por qué había elegido esta opción fue: 


\begin{tabular}{|l|l|}
\hline INF-LE-010 & Necesitamos mejores profesores. \\
\hline
\end{tabular}

EI INF-LE-017 dijo:

- a) Sí, sin duda el profesor de LE debe conocer y dominar la lengua que enseña;

- d) No, pero sería lo ideal (que el profesor de LE dé clase en la LE que enseña;

- c) Sí, por lo menos algo conoce el profesor de la LE que enseña;

- b) Al principio sí, pero después no me gustaban las clases de LE La respuesta abierta a por qué había elegido esta opción fue:

\section{\begin{tabular}{|l|l}
\hline INF-LE-017 & Porque perdí el interés, mi profesor no era bueno.
\end{tabular}}

EI INF-LE-040 dijo:

- a) Sí, sin duda el profesor de LE debe conocer y dominar la lengua que enseña;

- d) No, pero sería lo ideal (que el profesor de LE dé clase en la LE que enseña;

- d) No, pero sería lo ideal que el profesor conozca y domine la LE que enseña;

- d) Sí, en algunas ocasiones me gustaban las clases de LE

La respuesta abierta a por qué había elegido esta opción fue:

\begin{tabular}{|l|l|}
$\begin{array}{l}\text { INF-LE- } \\
040^{107}\end{array}$ & $\begin{array}{l}\text { El interés se mejora cuando el profesor sabe hacer la } \\
\text { clase, en mi caso no fue así siempre. }\end{array}$ \\
\hline
\end{tabular}

EI INF-LE-051 dijo:

107 En el anexo VIB encontrará todos los comentarios de los encuestados del G1 y G2 
- a)Sí, sin duda el profesor de LE debe conocer y dominar la lengua que enseña;

- a)Sí, sin duda, el profesor debe dar clase de LE en la lengua que enseña;

- d)No, pero sería lo ideal que el profesor conozca y domine la LE que enseña;

- c)No, para nada me gustaban las clases de LE

La respuesta abierta a por qué había elegido esta opción fue:

INF-LE-051

Les falta aprenderlo primero para poder enseñar.

Cada encuesta realizada revela un perfil diferente, una óptica diferente para entender el funcionamiento de la enseñanza de LE en la educación básica, aunque lo que sí llega a ser denominador común es el tema del descontento con relación a la calidad del aprendizaje, que sin duda también tiene implicaciones de otro orden, como carga horaria, recursos, apoyo y valorización como asignatura de relevancia en la formación del individuo.

En el gráfico 10 presentamos el resultado de la encuesta a la pregunta 6, pero antes presentamos aquí el contenido de cada alternativa:

Pregunta6: Como padre/madre de familia, ¿qué le parecería que su hijo aprendiera a hablar la LE que se enseña en la escuela primaria y/o secundaria?

a) Me parecería de lo más sensato, pero eso no ocurre para nadie.

b) Me parecería sorprendente, una verdadera hazaña, porque en mis tiempos de estudiante, no se aprendía a hablar, solo algo de gramática.

c) Me parece que eso sería lo cierto, pero el problema puede estar en los profesores que no incentivan mejor ese aprendizaje

d) Me parece que los estudiantes no valoran la asignatura en el colegio

e) Otro parecer:

En el G1 hubo 6 informantes que eligieron la alternativa 'a y con ello dijeron que les parecía sensato que su hijo aprendiera a hablar la LE que la escuela enseñaba, ya del G2 solo hubo 1 informante diciendo lo mismo. 
La alternativa 'b' fue elegida por 51 informantes del G1 y solo 5 del G2, los del G1 dijeron que sería una hazaña aprender LE en la escuela básica, claro, al parecer conocedores de esa realidad no apuestan en que la escuela básica consiga que sus alumnos lleguen a hablar la LE que se enseña.

Gráfico 10 Respuestas a la pregunta 6 de la encuesta 1.

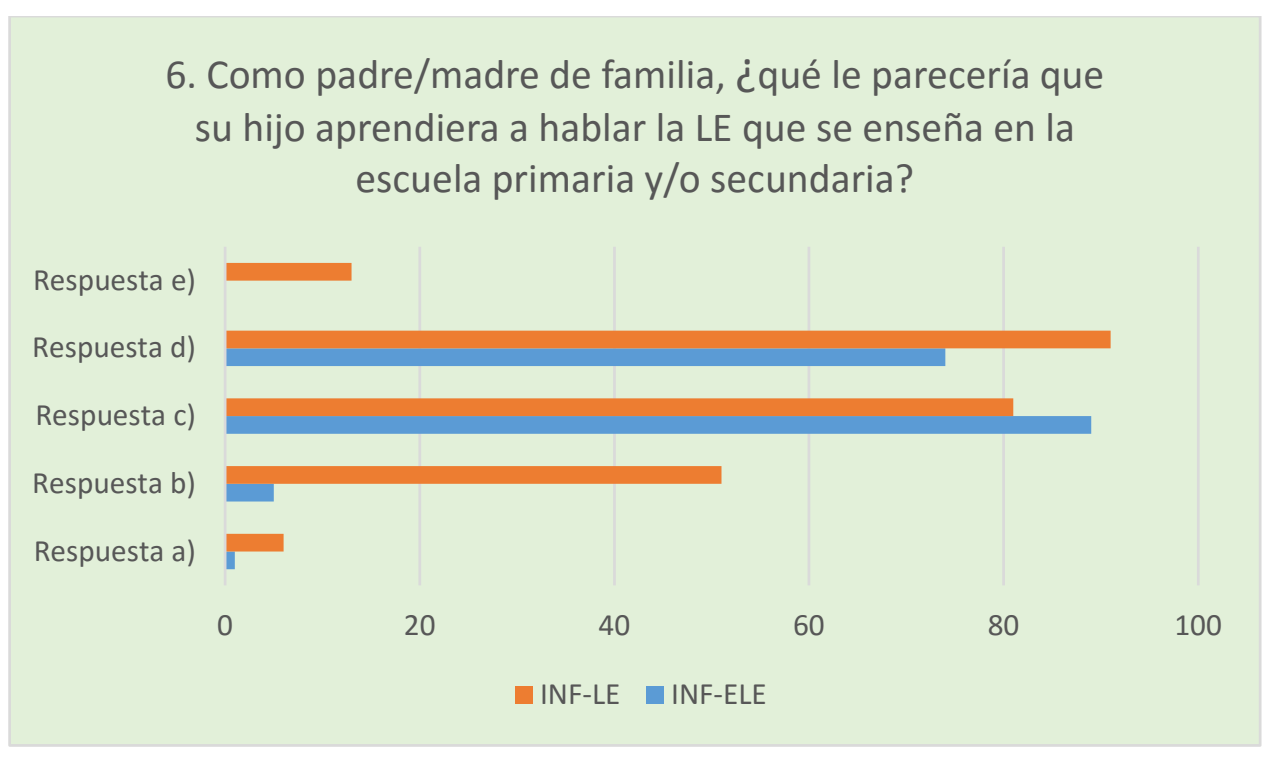

(Datos de investigación)

Las respuestas 'c' y 'd' tuvieron bastantes simpatizantes. Fueron 81 del G1 y 89 del G2 a quienes le parece que sería lo cierto que se aprendiera a hablar en la escuela básica, pero que eso no ocurría porque los profesores no incentivan mejor este aprendizaje. Y 91 del G1 con 74 del G2 eligieron la alternativa 'd', o sea, dijeron que les parecía que los estudiantes no valoraban la asignatura en el colegio.

Para finalizar, la respuesta 'e' era de carácter abierto, el informante podía emitir libremente su opinión, pero al juzgar por los 13 informantes ${ }^{108}$ que escribieron, los demás encontraron en las respuestas propuestas su parecer para la pregunta en cuestión.

108 En el apéndice 1B encontrará todos los comentarios de los encuestados del G1 y G2 


\subsubsection{Preguntas de investigación}

Presentados los datos de esta parte de la investigación, se evidencian algunas situaciones problemáticas que deberán ser analizadas más ampliamente, las mismas que nos conducen a la formulación de preguntas de investigación (PI) importantes para dilucidar la realidad de la enseñanza de LE en la educación básica y pública con respecto a la fluidez y dominio de lengua extranjera del docente de LE. De esta forma, pasamos a formular las preguntas de investigación $(\mathrm{PI})$ y las respectivas hipótesis $(\mathrm{H})$ :

PI-1 - ¿Por qué el estudiante de LE piensa que el docente de LE debe conocer y dominar con fluidez la lengua extranjera que enseña, pero basta aplicar aunque solo sea algo de ese conocimiento?

H1 - Existe un condicionamiento oculto en el estudiante de LE que lo lleva a conformarse con poca calidad en la enseñanza de lengua extranjera.

H2 - Aprender lengua española en la educación básica es algo del ámbito de lo ideal, o sea, no va a concretarse en la realidad.

PI-2 - ¿Dónde queda el aprendizaje de los marcadores del discurso en la enseñanza que emana del profesor de LE en la educación básica?

H3 - No llegan al estudiante de educación básica porque no forman parte del conocimiento y dominio del profesor de LE.

H4 - Aprender a usar los marcadores del discurso en la lengua española en la educación básica es utópico, no va a concretarse en la realidad.

PI-3 - ¿Qué hace falta para que el aprendizaje de una LE, en este caso español, cumpla el rol que se asigna en la sociedad actual? 
H5 - La visión de los gestores educativos es aceptable pero se queda en la demagogia, las acciones no llegan al ciudadano.

H6 - No hay armonía ni sincronía en los propósitos de la educación, jerárquicamente, al respecto del aprendizaje de una LE.

\section{PI-4 - ¿Será posible erradicar la creencia de que en la escuela pública no se aprende LE?}

H7 - Es una cuestión de las sociedades de muchas naciones, pero todas ellas al parecer tienen un denominador común con respecto a LE en la enseñanza básica: no se valoriza y eso es algo histórico.

H8 - Cuando los profesores opositen teniendo que demostrar dominio oral y escrito de la LE que van a enseñar, este día dejará de haber profesores que solo enseñen gramática, porque habrá preocupación por la solvencia oral, sobre todo.

\subsubsection{Análisis empírico}

Una relación que no se manifiesta clara y confunde bastante en todos los segmentos y ámbitos de la enseñanza de lengua extranjera es no entender cómo es que la mayoría de las personas, por lo general, piensa que el profesor debe conocer y dominar fluidamente la lengua que enseña ${ }^{109}$ y pocos opinan que las clases de LE deban ser dadas en LE, además de verificar que muchas menos personas piensan que el profesor de LE sepa la LE que enseña. Realidad viva que está en el cotidiano de todas las partes involucradas.

Esta realidad se constata también con los datos de la encuesta 1 en sus preguntas 1, 2 y 3, el profesor de LE:

(1) Debe saber la LE que enseña

${ }^{109}$ Ver Gráfico III.1. Respuestas a la pregunta 1 de la encuesta 1. 
(2) Debe impartir clase en la LE que enseña, y

(3) Crees que el profesor de LE sabe la LE que enseña

Gráfico 11 - Respuestas a 1, 2 y 3, alternativa a).

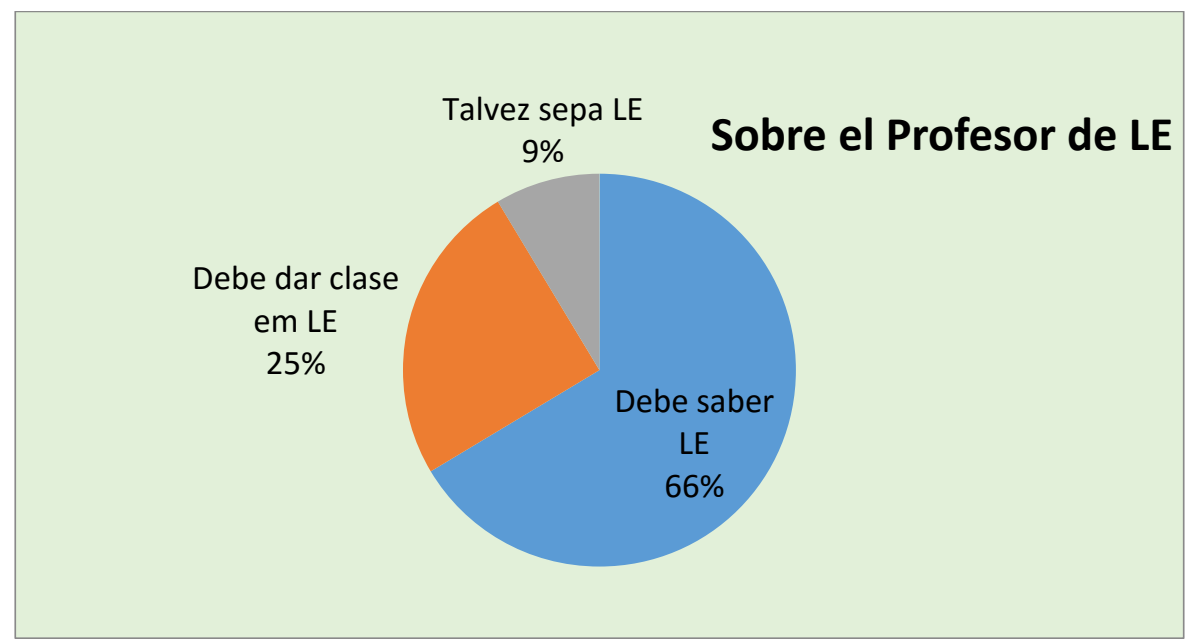

Datos de investigación

Si el profesor conoce y domina la LE que enseña debería implementarla en su clase y en su convivencia con los aprendientes, debería echar mano de la lengua materna del aprendiente en situaciones necesarias y sin ningún perjuicio en el aprendizaje de la LE, pero aún tenemos la realidad de siempre, en 1994 ya lo decía CASSANI y desde entonces (hace 22 años) ha habido cambios importantes pero lo subyacente sigue ahí:

En resumen, no hay demasiados maestros que dominen el sistema de la lengua que enseñan o en el que enseñan y, de ellos, pocos tienen una capacidad expresiva suficientemente amplia como correspondería a la persona que tiene que estimular y conducir la expresión. Por lo tanto, no hay demasiados maestros que puedan convertirse, con plena garantía, en modelo lingüístico. (CASSANI, 1994: 14)

Aunque dejemos claro que lo de convertirse en modelo lingüístico, no es lo que se propone este estudio, lo cierto es que muchos profesores no tienen la capacidad expresiva suficientemente amplia como correspondería al profesor de LE y porqué no ampliar esta formulación de ideas para el profesor de lengua materna. 
Que de 432 informantes, 415 digan que el profesor de LE debe conocer y dominar fluidamente la LE que enseña es un resultado categórico que además se constata en el día a día, es lo mínimamente esperado; no obstante que de esos 432 informantes solo 156 digan que el profesor debe impartir la clase de LE en LE no tiene lógica. El profesor de LE se hace profesor para contribuir con la formación del individuo, principalmente, pero si ese individuo cree que no hace falta, termina perjudicando a los que sí necesitan o aprecian ese conocimiento.

En el gráfico 12 presentamos un contraste entre la respuesta del informante que ha estudiado en la EB una LE, grupo 1, y el que estudia una LE para finalidades específicas, grupo 2. Podemos notar la cautela que se manifiesta al contestar las preguntas 1, 2 y 3, respuesta (a). Del G1 más informantes dicen que todo profesor de LE debe conocer la lengua que enseña, también más del G1 dicen que estos deben dar su clase en LE y creen que el profesor de EB domina fluentemente la LE que enseña. Al contrastar con el G2, estos son más criteriosos, poquísimos afirman que el profesor de EB domina la LE que enseña, también menos dicen que el profesor debe dar clase en la LE que enseña.

Gráfico 12 Contraste de respuesta $1^{a}$ entre el G1 y el G2.

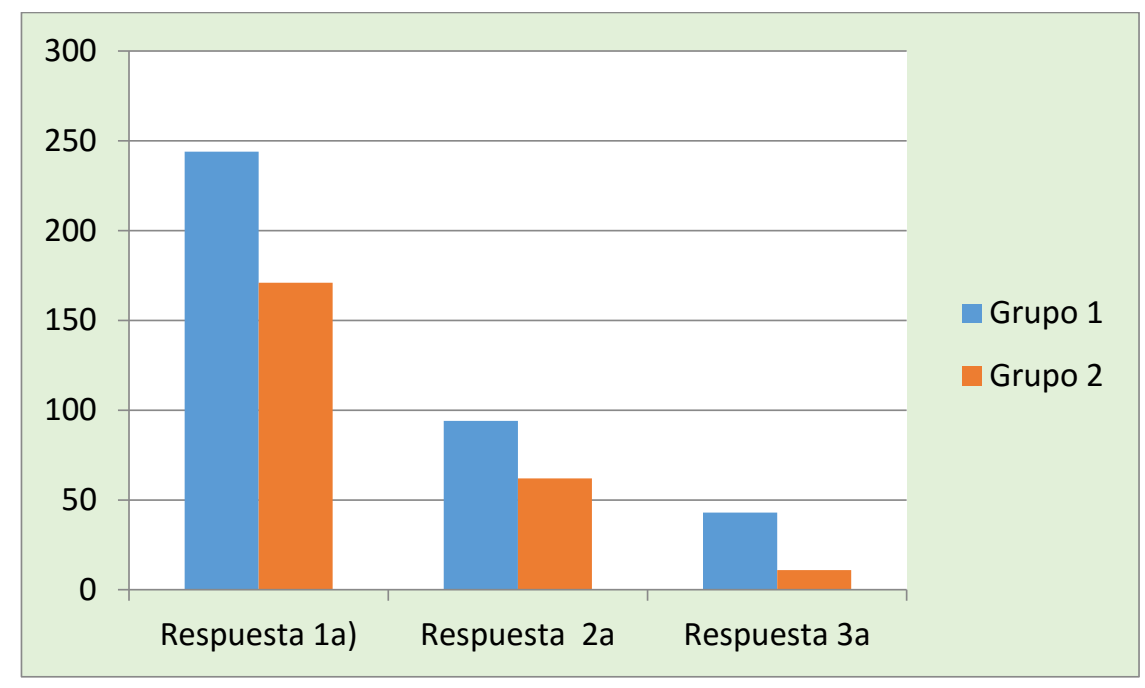

Datos de investigación

Estas respuestas tienen bastante sentido y hay congruencia con la realidad, pues se trata de personas que estudian la lengua por objetivos 
personales o profesionales y han tenido diversas experiencias con diversos profesores, y esa es la experiencia que los hace responder así. Porque si estudia LE después de haber concluido la EB es porque no ha conseguido avanzar en ese conocimiento o probablemente ni siquiera partir, ha pasado +8 años intentándolo. Cuando pocos dicen que el profesor debe dar la clase en la LE que enseña, significa para estas personas que en muchos casos es mejor escuchar lo que el profesor tiene para enseñar en su lengua materna porque no se soporta el grado de interlengua que muchos aún detienen, pero puede rescatarse la información que hace parte de la forma de la LE que se aprende.

\section{LOS MARCADORES DEL DISCURSO EN (LOS ESTUDIOS DE) ELE}

En este bloque de investigación se constituirán objetos de estudio los sujetos que directa o indirectamente están involucrados en el proceso de enseñanza y aprendizaje de ELE enfocando exclusivamente aspectos relacionados al aprendizaje, uso, presencia o ausencia de los marcadores del discurso en los diferentes instrumentos de investigación de los sujetos estudiados, a saber:

- $\quad$ el estudiante de enseñanza básica (3.1);

- el estudiante de grado en ELE de las IES contempladas en este estudio (3.2); y

- $\quad$ el docente de grado en ELE en IES contempladas en este estudio (3.3).

De esta forma, procedemos al procesamiento de los datos según la metodología empírica antes señalada.

\subsection{LOS MD EN LA PRODUCCIÓN ESCRITA EN ELE EN LA EDUCACIÓN BÁSICA}

Las lenguas extranjeras que se enseñan en la educación básica en este Estado de RN son inglés y español, el primero con una presencia en el currículo escolar bastante antigua e inclusive tradicional, la segunda es español 
que históricamente disputa espacio y atención para su enseñanza y aprendizaje en este país.

Tras conocer y analizar lo que el estudiante de LE piensa sobre la enseñanza en la EB, hemos creído conveniente presentar una muestra de la producción escrita de estudiantes de enseñanza secundaria de un instituto federal en donde realizamos actividades docentes.

\subsubsection{Descripción de los datos, instrumento de investigación y formateo}

A lo largo de dos bimestres de un año escolar y de 4 eventos de producción textual, o sea 16 clases de ELE, se han recogido, al azar, 3 producciones escritas de estudiantes del último año de enseñanza secundaria de institución pública.

Es pertinente comentar que en la actualidad la enseñanza secundaria en Brasil es ofertada también por institutos federales con un currículo volcado para la profesionalización, de esta forma, la duración de esta enseñanza no es de tres años como en las escuelas estatales, sino de cuatro años.

Los estudiantes autores de las producciones recogidas, tomaron ciencia y manifestaron estar de acuerdo en ceder sus trabajos para esta finalidad de investigación.

De las 12 producciones escritas, 4 serán de hecho objeto de análisis en esta investigación, nuevamente cogidas al azar, análisis objetivamente dirigido a la observación de la aplicación de MD en la producción de los textos, los mismos que obedecen la siguiente identificación: Tx-INF-ELE-EB-00.

Hemos generado dos cuadros con la reproducción ortográfica, tal cual ha sido escrito en su original, en el cuadro 27 están los textos de los informantes TX-INF-ELE-EB-01 y TX-INF-ELE-EB-02, mientras que en el cuadro 28, los de Tx-INF-ELE-EB-03 y Tx-INF-ELE-EB-04.

\subsubsection{Descripción de los parámetros de análisis}

Los cuatro textos presentados en los cuadros 27 y 28 son fruto de 16 clases de español de 135 minutos, dos proyectos aplicados con el objetivo de 
lograr la selección de contenidos (realizada por nosotros) propuesto en el manual didáctico "Cercanías 1" del Programa Nacional do Livro Didático PNLD do MEC-Brasil para la enseñanza media y muchas ganas más de oír que de ser oído.

Cuadro 27 Textos seleccionados de estudiantes EB (1)

\begin{tabular}{|c|c|}
\hline 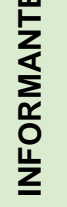 & $\begin{array}{c}\text { Texto - del informante estudiante de enseñanza básica Español como } \\
\text { lengua extranjera }\end{array}$ \\
\hline 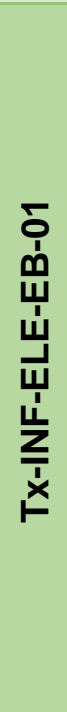 & $\begin{array}{l}\text { Las semejanças e las diferenças entre Brasil y Argentina } \\
\text { Argentina es un Pais muy rico culturalmente hablando, assi como és Brasil. El } \\
\text { tango es la dança más famosa de Argentina y es conocida internacionalmente } \\
\text { como el símbolo maior del Argetina. El tango está para Argentina así como samba } \\
\text { está para Brasil. Las comidas son outro punto en que Argentina és muy famosa. } \\
\text { Quém nunca ouvir hablar sobre lo grande pariada argentino y sus maravilhosos } \\
\text { alfajores. Pero nada supera la culinaria brasileira, la famosa feijoda, las } \\
\text { tradicionales comidas nordestinas. } \\
\text { Pero mismo tenendo cosas que los dos países son buenos, há un punto que hace } \\
\text { una grande rivalidade entre Brasil y Argentina, en los desportes. La discusión } \\
\text { sobre quen és mejor en fútbol vien desde del seculo pasado, Pelé ou Maradona } \\
\text { ¿Messi ou Neymar? Tirando estas coisas, Brasil y Argentina son dos países } \\
\text { maravillosos para morar ou visitar, pois los dos tienen diversos puntos turísticos, } \\
\text { ricos culturalmente e que vale a pena para ir sozinho ou con toda familia. }\end{array}$ \\
\hline 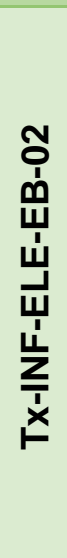 & $\begin{array}{l}\text { Cultura Argentina x Brasil } \\
\text { Es possible perceber muchas cosas en común quando observamos estes países. } \\
\text { Muy mais que el fútbol, el Brasil y la Argentna partilhan diversos costumes que se } \\
\text { asemelhan . Esto pode ser visto en sus festividades, por exemplo. En la Arentina, } \\
\text { ha danzas como carnavalito, chacarera y otras que son caracterizadas por sua } \\
\text { alegría y sentimentalidad. En el Brasil es vista esa miesma alegría en danzas } \\
\text { típicas. En la Argentina, a pesar de non ser el desporte oficial, o fútbol es muy } \\
\text { importante na cultura deste país. Argentina tiene mais de } 10 \text { títulos internacionales } \\
\text { e já gana dos copas del mundo. Sendo un de los principales rivais de Brasil. Neste } \\
\text { nosotros podemos perceber que el fútbol es muy importante, estando muy fuerte } \\
\text { en la cultura. }\end{array}$ \\
\hline
\end{tabular}

(Datos de investigación)

Aunque haya una riqueza fantástica de elementos de interesante análisis, los textos producidos serán exclusivamente usados para identificar la presencia de marcadores discursivos en la redacción. Es oportuno informar que 
estos alumnos no han visto los MD como contenido en ninguna clase específica. Estos elementos han estado presentes en la oralidad del docente, en la participación del estudiante, en la lectura (comprensión de textos) y en su producción escrita.

El primer texto producido por el informante TX-INF-ELE-EB-01 lleva por título: "Las semejanças e las diferenças entre Brasil y Argentina" y presentamos fragmentos en los que fueron aplicados elementos en la función de MD, a saber:

(1) [..] y es conocida internacionalmente [...]

(2) [...]. Pero nada supera la culinaria brasileira

(3) Pero mismo tenendo cosas que los dos países son buenos

\section{(4) Tirando estas coisas}

' $Y$ ', reconocida como una conjunción coordinante en el ámbito de la morfología, puede desempeñar el papel de un MD en determinadas situaciones, lo que a nuestro ver se configura en (1):

Pero las conjunciones [...] pueden emplearse más allá de la oración o de los constituyentes oracionales. [...] Es decir, las conjunciones pueden establecer conexiones no entre miembros lingüísticos, explícitos, sino entre lo implícito y lo explicito: [...] (MARTín ZORRAQUINO, 2010:115)

En (2) y (3) igualmente vemos la aplicación de 'pero' conectando extraoracionalmente el discurso lo que los configura como MD. Y en la estructura Tirando estas coisas de (5) en el contexto que fue aplicado en el texto producido por el estudiante, ejerce la función de un reformulador de distanciamiento (PORTOLÉS, 2011), porque la equivalencia semántica sería de 'de cualquier forma', 'de cualquier manera' encadenando el discurso global: De cualquier forma, Brasil y Argentina son dos países maravillosos para [..]

El segundo texto, producido por el informante Tx-INF-ELE-EB-02, presenta la construcción [...] 'Esto pode ser visto en sus festividades, por exemplo. A pesar de no estar totalmente gramaticalizado como marcador discursivo, esta 
estructura, clasificada como un operador discursivo de concreción, suele presentar al miembro del discurso en el que se localizan como algo concreto a partir de una generalización (PORTOLÉS, 2010:144)

El tercer y cuarto texto informado está en el cuadro 28:

Cuadro 28 Textos seleccionados de estudiantes EB (2)

\begin{tabular}{|c|c|}
\hline 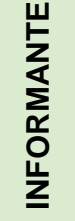 & $\begin{array}{c}\text { Texto - del informante estudiante de enseñanza básica Español como } \\
\text { lengua extranjera }\end{array}$ \\
\hline 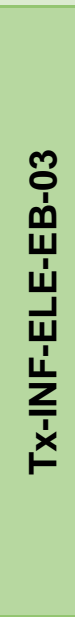 & $\begin{array}{l}\text { La Argentina y algunos aspectos culturales } \\
\text { La Argentina es una república federal representativa desde la constituición } \\
\text { Argentina de 1853. Lo país está dividido en } 23 \text { provincias y uno Distrito Federal, } \\
\text { Buenos Aires. La capital de la Argentina, Buenos Aires tiene muchas atractiones y } \\
\text { una arquitectura parecida con la España. } \\
\text { Así, como lo Brazil, la Argentina es famosa por su fútbol, pero por tener lo mejor } \\
\text { jugador del mundo, Leonel Messi. Y así como Brazil, la selección Argentina de } \\
\text { fútbol tiene muchos títulos mundiales ( } 25 \text { títulos) La gastronomya Argentina es } \\
\text { diferente del resto da America Latina, por haber sido influencyado por las culturas } \\
\text { Española y Italiana. Pero que los Argentinos amam, así como en el Brazil no } \\
\text { churrasco, picado, helado y alfajor. Lo alfajor es o dulce mas amado por los } \\
\text { hermanos. }\end{array}$ \\
\hline 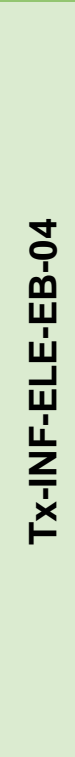 & $\begin{array}{l}\text { México } \\
\text { El cultura americana teve una grand influencia pré-colombiana e española. És una } \\
\text { cultura muy rica, de un puevo muy alegre y espontaneo. En el México até la muerte } \\
\text { é encarada de fuerma diferente, é tratada com muy música e de fuerma naturale } \\
\text { de passagem para más uno ciclo de vida. Losmexicanos gostam de muy colores, } \\
\text { se viesten de una manera singular. Las mujeres con sais y vestidos coloridos con } \\
\text { muy enfeites y los hombres usan una especie de túnica e grand chapeús. } \\
\text { Lo idioma falado pelos mexicanos é o español. Las escuelas del ensino médio son } \\
\text { diferentes de lo Brasil, lá os estudantes cursam un período de } 5 \text { años e en lo Brasil } \\
\text { apenas } 3 \text {. Los ritmos culturales son muy diferentes Del Brasil, lá son coñecidos la } \\
\text { ranchera e lo mariachi, porém alguns cantores mexicanos son conhecidos en lo } \\
\text { Brasil, como Anahí e Dulce Maria. Los brasileiros também gustan de muy colores, } \\
\text { porém se vestem diferentes del mexicanos, com roupas más curtas e justas. Em ló } \\
\text { Brazil a muerte tambiem é tratada de fuerma diferente, como uma profunda dolor y } \\
\text { tristeza ao perder um ente querido, sentimento conocido por luto. }\end{array}$ \\
\hline
\end{tabular}

(Datos de investigación)

Del tercer texto informado por Tx-INF-ELE-EB-03 y que se puede apreciar en el cuadro 28, recogemos las construcciones siguientes: 
(1) Así, como lo Brazil, la Argentina es famosa [...] pero por tener lo mejor jugador del mundo, Leonel Messi

(2) [...]. Pero que los Argentinos amam, así como en el Brasil [...]

En (1) apreciamos la aplicación de un conector de estructuración de texto con la función de continuidad que viene articulando lo dicho antes y lo que va a decirse luego.

En (2), el estudiante ha aplicado 'pero' en una situación que puede interpretarse como un reformulador recapitulativo.

En el cuarto y último texto escrito por estudiante de enseñanza secundaria identificado como Tx-INF-ELE-EB-04 no se ha apreciado ninguna estructura, en español, que contemple un MD a lo largo del texto producido.

\subsubsection{Preguntas de investigación}

Habiendo presentado los datos de investigación que se concretan en 4 textos escritos por estudiantes de enseñanza secundaria de forma libre y tras 16 sesiones de clase de 135 minutos, estamos ante importante pregunta de investigación $(\mathrm{PI})$ y su respectiva hipótesis $(\mathrm{H})$ respecto a los MD en el proceso de enseñanza y aprendizaje de ELE en la educación básica, que exponemos a continuación:

\section{PI-5 - ¿Para aprender a usar los marcadores del discurso es necesario presentar el contenido directamente?}

H9 - No. El dominio y la fluidez en la oralidad con que el docente de ELE se comunique y estimule a comunicarse a sus alumnos es un fuerte inductor al aprendizaje de partículas importantes como los MD para la articulación y fluidez en la comunicación en ELE, sea esta oral o escrita. 
H10 - Para aprender a usar los MD en ELE, a los estudiantes brasileños les bastaría percibirlos en el uso oral y escrito en situaciones reales de comunicación.

\subsubsection{Análisis empírico parcial}

Someter a análisis una muestra de producción textual realizada tras un corto periodo de clases de español a un grupo de 31 estudiantes es intencionado, pues a nuestro ver se concentraban en esta experiencia varios factores que intervendrían neutralmente en la idoneidad de los datos que evaluamos.

El análisis de los textos producidos, a pesar de la fuerte interlengua que presentan, ha sido con enfoque absoluto sobre uso de partículas discursivas y teniendo en consideración que el contenido sobre MD no ha sido abordado didácticamente en ningún momento del proceso de enseñanza y aprendizaje, resulta satisfactorio percibir que el dominio de estas partículas en su lengua materna se transfiera a la lengua extranjera que aprenden. Se observa también que es tímido, o deberíamos decir limitado, el número de partículas usadas, lo que nos lleva a pensar que también lo es en su lengua materna, una cuestión que podría merecer una investigación específica ya que podría explicar las sabidas dificultades que los brasileños tienen para discursar en textos escritos.

La incidencia del uso del MD 'pero' se nota también en esta muestra de producción escrita en ELE, pues conviene saber que en Brasil es generalizado el uso de la partícula 'mas' tanto en el papel de conjunción como en el de un MD, luego esta marca se refleja claramente en este resultado, al presentarse en 3 aplicaciones de MD de siete.

\subsection{LOS MD Y LOS ESTUDIANTES DE GRADO EN ELE}

La presente investigación se ha centrado en el estudio y el análisis de la aplicación de los marcadores del discurso desde una perspectiva de alcances en la enseñanza y aprendizaje de ELE que determinan el nivel de lengua que se logra a lo largo de la formación del profesorado que actuará en las escuelas 
públicas del país que a su vez determina también la calidad en el aprendizaje de ELE en la educación básica y pública.

Uno de los procedimientos más utilizados para lograr la meta es el de análisis de producción escrita y oral, que nos permite reflexionar de acuerdo con los resultados, llevándonos al campo de las conclusiones, sobre todo con nuevas ideas de cuño didáctico-pedagógico, metodológicas y también, lingüísticas que puedan contribuir positivamente al proceso.

Para conocer la realidad de los MD en el acervo informativo del futuro profesor de ELE, actual estudiante de grado, se ha optado por estudiar datos recogidos a través de dos instrumentos de investigación diferentes: una encuesta con posibilidad de respuestas abiertas y producción escrita individual. Los informantes son estudiantes del último bimestre de formación de años diferentes de egreso y de IES del Estado de Rio Grande do Norte.

\subsubsection{Encuesta a estudiantes de grado en ELE}

La encuesta ha sido realizada puntualmente a estudiantes del último bimestre de formación docente al que se le denomina en adelante $\mathbf{G 4}$ al ser referido como un grupo. Los estudiantes son de tres IES del Estado de RN que ofertan el grado en ELE. Se salvaguarda la identidad de los informantes asignando un código común, asignado indistintamente INF-EST-8-9-ELE

\begin{tabular}{|l|l|l|}
\hline G4 & $\begin{array}{l}\text { INF-EST-8-9-ELE - Grupo de informantes } \\
\text { constituido por estudiantes del último semestre } \\
\text { de graduación de Letras lengua española. }\end{array}$ & $\mathbf{1 7}$ \\
\hline
\end{tabular}

A modo de contextualización, la oferta de grado en ELE en este Estado se inicia mucho después de iniciado en el resto del país, en la capital del Estado solo en 2006 una IES y en 2009, otra, pero antes de estas dos ya había otra IES que tuvo su primer grupo de egresados en 2004. De cualquier forma, el número de estudiantes que finalmente culminaba la carrera se limitaba a un número promedio de 8 o 10. 
Al día de hoy, el número de estudiantes en fin de curso tiende a ser menor o a mantenerse, y señalamos para justificar el número de participantes de este estudio. Para nosotros es un trabajo bastante válido porque puede ser que a pleno camino de este análisis no surjan factores que expliquen el abandono de la carrera, muchas veces en el primer tercio de realización.

\subsubsection{Descripción de los datos, instrumento de investigación y formateo}

Bien, describiendo nuestros datos, se trata de una encuesta aplicada a 17 estudiantes de grado del último bimestre de formación ${ }^{110}$, la mayor parte prácticamente solo espera realizar la lectura del Trabajo Final de Curso (TFC).

El instrumento de investigación, la encuesta 3, consta de 9 preguntas que serán presentadas y ampliadas según los datos obtenidos y paso a paso.

Cuadro 29 Preguntas de encuesta 3

\begin{tabular}{|c|c|c|}
\hline $\mathbf{N}^{\mathbf{0}}$ & PREGUNTAS - ENCUESTA 3 & GRÁFICO \\
\hline 3 & $\begin{array}{l}\text { ¿En qué porcentaje considera Ud. que las clases de las } \\
\text { asignaturas específicas ya cursadas o cursando son dictadas } \\
\text { en español? }\end{array}$ & $\begin{array}{c}\text { Gráfico } \\
13\end{array}$ \\
\hline 4 & ¿Ha estudiado Ud. los marcadores del discurso? & $\begin{array}{c}\text { Gráfico } \\
14\end{array}$ \\
\hline 5 & $\begin{array}{l}\text { Si ha dicho Sí en la pregunta anterior, marque las asignaturas } \\
\text { en las que ha visto este tema. }\end{array}$ & -.- \\
\hline 6 & $\begin{array}{l}\text { Si su respuesta en (4) ha sido Sí marque la/s alternativa/s que } \\
\text { considere pertinente/s sobre MD: } \\
\text { a) Son unidades lingüísticas } \\
\text { b) Son variables, tienen género y número } \\
\text { c) Guían un discurso } \\
\text { d) Tienen función sintáctica } \\
\text { e) Condicionan el discurso } \\
\text { f) Dan espacio a inferencias } \\
\text { g) Son responsables por la fluidez oral y/o escrita }\end{array}$ & $\begin{array}{l}\text { Cuadro } \\
\qquad 30\end{array}$ \\
\hline
\end{tabular}

110 El formulario de la encuesta 3 se encuentra en el apéndice 2. 


\begin{tabular}{|c|c|c|}
\hline 7 & $\begin{array}{l}\text { ¿Considera que los MD son responsables de una mejor fluidez } \\
\text { oral y escrita? }\end{array}$ & $\begin{array}{c}\text { Gráfico } \\
15\end{array}$ \\
\hline 8 & $\begin{array}{l}\text { ¿Considera Ud. que los MD están más presente en: } \\
\text { a) la expresión oral? } \\
\text { b) la expresión escrita? } \\
\text { c) no sabe } \\
\text { d) en ambos? }\end{array}$ & $\begin{array}{c}\text { Gráfico } \\
16\end{array}$ \\
\hline 9 & $\begin{array}{l}\text { Marque la alternativa en donde haya un MD: } \\
\text { a) Se refiere a una comida especial, con todo. } \\
\text { b) No lo escuches, en cualquier caso. } \\
\text { c) Así, es ridículo lo que dices. } \\
\text { d) En una palabra, está feliz con lo suyo } \\
\text { e) Por un lado, ella admitía su error y por otro, también } \\
\text { se arrepentía } \\
\text { f) En cualquier caso, lo recompensaré. } \\
\text { g) Con todo, no pienso ceder. }\end{array}$ & $\begin{array}{c}\text { Cuadro } \\
31\end{array}$ \\
\hline
\end{tabular}

(Datos de investigación)

\subsubsection{Descripción de los parámetros de análisis}

Las preguntas 1 y 2 de la encuesta 3 indagan a tono de confirmación del informante si este es estudiante del último semestre de formación docente, a lo que los 17, el G4, responde que sí; y pregunta si aún existen asignaturas inconclusas, a lo que contestan que no. O sea estos estudiantes no recibirán ningún otro contenido programático inherente a su formación específica, información necesaria para poder continuar con la encuesta.

La tercera pregunta de la encuesta 3 indaga el porcentaje de español en las clases de asignaturas específicas impartidas (en español), estas respuestas las presentamos en el gráfico 13: 
Gráfico 13 Respuestas pregunta 3 de encuesta 3 sobre MD.

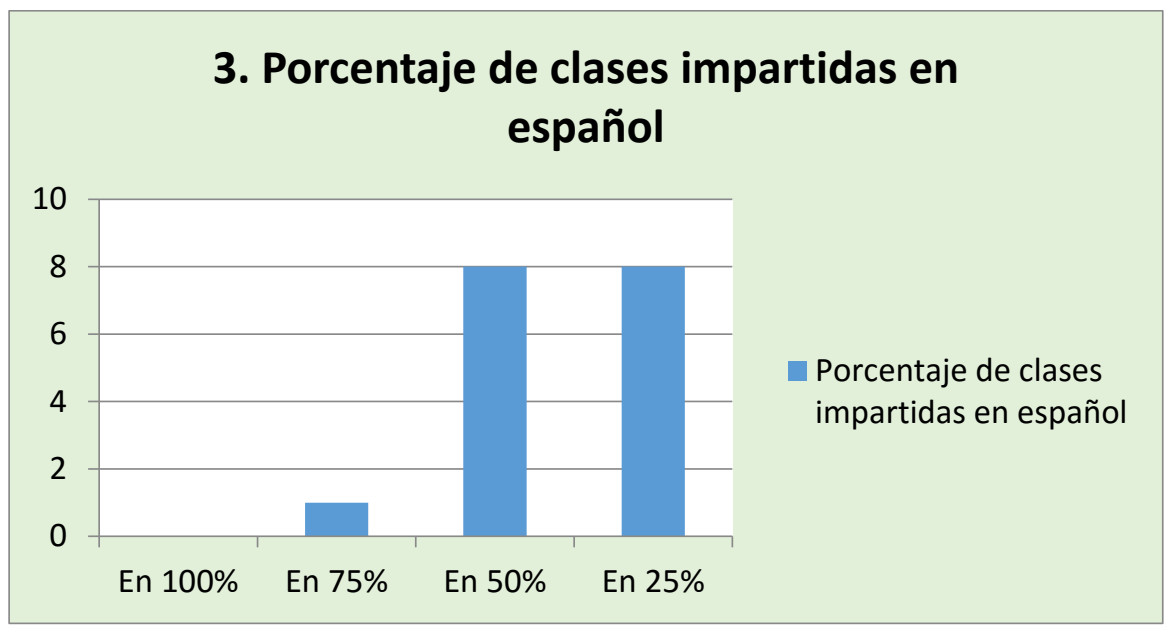

(Datos de investigación)

Una respuesta obvia de los informantes del G4 es que impartir la totalidad de las clases de las asignaturas específicas en lengua española, como está previsto y sería lo esperado, es algo que claramente no ha ocurrido en su formación. Uno de los informantes se ha dado en un $75 \%$ del total de las clases de las asignaturas específicas, mientras que para 8 ha sido en un 50\%, o sea que la mitad del tiempo la comunicación se hacía en español y la otra mitad en lengua materna, portugués; para los otros 8 informantes solo hubo español en un $25 \%$.

En la pregunta 4 se aborda directamente el tema de los marcadores discursivos indagando sobre su estudio en algún momento de la formación docente, aunque las respuestas nos parecieron dadas sin certeza, conseguimos registrar que solo 3 informantes admitían haber estudiado los MD, otros 6 informantes dijeron que 'no, que aún no' los habían estudiado y 8 dijeron que no recordaban si los habían estudiado o no.

Haber evidenciado esa vaguedad sobre haber visto o no el tema de los MD durante la graduación es un indicador de desvalorización hacia la fluidez y dominio de lengua que estas partículas pueden propiciar. En el gráfico 14 vemos objetivamente estas respuestas: 
Gráfico 14 Respuestas pregunta 4 de encuesta 3 sobre MD.

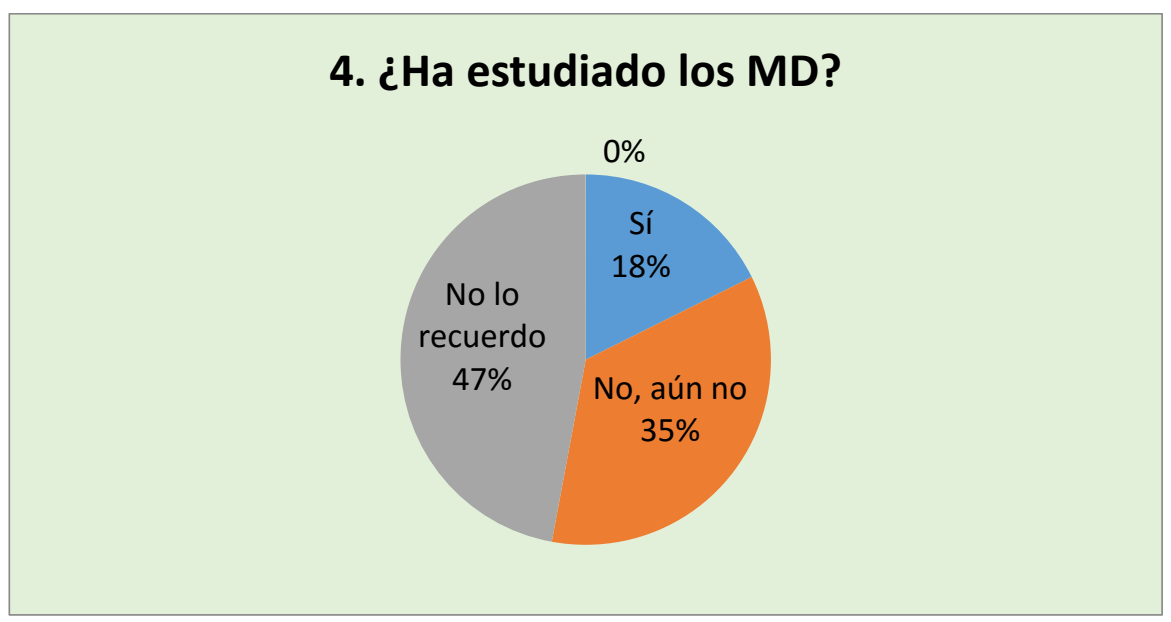

(Datos de investigación)

La quinta pregunta, dado el condicionamiento de la respuesta anterior, solo pudo ser respondida por 3 informantes, pues los otros catorce no estudiaron o no recuerdan haber estudiado los MD a lo largo de la formación docente. Los tres informantes que dijeron que sí habían visto los MD en asignaturas de formación docente, al ver la enumeración de las asignaturas específicas o la posibilidad de escribir el nombre de aquella en la que estudió los MD, no consiguió hacerlo y marcó la respuesta 'En otras', pero más adelante escribieron, 'no lo recuerdo'. De esta manera, tenemos una situación levemente diferente, estos casi profesores de ELE sí habían estudiado los MD, pero no tenían claro en qué asignatura, o sea, termina confirmándose el amplio universo de posibilidades que hay sobre si de hecho los MD fueron presentados como elementos de valor para el aprendizaje de ELE tanto en la oralidad como en el discurso escrito, o si no lo fueron; el intento serio de dotar al aprendiente de esta información que contribuiría fuertemente a su dominio y fluidez de la lengua no podría estar tan frágil en la formación de los futuros profesores de ELE.

Algo semejante ocurre con la pregunta 6 de esta encuesta, la condición para contestarla es haber dicho sí en la pregunta 4 y según eso, son tres los informantes que registraron el siguiente resultado: 
Cuadro 30 Respuestas pregunta 6 de encuesta 3 sobre MD

\begin{tabular}{|c|c|c|c|c|c|c|c|}
\hline $\begin{array}{l}\text { Nuestra } \\
\text { respuesta }\end{array}$ & Sí & No & Sí & No & Sí & Sí & Sí \\
\hline INF3 & Sí & Sí & Sí & Sí & Sí & Sí & No \\
\hline INF2 & Sí & Sí & Sí & Sí & Sí & Sí & Sí \\
\hline INF1 & Sí & No & Sí & Sí & Sí & Sí & Sí \\
\hline 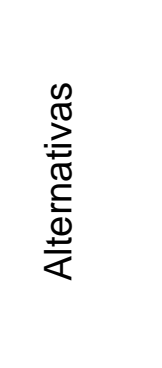 & 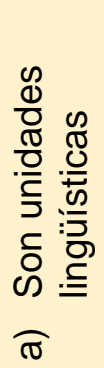 & 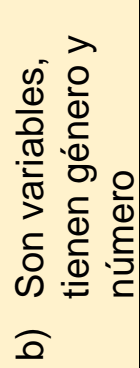 & 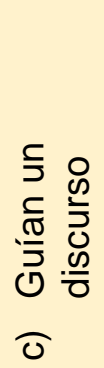 & 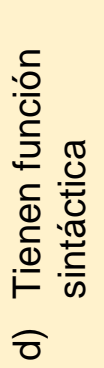 & 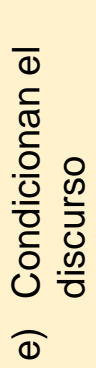 & 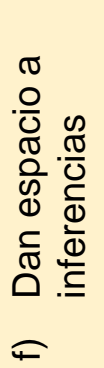 & 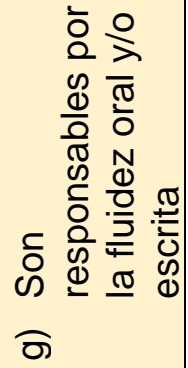 \\
\hline
\end{tabular}

(Datos de investigación)

El INF1 señaló que todas las alternativas estaban correctas menos la 'b', y claro, los MD son invariables, no tienen género ni número, entonces bien, pero se equivocó al decir que los MD tienen función sintáctica.

El INF2 señaló que todas las alternativas contenían información correcta respecto a los MD, no obstante sabemos que no, que las afirmaciones de 'b' y 'd' no están correctas, lo que comprueba que este informante, futuro profesor de ELE no detiene la información adecuada sobre las partículas discursivas, que el tema no está claro en aspectos conceptuales de los MD.

La séptima pregunta de esta encuesta fue contestada por el G4 en su totalidad y el resultado sigue confirmando lo que venimos sospechando desde la observación del resultado de la propia práctica cotidiana actual, categóricamente solo dos informantes afirman que los MD son responsables por una fluidez oral y escrita, 6 dicen que no, que quizás lo sean, pero no tanto y los otros 8 admiten que no lo saben, que no lo ven claro. Apreciemos el gráfico: 
Gráfico 15 Respuestas pregunta 7 de encuesta 3 sobre MD.

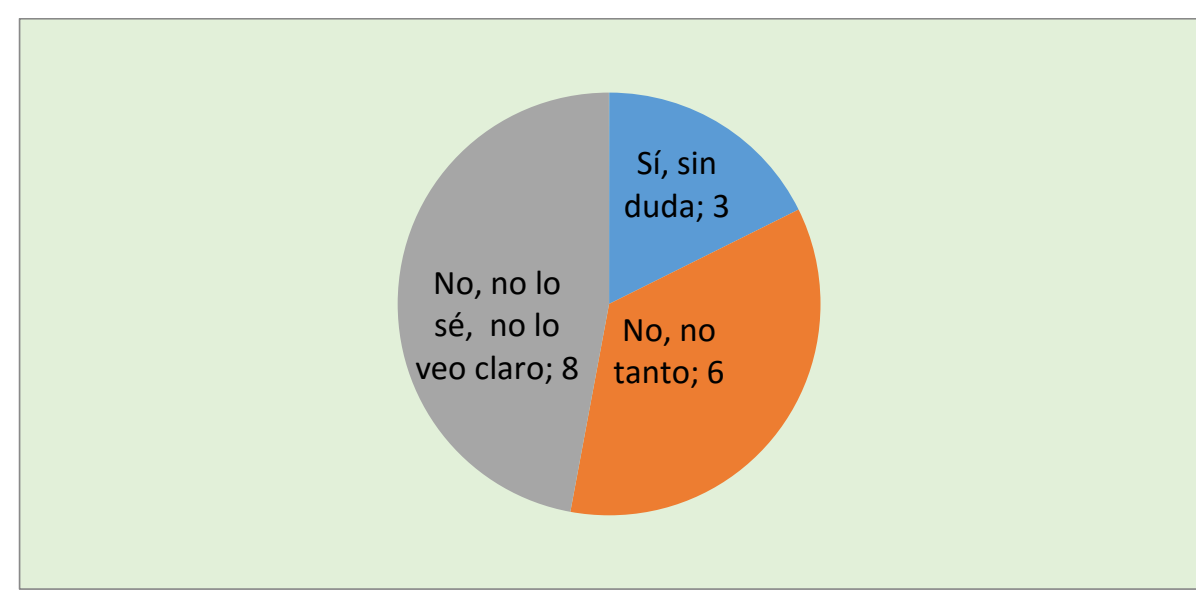

(Datos de investigación)

Indagamos sobre el conocimiento de los estudiantes del último semestre de curso de grado en ELE en la pregunta 8; hemos preguntado si consideraban que los MD estaban más presentes en la expresión oral, en la escrita, o en todo caso si no lo sabía o si lo veía en ambas formas, presente en la expresión oral y escrita. Las respuestas se distribuyeron entre las tres primeras alternativas, expresión oral, expresión escrita y no sabe. Ninguno de los informantes dijo que los MD estuvieran en ambas formas de expresión, lo que vamos viendo como algo preocupante.

Gráfico 16 Respuestas pregunta 8 de encuesta 3 sobre MD.

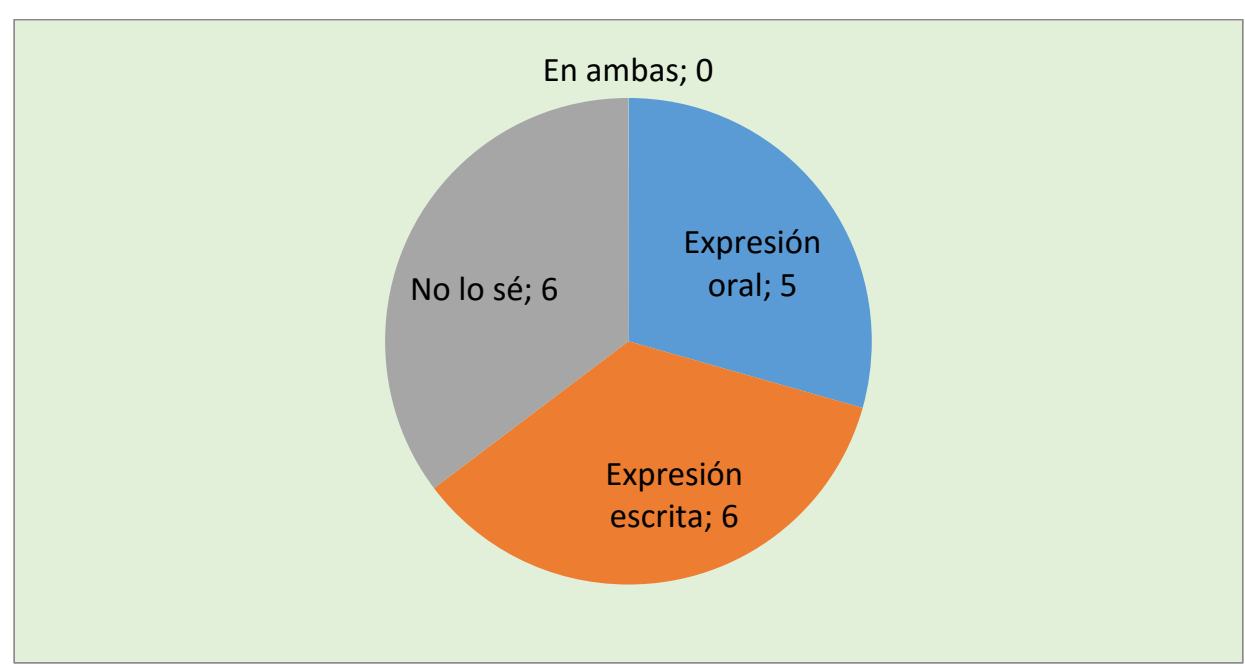

(Datos de investigación) 
En la novena pregunta de nuestra encuesta, hemos puesto a prueba, al menos, la idea de lo que sería un MD hilando informaciones más allá de lo propiamente dicho, hilando contextos y haciendo uso apropiado del discurso aplicando MD.

Le pedimos a nuestro informante que marque una alternativa en la que considere que haya aplicación de un MD y el resultado ha sido de lo más variado, veámoslo en el cuadro siguiente:

Cuadro 31 - Respuestas pregunta 9 de encuesta 3 sobre MD

\begin{tabular}{|c|c|}
\hline \begin{tabular}{|} 
9. Marque la alternativa en donde haya un MD: \\
Alternativas de la pregunta 9
\end{tabular} & $\begin{array}{c}\text { No Informantes que } \\
\text { señalaron } \\
\text { presencia de MD }\end{array}$ \\
\hline a. Se refiere a una comida especial, con todo. & 3 \\
\hline b. No lo escuches, en cualquier caso. & 4 \\
\hline c. Así, es ridículo lo que dices. & 5 \\
\hline d. En una palabra, está feliz con lo suyo & 0 \\
\hline e. Por un lado, ella admitía su error y por otro, \\
\hline también se arrepentía & 1 \\
\hline f. En cualquier caso, lo recompensaré & 2 \\
\hline g. Con todo, no pienso ceder. & \\
\hline
\end{tabular}

(Datos de investigación)

El resultado obtenido discrepa drásticamente de lo adecuado, pues entre las alternativas propuestas, solo hay una que no contempla aplicación de MD, la respuesta ' $a$ ' - 'Se refiere a una comida especial, con todo' En este contexto, ' con todo' se refiere a todo lo previsto para tal comida, no falta nada, está todo. Este uso, se nota y contrasta claramente diferente, y además, colocado adrede, al 'con todo' de la alternativa ' $g$ ' el que infiere una situación que desencadena la decisión de no ceder 'Con todo, no pienso ceder' se trata de un MD reformulador, aparentemente de distanciamiento al presentar como no relevante cualquier situación anterior y prevalecer la nueva como condición 
final, ocurre lo mismo en la alternativa 'b' - 'No lo escuches, en cualquier caso' y en la 'f' también.

A pesar de lo estrecho de las aseverativas presentadas a nuestro informante, es perceptible a las claras la marca de un contexto que está en lo subrepticio del MD, cuestiones que se infieren por la sola presencia de este tipo de palabras en la función de un MD.

En la alternativa 'd' vemos un reformulador explicativo, pues presentan el miembro del discurso que introducen aclarando lo que se ha querido decir en otro u otros miembros anteriores buscando dejar bien claro lo que se quiere comunicar.

En 'e' tenemos marcadores estructuradores de la información del tipo 'ordenadores', para decir algo así, definitivamente hay un discurso anterior que resulta en este tipo de afirmaciones.

\subsubsection{Preguntas de investigación}

Tras conocer el resultado de la encuesta, nos sentimos bastante respaldados para extraer determinadas conclusiones respecto a la relación que existe entre los marcadores del discurso y los estudiantes de grado del último semestre de formación docente; no obstante, procedemos a la formulación de nuestra pregunta de investigación $(\mathrm{PI})$ y su respectiva hipótesis $(\mathrm{H})$ :

\section{PI-6 - ¿La enseñanza de los MD en la formación docente en ELE carece de profundidad y valoración como elementos generadores de fluidez y dominio de lengua?}

(H11) - Los MD no forman parte del dominio oral y escrito de los docentes de grado, consecuentemente, aunque se presente el contenido, su papel se reduce a contenido y no a asimilación y aglutinación de elementos que estén presente en la oralidad y escritura del estudiante de ELE. 
(H12) - El uso de marcadores discursivos en la identidad de la lengua española es diferente del de la lengua portuguesa, lengua materna de los aprendientes de ELE, futuros profesores.

\subsubsection{Análisis empírico parcial}

Para poder afirmar la carencia de profundidad y valoración de los MD como elementos generadores de fluidez y dominio de lengua haría falta constatar, primero, la presencia o no de este contenido en el plan de estudios de las IES que ofertan el curso de grado en ELE, cuestión que a priori ya presenta una respuesta parcial ${ }^{111}$ al no contar con asignaturas obligatorias del ámbito funcional en la oferta de grado en la mayoría de las IES, asignaturas como Pragmática, semántica-pragmática, sociolingüística, ente otras que suponemos deban contemplar en su contenido programático unidades funcionales como lo son los marcadores del discurso, esto último será investigado en el punto 4 de esta investigación.

Segundo, poder contar con la convivencia académica como un elemento más que contribuya al aprendizaje de partículas discursivas, inclusive dentro de la clase de ELE es una cuestión que puede no estar garantizada, porque para ello tendría que haber desempeño oral suficiente en los docentes de grado y voluntad para que la práctica de la oralidad no se resuma al aula, del mismo modo de parte de los estudiantes.

El uso de MD es semejante en las lenguas, su función es la misma, articular el discurso, no obstante, el brasileño ve la lengua española como algo aparentemente "transparente", muy parecido y en esta creencia, va construyendo y con el tiempo fosilizando lo que no existe, en otras palabras va inventando su modo de hablar español y con ello, al graduarse, va a ser profesor, por consiguiente 'modelo' de quien busca aprender en la educación básica. A lo dicho, traducir MD no ayuda, más bien perjudica.

${ }^{111}$ Visto en el capítulo 1 - Estado de la cuestión. 


\subsubsection{Los MD en la producción escrita de los estudiantes de grado en ELE}

Lo que nos mueve a realizar esta investigación es sin duda la preocupación por la calidad de la enseñanza y del aprendizaje de lengua española tanto en el desempeño oral como en el escrito de todos aquellos que por las razones que fuera se interesen en cultivar el idioma español.

En este proceso están de forma general los que aprenden y los que enseñan, estos últimos que a su vez aprenden en un determinado momento para la finalidad posterior 'enseñar lengua española'; este grupo de personas tiene un rol especial que los coloca en una situación de responsabilidad y compromiso consigo y con la sociedad que más adelante va a involucrar en el ejercicio de su profesión.

Hemos sentido la necesidad de traer a estudio la producción escrita de estudiantes del último semestre de grado en una actividad directamente relacionada con MD. Se trata de producir un texto libre teniendo en cuenta lista explícita de MD del que pueden extraer los elementos que otorgue a su producción concatenación, armonía y sobre todo que exprese adecuadamente las ideas que en él se desean plasmar.

La denominación como grupo de estos informantes sigue siendo la de G4, los informantes y sus textos respectivos obedecen un código que será el que los identificará.

\begin{tabular}{|l|l|l|}
\hline G4 & $\begin{array}{l}\text { INF-EST-8-9-ELE - Grupo de informantes } \\
\text { constituido por estudiantes del último semestre } \\
\text { de grado en ELE. }\end{array}$ & $\begin{array}{l}\text { Tx-INF-EST-8-9-ELE } \\
\text { identificación de los textos de } \\
\text { este grupo de informantes. }\end{array}$ \\
\hline
\end{tabular}

\subsubsection{Descripción de los datos, instrumento de investigación y formateo}

Los datos provienen de una actividad escrita especialmente aplicada en clase de ELE sobre MD para esta investigación. Los MD son ofrecidos a los estudiantes en lista como si se tratara de un banco de recursos lingüísticos. En la actividad se le solicita que produzca un texto libre de tres párrafos en el que contextualice al menos la mitad de los marcadores propuestos, siendo estos: 
Por otra parte - además - así que - es más - encima - por cierto - sin embargo esto es - por consiguiente - en cambio - de todos modos - es decir - aunque con todo - de ahí que - no obstante - de hecho - en suma - a propósito - a todo esto - antes bien - eso sí - entonces - en definitiva - en todo caso

Fueron 13 los textos producidos, que en primeras observaciones presentan un uso semejante de los MD en relación a los elegidos y a la propia aplicación de estos, por tal razón se han seleccionado solo 5 para ser analizados en este estudio. No obstante, los 13 textos forman parte del apéndice 4 donde están identificados correlativamente, iniciándose con TX-INFEST-8-9-ELE-01, fielmente transcritos de su documento original, también incluido.

Para realizar el análisis recogemos los fragmentos del texto producido por el informante que contengan MD destacados por él mismo. No apreciaremos la producción de texto con MD que el informante no haya destacado por considerar que la producción no ha sido consciente, aunque expresamos lo interesante que sería hacerlo para verificar que es posible lograr fluencia y conocimiento de aplicación de estos marcadores en la lengua que aprenden a partir de su inconsciente lingüístico de la lengua materna. Pero, tratar de este tema sería desviarnos del objeto de nuestro estudio que es ahora mismo verificar la fluencia y dominio de la lengua española a través del conocimiento y aplicación de los MD por los estudiantes de grado, futuros profesores reciben el contenido del tema de los MD durante su formación académica.

De esta forma, hemos seleccionado una muestra de 5 de los 13 textos informados a partir de los cuales se irán tejiendo nuestras observaciones.

\subsubsection{Descripción de los parámetros de análisis}

De entrada puede parecer exagerado preocuparse por la calidad de los nuevos profesores, algunos compañeros de profesión parecen no entenderlo: es como si no pasara nada, lo normal es eso, qué tanto bullicio sobre este tema de la calidad del profesor de lengua extranjera. Por el contrario, nosotros 
pensamos que es el punto clave que puede librar el destino del aprendizaje y enseñanza de español en Brasil de un conformismo y pasividad como el que ya existe en inglés, por ejemplo, cuando hablamos de la educación básica.

Entonces, en el texto Tx-INF-EST-8-9-ELE-01, de entrada ya, es muy difícil admitir que sea de un estudiante de grado en ELE del último semestre de carrera, pero como habíamos dicho antes, nos atendremos al foco directo del uso de los MD en la producción del texto. De esa forma, el informante ha aplicado: de todos modos, a propósito, además, en definitiva, con todo y por cierto, todas, partículas discursivas extraídas del grupo de MD sugeridos para uso en la redacción.

Fragmentos del contenido TX-INF-EST-8-9-ELE-01

1. Se yo fuera presidente, trataría de se buena, (1) de todos modos, para que después las persona hablase (2) a propósito muy bien de yo, [...]

2. Trataría de hacer cosas buenas como ayuda los pobres, íso es muy importante (3) además los niños que no tiene que come y no tiene nada y (4)en definitiva lo que vesti, (5)con todo, yo tamben trataría de hacer doaciones de cosas,(6) por cierto yo lastimo las personas que no tiene onde vivir, $[\ldots]$

(1) tiene desempeño dudoso, a pesar de estar entre comas y a juzgar por el contexto es como si quisiera decir que trataría de ser buena de todos los modos, de todas las maneras y de esta forma no sería la función del MD de reformulador de distanciamiento la que estaría desempeñando en esa construcción;

(2) Igual, el uso de a propósito no está funcionando como MD estructurador de información, digresor, más bien como equivalente semántico de adrede;

(3) Además se presenta como sinónimo de también, situación que pone en duda la función de conector aditivo, el informante no reconoce la función de los MD, su aplicación no está siendo adecuada;

(4) En definitiva puede ser que haya sido aplicado como un MD, no obstante, la duda permanece.

(5) El conector contraargumentativo 'con todo' parece estar cumpliendo la función para la que existe, no obstante si seguimos la articulación del 
discurso, notamos que la orientación no es del todo contraria como debería serlo al aplicar este conector.

(6) El digresor, estructurador de información 'por cierto' parece estar ejerciendo la función de $M D$, no obstante la construcción de la idea es un tanto sin sentido en la comprensión de la lengua española.

En conclusión, el texto Tx-INF-EST-8-9-ELE-01 ha sido redactado para atender una demanda, pero sin la información ni el dominio que se esperaría de un estudiante de grado de fin de carrera en ELE. Se nota que el informante ha intentado en todo momento traducir literalmente las partículas y es como lo dice PORTOLÉS:

Quien traduce un marcador discursivo debe pensar qué instrucciones de procesamiento proporciona y qué enriquecimiento pragmático se ha conseguido gracias a él. PORTOLÉS (2011: 147)

Dicho esto, vamos a presentar ahora el texto Tx-INF-EST-8-9-ELE-03 en el que el informante ha aplicado los siguientes MD: a propósito, esto es, además, por otra parte, entonces, con todo eso, de hecho a todo esto. Observemos los fragmentos de textos:

\section{Fragmentos del contenido TX-INF-EST-8-9-ELE-03}

1. Señor Jose, escribo para te recuerdar que faltan menos de cuatro dias para su estadía en nuestro hotel, (1) a propósito recuerdamos también que [...]

2. en nuestro sistema no cuesta su pagamiento (2) esto es, sin su pagamiento usted se queda imposibilitado de se hospedar.

3. usted puede estar haciendo eso pagamiento personalmente en el día de la hospedaje o en depósito bancário, (3)además, usted también tiene la opción de pagar dejando el dinero encima de la televisión, (4)por otra parte, nuestros camareros poderán recibir su pagamiento

4. (5)Entonces Señor Jose, (6) con todo eso aguardamos [...]

5. [...] es más fácil una comunicación por teléfono, (7) de hecho de un movile. (8) A todo esto, muchas gracias por atención.

Los fragmentos son de un texto del género carta comercial, una vez más, es un poco difícil aceptar que se trata de la producción de un estudiante 
de grado en ELE del último semestre de formación, pero igual vamos a enfocar de hecho la presencia adecuada o no de los MD en esta redacción.

(1) El informante ha aplicado a propósito adecuadamente, MD digresor que estructura la información cumple en este fragmento de texto la función de MD.

(2) Esto es, reformulador explicativo cumple la función de MD en el contexto, pues aclara o explica lo que se ha dicho antes.

(3) Además, uno de los MD más usado por el luso hablante en su versión além do mais, lo usa es un conector aditivo, perfectamente adecuado al contexto.

(4) 'Por otra parte', no está cumpliendo satisfactoriamente su papel, la construcción no es adecuada, no es lógica, además no es un MD en este contexto.

(5) Entonces, conector discursivo, sí está bien aplicado en la función de marcador discursivo

(6) Con todo (eso), no es un conector contraargumentativo en el uso dado por el informante, no está presentándose como supresor o atenuador de lo expuesto en el miembro anterior, por lo tanto no es un marcador discursivo

(7) De hecho, como MD, operador de refuerzo argumentativo, es posible atribuirle idoneidad en la construcción de (7) pero al no salir de una relación como de subordinación de idea y no de refuerzo de argumento anterior.

(8) A todo esto, en el contexto cumple su rol digresor que estructura la información. Este es uno de los MD que tiene perfil difícil para el aprendiente brasileño de español.

Ahora comentaremos el texto Tx-INF-EST-8-9-ELE-04, en el que se han aplicado los siguientes MD: esto es, en todo caso, entonces, además, por consiguiente, a propósito, por cierto y en suma. Observemos los fragmentos del texto producido, una redacción: 


\section{Fragmentos del contenido Tx-INF-EST-8-9-ELE-04}

1. Em septiembre estoy de viaje para el Ceará - (1)esto es se yo terminar el curso [...], (2)en todo caso tengo que irme en definitivo porque meo esposo ja esta viviendo alla, (3)entonces terminado pelo menos las asiguinaturas yo me voy.

2. Por otra parte me quedó preocupada pela posibilidad de no terminar por completo el curso, (4)además de quedó preocupada pela distancia y [...]

3. (5)Por consiguiente voy estar más tranquila sin las asiguinaturas.

4. (6)A propósito conocí la ciudad y [...], (7)por cierto las personas también son agradables y receptivas.

5. (8)En suma no inicio vay ser difícil [...].Sin embargo voy estar con me esposo y con cierto tiempo voy acustumarse.

Procediendo al análisis:

(1) El reformulador explicativo 'esto es' ejerce la función de MD a pesar de la redacción, su aplicación es adecuada.

(2) Igualmente a 'en todo caso', reformulador de distanciamiento bien aplicado para expresar una nueva formulación en su discurso.

(3) En el fragmento 1 está la aplicación de 'entonces' desempeñando el papel de conector consecutivo.

(4) 'además' es un conector aditivo que cumple la función de unir a un miembro anterior a otro que vaya en la misma dirección.

(5) Actuando como conector consecutivo 'por consiguiente', relativamente bien estructurado.

(6) En el fragmento 4 tenemos la aplicación de 'a propósito', digresor, estructurador de la información con el que el informante introduce una información lateral a la prevista en el discurso anterior (ACíN:2000b en PORTOLÉS, 2011)

(7) Lo mismo pasa con 'por cierto', bien aplicado en este discurso.

(8) El reformulador recapitulativo 'en suma' aplicado en el fragmento 5 cumple con la función y está conectado con la totalidad del discurso. 
También comentaremos el texto Tx-INF-EST-8-9-ELE-06. LoS MD aplicados son: entonces, antes bien, con todo y a propósito. Observemos los fragmentos de la redacción producida:

\section{Fragmentos del contenido TX-INF-EST-8-9-ELE-06}

1. En el mes pasado conocir un chico llamado José, [...] (1) Entonces llamé a José para conocer un poco de mi solo en Natal, [...].

2. Yo aproveche todo el tiempo con José porque él era un chico bueno y me quedé enamorada (2) antes bien de su partida yo compré [...]

3. (3)Con todo él se quedó supreso con mi regalo y me dice que [...]

4. (4)A propósito fue una experiencia buena conocer un chico agradable como José.

(1) Entonces, como conector discursivo, en esta construcción sí está bien aplicado en la función de marcador discursivo. Vamos notando un acentuado uso de este término en la producción en español, consecuencia del uso masivo en la comunicación en lengua portuguesa de Brasil.

(2) El uso de 'antes bien' definitivamente no es correcto como MD, pues este es un conector contraargumentativo que debería presentar al segundo miembro como supresor del anterior y no ocurre esto en la construcción propuesta.

(3) Con todo, es un conector contraargumentativo y en la construcción analizada está presentándose como supresor o atenuador de lo expuesto en el miembro anterior, por lo tanto es un marcador discursivo

(4) 'a propósito' es un digresor, estructurador de información y cumple bien su papel en la construcción presentada.

TX-INF-EST-8-9-ELE-13 contiene los fragmentos del texto producido por un estudiante de ELE del último semestre del curso de grado, quien ha utilizado los siguientes MD: así que, es más, a propósito, además, no obstante, de hecho, por otra parte, por cierto, en suma, de ahí que, sin embargo, aunque y en definitiva. 


\section{Fragmentos del contenido TX-INF-EST-8-9-ELE-13}

1. He aprendido acerca de la família em el plan de nuestro Padre Celestial, (1)así que sé de su gran importancia en nuestras famílias en nuestras vidas, (2)es más en toda la familia humana.

2. (3)A propósito a causa de ellas, todo en el mundo fue y está hecho, es decir, todo el plan de salvación -o como me gusta decir- el plan de felicidad, [...].

3. (4)Además Él nos dío un Salvador y las escripturas para guiarnos. (5)№ obstante, el matrimonio, el ser una familia sigue siendo un desafio. [...] (6)De hecho es no fácil.

4. (7)Por otra parte, el matrimonio puede llegar a ser la cosa que más te dará placer en [...].

5. El amor que hoy tengo por mi esposo, (8) por cierto, llegará ser más y más profundo con el pasar del tiempo.

6. (9)En suma, te adviento, el matrimonio no és y jamás será fácil,(10) de ahí que, muchos 'desisten' o ni llegan a tentar, (11)sin embargo, aunque sea difícil, la verdad es que, vale la pena, (12) eso sí. [...](13) en definitiva, no hay precio.

(1) El uso de 'así que' como conector consecutivo cumple la función de presentar al miembro posterior como una consecuencia del primero.

(2) 'es más' se ordena en una misma escala argumentativa por lo tanto es un conector aditivo bien aplicado.

(3) 'a propósito', (4) 'además', (5) ‘no obstante', (6) 'de hecho', (7) 'por otra parte', (8) 'por cierto', y (9) 'en suma' ya clasificados antes, cumplen bien su función en los contextos aplicados.

(10) Es la primera vez que aparece este conector consecutivo, no obstante cumple la función.

(11) 'sin embargo' otro conector, pero esta vez contraargumentativo, bien aplicado por el informante

(12) 'eso sí' visto como un estructurador de información, digresor, es un marcador de uso bastante atípico en la lengua portuguesa, no obstante en bien aplicado en esta redacción.

(13) 'en definitiva' reformulador recapitulativo, bien aplicado en esta redacción. 


\subsubsection{Preguntas de investigación}

Tomando en consideración los datos presentados, formulamos las preguntas de investigación y sus respectivas hipótesis:

\section{PI-8 - ¿El estar en el último semestre de grado en ELE y el haber tenido acceso a una lista de MD ha permitido a los estudiantes aplicar más MD en su producción escrita?}

(H13) - El uso de los MD está en el uso diario de una lengua, lo que puede significar cierta 'inercia lingüística' para usarlos sin haber tenido un significativo cultivo durante los estudios de grado.

PI-9 - ¿Cuántos marcadores del discurso habrían sido aplicados si no hubiera habido una lista de sugerencias?

(H14) - La tendencia del brasileño es a utilizar las mismas palabras tanto en la oralidad como en la escritura, por eso se supone que no aplicaría más que MD del tipo de 'entonces', 'de ahí', 'por eso'.

\subsubsection{Análisis empírico}

Tras cuatro años de formación académica estos nuevos profesores de español, al hablar o escribir, dejan percibir carencias de lo más diversas y en especial carencias y omisiones de cohesión, coherencia y fluidez en su oralidad y/o en su producción escrita, especialmente la marcada por la aplicación o no de marcadores discursivos de diversos tipos, o en todo caso, su aplicación inadecuada, expresando muchas veces ideas diferentes, incluso contrarias, a aquellas que se desea transmitir. ¿Cómo podemos justificar este resultado? Y sobre todo, ¿qué se puede hacer para mejorarlo?

Puntualmente hablando del desempeño de los estudiantes de grado con relación a los $\mathrm{MD}$, se consigue ver que no hay claridad en la comprensión de 
su uso y de la importancia de eso para lograr fluidez y dominio de ELE. Señal de eso es que de los marcadores del discurso propuestos para la producción escrita, definitivamente no fueron aplicados y cuando sí, no fue del modo correcto: antes bien, en cambio y no obstante, o sea, no los conocían y al no existir o ser de rarísimo uso en su lengua materna, terminan sin espacio de aplicación a lo hora de guiarse lingüísticamente por la lengua materna.

Creemos que al haber tenido acceso a una lista de MD ha permitido a los alumnos arriesgar la aplicación de los mismos, eso se evidencia en la mayor parte de producciones escritas, de otra forma habrían oscilado en las mismas partículas que aplican en el cotidiano de su lengua materna y probablemente aún habría habido que aclararles que era un MD y ejemplificar para que pueda haber una redacción.

\subsection{LOS MD Y EL DOCENTE DE GRADO EN ELE (PRODUCCIÓN ORAL Y ENTREVISTA)}

La propuesta de esta investigación es mensurar la calidad del discurso y la aplicación de los $\mathrm{MD}^{112}$ en la práctica docente oral y escrita de los que forman el profesorado de ELE en IES, lo que consecutivamente afectará positiva o negativamente a aquellos que están en formación y futuramente actuarán en la enseñanza básica.

Partiendo de la lógica de que la responsabilidad del éxito y progreso en el aprendizaje de ELE también recae en la actuación del profesor, se procederá a investigar la fluidez y conocimiento de los MD en la lengua que se enseña, que en mayor o menor proporción, puede ser un dato clave que caracterice el éxito o el fracaso del aprendizaje de ELE en la educación básica y pública.

Enseñanza y aprendizaje se transforma en un círculo del que ambas fases se alimentan: el que aprende, de lo que se enseña, y el que enseña, del que aprende. Los profesores siempre estamos diciendo que nos hacemos

\footnotetext{
112 Los marcadores del discurso son unidades lingüísticas invariables que no ejercen función sintáctica en la construcción, sino en el discurso y son elementos que relacionan unidades de discurso y guían las inferencias que se realizan en la comunicación (MARTÍN y PORTOLÉS, 1999)
} 
mejores profesores siéndolo, desempeñando la tarea, ese también es nuestro pensamiento.

\subsubsection{Producción oral de los docentes de grado en ELE}

En este trabajo de investigación nos detenemos a observar el uso de los MD en la oralidad del docente de grado. Para tal finalidad se hicieron grabaciones con autorización de los respectivos docentes y de ese material vamos a presentar aquí un fragmento seguido de más o menos la mitad del discurso total de dos de los 6 informantes que se dispusieron a colaborar con este trabajo. Los textos transcritos de los docentes se identifican así:

\section{TX-INF-PROF-00 Texto - del informante docente de grado en ELE}

Ahora procedemos con los materiales propiamente dichos:

\subsubsection{Descripción de los datos, instrumento de investigación y formateo}

Los datos son los textos Tx-INF-PROF-01 y Tx-INF-PROF-02 recogidos a través del instrumento de investigación grabación de audio. Han sido grabaciones de 3min.53seg. y 3min.54seg., respectivamente, transcritos ortográficamente en su totalidad y constan en el Anejo 5 junto con las convenciones de transcripción aplicadas.

A partir de la observación previa del contenido de los audios y teniendo en cuenta que el único objetivo es sobre la presencia o no de los MD, hemos estimado conveniente presentar un recorte de la transcripción para ser analizada, cuya proporción aproximada es del 60\% de la grabación total. Esta decisión ha sido tomada debido a la repetición de los MD aplicados y a la no aparición de nuevos.

Presentamos el formateo de los datos de investigación antes descritos: 


\section{PRODUCCIÓN ORAL DOCENTE DE GRADO - TX-INF-PROF-01}

Entonces vamos empezar hablando un poco acerca de las signaturas las cosas que están ocurriendo acá () estamos terminando el semestre y entonces los alumnos ya presentaron los proyectos de TCC $\mathbf{y}$ también é:: hubo la:: hubo una fiesta para conmemorar el día del libro $\mathbf{y}:$ : los alumnos participaron cerca de unos treinta a cuarenta alumnos estaban allá $\mathbf{y}:$ lo/ la cosa más importante del evento fue la premiación de las poesías que fueran veintinueve poesías pero las tres mejores fueran de Brasilia la primera y la segunda fue de San Pablo y la tercera que fue de acá () Y por tanto solo estaba presente é:: la persona del tercer lugar y el director dice que para este seria dado una beca para un curso de FUNCERN que iba a estudiar lo que quiera () Puede ser que iba a estudiar inglés o español no sé lo que va a elegir pero creo que va a ser el español () $\underline{Y}$ también é:: ayer fue presen/ fueron presentados los proyectos integradores de los periodos de tercer periodo y quinto periodo () y los alumnos presentaron é:: temas de:: enseñanza de lenguas y muchos de ellos presentaron estrategias para utilizar músicas en clases de español como lengua extranjera en la escuela () otros presentaron juegos () pero lo más interesante fue cuando presentaron telenovelas para la enseñanza de español como lengua extranjera ()

$/ / \ldots$

\section{PRODUCCIÓN ORAL DOCENTE DE GRADO - Tx-INF-PROF-02}

\section{...II}

Cuando yo tenía diez años () desde niña que yo pasaba/ yo paso las vacaciones en::/ en la casa de mi abuela () Entonces como siempre en una vacacione () una de estas vacaciones me fue a casa de mi abuela $\mathbf{y}:$ : mi tía me pidió para volver antes como un mes antes () Entonces volví pero no comprendí muy bien cuando llegué a casa estaba todo muy diferente () No estaba mi papá porque:: estaba enfermo () descubrió un como que un día siguiente a mi viaje entonces descubrió que estaba enfermo $\mathbf{y}$ cuando llegué a casa ya no estaba () Estaba en el hospital $\underline{y}$ no pude visitarlo porque tenía diez años solamente $\mathbf{y}$ no querían decirme lo que era () Entonces solo he visto mi papá antes de las vacaciones por que cuando volví ya no estaba en casa $\mathbf{y}$ quince días después se moreu_y:: mi mamá estaba embarazada y perdió el:: mi hermano la misma época entonces fueron días muy difíciles para todos porque yo tenía un::/ una familia y cuando volví porque ya no tenía hermano tampoco papá y ya no tenía nada más () Pero:: todo fue superado y:: ahora está todo muy bien () Sigo sin hermanos porque mi mamá se ha casado pero no ha tenido más hijos $\mathbf{y}:$ : ahora se ha divorciado estamos solamente ella y yo () Pero yo en Natal y ella viviendo solita en Fortaleza () Pero sigue bien y quizá un día cuando esté jubilada venga a viver conmigo aquí en Natal

\subsubsection{Descripción de los parámetros de análisis}

La más pura de las verdades es que nunca lo sabremos todo y que no nos alcanza la vida para ello; no obstante esta reflexión, lo que no puede 
detenerse en un profesor es aproximarse más y de la mejor manera al conocimiento que les debe a los que se ponen en sus manos para recibir una formación profesional; sobre todo, porque sobre esos, más adelante, la confianza de la sociedad al poner en sus manos la educación básica de los hijos.

En los textos informados Tx-INF-PROF-01 y Tx-INF-PROF-02, es perceptible un desempeño oral parecido; los MD aplicados en ambos son: entonces, $y$, pero Es relevante manifestar que las grabaciones fueron realizadas por separado y de forma absolutamente sigilosa.

Los marcadores discursivos aplicados son los mismos que están muy presentes en el desarrollo oral cotidiano en la lengua portuguesa, lo que puede significar que estos profesores tampoco han accedido durante su formación de grado en ELE al contenido MD y, por consiguiente, no han notado la sensible ausencia de estos en su desempeño en ELE.

En el Tx-INF-PROF-01, el MD entonces fue aplicado 2 veces, el MD y 7 veces, el MD pero 2 veces y el MD por lo tanto solo 1 vez, y a propósito. Es el único diferente en los dos textos en cuestión.

En el Tx-INF-PROF-02, el MD entonces fue aplicado 5 veces, el MD $\boldsymbol{y}$ 11 veces y el MD pero 4 veces, sin ningún otro.

\subsubsection{Preguntas de investigación}

De acuerdo con los datos presentados, planteamos las preguntas de investigación y sus respectivas hipótesis:

PI-10 - ¿Por qué los MD no forman parte de los contenidos y de la propia práctica de los docentes de grado si es que estos conocen la teoría y la práctica?

(H15) - Los docentes de grado conocen poco, quizás no lo suficiente, pero el problema parece más bien estar en la poca valoración que otorgan a estas partículas como elementos clave que contribuyen a la fluidez y dominio de ELE, 
además buscan llenar el vacío de la articulación en el discurso echando mano de lo que hay al respecto en su lengua materna.

\section{PI-11 - ¿Los docentes de grado enseñan en los estudios de grado la teoría y la práctica de los MD en ELE?}

(H16) - Los docentes enseñan lo que consta en los contenidos programáticos del plan de estudios, documento que es construido por un grupo de profesores de diversas áreas, no solo por especialista en lengua.

\subsubsection{Análisis empírico}

En general y por lo expuesto, lo que nos parece obvio es que los MD no están presente en la oralidad del docente de grado de IES del nordeste brasileño. En cualquier caso y partiendo del refrán, 'Para muestra, un botón', comprobamos que hay docentes de grado que no tendrían la posibilidad de estimular el uso de los MD en la convivencia académica, justo por lo visto aquí: no forman parte de su propio conocimiento lingüístico, por lo tanto, cómo podrían enseñarlo, aplicarlo y mostrarlo en la práctica.

Por otro lado, en el caso de constar como contenido programático en alguna o algunas asignaturas del plan de estudios, los MD no pasan al nivel pragmático, permanecen como un conocimiento teórico que no alimenta la fluidez y dominio de la lengua.

\subsubsection{Entrevista a docentes de grado en ELE}

La postura, el conocimiento y el pensamiento del docente en general, a la hora de impartir sus clases, es el punto de partida al estímulo y a la ilusión por llegar allí, pero lo contrario también. Luchar contra toda una trayectoria histórica de mediocridad en el resultado de la enseñanza de una LE en la EB puede parecer algo ilusorio, pero debe hacerse.

En el circuito de factores que intervienen, los profesores de grado en ELE, formadores de los profesores de la EB, constituyen no solo parte 
importante, sino fundamental. A todo esto, se ha buscado escuchar directamente a docentes de grado de cada IES de este Estado, pudiendo además contestar, comentar o ampliar su respuesta libremente.

\subsubsection{Descripción de los datos, instrumento de investigación y formateo}

Los datos han sido recogidos a través de entrevista presencial o virtual; cuando presencial, en el local de trabajo del informante. El docente que ha aceptado atender nuestro pedido no ha sido elegido previamente bajo ningún criterio en especial que no sea el de ejercer la docencia de ELE en curso de grado, la razón ha sido, antes bien, que haya estado dispuesto a colaborar en aquel momento.

El instrumento de investigación lo presentamos directamente aquí ya formateado, de manera que se pueda apreciar la respuesta simultánea de los informantes. Se trata de una secuencia de 16 preguntas respecto a su postura, conocimiento y pensamiento sobre la enseñanza de ELE en su quehacer académico diario. En la formulación de las respuestas se ha dejado en total libertad la elección del idioma en el que el informante deseara contestar el cuestionario, lo que sí, en este instrumento hemos registrado las respuestas de la forma más fiel posible, para todos los efectos, asimismo, la identidad de los informantes está absolutamente protegida en todos los contextos y momentos de este estudio. Informamos que solo un docente contestó a las preguntas en lengua portuguesa.

Cuadro 32 - Preguntas y respuestas entrevista a docentes de grado en ELE

\begin{tabular}{|c|c|c|c|}
\hline \multicolumn{4}{|c|}{ RESULTADO ENTREVISTA A DOCENTES DE GRADO EN ELE } \\
\hline \multicolumn{2}{|r|}{ PREGUNTA } & IES & Respuesta Docente de grado \\
\hline \multirow[t]{3}{*}{1} & \multirow{3}{*}{$\begin{array}{l}\text { ¿Actúa Ud. como docente de grado en } \\
\text { ELE? }\end{array}$} & IES-1 & Sí \\
\hline & & IES-2 & Sí \\
\hline & & IES-3 & Sim \\
\hline \multirow[t]{3}{*}{2} & \multirow{3}{*}{$\begin{array}{l}\text { ¿Es Ud. responsable por asignaturas de } \\
\text { formación específica de grado en ELE? }\end{array}$} & IES-1 & Sí \\
\hline & & IES-2 & Sí \\
\hline & & IES-3 & $\operatorname{sim}$ \\
\hline
\end{tabular}


3 ¿Ud. imparte sus clases en la lengua, objeto de esa formación?

¿Qué asignaturas imparte Usted?

5

¿Qué asignaturas cree Ud. que deben ser impartidas en español?

6a En sus clases de ELE como formador de nuevos profesores de ELE, ¿usa siempre materiales actuales y auténticos?

6b ¿Ud. formula actividades de valoración de aprendizaje o usa las actividades ya preparadas en los manuales?

6c ¿Estimula y valora el diálogo, participación y contacto en español, en las clases, en la lengua que les enseña?

7 ¿Conversa en español con sus alumnos fuera de clase?

$8 \quad ¿$ Cree Ud. que un profesor de grado debe impartir sus clases en la lengua extranjera que enseña?

9 ¿Considera correcto dar clases de español en lengua portuguesa?
IES-1 Sí, siempre y pido para recibir respuestas en la misma lengua

IES-2 La mayoría de las veces

IES-3 Sim

Lengua Española I, II, III IV, V y VI;

IES-1 Lingüística; Metodología de la enseñanza de ELE; Español para fines específicos; Lectura y producción de textos en español.

IES-2 Lengua Española I, II, III IV, V y VI; Lingüística; Metodología de la enseñanza de ELE; Lectura y producción de textos en español

Língua Espanhola I, II, III IV, V y VI;

IES-3 Fonética / Fonologia; Semântica / Lexicografia; História da língua; Análise e elaboração de materiais; Leitura e produção de textos em espanhol

IES-1 Todas deben ser, y son, en español

IES-2 Debía ser todas

IES-3 É necesário em todas.

IES-1 Sí

IES-2 Sí

IES-3 Sim

IES-1 Hago ambas cosas.

IES-2 Ambas cosas

IES-3 Ambas coisas

IES-1 Sí

IES-2 Sí

IES-3 Sim

IES-1 Sí, en todo momento.

IES-2 Algunas veces

IES-3 Não. Gosto da língua materna para resolver assuntos não acadêmicos. Preferência pessoal.

IES-1 Sí, por supuesto, por eso es profesor de español.

IES-2 Sí, dentro de lo que puede

IES-3 Sim

IES-1 No, es cosa de correcto o no, es lo adecuado, lo conveniente, no debería ser.

IES-2 Claro que no

IES-3 Não sei. 


\begin{tabular}{|c|c|c|c|}
\hline \multirow[t]{3}{*}{10} & \multirow{3}{*}{$\begin{array}{l}\text { ¿Enseñar español a brasileños permite } \\
\text { impartir las clases en español? }\end{array}$} & IES-1 & Sí, siempre \\
\hline & & IES-2 & Sí \\
\hline & & IES-3 & $\operatorname{sim}$ \\
\hline \multirow[t]{3}{*}{11} & \multirow{3}{*}{$\begin{array}{l}\text { ¿Es el profesor de español el que decide } \\
\text { qué variante debe aprender el alumno o es } \\
\text { el propio alumno? }\end{array}$} & IES-1 & Es el alumno \\
\hline & & IES-2 & El alumno \\
\hline & & IES-3 & O aluno \\
\hline \multirow[t]{3}{*}{12} & \multirow{3}{*}{$\begin{array}{l}\text { ¿El plan de estudios define qué variante } \\
\text { de español se debe estudiar? }\end{array}$} & IES-1 & No, claro que no. \\
\hline & & IES-2 & No, no \\
\hline & & IES-3 & Não \\
\hline \multirow[t]{3}{*}{13} & \multirow{3}{*}{$\begin{array}{l}\text { ¿EI MEC aprecia el MCER para la } \\
\text { formulación de sus orientaciones } \\
\text { curriculares? }\end{array}$} & IES-1 & Sí, está siempre contemplado \\
\hline & & IES-2 & Sí \\
\hline & & IES-3 & Sim, é verdade \\
\hline \multirow[t]{3}{*}{14} & \multirow[t]{3}{*}{$\begin{array}{l}\text { ¿Cuál es el lugar en el que el futuro } \\
\text { profesor debe aprender la lengua que va a } \\
\text { enseñar? }\end{array}$} & IES-1 & $\begin{array}{l}\text { El plan de estudios del curso de grado } \\
\text { contempla en sus objetivos la meta de } \\
\text { lengua en un nivel C1, entonces es en el } \\
\text { curso de grado, el plan está diseñado para } \\
\text { eso. }\end{array}$ \\
\hline & & IES-2 & $\begin{array}{l}\text { El alumno puede no conseguir la meta en } \\
\text { el curso de grado, por eso buscar en otra } \\
\text { fuente ese saber no estaría mal, pero } \\
\text { definitivamente es en el curso de grado. }\end{array}$ \\
\hline & & IES-3 & $\begin{array}{l}\text { O objetivo do curso de grado em ELE é } \\
\text { fazê-lo professor e dentro disso estaria } \\
\text { aprender a língua. }\end{array}$ \\
\hline
\end{tabular}

(Datos de investigación) aprender a língua.

3.3.2.2 Descripción de los parámetros de análisis

Las respuestas a la pregunta 1 y 2 de los tres informantes docentes, uno de cada IES que oferta el grado en ELE en este Estado, son semejantes.

La respuesta a la pregunta 3 respecto a si imparten sus clases en lengua española, es afirmativa con ampliación de respuesta por el informante de la IES 1 quien añade que no solo imparte sus clases en español, sino que según sus propias palabras: "pido para recibir respuestas en la misma lengua"

Al preguntárseles (pregunta 4) sobre las asignaturas que estos informantes imparten coinciden bastante en sus respuestas, imparten en común las secuencia de I a VI de la asignatura de lengua española además de lectura y producción de textos en español, por otro lado, los informantes de las 
IES 1 y 2 coinciden en impartir lingüística y metodología de la enseñanza de ELE. Todas asignaturas de formación específica de grado en ELE.

La respuesta a la pregunta 5 sobre qué asignaturas consideran los informantes docentes que deben ser impartidas en español, es similar, no obstante se denota cierto énfasis en la respuesta de la IES-1 y también en la de la IES-2. La respuesta de la IES-3 que dice "Debía ser todas" nos abre paso a inferencias: No son impartidas en español todas las clases de formación específica en esa IES. Algunas no son impartidas, otras sí. Parte del tiempo de clase es en español, parte no. En fin,

Por otro lado la respuesta de la IES-2 pudiera ser que a la hora de decirlo en español el informante haya aplicado la estructura lingüística de la lengua portuguesa, ha dicho 'debía' en vez de 'debería', así y todo, la comprensión se mantiene.

En la respuesta a la secuencia de preguntas $6 \mathbf{a}, \mathbf{6 b}$ y $6 \mathbf{c}$, los informantes coinciden plenamente.

La pregunta 7 indaga sobre la forma de comunicarse con los alumnos fuera de la clase de ELE y aquí sí que las respuestas son diferentes. El informante de la IES1 dijo que sí y que lo hacía en todo momento; el de la IES2 dijo que lo hacía algunas veces, en cambio, el de la IES3 dijo que no, que le gustaba la lengua materna para asuntos no académicos, que era una preferencia personal.

La respuesta a la pregunta 8 es variada según cada informante, el docente de la IES1 es categórico al decir que no solo cree que el profesor de grado debe impartir sus clases en la lengua que enseña, sino que esa es la función principal del profesor de lengua extranjera. El docente de la IES2 fue un poco menos convincente afirmando que sí cree en ello, pero eso dentro de lo que se podía hacer, o sea, dentro de las limitaciones de esos docentes de grado de LE. Ya el informante de la IES3 solo se concretó a responder que sí creía que el docente de lengua extranjera debía impartir sus clases en la lengua que enseñaba.

En la pregunta 9 se quiere saber si los informantes docentes consideran correcto impartir clases de español en lengua portuguesa. El informante de la IES1 dice que no se trata de algo correcto o no, sino de lo adecuado, lo 
conveniente o lo que no debería ocurrir, ya el de la IES2 dijo que obviamente no, en cambio la respuesta del informante de la IES3 fue que no sabía si era correcto o no impartir en portugués la clase de español.

Para los tres informantes la respuesta a la pregunta 10 fue sí es posible impartir siempre en español las clases a alumnos brasileños, con realce para la IES1 que dijo por añadidura que siempre era posible hacerlo

Las respuestas a las preguntas 11 y 12 sobre quién decide qué variante de lengua española estudiar, si el profesor o el plan de estudios, los informantes dijeron que en definitiva era el alumno.

La pregunta 13 busca saber si los informantes están enterados de si el MEC-Brasil estructura sus orientaciones curriculares con el soporte y respaldo del MCER, los informantes afirmaron que sí.

Y las respuestas a la última pregunta, la 14, se presentaron bastante diferentes en una línea de postura y pensamiento ante la enseñanza de ELE en los cursos de grado. El informante de la IES1 afirmó que el lugar para que el estudiante de grado en ELE aprenda español era el curso de grado, que eso ya estaba contemplado en los objetivos del curso, que el curso estaba diseñado para lograr esa finalidad; en cambio el informante de la IES2 se manifestó desde un punto de vista más realista diciendo que el plan de estudios contempla la meta, pero si el estudiante no lograra ese objetivo, no estaría mal buscar otras fuentes; no obstante enfatizó que definitivamente era el curso de grado en donde debería aprenderla. El informante de la IES3 destacó que el objetivo del curso de grado en ELE era convertirlo en profesor. Al decir que la fluidez en la lengua objeto de esa especificidad docente estaría dentro de eso, a nuestro ver quedo un poco así como si no fuera este también un objetivo prioritario en la formación docente y sí más bien secundario.

\subsubsection{Preguntas de investigación e hipótesis}

PI-12 - ¿Los docentes discrepan en la valoración sobre la fluidez y dominio de la lengua extranjera que los estudiantes de grado deben lograr tras concluir los estudios? 
(H17) - Es oportuno considerar la variable de que los profesores tienen ambiciones e intereses diferentes con relación al progreso en la fluidez y dominio de la lengua que ellos mismos hablan y los estudiantes también.

\subsubsection{Análisis empírico}

Ser profesor en Brasil es un verdadero desafío, como también lo es ser alumno o estudiante. Tanto uno como otro luchan en su día a día para superar dificultades y avanzar hacia sus metas. En nuestro caso, el profesor de lengua extranjera tiene un desafío más: dominar la LE que enseña fluidamente de forma oral y escrita, y para llegar a esta meta necesita contar con todo el aparato de la enseñanza de grado, y es ahí donde se sitúa el cuerpo docente de área específica, los que supuestamente están altamente cualificados y tienen por misión buscar los mejores caminos para que esos nuevos profesores realicen plenamente su formación y garanticen su espacio en el mercado de trabajo con su buena preparación.

Se percibe un claro y categórico entusiasmo en las respuestas del entrevistado de la IES1, una conformidad y pasividad en el de la IES2 y una altivez e indiferencia en el de la IES3, apreciación que se hace a partir de las respuestas enunciadas por los entrevistados, véase en las respuestas a (8), (9) y (14)

En cualquier caso, se nota en las respuestas de los informantes, pero no deja de haber espacio para las valoraciones que se hagan, cuentan intereses y prioridades y en ello, hasta qué punto estas cuestiones no influyen en la formación de los nuevos profesores.

\section{La formación del profesorado de ELE}

En este apartado de nuestro estudio, abordaremos 3 aspectos que se consideran importantes para comprender, como muestra, el engranaje en el que se desarrolla la formación del profesorado de grado en ELE que puedan 
explicar o al menos señalar las posibles causas que inciden directamente en el logro de la fluidez y dominio de lengua española y su calidad en la enseñanza.

Es importante aclarar que este estudio involucra directamente componentes que intervienen en la formación específica de estudiantes de grado en ELE, a saber, el docente de grado, su posicionamiento respecto al formalismo y funcionalismo en la enseñanza de lengua española, el plan de estudio directamente relacionado con las asignaturas específicas en las que los MD pudieran estar incluidos en el contenido programático y el propio estudiante de grado en ELE.

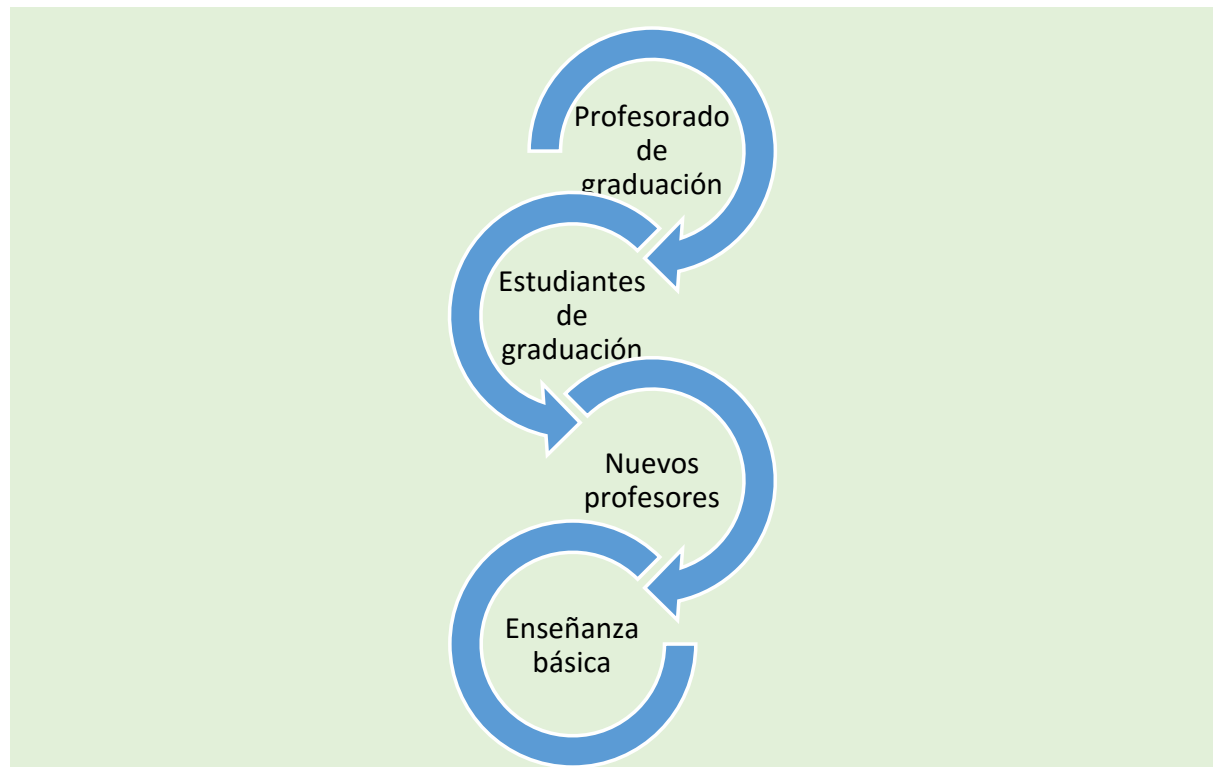

Figura 15 - El ciclo del aprendizaje de lengua extranjera (Creada por el autor)

La realidad de la enseñanza y aprendizaje de ELE es el producto que se genera en este proceso en el que intervienen diferentes factores que, hasta donde se ha visto, son estudiados de forma aislada, nada más oportuno dada la amplitud de cada tema; pero también se observa que esos estudios de las partes no se juntan en la práctica, lo que lleva a soluciones parciales y no sincronizadas que mantienen los problemas sin mayores avances rumbo a una mejoría de su actual situación. Es justo eso lo que intentamos indirectamente probar, que el resultado de la enseñanza de una LE, en este caso de español, es la suma de los problemas, que al no verlos como conjunto, difícilmente saldremos del repetido 'hacer que enseñamos una LE' 
Aparentemente, las mejorías que se implementan están desconectadas y no se concentran en pro del objetivo que plantea el MEC-Brasil para los ciudadanos brasileños: aprendizaje y dominio suficiente de ELE para una buena comunicación.

De esta forma, en este bloque de datos, se investigará, a modo de muestra, de un lado, el perfil de los docentes de grado que imparte asignaturas de contenidos específicos y que deberían ser impartidos en español, su posicionamiento respecto al formalismo y funcionalismo en la enseñanza de grado, muestra de la evolución del plan de estudio de grado de una de las IES directamente relacionada con las asignaturas en las que los MD pudieran estar incluidos en el contenido programático y analizaremos una muestra del paso del estudiante de grado en ELE por la formación superior. Creemos que nuestro corpus en este apartado no es extenso, pero si diverso en virtud de los objetivos trazados en esta investigación, por eso, nos proponemos seguir una dinámica que permita crear un flujo lógico de los datos.

\subsection{EL PERFIL DE LOS DOCENTES DE GRADO}

Este corpus presenta datos de docentes de grado de instituciones de enseñanza superior (IES) del estado nordestino de Rio Grande do Norte Brasil, participantes de esta investigación, no obstante se establecerá diálogo en determinados momentos con datos de IES de otros estados brasileños, a título de referencia. Son tres las IES públicas que ofertan el grado en ELE en este Estado y cada una de estas instituciones será referida en todo momento como IES-1; IES-2 e IES-3 sabiendo que identifican instituciones públicas de enseñanza superior.

Los docentes de grado de los que se ha recogido audio, video o producción escrita, tendrán salvaguardada su identidad al ser identificados en todo momento como informantes (INF), con el código INF-PROF-( $\mathrm{n}^{\circ}$ correlato), indistintamente, de esta forma un determinado docente sería INF-PROF-1, por ejemplo. 


\subsubsection{Descripción de los datos, instrumento de investigación y formateo}

La recogida de datos para conformar el perfil de los docentes de grado de asignaturas específicas de formación de IES públicas, se ha realizado consultando directamente en fuentes institucionales ${ }^{113}$, sitios gubernamentales y/o se han obtenido directamente en visitas a las instituciones involucradas, además de haber consultado el curriculum lattes ${ }^{114}$ de los profesionales en actuación docente. El formateo de esta información se ha realizado de forma objetiva, en cuadros y/o gráficos que permiten visualizar los datos de forma más cuantitativa que cualitativamente.

De esta forma, el cuadro 33 revela la titulación de los docentes de las IES del estado de RN, el cuadro 34 muestra el tiempo de servicio de los docentes y el cuadro 35 revela la situación del docente con relación a si es docente del cuadro permanente, o no, y si es nativo de lengua portuguesa de Brasil o no.

Cuadro 33 Titulación del profesorado de grado en IES- Asignaturas de ELE.

\begin{tabular}{|c|c|c|c|}
\hline \multicolumn{4}{|c|}{$\begin{array}{c}\text { Titulación del profesorado de grado en IES - Actuación en } \\
\text { asignaturas de ELE }\end{array}$} \\
\hline Titulación & IES-1 & IES-2 & IES-3 \\
\hline Doctorado & 7 & 2 & 0 \\
\hline Máster & & 4 & $6^{115}$ \\
\hline Especialista & 0 & 1 & 1 \\
\hline Grado & 0 & 1 & $1^{116}$ \\
\hline
\end{tabular}

Fuente: [En línea] http://goo.gl/KAcknz

113 Al tratarse de instituciones de enseñanza superior públicas, el acceso a toda información al respecto de las mismas, está disponible en: IES-1 [En línea] https://goo.gl/WHmEEm - IES-2: [En línea] http://goo.gl/8rOs9K e IES-3: [En línea] http://goo.gl/Qkx50B

114 La Plataforma Lattes es una plataforma, creada y mantenida por la Coordenação nacional de Investigación CNPq. Integra las bases de datos de currículos, grupos de investigación e instituciones, en un único sistema de informaciones de las áreas de Ciencia y Tecnología, actuando en Brasil.

115 Dos docentes en programa nacional de doctorado.

116 Docente con diploma de estudios avanzados en tramitación de validación académica en Brasil y actualmente vinculada a programa de doctorado en el Exterior. 
Cuadro 34 Tiempo de servicio de los docentes de RN

\begin{tabular}{|c|c|c|c|}
\hline \multicolumn{4}{|c|}{ Tiempo de docencia del Profesorado de lengua española } \\
en IES \\
\hline Tiempo de docencia & IES-1 & IES-2 & IES-3 \\
\hline $0-5$ años & 2 & 2 & 4 \\
\hline $5-10$ años & 4 & 2 & 2 \\
\hline $10-15$ años & 1 & 4 & 2 \\
\hline $15-25$ años & 0 & 0 & 0 \\
\hline
\end{tabular}

(Datos de investigación)

Cuadro 35 - Datos del profesorado con actuación en asignaturas de ELE.

\begin{tabular}{|c|c|c|}
\hline Código & Permanente & $\begin{array}{c}\text { Brasileño / } \\
\text { naturalizado* }\end{array}$ \\
\hline INF-PROF-1 & Sí & Sí \\
\hline INF-PROF-2 & Sí & Sí \\
\hline INF-PROF-3 & Sí & Sí \\
\hline INF-PROF-4 & Sí & Sí \\
\hline INF-PROF-5 & Sí & Sí \\
\hline INF-PROF-6 & Sí & Sí \\
\hline INF-PROF-7 & Sí & Sí \\
\hline INF-PROF-8 & Sí & Sí \\
\hline INF-PROF-9 & Sí & Sí \\
\hline INF-PROF-10 & Sí & Sí \\
\hline INF-PROF-11 & Sí & Sí \\
\hline INF-PROF-12 & Sí & Sí \\
\hline INF-PROF-13 & Sí & Sí \\
\hline INF-PROF-14 & No & Sí \\
\hline INF-PROF-15 & Sí & Sí \\
\hline INF-PROF-16 & Sí & Sí \\
\hline INF-PROF-17 & Sí & Sí \\
\hline INF-PROF-18 & Sí & Sí \\
\hline INF-PROF-19 & Sí & Sí \\
\hline INF-PROF-20 & Sí & Sí \\
\hline INF-PROF-21 & No & Sí \\
\hline INF-PROF-22 & Sí & Sí \\
\hline
\end{tabular}

(Datos recogidos en encuesta)

\subsubsection{Descripción de los parámetros de análisis}

Los docentes aquí contabilizados son aquellos que imparten asignaturas específicas y en ELE. Sobre la titulación de los docentes, los de la IES-1 son todos doctores y actúan como profesores de asignaturas de formación 
específica de lengua española y literatura, mientras que en la IES-2, solo hay 2 y en la IES-3, ninguno, o mejor dicho, 3 en camino de doctorarse. La enseñanza superior en Brasil tiene sus aparentes 'insensateces'; por ejemplo cuando hay un proceso selectivo docente para una universidad federal, la titulación mínima del candidato es la de 'doctor', pero eso no ocurre en la IES-2 e IES3.

Se han analizado las convocatorias a selección docente de la IES2, intentando encontrar explícitamente la razón por la que la titulación mínima exigida en las convocatorias no es la de 'doctor', pero ha sido infructuosa la búsqueda; no obstante, en el plan de estudios de grado (PEG) de la IES-2, encontramos la respuesta al constatar que tras concluir el grado en ELE, ese nuevo profesor está habilitado para la enseñanza superior también. Al mismo tiempo, se ha indagado entre docentes y alumnos de la IES2, pero igual, no se ha conseguido delimitar la razón que justifique que en la enseñanza superior, un graduado dé clases a un alumno de grado, situación que es señalizada como impropia por los órganos que evalúan la enseñanza superior en Brasil, como el INEP ${ }^{117}$, por ejemplo.

Son posturas legales distintas para un mismo nivel de enseñanza, lo que es algo contradictorio y el resultado se manifiesta en la calidad de la formación. Todavía hay profesores de grado que piensan que basta estar dentro del aula (intentando) hablar español, intentando enseñar la gramática o practicar ejercicios escritos y practicar lectura para sentirse cumpliendo con su papel 'importante' de formador, no percibe la relevancia de la investigación como camino al conocimiento más profundo, sin hablar de las actividades de extensión que contribuyen con la madurez profesional propia y la del pupilo de ELE.

117 INEP -SINAES El Sistema nacional de evaluación de la educación superior -SINAES, se encarga de evaluar instituciones, cursos de grado y desempeño de los estudiantes. Evalúa según los indicadores al respecto de enseñanza, investigación y extensión. Fue creado en 2004, ley no 10.861 . Los procesos evaluativos son coordenados y supervisados por la Comisión Nacional de Evaluación de la Educación Superior -CONAES. 
De la IES-3, sin embargo, sí se sabe la razón que le impide legalmente requerir el título de 'doctor' como requisito mínimo en las convocatorias para la selección docente, pues al tener una institucionalidad diferente (es instituto, no universidad) y al ofertar varios niveles de enseñanza, (que dicho de paso, es mayoritaria en número de alumnos), la titulación requerida, lógicamente es la de grado, pero vale aclarar que estando miembro de la comunidad académica, la institución federal favorece y estimula la continuidad de estudios de posgrado, formando de esta manera su cuerpo docente con 'doctores' a corto y mediano plazo.

De esta forma, aun hablando de la IES-3, es penoso tener que admitir que cuestiones legales interfieran indirectamente en la calidad de la formación de profesores para la educación básica, pues no se ve claro cuál sería el impedimento para realizar convocatorias de carácter específico y encaminadas para el cuadro docente de su curso de grado.

De una forma u otra, y en la mayoría de las naciones, lograr un empleo público es el deseo de la mayoría de los ciudadanos, es el empleo seguro, las oposiciones en Brasil son igual de difíciles que en muchos países y, también, cada vez más escasas, marcadas al ritmo de la política y/o de la economía local, regional, nacional e inclusive internacional. Formar parte del cuadro permanente de docentes de una IES pública, puede generar dos actitudes en este profesor (1) dedicarse a la práctica docente consciente, buscando siempre profundizar el conocimiento, contribuir en investigaciones del área, producir científicamente, incentivar con su ejemplo la esencia de la profesión profesor, y del otro lado (2) darse por satisfecho y conformarse con cumplir horarios y compromisos académicos formales y llevar los días más leves dedicados inclusive a otras actividades externas que le rindan financieramente algo más.

Luego, sobre el tiempo de servicio docente, la idea de que 'escobita nueva, barre bien', o lo de 'dormirse en los laureles', o sea, docentes recién ingresados en una IES llevan más ganas a la tarea docente, o docentes antiguos se conforman y realizan su trabajo sin plazos, sin metas, sin fuerza, en otras palabras, sin ilusión, es un factor difícil de comprobar a partir de la incidencia del tiempo de trabajo docente, como al principio se pensaba. 
Definitivamente, lo más que se puede hacer en este sentido es describir el dato sin poder recoger cualquier información adicional o inferencial concreta.

No es la edad ni el tiempo que se lleve de actividad docente lo que va a incidir en el aporte a la formación del profesorado de ELE y de LE en general, sin duda, es estar preparado para la tarea, tener estímulo y fuerza.

El perfil del docente de grado en ELE en el nordeste brasileño, en concreto en el estado de RN es diverso, porque diversa es la institucionalidad de las IES que forman estos profesores. Sobre la relación que hay entre el tiempo de servicio del docente de grado y su desempeño, no se encuentran elementos que respalden tales afirmaciones de descuido y conformismo en su actuación docente.

Sobre la situación laboral del docente, la mayoría son de la plantilla permanente; no obstante, en determinados periodos y por fuerza de la necesidad, se contratan docentes sustitutos para suplir la ausencia de los permanentes, pero sus estancias no superan los dos años de servicio.

Lo de ser profesor nativo o no nativo ${ }^{118}$, al principio, lo veía como algo sin sentido y sobre todo sin fundamentos, igual realmente no lo sea, pero por haberlo escuchado más de dos veces en ámbitos académicos y haber tenido acceso a artículos y manifestaciones públicas al respecto, se ha relatado en el cuadro 35 si el docente en cuestión es brasileño nato o extranjero naturalizado. De cualquier forma al tratarse de un ciudadano nacionalizado y con formación superior compatible a la función, qué más da si ha nacido o no en Brasil, lo importante es la calidad del trabajo que realice, igual habrá brasileños en el mundo que son profesores de portugués de Brasil y no por eso son "menos mejores" que los nacidos en aquella nación. De la totalidad de los docentes de grado, contamos 3 no nativos brasileños.

\footnotetext{
118 Aunque este es un tema que ha generado una serie de artículos científicos y que también divide opiniones y posturas, no nos detendremos a tratarlo en esta ocasión por no estar comprendido en nuestro trayecto investigativo, no obstante y a modo de comentario, el punto de partida de esta polémica es la amenaza profesional que los profesores brasileños de LE sienten al ser confrontados con la fluidez y dominio del idioma extranjero de los docentes nativos de esa LE. De esta forma, el docente de LE brasileño señala que el mejor profesor de LE para enseñar a brasileños es el profesor de LE brasileño, pues este conoce y ha superado todas las dificultades de aprendizaje de la lengua, especificidad de esa formación de grado, defiende y se adjudica esta posición al punto de en determinadas circunstancias tornarse anti-ético con este tipo de afirmaciones, las mismas de las que, particularmente, nosotros, no tenemos registro de ocurrencia en otras realidades.
} 


\subsubsection{Preguntas de investigación}

Informamos nuestra pregunta de investigación y su respectiva hipótesis sobre este punto:

PI-13 - ¿En general, el perfil de los docentes de grado en ELE está de acuerdo a las exigencias del desempeño de su función?

(H17) - Los docentes de grado en ELE para desempeñar su función aprueban una oposición y cumplen requisitos legales que los posiciona como profesionales idóneos.

\subsubsection{Análisis empírico parcial}

La actuación del docente de grado es fundamental en la formación del estudiante; son parámetros elementales su conocimiento, su dominio y fluidez, además de su postura y visión de mundo. A partir de los datos recogidos constatamos que los docentes de asignaturas específicas de ELE en promedio poseen el nivel de conocimiento necesario acreditado por la titulación y las oposiciones, y aparentemente hay equilibrio en el número de docentes según las IES que forman parte de este estudio.

\subsection{EL POSICIONAMIENTO DE LOS DOCENTES DE GRADO RESPECTO AL FORMALISMO Y FUNCIONALISMO EN LA ENSEÑANZA DE GRADO}

Con el asentamiento de los estudios en el ámbito del funcionalismo y la consecuente mayoritaria comprensión de que el formalismo debería ser desterrado, conceptos que en la actualidad aún confunden al docente de lengua llevándolo a su autodenominación como funcionalista o formalista (lo que, por cierto, trae consigo la consecuencia de desvalorizar el conocimiento y cultivo formal de la lengua en el curso de grado en ELE) esta encuesta busca saber la posición del profesorado de ELE con relación a sus ánimos profesionales sobre este tema. 


\subsubsection{La recogida de datos, instrumento de investigación y formateo}

Los datos han sido recogidos en el ámbito de las IES públicas del estado de RN y fue aplicada a un total de 15 profesores de grado en ELE.

El instrumento de investigación es el cuestionario sobre formalismo y funcionalismo que consta en el Apéndice 3. Son 7 preguntas que han sido organizadas en el cuadro 36 en donde se puede apreciar la respuesta docente a este respecto.

Cuadro 36 Docentes de grado respecto al formalismo y funcionalismo.

\begin{tabular}{|c|c|c|c|c|c|c|c|}
\hline \multirow{2}{*}{\multicolumn{2}{|c|}{ PREGUNTA }} & \multicolumn{6}{|c|}{ Respuestas } \\
\hline & & \multirow{2}{*}{$\begin{array}{l}\text { Sí } \\
15\end{array}$} & \multirow{2}{*}{$\begin{array}{c}\mathrm{NO} \\
0\end{array}$} & \multirow[t]{2}{*}{ Ambas } & & & \\
\hline 1 & $\begin{array}{l}\text { ¿Usted da clases en asignaturas } \\
\text { de lengua ELE y/o específicas? }\end{array}$ & & & & & & \\
\hline 2 & $\begin{array}{c}\text { ¿Sus clases son prácticas o } \\
\text { teóricas? }\end{array}$ & $8 \mathrm{PR}$ & $8 \mathrm{TE}$ & 3 & & & \\
\hline 3 & $\begin{array}{c}\text { ¿Usted presenta la gramática en } \\
\text { sus clases de español? }\end{array}$ & 10 & 5 & & & & \\
\hline 4 & $\begin{array}{c}\text { ¿Conoce las bases teóricas del } \\
\text { formalismo lingüístico? }\end{array}$ & 11 & 4 & & & & \\
\hline 5 & $\begin{array}{c}\text { ¿Qué asignaturas forman parte } \\
\text { del formalismo? }\end{array}$ & 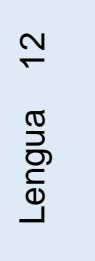 & 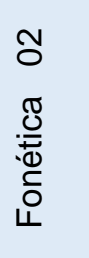 & 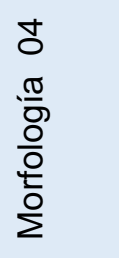 & 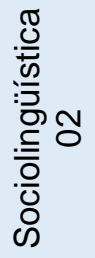 & 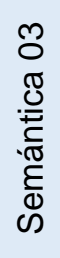 & 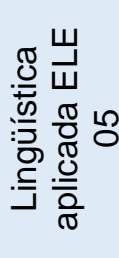 \\
\hline 6 & $\begin{array}{l}\text { ¿Conoce las bases teóricas del } \\
\text { funcionalismo lingüístico? }\end{array}$ & 12 & 03 & & & & \\
\hline 7 & $\begin{array}{l}\text { ¿Qué asignaturas forman parte } \\
\text { del funcionalismo }\end{array}$ & $\begin{array}{l}\text { N } \\
\text { ত } \\
\frac{\sigma}{0} \\
\frac{c}{0}\end{array}$ & 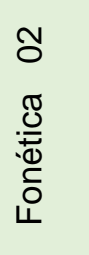 & 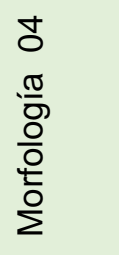 & 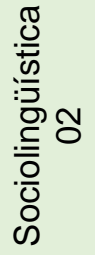 & 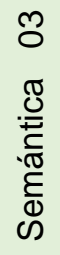 & 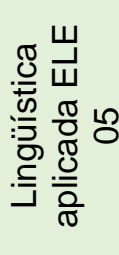 \\
\hline
\end{tabular}

(Datos recogidos en encuesta)

PR - Clases prácticas

TE - Clases teóricas 


\subsubsection{Descripción de los parámetros de análisis}

El objetivo de esta encuesta es percibir la dimensión del conocimiento docente de grado sobre las corrientes teóricas funcionalistas o formalistas que a su vez implementan en su práctica.

La respuesta a la pregunta 1, objetivamente confirma que los 15 profesores encuestados dan clases de asignaturas específicas en curso de grado en ELE.

En la segunda pregunta, sobre si el docente imparte sus clases de forma más práctica que teórica o viceversa, tenemos que 8 profesores han dicho que sus clases son prácticas; 4 han dicho que son teóricas y 3 dijeron que las impartían con teoría y práctica.

En la tercera pregunta se indaga si se imparte gramática en las clases de lengua, sobre esto, 10 profesores dijeron que sí enseñaban gramática y 5 que no.

Conocer o no las bases teóricas del formalismo lingüístico es lo que se indaga en la pregunta 4. De los 15 informantes, 11 profesores dijeron que sí las conocían y 4 dijeron que no.

En la pregunta 5, a pesar de haber sido solo 9 de los 15 informantes los que realmente identificaron las asignaturas relacionadas a la teoría del formalismo lingüístico (Fonética, Morfología, Semántica), no hubo uno que solo haya marcado estas, también marco por lo menos una más que no era del funcionalismo, como lengua, por ejemplo.

Sobre conocer las bases teóricas del funcionalismo se indaga en la pregunta 6 y fueron 12 de los 15 informantes los que dijeron conocerla.

En las respuestas a la pregunta 7 , en la que se solicita que reconozca las asignaturas que forman parte del funcionalismo, solo 7 profesores, de los 15, realmente identificaron las asignaturas relacionadas al funcionalismo lingüístico (Sociolingüística y Lingüística aplicada a ELE), pero igual que en el resultado de 5, ninguno dejó de marcar al menos una asignatura más, por lo general, lengua, también como asignatura funcionalista. 


\subsubsection{Preguntas de investigación e hipótesis}

\section{PI-14 - ¿Los profesores de grado en ELE no tienen claro las asignaturas del formalismo y las del funcionalismo?}

H18 - Los docentes de grado no reflexionan sobre la importancia de estas teorías en la enseñanza de una lengua extranjera.

H19 - Los docentes limitan la esencia del formalismo a la gramática, sobre todo, y ante la creciente adhesión al funcionalismo terminan generando un ánimo negativo que confunde su acción docente $\mathrm{y}$, sobre todo, a los estudiantes de grado que siguen lo que escuchan en el discurso del profesor.

\subsubsection{Análisis empírico}

Las preguntas de la encuesta se han delimitado lo más posible para captar de hecho la realidad del conocimiento del docente de grado respecto al formalismo y funcionalismo en la formación de grado de ELE. El saber delimitar las asignaturas que hacen parte del formalismo de la lengua, así como las del funcionalismo, es una fuerte señal de la clareza que se tenga respecto a estos temas, pero ante el resultado obtenido, comentamos que en media 8 de los 15 profesores, realmente conocen las bases teóricas del formalismo y del funcionalismo, esto a pesar de haber indicado que la asignatura de lengua es para unos formalista y para otros funcionalista, lo que podría explicarse por cómo realiza su propia práctica.

El resultado de esta encuesta puede estar directamente relacionado con el conocimiento de los marcadores del discurso y las dificultades que se han observado en la producción escrita y en la oralidad de docentes y estudiantes de grado. A priori, en el gráfico siguiente mostramos la división de docentes según manifestaron su conocimiento de las respectivas teorías, pero disminuimos el número de informantes que en la elección de asignaturas formalistas o funcionalistas no acertaron, pues eso es un indicador de que no 
conoce lo que dice que conoce, de esa forma tenemos el resultado en el gráfico 17.

Gráfico 17 Formalistas y funcionalistas

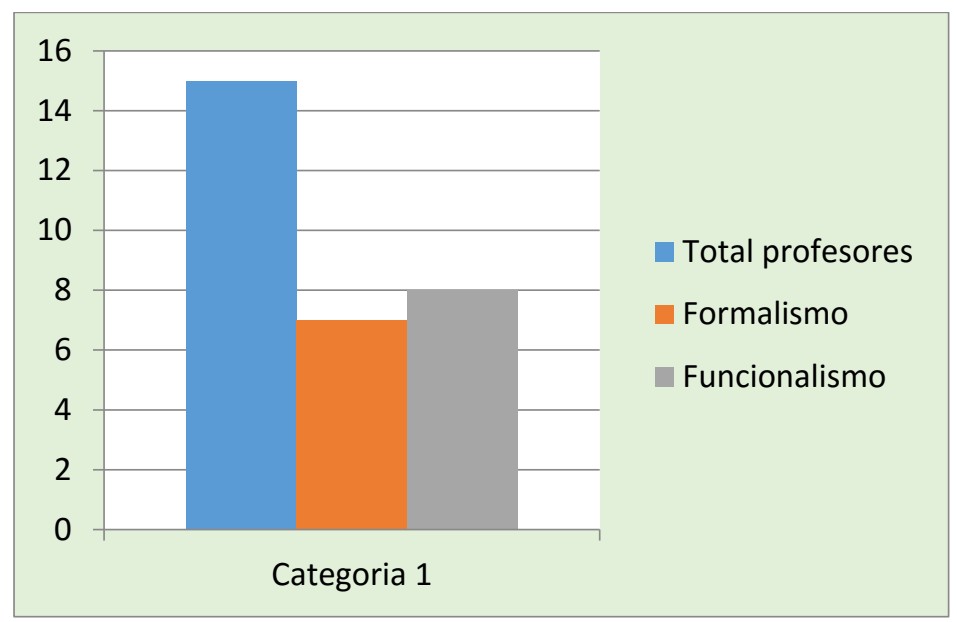

(Datos de investigación)

Los marcadores del discurso, como sabemos, son unidades lingüísticas que ciertamente deberían ser estudiadas en asignaturas funcionalistas, pero estas en la mayoría de los planes de estudio en Brasil tienen cierta tendencia a ser asignaturas de libre elección o en todo caso asignaturas para cursos de posgrado lato sensu, razón que justifica la carencia de este conocimiento en los estudiantes de grado.

Por otro lado, los marcadores discursivos forman parte esencial de objetivos de asignaturas como la de lengua que busca lograr desempeño oral y escrito de los estudiantes aplicando cuestiones de cohesión y coherencia y es cuando estas partículas ciertamente surgen en el uso, pero resta saber si hay espacio, plan y ejecución dentro de esas asignaturas.

4.3 EL PLAN DE ESTUDIO DE GRADO (PEG) EN ELE, LOS PROGRAMAS DE ASIGNATURAS ESPECÍFICAS Y EL CONTENIDO PROGRAMÁTICO MD.

Volvemos al plan de estudios en esta sección porque nos hace falta hilvanar informaciones que nos den, en definitiva, pistas claras sobre la enseñanza de los MD en la formación docente. En teoría, el plan de estudios 
es una estructura fija y sapiente que contiene la organización del aprendizaje que revela metas, objetivos y experiencias educativas a ejecutarse para el logro de metas. Como todo lo que es de los vivos, el plan de estudios también cambia, se redimensiona o ajusta para su implementación.

A partir de este punto ya podemos hablar de los factores que conducen al proceso de elaboración o reelaboración: la ideología de los elaboradores sobre el perfil y las necesidades del curso, la naturaleza de las personas involucradas en la elaboración y el tipo de programa de la educación para el que se elabora el plan de estudios.

Lo esencial de un plan de estudios de grado es el conocimiento que los docentes deben tener sobre qué objetivos se desea alcanzar, si son objetivos pedagógicos más que lingüísticos o más lingüísticos que pedagógicos, o si ambos en la justa medida, al tratarse de lengua extranjera o inclusive materna. No es, en definitiva, lo mismo un plan de estudios para el aprendizaje de una lengua extranjera para uso personal o incluso profesional que el aprendizaje de una LE para enseñarla a terceros. A nuestro simple ver, esto está muy claro. De igual forma, elaborar un plan de estudios adecuado a la formación de profesores y no cumplirlo significa poner en riesgo y compromiso a todos los que de alguna forma están involucrados en el proceso.

Sobre la ideología de los elaboradores del plan de estudios del curso de grado en ELE hay mucho que decir empíricamente, muchas pugnas que buena parte del tiempo solo se levantan en pro de intereses particulares, insuficiencia de conocimientos, inexperiencia o aún cuestiones que poco o nada tienen a ver con la finalidad de oferta del curso de grado, este punto está relacionado con el de la naturaleza de las personas involucradas, no obstante no nos extenderemos en este tema porque lo que nos toca ahora mismo es delimitar los ámbitos hasta llegar a los contenidos programáticos en donde podremos verificar si los MD están contemplados y en que asignaturas. 


\subsubsection{El plan de estudio de las IES y las asignaturas funcionalistas: buscando los MD}

En este apartado buscamos delimitar la incidencia de asignaturas funcionalistas en el plan de estudio de las IES de Rio Grande do Norte, inclusive en los anteriores al actual PEG en la intención de confirmar o no el estudio del contenido programático "Marcadores del discurso", sea con esta nomenclatura u otra similar.

En concreto, nos detendremos en los PEG, luego en la verificación de la existencia de asignaturas de cuño funcionalista en la oferta obligatoria de la formación docente y finalmente en la observación de los contenidos programáticos de esas asignaturas, buscando el contenido de los MD.

\subsubsection{Descripción de los datos, instrumentos de investigación y formateo}

Los datos obtenidos proceden de fuentes fidedignas de cada IES a las que hemos accedido personalmente con visitas a las coordinaciones de los cursos de grado y también virtualmente ${ }^{119}$.

El plan de estudios de cada una de las tres IES estudiadas no es único, queremos decir que este no es el que se aplica desde el inicio de la oferta del grado en ELE hasta ahora, este ha ido siendo ajustado de acuerdo con normas establecidas por el MEC para la enseñanza de grado, las necesidades del perfil del curso o inclusive de acuerdo con la visión de los docentes de grado.

Desde a criação, inúmeras foram as alterações ocorridas na proposta curricular, provocadas, sempre, pelas necessidades advindas, ora de normas e preceitos estabelecidos em nível nacional, ora pelas imposições de mercado de trabalho local. (PPC-Letras, UERN, 2003)

Presentamos a continuación el formateo de informaciones puntuales y relevantes en nuestra investigación: (1) el PEG original y las reformulaciones

119 IES-1 [En línea] https://goo.gl/WHmEEm IES-2 [En línea] http://goo.gl/8rOs9K IES-3 [En línea] http://goo.gl/Qkx50B 
que cada IES ha implementado; (2) la oferta obligatoria de asignaturas funcionalistas en cada versión reformulada y (3) las asignaturas cuyo contenido programático contemple el tema de los MD.

Cuadro 37 - Modificaciones al Plan de estudios de grado - IES estudiadas

\begin{tabular}{|l|c|c|c|}
\hline & IES-1 & IES-2 & IES-3 \\
\hline $\begin{array}{l}\text { Plan de estudios original para } \\
\text { grado en ELE }\end{array}$ & 2009 & 2000 & 2006 \\
\hline $1^{\text {a } \text { reformulación }}$ &.-- & 2003 & 2012 \\
\hline $2^{\text {a }}$ reformulación &.-- & 2012 & 2014 \\
\hline
\end{tabular}

(Datos de investigación (2014)

Cuadro 38 - Oferta de asignaturas de perspectiva funcional en PEG de IES estudiadas.

\begin{tabular}{|c|c|c|c|c|c|c|}
\hline \multirow[b]{2}{*}{ IES } & \multicolumn{6}{|c|}{ Asignaturas obligatorias } \\
\hline & 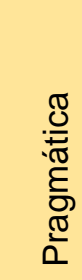 & 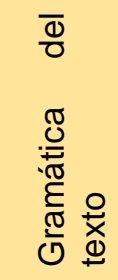 & 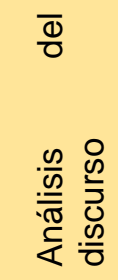 & 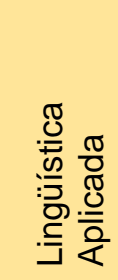 & 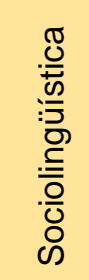 & 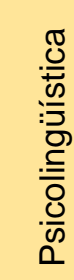 \\
\hline IES-1 - PEG original - 2009 & No & No & No & Sí & No & No \\
\hline \multicolumn{7}{|c|}{ IES-2 } \\
\hline PEG original - 2000 & No & No & No & No & Sí120 & No \\
\hline PEG $1^{\text {a }}$ reformulación - 2003 & No & No & Sí & No & Sí & Sí \\
\hline \multicolumn{7}{|c|}{ IES-3 } \\
\hline PEG original - 2006 & No & No & No & No & No & No \\
\hline PEG 1ª reformulación - 2012 & No & No & No & No & No & No \\
\hline PEG $2^{\mathrm{a}}$ reformulación - 2014 & No & No & No & No & Sí & No \\
\hline
\end{tabular}

Fuente: [En línea] https://goo.gl/WHmEEm

[En línea] http://goo.gl/8rOs9K

[En línea] http://goo.gl/Qkx50B

120 Ofertada en el 4오 semestre del PEG Letras Lengua Española y sus Literaturas. 
A continuación están las asignaturas obligatorias funcionalistas en las que puedan estar contemplados los MD entre los temas de sus programas.

Cuadro 39 Asignaturas obligatorias funcionalistas de las IES

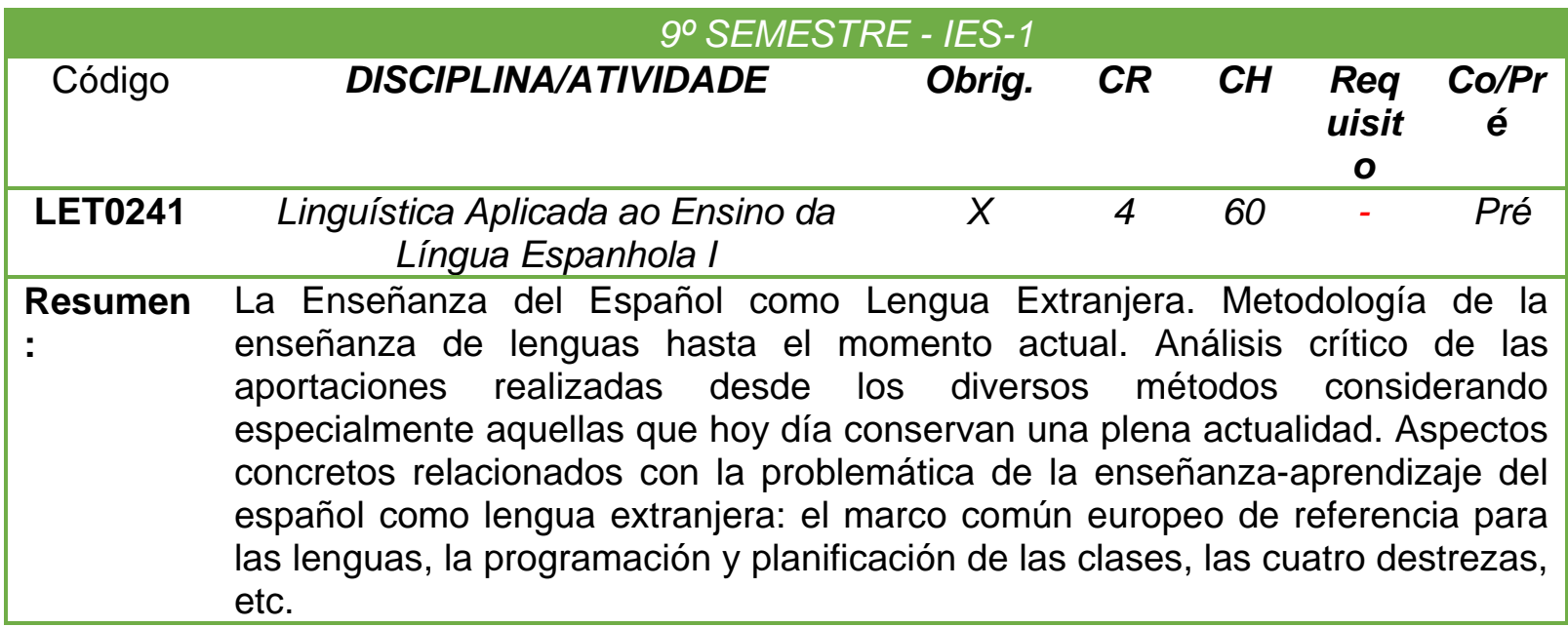

ASIGNATURAS OBLIGATORIAS FUNCIONALISTAS - IES 2

\begin{tabular}{|c|c|}
\hline Código & Resumen \\
\hline $\begin{array}{l}\text { 0402070-1 - Sociolinguística } 60 \\
\text { h/a - Créditos/Aula: } 02 \text { Créd. } \\
\text { Trabalho } 01\end{array}$ & $\begin{array}{l}\text { Relação entre língua e sociedade. Sociolinguística } \\
\text { variacional: objeto de estudo e pressupostos. Variedades } \\
\text { geográficas e socioculturais. Variação linguística e ensino de } \\
\text { língua portuguesa. A sociolinguística interacional. }\end{array}$ \\
\hline $\begin{array}{l}\text { 0402065-1 - Psicolinguística } \\
\text { C.H: } 60 \text { h/a - Créditos/Aula: } 0 \\
\text { Crédito/Trabalho: } 01\end{array}$ & $\begin{array}{l}\text { Introdução à psicolinguística. Teorias de aquisição da } \\
\text { linguagem. Natureza da leitura e da escrita. Estratégias do } \\
\text { processamento. }\end{array}$ \\
\hline $\begin{array}{l}\text { 0402032-1 - Análise do Discurso } \\
\text { C.H: } 120 \text { h/a - Créditos/Aula: } 04\end{array}$ & $\begin{array}{l}\text { Uma abordagem interacional da linguagem. A análise do } \\
\text { discurso }(A D) \text { de linha francesa. Noções sobre lingua, fala, } \\
\text { discurso e ideologia. Formação Ideológica e formação } \\
\text { discursiva. }\end{array}$ \\
\hline
\end{tabular}

\section{ASIGNATURAS OBLIGATORIAS FUNCIONALISTAS - IES 3}

Disciplina: Sociolinguística da Língua Espanhola Carga-Horária: $60 \mathrm{~h}(80 \mathrm{~h} / \mathrm{a})$

Pré-requisito: Língua Espanhola IV Número de créditos 4
Uma visão ampla da variação linguística do espanhol atualmente no mundo, diferenças e semelhanças dessas variedades. A unidade fundamental que se dá no espanhol como língua única, apesar de sua diferenciação. $O$ valor da variação como elemento enriquecedor da língua.

(Datos de investigación) 


\subsubsection{Descripción de los parámetros de análisis}

Nos hemos detenido en la observación de la reformulación de los PEG de las IES del Estado para verificar si en planes anteriores no han formado parte de ese PEG asignaturas funcionalistas que puedan haber contemplado el tema de los MD, pero ha sido infructuosa la averiguación.

Consideramos absolutamente pertinente señalar que la IES-1 ya ofertaba el grado en lengua portuguesa, inglesa y francesa, mientras que la IES-2, solo portuguesa e inglesa. La IES-3, ninguna. Esta información explica la presencia de asignaturas tan específicas del estudio del lenguaje en los respectivos PEG, pues ya existían en la oferta de la lengua vernácula ofertada en esas IES y fueron impartidas tal cual estaban, o sea, diseñadas para la lengua materna, portugués y algunas como asignaturas de libre elección. Este análisis lo haremos en el siguiente apartado.

En concreto, informaremos de inicio las asignaturas específicas de carácter obligatorio que de alguna forma estudian los fenómenos del lenguaje desde una perspectiva funcional que se daban por el 1970 y que a día de hoy se encuentran en una fase madura y de permanente investigación y actualización. Se considera que sería ese el ámbito en el que sería posible el abordaje del tema de los MD, pudiendo ser objeto de comentarios o incluso de presentación para estudio y reflexión en algún momento del plan de estudios de grado (PEG) de ELE, de cada IES.

Las asignaturas contempladas son:

$\checkmark$ Pragmática;

$\checkmark$ Gramática del texto;

$\checkmark$ Análisis del discurso;

$\checkmark$ Lingüística aplicada a la enseñanza de LE o de ELE;

$\checkmark$ Sociolingüística;

$\checkmark$ Psicolingüística.

En el primer cuadro presentado (37) describimos el PEG de cada IES con las reformulaciones por las que han pasado. Actualmente la IES-1 aplica un nuevo plan de estudios, levemente reformulado pero no está oficialmente registrado, por eso no lo hemos tomado en cuenta en este estudio. De modo 
que a partir del cuadro 38 buscamos reconocer claramente el 'contenido' Marcadores del discurso (MD) en las asignaturas obligatorias que forman parte del plan de estudio de grado (PEG) en ELE de las IES de este Estado.

\section{PEG - IES-1.}

La IES-1 solo tiene un PEG oficial en vigor y que en este solo se contempla la asignatura de Lingüística aplicada a la enseñanza de la lengua española I, que por cierto es obligatoria. Además, en el documento llamado Projeto Político Pedagógico do curso, se incluye el programa de la asignatura, pero no detalla los contenidos que son abordados. Visto esto, hemos reparado en el resumen de la asignatura intentando encontrar algún indicio concreto que nos señalice el estudio de los MD; desafortunadamente, no hay ninguno.

\section{PEG - IES-2}

El primer PEG en ELE data del año 2000 y registra únicamente la asignatura de Sociolingüística en el cuarto semestre. En su resumen dice:

\footnotetext{
0402070- Sociolinguistica 60h/a - Créd. Trabalho 01

Relação entre língua e sociedad. Sociolinguistica variacional: objeto de estudo e pressupostos. Variedades geográficas e socioculturais. Variação linguistica e ensino de língua portuguesa. A sociolinguistica interacional. (PPC-Letras, UERN, 2003)
}

Para esta asignatura y en aquel tiempo, en Brasil y en el nordeste menos, aún no había intensidad de discusiones en la academia volcada para español como lengua extranjera, no obstante, la asignatura de sociolinguistica ya era un indicador de la diversidad cultural y también lingüística de la que había necesidad de tomar conciencia plena.

En el PEG de la IES-2 del año 2000, plan original, observamos que consta la asignatura de Metodologia I, en cuyo resumen dice:

0402066-1 - Metodologia I (Espanhol) - C.H: 90 h/a; Créditos/Aula: 04; Créd./Trab. 01. 
Estudo teórico e prático sobre as principais abordagens para o ensino de línguas estrangeiras, aplicadas ao ensino de Língua Espanhola. (PPC-Letras, UERN, 2003)

Consideramos que ya se trataba de un primer intento de la oferta de la asignatura de Lingüística Aplicada a la enseñanza de lenguas extranjeras, lo que significaba para este entonces un loable avance.

El segundo PEG en ELE de la IES-2 data del año 2003 y en este sí que es notoria la presencia de la corriente funcional del lenguaje en la comunidad académica deduciendo esto en virtud de la oferta de las asignaturas de Sociolingüística, Psicolingüística y Análisis del discurso, sin comentar que la lingüística aplicada a la enseñanza de lenguas extranjeras continua disfrazada en la asignatura de Metodologia I y la novedad es que surge la asignatura de Argumentação que en su sumilla dice:

04041042-1 - Argumentação - C.H: 60 h/a - Créditos/Aula: 02 Créd/Trabalho:01

A argumentação no discurso e na língua. Da retórica aristotélica aos estudos contemporâneos. Processos pragmáticos da argumentação. (PPC-Letras, UERN, 2003)

Al no tener cómo acceder a los programas de las asignaturas, nos estamos rigiendo por la lectura de los resúmenes, que no son más que eso: un resumen de lo que se va a estudiar en esa asignatura.

En suma y en concreto, nada. No hemos conseguido encontrar explícitamente el contenido Marcadores del discurso o nombre similar en ninguno de los programas de la IES-2. Lo que nos lleva a creer que este contenido no es presentado a los estudiantes de grado actualmente y que por supuesto, si algunos docentes cursaron el grado en el mismo Estado, tampoco fueron vistos por ellos con lo que se explicaría las deficiencias que se detectan en la oralidad y en la producción escrita. 


\section{PEG - IES-3}

El primer PEG en ELE de la IES-3 fue elaborado en $2006^{121}$ y en este no se registra ninguna asignatura del ámbito funcional del lenguaje. Muy probablemente y a juzgar por el historial de esta IES, el PEG fue elaborado principalmente con la preocupación de formar lingüísticamente como prioridad, lo que, parece, rindió en efecto resultados alentadores en lo que se refiere a fluidez y dominio de ELE.

A pesar de lo expuesto, en el análisis realizado al PEG de 2006 encontramos la asignatura de Teoria e Prática da Tradução, en la que también se propone un análisis contrastivo de aspectos pragmáticos, culturales y lingüísticos entre el portugués y el español, es posible que al desarrollar este contenido programático, se manifieste el papel de los MD lejos de una visión meramente formalista, cabría perfectamente la posibilidad, pero esto no significa que sea de hecho realizado a la hora de impartir la asignatura.

\section{Teoria e Prática da Tradução}

Estudos dos diversos modelos da teoria e prática da tradução. $O$ contato entre línguas e o problema da equivalência. O conceito de fidelidade: ganhos e perdas. Os limites da tradução. Estudo das estratégias de tradução direta e inversa. Procedimentos básicos de tradução e estilo na língua espanhola e portuguesa. Análise do léxico geral e especializado. Análise contrastiva de aspectos pragmáticos, culturais e lingüísticos entre o portuquês e o espanhol. PPCLicenciatura em Espanhol. [En línea] http://goo.gl/Qkx50B (subrayado nuestro).

En el segundo plan de estudios de la IES-3, primera reformulación, tampoco se registran asignaturas funcionalistas, pero la asignatura Teoria $e$ Prática da Tradução se mantiene.

En la segunda reformulación, surge la asignatura 'sociolingüística'; no obstante, está volcada al estudio de las variantes de ELE según se puede apreciar en el programa de la asignatura que se encuentra en el anejo 3. En 
resumidas cuentas, tampoco vemos claramente en ninguna de las tres versiones del PEG de esta IES el tema de los marcadores de discurso.

\subsubsection{Preguntas de investigación e hipótesis}

PI-15 - ¿Cuándo y cómo se presentan los MD a los estudiantes de grado en las IES de Rio Grande do Norte?

H20 - No se presentan explícitos ni directamente, aunque sí contextualizados en situaciones comunicativas principalmente escritas; orales, no. Al parecer no forman parte del acervo lingüístico de los docentes, por consiguiente cómo podrían llegar a los estudiantes?

\subsubsection{Análisis empírico}

Pretender fluidez y dominio de una lengua sin conocer los elementos que articulan las ideas a la hora de expresarlas, sea oralmente o por escrito, es un absurdo que tendría que revertirse de inmediato. Exponemos la información constatada de que los MD no forman parte de los contenidos formales ni funcionales del plan de estudios de grado actual ni anteriores de ninguna de las IES del Estado, no hay evidencia concreta en documentos formales y públicos. Tenemos docentes pregonando el funcionalismo como más importante, actual, moderno, etc., desprestigiando el formalismo, inclusive tachándolo de inútil a los intereses del dominio y fluidez de una lengua, cuando los propios no notan que las partículas cohesivas que sustentan teóricamente a disciplinas funcionales como la pragmática y el análisis del discurso no constan en el plan de estudio en ningún lugar claramente registrado para su abordaje paulatino en la clase de ELE. 
Es oportuno afirmar que tampoco se registra ningún contenido que trate directamente del tema de los MD en cualquier asignatura de lengua española 0 semejante del plan de estudios de grado de las IES de RN ${ }^{122}$

\subsubsection{La distribución de asignaturas según el PEG de las IES, una muestra.}

La enseñanza superior, a nuestro humilde ver, debería conservar cierto diálogo y homogeneidad en el plan de estudios, en los procedimientos, en el ambiente académico, etc. Lo que se nota muy claro es que ese diálogo no existe, cada institución va por su lado y por su propio modo de interpretar la normativa emanada del MEC para la enseñanza superior. Al tratarse de IES de una misma región cuya comunidad académica estudiantil es la misma, estas deberían privilegiar un diálogo sobre las cuestiones de este ámbito. No es sensato que haya discrepancia en esos aspectos académicos sabiendo que la enseñanza superior está regidas por el MEC a través de leyes, resoluciones, porterías y orientaciones que valen para la totalidad de instituciones de enseñanza superior.

En este estudio se procura ver la igualdad de horas en asignaturas específicas, se quiere saber si el porcentaje de asignaturas específicas del PEG de las IES es semejante o al menos aproximado.

\subsubsection{Descripción de los datos, instrumento de investigación y formateo}

Los datos han sido recogidos del banco de datos de las IES, estos datos son de carácter público y cualquier ciudadano puede acceder a ellos, están en internet $^{123}$. Sobre la totalidad de horas del plan de estudios de grado de cada

\footnotetext{
122 Rio Grande do Norte.

123 Fuente: [En línea] https://goo.gl/WHmEEm

[En línea] http://goo.gl/8rOs9K

[En línea] http://goo.gl/Qkx50B
} 
IES se ha realizado un recuento de las horas de las asignaturas de formación específica

\subsubsection{Parámetros de análisis}

El plan de estudios de la IES-1 totaliza 1.080 horas de clases de asignaturas específicas del total de 3.210 impartidas a lo largo de 9 semestres o 4 años y medio. Al no tener un registro formal de reformulación de PEG, representamos objetivamente esa proporción:

Gráfico 18 Asignaturas específicas IES-1

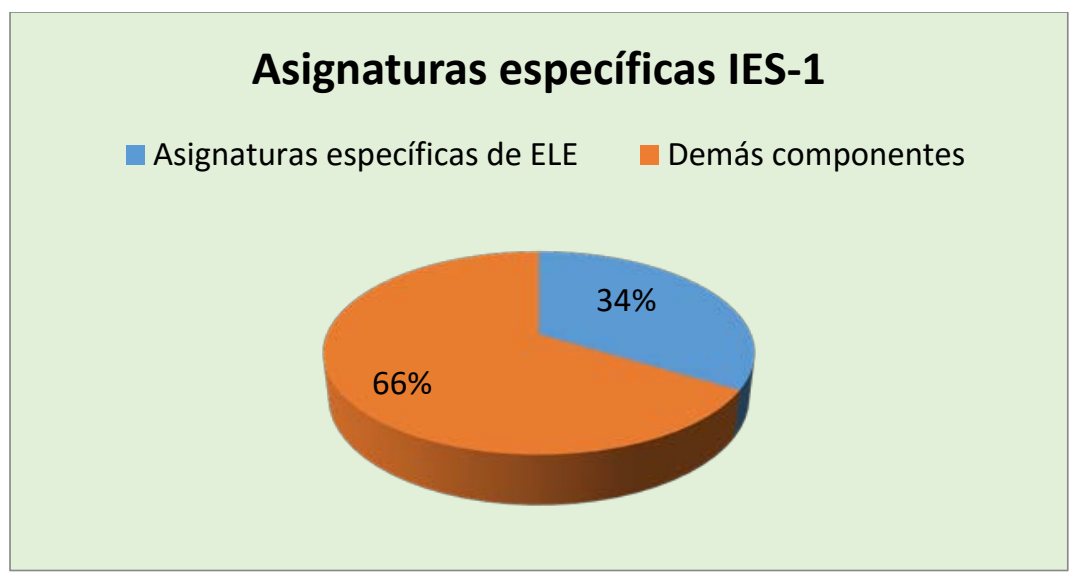

[En línea] https://goo.gl/WHmEEm

El plan de estudios de la IES-2 totaliza 3.350 horas de clases, de las cuales 920 son de asignaturas específicas de ELE. Aunque su plan de estudios fue reformulado en 2003, la carga horaria de asignaturas específicas se mantuvo: 
Gráfico 19 Asignaturas específicas IES-2

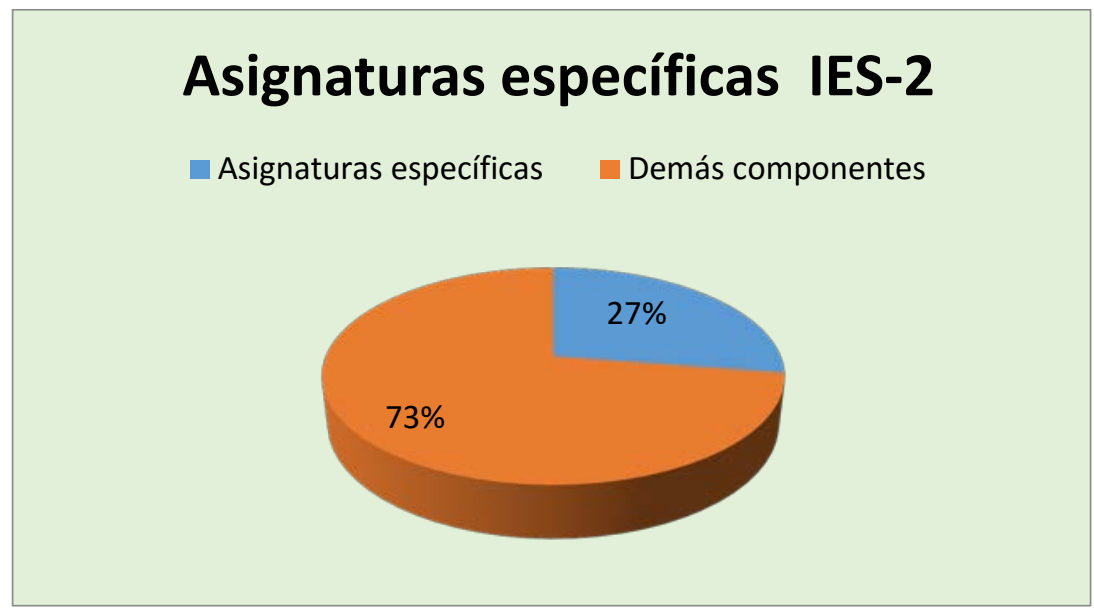

[En línea] http://goo.gl/8rOs9K

En contrapartida, el plan de estudios de la IES-3 ha sido reformulado 2 veces, o sea que tiene 3 PEG hasta hoy, de los cuales dos están en vigor y aquí presentamos el contraste con relación a la carga horaria de asignaturas específicas. El plan original tenía una configuración diferente, era un curso de grado seriado, semestral, predominantemente presencial, y tenía La posibilidad de impartir hasta $20 \%$ de sus contenidos a distancia, conforme Portería №. 4.059 de 10 de diciembre de 2004. El total de horas de lengua española y asignaturas específicas del plan original fue impactantemente modificado en sus reformulaciones posteriores.

\section{Gráfico 20 Asignaturas específicas IES-3}

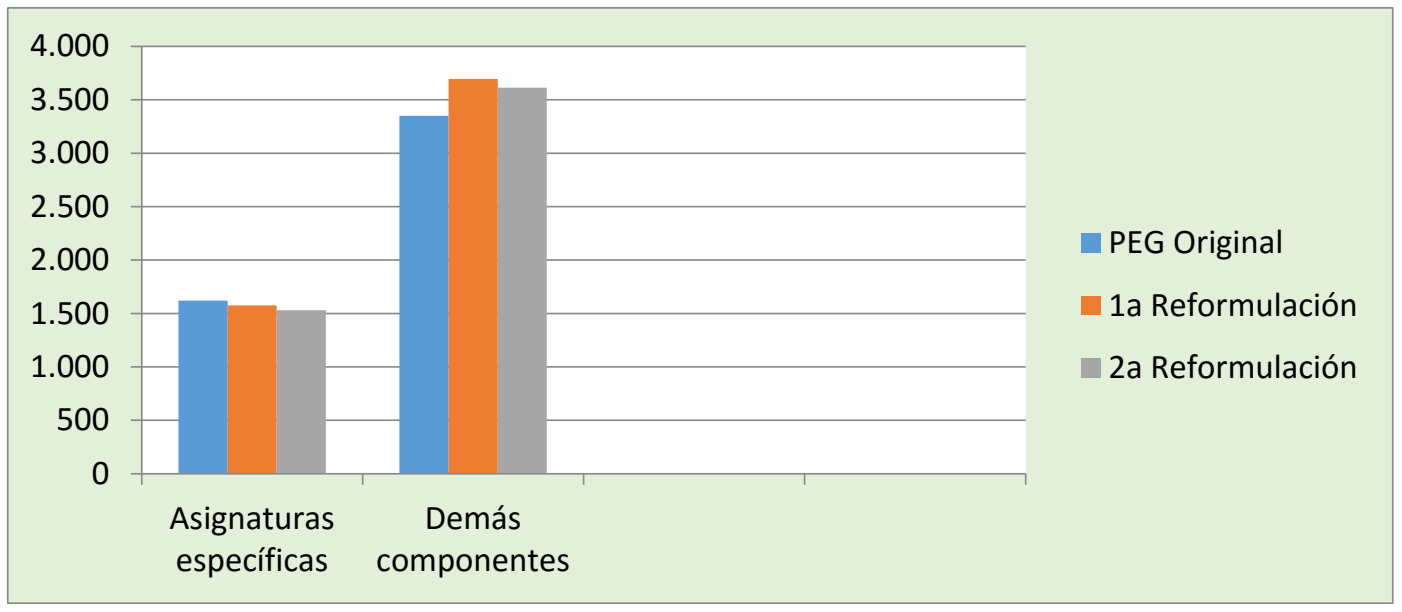

[En línea] http://goo.gl/Qkx50B 
Al observar el gráfico anterior, no parece haber tanta diferencia en la totalidad de horas de asignaturas específicas, pero esto se justifica en la disminución de horas de asignaturas de lengua española, por ejemplo, en beneficio de la creación de nuevas asignaturas preponderantemente del campo de la Literatura y de orden teórico. El gráfico siguiente muestra el porcentaje actual de esa carga horaria en la IES-3

Gráfico 21 Asignaturas específicas IES-3. Actual

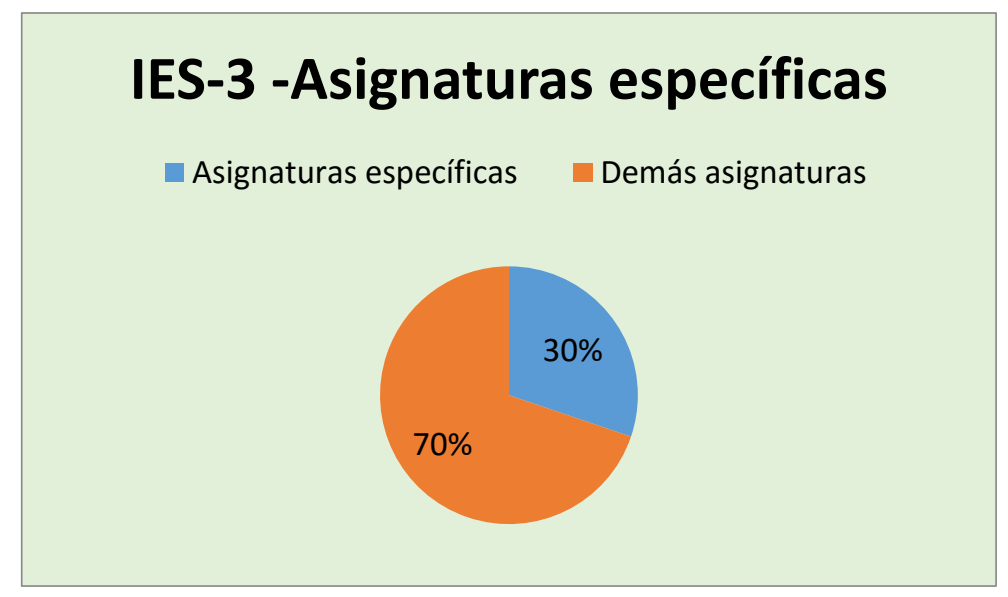

[En línea] http://goo.gl/Qkx50B

\subsubsection{Preguntas de investigación}

Al observar el porcentaje de asignaturas específicas que cada IES presenta, surge la indagación.

PI-16 - ¿La legislación universitaria tiende a uniformar solo datos? ¿Qué hacer para sincronizar acciones educativas de nivel superior?

H21 - La legislación debe ser cumplida en números y formatos, sin embargo, cada IES vive su realidad y enfrenta sus dificultades aisladamente, algo que podría ser superado con diálogo y unión de fuerzas. 


\subsubsection{Análisis empírico}

En la diversidad de un país como Brasil, en el que todo cambia, se reestructura, se ajusta, también la educación depende de la visión y expectativa de los agentes de esos cambios, que por lo general son, o demasiado amplias, hasta el punto de generalizar o demasiado estrechas, al punto de transformar en realidad, ánimos y visión personalizada. En la enseñanza superior en el Estado de RN, tenemos los dos fenómenos y ya se puede ir viendo lo que pensamos que sería mejor; por supuesto, pensamos que lo más importante es conocer lo suficiente para definir rumbos en un curso de grado, analizar lo que funciona y es importante, en otras palabras, saber el porqué cambiar o no algo que puede significar mucho para la sociedad expectante y cumplidora de esos (no) cambios.

El plan de curso de la IES-1 inició su vigencia académica en 2009, y pese a su autonomía, internamente ya se viene discutiendo la actualización o ajuste del PEG en vigor, de forma cautelosa y ponderada hace más de un año, vale comentar que el PEG en vigor lleva 6 años.

La IES-2, que es la más antigua en la oferta de grado en ELE, inició las actividades en el año 2000 y hasta ahora ya son 15 años de experiencia, no obstante tuvo años de oferta muy difíciles ante las circunstancias que en este Estado se vivían, siendo una de las principales la falta de profesores de español. Extraoficialmente se relata que el surgimiento de esta oferta fue de origen bastante atípico hablando académicamente, en definitiva, lo que es importante ahora es delimitar las responsabilidades y la seriedad con que se toman las decisiones al tratarse del plan de un curso que va a definir la vida profesional de un ciudadano.

Ante algunas situaciones muy atípicas, lo que hemos pensado es que los profesionales de grado olvidan que sus decisiones no son suyas, son decisiones profesionales por lo tanto estas deben ser discutidas con calma, con fundamento teórico, con experiencia y sobre todo con ética profesional y no a la ligera.

En la IES-3 la oferta surge de la promulgación 11.161, la ley del español y con ello una nueva institucionalización a la que el MEC le delega autonomía 
para la enseñanza superior. El plan de estudios original tenía como objetivo la formación del profesor con un potencial importante desde el punto de vista lingüístico lo que le supuso un interesante prestigio por el perfil del profesor de español que egresaba de esta IES. El plan de estudios tuvo su primera reformulación 6 años después, por una necesidad imperiosa de reformular el tipo de oferta: de modular al sistema de créditos. En esa primera reformulación con nuevos profesores, encontraron que no hacía tanta falta que el PEG tuviera ese perfil, que los estudiantes estaban allí para ser profesores no fluidos en ELE, se disminuyó sensiblemente la carga horaria de lengua, se crearon también nuevas asignaturas y se acataron otras más de cuño pedagógico, exigencia de la Institución. El curso pasó menos de dos años y por solicitud de la Rectoría, de inmediato vino una nueva reformulación en 2014 en la que se retiró las asignaturas específicas de semántica, traducción, análisis y elaboración de materiales didácticos, y se crearon nuevas, o mejor, se les cambiaron los nombres, la defensa de los cambios era que el formalismo no servía para nada que entonces no tenía sentido que esas asignaturas permanecieron. Bueno, entonces bien, el grupo de profesores que reformulaba entendía que las asignaturas creadas o cambiadas de nombre eran funcionalistas, equívoco nuestro, no, y si la pretensión era esa, pues se quedó en ilusión, porque en concreto ninguna a excepción de sociolingüística era de ese cuño.

Se observó que en el PEG uno de los objetivos era 'propiciar al estudiante otras esferas de actuación además de la docente', pero curiosamente fueron retiradas de las asignaturas obligatorias aquellas que podrían estimular esa amplitud de actuación tras la culminación del estudio de grado.

Por todo esto, el instrumento de valor con el que se puede hacer mejor 0 peor trabajo, es sin duda el PEG y ese motivo basta para que las IES dialoguen de forma abierta y profesional a este respecto en eventos académicos, seminarios, etc., y que la comunidad estudiantil participe y opine, pues en esta IES, el estudiante de grado no tiene derecho al voto, aún y es representado por un líder de clase para efecto de decisiones. 


\subsubsection{El Trabajo de fin de curso en el Plan de estudio de grado en ELE}

El trabajo de fin de grado, llamado en Brasil Trabalho de conclusão de curso (TFC), es una producción académica ampliamente utilizada en la enseñanza superior como una forma de evaluar a los estudiantes que están a punto de concluir el grado. Estos pueden ser redactados a partir de un proyecto creado por el estudiante y orientado por un docente, sobre uno de los muchos temas de la diversidad de aspectos de su formación de grado. Por lo general un TFC no aprobado implica en el impedimento de obtención del diploma y consecuentemente ejercer la profesión.

EI TFC tras un periodo de obligatoriedad y luego de libre elección por parte de la IES con relación a su implementación, al día de hoy, el Ministerio de Educación y Cultura (MEC) a través del Conselho Nacional de Educação, en su PARECER NN CNE/CES 67/2003 declara la no obligatoriedad de presentación del TFC para los cursos de graduación; sin embargo en Rio Grande do Norte hay un realidad diversa.

\subsubsection{Descripción de los datos, instrumento de investigación y formateo}

Los datos proceden del plan de estudios de las IES, a excepción de la IES-1, para la que, al no recoger ninguna información en el plan de estudios, tuvimos que acercarnos a la coordinación del curso para indagar la información. Hemos sistematizado los datos en el siguiente cuadro: 
Cuadro 40 El trabajo de fin de curso en el grado en ELE

\begin{tabular}{|c|c|l|}
\hline IES & $\begin{array}{c}\text { Trabajo de fin } \\
\text { de curso }\end{array}$ & \multicolumn{1}{|c|}{ Descripción } \\
\hline IES-1 & No & $\begin{array}{l}\text { No registra información a este respecto en el plan de } \\
\text { estudios de grado. }\end{array}$ \\
\hline IES-2 & Sí & $\begin{array}{l}\text { Se registra como requisito obligatorio para la conclusión } \\
\text { del grado en el plan de estudios. La presentación es solo } \\
\text { escrita, o sea, no hay lectura o defensa pública. }\end{array}$ \\
\hline IES-3 & Sí & $\begin{array}{l}\text { Se registra como requisito obligatorio en el plan de } \\
\text { estudios. La presentación es escrita y oral ante tribunal } \\
\text { en acto público. }\end{array}$ \\
\hline
\end{tabular}

(Datos de investigación)

\subsubsection{Parámetros de análisis}

Tal como vamos haciendo notar, los tiempos cambian muy de prisa, lo que era antes, ahora se cuestiona o se vuelve a poner en vigor, todo es relativo. Según nuestro humilde modo de pensar el hecho de realizar un TFC acarrea mucho de positivo; de hecho, detenerse a pensar, trazar un proyecto, ejecutarlo y luego informarlo solo puede aportar elementos positivos al perfil de un profesional, sin duda. Nada más coherente que finalizar el grado y cada uno de los posteriores posgrados con un trabajo de investigación que muestre claro al profesional que se ha formado y se abre paso al ejercicio de esa formación.

No obstante, la sociedad de hoy, en Brasil, no lo ve así; luego las leyes llegan para que se cumpla el ansia de esa sociedad, pero el acatamiento es parcial o, simplemente, ninguno como lo vemos en los fragmentos sobre TFC de dos IES de Rio Grande do Norte, primero la IES2 y enseguida la IES-3:

\section{IES-2}

\section{TÍTULO III DA MONOGRAFIA}

Artigo 34 - A monografia do curso de graduação em letras consiste num trabalho individual do aluno, sob a orientação de um professor com titulação mínima de especialista, e submetida a apresentação e apreciação de uma banca examinadora. (PPC-Letras, 2003) 


\section{IES-3}

\subsection{TRABALHO DE CONCLUSÃO DE CURSO}

Para os cursos superiores de Licenciatura, o Trabalho de Conclusão do Curso (TCC) é componente curricular obrigatório para a obtenção do título de Licenciado e será materializado por meio de uma monografia. [...] A elaboração da monografia é acompanhada por um professor orientador [...] avaliação e defesa pública do TCC perante uma banca examinadora. [...] composta pelo professor orientador e mais dois componentes, podendo ser convidado, para compor essa banca, um profissional externo de reconhecida experiência profissional na área de desenvolvimento do objeto de estudo. (PPC-Espanhol, 2014)

La primera exige EI TFC pero solo en documento académico escrito, y la segunda en ambos, oral y escrito. Al tratarse de grado en ELE, es de suponer que el TFC sea en español, pero no se ha detectado ninguna información acerca del idioma de la redacción y de la presentación oral del TFC, lo que lleva a deducir que es de libre elección para el estudiante. A nuestro ver, se debería apreciar lo de ser 'preferencialmente en español' con la debida mención en el Informe académico.

\subsubsection{Preguntas de investigación e hipótesis}

\section{PI-17 - ¿Es un beneficio para el estudiante de grado en ELE el hecho de que sea legal la no realización de un TFC, preferentemente en la lengua que enseñará?}

H22 - No es un beneficio, igual tampoco un perjuicio, pero sí una especial oportunidad de consagrar su conocimiento, fluidez y dominio de la lengua que va a enseñar.

\subsubsection{Análisis empírico}

La manera de estar mejor preparado para la docencia es dedicándose más, estando más seguro y suficiente en aquello que vamos a enseñar. 
Siguiendo esa línea de raciocinio, elaborar un TFC, en español, va a exigir del estudiante, lectura, investigación, producción formal de la lengua y preparación para la defensa del TFC, en español además. Todo ese proceso le supondría a cualquier persona una inmersión lingüística que va a proporcionarle conocimiento, fluidez y dominio de aquel asunto, seguridad y sobre todo mayores alcances como docente.

Desde mi humilde punto de vista, critico la práctica del Gobierno Estatal cuando aplica oposiciones para plazas de profesorado de LE y evalúa con una prueba escrita de carácter objetivo y no hay ningún momento en el que la fluidez y dominio oral de la lengua sean valorados para estos efectos. Pensamos que este es un factor importante y quizás sea el responsable de muchos de los problemas que se presentan en la educación básica y no dejan que se logre aprender la LE en el colegio.

Pensamos que si la fluidez y dominio de la LE del estudiante a punto de egresar, tanto como la del docente que busca colocarse en el mercado laboral, fuera requisito a ser valorado y comprobado, en el TFC para el estudiante, y en la oposición para obtener una plaza, mucho de la realidad actual cambiaría.

\subsection{EL ABANDONO DE LA CARRERA DE ELE}

Comprender mejor la dicotomía formación de profesores y enseñanza de una lengua extranjera como algo que históricamente afecta directa e indirectamente a la educación básica en la sociedad brasileña puede desencadenar acciones que anulen ciertos paradigmas individuales o de pequeños grupos sobre la enseñanza de ELE en la escuela pública dejando de confundir, generalizar o reducir la percepción de lo adecuado en la propia formación del profesorado.

En esa dicotomía, la formación y el perfil del profesorado de lengua extranjera cuenta como aspecto relevante que compromete la calidad del proceso de enseñanza y aprendizaje de LE en la escuela pública, no obstante, y quizás tan importante como el profesorado es la realidad que vive la educación en el país y en el Estado, y sobre todo el trato que la enseñanza de 
ELE tiene en este Estado, con el espacio siempre limitado lo que actualmente, cuenta y contribuye al contraflujo de los mismos objetivos.

En suma, lo que queremos decir es que, por muy buenos profesores que se consigan formar en las universidades, si no hay valorización y respaldo a la profesión docente de ELE y al conocimiento de la lengua española, difícilmente lograremos los objetivos que el propio MEC ha trazado. $Y$ lo que se viene notando es que cada vez más los estudiantes están desestimulados de avanzar en la carrera y depararse con un mercado laboral que limita las condiciones de trabajo.

\subsubsection{Descripción de los datos, instrumento de investigación y formateo}

Los datos surgen de la visita al Departamento de registros académicos de una de las IES, hubo una cita marcada para acceder al local y tener la asesoría de uno de los funcionarios del sector, la colecta de datos se realizó en 3 días.

Los datos se han organizado por año de ingreso y se han plasmado en un gráfico por clase, donde se mostrará el número de matriculados por semestre académico hasta llegar a la conclusión del curso de grado.

\subsubsection{Parámetros de análisis}

Comenzaremos por el primer ingreso, que corresponde a los matriculados en el semestre 2006.2: 
Gráfico 22 Estudiantes ingreso 2006.2
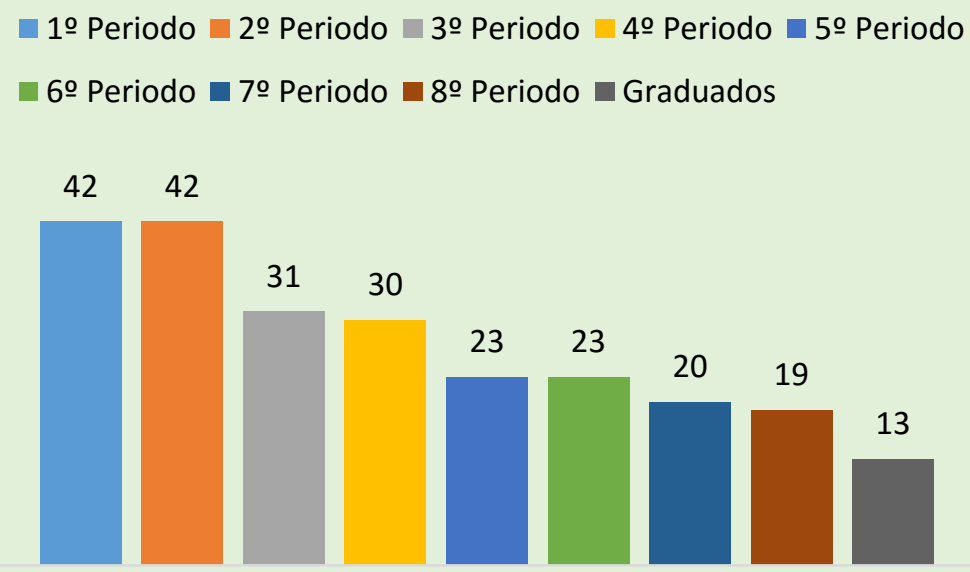

Ingreso 2006.2

(Datos de investigación)

Pudimos acceder a datos de demanda para la oferta de las 43 plazas para el curso de grado en ELE de 2006.2 y comprobamos que las peticiones de ingreso eran 3 veces más el número de plazas ofrecidas. Esto se explica por la novedad de la oferta y por el mercado laboral prácticamente seguro tras culminar los estudios de grado. Esta oferta era matutina.

El grupo de estudiantes de la clase 2006.2 pasó de 42 estudiantes en el primer semestre académico a 19 estudiantes que completaron el $8^{\circ}$ semestre, pero realmente cumplieron los requisitos y recibieron el diploma de profesor de ELE, solo 13 estudiantes.

En el siguiente gráfico vemos el paso de la vida académica en número de matrículas para el ingreso 2007.2, de oferta vespertina. 


\section{Gráfico 23 Estudiantes ingreso 2007.2}

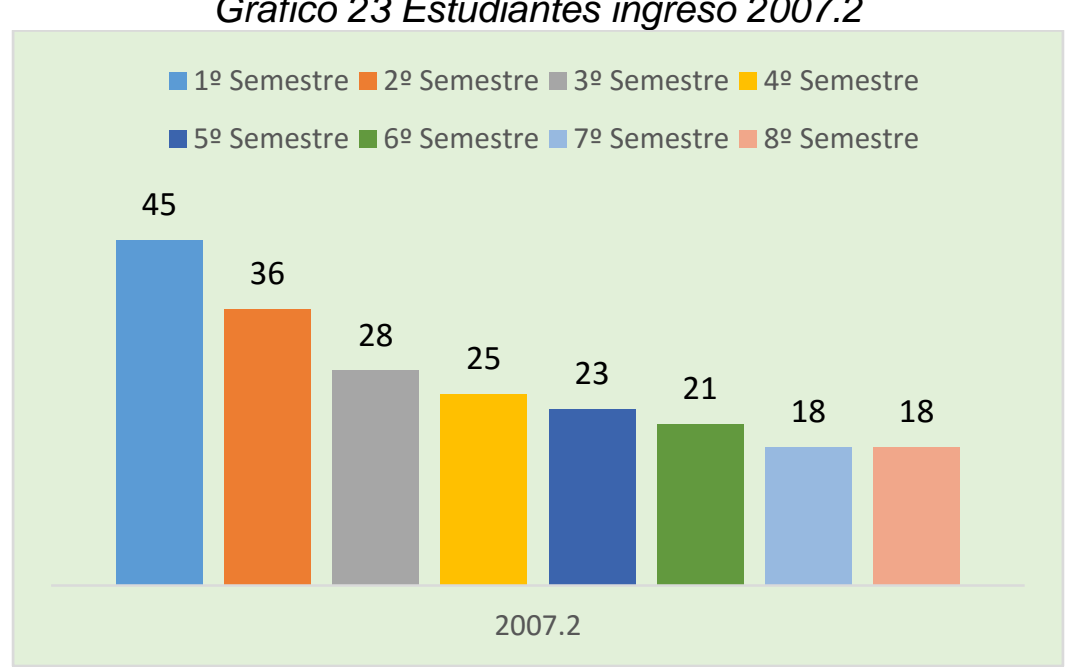

(Datos de investigación)

La salida gradual de estudiantes obedece por lo general a una diversidad de razones, pero en este y todos los tiempos. La que más interfiere en la vida de los universitarios brasileños es la necesidad de tener una renta que los ayude a ser menos dependientes financieramente de los padres. De esta forma, en el ingreso 2007.2 fueron matriculados 45 estudiantes de los cuales egresaron con la carrera concluida 18.

En el ingreso 2008.2 iniciaron los estudios 45 estudiantes y concluyeron los estudios 18. Un número razonable, como en el caso anterior, de nuevos profesores de ELE.

\section{Gráfico 24 Estudiantes ingreso 2008.2}

च 1ㅇ Semestre $\square$ 2ㅇ Semestre $\square$ 3ㅇ Semestre $\square$ 4ㅇ Semestre

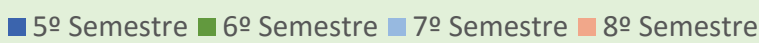

45

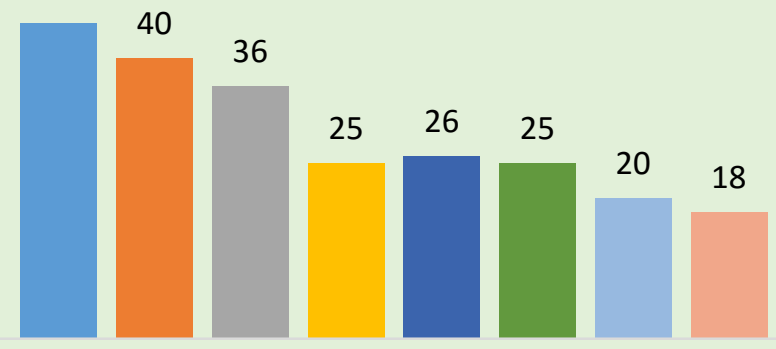

2008.2

(Datos de investigación) 
Lo mismo ocurre en el ingreso 2009.2. Se relata que al existir oferta de grado en ELE en dos IES en el Estado, los estudiantes intentan el ingreso en ambas, para luego elegir una y concluir en ella, esa una, solía ser otra la IES-3. Porque estaba vista como la que realmente formaba profesores de ELE, tanto lingüística como pedagógicamente. Pero el nivel de abandono de carrera no era significativo.

De este grupo de alumnos, ingresaron 45 y terminaron la carrera 20 de ellos.

Gráfico 25 Estudiantes ingreso 2009.2

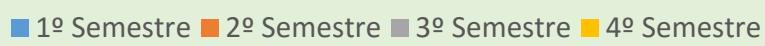

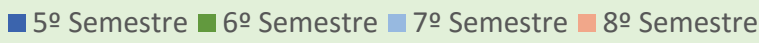

45

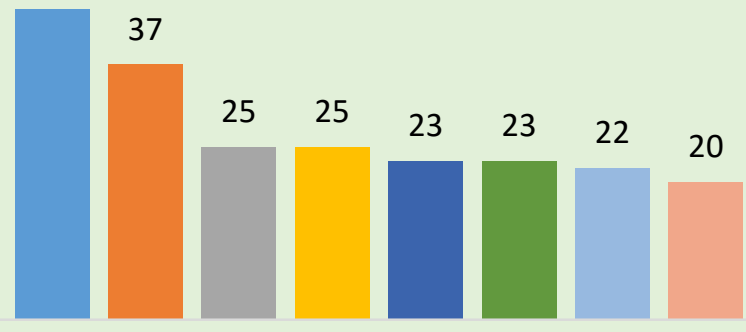

2009.2

(Datos de investigación)

En el ingreso 2010.2, se mantuvo el nivel de permanencia en el curso e, incluso, en el semestre 3 retornaron a estudiar 3 estudiantes que habían dejado el curso para estudiar otro. De este grupo, también se graduaron 20. Estos años fueron en términos de formación, los mejores, y además con buena formación. 
Gráfico 26 Estudiantes ingreso 2010.2

$\square$ 1으 Semestre $\square$ 2ㅇ Semestre $\square$ 3으 Semestre $\square$ 4으 Semestre

$\square$ 5은 Semestre $\square$ 6으 Semestre $\square$ 7은 Semestre $\square$ 8ㅇ Semestre

45

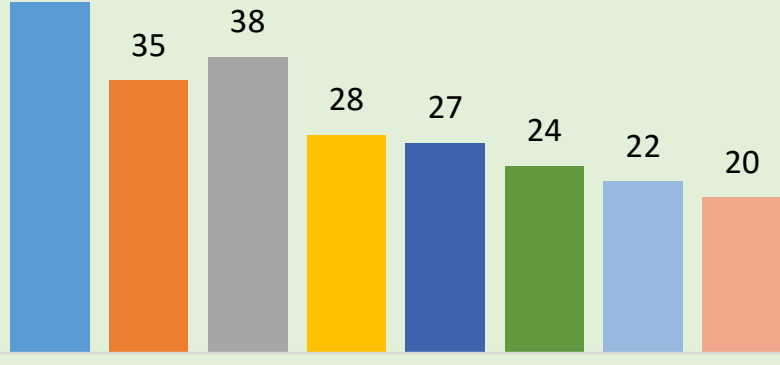

2010.2

(Datos de investigación)

Aunque los ingresos iban incrementándose y también el cuerpo docente, el número de egresados se mantuvo equilibrado. De los 45 ingresos de 2011.2, 12 de ellos culminaron la carrera.

\section{Gráfico 27 Estudiantes ingreso 2011.2}

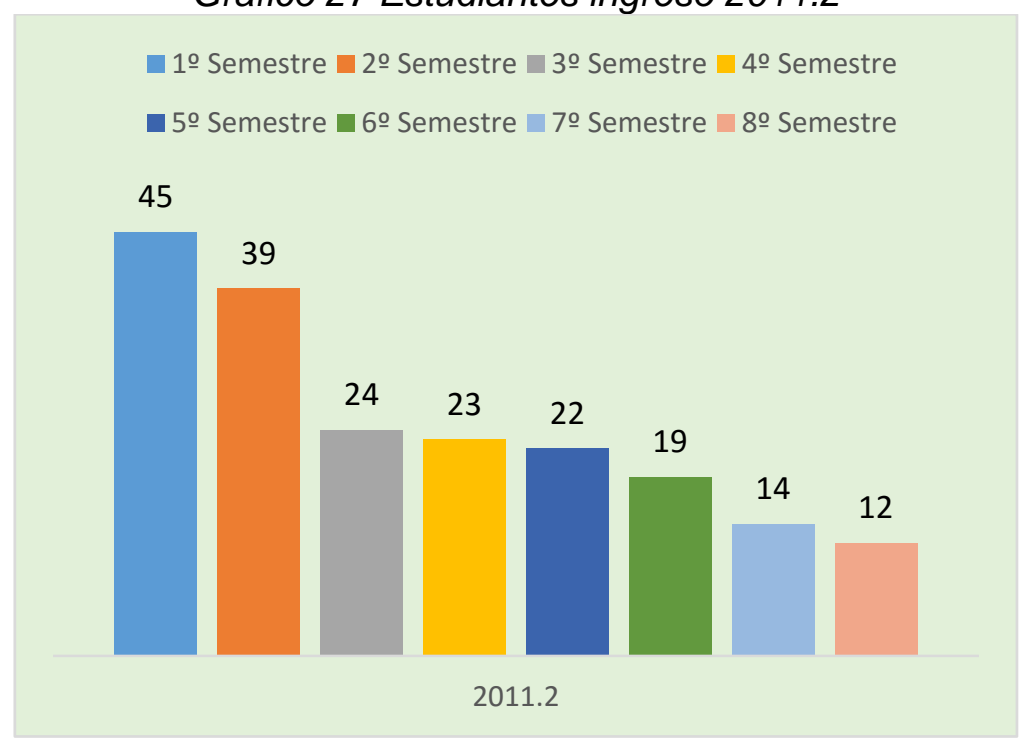

(Datos de investigación)

En el grupo del ingreso 2012.2, igualmente ingresaron 45 y en el sexto semestre permanecían 17 futuros profesores de lengua española para atender la demanda educativa de la educación básica y pública. 
Gráfico 28 Estudiantes ingreso 2012.2

1은 Semestre $\square$ 2ㅇ Semestre $\square$ 3으 Semestre

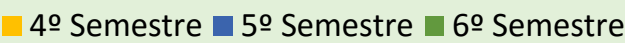

45

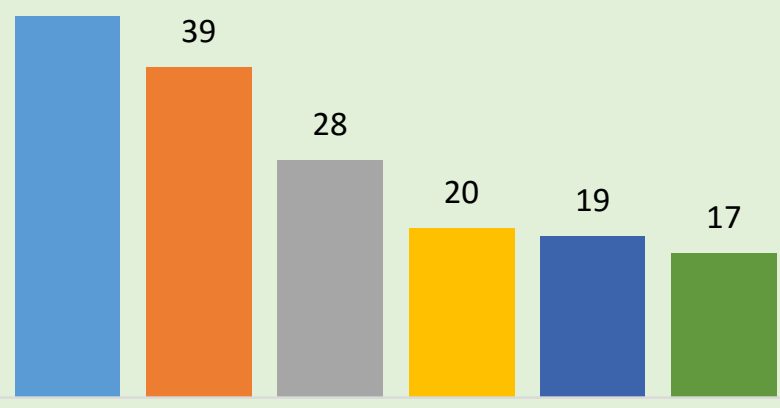

2012.2

(Datos de investigación)

El grupo de estudiantes ingresados en 2013.2, que actualmente estudian el 5 semestre de la carrera docente en ELE, se ha reducido drásticamente a 9 de 45 inicialmente matriculados; aún les quedan 3 semestres y una fuerte tendencia a disminuir aún más este número.

\section{Gráfico 29 Estudiantes ingreso 2013.2}

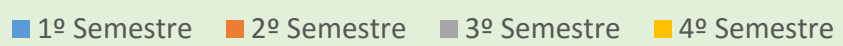

45

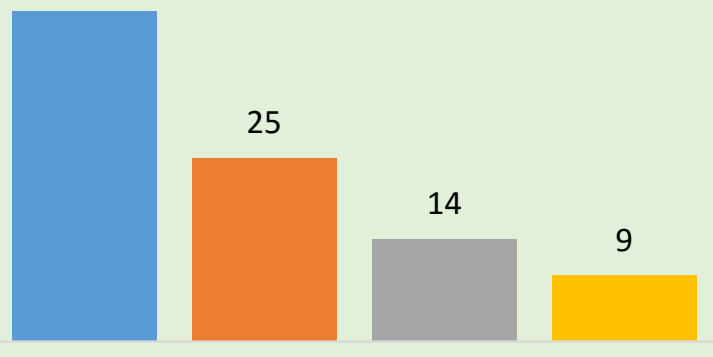

2013.2

(Datos de investigación)

Lo mismo ocurre con el grupo de alumnos de ingreso 2014.2, actualmente en el tercer semestre, disminuyó sensiblemente de 45 a 7 estudiantes matriculados. Nos preguntamos qué es lo que está desencadenando esta fuerte disminución de estudiantes de esta IES.

Gráfico 30 Estudiantes ingreso 2014.2 


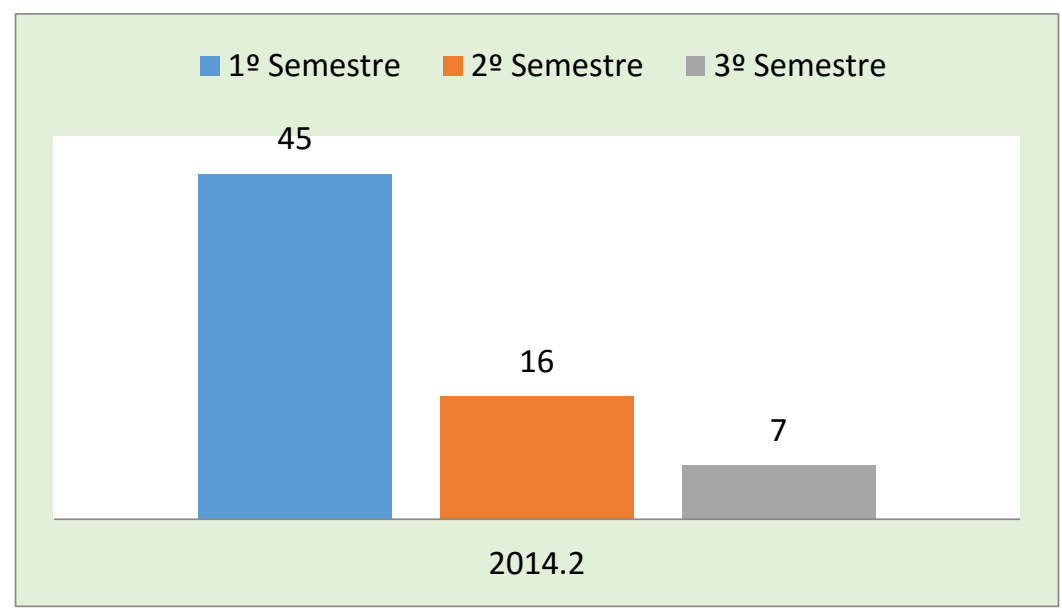

(Datos de investigación)

\subsubsection{Preguntas de investigación}

Que haya abandono de carrera es, a nuestro humilde ver, señal de que las cosas no están bien, luego lo más sensato, sería averiguar más profundamente e intentar atajar las dificultades de la mejor forma posible, por eso nuestra pregunta de investigación es:

\section{PI-18 - ¿La IES3 nota que está ante un problema de abandono de carrera muy fuerte desde 2013.2 hasta ahora?}

H23 - El acentuado abandono de estudios de grado es consecuencia de la insatisfacción en su día a día académico, y también de las no muy buenas expectativas en relación con el mercado de trabajo y la valoración de la profesión en el medio educativo.

\subsubsection{Análisis empírico}

Que está instalado un problema acentuado de abandono de carrera en la IES-3, está ahí, es un hecho; seguramente la administración y el equipo docente habrán reflexionado, hecho análisis, y reflexión nuevamente sobre la situación del curso para intentar llegar al problema y, unidos, implementar un plan reparador, aunque no siempre está al alcance del cuerpo docente. 
Pero no es el problema de esta IES-3 lo que traemos a esta investigación, sino el tema específico del abandono de los estudios de grado en ELE. Pensamos que no basta permanecer comprensivos a las razones varias que puedan justificar el abandono del curso, sino hasta qué punto esas justificaciones no son sino nada más que justificaciones porque lo que de hecho está generando ese desánimo en el estudiante es la suma de diversas cuestiones del quehacer académico que parecen poco importantes, pero que juntas, es mucho y respalda ampliamente una decisión de abandonar. La estructura institucional acoge al estudiante de grado, la dirección académica acoge a este estudiante de grado, la coordinación del curso acoge y ofrece el clima, ambiente, atención, cuidados y sobre todo identidad de curso de grado que haga sentir a estos estudiantes que están en el lugar correcto, todo eso es necesario saber, las fuerzas deben confluir para que el abandono no ocurra con tanta facilidad.

Y los docentes en este punto del abandono de carrera tienen un papel fundamental porque son ellos los que cautivan o no al conocimiento, al aprender más y mejor.

De otro lado, están las cuestiones ajenas a la universidad, aquellas que tienen relación directa con el número de vacantes abiertas al mercado de trabajo en condiciones razonables.

\section{CONCLUSIONES}

Sabiendo conscientes de que que para llegar hasta aquí, a las conclusiones del capítulo 3 tendríamos que ser muy claros y concisos en la presentación de los datos para mantener el hilo de pensamiento que nos habíamos propuesto, creemos que lo hemos conseguido, con mucho esfuerzo, pero con tino. Creemos que estamos en condiciones de mostrar resultados de un proceso altamente complejo en el que intervienen ciclos internos y además muchos factores y actores que, ciertamente, siempre han sido estudiados de forma aislada y del mismo modo solucionados, aisladamente. Este es un proceso que a nuestro sencillo modo de ver las cosas, tiene que verse como un 
proceso y solucionarse como tal, y que si desde dentro no se reacciona, veremos otros decenios de años intentando e intentando y no consiguiendo salir de un resultado no merecido por ninguna de las partes que componen este engranaje, partiendo en primer lugar de los que están en la educación básica confiando en la formación de grado para un futuro mejor.

Hemos presentado la dinámica de la investigación empírica para enseguida dedicarnos punto a punto a nuestros datos de investigación, a saber:

(1) La encuesta aplicada a ciudadanos comunes y a ciudadanos que estudian una lengua extranjera (III.2.1) nos deja muy claro que todo ciudadano espera que un profesor de LE conozca y domine fluidamente la lengua que enseña, pero la mayoría se conforma con que ese mismo profesor imparta aunque sea algo de la clase en LE. Esta realidad está generalizada, no hay confianza en el conocimiento y preparación del docente de LE, de ELE en nuestro caso, que está impartiendo clases en la educación básica.

(2) La producción escrita en ELE de estudiantes de educación básica analizada bajo el criterio de uso de marcadores del discurso (III.3.1.1), a juzgar por la carga horaria (16 clases de 135 minutos cada una) y por no tener antecedentes de aprendizaje de español, ha arrojado datos interesantes. Los estudiantes han aplicado en su redacción MD sin antes haber estudiado el tema como contenido del programa, se ha encontrado articulación del discurso con partículas que no pertenecen a su lengua materna (así), lo que quiere decir que esa información ha sido absorbida indirectamente. EI MD 'pero' ha sido el más aplicado en las redacciones, a priori pensamos que es una traducción literal de 'mas' de la lengua materna de los informantes, (portugués de Brasil). El docente ha impartido por entero las clases en español, se ha comunicado dentro y fuera de clase también en español y ha trabajado los contenidos a través de dos proyectos, uno a cada bimestre.

(3) Las respuestas de la encuesta a estudiantes de grado en ELE sobre MD (III.3.2.1) nos arroja informaciones muy importantes.

$\checkmark$ De 17 estudiantes del último bimestre de carrera de 3 IES, 8 dicen que el $25 \%$ del tiempo de cada clase es en español, otros 8 dicen que el $50 \%$ y solo 1 estudiante dice que el $75 \%$. Haciendo un 
promedio tenemos que el $37,5 \%$ de cada clase es impartida en español. Los estudiantes generalizaron sus respuestas, es decir, incluyeron las clases de lengua española.

$\checkmark$ Al ser indagados sobre el estudio de MD, solo 3 de los 17 dijeron que sí los habían estudiado, 6 que no los habían estudiado aún y 8 que no recordaban si los habían estudiado o no; en definitiva, hay poca o ninguna diferencia a excepción de los 3 estudiantes que dicen haber estudiado los MD.

$\checkmark$ Al pedir a los 3 estudiantes que identificaran la asignatura en la que habían estudiado los MD, dijeron que no recordaban cuál había sido.

$\checkmark$ Al presentar a los 3 estudiantes que dijeron que habían estudiado los MD alternativas que recogían informaciones conceptuales de los MD y solicitar que identificaran aquellas correctas, ninguno acertó totalmente. Estas respuestas, a nuestro ver, fueron aleatorias.

$\checkmark$ Preguntamos a los 17 estudiantes si consideraban que los MD eran responsables por una fluidez oral y escrita: 3 afirmaron que sin duda sí lo eran, 6 dijeron que no tanto y 8 dijeron que no lo sabían

$\checkmark$ Aún les preguntamos si consideraban que los MD estuvieran más presentes en la expresión oral, en la escrita o en ambas. El resultado fue inesperado, porque no había lógica, ningún estudiante dijo 'en ambas', los estudiantes contestaron, 6 que no sabían, 5 que era en la expresión oral y los 6 que era en la escrita.

$\checkmark$ La última de las preguntas pedía que los estudiantes señalaran una alternativa que contuviera un MD, todos menos 3 señalaron correctamente, pero permanece la duda de este resultado al considerar las respuestas anteriores. 
En conclusión, estos estudiantes no están bien enterados de los MD, y si el contenido MD fue realmente visto en alguna asignatura, no significó mucho en la formación específica de estos futuros docentes.

(4) La producción escrita de los estudiantes de grado en ELE (III.3.2.2), analizada bajo la óptica del uso de MD, se nota condicionada a los MD propuestos en el enunciado de la actividad. La aplicación de los MD se nota forzada y en diversos momentos sin sentido. Al tratarse de estudiantes del último bimestre de la carrera la producción formal de la lengua presenta carencias de lo más diversas de cohesión, coherencia y fluidez en su producción escrita, especialmente

(5) El análisis de la producción oral del docente de grado (III.3.3.1) surge de grabaciones de audio que pasaron por un proceso de transcripción ortográfica previo al análisis, y arroja un parecer no muy alentador, basado puramente en la observación de la articulación de su discurso con MD o no. Las partículas discursivas aplicadas son un calco de la lengua materna del docente nativo, que por cierto, a nuestro ver, no suele aplicar en su discurso oral tantos MD como ocurre en la lengua española. Añadimos que, debido al desempeño analizado, los profesores de grado, no aprendieron los MD en su formación universitaria.

(6) La entrevista con los docentes de grado (III.3.3.2) fue realizada personal o virtualmente, no hubo ningún otro criterio para seleccionarlo que no fuera su actuación en área específica de formación de ELE, o sea, que fuera profesor de lengua española. Un docente de cada IES contestó y si lo hubiera deseado podría haber comentado o ampliado su respuesta, incluso se dejó en total libertad para elegir la lengua con la que quisieran contestar las preguntas de la entrevista. A todo esto, el docente de la IES-3 dijo que respondería en portugués. En general las respuestas de los docentes coinciden, pero hay un matiz de mayor ánimo y disposición a que el trabajo que se realiza en el IES-1 sea completo, bien articulado y sobre todo buscando los mejores resultados en el perfil del estudiante egreso de esa IES-1. En la IES-2 e IES-3 ya se siente diferente su respuesta, no comentan mucho ni amplían su respuesta, es como si hubiera un convencimiento de que su posicionamiento es el correcto, sus acciones resultado de las condiciones externas a sí. Es fuerte, sobre todo en la 
IES3 el creer en que el mejor profesor de lengua extranjera es el profesor nativo, el brasileño, porque este ha superado ya todo el proceso de aprendizaje y al haber pasado por él, este, sin duda, tiene mejores condiciones de ayudar al alumno. Lo que nos preguntamos de inmediato es: cómo lo va a ayudar si este docente aún tendría que avanzar más.

(7) Analizamos el perfil del docente de grado (III.4.1) con datos extraídos de fuentes fidedignas con relación a su titulación, tiempo de servicio, situación laboral y si es nativo o no nativo. Los docentes de la IES1, son todos doctores, de la IES-2 solo 2 y de la IES-3 aún ninguno, la explicación de este cuadro obedece a cuestiones legales que no vienen al caso repetir aquí, solo queremos confirmar los datos y el perfil que estos datos dan a cada equipo docente, en el que se destaca la IES-1, por supuesto. Son 3 los docente no nativos en las IES de RN.

(8) La encuesta sobre el posicionamiento del docente de grado con respecto al funcionalismo y al formalismo (III.4.2) nos da a conocer datos inesperados y sorprendentes como el saber que 8 de los 15 docentes de grado no tienen claro lo que es y lo que implican las teorías del formalismo y del funcionalismo. Los resultados de esta encuesta nos conectan con la esencia de los MD en el seno del funcionalismo y estas respuestas pueden explicar la razón por la que los MD no hacen parte de la consciencia lingüística de buena parte de los docentes de ELE en RN.

(9) En el punto (III.4.3.1) volvemos al plan de estudio de las IES para verificar en las asignaturas funcionalistas el contenido programático de Ios MD, pero la búsqueda es un tanto infructífera. Al investigar y analizar el plan de estudio de las IES, el actual y los anteriores, encontramos que la IES-1 solo tiene Lingüística aplicada, la IES-2 presenta Análisis del discurso sociolingüística y Psicolingüística, pero son asignaturas volcadas a la lengua portuguesa, sin embargo, no contienen el tema MD. La IES-3 solo oferta en la última versión de su plan de estudios, sociolingüística en la que tampoco se ve nada de contenido relacionado a los MD.

(10) Sobre la distribución de asignaturas específicas según el PEG de las IES (III.4.3.2), verificamos que es relativamente homogéneo y que las asignaturas que forman al profesor de grado en ELE son más o menos las 
mismas, lo que haría suponer una enseñanza semejante entre las IES. Consideramos que el diálogo entre las IES es fundamental para unificar las fuerzas a la hora de reivindicar atención al Gobierno para implementación de cambios que mejoren el resultado de la enseñanza en la educación básica, como también para dialogar sobre lo relevante de las asignaturas y los detalles sobre el PEG en pro del éxito de una formación de excelencia.

(11) El Trabajo de Final de Curso (III.4.3.3) se ha sometido a estudio por la importancia que puede tener como instrumento de aprendizaje o perfeccionamiento de ELE. Buscamos saber si las IES lo requerían como obligatorio para conclusión de la carrera, y para dos de ellas, sí lo es, la IES2 solo por escrito, la IES3 escrito y defensa oral ante tribunal; para la IES1 no existe. A pesar de la ley de la no obligatoriedad, en el nordeste sigue vigente la exigencia del TFC.

(12) El grado de satisfacción en ámbitos académicos suele medirse por la permanencia de su comunidad académica; pues bien, es de eso de lo que trata nuestra averiguación en este punto (III.4.4). Indagamos el ingreso, la permanencia y el abandono del grado en una de las IES, sin que esto sea parámetro y solo dato de reflexión, se investiga la IES-3 en ese campo, obteniendo un resultado que señala abandono de carrera acentuado desde el año de 2012. Hemos elegido esta IES-3 y la trayectoria de ingreso, permanencia y abandono de carrera porque en ella es visible que hay medidas que se deben accionar para detener esa elevada tasa de abandono. Tema sin duda, muy oportuno a investigar como contribución a la enseñanza de ELE y de lo que concluimos que los aspectos sobre lengua extranjera influyen marcadamente en esa tasa alta de deserción. 
CONCLUSIONES GENERALES 


\section{CONCLUSIONES GENERALES}

Lo poco que he aprendido carece de valor, comparado con lo que ignoro y no desespero en aprender René Descartes

Es obvio que la natural identidad individual del ser humano, la forma como aprende y el universo en el que está inserto condicionen, sin duda, el ámbito de aprendizaje o de adquisición de una lengua extranjera. Factores de mucha relevancia en este proceso como el papel del docente formador, los objetivos, el medio, los recursos y demás para aprender una lengua extranjera LE se configuran como primordiales para determinar el camino a seguir, que visto desde cualquier ángulo, es altamente complejo y de continua exploración.

Es importante percatarse de que el aprendizaje funcional es una meta además de un proceso, que no podemos enseñar siguiendo la estricta orientación de un solo método, ni de una corriente, ni de un tiempo. Debemos recordar la famosa frase de Dewey: "Si enseñamos a los alumnos de hoy, como enseñamos a los de ayer, les estaremos robando el mañana"

Lo de profesor sujeto-agente y estudiante sujeto-paciente es cosa del pasado; para el presente, el aprendizaje es acción, reflexión, saber moverse en diversos contextos sabiendo que el conocimiento hoy está en muchísimas más fuentes y se accede a él de diversas formas. En definitiva, la naturaleza del aprendizaje es absolutamente personal, siempre lo ha sido, los profesores de hoy ya lo sabemos.

La sociedad necesita profesores que formen a los futuros profesores sabiendo mucho de sus campos de conocimiento (obviamente), pero también que los formen para que sepan llevar, estimular ese conocimiento, que sepan promover las ganas de aprender de sus alumnos. Desgraciadamente y en general, no es lo que ocurre.

Para conocer y determinar las razones que conducen el estudio de lengua española a resultados insatisfactorios en la enseñanza pública y básica 
del ciudadano brasileño, hemos pretendido analizar todo lo que puede significar información pertinente sobre ciclo del proceso de enseñanza y aprendizaje de ELE, empezando por recoger informaciones que evidencian el perfil histórico del aprendizaje de una lengua extranjera en general y, en concreto, contemplando a continuación todos los aspectos que han intervenido o influido directa e indirectamente en este proceso.

Nuestra búsqueda ha llegado a su fin, por el momento, y nuestras observaciones y conclusiones son las que siguen:

En el capítulo 1 se inician presentando el estado de la cuestión sobre tres puntos fundamentales en esta investigación: la formación de profesores de español como lengua extranjera; la incidencia de los marcadores del discurso en la formación de profesores, y la presencia de estos en la enseñanza y aprendizaje de ELE en la educación básica y pública brasileña

Sobre la formación del profesorado de grado en ELE, en Rio Grande do Norte-Brasil, se concluye que la iniciativa ha sido resultado, a priori, de la promulgación de la ley 11.161, que surge de acuerdos internacionales de comercio con países hispanos y también de la creciente globalización que con la contribución de la tecnología da acceso a la información.

De las IES analizadas se concluye que hay incongruencia entre lo que el plan de curso dice sobre el perfil del futuro profesor de grado en ELE y la realidad tras cuatro años de carrera; sobre todo por el resultado de su actuación docente en la escuela pública.

Los cursos de grado, en general, siguen la política de no privilegiar ninguna variedad lingüística en respeto a la identidad cultural de las naciones hispanohablantes, aunque el diseño del plan de estudio de grado en el amplio contenido intenta conocerlas desde varias ópticas de estudio.

La educación brasileña contempla las orientaciones del Marco común europeo de referencia para las lenguas en la elaboración y diseño de las metas, niveles y procedimientos de enseñanza para la formación del profesorado, así como reconoce la institucionalización de las Academias de la Lengua de los distintos países de habla hispana como un todo. El MCER es aplicado como parámetro en el plan de estudios de grado y también en las orientaciones curriculares nacionales para la enseñanza básica, pero tendría 
que haber una proporcionalidad y delimitación adecuadas a los niveles y finalidades de enseñanza de LE.

Se concluye que la incidencia de los marcadores del discurso en la formación del profesorado de ELE no es expresamente incluida en el plan de curso vigente de las tres IES del Estado de RN, tras el análisis de las asignaturas específicas de formación en ELE.

Se observa a partir del análisis de audios transcritos que la fluidez y dominio de la lengua en los docentes de grado en ELE es, en general, razonable, aunque el uso de marcadores del discurso podría tener un mayor y mejor presencia. Al analizar la muestra escrita de discurso de un estudiante, notamos que su desempeño en lengua no está en el nivel que se esperaría para un estudiante que está próximo a titularse.

En lo que se refiere a la enseñanza de lenguas extranjeras en Brasil, desde 1500 hasta hoy seguimos teniendo dificultades. Al evaluar los reglamentos y normativas oficiales en el contexto nacional, se concluye que ha habido aciertos como el de la aplicación del método directo en su momento y fallos importantes como el de limitar la enseñanza de una lengua extranjera a la práctica de la lectura en la enseñanza básica y publica, fortaleciendo indirectamente el formalismo puro de la lengua extranjera en un contexto educativo. Y cerramos el capítulo con los mitos de docentes y estudiantes de grado sobre la carrera de ELE, que no son del todo mitos para los estudiantes, sino que casi diríamos que son sus derechos

En el capítulo 2, procurando evitar caer en la repetición de cuestiones teóricas, nos hemos detenido sobre conceptos clave y explicaciones sobre fenómenos lingüísticos que intervienen en el proceso de enseñanza y aprendizaje de una lengua y, sobre todo, en aspectos de fluidez y dominio oral y escrito, como los marcadores del discurso, fundamentándonos en el concepto y clasificación de PORTOLÉS (1998) y también en la importancia de estas partículas discursivas, los MD para la consolidación de la lingüística del texto afianzando la teoría pragmática y el análisis del discurso, situando el texto como unidad del lenguaje y no la oración como era visto desde la sintaxis, conocimiento del ámbito formalista. 
Ante lo concreto del funcionalismo, muchas seudoteorías se han ido fortaleciendo hasta el punto de condenar el conocimiento formal de la lengua a la inutilidad y, por consiguiente, a su desvalorización en la clase de ELE. Posicionamiento radical este, que más que beneficios ha ido trayendo perjuicios también en el aprendizaje o adquisición de la lengua materna. De ahí que en este trabajo hacemos un llamamiento a la reflexión y al equilibrio, partiendo del principio de que toda comunicación necesita un código común entre el emisor y el receptor; la cuestión inferencial viene tras ese punto de partida. Pensamos que la alianza formalismo y funcionalismo ayudaría a resolver los problemas de aprendizaje y de enseñanza de lenguas en la formación del profesorado.

Hablamos de la gramática, de la semántica y de la fonética como conocimientos de relevante aporte a la formación de un profesor de ELE, ya que este sí debe dominar esos ámbitos, pues se trata de un profesor, no de un usuario de ELE. En definitiva, la gramática pedagógica de CELCE-MURCIA (1991) dice mucho de lo que nosotros decimos formalmente aquí e informalmente en la actividad docente: creemos que aprender la forma, el significado y ponerlos en uso es el camino certero para un aprendizaje fluido de lengua.

En cuanto al capítulo 3, agruparemos las conclusiones por tema tratado:

En general, la enseñanza y aprendizaje de una lengua extranjera es un proceso en el que intervienen elementos internos, factores y actores que deben estudiarse como un todo.

Sobre el docente de ELE de educación básica concluimos que los ciudadanos en general y los estudiantes de una LE esperan que un profesor de LE domine fluidamente la lengua que enseña; pero se conforma con que las clases sean impartidas en la lengua meta aunque solo sea en parte. No hay confianza en el conocimiento del docente de LE. (III.2.1).

Sobre los marcadores del discurso, concluimos que:

- (III.3.1.) La presencia de MD en la producción escrita de estudiantes de educación básica es razonable tras 16 clases de 135 minutos e 
impartición de clases por entero en español y usando proyectos como metodología de enseñanza. EI MD 'pero’ ha sido el más usado.

- (III.3.2.1) Lo que se concluye a partir de la encuesta sobre MD a estudiantes de grado del último semestre de carrera es que, en definitiva, estos estudiantes no conocen bien los MD; no se puede establecer si el contenido MD fue realmente visto en alguna asignatura, pero si lo hubiera sido, no significó mucho en la formación específica de estos futuros docentes. Las respuestas emitidas han sido demasiado contradictorias.

- (III.3.2.2) La presencia de MD en la producción escrita de los estudiantes de grado en ELE está condicionada a la estructura propuesta en la actividad, no hay autonomía y sí baja calidad de producción de lengua en cohesión, coherencia y fluidez por parte de los estudiantes.

- (III.3.3.1) Sobre la presencia de los MD en la producción oral del docente de grado, concluimos que el resultado no es satisfactorio, se nota claramente un calco aplicado a las partículas discursivas. Añadimos que, debido al desempeño analizado, los profesores de grado, no aprendieron los MD en su formación universitaria.

\section{Sobre el docente de grado en ELE:}

- (III.3.3.2) Entrevista realizada a docentes de IES de RN. Concluimos que los profesores entrevistados tuvieron distinta disposición y ánimo al contestar las preguntas. Se percibe un claro y categórico entusiasmo en las respuestas del entrevistado de la IES1, una conformidad y pasividad en el de la IES2 y una altivez e indiferencia en el de la IES3, según se desprende de las respuestas emitidas por los entrevistados (respuestas a (8), (9) y (14)).

- (III.4.1) El perfil del docente de grado con relación a la titulación, el tiempo de servicio, la situación laboral y el hecho de si es nativo o no nativo. En la IES-3 están los docentes con menor titulación y en la IES-1 con la mayor; hay 3 docentes no nativos. Hicimos estas indagaciones para verificar la uniformidad del cuerpo docente de las IES que ofertan el grado en ELE. 
- (III.4.2) La encuesta sobre el posicionamiento del docente de grado con respecto al funcionalismo y al formalismo nos revela datos inesperados y sorprendentes. Ocho de los 15 docentes de grado no tienen claro lo que es y lo que implican las teorías del formalismo y del funcionalismo, información lo que puede explicar la razón por la que los MD no hacen parte de la consciencia lingüística de los docentes.

\section{Sobre el plan de estudios de grado en ELE:}

- (III.4.3.1) Investigamos el contenido programático de los MD en las asignaturas funcionalistas, sin éxito. Fueron analizados los planes originales y las reformulaciones y concluimos que este contenido no forma parte de ninguna asignatura y de ninguno de los planes de estudios analizados de las tres IES.

- (III.4.3.2) Comprobamos la distribución de asignaturas específicas según el PEG de las IES procurando saber si existía igualdad o semejanza, y concluimos que sí, aunque solo a nivel de carga horaria, porque las asignaturas varían.

- (III.4.3.3) Indagamos sobre si las IES aplicaban como requisito obligatorio el Trabajo final de curso TFC, a pesar de la ley que ha anulado esa obligación, y constatamos que hay una gran diversidad: la IES-1 no lo recoge en su plan de estudio; la IES-2, sí pero solo escrito, y la IES-3, escrito y con defensa oral pública. Concluimos que el TFC es de relevancia y ventajoso para el estudiante en su formación específica, sobre todo si es elaborado en lengua española.

Para terminar y como cierre de este trabajo, quiero decir que ha sido fruto de las inquietudes profesionales que han ido surgiendo a lo largo de mi ejercicio docente en el nordeste brasileño, hasta convertirse en una verdadera cuestión de responsabilidad. Las ponderaciones, las sugerencias y las conclusiones de este trabajo esperamos que puedan ser útiles para una mejora cualitativa de la formación de profesores brasileños de lengua española. 


\section{BIBLIOGRAFÍA}

\section{LENGUAJE, LENGUA, LENGUA MATERNA Y ENSEÑANZA $Y$ APRENDIZAJE DE LENGUA EXTRANJERA}

ANSCOMBRE, J. C. y DUCROT, O. (1983): La argumentación en la lengua. 1994ª edición. Madrid: Gredos.

AUSTIN, J. L. (1969): How to do things with words, Oxford: Clarendom express. (Como hacer cosas con palabras, trad. Genaro R. Carrió y Eduardo A. Rabossi, Barcelona: Paidós, 1990)

BECHARA, E. (2000). Dramática da Língua Portuguesa. São Paulo: Loyola.

BERNAUS, M. (Ed.), (2001): Didáctica de las lenguas extranjeras en la Educación Segundaria Obligatoria. Madrid: Síntesis educación.

BIKANDI, U. R., (Ed), (2000): Didáctica de la segunda lengua en la educación infantil y primaria. Madrid: Síntesis Educación.

BRASIL (2011). Lei de Diretrizes e Bases da Educação Nacional $n^{\circ}$ 9394, de 20 de dezembro de 1996. Estabelece as Diretrizes e Bases da Educação Nacional. 6. ed. Brasília: Câmara dos Deputados.

CASSANY, D., LUNA, M., SANZ, G. (1994): Enseñar lengua. Barcelona: Editorial GRAÓ.

CELCE-MURCIA, M., \& LARSEN-FREEMAN, D. (1999): The grammar book: An ESL/EFL teacher's course (2nd ed.) Boston, MA: Heinle.

CELCE-MURCIA, M. (1991) Teaching English as a second or foreign language. 2nd ed. Boston: Heinle \& Heinle Publishers.

CHAGAS, R. V. C. (157). Didática especial de línguas modernas. São Paulo: Companhia Editora Nacional. 
CONVENIO ANDRÉS BELLO (2014) Tablas de equivalencias de la educación primaria o básica y media o secundaria de los países del Convenio Andrés Bello. Bogotá. [En línea] http://tablas.convenioandresbello.org/pdf/tabla_equivalencias.pdf

COTS, J. M., et al. (2007): La conciencia lingüística en la enseñanza de lenguas. Lomas, et al. (direct). Barcelona: Editorial GRAÓ, de IRIF S.L, 2007. 144 p. Serie didáctica de la lengua y la literatura. ISBN: 978847827-508-3

CUNHA, C.; CINTRA, L. (1985) Nova Gramática do Português Contemporâneo. $2^{\mathrm{a} e d .}$ Rio de Janeiro: Nova Fronteira.

GARCIA, Santos, J. F. Sintaxis del español. Nivel de perfeccionamiento. Salamanca: Ed. Santillana.

GARCIA, Santos, J. F. (1994). ¿Qué gramática? En Centro Virtual Cervantes. La enseñanza de la gramática. Actas del IV ASELE [En línea] http://cvc.cervantes.es/ensenanza/biblioteca_ele/asele/pdf/04/04_0069.p df

GERALDI, J. W. (1987). O texto na sala de aula. Cascavel: Assoeste.

INSTITUTO CERVANTES (2006): Plan Curricular del Instituto Cervantes: Niveles de referencia para el español A1 y A2. Madrid: Editorial Biblioteca Nueva, S.L.

INSTITUTO CERVANTES (2006): Plan Curricular del Instituto Cervantes: Niveles de referencia para el español B1 y B2. Madrid: Editorial Biblioteca Nueva, S.L.

INSTITUTO CERVANTES (2006): Plan Curricular del Instituto Cervantes: Niveles de referencia para el español C1 y C2. Madrid: Editorial Biblioteca Nueva, S.L.

INSTITUTO CERVANTES. Memoria anual del Instituto Cervantes (2012): El español: una lengua viva. Informe 2012. Madrid. 
http://cvc.cervantes.es/lengua/anuario/anuario_12/i_cervantes/p01.h tm

KRASHEN, S. (1982): Principles and Practice in Second Language Acquisition. Oxford: Pergamon Press.

KRASHEN, S. (1982): Principles and Practice in Second Language Acquisition. Oxford: Pergamon Press.

LARSEN-FREEMAN, D. (1991): Teaching Grammar. En Celce-Mauricia, M (comp). Teaching English as a Second or Foreign Language (pp.279283): EU: Hine \& Heinle. [En línea] http://recursos.udgvirtual.udg.mx/biblioteca/bitstream/123456789/1372/1/ Teaching_Grammar.pdf

LEÃO, A. Carneiro. (1935). O ensino das línguas vivas. São Paulo: Companhia Editora Nacional.

LÓPEZ MORALES, H. (1989). Sociolingüística. Madrid: Gredos.

MARTÍNEZ-CACHERO, ÁLVARO L. (2008): O ensino do espanhol no sistema educativo brasileiro = La enseñanza del español en el sistema educativo brasileño / Álvaro Martínez-Cachero L.; tradução de Elaine Elmar Alves Rodrigues. - Brasília: Thesaurus, 532 p. (Colección Orellana, 19: Coleção Orellana, 19)

MARTÍNEZ-CACHERO, ÁLVARO L. (2009): La enseñanza del español en el sistema educativo brasileño: situación y posibles actuaciones [en línea]. En: Análisis del Real Instituto Elcano (ARI), №. 140, Madrid 2009.

MINISTERIO DE EDUCAÇÃO E CULTURA DO BRASIL (2006):. Orientações curriculares para o ensino medio: LINGUAGENS, CÓDIGOS E SUAS TECNOLOGIAS. Volume 1. Secretaria de Educação Básica. Brasília.

MINISTERIO DE EDUCACIÓN, CULTURA Y DEPORTE. (2002): Marco Común Europeo de Referencia para las Lenguas: Aprendizaje, Enseñanza, 
Evaluación. Madrid: Instituto Cervantes. Online en http://cvc.cervantes.es/obref/marco

Moreno Fernández, F. (1998). Principios de sociolingüística y sociología del lenguaje. Barcelona: Ariel.

MUÑOZ, C. (2002): Aprender idiomas. Barcelona: Paidós.

PAIVA, V.L.M.O. (1997) A identidade do professor de inglês. APLIEMGE: ensino e pesquisa. Uberlândia: APLIEMGE/FAPEMIG, n.1, 1997. p. 9-17

RÁBADE, S. (1995): Teoría del conocimiento. Akal.

ROBÁU S., D., OCAÑA H. y Elena Murgunova (2013). Nuevas tendencias de la lingüística. En: De la lingüística científica a la lingüística textual. La Habana. Editorial Pueblo y Educación.

SANTOS GARGALLO, I. (1999): Lingüística aplicada a la enseñanza/aprendizaje del español como lengua extranjera. Madrid: Arco/Libros.

SAVIANI, Dermeval. (2004) O legado educacional do século XX no Brasil. Campinas, SP: autores associados.

SIGUAN, M., Y MACKEY, W. F. (1989): Educación y Bilingüismo. Madrid, Santillana.

TANURI, L. M. (2000). História da formação de professores. Revista Brasileira de Educação, n. 14, p. 61-88, mai./jun./jul./ago-2000.

TUSÓN, J. (2009): Patrimonio natural: Elogio y defensa de la diversidad lingüística. Traducción de Amparo Tusón Valls. $1^{\mathrm{a}}$ edición. Barcelona: Editorial Ariel SA 


\section{MARCADORES DEL DISCURSO}

(SPERBER y WILSON, 1994)

BERNÁRDEZ, E. (1982): Introducción a la lingüística del texto. Madrid: EspasaCalpe.

BRIZ, A. (1993a): Los conectores pragmáticos en español coloquial (I): su papel argumentativo, Contextos, XI, 21-22, pp 145 a 188.

BRIZ, A. (1993b): Los conectores pragmáticos en español coloquial (II): su papel metadiscursivo. Español Actual, 39, pp.39-56.

BRIZ, A. (1998): El español coloquial en la conversación coloquial. La incidencia de los conectores pragmáticos. Esbozo de pragmagramática, Barcelona: Ariel.

BRIZ, A.; PONS, S. y PORTOLÉS, J. (2008), Diccionario de partículas discursivas del español. [En línea] http://www.dpde.es

BUSTOS TOVAR, J. J.; CHARAUDEAU, P.; GIRÓN, J. L.; IGLESIAS, S.; LÓPEZ, C. (eds) Lengua, discurso, texto (2000): Actas del I Simposio Internacional del discurso. Madrid: Visor. Universidad Complutense. 2 vols.

BROWN, G. y YULE, G. (1983). El análisis del discurso. Madrid: Visor.

CASADO VELARDE, M. (1991): Los operadores discursivos es decir, esto es, o sea y a saber en español actual: valores de lengua y funciones textuales. Lingüística Española Actual, XIII, 1, pp. 87-116.

CASADO VELARDE, M. (1993): Introducción a la gramática del texto en español. Madrid: Arco Libros.

CASADO VELARDE, M. (1998): Lingüística del texto y marcadores del discurso en M. A. Martín Zorraquino y E. Montolío Durán (Coords.) pp. 35-70. 
CALSAMIGLIA B. H., \& TUSON, A. (1999). Las cosas del decir. Manual de análisis del discurso. Barcelona: Ariel.

DILLINGER, M. (1991). Forma e função na Linguística. DELTA, v. 7, n. 1, p. 397-407, São Paulo.

ESCANDELL VIDAL, M. V. (1993): Introducción a la Pragmática. Madrid: Universidad Nacional de Educación a Distancia.

GONZÁLEZ, E. (2013) Uso y función de los marcadores del discurso en el discurso argumentativo oral: desde la tertulia hasta el debate político televisivo. Tesis doctoral. Universidad de León.

GUTIÉRREZ ORDÓÑEZ, S. (2002): De pragmática y semántica. Madrid: Arco Libros.

HARRIS, R. (1989) Saussure on Language and Thought. In HARRIS, R.; TALBOT, J. T. Landmarks in linguistic thought. The Western Tradition from Socrates to Saussure. London: Routledge, 1989, p. 209-224.

JAKOBSON, R. (2007) Linguística e comunicação. São Paulo: Cultrix: Pensamento.

LEVINSON, S. (1983): Pragmatics. Cambridge. Cambridge University Press. (Trad. Esp.: Pragmática. Barcelona, Teide, 1989)

LOUREDA, Ó. y Acín, E. (coords.) (2010), Los estudios sobre marcadores del discurso en español hoy, Madrid, Arco Libros.

MARTÍN ZORRAQUINO, M. A. (1992): "Partículas y modalidad”, en Holtus G. y otros (eds.), Lexicon der Romanistischen Linguistik, VI: 1. Tubinga: Niemeyer.

MARTÍN ZORRAQUINO, M. A. (1994); Gramática del discurso. Los Ilamados marcadores del discurso. Congreso de la lengua española Sevilla 7 a 10 de octubre de 1992), Madrid: Instituto Cervantes, pp. 709-720. 
MARTIN ZORRAQUINO, M. A. y MONTOLÍO DURÁN, E. (eds.) (1998): Los marcadores del discurso: teoría y análisis. Madrid: Arco-Libros.

MARTIN ZORRAQUINO, M. A. y PORTOLÉS LÁZARO, J. (1999): “LoS marcadores del discurso", en Bosque, I. y Demonte, V. (eds), Gramática Descriptiva de la Lengua Española. Madrid: Espasa-Calpe.

MARTÍN ZORRAQUINO, M. A.(2010): "Los marcadores del discurso y su morfología", en Loureda, O. y Acín, E. (eds.), Los estudios sobre marcadores del discurso en español, hoy. Madrid: Arcos Libros.

ORLANDI, ENI P. (2005): Análise do discurso: Princípios e procedimentos. 6a edição. Campinas/SP: Pontes.

PONS BORDERÍA, S. (1998a): Oye y mira o los límites de la conexión. En M. A. Martín Zorraquino y E. Montolío Durand (Coord.)

PONS BORDERÍA, S. (1998b): Conexión y conectores. Estudio de su relación en el registro informal de la lengua. Valencia: Universitat de Valencia. Portolés, J. Marcadores del discurso. $1^{\mathrm{a}}$ edición. Ariel Practicum: Barcelona, 1998.

REYES, G. (1994): La pragmática lingüística. El estudio del uso del lenguaje. $2^{\mathrm{a}}$ edición. Barcelona: Montesinos.

REYES, G. (2003): El Abecé de la pragmática. Cuadernos de Lengua Española, dirección de L. Gómez Torrego. 6ª edición. Madrid: Arco Libros.

SEARLY, J. (1969): Speech acts. An essay in the philosophy of language.

STUBB, M. (1983): Análisis del discurso. Análisis sociolingüístico del lenguaje natural. (Trad. Esp.: Celina González. Madrid, Alianza Editorial, 1987)

KOCH, I. V. \& MARCUSCHI, L. A.(1998). Processos de referenciação na produção discursiva. In DELTA,vol. 14, nº Especial. EDUC: São Paulo.

DUCROT, O. (1987) O dizer e o dito. Campinas: Pontes. 
FÁVERO, L. L. \& KOCH, I. G. V. (1988). Linguística textual: introdução. São Paulo: Cortez.

PÊCHEUX, M. (1997): Semântica e discurso. Campinas: Editora da Unicamp.

\section{FORMACIÓN DE PROFESORADO DE ELE}

BENÍTEZ P., P.; MARTÍNEZ-CACHERO L., A. (2009): El español en Brasil. Situación actual y perspectivas de futuro. En: El español en el mundo: anuario del Instituto Cervantes.

CELANE, A. (2009): Antonieta Celani fala sobre o ensino de Língua Estrangeira. Revista Nova Escola. Edição 222, maio 2009. En línea: < http://abr.ai/10wpJY5>

PAIVA, V. L. M. O. (1997): A identidade do professor de inglês. APLIEMGE: ensino e pesquisa. n. 1, p. 9-17. Uberlândia.

PRESIDÊNCIA DA REPÚBLICA DO BRASIL. (1996) LDB: Lei de Diretrizes e $\begin{array}{lllll}\text { Bases } & \text { da } & \text { Educação: } & \text { Lei } & n^{\circ}\end{array}$ http://portal.mec.gov.br/arquivos/pdf/ldb.pdf [fecha de consulta: 14/05/2013]

PRESIDÊNCIA DA REPÚBLICA DO BRASIL. (2006): Lei 11.161. http://www.planalto.gov.br/ccivil_03/_Ato2004-2006/2005/Lei/L11161.htm [fecha de consulta: 26/02/13].

\section{OTROS DE INTERÉS}

ALARCOS LLORACH, E. (1969): Gramática estructural. Madrid: Gredos. 
ALARCOS LLORACH, E. (1994): Gramática de la lengua española. Madrid: Espasa-Calpe.

ALONSO, R., CAL, N., RÚA, P., et al. (1997): Diccionario de enseñanza y aprendizaje de lenguas. Madrid: enCLAVE-ELE.

BELLO, A. (1847): Gramática de la lengua castellana destinado al uso de los americanos. Santa Cruz de Tenerife / La laguna: Cabildo de Tenerife, 1981.

BELLO, A. (1847): Gramática de la lengua castellana. Madrid: EDAF (1990)

ESPAÑOLA (2005): Diccionario Panhispánico de Dudas. Madrid: Santillana Ediciones Generales, S.L.

CABRÉ, M.T. (2004). La terminología en la traducción especializada. En GONZALO C. Editores. Manual de documentación y terminología para la traducción especializada. Madrid: Arco Libros.

GILI GAYA, S. 1943 (1961): Curso superior de sintaxis española. Barcelona.

GÓMEZ TORREGO, L. (1998): Gramática didáctica del español. Madrid: SM

LÁZARO CARRETER, F. (1987): Diccionario de términos filológicos. Madrid: Gredos.

LOMAS, C. (2007). La conciencia lingüística en la enseñanza de lenguas. Barcelona: GRAÓ.

MOLINER, M. (2008): Diccionario de uso del español, A-D. 2ª edición, edición abreviada. Madrid: Gredos, S.A.

MOLINER, M. (2008): Diccionario de uso del español, E-O. 2a edición, edición abreviada. Madrid: Gredos, S.A.

MOLINER, M. (2008): Diccionario de uso del español, P-Z. $2^{\mathrm{a}}$ edición, edición abreviada. Madrid: Gredos, S.A. 
RABADÁN, A. R. (1991): Equivalencia y traducción. León: Servicio de publicaciones.

REAL ACADEMIA ESPAÑOLA (2001): Diccionario de la lengua española. Madrid: Espasa, 22a ed. También está disponible online en www.rae.es

REAL ACADEMIA ESPAÑOLA y ASOCIACIÓN DE ACADEMIAS DE LA LENGUA ESPAÑOLA (2010): Manual de la Nueva Gramática de la lengua española. Madrid: Espasa Libros, S.L.

SAUSSURE, F. (1985) Curso de Lingüística General. Madrid: AKAL 
APÉNDICES 


\section{APÉNDICES}

APÉNDICE 1: ENCUESTA 1 SOBRE ESTUDIO DE LENGUA EXTRANJERA

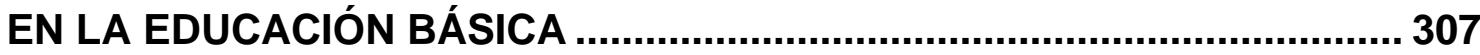

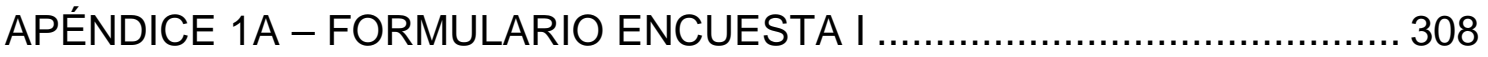

APÉNDICE 1B - INFORME RESPUESTA ABIERTA DE (I) …..................... 309

APÉNDICE 1C - INFORME RESPUESTA ABIERTA DE (6)....................... 312

APÉNDICE 2: FORMULARIO ENCUESTA 3 - ESTUDIANTES DE GRADO

EN ELE

APÉNDICE 3: FORMULARIO DE ENCUESTA SOBRE FORMALISMO Y FUNCIONALISMO

APÉNDICE 4: PRODUCCIÓN ESCRITA DE LOS ESTUDIANTES DE GRADO EN ELE 
APÉNDICE 1: ENCUESTA 1 SOBRE ESTUDIO DE LENGUA EXTRANJERA EN LA EDUCACIÓN BÁSICA

- Apéndice 1A - Formulario

- Apéndice 1B - Informe respuesta abierta de (5)

- Apéndice 1C - Informe respuesta abierta de (6) 


\section{Apéndice 1A - Formulario Encuesta I}

Instrumento de investigación: Tesis doctoral LOS MARCADORES DEL DISCURSO Y LA FORMACIÓN DE PROFESORES DE ELE

\section{ENCUESTA 1}

Dirigida a CIUDADANOS, respecto a su vivencia sobre Lengua Extranjera - LE

1. Considera Ud. que un profesor de LE de primaria y/o secundar ia debe conocer y dominar fluidamente la lengua que enseña:
a) Sí, sin duda
b) No, no es necesario
c) Sí, por lo menos algo
d) No, pero sería lo ideal

2. Considera Ud. que un profesor de LE de primaria y/o secundaria debe dar sus clases en la lengua que enseña:
a) $\mathrm{Si}$, sin duda
c) Sí, por lo menos algo
b) No, no es necesario
d) No, pero sería lo idea

3. Considera Ud. que los profesores de LE de primaria y/o secundaria, generalmente, conocen y dominan fluentemente la lengua que enseñan:
a) Sí, sin duda
c) Sí, por lo menos algo
b) No, la mayoría no.
d) No, pero sería lo ideal

4. ¿Quélengua extranjera estudia/estudió en la escuela primaria/secundaria?
a) Inglés
b) Francés
c) Español
d) Otra:

5. Mientras estudiaba primaria y/o secundaria, a Ud. le gustaban las clases de lengua extranjera? Marque una respuesta
a) Sí, mucho
b) Al principio sí, pero después no
d) Si, en algunas ocasiones
No, para nada
e) Me daba igual tenerlas o no
f) No sé responder
Díganos el porqué:

6. Como padre/madre de familia, a Ud. qué le parecería si su hijo aprendiera a hablar la LE que se enseña en la escuela primaria y/o secundaria:
a) Meparecería de lo más sensato, pero eso no ocurre para nadie
b) Me parecería sorprendente, una verdadera hazaña, porque en mis tiempos de estudiante, no se aprendía a hablar, solo algo de gramática
c) Me parece que eso sería lo cierto, pero el problema puede estar en los profesores que no incentivan mejor ese aprendizaje
d) Meparece que los estudiantes no valoran la asignatura en el colegio
e) Otro parecer: 
Apéndice 1B - Informe respuesta abierta de (i)

\begin{tabular}{|c|c|c|}
\hline \multirow[b]{2}{*}{ INF-LE-000 } & \\
\hline & $\begin{array}{l}\text { RESPUESTAS CERRADAS } \\
(\mathrm{a}, \mathrm{b}, \mathrm{c}, \mathrm{d}, \mathrm{e}, \mathrm{f})\end{array}$ & Diganos el porquè. \\
\hline INF-LE-002 & a) $\mathrm{Si}$, mucho. & $\begin{array}{l}\text { Es divertido y abre un nuevo mundo de opciones. Además es muy importante } \\
\text { profesionalmente. }\end{array}$ \\
\hline INF-LE-003 & a) Si, mucho. & $\begin{array}{l}\text { Las clases eran dinámicas y, particularmente, el estudio de lenguas extranjeras me } \\
\text { agrada. }\end{array}$ \\
\hline $\mathrm{INF}=\mathrm{LE}=004$ & a) Si, mucho. & Las lenguas me parecen interesantes. \\
\hline INF-LE=005 & a) Si, mucho. & Yo realmente aprendia y me ayudó mucho a aprender la lengua. \\
\hline $\mathrm{NNF}=\mathrm{LE}=006$ & a) Si, mucho. & El profesor era muy didáctico. \\
\hline INF-LE-007 & a) Si, mucho. & $\begin{array}{l}\text { Abordaba lo básico de la gramática y me incentivó a continuar estudiando la lengua } \\
\text { por mi cuenta. }\end{array}$ \\
\hline INF-LE-008 & a) Si, mucho. & Es importante saber otra lengua para la graduación. \\
\hline NNF-LE-009 & a) $\mathrm{Si}$, mucho. & $\begin{array}{l}\text { Me gustaba, pues creo importante que las lenguas sean enseñadas desde la enseñanza } \\
\text { primariay descubrirla era algo que me fascinaba. }\end{array}$ \\
\hline INF-LE-010 & a) Si, mucho. & Por motivos personales siempre me han gustado las lenguas, inglés, francés y espanol. \\
\hline INF-LE-011 & a) Si, mucho. & Aprender otra lengua es aprender otra cultura. \\
\hline INF-LE-012 & a) Si, mucho. & Por la posibilidadde interacción con personas que hablan esa lengua extranjera. \\
\hline INF-LE-013 & a) Si, mucho. & Por gustarme el idioma y la didáctica del profesor. \\
\hline INF-LE-014 & a) Si, mucho. & Porque me gusta aprender idiomas. \\
\hline INF-LE-015 & a) Si, mucho. & Porque eran muy didácticas. \\
\hline INF-LE-016 & a) $\mathrm{Si}$, mucho. & Porqque podia poner en práctica por mi mismo aquello que estudiaba. \\
\hline INF-LE-017 & a) $\mathrm{Si}$, mucho. & Es una lengua que admiro mucho, tienes canciones óptimas (refiriéndose a español) \\
\hline INF-LE-018 & a) $\mathrm{Si}$, mucho, & Por motivos personales, me fascina el inglés, es importante. \\
\hline INF-LE-019 & a) Si, mucho. & Porqque es inevitableel dominio de una segunda lengua en la sociedad actual. \\
\hline INF-LE-020 & a) Si, mucho. & Porque siempre me ha gustado aprender nuevas lenguas. \\
\hline INF-LE-021 & a) Si, mucho. & $\begin{array}{l}\text { Porque con ellas he tenido noción sobre otras lenguas extranjeras y más adelante hice } \\
\text { un curso para profundizar mi conocimiento sobre una de ellas, el inglés. }\end{array}$ \\
\hline INF-LE-022 & $\begin{array}{l}\text { b) Al principio si, pero después } \\
\text { no. }\end{array}$ & Me gustaba, pero el método era malo. \\
\hline NNF-LE-023 & e) No, para nada. & Solo era el verbo To be. \\
\hline INF-LE-024 & d) $\mathrm{Si}$, algunas veces. & Me gusta la vivencia con otros idiomas, pero a veces la metodologia no es interesante. \\
\hline INF-LE-025 & d) $\mathrm{Si}$, algunas veces. & Solo aquello que sabia. \\
\hline INF-LE-026 & d) Si, algunas veces. & Porque yo practicaba mucho. \\
\hline INF-LE-027 & d) $\mathrm{Si}$, algunas veces. & No tenia mucho tiempo para dedicar al estudio. \\
\hline INF-LE-028 & d) Si, algunas veces. & A veces no entendia \\
\hline INF-LE-029 & d) Si, algunas veces & Era diferente. \\
\hline INF-LE-030 & d) Si, algunas veces. & Enfocaban el verbo To be. \\
\hline INF-LE-031 & d) $\mathrm{Si}$, algunas veces. & $\begin{array}{l}\text { Eran clases dinámicas e interactivas que motivaban la participación, pero eran dirigidas } \\
\text { solo para el aprendizaje académico, sin la valorización de la lengua extranjera en otros } \\
\text { ámbitos del cotidiano. }\end{array}$ \\
\hline INF-LE-032 & d) $\mathrm{Si}$, algunas veces. & Le falta preparo al profesor. \\
\hline INF-LE- 033 & d) Si, algunas veces. & Me parecia repetitivo lo del verbo To be. \\
\hline INF-LE-034 & d) Si, algunas veces. & Los métodos de enseñanza aplicados eran precarios y habia discontinuidad de asuntos. \\
\hline NFF-LE-035 & $\begin{array}{l}\text { e) Me daba igual tener estas } \\
\text { clases. }\end{array}$ & Aprecio lenguas latinas. \\
\hline INF-LE-036 & $\begin{array}{l}\text { e) Me daba igual tener estas } \\
\text { clases. }\end{array}$ & No eran constructivas. \\
\hline INF-LE-037 & $\begin{array}{l}\text { e) Me daba igual tener estas } \\
\text { clases. }\end{array}$ & Porque no hacia esfuerzo para aprender los asuntos. \\
\hline INF-LE- 038 & d) Si, algunas veces. & El profesor hacia muchas dinámicas. \\
\hline NFF-LE-039 & d) $\mathrm{Si}$, algunas veces. & $\begin{array}{l}\text { Porque actualmente es fundamental que tengas el conocimiento de varias lenguas, } \\
\text { mientras mas, mejor para el mercado de trabajo. En los dias de hoy es muy importante. }\end{array}$ \\
\hline
\end{tabular}

\begin{tabular}{|c|c|c|}
\hline INF-LE-040 & d) $\mathrm{Si}$, algunas veces. & Como profesor me gusta pasar mis conocimientos a otras personas. \\
\hline INF-LE-041 & d) Sí, algunas veces. & Era muy bueno cuando habia canciones. \\
\hline NFF-LE-042 & d) Si, algunas veces. & El profesor era impaciente con la clase y no enseñaba bien. \\
\hline NF-LE-0.43 & d) Si, algunas veces. & $\begin{array}{l}\text { Creo que los profesores han influenciado en mi respuesta, porque en este tiempo pocos } \\
\text { han sido los profesores de los que realmente me haya gustado su trabajo }\end{array}$ \\
\hline INF-LE-044 & d) Si, algunas veces. & Las clases con música y peliculas eran siempre más divertidas y captaban la atención. \\
\hline INF-LE-045 & d) Si, algunas veces. & El interés por el nuevo idioma era estimulante. \\
\hline INF-LE-046 & d) Si, algunas veces. & Porque a veces era dificil comprender lo que el profesor realmente queria enseñar. \\
\hline INF-LE-047 & d) Si, algunas veces. & Los profesores no despertaban el interés de los alumnos. \\
\hline INF-LE-048 & d) $\mathrm{Si}$, algunas veces. & No habia métodos pedagógicos adecuados. \\
\hline NF-LE- 049 & d) Si, algunas veces. & El profesor era muy dinámico. \\
\hline INF-LE-050 & c) No, para nada. & El profesor era completamente incompetente para el trabajo. \\
\hline INF-LE-051 & c) No, para nada & No habia una didáctica enfocada en la enseñanza. \\
\hline NFF-LE-052 & c)No, para nada & $\begin{array}{l}\text { Porque faltan conocimientos, la gan mayoria de los profesores no proporcionan clases } \\
\text { agradables y de comprensión del asunto enseñado. }\end{array}$ \\
\hline INF-LE-053 & c)No, para nada & $\begin{array}{l}\text { El profesor no poseia didáctica apropiada para enseñar la asignatura, asi como tenia } \\
\text { conocimientolimitado. }\end{array}$ \\
\hline INF-LE-054 & c) No, para nada & Porque nunca aprendi nada. \\
\hline INF-LE-055 & c) No, para nada & Porque nunca me han gustado las lenguas extranjeras. \\
\hline INF-LE-056 & a) Si, mucho. & Pues es fundamental para conseguir mejores relaciones laborales. \\
\hline INF-LE-057 & a) Si, mucho. & Porqque es una lengua universal (refiriéndose a la lengua inglesa). \\
\hline INF-LE-058 & a) Si, mucho. & La didáctica era fundamental, así como el uso del arte en la educación. \\
\hline INF-LE-059 & a) Si, mucho. & $\begin{array}{l}\text { Porque es estimulante aprender otro idioma, principalmente, tener más de una lengua } \\
\text { en el curriculo para futuras oportunidades y entretenimientos que el mundo ofrece. }\end{array}$ \\
\hline INF-LE-050 & a) Si, mucho. & $\begin{array}{l}\text { Porque me gustaba la lengua inglesa. Buena parte de lo que sé, lo aprendi en la } \\
\text { enseñanzaprimariay secundaria. }\end{array}$ \\
\hline INF-LE-060 & a) Si, mucho. & Porque me gusta aprender otros idiomas y otras culturas. \\
\hline INF-LE-061 & a) $\mathrm{Si}$, mucho. & $\begin{array}{l}\text { Los profesores que tuve dominaban la lengua que enseñaban, hacian actividades } \\
\text { dinámicas y hablaban en la lengua que enseñaban, en clase. }\end{array}$ \\
\hline
\end{tabular}


... Apéndice 1B - Informe respuesta abierta de (ii)

\begin{tabular}{|c|c|c|}
\hline INF-LE-062 & a) Si, mucho. & Porque siempre me han gustado los idiomas. \\
\hline INF-LE-063 & a) Si, mucho. & Porque me gusta. \\
\hline INF-LE=064 & a) Si, mucho. & Porque me gustan las lenguas extranjeras. \\
\hline INF-LE-065 & d) Si, algunas veces. & Porque la mayor parte del tiempo el profesor no estaba de buen humor. \\
\hline INF-LE-066 & d) Si, algunas veces. & $\begin{array}{l}\text { Porque solo era bueno cuando entendia el asunto. } \\
\end{array}$ \\
\hline INF-LE-067 & d) Si, algunas veces. & Solo cuando habia música. \\
\hline INF-LE-068 & d) $\mathrm{Si}$, algunas veces. & $\begin{array}{l}\text { Porque pensaba que era necesario y entonces me disponia para gustar y realmente me } \\
\text { gustaba más la ensenanza de la lengua espanola que la inglesa, por eso pretendo } \\
\text { estudiarla muchomás. }\end{array}$ \\
\hline INF-LE=069 & d) Si, algunas veces. & Porque algunos profesores no sabian explicar bien el tema. \\
\hline INF-LE=070 & d) Si, algunas veces. & $\begin{array}{l}\text { Porque algunas veces los profesores no sabian aplicar una didáctica que los alumnos } \\
\text { pudierancomprender. }\end{array}$ \\
\hline INF-LE=071 & d) Si, algunas veces. & Porque no siempre he tenido buenos profesores. \\
\hline INF-LE=072 & d) $\mathrm{Si}$, algunas veces. & A veces, las clases son bien dinámicas. \\
\hline INF-LE=073 & & $\begin{array}{l}\text { Me proporcionó buenas experiencias, pero generalmente, lo que es presentado no es } \\
\text { suficiente para alcanzar la fluencia. }\end{array}$ \\
\hline INF-LE-074 & e) Me daba igual tener estas clases. & Porqque la metodologia era arcaica. \\
\hline INF-LE:075 & e) Me daba igual tener estas clases. & $\begin{array}{l}\text { Porque sentia que no aprendia mucho. Lo que se presentaba en clase no me agregaba lo } \\
\text { que era necesario. Vine a notar que me gustaban las lenguas extranjeras cuando } \\
\text { empecé a estudiar en escuelas especializadas, porque alli habia una ensethanza màs } \\
\text { intuitiva, no obstante, sigo sintiendome insatisfecha. }\end{array}$ \\
\hline INF-LE-076 & e) Me daba igual tener estas clases. & $\begin{array}{l}\text { Porque en la enseñanza básica, prácticamente solo estudié inglés y eso significa haber } \\
\text { estudiado solo el verbo 'To be' }\end{array}$ \\
\hline INF-LE-077 & a) Si, mucho. & $\begin{array}{l}\text { Porque aprender una lengua extranjera trae consigo otros beneficios, tal como aprender } \\
\text { una nueva cultura. }\end{array}$ \\
\hline INF-LE-078 & a) Si, mucho. & $\begin{array}{l}\text { Mi interés por otras culturas y el mundo me estimularon el gusto por lenguas y un dia } \\
\text { ser un poliglota. }\end{array}$ \\
\hline INF-LE-079 & a) Si, mucho. & Porque las clases eran bien didácticas, con dinímicas y otras cosas que facilitaban el \\
\hline INF-LE-080 & a) $\mathrm{Si}$, mucho. & $\begin{array}{l}\text { Porque eran clases interesantes, bien didácticas y acababan entreteniendo a los } \\
\text { alumnos. }\end{array}$ \\
\hline INF-LE-081 & a) Si, mucho. & $\begin{array}{l}\text { Porque siempre me ha interesado conocer otras culturas e idiomas. } \\
\end{array}$ \\
\hline INF-LE=082 & a) Si, mucho. & Porque siempre he tenido interés y facilidad en lenguas extranjeras. \\
\hline NNF-LE-083 & $\begin{array}{l}\text { b) Al principio si, pero después } \\
\text { no. }\end{array}$ & Porque solo aplicaba el verbo 'To be' \\
\hline INF-LE-084 & $\begin{array}{l}\text { b) Al principio si, pero después } \\
\text { no. }\end{array}$ & $\begin{array}{l}\text { Porque el problema no estaba en que me guste la lengua, sino en que las clases no eran } \\
\text { atractivas y no habia evolución en los contenidos. }\end{array}$ \\
\hline INF-LE=085 & c) No, para nada. & $\begin{array}{l}\text { Porque notaba que los profesores no dominaban el contenido o entonces tenian } \\
\text { 'pereza' dar clase. Además, el contenido era bastante vago. }\end{array}$ \\
\hline INF-LE-086 & c) No, para nada. & $\begin{array}{l}\text { Porque no habia horas de clase suficientes y los profesores ensenaban lo básico y era } \\
\text { aburrido. }\end{array}$ \\
\hline INF-LE=087 & a) $\mathrm{Si}$, mucho. & Porque ayuda en la formación. \\
\hline INF-LE-088 & c)No, para nada. & Porque las clases no tenian rendimiento ni objetivo. \\
\hline INF-LE-089 & c) No, para nada. & Porque la didáctica no era buena. \\
\hline INF-LE-090 & c) No, para nada. & Porque siempre era el verbo 'To be' \\
\hline INF-LE-091 & c) No, para nada. & $\begin{array}{l}\text { Porque no se aprendia nada de forma satisfactoria, y eso hacia que los alumnos vieran } \\
\text { esa enseñanza innecesaria. }\end{array}$ \\
\hline INF-LE-092 & c) No, para nada. & Porque era cansado el aprendizaje de la asignatura. No aprendia. \\
\hline INF-LE-093 & c) No, para nada. & $\begin{array}{l}\text { Porque solo habia gramática, algo como pasar la frases para negativa e interrogativa y } \\
\text { memorizar algunos verbos. }\end{array}$ \\
\hline INF-LE-094 & d) Si, algunas veces. & Porque me gustaba el método de la profesora y estudiar otra lengua es necesario. \\
\hline INF-LE-095 & Si, mucho. & Porque me gustaba la asignatura y los profesores que la enseñaban. \\
\hline INF-LE-096 & Si, mucho. & Porque era divertido. \\
\hline INF-LE-097 & Si, mucho. & Porque me gustaba estudiar otras lenguas. \\
\hline INF-LE-098 & Si, mucho. & Por el hecho de gustarme conocer otros idiomas. \\
\hline INF-LE-099 & Si, mucho. & Es la oportunidad de conocer una nueva cultura. \\
\hline INF-LE-100 & Si, mucho. & Porque siempre me ha gustado el inglés. \\
\hline INF-LE-101 & Si, mucho. & Porque me parecia interesante conocer otra lengua, he tenido buenos profesores, lo que \\
\hline & & me ha incentivado más el gusto por la asignatura. \\
\hline INF-LE-102 & Si, mucho. & Porqque la didáctica del profesor era muy buena. \\
\hline NAF-LE-103 & Si, mucho. & Porque era muy dinámica e interesante. \\
\hline INF-LE-104 & Sí, mucho. & Porque conocer otras lenguas es de una gran importancia cultural. \\
\hline INF-LE-105 & Si, mucho. & Porque el profesor sabia enseñar. \\
\hline INF-LE-106 & Si, mucho. & $\begin{array}{l}\text { Porque era más significativo mi gusto e interés por la lengua inglesa, al punto de } \\
\text { superar la deficiencia que presentaban los profesores en su ensehanza. }\end{array}$ \\
\hline INF-LE-107 & Si, mucho. & $\begin{array}{l}\text { Porque lo docentes tenian estrategias de enseñanza que facilitaban el aprendizaje para } \\
\text { los alumnos, inclusive ese aspecto me estimulaba a aprender más. }\end{array}$ \\
\hline INF-LE-108 & Si, mucho. & Porque me encantan las canciones en inglés. \\
\hline INF-LE-109 & Si, mucho. & Pues, me parecia interesante aprender una lengua extranjera y también su cultura. \\
\hline INF-LE-110 & Si, mucho. & Porque es necesario hoy en dia. \\
\hline INF-LE-111 & Si, mucho. & Porque es necesario saber otras lenguas. \\
\hline INF-LE-112 & c)No, para nada. & Los profesores no entendian los asuntos que aplicaban. \\
\hline INF-LE-113 & d) Si,algunas veces. & Porque algunos asuntos son bien interesantes. \\
\hline INF-LE-114 & e) Me daba igual tener estas clases. & $\begin{array}{l}\text { Porque las clases no lograban cualquier expectativa y no eran atractivas para los } \\
\text { alumnos. Estaban en el plan de estudios solo por su caracter obligatorio. }\end{array}$ \\
\hline INF-LE-115 & d) Si, algunas veces. & Porque a veces no entendia nada y el profesor era aburrido. \\
\hline $\mathrm{INF}=\mathrm{LE}=116$ & Si, mucho. & Porque el francés es muy sofisticado \\
\hline INF-LE-117 & Si, mucho. & Porque el profesor era correcto y muy competente. \\
\hline INF-LE-118 & Si, mucho. & $\begin{array}{l}\text { Porque es esencial conocer otro idioma en los dias actuales, principalmente el inglés en } \\
\text { el contexto académico. }\end{array}$ \\
\hline INF-LE-119 & Si, mucho. & Porq̨ue los profesores son muy competentes. \\
\hline INF-LE-120 & Si, mucho. & $\begin{array}{l}\text { Porque siempre me ha interesado el hecho de saber otra lengua. Al principio, pensaba } \\
\text { que era bonito, pero ahora veo ese saber como algo necesario, saber al menos una } \\
\text { lengua extranjera. }\end{array}$ \\
\hline INF-LE-121 & Si, mucho. & Porque facilita la comprensión de las canciones en lengua extranjera. \\
\hline INF-LE-122 & Si, mucho. & Porq̨ue eran dinámicas y los profesores tenian una buena didáctica de enseñanza. \\
\hline INF-LE-123 & Si, mucho. & Porqque siempre he tenido interés en otra lengua como una puerta de entrada para \\
\hline
\end{tabular}




\section{...Apéndice 1B - Informe respuesta abierta de (iii)}

Instrumento de investigación: Tesis doctoral: LOS MDY LA FORMACIÓN DE PROFESORES DE ELE Informe de respuestas abiertas a la pregunta 5 de la ENCUESTA 1 -Informantes estudiantes de espantol como lengua extranjera - INF-ELF, respecto a su vivencia de lengua extranjera en la educación basica.

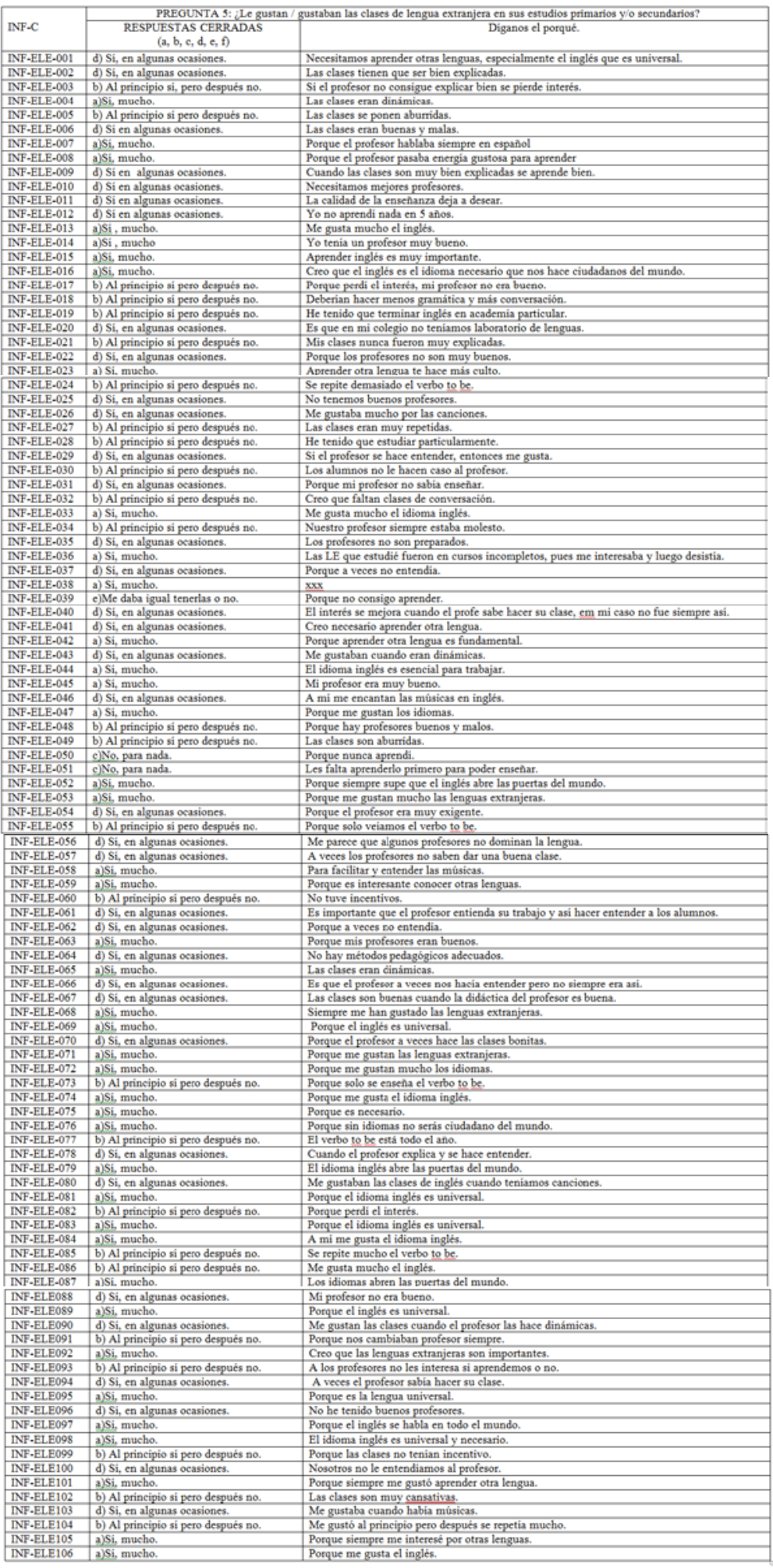




\section{Apéndice 1C - Informe respuesta abierta de (6)}

\begin{tabular}{|c|c|c|}
\hline \multirow[t]{2}{*}{ INF-C } & \multicolumn{2}{|c|}{$\begin{array}{l}\text { PREGUNTA 6: Como padre/madre de familia, a Ud. qué le pareceria que su hijo aprendiera a hablar la lengua extranjera que se } \\
\text { ensena en la escuela primaria y/o secundaria }\end{array}$} \\
\hline & \begin{tabular}{c|c|} 
RESPUESTAS CERRADAS \\
$(\mathrm{a}, \mathrm{b}, \mathrm{c}, \mathrm{d})$
\end{tabular} & e) Otro parecer: \\
\hline INF-LE-051 & $\begin{array}{l}\text { c) Me parece que eso seria lo cierto, } \\
\text { pero el problema puede estar en los } \\
\text { profesores que no incentivan mejor ese } \\
\text { aprendizaje. }\end{array}$ & $\begin{array}{l}\text { El problema es tan grave que es iniciativa de los alumnos (los que pueden pagar) } \\
\text { buscar un estudio más profundo del idioma en instituciones particulares que prioricen } \\
\text { el estudio de lenguas. }\end{array}$ \\
\hline INF-LE-114 & $\begin{array}{l}\text { d) Me parece que los estudiantes no } \\
\text { valoran la asignatura en el colegio. }\end{array}$ & Al no valorizar las clases, estas pierden calidad. \\
\hline INF-LE-117 & 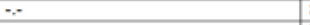 & Seria lo correcto, pero no son todas las escuelas que ofrecen un buen aprendizaje de LE \\
\hline INF-LE-118 & $\because$ & $\begin{array}{l}\text { Me parece excelente, asi como voy a estimular el aprendizaje de otras lenguas desde } \\
\text { temprana edad. }\end{array}$ \\
\hline INF-LE-119 & $\because$ & Es básico, hoy en dia es obligatorio por el mercado de trabajo. \\
\hline INF-LE-120 & $\because$ & $\begin{array}{l}\text { Me pareceria satisfactorio. Aprender a hablar otras lenguas favorece la ampliación de } \\
\text { horizontes y de alternativas para la vida en tiempos de globalización. }\end{array}$ \\
\hline INF-LE-121 & $\begin{array}{l}\text { c) Me parece que eso seria lo cierto, } \\
\text { pero el problema puede estar en los } \\
\text { profesores que no incentivan mejor ese } \\
\text { aprendizaje. }\end{array}$ & El profesor tiene que valorizar su formación. \\
\hline INF-LE-122 & $\because$ & Me pareceria óptimo e importante para su formación básica. \\
\hline INF-LE-123 & $\because$ & $\begin{array}{l}\text { Me parece que es necesario, pero existe un problema en el modelo de enseñanza de } \\
\text { lengua extranjera que no busca el aprendizaje en el sentido de la fluencia, mas solo de }\end{array}$ \\
\hline & & lo que es necesario gramaticalmente objetivando selectividad y lecturas básicas. \\
\hline INF-LE-124 & 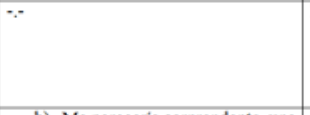 & $\begin{array}{l}\text { Pienso que la enseñanza de lengua extranjera, además de lo que se ve en la escuela, } \\
\text { involucra el esfuerzo del alumno, una inmersión cultural que puede referirse a una } \\
\text { conexión afectiva que el alumno tenga por aprender otra lengua. (el interés personal del } \\
\text { alumno) Esa inmersión puede ser iniciada también en la escuela partiendo del esfuerzo } \\
\text { de la escuela en comprender las necesidades especificas de aquellos alumnos. }\end{array}$ \\
\hline INF-LE-127 & $\begin{array}{l}\text { b) Me pareceria sorprendente, una } \\
\text { verdadera hazana, porque en } \\
\text { mis tiempos de estudiante, no } \\
\text { se aprendia a hablar, solo algo } \\
\text { de gramática. }\end{array}$ & Los profesores deben dar clases de acuerdo con su graduación. \\
\hline NFF-LE-132 & $\because$ & Me pareceria muy bueno, estudiar inglés es necesario. \\
\hline INF-LE-133 & $\because$ & $\begin{array}{l}\text { Me pareceria muy bien, pues ayudaria a cada alumno en el caso de mi hijo a agiliar ese } \\
\text { procesoy no seria tan importante estudiar en escuela de idiomas. }\end{array}$ \\
\hline
\end{tabular}

Instrumento de investigación: Tesis doctoral LOS MD Y LA FORMACIÓN DE PROFESORES DE ELE

Informe de respuestas abiertas a la pregunta 6 de la ENCUESTA 1- Informantes estudiantes de español como lengua extranjera - INF-ELE, respecto a su vivencia de lengua extranjera en la educación básica.

Observación: Eneuesta aplicada con formulario en español. Las respuestas fueron emitidas también español.

\begin{tabular}{|c|c|c|}
\hline \multirow[t]{2}{*}{ INF-C } & \multicolumn{2}{|c|}{$\begin{array}{l}\text { PREGUNTA 6: Como padre madre de familia, a Ud. qué le pareceria que su hijo aprendiera a hablar la lengua extranjera que se enseña en } \\
\text { la escuela primaria y/o secundaria }\end{array}$} \\
\hline & $\begin{array}{c}\text { RESPUESTAS CERRADAS } \\
(\mathrm{a}, \mathrm{b}, \mathrm{c}, \mathrm{d})\end{array}$ & a) Otro parecer: \\
\hline INF-eLE036 & & 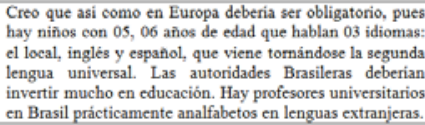 \\
\hline
\end{tabular}




\section{APÉNDICE 2: FORMULARIO ENCUESTA 3 - ESTUDIANTES DE GRADO \\ EN ELE}

Observación: Encuesta aplicada a estudiantes del último semestre de carrera.
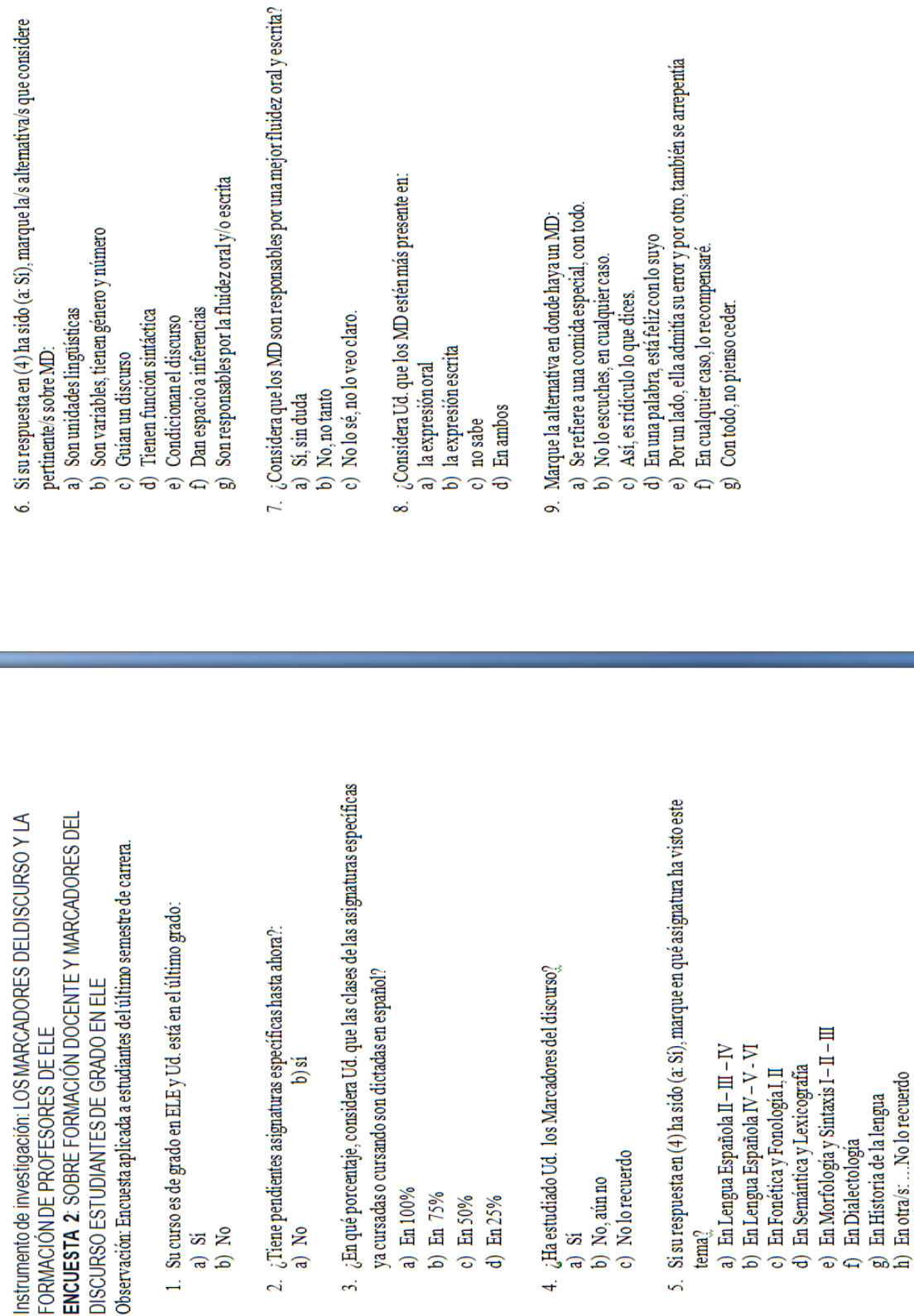
APÉNDICE 3: FORMULARIO DE ENCUESTA SOBRE FORMALISMO Y FUNCIONALISMO

\section{ENCUESTA FUNCIONALISMO X FORMALISMO}

Dirigida a; $P R O E E S O R E S$ DE GRADO EN ELE

Apreciado Colega!

Esta encuesta hace parte de la investigación intitulada: Los marcadores del discurso y la formación del profesorado en ELE. Solicitamos su gentil colaboración respondiendo las siguientes preguntas:

1. ¿Usted da clases de asignaturas de lengua ELE y/o especificas?
() $\mathrm{Sí}$
( ) No

2. ¿Sus clases son prácticas o teóricas?
( ) Teóricas
() Prácticas
() De ambas formas

3. ¿Usted presenta la gramática en sus clases de espaniol?
( ) $\mathrm{Sî}$
( ) No

4. ¿Conoce las bases tećricas del formalismo lingüistico?
() $\mathrm{Si}$
( ) No

5. ¿Qué asignaturas hacen parte del formalismo?
() Lengua
() Fonética
() Morfología
() Sociolingüistica
() Semántica
() Lingüistica aplicada a ELE

6. Conoce las bases teóricas del funcionalismo lingüístico?
( ) $\mathrm{Si}^{\prime}$
( ) No

7. ¿Qué asignaturas hacen parte del funcionalismo
() Lengua
() Fonética
() Morfología
() Sociolingüistica
() Semántica
() Lingüistica aplicada a ELE 


\section{APÉNDICE 4: PRODUCCIÓN ESCRITA DE LOS ESTUDIANTES DE GRADO EN ELE}

\begin{tabular}{|c|c|}
\hline Texto & Contenido \\
\hline & $\begin{array}{l}\text { Se yo fuera presidente, trataría de se buena, de todos modos, para que después las } \\
\text { persona hablase a propósito muy bien de yo, y después mi hicieran una estatua en la } \\
\text { ciudad en que vivem. Trataría de hacer cosas buenas como ayuda los pobres, íso es } \\
\text { muy importante además los niños que no tiene que come y no tiene nada y en } \\
\text { definitiva lo que vesti, con todo, yo tamben trataría de hacer doaciones de cosas, por } \\
\text { cierto yo lastimo las personas que no tiene onde vivir, para los niños, eso sí, entonces } \\
\text { les daría tortas de chocolates y todo es decir que sí, y que you soy una presidenta } \\
\text { muy buena y geniel por consiguiente tudo iso. }\end{array}$ \\
\hline & $\begin{array}{l}\text { Hotel Caribeño } \\
\text { Natal, } 27.07 .2015 \\
\text { Señor Jose, escribo para te recuerdar que faltan menos de cuatro dias para su } \\
\text { estadía en nuestro hotel, a propósito recuerdamos también que en nuestro sistema no } \\
\text { cuesta su pagamiento esto es, sin su pagamiento usted se queda imposibilitado de se } \\
\text { hospedar. } \\
\text { Tendremos algunas formas de pagamientos para usted. Los pagamientos son hechos } \\
\text { de la siguiente manera: usted puede estar haciendo eso pagamiento personalmente } \\
\text { en el día de la hospedaje o en depósito bancário, además, usted también tiene la } \\
\text { opción de pagar dejando el dinero encima de la televisión, por otra parte, nuestros } \\
\text { camareros poderán recibir su pagamiento. } \\
\text { Entonces Señor Jose, con todo eso aguardamos su estadia en nuestro hotel, así que } \\
\text { tuvier una respuesta, nos comunique, es más fácil una comunicación por teléfono, de } \\
\text { hecho de un movile. A todo esto, muchas gracias por atención. }\end{array}$ \\
\hline & $\begin{array}{l}\text { Hace cuatro años que estudio en XXX en el curso de Español, además participo de } \\
\text { XXXX y XXXX. Sin embargo, antes de estudiar en esta instituición ya hice el curso de } \\
\text { Turismo también por cuatro años en XXXXX. No obstante me guste estudiar, estoy } \\
\text { muy cansada. Entonces cuan terminar este curso deseo hacer otras actividades. En } \\
\text { todo caso no voy a parar de estudiar, de hecho no consiguiría, solo voy a dar un } \\
\text { tiempo para dedicarme más a mi familia. } \\
\text { Mis planes son de concluir el curso septiembre, aunque a veces creo que no será } \\
\text { posible. De todos modos hasta fines de este año lo voy a terminar, hasta porque ayer } \\
\text { escuché que tendrá concurso para profesores en la enseñanza pública estatal y } \\
\text { pretendo hacerlo. Después del curso, mis proyectos son de viajar así que mi esposo } \\
\text { estuvier de vacaciones para reencontrar a mis amigos y familiares que viven en } \\
\text { xXXXXX y que no los veo desde dos mis trés y para que mi esposo los conozca a todos } \\
\text { y también donde viví gran parte de mi vida. } \\
\text { Por consiguiente, después de volvermos de viaje vamos a intentar aumentar la familia } \\
\text { con un hijo. A todo esto si Dios permitir. Con todo, hacer la maestría también está en } \\
\text { mis planes futuros. Sólo no sé si voy a consiguir conciliar todo. En suma, esos son } \\
\text { mis deseos pero quizás no ocurran y todo sea distinto porque la vida está llena de } \\
\text { sorpresas. }\end{array}$ \\
\hline
\end{tabular}




\begin{tabular}{|c|c|}
\hline & $\begin{array}{l}\text { Em septiembre estoy de viaje para el Ceará - esto es se yo terminar el curso de } \\
\text { licenciatura en español, en todo caso tengo que irme en definitiva porque meo esposo } \\
\text { ja esta viviendo alla, entonces terminado pelo menos las asiguinaturas yo me voy. Por } \\
\text { otra parte me quedó preocupada pela posibilidad de no terminar por completo el } \\
\text { curso, además de quedó preocupada pela distancia y de que de hecho no consiga } \\
\text { producir. } \\
\text { Por consiguiente voy estar más tranquila sin las asiguinaturas y estaré en casa, esto } \\
\text { es no terei las asiguinaturas para preocuparme. } \\
\text { A propósito conocí la ciudad y me fue agradable aunque sea interiorana es } \\
\text { desenvolvida, por cierto las personas también son agradables y receptivas. En suma } \\
\text { no inicio vay ser difícil pero e que que vai me hacer falta realmente es mi familia eso } \\
\text { sí me hace falta. } \\
\text { Sin embargo voy estar con me esposo y con cierto tiempo voy acustumarse. }\end{array}$ \\
\hline & $\begin{array}{l}\text { Hoy, oír una noticia no muy agradable, que los autobuses habían sido retirados de las } \\
\text { calles por irregularidad, la pregunta era, irregularidad de que? Nadie sabia. Entonces } \\
\text { en el primer momento no teníamos las informaciones necesarias con los reales } \\
\text { motivos de este hecho. Las personas hablaban lo que oian de las otras sin saber en } \\
\text { difinita el certo. } \\
\text { Por otra parte los noticiarios relataban que el motivo era por irregularidad, a propósito } \\
\text { nin ellos sabían en suma lo que realmente había ocurrido, en todo caso, las } \\
\text { informaciones que llegaban mismo sin saber que eran verdaderas ellos estaban } \\
\text { repasando de todos os modos. } \\
\text { Las personas no obstante que recibieron la noticia se quedaron muy aburridas, con } \\
\text { toda razón, pues la mayoria sin embargo necesitan de ellos, ádemas las personas } \\
\text { que saliran temprano de sus casa de hecho no supieran de la noticia, entonces se } \\
\text { quedaran, esperando todo el tiempo en las paradas de autobús y como el no venia, } \\
\text { empezaron a se preocupar, entonces algunas de ellas cogerán su teléfono y llamaran } \\
\text { a otras para saber o que realmente estaba ocurriendo. Algunas, después de hablar } \\
\text { por teléfono, decían o que etava ocurriendo y dijeron que fue por irregularidad de } \\
\text { documentación que ellos fueron retirados de las calles, entonces fue cuando yo supe } \\
\text { el real motivo de este hecho. }\end{array}$ \\
\hline & $\begin{array}{l}\text { En el mes pasado conocir un chico llamado José, muy guapo y gentil y me sentir } \\
\text { atraída por él, nosotros hablamos mucho, un poco de todo, pero él era de São Paulo y } \\
\text { solo estaba de vaciones aqui. } \\
\text { Entonces llamé a José para conocer un poco de mi solo en Natal, le presenté algunas } \\
\text { partes de la ciudad y por la noche fuimos para una discoteca bailar un poco y beber } \\
\text { una buena cerveja, eso si le pareció divertido. } \\
\text { Yo aproveche todo el tiempo con José porque él era un chico bueno y me quedé } \\
\text { enamorada antes bien de su partida yo compré un regalo para él siempre recuérdese } \\
\text { de mi. Con todo él se quedó supreso con mi regalo y me dice que yo era una chica } \\
\text { incrible y que no olvidaría de nuestros momientos aquí. A propósito fue una } \\
\text { experiencia buena conocer un chico agradable como José. }\end{array}$ \\
\hline
\end{tabular}




\begin{tabular}{|c|c|}
\hline & $\begin{array}{l}\text { "Las crónicas de hielo y fuego" son una colección de libros que todavía no han sido } \\
\text { finalizadas. Empezaron a ser escritas por George R.R> Martín en los años noventa, } \\
\text { sin embargo los fans de esa obra siguen sin un final para la historia. De todos modos, } \\
\text { aunque haya pasado tanto tiempo desde la publicación del primer volumen, titulado } \\
\text { "El fuego de los tronos", los lectores y el éxito de esta saga continúa cruzando } \\
\text { fronteras. } \\
\text { De ahí que la cadena americana HBO compró la historia y produjo una de las series } \\
\text { de televisión más vistas y comentadas en todo el mundo. La serie ya está en su } \\
\text { quinta temporada y el guión sigue avanzando, haciendo cambios, adaptaciones y } \\
\text { dejando los fans de la serie cada año más adictos. Por otra parte, hay los que } \\
\text { acompañan no solamente por TV, como por los libros, y por eso tienen duras críticas } \\
\text { a la adaptación, al cambio de personajes, etc. De hecho los cambios son muchos y la } \\
\text { historia llegó a un punto en lo cual todos los libros escritos ya fueran reproduzidos en } \\
\text { pantalla. } \\
\text { George R.P. Martín ha prometido finalizar su obra maestra con siete libros, cinco } \\
\text { fueron publicados y miles de personas en todo el mundo esperan los dos últimos } \\
\text { volúmenes. Muchos ya han entendido que el final de "Las crónicas de hielo y fuego" } \\
\text { será visto primero que leído. Además, el autor ya es un anciano y los adictos de su } \\
\text { obra tienen miedo que se muera antes de darle un fin a la historia de Westeros -reino } \\
\text { donde se desarrolla la ciudad. A propósito, teniendo esto, se rumorea que el propio } \\
\text { Martin ya les ha entregado a los productores de HBO una versión final del guión. En } \\
\underline{\text { todo caso, si eso es cierto o no, nadie lo sabrá decir. Entonces, solo nos toca a }} \\
\text { nosotros esperar y disfrutar de esta increíble historia en la cual los dragones } \\
\text { comparten escenas con los seres humanos. }\end{array}$ \\
\hline
\end{tabular}




\begin{tabular}{|c|c|}
\hline & $\begin{array}{l}\text { Como todos los días de la semana, es decir, en los fines de semana no hago todas } \\
\text { esas cosas, me levanté temprano, me duché, tomé un café y sali de casa, esperé } \\
\text { algunos minutos el autobús con destino a la universidad que está situada muy lejos } \\
\text { de mi casa, en suma, tardo más de una hora para llegar. Yá en el autobús todo } \\
\text { parecía tal cual los días anteriores hasta que un hombre empezó a hablar de su } \\
\text { proyecto: una librería en la cual los libros tienen valor simbólico, además no era } \\
\text { necesario tener un tiempo libre para visitar a esa librería, pues los libros estaban allí } \\
\text { en el autobus de ahí que esas noticias fueron suficientes para alegrar definitivamente } \\
\text { mi día, solo era necesario elegir el libro que más me gustaba y pagar por ello, ese no } \\
\text { era un día común, en definitiva a causa de la propuesta que nadie jamás había oído } \\
\text { antes en un autobús. } \\
\text { Aunque los libros no era nuevos, todos estaban tan bien cuidados que parecían } \\
\text { nuevos. De todos modos, nuevos o no, los precios estaban tan bajos que sin dudas } \\
\text { las personas encantadas por lectura que estaban en el autobús se quedaron sin } \\
\text { saber cual libro llevar para casa delante de tantas opciones, así que algunas } \\
\text { personas compraron más de un libro. Por otra parte por ser una situación muy atípica } \\
\text { algunas personas no estaban preparadas financeiramente, sin embargo un amigo } \\
\text { subia en el autobús en el decorrer del viaje esa persona que no tenía la plata } \\
\text { explicaba la situación al amigo hasta convencerlo a comprar un libro. } \\
\text { De echo la actitud del hombre cambió el día de la mayoría de las personas con quien } \\
\text { él habló. El día gris, como todos los demás se ha convertido en un día lleno de } \\
\text { colores, principalmente para las personas que por primera vez pudieron comprar un } \\
\text { libro, en todo caso, una xxxx relativamente simple es capaz de cambiar una vida. A } \\
\text { propósito me lo compré 'el principito' un libro que hacia mucho tiempo que yo quería } \\
\text { tener, en fin voy a conseguirlo ahora. }\end{array}$ \\
\hline & $\begin{array}{l}\text { La vida del profesor iniciante de lenguas, hoy en día es muy difícil, aunque se salga } \\
\text { de la universidad con buenas notas. Se exige una buena formación, post grado y } \\
\text { experiencia en clase de aula. A todo esto, se añade la necesidad de tener un buen } \\
\text { domínio del idioma. Es decir, el mercado necesita profesores que, en suma, deben } \\
\text { ser perfectos. } \\
\text { De hecho, para ser un buen profesional es necesario estar preparado y tener } \\
\text { experiencia. Sin embargo, hay que dar espacio para estos nuevos profesionales } \\
\text { practicaren. Vivir algún tiempo en un país que tiene como lengua materna la que } \\
\text { estudia es bueno para su currículo, no obstante, es difícil, lograr éxito en conseguir } \\
\text { becas para estudiar algunos meses en otro país, esto es, los programas siderales en } \\
\text { las universidades privilegian otras areas como la tecnológica. Por cierto, siguen } \\
\text { pensando que los profesorados no son tan importantes como las ingenierías, por } \\
\text { conseguinte, nunca valoraran otros profesionales. Por otra parte, es casi imposible, } \\
\text { para la mayoría de los alumnos de la red pública teneren recursos para todo esto. } \underline{A} \\
\text { propósito, el tema de las becas es un asunto para otra discusión, así que, lo } \\
\text { abordaremos en el futuro. } \\
\text { En todo caso, es necesario buscando mejorías y ayuda. }\end{array}$ \\
\hline
\end{tabular}




\begin{tabular}{|c|c|}
\hline & $\begin{array}{l}\text { Hablar de familia es algo muy singular, es más que simplemente hablar de hombres y } \\
\text { decirles la función de cada uno de los miembros dentro de la. Por otra parte, sabemos } \\
\text { que la familia es nuestra primera base para la construcción de nuestros principios } \\
\text { morales, esto es sirve como un referencial para nuestro desarrollo como persona, } \\
\text { aunque nosotros no tengamos una educación buena necesitamos buscar, juntar } \\
\text { valores que nos ayuden a un desarrollo personal. De hecho, algunas personas tienen } \\
\text { una predisposición a hacer cosas malas por toda la vida, además de hacer tales } \\
\text { cosas con las personas también. De ahí que, con el transcurrir de su vida va a sufrir } \\
\text { las consecuencias que un día, empezó, es decir, las cosas malas que hizo a las } \\
\text { personas. } \\
\text { De todo modo, no podemos dejar de valorar nuestra familia pues, ella es nuestra } \\
\text { fuerza mayor acá en la tierra. Entonces, procure salir más con ella, sea con sus } \\
\text { padres, sus hermanos, su mujer, sea cual sea su realidad. A todo esto, en el caso, la } \\
\text { familia, debemos siempre estar junto a ella para ampliar nuevos conocimientos, y por } \\
\text { cierto, mejorar todos los días de nuestras vidas como personas. En todo caso, todo } \\
\text { esto que he hablado, no es la única manera que existe en la vida, sin embargo, es la } \\
\text { más fiable. En suma, onra tu familia encuanto hay tiempo, pues, no sabes hasta } \\
\text { cuando vas a tenerlos en su vida. }\end{array}$ \\
\hline & $\begin{array}{l}\text { La situación de Venezuela } \\
\text { Yo conocí una venezuelana que vino con la intención de vivir en Natal que se llama } \\
\text { Cárolin que es una cantante, con todo ella no tuve condiciones de se quedar acá por } \\
\text { mucho tiempo, pues su pasaporte expirou. Por otra parte aprendi muchas cosas con } \\
\text { ella tanto musicalmente como en la situación de su país. } \\
\text { Cárolin ha dicho que en Venezuela para comprar un único papel higiénico tiene una } \\
\text { fila enorme, la opresión es muiy grande y su decepción también. } \\
\text { Además Cárolin está bien fue para la California y está viviendo con su prima y dando } \\
\text { clases para cantantes. Ella también habló de la ditadura en Venezuela y su familia } \\
\text { que dejó allá de todos os modos por más que ella está en otro país su corazón estaba } \\
\text { en Venezuela y con su familia y esto es decir que ella nunca dejará de amar su país } \\
\text { que decidió salir por necesidad. } \\
\text { Cárolin llegó en Natal sin diñero vivo en manos, ella que todo era controlado. Ella } \\
\text { buscó uno empleo en Natal y consiguió dar clases para chicos en uno proyeto en } \\
\text { Macaíba estaba contente en Natal. Cárolin se quedó emocionada así que entro en } \\
\text { una tienda pues ella podía comprar lo que quería. Miré un video en la internet de una } \\
\text { mujer que habla justamente de la democracia y de los derechos humanos en } \\
\text { Venezuela, esta mujer pedía a presidente Dilma una ayuda para soltar los presos } \\
\text { políticos de Venezuela, incluso su esposo que está en cárcere. } \\
\text { Entonces ella también defende que Venezuela devería tener una democracia y que el } \\
\text { pueblo devería elijir sus governantes y que a propósito es un derecho e todos los } \\
\text { ciudadanos. } \\
\text { En definitiva la situación de Cárolin como la situación de esta mujer nos hace refletir } \\
\text { sobre las personas que viven allá. } \\
\text { Ya había escuhado hablá de las vida de estos pueblos, pero no mire los ojos cuando } \\
\text { presenciei ella hablado de su realidade. En todo caso fue muy bueno conocerla. } \\
\text { Sin embargo actualmente tengo contato con Cárolin charla en facebook, ella me } \\
\text { cuenta que está muy bien en California y que retornará para Natal en breve. }\end{array}$ \\
\hline
\end{tabular}




\begin{tabular}{|c|c|}
\hline & $\begin{array}{l}\text { Hace desde el año } 2005 \text { se aprobó em Brasil, la ley } 11.165 / 2005 \text { que establece la } \\
\text { obligatoriedad de enseñanza de lengua española en las escuelas de enseñanza } \\
\text { media. Esta ley fue aprobada tras el acuerdo firmado entre Brasil y los demás países } \\
\text { del Mercosur, que tienen como idioma oficial el español. Este acuerdo trata de } \\
\text { relaciones económicas y políticas entre estos países, así que, la lengua española } \\
\text { pasó a ser aún más importante para los brasileños. } \\
\text { Aunque la oferta de español ya esté en evidencia, de hecho no está siendo aplicada } \\
\text { como deveria ser. Eso se debe a factores que se extenden desde la falta de } \\
\text { profesores formados en esta área, además la no contratación de profesores } \\
\text { específicos, por las consejerías de educación de los 'estados' de Brasil, en suma me } \\
\text { parece negligencia. } \\
\text { Ojalá que la enseñanza de español no siga el mismo rumbo que la de inglés, que a } \\
\text { muchos años es ofrecida en las escuelas públicas. Por outra parte, hay que } \\
\text { considerar que la busca por curso de formación de profesores de español hay } \\
\text { aumentado. En Rio Grande do Norte hay tres universidades públicas que orece este } \\
\text { curso. La Universidad Federal (UFRN), el Instituto (IFRN) y la universidad (UERN). } \\
\text { Además, algunas universidades particulares como universidad Potiguar (Unp) y la } \\
\text { Universidad Mauricio de Nassau que tienen curso posgrado en legua española. } \\
\text { Con todo, es esencial que estas formaciones sean de cualidad, que los futuros } \\
\text { profesores luchen y contribuyan en la busca de solución, en lo que se refiere a los } \\
\text { problemas en el enseño de español. En definitiva, ien este país todo se logra con } \\
\text { lucha! }\end{array}$ \\
\hline & $\begin{array}{l}\text { He aprendido acerca de la família em el plan de nuestro Padre Celestial, así que sé } \\
\text { de su gran importancia en nuestras famílias en nuestras vidas, es más en toda la } \\
\text { familia humana. } \\
\text { A propósito a causa de ellas, todo en el mundo fue y está hecho, es decir, todo el plan } \\
\text { de salvación -o como me gusta decir- el plan de felicidad, la iglesia, la religión, todo } \\
\text { fue hecho para ayudarnos con nuestras famílias. } \\
\text { Además Él nos dío un Salvador y las escripturas para guiarnos. No obstante, el } \\
\text { matrimonio, el ser una familia sigue siendo un desafio. As veces es necesario negar a } \\
\text { sí mismo, hay que saber perdonar, callar, saber decir 'sí' y otras veces decir 'no'; hay } \\
\text { que tener fe, paciencia y mucho, mucho amor. De hecho es no fácil. } \\
\text { Por otra parte, el matrimonio puede llegar a ser la cosa que más te dará placer en } \\
\text { esta vida. Con los desafíos, con las pruebas, llegan también más fuerzas, más unión } \\
\text { y a todo esto se suma el aumento, el crecimiento del amor. El amor que hoy tengo por } \\
\text { mi esposo, por cierto, llegará ser más y más profundo con el pasar del tiempo. } \\
\text { En suma, te adviento, el matrimonio no és y jamás será fácil, de ahí que, muchos } \\
\text { 'desisten' o ni llegan a tentar, sin embargo, aunque sea difícil, la verdad es que, vale } \\
\text { la pena, eso sí. Tener un hogar hacia donde volver, tener hijos para llamarte 'mamá', } \\
\text { tener una familia eterna, para eso no hay precio, en definitiva, no hay precio. } \\
\text { Ningún sacrificio es demasiado grande, sí la recompensa es el retorno al hogar de } \\
\text { nuestro Padre Celestial con las personas que más amamos -nuestra familia- }\end{array}$ \\
\hline
\end{tabular}




\section{TX-INF-EST-8-9-ELE-01}

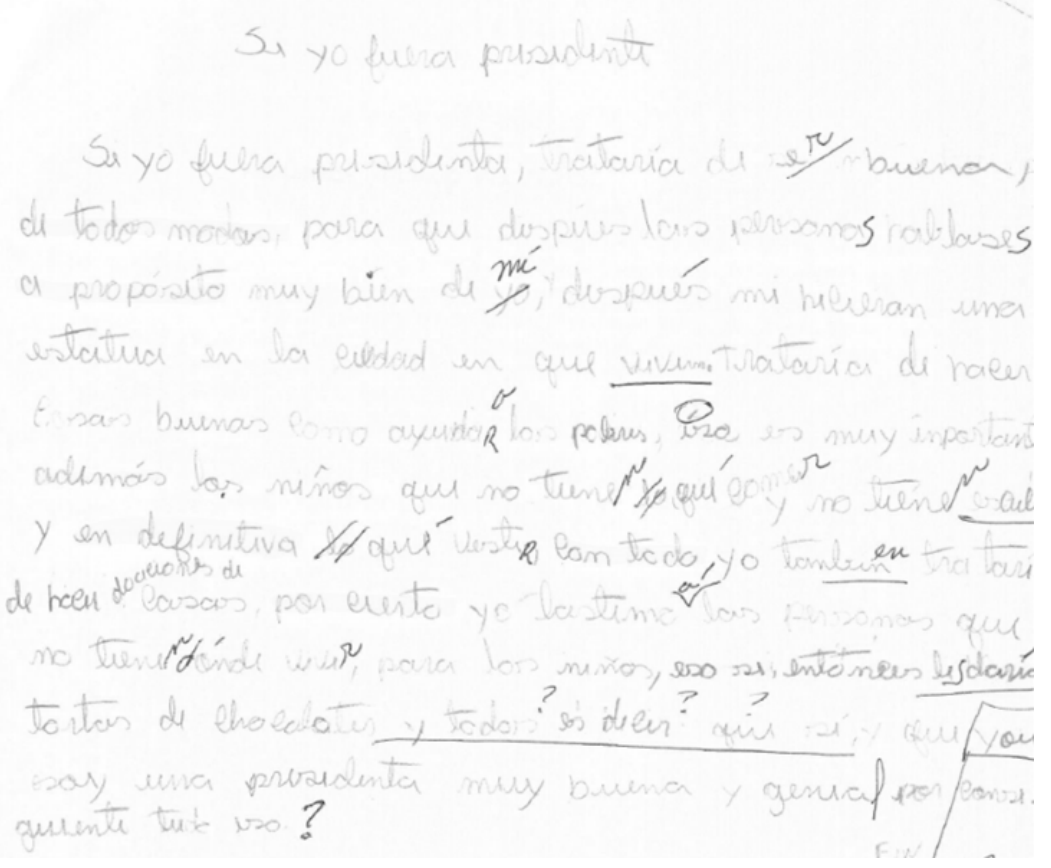

TX-INF-EST-8-9-ELE-02

Hotel comiveño

Natol, 27.07.2015

Scror yose, escribo Pona te recuerdan que

qultan nenos de cuotro dias Pana su estodia in nuevtro hotel, a Ropósito recuerdamos también que

en nuestro sistema no clesta se pacameintes ento bs, sin su proamunto ustid se queda imposi bi ilitóde de se hosploby.

Yerdremas alouras permas de Paopamientos Pona unted. Les pacamientes son rechos de la squeiente manke a dinero o con tomplea de cídito, en todo cono untid prede evtor haciendo eso Popamiento Pervoralmente

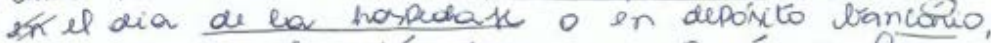
aderiós, usted tambrión tene la OPción de bapon denando el dinto encima de la televiseor, far

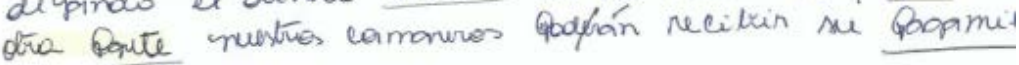

Ertences señon yose, con tóds no oquandormos su estrodia en muestro hotel, ani que tut tuvier una nespunta, nos comunigue, es món zocil una comurica tolo esto, muchos Grocion par se alanción. Hotel correbrño. 


\section{TX-INF-EST-8-9-ELE-03}

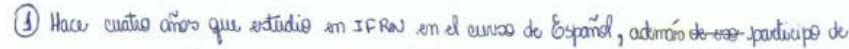

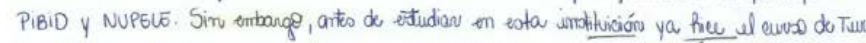

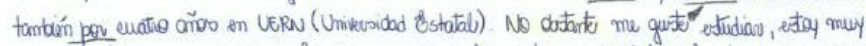

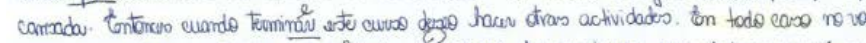

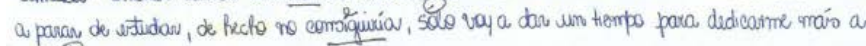
mi poritia.

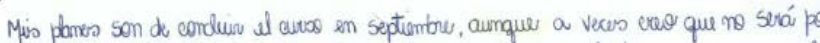
ble. De todos modos hastas fines de etes ä́o lo vay a terminas, tartas perque ayer excuch

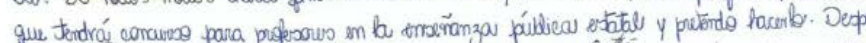

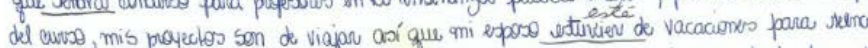
tras a mirs amiges y tomitious que vivers en Rio de domares y que ro los veo desde dos mi

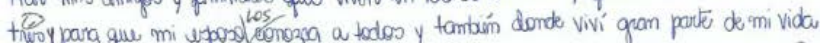

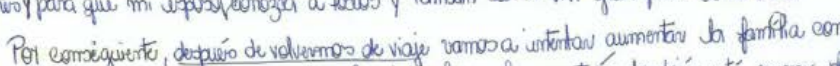

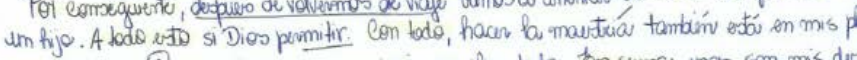
nes futures, Solo no sé si vay a corriguir concitiar todo. Ton sumar, vaos son mis der pho quizás no ocurrian y todo sea distirto porque la vida está llema de serpewsas.

(2) Faz quatro anos que urtudg no IFRN ro anvo de tespantol, alom disso participo do

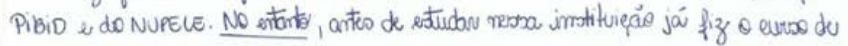

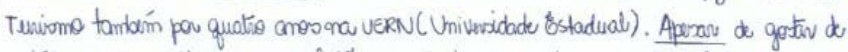

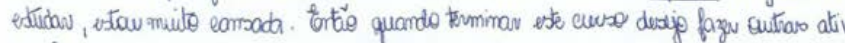

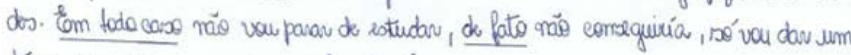
Kempe tarta dedicarme mais a misha famitia.

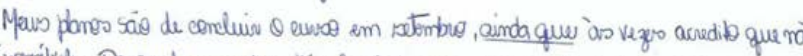

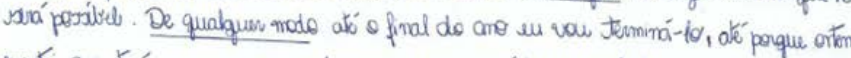

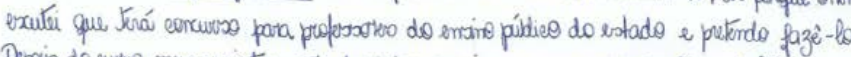

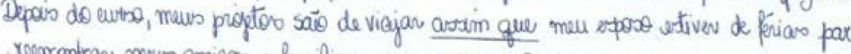

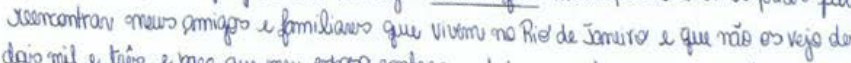

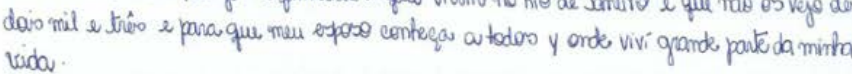

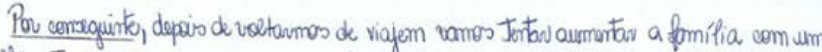
filto. Tudo isso se Dews permitir. Contudo, fazer o mustrado tombém está res meu

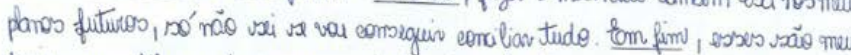

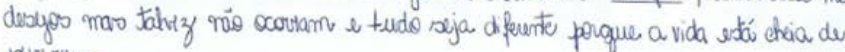
sulpusoro

\section{TX-INF-EST-8-9-ELE-04}

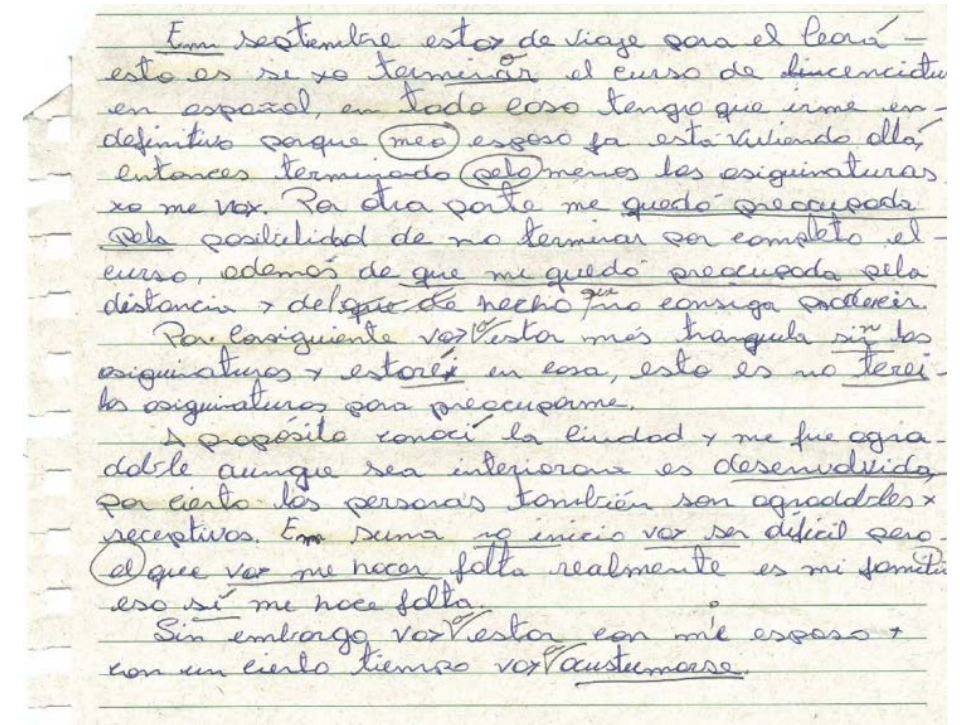




\section{TX-INF-EST-8-9-ELE-05}

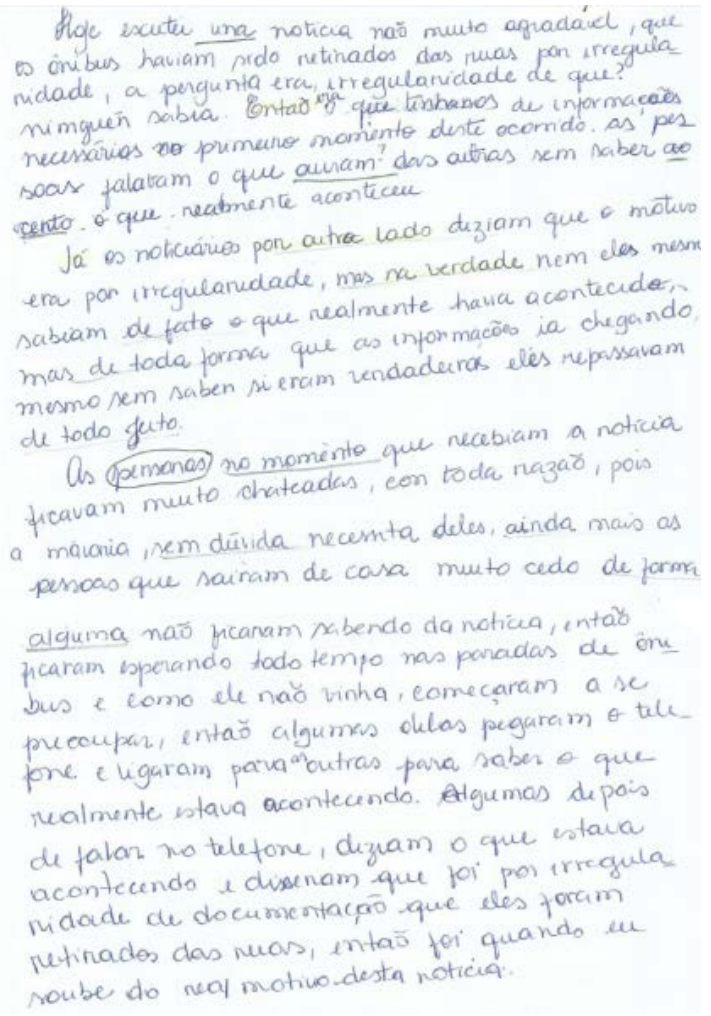

\section{TX-INF-EST-8-9-ELE-06}

I-

Hoy, oir una notréa no muy aqradáble, que las autobuses 'rén sido neturados de las calles por irreqularidad. La spregunta ena, uregulanidad de que? nadie sabiá. Entoces en el primer momento no teníamos las informaciones ne cescruas con los neales motivos de este hecho. las personas hablaban lo que óán de las otras un saben en difinta elferto. ena por inregulanidad, a propósito nix ellos sabian en suma lo que realmente había ocurrido, en todo coso. las informaciones que llegaban. musmo in saben que erain verdaderas ellos estaban repasaudo de todos as modos.

no obstante que necibieron la noticia

has personas no obstante que necazón, pues la mayonis, su cquedaron muy aburridas ellos, ádemas las porsonas que sín emborgo necextan de casas de hecho no supieran de saliran temprano de sus caseran, espenando todo el trempo en

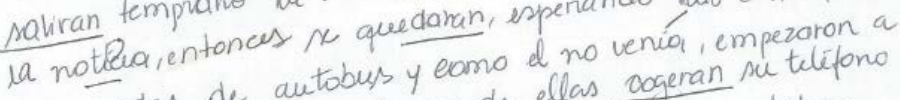
las paradas de autobus y eamo ellas cogeran su teléfono se preocepor, entonces algunas de que nealmente istaba y llamaran a otras pana saber de hablar por telejons, decián ocurriendo. Algunas, sespues dijeron que fue por irregularidad o que ettava documentación que ellos fueron retirades motivo de ealles, entonces fue cora

iste hecho. 


\section{TX-INF-EST-8-9-ELE-07}

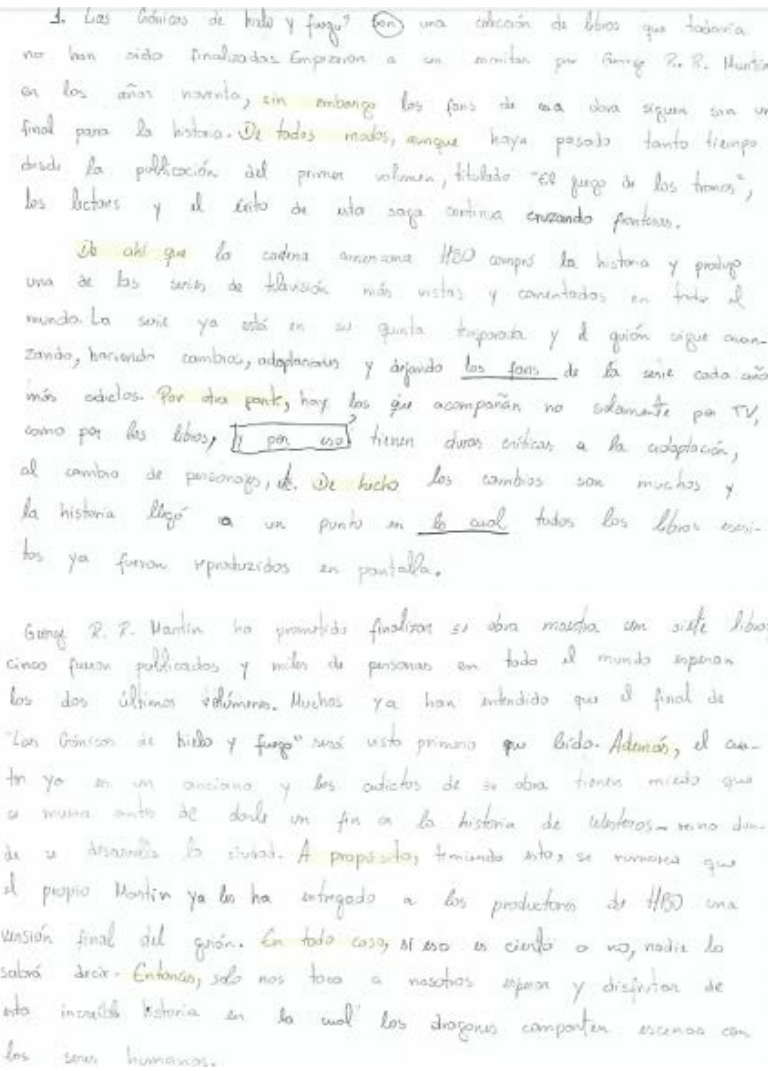

\section{Tx-INF-EST-8-9-ELE-08}

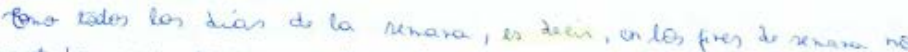

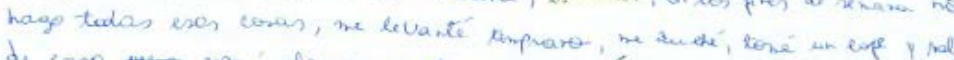

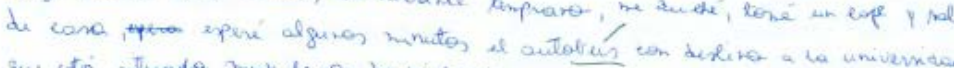

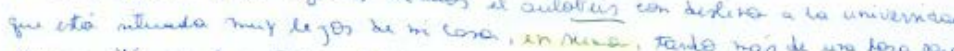

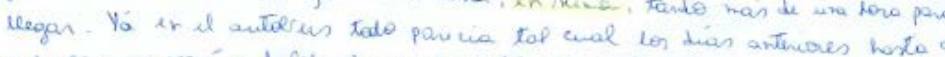

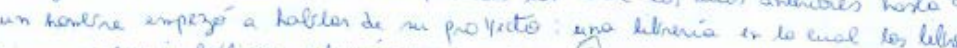

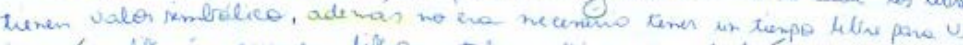

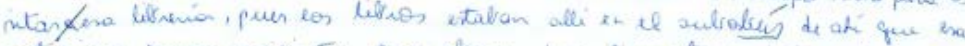

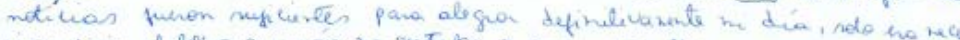

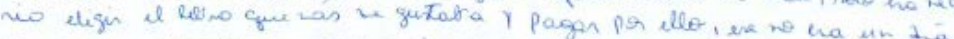

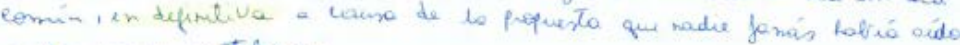
antes en un sutobus

Aunque los libros ne han nuevos, todes haljan tan buen undados

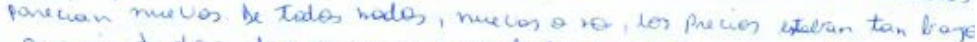

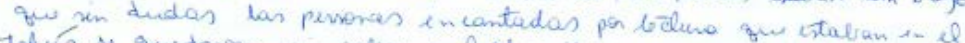

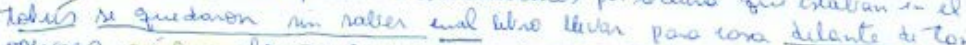

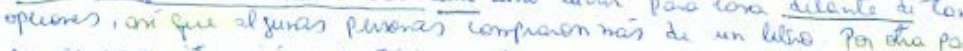

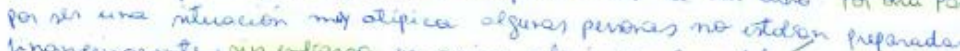

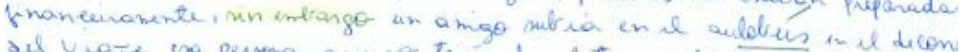

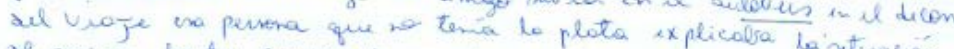

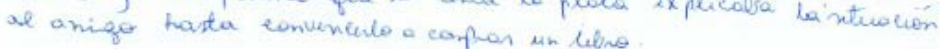

De whe la actitud del hentine cambió it dia de la nayouia de 4

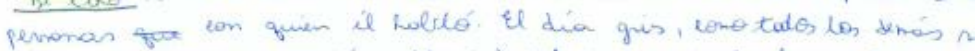
La convestude in un die lleno de clores, pruncepolmente para las pur zue per printra vez pudueron compras un lisso, en tado cono, una ad

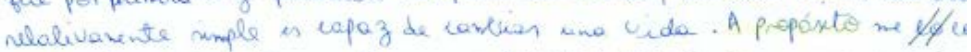

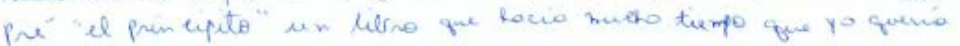
en fin vor a connegurlo ahora 


\section{Tx-INF-EST-8-9-ELE-09}

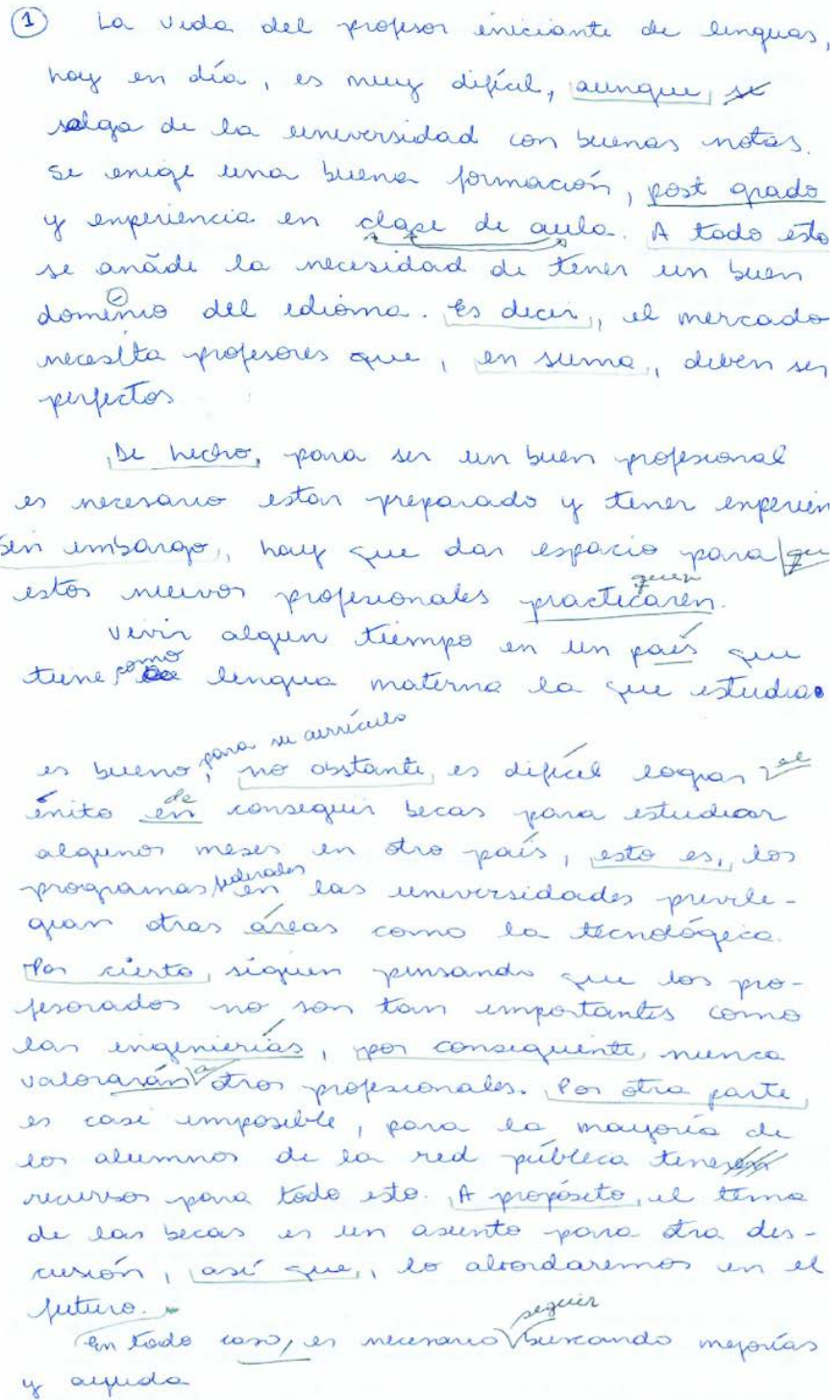

\section{TX-INF-EST-8-9-ELE-10}

Hablar de familion as algo miny hingular, is no que simplemente habron de nombers y decules la pinción de cada ur. de lo membar dentus de eller.

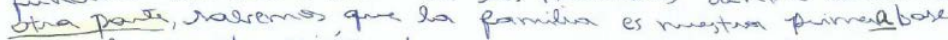
parar la carstruncción de ruestras puncipios moralas, grsto es sinve corro un jeferencial pans nuestros deramellocorro per

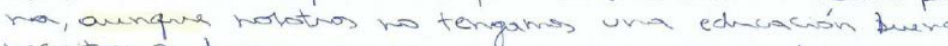
necentamos buscan, funtan valones que nos ayudena un

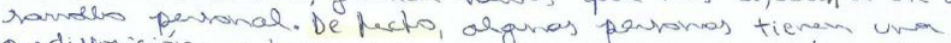
pudisporición a hacen was mabas por toda la vida, a denva

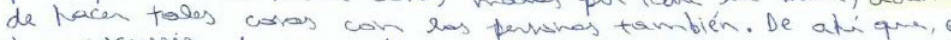

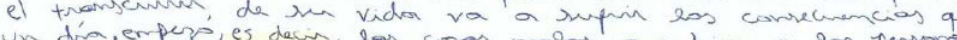

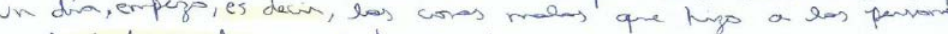
De todo modo, no padernos dejar de valover nuestra fami. pues, ella es ruestroa fuerza mayo acd en la tierra. Entons

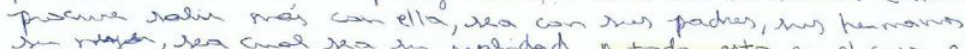
far en el cass, en

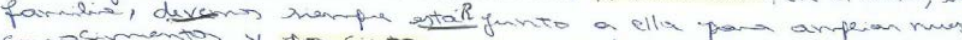

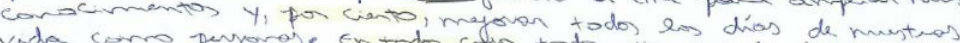
es la únse mavera of existe en la vida qua he habeado, w En surna, avma tu familia encmants brin embarge,

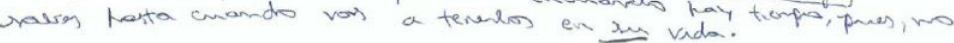




\section{TX-INF-EST-8-9-ELE-11}

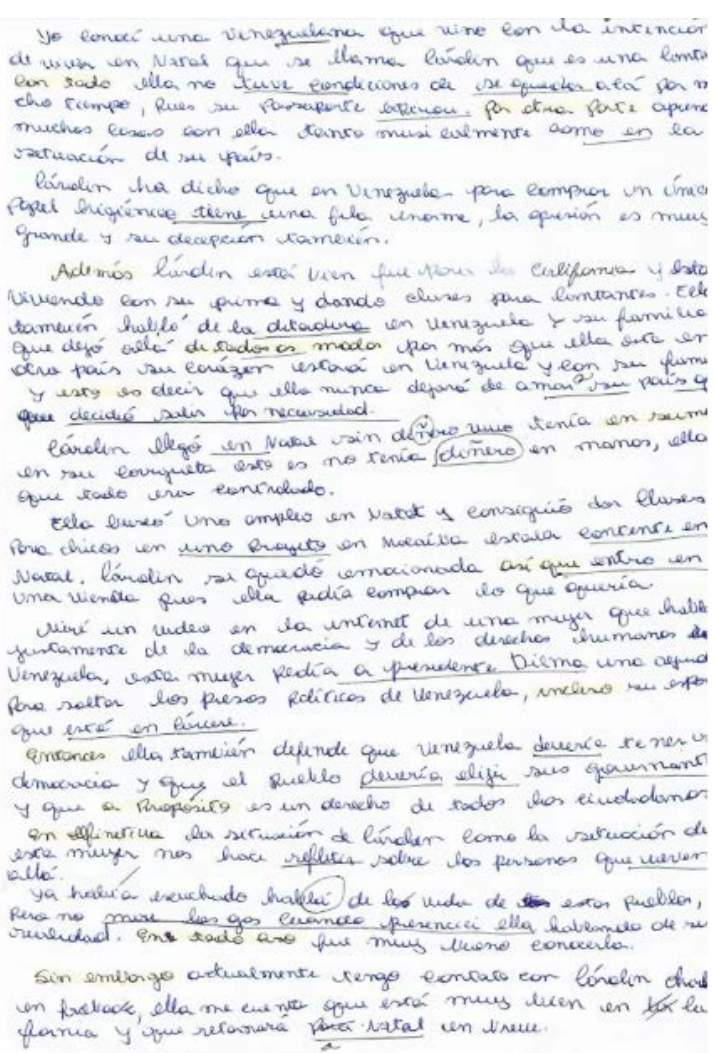

\section{TX-INF-EST-8-9-ELE-12}

Hace descle $3^{3}$ el año 200 s, se aprobó em Brasti la ley 11.165/2005 que establece lo obtigatoriedad de enseñonza de lengua española en las escuelas de enseñango médí. Esta ley tive apromalo trás el acuerdo girmado entre

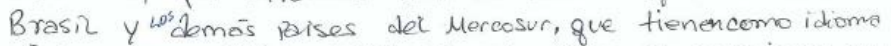
aicial el esprñol. Este acuerch trata de relaciones económicas y políticos entre estos paises, asique, la lengua espoñola pasó a ser aún más importamte para los brasineños.

Aunque lo oferta de español ya esté en evidencia, dehecho no está siendo aplicada corno devería ser. Geso se deve a factores que se extienden dosde la falto de profesores formados en osta áraa, aderrás la no contratrción de profeseres especificos, por las consejerias de educación de los "Estados" de Brasiz, en suma me Parece negliguncio

Ojalá que la enseñanza de españor no sigo el mismo rumbo que la de inglés, que hao muchos años es ofrecida en las escuelas públicos. Por outra arte, hay que considerar que 22 busco por curso de formación de protesores de espoñor hy and hio Grande de norte hoy tres universidades publicas que oqrecen este curso, lo universidad Federar (UFRN), el instituto (IFRN) y la universidad (UERN). Además, argunas umiversidades particutares conno universicad Potiguar (UNP), y la unilersidad Nauricio de Nassar que tienen curso de posgrado en lengua essiñole.

Con todo, es esencior que estas formaciones seande clavidad, que los futuras profesores 2uchen y contribuysol en la busce de sowción, en 10 que se refiere lagre con 2ucha? espoñor. En defititiva, ion 


\section{TX-INF-EST-8-9-ELE-13}

He apnendido acenca de la faniria en el plan de nuestro Padne G lestial, arique bé de su gnan impontanaia en nuestrias famirlias en nuestrias vidas, es más en tuda la familia humona.

A propisito, a causa de ellas, todo en el mundo fue y estó he cho, es decir, todo el plan de salvación -o como me gusta decir. - el plan de felicidad, la iglesia, la neligión, todo fue heciwo pana ayudannos con nuestras fanklias.

Además El nos dio un Salvadar y las escnipturas pana e

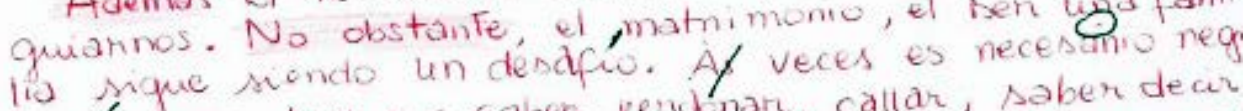
ira śmismo, hay que saben perdonar, callar, saber decer "is" y ctras veces dear "no"; hay que Tener fe, pacienua y macho, mucho amon. De hecho no es facal

Pon ctria pante, el matrimonio puede llegan a sen la cosa, cue más te danó placen en esta vida. Cón pnuebas, llegan también mós fuetizas, más unión y a todo esto use suma el aumento, el cnecimiento del amon.

el amar aue hoy tengo por mi esposo, pon ciento, llegará sen más y más pnofundo con el pasar del tiempo.

En suma, téadviefito, el matrimonio no \& y jamás ser facil, de ahi que, muchos desisteri o ni llegan a lentar.

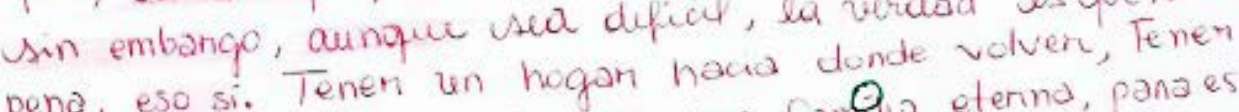
hend, eso si. Tent pana llamante mamd, tenen una famelo eterina, pana es: no hay precio, en defunitiva, no hay precio.

Ningun sacnifica us demasiado gnande, $Q_{10}$ recompense

as el netunino al hugan de nuestro fadre Celestial con las perisonas que más amamos - nuestra famela=. 


\section{ANEJOS}




\section{ANEJOS}

ANEJO 1: DOCUMENTOS ACADÉMICOS DE LA IES-1 ......................... 331

ANEJO 1A - PLAN DE ESTUDIOS ORIGINAL - 2009 - IES-1 (1/2) .............. 332

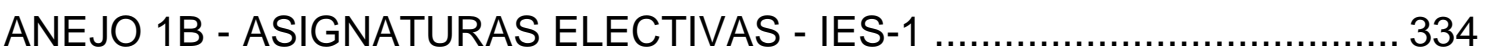

ANEJO 1C - ASIGNATURAS OBLIGATORIAS FUNCIONALISTAS ............. 334

ANEJO 2: DOCUMENTOS ACADÉMICOS IES-2..................................... 335

ANEJO 2A - PLAN DE ESTUDIOS ORIGINAL - 2000 - IES-2 (1/2) .............. 336

ANEJO 2B - PLAN DE ESTUDIOS $1^{\mathrm{a}}$ REFORMULACIÓN 2003 - IES-2 (1/2)..

ANEJO 2C - PLAN DE ESTUDIOS EN VIGOR 2015 - IES-2 (1/2) .............. 340

ANEJO 2C - PLAN DE ESTUDIOS EN VIGOR 2015 - IES-2 (2/2) .............. 341

ANEJO 2C - PLAN DE ESTUDIOS EN VIGOR - IES-2 CON RESUMEN (1/3) ...

ANEJO 2C - PLAN DE ESTUDIOS EN VIGOR - IES - 2 CON RESUMEN (2/3).

ANEJO 2C - PLAN DE ESTUDIOS EN VIGOR - IES - 2 CON RESUMEN (3/3).

ANEJO 3: DOCUMENTOS ACADÉMICOS IES-3.................................... 345

ANEJO 3A - PLAN DE ESTUDIOS ORIGINAL - 2006 - IES-3 ...................... 346

ANEJO 3B - PLAN DE ESTUDIOS 1ª REFORMULACIÓN 2012- IES-3........ 350

ANEJO 3C - PLAN DE ESTUDIOS 2a REFORMULACIÓN 2014- IES-3 (1/2)351

ANEJO 3C - PLAN DE ESTUDIOS 2a REFORMULACIÓN 2014- IES-3 (2/2)352

ANEJO 3D - ASIGNATURAS ELECTIVAS - IES-3 .............................. 353

ANEJO 3E - PROGRAMA ASIGNATURA FUNCIONALISTA - IES-3 .......... 354

ANEJO 4: SCRIPT VÍDEO-CLASE MARCADORES DEL DISCURSO IES-3

ANEJO 5: PRODUCCIÓN ORAL DOCENTE.............................................. 356

ANEJO 5A: TRANSCRIPCIÓN ORTOGRÁFICA DE PRODUCCIÓN

DOCENTE.

ANEJO 5B: CONVENCIONES DE TRANSCRIPCIÓN ORTOGRÁFICA

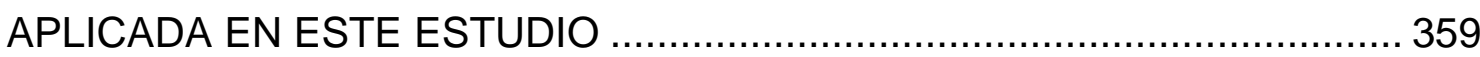

ANEJO 6: TEXTOS INFORMANTE ENSEÑANZA BÁSICA ELE................. 360 
ANEJO 7: PRESENTACIÓN GENERAL DE MARCADORES DISCURSIVOS:

DIFERENTES NOMENCLATURAS, DISTINTOS AUTORES TRATADOS .. 362

ANEJO 7A: PRESENTACIÓN GENERAL DE MARCADORES DISCURSIVOS:

DIFERENTES NOMENCLATURAS, DISTINTOS AUTORES TRATADOS EN

ESPAÑA. 363 


\section{ANEJO 1: DOCUMENTOS ACADÉMICOS DE LA IES-1}

- Anejo 1A - Plan de estudios original - 2009 - IES-1

- Anejo 1B - Asignaturas electivas - IES-1

- Anejo 1C - Asignaturas obligatorias funcionalistas 
Anejo 1A - Plan de estudios original - 2009 - IES-1 (1/2)

Detalmes da Estrutura Currtcular

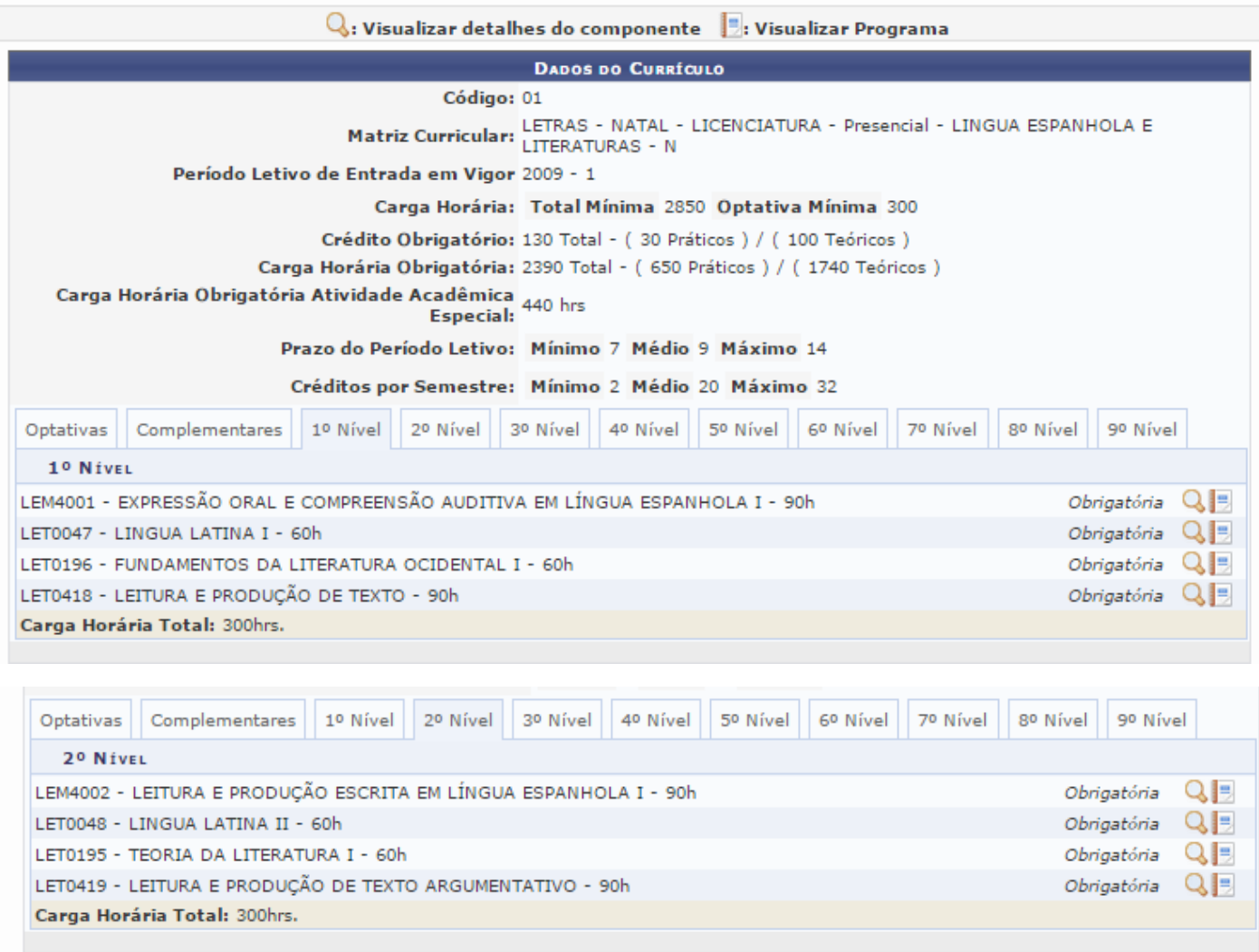

\begin{tabular}{|l|l|l|l|l|l|l|l|l|l|l|}
\hline Optativas & Complementares & $10 \mathrm{Nivel}$ & $20 \mathrm{Nivel}$ & $30 \mathrm{Nivel}$ & $40 \mathrm{Nivel}$ & $50 \mathrm{Nivel}$ & $60 \mathrm{Nivel}$ & $70 \mathrm{Nivel}$ & $80 \mathrm{Nivel}$ & $90 \mathrm{Nivel}$
\end{tabular}

$$
30 \mathrm{~N} \text { IVEL }
$$

FPE0680 - FUNDAMENTOS SÓCIO-FILOSÓFICOS DA EDUCAÇÃO - 60h

LEM4003 - FONÉTICA E FONOLOGIA DA LINNGUA ESPANHOLA I - 60h

LEM4004 - LEITURA E PRODUÇÃO ESCRITA EM LÍNGUA ESPANHOLA II - 60h

LETO058 - TEORIA DA LITERATURA II - 60h

LET0194 - LINGUISTICA I - 60h

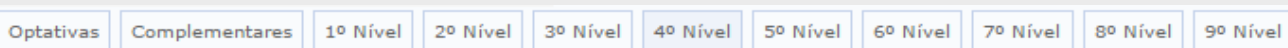

$$
40 \text { N IVEL }
$$

EDUO681 - FUNDAMENTOS DA PSICOLOGIA EDUCACIONAL - 60h

LEM4005 - MORFOLOGIA DA LINGUA ESPANHOLA I - 60h

LEM4006 - SINTAXE DA LINGUA ESPANHOLA I - 6Oh

LEM4007 - LÉXICO DA LÍNGUA ESPANHOLA - 60h

LET0197 - LINGUISTICA II - 60h

Carga Horária Total: $300 \mathrm{hrs}$. 
...// Anejo 1A - Plan de estudios original - 2009 - IES-1 (2/2)

\section{SIGAA}

Sistema Integrado de Gestão de Atividades Acadêmicas

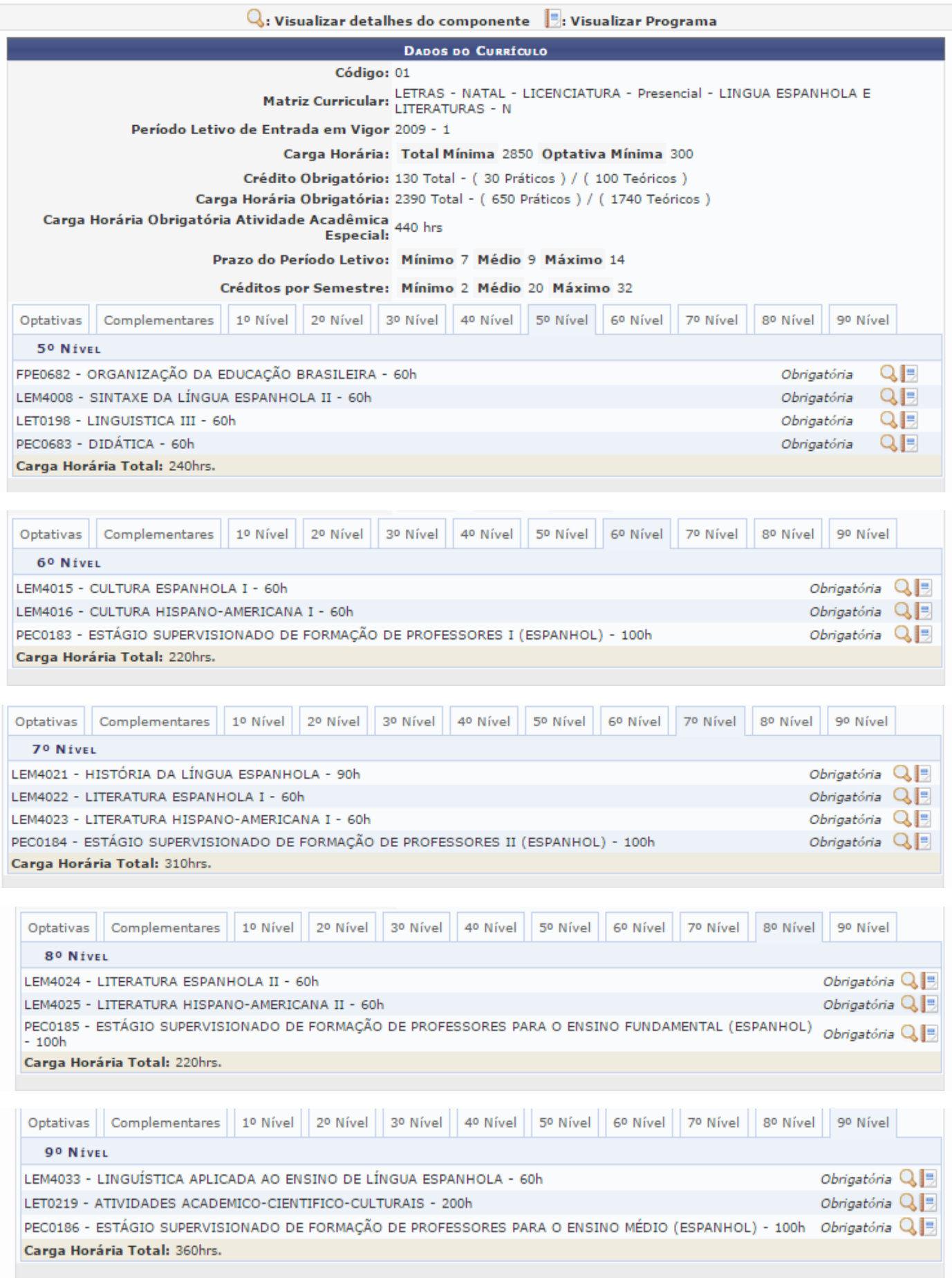




\section{Anejo 1B - Asignaturas electivas - IES-1}

9.4 DISCIPLINAS OPTATIVAS

\begin{tabular}{|c|c|c|c|}
\hline Ordem & CODIGo & Disciplinas Optativas & Pré-requisito \\
\hline 1 & LET0062 & Semióticag I & LET0038 / LET0056 \\
\hline 2 & LET0257 & Epistemologia Linguistica & - \\
\hline 3 & LET0252 & Espanhol Turistico & - \\
\hline 4 & LET0248 & Estudos Gramaticais Avangrados I & LET0233 \\
\hline 5 & LET0250 & Lexiceprafia & LET0228 \\
\hline 6 & LET0249 & $\begin{array}{l}\text { Fonéticae Fonologia da Língua } \\
\text { Espanhola II }\end{array}$ & LET0231 \\
\hline 2 & LET0253 & Lingua Galega & - \\
\hline$\&$ & LET0380 & Literatura Ibero-americana I & - \\
\hline 2 & LET0396 & Literatura Ibero-americana II & - \\
\hline 10 & LET0245 & Literatura Latino-amenicana I & - \\
\hline 11 & LET0261 & Literatura Latino-americana II & - \\
\hline 12 & LET0258 & $\begin{array}{l}\text { Literatura Infantil de Lingua } \\
\text { Esppanhola }\end{array}$ & LET0056 \\
\hline 13 & LET0255 & Cultura Hispano-americana II & - \\
\hline 14 & LET0254 & Cultura da Civilizaçăa Espanhola II & - \\
\hline 15 & LET0259 & $\begin{array}{l}\text { Fundamentos do Romancoe em } \\
\text { Cervantes }\end{array}$ & - \\
\hline 16 & LET0260 & $\begin{array}{l}\text { Express sâofeminina na Literatura } \\
\text { Hispano-americana }\end{array}$ & - \\
\hline
\end{tabular}

\begin{tabular}{|c|c|c|c|}
\hline 17 & LET0251 & $\begin{array}{l}\text { Radagajo Tésnica am Língua } \\
\text { Espanhola }\end{array}$ & LET0233 \\
\hline 18 & LET0058 & Teoria da Literatura II & LET0056 \\
\hline 19 & LET0059 & Teoria da Literatura III & LET0056 \\
\hline 20 & LET0078 & Literatura Portuguess I & LET0056 \\
\hline 21 & LET0079 & Literatura Portuguesa II & LET0078 \\
\hline 22 & EDU0587 & Introduçăo i Educaģ̄o Esppecial & - \\
\hline 23 & FIL 0220 & Filosofia da Linguagem & - \\
\hline 24 & LET0065 & Literatura Brasileira I & LET0056 \\
\hline 25 & LET0066 & Literatura Brasiletira II & LET0065 \\
\hline 26 & LET0063 & \begin{tabular}{|l|} 
Fundamentos da Literatura Ocidental \\
II
\end{tabular} & LET0055 \\
\hline 27 & LET0247 & Literatura Hispano-amenicana II & - \\
\hline 28 & LET0238 & Dialetologia & - \\
\hline
\end{tabular}

\section{Anejo 1C - Asignaturas obligatorias funcionalistas}

UNIVERSIDADE FEDERAL DO RIO GRANDE DO NORTE PRÓ-RETTORUA DE GRADUAC̃̃O

CADASTRO DE DISCIPLINAS
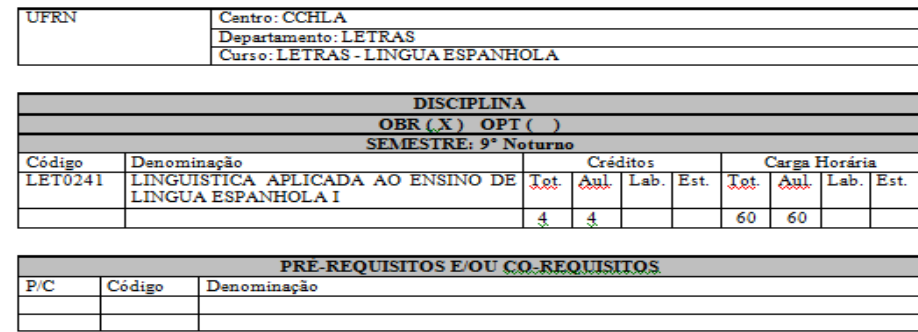

襾

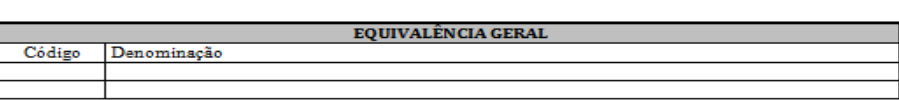

EMIENTA

L.a Enseñanza del Español como Lengua Extranjera. Metodologia de la enseñanza de lenguas hasta el momento actual. Análisis crítico de las aportaciones realizadas desde los diversos métodos considerando especialmente aquellas que hoy dia conservan una plens actualidad. Aspectos concretos relacionados con la problematica de la enseñanza-aprendizaje del espaniol como lengua extranjers. el marco comun europeo de referencia para las

\section{BIBLIOGRAFIA} ALARCOS LIORACH, E. Gramática de la lengua española. Madrid: Espasa-Calpe, 1994.
BOSQUE, I. y DEMONTE V. (dirs.). Gramática descriptiva de la lengua española, 3 vols. Madrid: Espasa-

CONSEJO DE EUROPA. Marco de referencia europeo para el aprendizaje, la enseñanza y la evaluación de lenguas. Madrid: Ministerio de Educación, Cultura y Deporte; Instituto Cervantes, Anaya, 2003. 


\section{ANEJO 2: DOCUMENTOS ACADÉMICOS IES-2}

- Anexo 2A - Plan de estudios original - 2000 - IES-2

- Anexo 2B - Plan de estudios $1^{a}$ reformulación 2003 - IES-2

- Anexo 2C - Plan de estudios $2^{\mathrm{a}}$ reformulación 2013- IES-2

- Anexo 2D - Asignaturas electivas - Plan de estudios en vigor - IES-2 
Anejo 2A - Plan de estudios original - 2000 - IES-2 (1/2)

\begin{tabular}{|c|c|c|c|c|c|c|c|c|c|}
\hline \multicolumn{10}{|l|}{ 1 Periodo } \\
\hline DISCIPLINAS & Depto. & Codigo & $\begin{array}{l}\text { Horal } \\
\text { Aula }\end{array}$ & $\begin{array}{c}\text { Crédito } \\
\text { Teoric } \\
0\end{array}$ & \begin{tabular}{l|c} 
& Hora Trab. \\
$c$ & Extra Classe
\end{tabular} & $\begin{array}{c}\text { Crédito } \\
\text { Trab. }\end{array}$ & \begin{tabular}{|l|} 
C.H. \\
Total
\end{tabular} & $\begin{array}{l}\text { Créd. } \\
\text { Total }\end{array}$ & \begin{tabular}{|l|l} 
Pré- \\
requisito
\end{tabular} \\
\hline Produçăo Textual & DLV & 0401033-1 & 60 & 04 & - & - & 60 & 04 & $\cdot$ \\
\hline Fundamentos da Lingua Espanhola & DLE & 0402019-1 & 60 & 04 & - & . & 60 & 04 & - \\
\hline Fundamentos da Lingua Inglesa & DLE & $0402020-1$ & 60 & 04 & - & - & 60 & 04 & - \\
\hline Linguistica | & DLE & $0402010-1$ & 60 & 04 & - & - & 60 & 04 & - \\
\hline Metodologia do Trabalho Cientifico & DLV & 0401059-1 & 60 & 04 & - & - & 60 & 04 & - \\
\hline Pratica Desportiva | & DEF & $0401041-1$ & - & - & - & - & - & - & - \\
\hline TOTAL & & & 300 & 20 & - & - & 300 & 20 & \\
\hline \multicolumn{10}{|l|}{$2^{\circ}$ Periodo } \\
\hline \multirow[t]{2}{*}{ DISCIPLINAS } & Depto. & Codigo & Horal & Crédito & \begin{tabular}{|l|l} 
Hora Trab. \\
\end{tabular} & Crédito & C.H. & Créd. & Pré- \\
\hline & & & Aula & $\begin{array}{c}\text { Teóric } \\
0\end{array}$ & Extra Classe & Trab. & Total & Total & requisito \\
\hline Lingua Espanhola I & DLE & $0402042-1$ & 90 & 06 & - & - & 90 & 06 & $0402019-1$ \\
\hline Filosoffa da Linguagem & DFI & 0702018-1 & 60 & 04 & - & - & 60 & 04 & - \\
\hline Linguistica II & DLE & $0402011-1$ & 30 & 02 & 30 & 01 & 60 & 03 & 0402011-1 \\
\hline Tóp. De Gramática do Portugués & DLV & $0401035-1$ & 60 & 04 & 30 & 01 & 90 & 05 & $\cdot$ \\
\hline Teoria de Literatura I & DLE & $0402012-1$ & 60 & 04 & - & - & 60 & 04 & - \\
\hline Prática Desportiva II & DEF & $0601042-1$ & - & - & - & - & - & - & - \\
\hline TOTAL & & & 300 & 20 & - & 03 & 360 & 22 & \\
\hline
\end{tabular}

$3^{\circ}$ Periodo

\begin{tabular}{|c|c|c|c|c|c|c|c|c|c|}
\hline DISCIPLINAS & Depto. & Código & $\begin{array}{l}\text { Horal } \\
\text { Aula }\end{array}$ & $\begin{array}{l}\text { Crédito } \\
\text { Teóric }\end{array}$ & $\begin{array}{l}\text { Hora Trab. } \\
\text { Extra Classe }\end{array}$ & $\begin{array}{c}\text { Crédito } \\
\text { Trab. }\end{array}$ & $\begin{array}{l}\text { C.H. } \\
\text { Total }\end{array}$ & $\begin{array}{l}\text { Crèd. } \\
\text { Total }\end{array}$ & $\begin{array}{l}\text { Prè- } \\
\text { requisito }\end{array}$ \\
\hline Lingua Espanhola II & DLE & 0402043-1 & 90 & 06 & - & - & 90 & 06 & $0402042-1$ \\
\hline Teoria da Literatura II & DLEI & 0402013-1 & 60 & 04 & 30 & 01 & 90 & 05 & - \\
\hline Psicologia da Educaçăo & DE & 0301017-1 & 60 & 04 & 30 & 01 & 90 & 05 & - \\
\hline Fonética e Fonologia (Espanhol) & DLE & 0402071-1 & 90 & 06 & - & - & 90 & 06 & - \\
\hline TOTAL & & & 300 & 20 & 60 & 02 & 360 & 22 & \\
\hline
\end{tabular}

$4^{\circ}$ Periodo

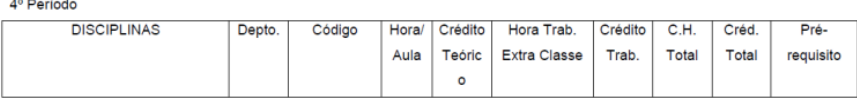

\begin{tabular}{|l|c|c|c|c|c|c|c|c|c|}
\hline Lingua Espanhola III & DLE & $0402044-1$ & 90 & 06 & - & - & 90 & 06 & $0402043-1$ \\
Leitura e Prod. de Textos & DLE & $0402061-1$ & 30 & 02 & 30 & 01 & 60 & 05 & - \\
Esspanhal) & DLV & $0401012-1$ & 60 & 04 & - & - & 60 & 05 & $0402012-1$ \\
Literatura Portuguesa I & DLV & $0401015-1$ & 60 & 04 & - & - & 60 & 06 & $0401012-1$ \\
Literaruara Brasileira I & DE & $0301018-1$ & 30 & 02 & 30 & 01 & 60 & & - \\
Didatica Geral & DLV & $0402070-1$ & 30 & 02 & 30 & 01 & 60 & & $0402010-1$ \\
Sociolinguistica & & & & & & & & & \\
\hline TOTAL & & & 300 & 20 & 90 & 03 & 390 & 23 & \\
\hline
\end{tabular}

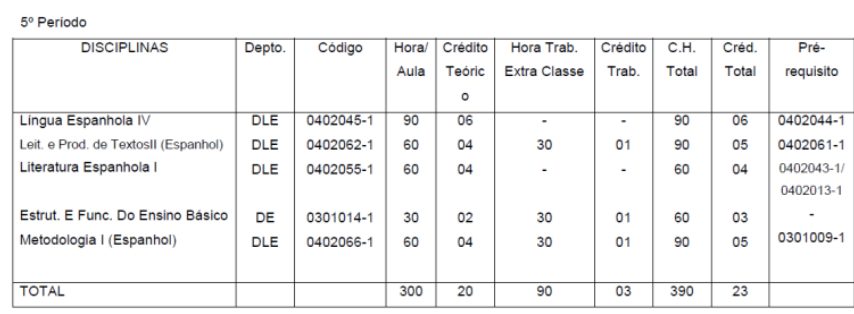


...// Anejo 2A - Plan de estudios original - 2000 - IES-2 (2/2)

\begin{tabular}{|c|c|c|c|c|c|c|c|c|c|}
\hline \multirow{2}{*}{ DISCIPLINAS } & \multirow{2}{*}{ Depto. } & \multirow{2}{*}{ Codigo } & Horal & Crédito & Hora Trab. & Creditio & C.H. & Créd. & \multirow{2}{*}{ Pré-requisito } \\
\hline & & & Aula & $\begin{array}{c}\text { Teoric } \\
0\end{array}$ & Extra Classe & Trab. & Total & Total & \\
\hline Lingua Espanhola V & DLE & $0402046-1$ & 90 & 06 & $\cdot$ & - & 90 & 06 & $0402045-1$ \\
\hline Literatura Espanholall & DLE & $0402056-1$ & 60 & 04 & - & - & 60 & 04 & 0402012-1 \\
\hline Lit. Hispano-americana I & DLE & 0402058-1 & 60 & 04 & - & - & 60 & 04 & $0402013-1$ \\
\hline Pratica de Ensino de Espanhol I & DLE & 0402075-1 & 30 & 02 & 120 & 04 & 150 & 06 & Todas as anteriores \\
\hline Metodologia I (Espanhol) & DLE & 0402067-1 & 60 & 04 & 30 & 01 & 90 & 05 & \\
\hline TOTAL & & & 300 & 20 & 150 & 05 & 450 & 25 & \\
\hline
\end{tabular}

\begin{tabular}{|c|c|c|c|c|c|c|c|c|c|}
\hline DISCIPLINAS & & & A & Teaticen & Extra classe & Tollo & . & That & \\
\hline Lingua Espanhola VI & DLE & $0402047-1$ & 60 & 04 & . & - & 60 & 04 & $0402047-1$ \\
\hline Literatura Espanhola III & DLE & $0402057-1$ & 30 & 02 & - & - & 30 & 02 & $0402012-10402013-1$ \\
\hline Lit. Hispano-americana II & DLE & 0402056-1 & 30 & 02 & - & - & 30 & 02 & 0402012-1 040202013-1 \\
\hline Prática de Ensino II (Espanhol) & DLE & $0402076-1$ & 30 & 02 & 120 & 04 & 150 & 06 & $0402075-1$ \\
\hline Sem. de Monografia I (Espanhol) & DLE & $0402079-1$ & 30 & 02 & 60 & 02 & 90 & 04 & 040207 \\
\hline
\end{tabular}

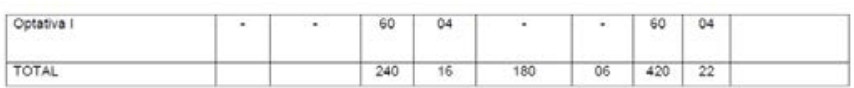

\begin{tabular}{|c|c|c|c|c|c|c|c|c|c|}
\hline \multicolumn{10}{|l|}{ Pentiono } \\
\hline DISCIPLINAS & Depto & Codigo & $\begin{array}{l}\text { Moral } \\
\text { Aulo }\end{array}$ & \begin{tabular}{|l} 
Credito \\
Teprice
\end{tabular} & \begin{tabular}{|l|} 
Mora Trab. \\
Extra Closse
\end{tabular} & $\begin{array}{l}\text { Crededno } \\
\text { Trab }\end{array}$ & C.M. & Cred & Pro-requisto \\
\hline Lit. Hispano-amencicana III & DLE & $0402060-1$ & 30 & 02 & $\cdot$ & . & 30 & 02 & O402013-1 \\
\hline Sem do Menografia II (Espantiofi) & OLE & $0402080-1$ & 30 & 02 & 90 & 03 & 120 & 05 & Trosis as antencer \\
\hline Optativa || & . & . & 60 & 04 & . & . & 60 & 04 & \\
\hline TOTAL & & & 120 & 08 & 90 & 03 & 210 & 11 & \\
\hline TOTAL GERAL & & & 2160 & 144 & 690 & 23 & 2050 & 168 & \\
\hline
\end{tabular}


Anejo 2B - Plan de estudios $1^{\mathrm{a}}$ reformulación 2003 - IES-2 (1/2)
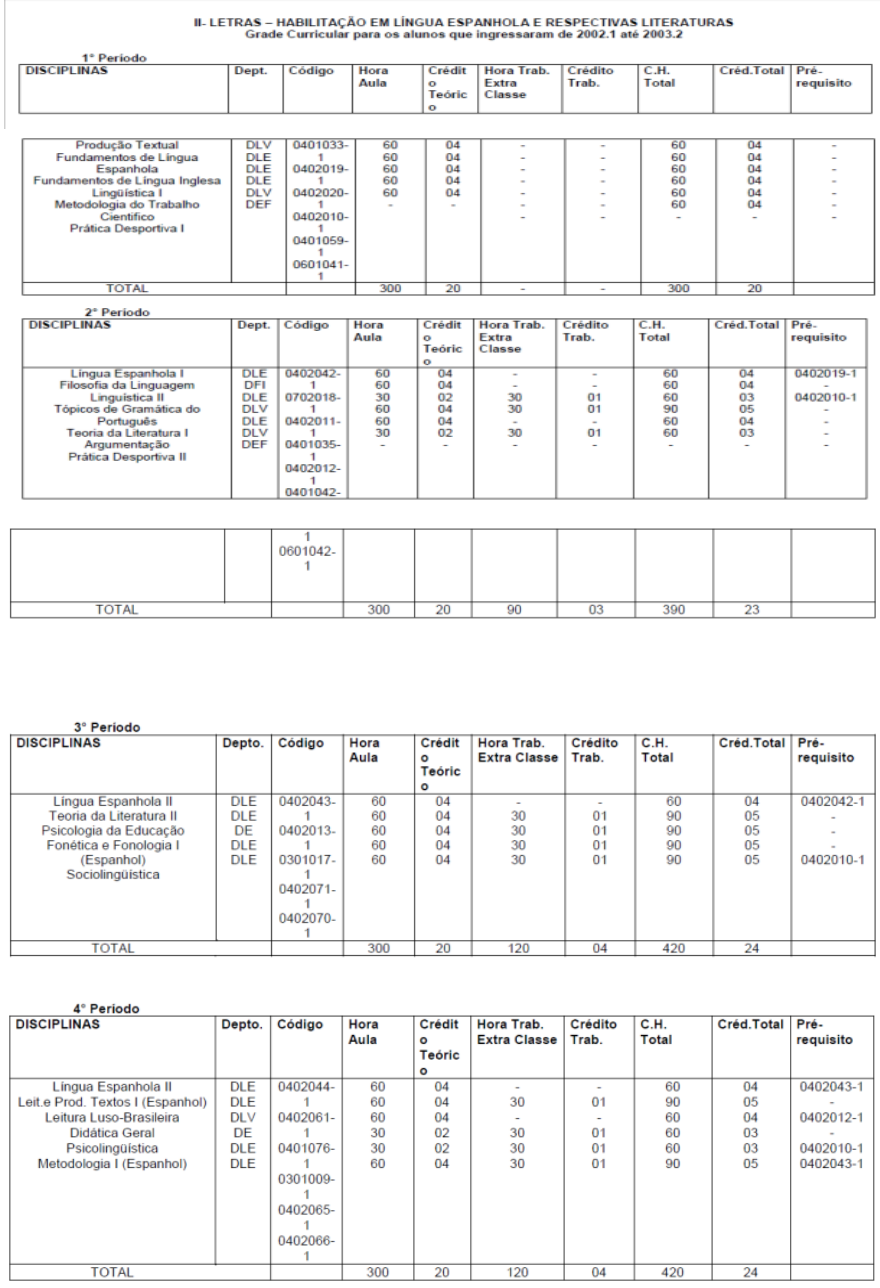

\begin{tabular}{|c|c|c|c|c|c|c|c|c|c|}
\hline \begin{tabular}{|l}
$5^{6}$ Periodo \\
DISCIPLINAS
\end{tabular} & \begin{tabular}{|l} 
Depto. \\
\end{tabular} & Código & \begin{tabular}{|l} 
Hora \\
Aula
\end{tabular} & $\begin{array}{l}\text { Crédit } \\
\text { óóric }\end{array}$ & \begin{tabular}{|l}
$\begin{array}{l}\text { Hora Trab. } \\
\text { Extra Classe }\end{array}$ \\
\end{tabular} & \begin{tabular}{|l|} 
Crradito \\
Trab.
\end{tabular} & \begin{tabular}{|l} 
C.H. \\
Total
\end{tabular} & \begin{tabular}{|c|} 
Créd.Total \\
\end{tabular} & \begin{tabular}{|l|}
$\begin{array}{l}\text { Pré. } \\
\text { requisito }\end{array}$ \\
\end{tabular} \\
\hline $\begin{array}{c}\text { Lingua Espanhola IV } \\
\text { Leite Prod. Textos II (Espanhol) } \\
\text { Literaturar Espanhola I } \\
\text { Estrut. E Func. oo Ensino } \\
\text { Básico } \\
\text { Optativa I. }\end{array}$ & $\begin{array}{l}\text { DLE } \\
\text { DLE } \\
\text { DLE } \\
D E \\
D L E \\
D L E \\
D L E\end{array}$ & $\begin{array}{c}0402045- \\
1 \\
0402062- \\
1 \\
0402055- \\
1\end{array}$ & $\begin{array}{l}60 \\
60 \\
60 \\
30 \\
60 \\
30\end{array}$ & $\begin{array}{l}04 \\
04 \\
04 \\
02 \\
04 \\
02\end{array}$ & $\begin{array}{l}30 \\
30\end{array}$ & $\begin{array}{l}1 \\
01 \\
01 \\
01 \\
01\end{array}$ & $\begin{array}{l}90 \\
90 \\
60 \\
60 \\
90 \\
30\end{array}$ & $\begin{array}{l}05 \\
05 \\
04 \\
03 \\
05 \\
02\end{array}$ & \begin{tabular}{|c|}
$0402044-1$ \\
$0402061-1$ \\
$0402013-1$ \\
$\vdots$ \\
- \\
$0402013-1$
\end{tabular} \\
\hline
\end{tabular}


...// Anejo 2B - Plan de estudios 1ª reformulación 2003 - IES-2 (2/2)
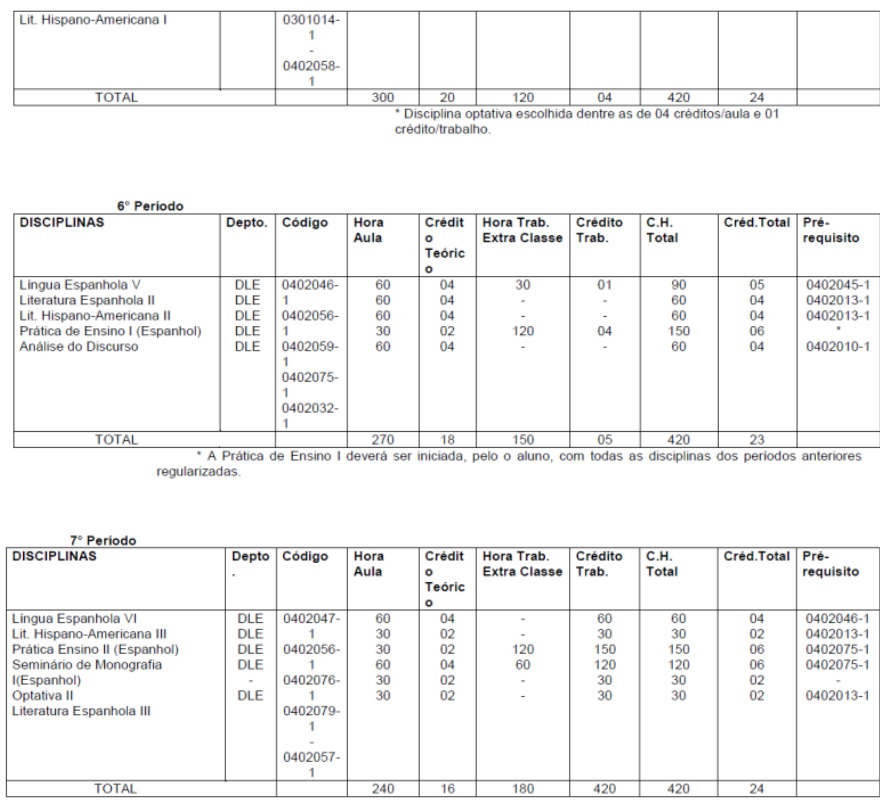

\begin{tabular}{|c|c|c|c|c|c|c|c|c|c|}
\hline $\begin{array}{l}\varepsilon^{2} \text { Period } \\
\text { DISCIPLAS }\end{array}$ & \begin{tabular}{|l|l|} 
Depto. & \\
\end{tabular} & Codigo & \begin{tabular}{|l} 
Hora \\
Aula
\end{tabular} & \begin{tabular}{|l} 
crodith \\
oroutlc
\end{tabular} & \begin{tabular}{|l|} 
Hora Trab \\
Extra Classe
\end{tabular} & $\begin{array}{l}\text { Credito }_{\text {Trab. }} \\
\text { Tre }\end{array}$ & $\mid \begin{array}{c}\text { Total } \\
\text { Total }\end{array}$ & Crod.Total & \begin{tabular}{|l}
$\begin{array}{l}\text { Pre- } \\
\text { requisito }\end{array}$ \\
\end{tabular} \\
\hline 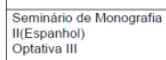 & DLE & $\begin{array}{c}0402080- \\
1\end{array}$ & $\begin{array}{l}30 \\
60 \\
60\end{array}$ & $\begin{array}{l}02 \\
04 \\
04\end{array}$ & 90 & 03 & $\begin{array}{l}120 \\
60\end{array}$ & $\begin{array}{l}055 \\
04\end{array}$ & 040202079-1 \\
\hline $\begin{array}{c}\text { TOTAL } \\
\text { TOTAL GERAL }\end{array}$ & & & $\frac{90}{2100}$ & $\frac{06}{140}$ & $\begin{array}{l}90 \\
870 \\
\end{array}$ & $\begin{array}{l}03 \\
29\end{array}$ & $\begin{array}{l}180 \\
2.970 \\
\end{array}$ & $\begin{array}{l}\frac{09}{169} \\
169\end{array}$ & \\
\hline
\end{tabular}


Anejo 2C - Plan de estudios en Vigor 2015 - IES-2 (1/2)

7. MATRIZ CURRICULAR

Os composentes curriculares que compsem o Curriculo Pleso do Carso de Letras Lingas Espanbola e respectivas linerataras eståo ditrnbaidas pelos 08 (oito) semestres letivos, considerando uma hierarouia de conhecimentos térico-príticos secessários à formaçăo dos futuros profetsores de Lingua Espanhola e Literaturas de Lingua Espanhola

\begin{tabular}{|c|c|}
\hline 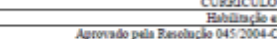 & 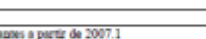 \\
\hline CrEDITOS:AULUS: 182 crodin. & CH TOTAL: 3.3502 \\
\hline CREDTrOS TRAB: As ates mith. & CH OBREGTORLA: 290 \\
\hline 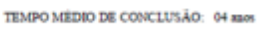 & CB Optatri: $190 \%$ \\
\hline 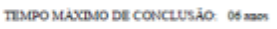 & 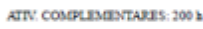 \\
\hline
\end{tabular}

\begin{tabular}{|c|c|c|c|c|c|c|c|c|c|}
\hline \multicolumn{10}{|c|}{ VADAERO DERTODO } \\
\hline $\begin{array}{l}\text { Canposonte } \\
\text { Comscrulut }\end{array}$ & $D e$. & costiso & H nida & $\begin{array}{l}\text { Crid } \\
\text { Tewasco }\end{array}$ & $\begin{array}{l}\text { Hers Inth } \\
\text { Extaclasue }\end{array}$ & cried & 空视 & Sembell & $\frac{\text { hit }}{\text { Bate }}$ \\
\hline hoduplo Tensal & DEv & 0401033.1 & $\infty 0$ & 04 & & & 60 & os & \\
\hline 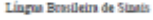 & $\mathrm{Dtw}$ & 0401009-1 & $\infty$ & 04 & * & . & 60 & or & . \\
\hline 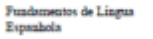 & DLS & 04020019-4 & $\infty 0$ & 04 & - & - & 60 & at & - \\
\hline 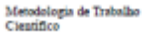 & 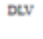 & $0401099-1$ & $\$ 0$ & 04 & - & - & 60 & at & - \\
\hline Lampistocat & $D C E$ & 0402000-1 & $\$ 0$ & ot & & & 60 & of & \\
\hline TOTA2 & & & 300 & 20 & . & - & 200 & 20 & - \\
\hline
\end{tabular}
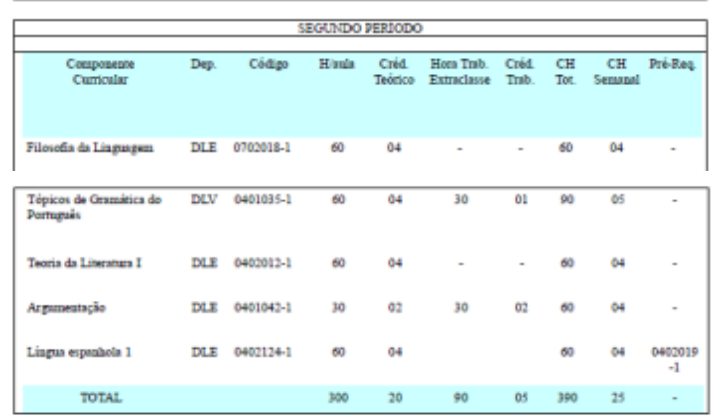
$30 \quad 20$

\begin{tabular}{|c|c|c|c|c|c|c|c|c|c|}
\hline 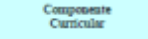 & Dep & $\cos \theta 0$ & Heds & $\begin{array}{l}\text { Cide } \\
\text { Townico }\end{array}$ & $\begin{array}{l}\text { Hern Tmb } \\
\text { Extadinse }\end{array}$ & crist & $\frac{\mathrm{Ch}}{\mathrm{Tra}}$ & senand & $\underset{R e q}{R e q}$ \\
\hline 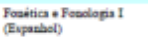 & DCE & 6es2113-1 & 60 & ot & 30 & 01 & 90 & $\infty$ & - \\
\hline Lingue Evpratis II & des & $0402223-1$ & $\infty$ & 04 & - & - & ${ }^{\circ 0}$ & of & $\underset{4-1}{0002212}$ \\
\hline socoblapulitica & DLE & 00023127.1 & $\infty$ & 04 & 30 & ต & 90 & os & $\operatorname{los}_{0.1}^{0.1201}$ \\
\hline 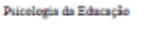 & $\mathrm{DE}$ & 03001017-1 & $\infty$ & 04 & 30 & 01 & 90 & as & - \\
\hline 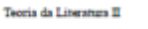 & DLS & 0452013-1 & 60 & ${ }^{04}$ & 30 & ol & so & os & - \\
\hline TOLAL & & & 300 & 20 & 130 & ou & 400 & 24 & . \\
\hline \multicolumn{10}{|c|}{ QUURTO PENODO } \\
\hline 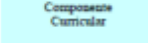 & Dop & Cotsopos & H & $\begin{array}{l}\text { Grid } \\
\text { Trétiono }\end{array}$ & 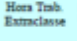 & Thas & 空 & semsol & hithens \\
\hline Lapu Eppobasus III & DLE & $0402123-1$ & $\infty$ & 04 & - & - & $\infty 0$ & 04 & $\underset{-1}{0402125}$ \\
\hline 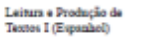 & DLE & $0402329-1$ & 60 & of & 30 & 01 & $\infty$ & os & - \\
\hline Laremen Laso-Brestern & $\mathrm{Dtv}$ & $0401079-1$ & $\infty$ & ot & - & & $\infty$ & of & $\begin{array}{c}0+102013 \\
-1\end{array}$ \\
\hline 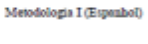 & DLE & $0402005-1$ & $\infty$ & of & 30 & or & 90 & os & $\begin{array}{c}0.002125 \\
-1\end{array}$ \\
\hline Dasibica Geral & DEv & 0301039.1 & ${ }^{30}$ & 02 & ${ }^{30}$ & 02 & $\infty$ & 04 & \\
\hline Dicolispribsea & DLE & $0402065-1$ & 30 & $\alpha^{2}$ & 30 & 02 & $\infty 0$ & 04 & 0400010 \\
\hline
\end{tabular}


Anejo 2C - Plan de estudios en vigor 2015 - IES-2 (2/2)
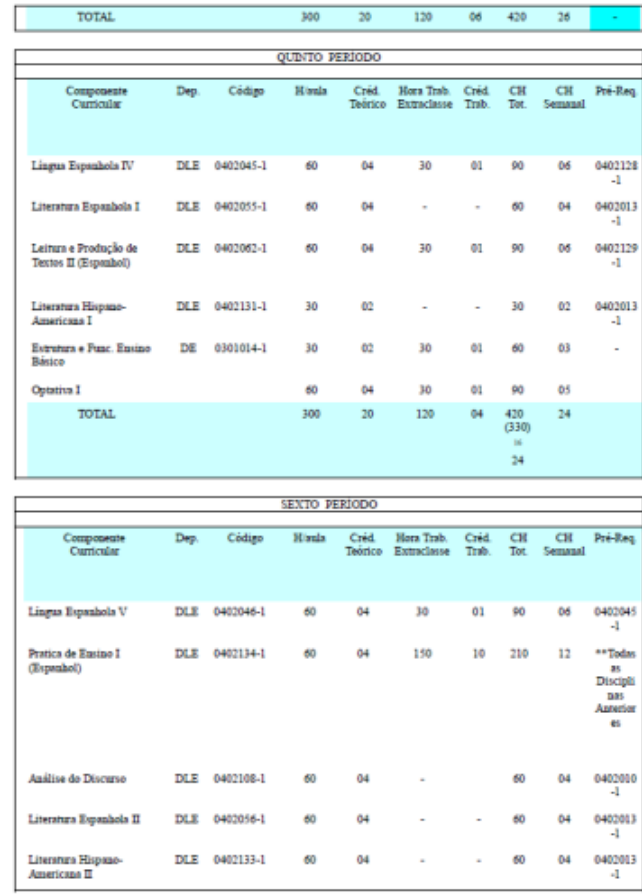

"Toad uns a quatitis
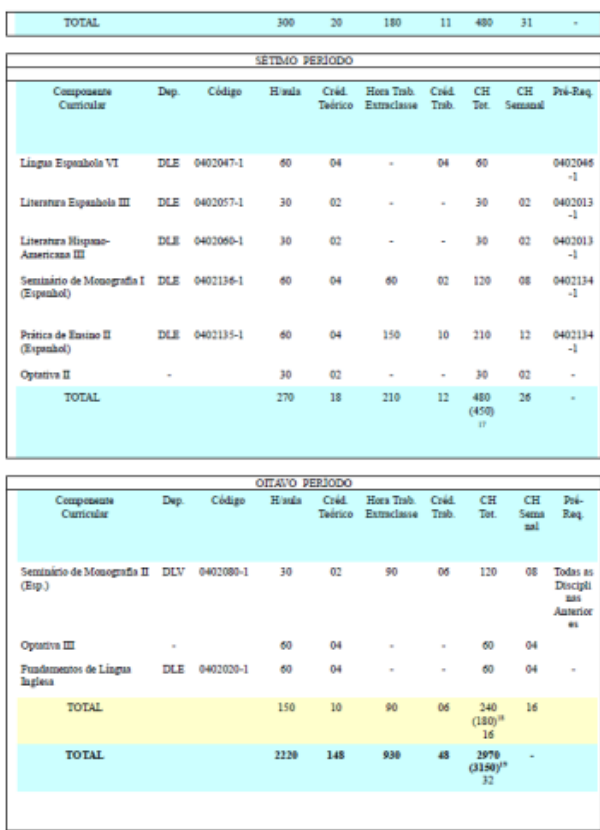

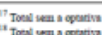

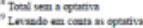


Anejo 2C - Plan de estudios en vigor - IES-2 con resumen (1/3)
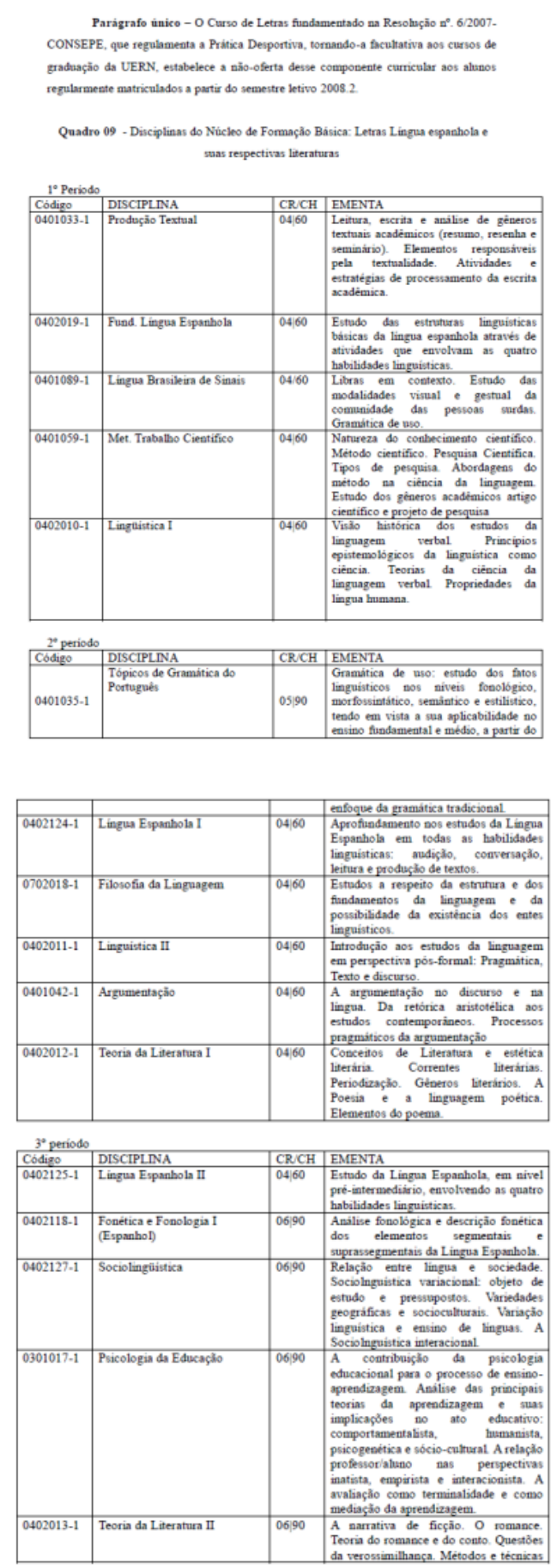
Anejo 2C - Plan de estudios en vigor - IES - 2 con resumen (2/3)
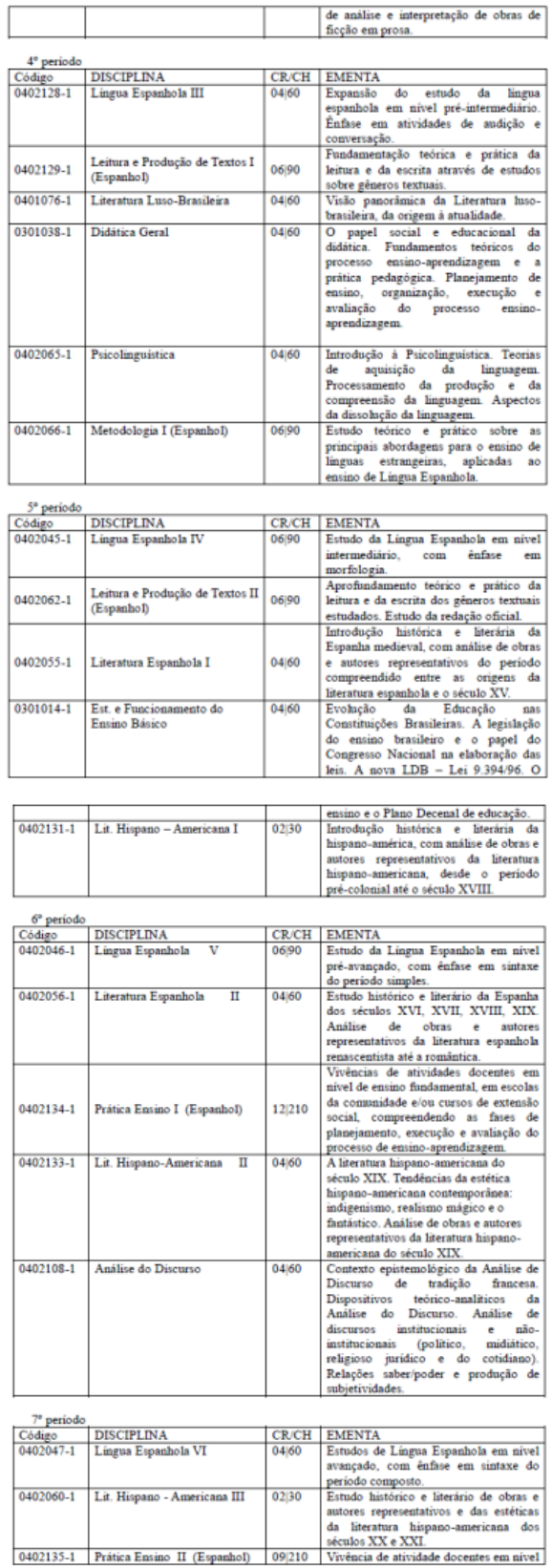
Anejo 2C - Plan de estudios en vigor - IES - 2 con resumen (3/3)

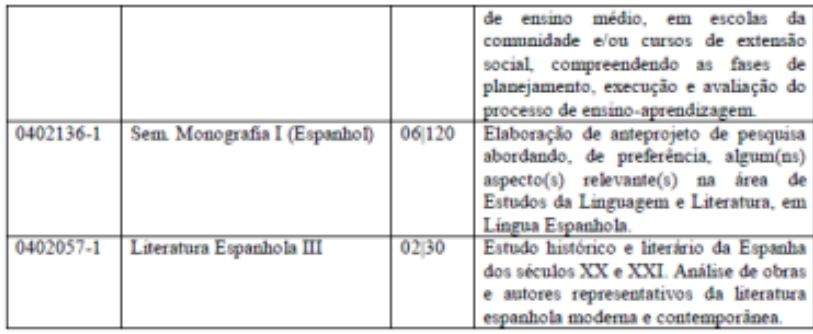

\begin{tabular}{|c|c|c|c|}
\hline Código & DISCIPLINA & $\mathrm{CR} / \mathrm{CH}$ & EMENTA \\
\hline $0402080-1$ & $\begin{array}{l}\text { Sem Monografia II } \\
\text { (Espanhol) }\end{array}$ & 08,120 & $\begin{array}{l}\text { Fundamentação teórica e metodológica } \\
\text { para embasar o processo de elaboraçăo } \\
\text { de monografia nas areas de estudos da } \\
\text { linguagem e literatura, em lingua } \\
\text { espanhola. Normas para a elaboraçãa de } \\
\text { traballho cientificos. }\end{array}$ \\
\hline $0402020-1$ & Fund. Lingua Inglesa & 0460 & $\begin{array}{l}\text { Estudo das estruturas léxico-gramaticais } \\
\text { da lingua inglesa em nivel elementar } \\
\text { atraves de atividades envolvendo as } \\
\text { quatro habilidades linguisticas. Estudo } \\
\text { de aspectos histónicos e sociocultrurais } \\
\text { de paises de lingua inglesa. }\end{array}$ \\
\hline
\end{tabular}

Quadro 2 - Optativas do Departamento de Letras Estrangeiras (Disciplinas comuns para os Curnos de Lingua espanhola e suas respectivas literaturas e Lingua Inglesa

\begin{tabular}{|c|c|c|c|}
\hline Código & DISCIPLINA & $\mathrm{CR} / \mathrm{CH}$ & EMENTA \\
\hline $0402021-1$ & Civilizaçẫo Anglo-Americana & 30 & $\begin{array}{l}\text { Estudo da formaçăio histónico-cultural } \\
\text { das sociedades britinica e norte- } \\
\text { americana. }\end{array}$ \\
\hline $0402074-1$ & \begin{tabular}{|l|} 
Civilização \\
Americana
\end{tabular} & 30 & $\begin{array}{l}\text { Estudo da formaçăo histónico-cultural } \\
\text { da sociedade espanhola. Os espanbois } \\
\text { ma América. }\end{array}$ \\
\hline $0402099-1$ & $\begin{array}{l}\text { Ensimo de Linguas e } \\
\text { Imperialismo Cultural }\end{array}$ & 60 & $\begin{array}{l}\text { Conceito de cultura. Lingua, sdeologia e } \\
\text { identidade cultural. Alienaçio } \\
\text { aculturaç̧⿸丆口 }\end{array}$ \\
\hline 0402093-1 & $\begin{array}{l}\text { Fonética e Fonologin II } \\
\text { (Inglés) }\end{array}$ & 30 & $\begin{array}{l}\text { Aprofundamento dos estudos iniciados } \\
\text { em Fonetica e Fonologia I. }\end{array}$ \\
\hline $0402165-1$ & $\begin{array}{l}\text { Interpretaçilo } \\
\text { (EspanholPortugués) }\end{array}$ & 30 & $\begin{array}{l}\text { Teoria da interpretaçàlo. Pritica de } \\
\text { interpretaçâo de dialogos e de situarỏes }\end{array}$ \\
\hline
\end{tabular}




\section{ANEJO 3: DOCUMENTOS ACADÉMICOS IES-3}

- Anejo 3A - Plan de estudios original - 2006 - IES-3

- Anejo 3B - Plan de estudios 1ª reformulación 2012 - IES-3

- Anejo 3C - Plan de estudios $2^{\mathrm{a}}$ reformulación 2014- IES-3

- Anejo 3D - Asignaturas electivas - IES-3

- Anejo 3E - Programa asignatura funcionalista - IES-3 


\section{Anejo 3A - Plan de estudios original - 2006 - IES-3}

+

Quadro 1 - Matriz Curricular do Cureo de Licenclatura em Espanhol

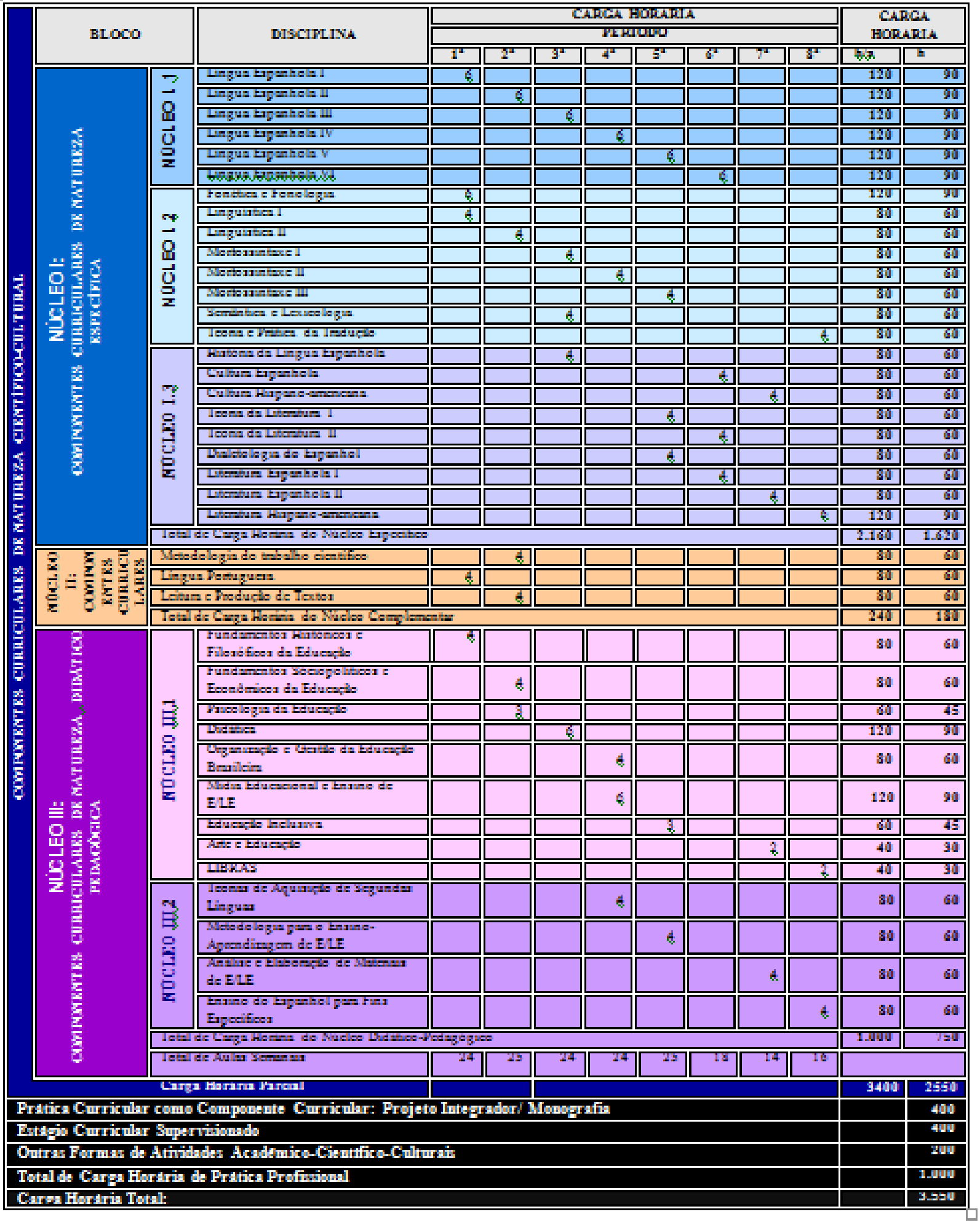




\subsubsection{Disciplinas e Cargas Horárias por Período Letivo}

Quadro 2 - Disciplinas e carga horária do $1^{\circ}$ período

\begin{tabular}{|l|c|c|c|}
\hline \multicolumn{3}{|c|}{$\mathbf{1}^{\mathbf{0}}$ Período } \\
\multicolumn{1}{|c|}{ Disciplina } & $\mathbf{C H} / \mathbf{s e m}$ & \multicolumn{2}{c|}{ CH Total } \\
\cline { 3 - 5 } & $\mathbf{( h / a )}$ & $\mathbf{h} / \mathbf{a}$ & $\mathbf{h}$ \\
\hline 1. Língua Espanhola I & 06 & 120 & 90 \\
\hline 2. Fonética e Fonologia & 06 & 120 & 90 \\
\hline 3. Lingüística I & 04 & 80 & 60 \\
\hline 4. Língua Portuguesa & 04 & 80 & 60 \\
\hline 5. Fundamentos Históricos Filosóficos da Educação & 04 & 80 & 60 \\
\hline \multicolumn{1}{|c|}{ Carga horária parcial } & 24 & 480 & 360 \\
\hline
\end{tabular}

Quadro 3 - Disciplinas e carga horária do $2^{\circ}$ período letivo

\begin{tabular}{|c|c|c|c|}
\hline \multicolumn{4}{|l|}{$2^{\circ}$ Período } \\
\hline \multirow[t]{2}{*}{ Disciplina } & \multirow{2}{*}{$\begin{array}{c}\text { CH/sem } \\
\text { (h/a) }\end{array}$} & \multicolumn{2}{|c|}{ CH Total } \\
\hline & & h/a & $\mathbf{h}$ \\
\hline 1. Língua Espanhola II & 06 & 120 & 90 \\
\hline 2. Lingüística II & 04 & 80 & 60 \\
\hline 3. Leitura e Produção de Textos & 04 & 80 & 60 \\
\hline 4. Fundamentos Sóciopolíticos e Econômicos da Educação & 04 & 80 & 60 \\
\hline 5. Psicologia da Educação & 03 & 60 & 45 \\
\hline 6. Metodologia do Trabalho Científico & 04 & 80 & 60 \\
\hline $\begin{array}{c}\text { Carga horária parcial } \\
\end{array}$ & 25 & 500 & 375 \\
\hline Prática como Componente Curricular: Projeto Integrador & 02 & 40 & \\
\hline
\end{tabular}

Quadro 4 - Disciplinas e carga horária do $3^{\circ}$ período letivo

\begin{tabular}{|c|c|c|c|}
\hline \multicolumn{4}{|l|}{$3^{\circ}$ Período } \\
\hline \multirow{2}{*}{ Disciplina } & \multirow{2}{*}{$\mathrm{CH} / \mathrm{sem}$ (h/a) } & \multicolumn{2}{|c|}{ CH Total } \\
\hline & & h/a & $\mathbf{h}$ \\
\hline 1. Língua Espanhola III & 06 & 120 & 90 \\
\hline 2. Morfossintaxe I & 04 & 80 & 60 \\
\hline 3. Semântica e Lexicologia & 04 & 80 & 60 \\
\hline 4. História da Língua Espanhola & 04 & 80 & 60 \\
\hline 5. Didática & 06 & 120 & 90 \\
\hline Carga horária parcial & 24 & 480 & 360 \\
\hline Prática como Componente Curricular: Projeto Integrador & 02 & 40 & \\
\hline
\end{tabular}

Quadro 5 - Disciplinas e carga horária do $4^{\circ}$ período letivo

\begin{tabular}{|l|c|c|c|}
\hline \multicolumn{1}{|c|}{$\mathbf{4}^{\circ}$ Período } \\
\hline \multicolumn{1}{|c|}{ Disciplina } & \multirow{2}{*}{ CH/sem(h/a) } & \multicolumn{2}{c|}{ CH Total } \\
\cline { 3 - 5 } & & h/a & h \\
\hline 1. Língua Espanhola IV & 06 & 120 & 90 \\
\hline 2. Morfossintaxe II & 04 & 80 & 60 \\
\hline 3. Organização e Gestão da Educação Brasileira & 04 & 80 & 60 \\
\hline 4. Mídia Educacional e Ensino do E/LE & 06 & 120 & 90 \\
\hline
\end{tabular}




\begin{tabular}{|c|c|c|c|}
\hline 5. Teorias de Aquisição de Segundas Línguas & 04 & 80 & 60 \\
\hline Carga horária parcial & 24 & 480 & 360 \\
\hline Prática como Componente Curricular: Projeto Integrador & 02 & 40 & \\
\hline
\end{tabular}

Quadro 6 - Disciplinas e carga horária do $5^{\circ}$ período letivo

\begin{tabular}{|c|c|c|c|}
\hline \multicolumn{4}{|l|}{$5^{\circ}$ Período } \\
\hline \multirow{2}{*}{ Disciplina } & \multirow{2}{*}{$\mathrm{CH} / \operatorname{sem}(\mathrm{h} / \mathrm{a})$} & \multicolumn{2}{|c|}{ CH Total } \\
\hline & & h/a & $\mathbf{h}$ \\
\hline 1. Língua Espanhola V & 06 & 120 & 90 \\
\hline 2. Morfossintaxe III & 04 & 80 & 60 \\
\hline 3.Teoria da Literatura I & 04 & 80 & 60 \\
\hline 4. Dialetologia do Espanhol & 04 & 80 & 60 \\
\hline 5. Educação Inclusiva & 03 & 60 & 45 \\
\hline 6. Metodologia do Ensino-Aprendizagem do E/LE & 04 & 80 & 60 \\
\hline Carga horária parcial & 25 & 500 & 375 \\
\hline Prática como Componente Curricular: Projeto Integrador & 02 & 40 & \\
\hline Estágio Curricular Supervisionado & \multicolumn{3}{|c|}{100 horas } \\
\hline
\end{tabular}

Quadro 7 - Disciplinas e carga horária do $6^{\circ}$ período letivo

\begin{tabular}{|l|c|c|c|}
\hline \multicolumn{3}{|c|}{$\mathbf{6}^{\mathbf{0}}$ Período } \\
\hline \multicolumn{1}{|c|}{ Disciplina } & \multirow{2}{*}{ CH/sem(h/a) } & \multicolumn{3}{c|}{ CH Total } \\
\cline { 3 - 5 } & & $\mathbf{h} / \mathbf{a}$ & $\mathbf{h}$ \\
\hline 1. Língua Espanhola VI & 06 & 120 & 90 \\
\hline 2. Cultura espanhola & 04 & 80 & 60 \\
\hline 3. Teoria da Literatura II & 04 & 80 & 60 \\
\hline 4. Literatura Espanhola I & 04 & 80 & 60 \\
\hline \multicolumn{1}{|c|}{ Carga horária parcial } & 18 & 360 & 270 \\
\hline Prática como Componente Curricular: Projeto Integrador/Monografia & 04 & 80 & \multicolumn{3}{|c|}{100 horas } \\
\hline \multicolumn{2}{|c|}{} \\
\hline
\end{tabular}

Quadro 8 - Disciplinas e carga horária do $7^{\circ}$ período letivo

\begin{tabular}{|c|c|c|c|}
\hline \multicolumn{4}{|l|}{$7^{\circ}$ Período } \\
\hline \multirow[t]{2}{*}{ Disciplina } & \multirow[t]{2}{*}{$\mathrm{CH} / \mathrm{sem}(\mathrm{h} / \mathrm{a})$} & \multicolumn{2}{|c|}{ CH Total } \\
\hline & & h/a & $\mathbf{h}$ \\
\hline 1. Cultura Hispano-americana & 04 & 80 & 60 \\
\hline 2. Literatura Espanhola II & 04 & 80 & 60 \\
\hline 3. Arte e Educação & 02 & 40 & 30 \\
\hline 4. Análise e Elaboração de materiais de E/LE & 04 & 80 & 60 \\
\hline Carga horária parcial & 14 & 280 & 210 \\
\hline Prática como Componente Curricular: Monografia & 04 & 80 & \\
\hline Estágio Curricular Supervisionado & \multicolumn{3}{|c|}{100 horas } \\
\hline Atividades Acadêmico-científico-culturais & \multicolumn{3}{|c|}{100 horas $^{*}$} \\
\hline
\end{tabular}


Quadro 9 - Disciplinas e carga horária do $8^{\circ}$ período letivo

\begin{tabular}{|l|c|c|c|}
\hline \multicolumn{1}{|c|}{$\mathbf{8}^{\circ}$ Período } & \multicolumn{2}{c|}{ CH Total } \\
\cline { 2 - 4 } & CH/sem(h/a) & h/a & h \\
\hline 1. Teoria e Prática da Tradução & & 80 & 60 \\
\hline 2. Literatura Hispano-americana & 04 & 120 & 90 \\
\hline 3. Ensino do Espanhol para Fins Específicos & 06 & 80 & 60 \\
\hline 4. LIBRAS Carga horária parcial & 04 & 40 & 30 \\
\hline \multicolumn{1}{|c|}{ Estágio Curricular Supervisionado } & 02 & 280 & 240 \\
\hline Prática como Componente Curricular: Monografia & 14 & $\mathbf{8 0}$ & \\
\hline Atividades Acadêmico-científico-culturais & 04 & 100 horas \\
\hline
\end{tabular}

${ }^{\star}$ ) Acontecem ao longo da formação docente 
Anejo 3B - Plan de estudios $1^{\text {a }}$ reformulación 2012- IES-3

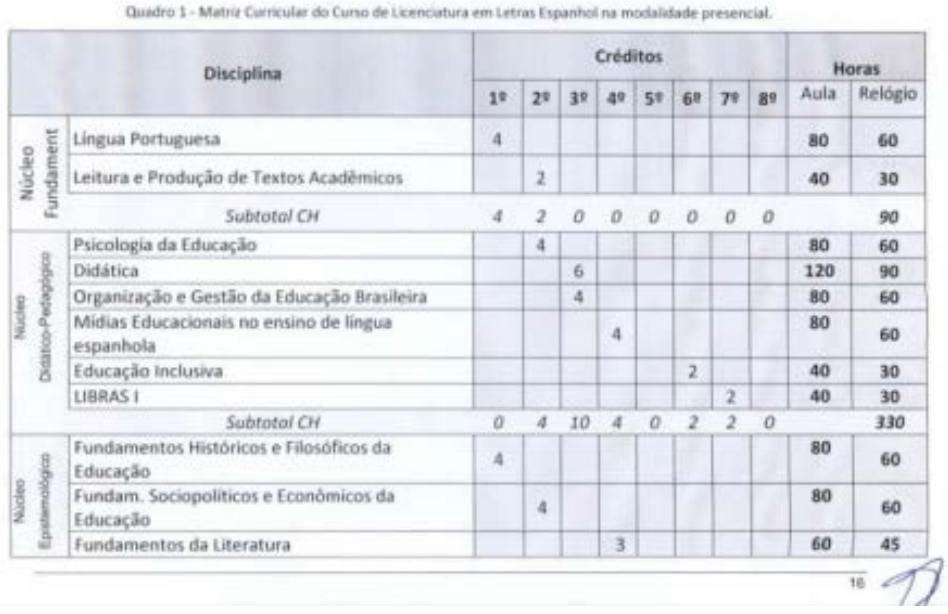

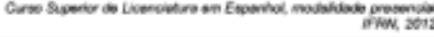

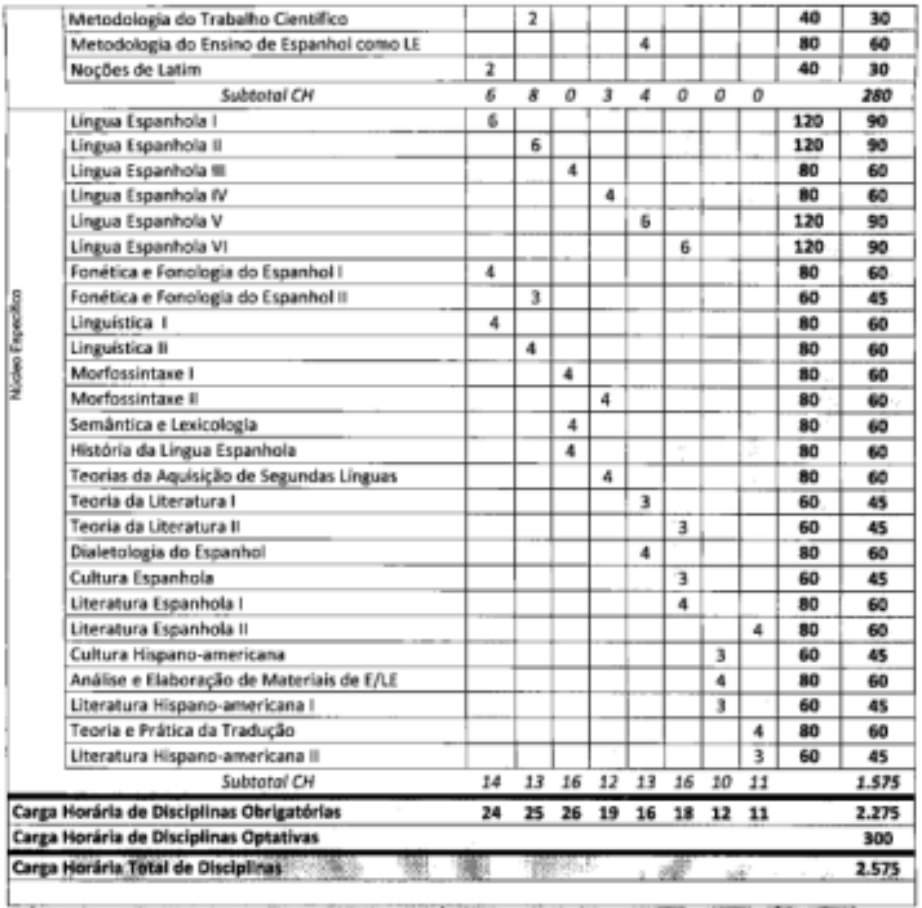

\begin{tabular}{|c|c|c|c|c|c|c|c|c|c|}
\hline \multirow{2}{*}{ E. Componente Curricular } & \multicolumn{8}{|c|}{ Carga Horária por Semestre } & \multirow{2}{*}{ Horgs } \\
\hline & 10 & 20 & 3" & 40 & 5. & 60 & 70 & 3 & \\
\hline Orientachio de Projetos integradores & & & & 15 & 15 & & & & 30 \\
\hline Orientaglo de Pesquins & & & & & & & 15 & 15 & 30 \\
\hline Orientes ko de fstigio Docente & & & & & 15 & 15 & 15 & 15 & 60 \\
\hline CH Total de Semindirios curniculares & 0 & 0 & 0 & 15 & 30 & 15 & 30 & 30 & 120 \\
\hline Projetos intey abores & & & & 80 & 80 & & & & 160 \\
\hline Wintica de Metodelofia do Envino de Evapantol & & & & & 60 & so & & & 120 \\
\hline Trabaltha de Candinsio de Curse & & & & & & & 60 & 60 & 120 \\
\hline Atividades Acadomico-Clentifico-Culturais & & & & & & & & & 200 \\
\hline Fstagio Docente Supervisionado & & & & & 100 & 100 & 100 & 100 & 400 \\
\hline CH Total de Prablea Profissional & 0 & 0 & 0 & 80 & 240 & 160 & 160 & 160 & 1.000 \\
\hline
\end{tabular}

CH Total de Prditica Profissional 
Anejo 3C - Plan de estudios $2^{\mathrm{a}}$ reformulación 2014- IES-3 (1/2)

Quadro 1 - Matrir curricular do Curvo Superior de Licenciatura em Latras - fspanhel na modalidade presencial

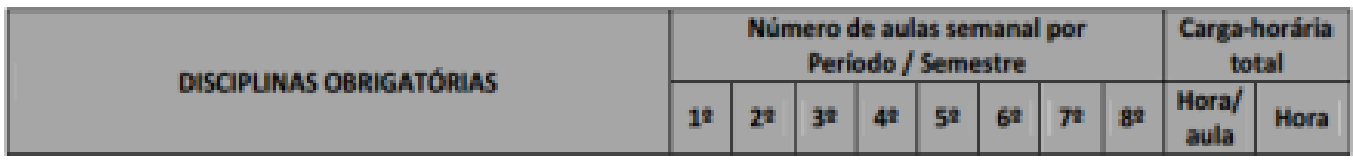

\begin{tabular}{|l|c|c|c|c|c|c|c|c|c|c|}
\hline Núcleo Fundamental & 4 & & & & & & & & 80 & $\mathbf{6 0}$ \\
\hline Lingua Portuguesa & & 4 & & & & & & & 80 & 60 \\
\hline Leitura e Produçå̀o de Textos Acadêmicos & 4 & 2 & 0 & 0 & 0 & 0 & 0 & 0 & 160 & 120 \\
\hline Subtotal de carga-horária do núcleo fundamental &
\end{tabular}

\begin{tabular}{|c|c|c|c|c|c|c|c|c|c|c|}
\hline \multicolumn{11}{|l|}{ Núcleo Didático-Pedagógico } \\
\hline Psicolopia da Educaçăo & & 4 & & & & & & & 80 & 60 \\
\hline Didstica & & & 6 & & & & & & 120 & 90 \\
\hline Organização e Gestão da Educação Brasileira & & & & 4 & & & & & 80 & 60 \\
\hline Midias Educacionais & & & & & 4 & & & & 80 & 60 \\
\hline Educaçăo Inclusiva & & & & & & 4 & & & 80 & 60 \\
\hline UIBRAS I & & & & & & 4 & & & 80 & 60 \\
\hline Subtotal de carga-horária do núcleo didático-pedagógico & 0 & 4 & 6 & 4 & 4 & 2 & 2 & 0 & 520 & 390 \\
\hline
\end{tabular}

\begin{tabular}{|l|l|c|c|c|c|c|c|c|c|c|c|}
\hline Núcleo Epistemológico & & & & \\
\hline Fundamentos Históricos e Fllosóficos da Educaçăo & 4 & & & & & & & & 60 \\
\hline Fundamentos Sociopoliticos e Económicos da Educação & & & 4 & & & & & & 80 & 60 \\
\hline Metodologia do Trabalho Cientifico & & 4 & & & & & & & 80 & 60 \\
\hline Subtotal de carga-horária do núcleo epistemológico & 4 & 4 & 4 & 0 & 0 & 0 & 0 & 0 & $\mathbf{2 4 0}$ & 180 \\
\hline
\end{tabular}

\begin{tabular}{|c|c|c|c|c|c|c|c|c|c|c|}
\hline Núcleo Especifico & & & & & & & & & & \\
\hline Lingua Espanhola I & 4 & & & & & & & & 80 & 60 \\
\hline Lingua Espanhola II & & 4 & & & & & & & 80 & 60 \\
\hline Lingua Espanhola III & & & 4 & & & & & & 80 & 60 \\
\hline Língua Espanhola N & & & & 4 & & & & & 80 & 60 \\
\hline Leitura e Produção de Textos em E/LE & & & & & 4 & & & & 80 & 60 \\
\hline Práticas Orais e Auditivas em E/LE & & & & & & 4 & & & 80 & 60 \\
\hline Linguística I & 4 & & & & & & & & 80 & 60 \\
\hline Linguistica II & & 4 & & & & & & & 80 & 60 \\
\hline Fonética e Fonologia da Língua Espanhola I & & 4 & & & & & & & 80 & 60 \\
\hline Fonética e Fonologia da Língua Espanhola II & & & 4 & & & & & & 80 & 60 \\
\hline Morfologia da Lingua Espanhola & & & & 4 & & & & & 80 & 60 \\
\hline Sintaxe da Lingua Espanhola I & & & & & 4 & & & & 80 & 60 \\
\hline Sociolinguistica da Lingua Espanhola & & & & & 4 & & & & 80 & 60 \\
\hline Lingua Latina & & & & & & 4 & & & 80 & 60 \\
\hline Filologia Hispănica & & & & & & & 4 & & 80 & 60 \\
\hline Fundamentos da Literatura Ocidental & 4 & & & & & & & & 80 & 60 \\
\hline Teoria da Literatura I & & & & 4 & & & & & 80 & 60 \\
\hline Teoria da Literatura II & & & & & 4 & & & & 80 & 60 \\
\hline Literatura Espanhola I & & & & & 4 & & & & 80 & 60 \\
\hline Literatura Espanhola II & & & & & & 4 & & & 80 & 60 \\
\hline Literatura Hispano-Americana I & & & & & & & 4 & & 80 & 60 \\
\hline Literatura Hispano-Americana II & & & & & & & & 2 & 40 & 30 \\
\hline Cultura Espanhola & & & 4 & & & & & & 80 & 60 \\
\hline Cultura Hispano-Americana & & & & 4 & & & & & 80 & 60 \\
\hline
\end{tabular}


Anejo 3C - Plan de estudios $2^{\mathrm{a}}$ reformulación 2014- IES-3 (2/2)

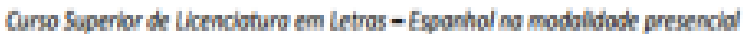
IFW . NOH

\begin{tabular}{|l|c|c|c|c|c|c|c|c|c|c|}
\hline Tcorias de Aquisiclo de Segundas Linguar & & & & & & 4 & & & 30 & 60 \\
\hline Metodolopia do Engino de E/E & & & & & & & 4 & & 80 & 60 \\
\hline Subtotal de carga-horária do nuteleo especifico & 12 & 12 & 12 & 16 & 20 & 16 & 12 & 2 & 2040 & 1530 \\
\hline
\end{tabular}

\begin{tabular}{|c|c|c|c|c|c|c|c|c|c|c|}
\hline \multirow{2}{*}{ DISCIPLINAS OPTATIVAS } & \multicolumn{8}{|c|}{$\begin{array}{l}\text { Número de aulas cemanal por } \\
\text { Periodo / Semestre }\end{array}$} & \multicolumn{2}{|c|}{$\begin{array}{l}\text { Cargahorairla } \\
\text { total }\end{array}$} \\
\hline & 18 & 2 & 3i & 48 & $5 n$ & 60 & 7 & 8 & $\begin{array}{c}\text { Horal } \\
\text { aula }\end{array}$ & Hora \\
\hline Subtatal de carga-horairia de disciplinas optativas & . & $=$ & 2 & . & 4 & 2 & 4 & 4 & 320 & 240 \\
\hline
\end{tabular}

\begin{tabular}{|l|l|l|l|l|l|l|l|l|l|l|}
\hline Total de carga-horatia de disciplinas & 20 & 24 & 22 & 20 & 22 & 24 & 12 & 2 & 32840 & 2460 \\
\hline
\end{tabular}

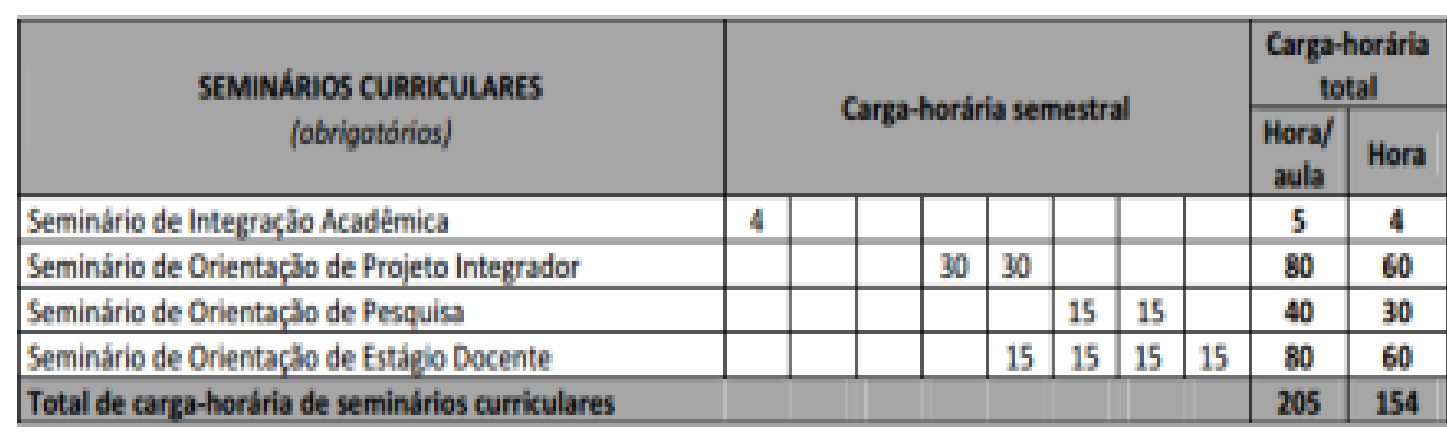

\begin{tabular}{|c|c|c|c|c|c|c|c|}
\hline \multirow{2}{*}{ PRÁTICA PROFISSIONAL } & \multirow{2}{*}{\multicolumn{5}{|c|}{ Grga-hordíla semestral }} & \multicolumn{2}{|c|}{$\begin{array}{c}\text { Carga-horatia } \\
\text { total }\end{array}$} \\
\hline & & & & & & $\begin{array}{c}\text { Horyl } \\
\text { aula }\end{array}$ & Hora \\
\hline \multicolumn{8}{|l|}{ Pritica como Componente Curnoular } \\
\hline Desenuvbimento de Proletos lnteradores & 80 & 80 & & & & 213 & 160 \\
\hline Atividades de Metodolotia do Ensino de E/LE & & 60 & 60 & & & 160 & 120 \\
\hline Desenvolimento de Pesquisa Acadénico-Gientifica & & & & 60 & 60 & 160 & 120 \\
\hline Âtwidades Acadêmico-Cientifico-Culturais & \multicolumn{5}{|c|}{200} & 267 & 200 \\
\hline Esthelo Curricular Sypervisionado (Estágo Docente) & & 100 & 100 & 100 & 100 & 533 & 400 \\
\hline Total de carga-hordiria de prática profissional & & & & & & 1.333 & 1.000 \\
\hline
\end{tabular}

TOTAL DECARCA-HORARIA DO CURSO

Obsenoçio: A hora-aula considerada possui 45 minutos. 
Anejo 3D - Asignaturas electivas - IES-3

\begin{tabular}{|c|c|}
\hline DISCIPLINAS OPTATIVAS & DISCIPLINA(S) PRÉ-REQUISITOS \\
\hline \multicolumn{2}{|l|}{ Núcleo Fundamental } \\
\hline Informática & --- \\
\hline \multicolumn{2}{|l|}{ Núcleo Didático-Pedagógico } \\
\hline Arte e Educação & $-\ldots$ \\
\hline Educação Ambiental & $-\cdots$ \\
\hline Fundamentos da Educação de Jovens e Adultos & Didática; Organização e Gestão da Educação Brasileira \\
\hline LIBRAS II & LIBRAS I \\
\hline Metodologia do Ensino a Distância & --- \\
\hline \multicolumn{2}{|l|}{ Núcleo Epistemológico } \\
\hline Filosofia da Linguagem & $-\cdots$ \\
\hline \multicolumn{2}{|l|}{ Núcleo Específico } \\
\hline Análise e Elaboração de Materiais de E/LE & Metodologia do Ensino de E/LE \\
\hline Cultura Hispano-Africana & Cultura Espanhola; Cultura Hispano-Americana I \\
\hline Didática do Texto Literário no Ensino de E/LE & Didática; Teoria da Narrativa \\
\hline Ensino de Espanhol para Fins Específicos & Metodologia do Ensino de E/LE \\
\hline Filologia Românica & Língua Latina \\
\hline Linguística III & Linguística II \\
\hline Multilinguismo no Mundo Hispânico & Sociolinguística da Língua Espanhola \\
\hline $\begin{array}{l}\text { Narrativas Contemporâneas em Língua } \\
\text { Espanhola }\end{array}$ & Literatura Espanhola II \\
\hline Ortografia da Língua Espanhola & $\begin{array}{ll}-- \\
\end{array}$ \\
\hline Sintaxe da Língua Espanhola II & Sintaxe da Língua Espanhola I \\
\hline Teoria e Prática da Tradução & Leitura e Produção de Textos em E/LE \\
\hline Variação Linguística e Ensino de Espanhol & Sociolinguística da Língua Espanhola \\
\hline
\end{tabular}

\begin{tabular}{|c|c|}
\hline SEMINÁRIOS CURRICULARES & DISCIPLINA(S) VINCULADAS \\
\hline Seminário de Integração Acadêmica & --- \\
\hline Seminário de Orientação de Projeto Integrador & --- \\
\hline Seminário de Orientação de Pesquisa & $--\cdot$ \\
\hline Seminário de Orientação de Estágio Docente & -.. \\
\hline
\end{tabular}




\section{Anejo 3E - Programa asignatura funcionalista - IES-3}

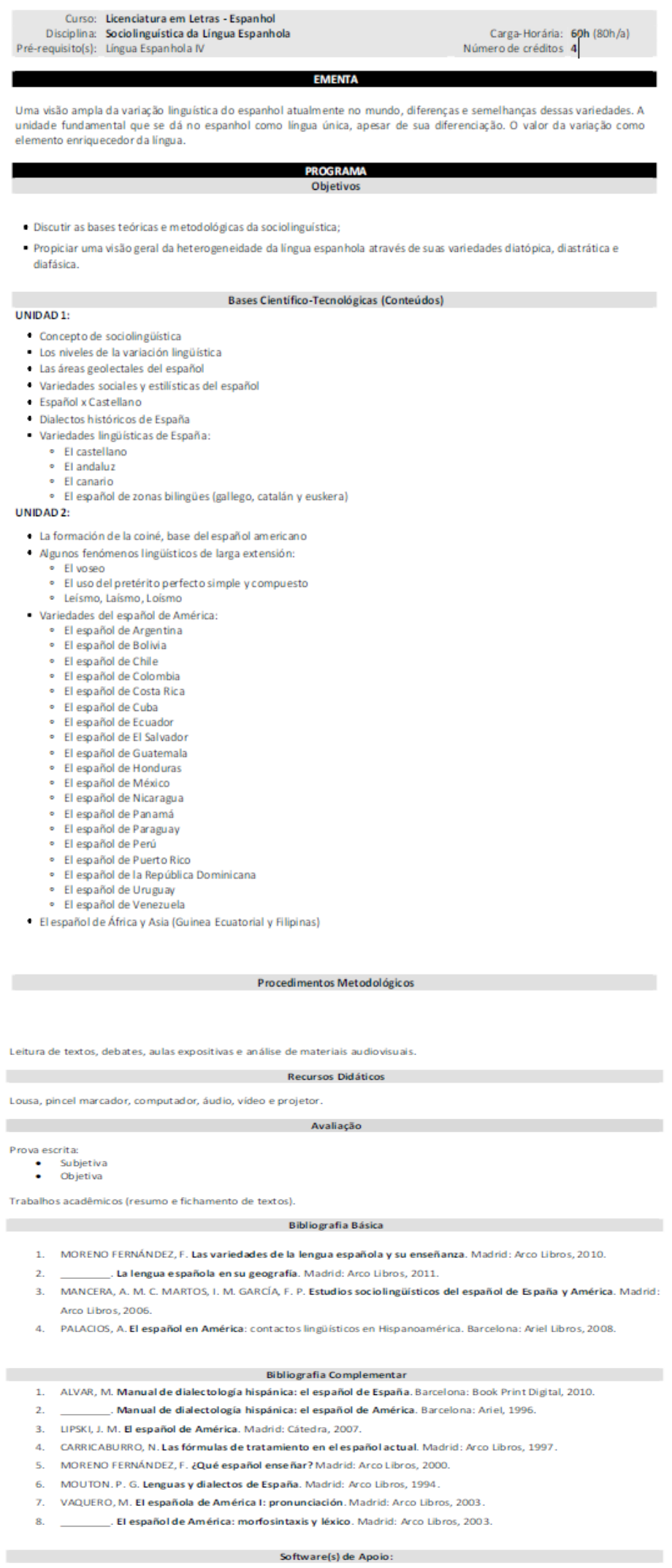


ANEJO 4: SCRIPT VÍDEO-CLASE MARCADORES DEL DISCURSO IES-3

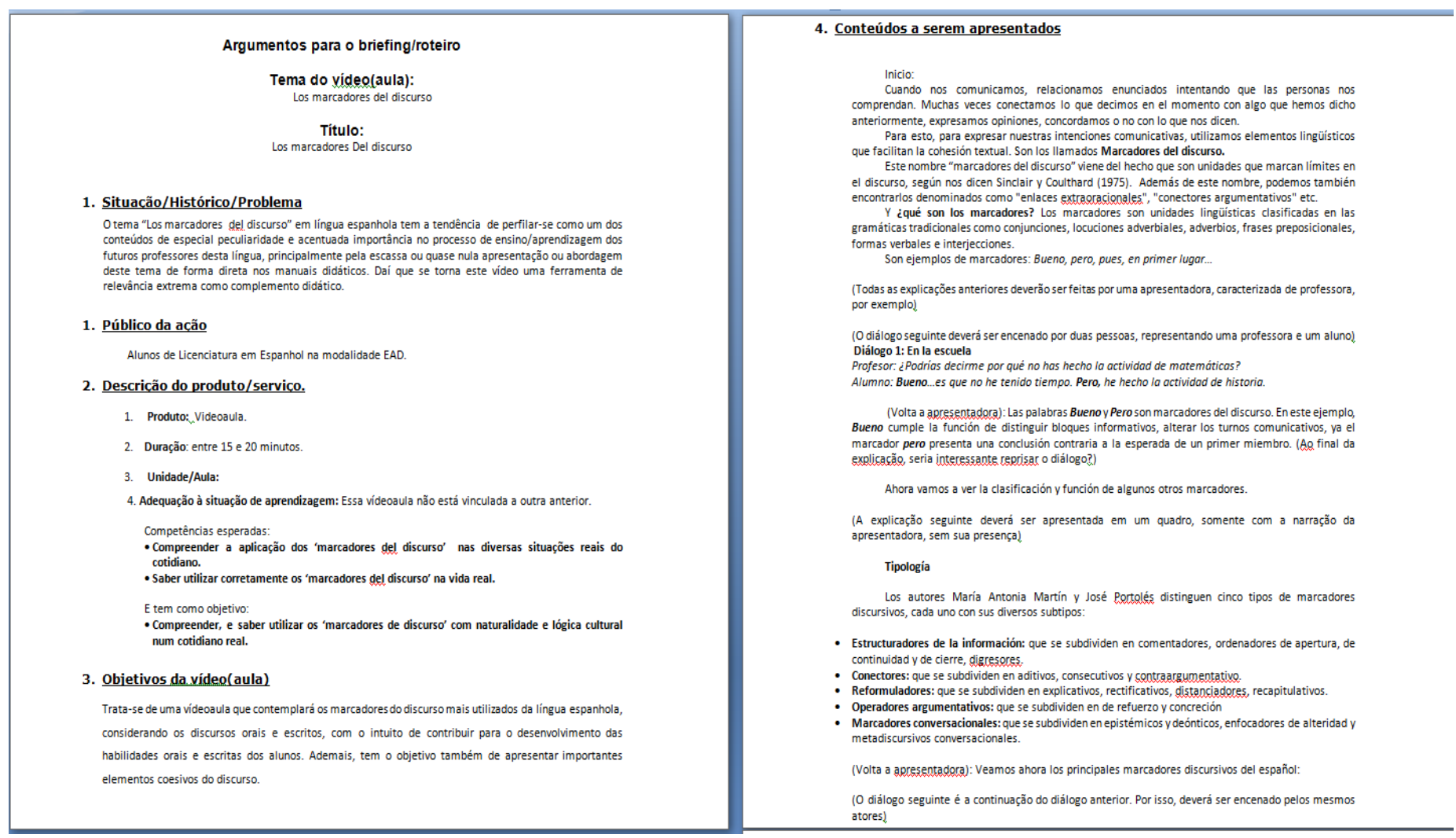

Diálogo 2: En la escuela
Profesora: En realidad, me interesaría más que hubieras hechola actividad de matemáticas. Alumno: Lo siento, profe. Pero no te olvides que soy un buen alumno, éeh?

Profesora: ya lo veo

(Volta a gopesesentadera): El marcador En realidad presenta una verdad más fuerte, refuerza un argumento frente a otro. El marcador discurssivo ¿Eh? se sitúa en el final de turnos comunicativos para que el hablante indique a su interlocutor que ha terminado de hablar. Es como un pedido de o diấlogo??

(O diálogo seguinte poderá ser interpretado por duas pessoas, indiferente de secc homens ou mulheres) Diálogo 3: Dos amigos

the hue has conseguido un nuevo empleo?

Amigo 2: Si. Ahora recibiré un buen sueldo. De ahi que podré vivir mejor.

Amigo 1: Felicitaciones
Amigo 2: Gracias.

(Volta a appresentadedra): Como ejemplificado, el marcador Oye sirve, entre otras aplicaciones, para introducir una información importante. $Y$ el conector De ahi señala la consecuencia de lo dicho anteriormente. (Ao final da explicação, seria interessante reprisar o diálogo??

(0 diálogo seguinte é a continuação do diálogo anterior. Por isso, deverá ser encenado pelos mesmos atores!

Diálogo 4: Dos amigos

Amigo : : Pues no. Trabajaba mucho y ganaba poco. $O$ sea, no era un buen trabajo.

Amigo 1: De hecho. Comprendo. Vale Felicitaciones.

Amigo 2: Gracis

(Volta a apresentatadera) El conector Pues es muy utilizado en el discurso oral. Es utilizado para reafirmar una opinión. El marcador $O$ sea se utiliza para reformular lo dicho anteriormente, pero con un matiz
conclusivo. Es un marcador muy frecuente, especialmente en el discurso oral. Para expresar la misma idea de este marcador en el discurso escrito, se utiliza el conector es decin.

El otro marcador presentado en el dialogo es De hecho. Su función es reafirmar la idea expuesta diálogo?!

(Volta a apresentadora): En resumen, podemos concluir que los marcadores del discurso: (agora as informaçōes seguintes deverão agparaçec em um quadro, somente com a narração d esentadora).

Son invariables,

La posición en la frase de muchos marcadores es variable, pudiendo aparecer en el inicio,

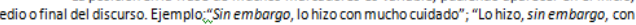
mucho cuidado"; "Lo hizo con mucho cuidado, sin embargo".

especificas de cada registro.

(Volta a apresentadodra): Espero que hayan comprendido todo. Ahora vamos a practicar para reforzar el
Completa los diálogos con los marcadores del recuadro:

¿ęh? - bueno - de ahí que - de hecho - en realidad - o sea - oye - pues - sin embargo - vale

Diálogo 1

Juan: Voy a hacer compras. Vienes conmigo,

Pedro:

Pedro:

Diálogo 2:

Jefe: Quisisera informates que, a partir de hoy, no se permitión mis los retros. quien llegue con retraso será demitido. hay situaciones que no podemos controlar. El tráfico o alguna enfermedad pueden provocar retrasos. ine crees? Carmen (Funcionaria):
prevenir las enfermedades, para evitar problemas.

Diálogo 3

¿no tenías que entregar hoy el trabajo de inglés?

Maria: cY por qué no has ido al cole?

5. Sugestões de imagens e de abordagens

1. Oritmo da Videoaula é diferente do ritmo de um institucional ou de uma peça publicitária para a grande mídia. Portanto, é importante a definição de cenas e sequencias com tempos diferentes, voltadas mais para a fixação qualitativa da informaçăo e menos para a apresentação quantitativa delas.

2. Recomenda-se que durante $O$ vídeo sejam inseridos breaks demarcadores „de mudanças de conteúdos ou blocos, para evitar a linearidade do discurso.

3. Comoesta videoaula faz parte de um programa que inclui outras, deverá ser mantido um padrão, caso seja possivel, em termos de recursos e efeitos sonoros e visuais.

6. Obriqacões e restricões:

2010-2011 


\section{ANEJO 5: PRODUCCIÓN ORAL DOCENTE}

- Anejo 5A: Transcripción ortográfica de producción docente.

- Anejo 5B: convenciones de transcripción ortográfica aplicada en este estudio 


\section{Anejo 5A: Transcripción ortográfica de producción docente.}

\section{PRODUCCIÓN ORAL DOCENTE DE GRADO INF-PROF-1}

Tiempo: 3min.53seg.

Entrevistadora: Grabación de la profesora xxxx ()

Girlene: Entonces vamos empezar hablando un poco a cerca de las signaturas las cosas que están ocurriendo acá () estamos terminando el semestre y entonces los alumnos ya presentaron los proyectos de TCC y también é:: hubo la:: hubo una fiesta para conmemorar el día del libro y:: los alumnos participaron cerca de unos treinta a cuarenta alumnos estaban allá y:: lo/ la cosa más importante del evento fue la premiación de las poesías que fueran veintinueve poesías pero las tres mejores fueran de Brasília la primera y la segunda fue de San Pablo y la tercera que fue de acá () Y portanto solo estaba presente é:: la persona del tercer lugar y el director dice que para este seria dado una beca para un curso de FUNCERN que iba a estudiar lo que quiera () Puede ser que iba a estudiar inglés o español no sé lo que va a elegir pero creo que va a ser el español () Y también é:: ayer fue presen/ fueron presentados los proyectos integradores de los periodos de tercer periodo y quinto periodo () y los alumnos presentaron é:: temas de:: enseñanza de lenguas y muchos de ellos presentaron estrategias para utilizar músicas en clases de español como lengua extranjera en la escuela () otros presentaron juegos () pero lo más interesante fue cuando presentaron telenovelas para la enseñanza de español como lengua extranjera () Entonces las telenovelas mejicanas las:: brasileñas no por que era en portugués y entonces solo consideraban las que estaban en español y entonces/ pero muchos de los brasileños conocen una versión brasileña de las telenovelas mejicanas y entonces para ellos cre/ para los estudiantes creo que va a ser una cosa interesante y::: creo que:: muchos de los alumnos del primer periodo que no/ no:: todavía no/ no::/ no conocían ese tipo de trabajo y entonces para ellos fue más interesante que para los otros alumnos () é::: falta aí () entonces vamos a:: hacer una reunión con los profesores para saber como van a ser las cosas el próximo semestre a causa de los horarios por que muchos de los profesores tienen que é:: estar en clases en nivel superior pero también en el nivel técnico y no hay tantos profesores para hacer las dos cosas pero los directores/ las personas que están arriba dicen que necesitamos estar en los dos sitios () y a causa de eso vamos a ver cuales son los profesores que van a estar sólo en la licenciatura y los que van a estar en los dos. Creo que para los profes de lengua eso es más difícil a causa de la carga de trabajo que nosotros tenemos además de las clases tenemos que orientar los alumnos tenemos que:: é::: orientar traba/ trabajos y otras cosas no sólo en el aula () Terminó? 


\section{PRODUCCIÓN ORAL DOCENTE DE GRADO INF-PROF-2}

Tiempo: $3 \min .54 \operatorname{seg}$.

Entrevistadora: INF-PROF-2

Entrevistada: Bueno yo voy a contar la historia de como::.: llegue a ser profesora de español () Desde niña no me gustaba el inglés () Entonces empecé a estudiar el español y::: me enamoré y entonces estudié un cursos libres y después hice la facultad pero a mi no me gustaría ser profesora sino azafata pe-ro cuando empecé a dar clases de español por que era obliga/ obligatorio en la facultad me enamoré y entonces desde dos mil cinco que soy profesora de español () Intenté alguna::/ algunos concursos y:: trabajé en otra universidad y en Instituto estoy hace tres años () Pero para llegar aquí fue todo muy muy raro muy divertido por que:: no conocía la ciudad y en el día de la prueba de la prueba didáctica yo:: he perdido el::: no sél el canino me olvidé como era y salí por la lluvia hasta la clase () me perdí () No había comido no había dormido entonces estaba totalmente fatal () Pero al final todo funcionó correctamente y trabajo aquí y me gusta mucho () Ahora quiero seguir siendo profesora pero también quiero perfeccionarme más () estudiar () hago el doctorado ya y quiero vivir un tiempo en España por que realmente me gusta el español () Entonces () es eso () a ver ()

Entrevistadora: (posso) contar outra historia?

Carla: Vale otra historia de mi vida () a ver

Entrevistadora: sí alguna historia más

Carla: Vale () una mala () cuando yo tenía diez años () desde niña que yo pasaba/ yo paso las vacaciones en::/ en la casa de mi abuela () Entonces como siempre en una vacacione () una de estas vacaciones me fue a casa de mi abuela y:: mi tía me pidió para volver antes como un mes antes () Entonces volví pero no comprendí muy bien cuando llegué a casa estaba todo muy diferente () No estaba mi papá porque:: estaba enfermo () descubrió un como que un día siguiente a mi viaje entonces descubrió que estaba enfermo y cuando llegué a casa ya no estaba () Estaba en el hospital y no pude visitarlo por que tenía diez años solamente y no querían decirme lo que era () Entonces solo he visto mi papá antes de las vacaciones por que cuando volví ya no estaba en casa y quince días después se moreu y:: mi mamá estaba embarazada y perdió el:: mi hermano la misma época entonces fueron días muy difíciles para todos por que yo tenía un::/ una familia y cuando volví por que ya no tenía hermano tampoco papá y ya no tenía nada más () Pero:: todo fue superado y:: ahora está todo muy bien () Sigo sin hermanos por que mi mamá se ha casado pero no ha tenido más hijos y:: ahora se ha divorciado estamos solamente ella y yo () Pero yo en Natal y ella viviendo solita en Fortaleza () Pero sigue bien y quizá un día cuando esté jubilada venga a viver conmigo aquí en Natal

Entrevistadora: Vale 
Anejo 5B: convenciones de transcripción ortográfica aplicada en este estudio

\begin{tabular}{|c|c|}
\hline SÍMBOLO & SIGNIFICADO \\
\hline- & Pausa breve \\
\hline-- & Pausa larga \\
\hline PALABRA & Secuencia enfatizada \\
\hline Palabra & Pronunciación acelerada \\
\hline Palabra ::: & Alargamiento \\
\hline Palabra I & Secuencia interrumpida \\
\hline Palabra / I & Palabra cortada \\
\hline [Palabra & Solapamiento \\
\hline$=$ & $\begin{array}{l}\text { Continuación de un hablante tras un } \\
\text { solapamiento }\end{array}$ \\
\hline$[=$ & $\begin{array}{l}\text { Solapamiento y continuación de ese } \\
\text { hablante al mismo tiempo }\end{array}$ \\
\hline (inc.) & Secuencia incomprensible \\
\hline (palabra) & Transcripción dudosa \\
\hline ((palabra)) & Comentario del analista \\
\hline Palabra & Cita textual \\
\hline$\uparrow$ & Entonación ascendente \\
\hline$\downarrow$ & Entonación descendente \\
\hline$\rightarrow$ & Entonación continuativa \\
\hline
\end{tabular}

(Tomado de GONZÁLEZ, 2013) 


\section{ANEJO 6: TEXTOS INFORMANTE ENSEÑANZA BÁSICA ELE}

\section{TX-INF-ELE-EB-01}

\section{Las semejoncas e las diferengess entre Brosil y Arogentina}

Aroentina en un Pais muy rico culturalmente hoblonob, orvi coma Brant és Bnoxil. El tongo es la donga más fomerso de Anaentina y es cono cida intennocionolmente comng el simbero moir del Angatina. Eal tango entá poria Angentina wasi como somba está pana Brasil. Lor comidar halfor selire punto en que Araentine is muy fomose. Quién nunce oun

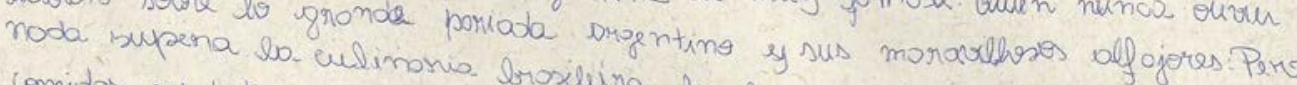
comidas merdestinos.

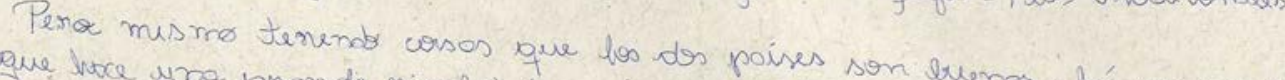

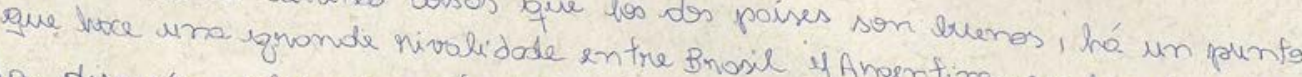
La discusion sobre quen és mejor en duse Iy Angentima, en los desprestes. do, Relé ou Monadona ?Mass ar Neymor? Tixiondo estas' corpas Br.

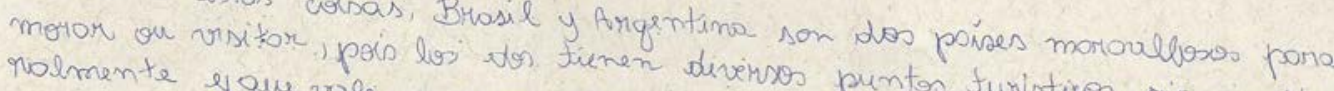

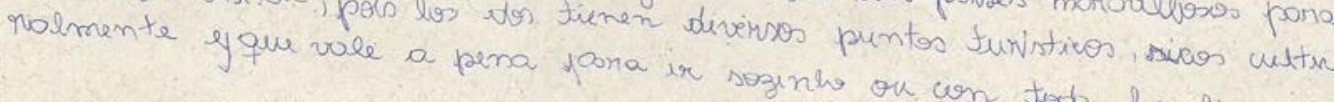

TX-INF-ELE-EB-02

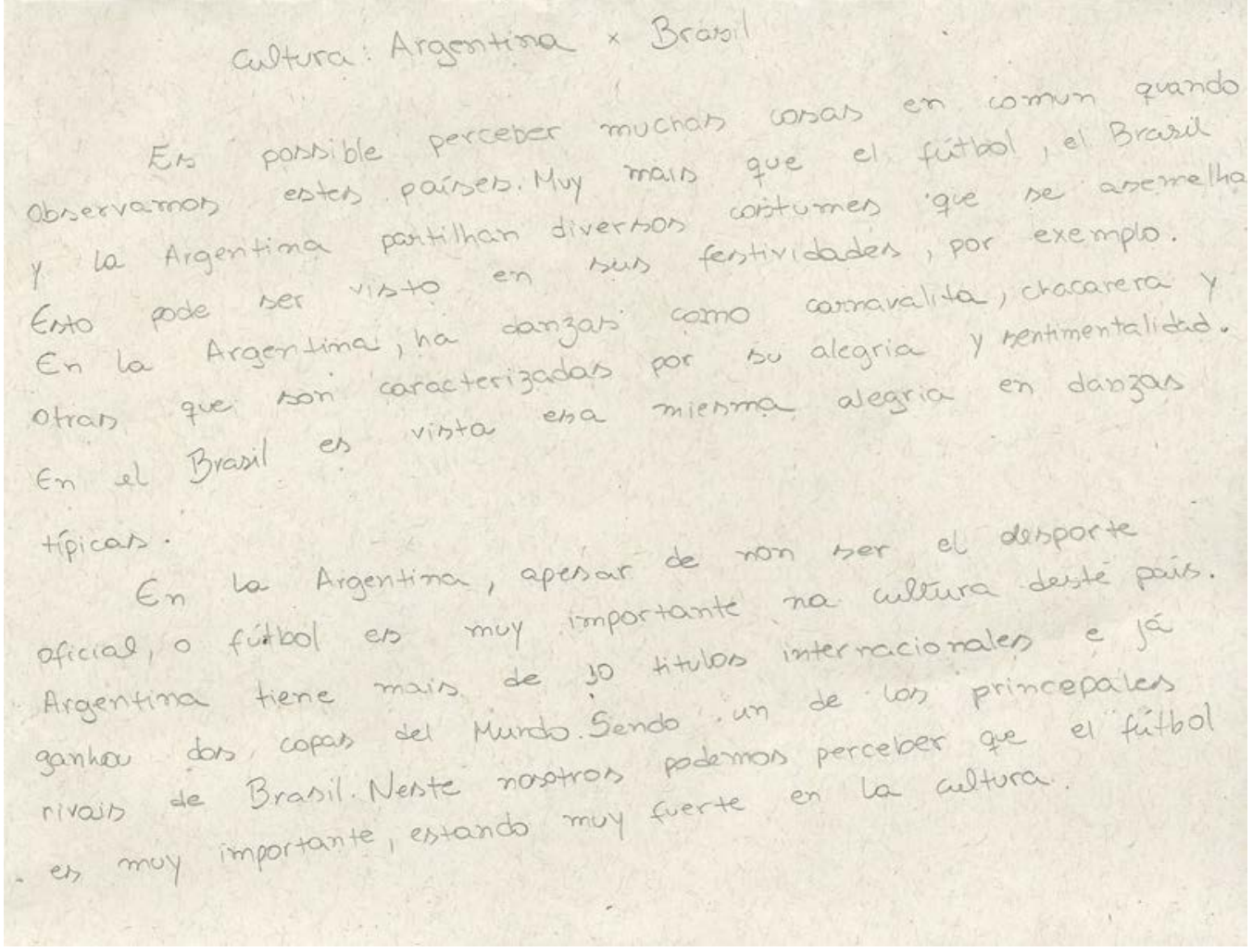




\section{TX-INF-ELE-EB-03}

$$
\text { Lo Angentina y algunos aspertos culturales }
$$

La troentina es una repuldica federal representatioia dusde la Constutuicion Argentina de 1853. ho país está duridido en 23 provín cias y uno sistrito Federal. Bumos tirus. La zapital de la Argentima, Buenos tires tume muchas atractiones y una orquifuctura pare cida con la España.

$$
\text { Arsí, como lo Bragil, la Argentine es famosa por sú fúbíbol, pero }
$$
por timer lo' melor jugado del mundo, hiond Mersi. Y Axi como Bra. zil, la selecion trgentiona de fubbol tiene muchos titules mundiales (25 titulos). La gasteronomya Angentina us difiremte del resto da Amurica Latima, por halcer sido enfluencyado por las culturas Española y Italiona. Pero que los Argentinos amam, asi como en il Brazil uno churrasco, picodo, helado y Nfafor. ho Nfafor es o dulce mas amado por los hermanos.

\section{TX-INF-ELE-EB-04}

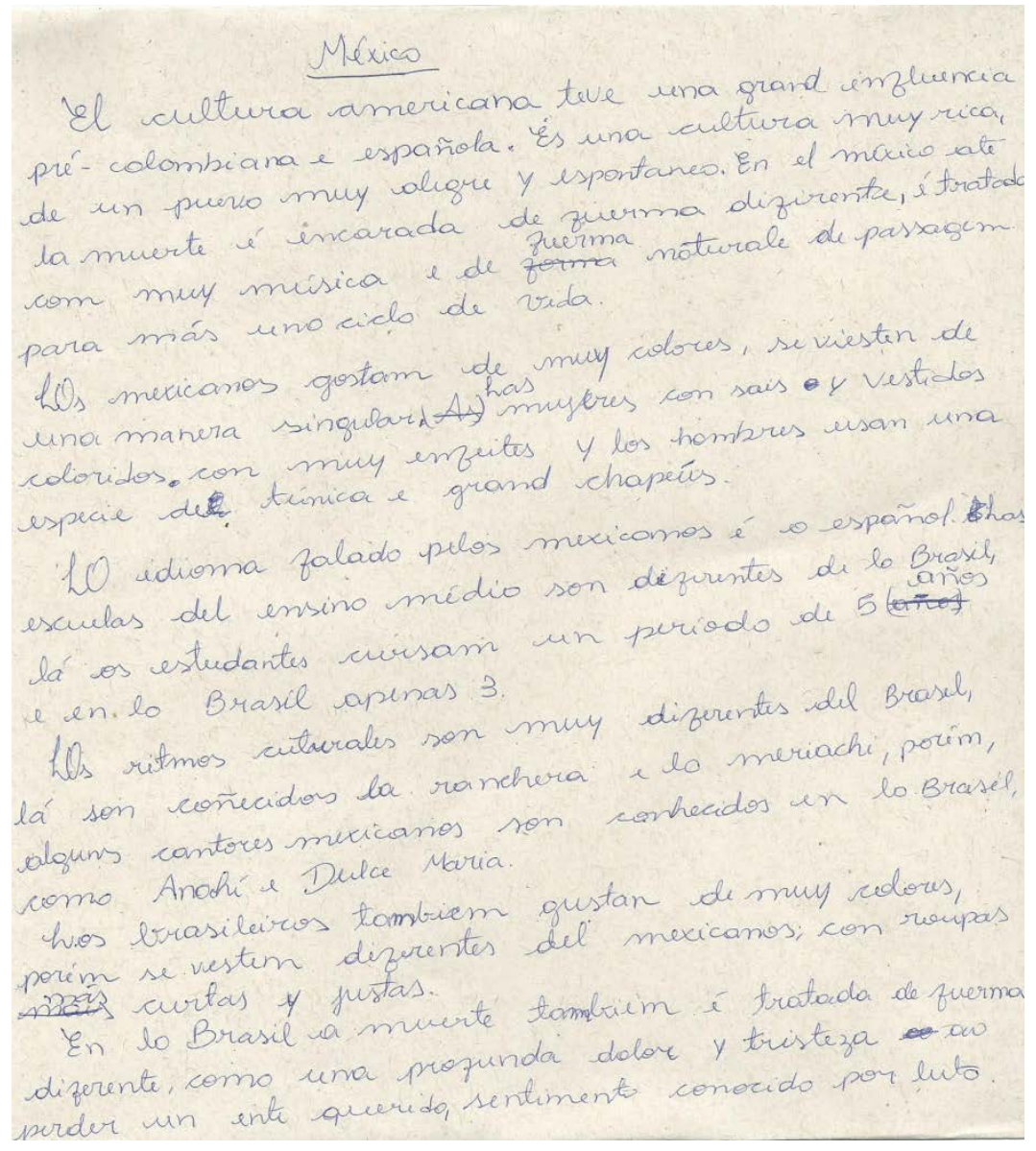


ANEJO 7: PRESENTACIÓN GENERAL DE MARCADORES DISCURSIVOS: DIFERENTES NOMENCLATURAS, DISTINTOS AUTORES TRATADOS

(Tomado de CORRAL, 2010: 22)

\begin{tabular}{|c|c|c|c|c|}
\hline TEORİA & $\begin{array}{c}\text { AUTORES } \\
\text { DESTACADOS }\end{array}$ & TERMINOLOGIA & $\begin{array}{c}\text { TIPO DE } \\
\text { ELEMENTOS }\end{array}$ & DIVISIÓN \\
\hline $\begin{array}{l}\text { LINGÜISTICA } \\
\text { TEXTUAL }\end{array}$ & Halliday y Hasan. & Conjunciones. & $\begin{array}{l}\text { Diferente naturalexa } \\
\text { gramatical. }\end{array}$ & $\begin{array}{l}\text { - Aditivas. } \\
\text { - Adversatives. } \\
\text { - Causales. } \\
\text { - Temporales. }\end{array}$ \\
\hline $\begin{array}{l}\text { Función: construyen } \\
\text { textos coherentes y } \\
\text { cohesionados. }\end{array}$ & $\begin{array}{l}\text { Van D棸 } \\
\end{array}$ & $\begin{array}{l}\text { Conectivos del lenguaje } \\
\text { natural. }\end{array}$ & $\begin{array}{l}\text { Conjunciones } \\
\text { tradicionales y algunos } \\
\text { adverbios. }\end{array}$ & $\begin{array}{l}\text { - Aditivas. } \\
\text { - Disyuntivas } \\
\text { - Condicionales } \\
\text { - Contrastivas. }\end{array}$ \\
\hline $\begin{array}{llr}\text { TEORIA DE } & \text { LA } \\
\text { ARGUMENTACIÓN }\end{array}$ & Anscombre y Ducrot & Conectores angumentativos. & $\begin{array}{l}\text { Diferente naturalexa } \\
\text { gramatical. }\end{array}$ & \\
\hline $\begin{array}{l}\text { Función: instauran } \\
\text { estructuras } \\
\text { angumentativas. }\end{array}$ & $\begin{array}{l}\text { Escuela de Gincbra } \\
\text { (Meceschler, 1985). } \\
\text { En este momento, } \\
\text { trabajan en el aimbito } \\
\text { de h conversación, } \\
\text { aunque con con una } \\
\text { gran influencia de la } \\
\text { Teoria de la } \\
\text { Angumentución. } \\
\end{array}$ & Conectores angumentativos. & $\begin{array}{l}\text { Diferente naturalexa } \\
\text { gramatical. }\end{array}$ & $\begin{array}{l}\text { Dependiendo de su orientacioin, su } \\
\text { valencia y su funcioin: introducción de un } \\
\text { argumento o conclusion. }\end{array}$ \\
\hline $\begin{array}{l}\text { ANALISIS DE LA } \\
\text { CONVERSACIÓN }\end{array}$ & $\begin{array}{l}\text { Escuela de Ginchra } \\
\text { (Roulet et alfi, 1985) }\end{array}$ & $\begin{array}{lll}\begin{array}{l}\text { Marcadores } \\
\text { interactive }\end{array} & \text { de } & \text { funcioin } \\
\end{array}$ & $\begin{array}{l}\text { Diferente naturakera } \\
\text { gramatical. }\end{array}$ & 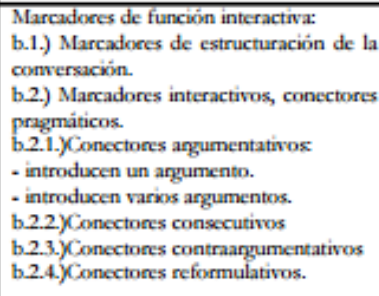 \\
\hline \multirow[t]{2}{*}{$\begin{array}{lrr}\text { Función: unen } & \text { dos } \\
\text { fragmentos } & \text { de } & \text { la } \\
\text { conversación } & & \\
\text { ascgurando } & & \text { su } \\
\text { continuación } & & \end{array}$} & Miche & Conectores priggmáticos. & $\begin{array}{l}\text { Diferente naturakera } \\
\text { gramatical. }\end{array}$ & 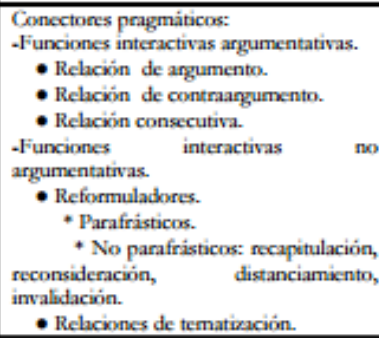 \\
\hline & Roukt (2006) & $\begin{array}{l}\text { Marcadores de relación } \\
\text { textual. }\end{array}$ & $\begin{array}{l}\text { Diferente naturalexa } \\
\text { gramatical. }\end{array}$ & $\begin{array}{l}\text { Ocho relaciones genéricas interactivas: } \\
\text { a) angumento, } \\
\text { b) contrangumento, } \\
\text { c) reformulacion, } \\
\text { d) topicalización, } \\
\text { c) sucesion, } \\
\text { f) preliminar, } \\
\text { g) comentario, } \\
\text { h) clarificación. }\end{array}$ \\
\hline $\begin{array}{lll}\text { TEORIA DE } & \text { LA } \\
\text { RELEVANCIA } & \end{array}$ & $\begin{array}{l}\text { Blakemore } \\
\text { Bate }\end{array}$ & Marcadores del discurso. & $\begin{array}{l}\text { Diferente } \\
\text { gramatical. }\end{array}$ & $\begin{array}{l}\text { a) Concetores discursiros que introducen } \\
\text { implicuiones contextuales } \\
\text { b) Conectores discursivos que refuerzan } \\
\text { supuestos. } \\
\text { c) Concetores discursivos que contradicen } \\
\text { supuestos. }\end{array}$ \\
\hline $\begin{array}{l}\text { Función: orientan el } \\
\text { procesamiento al restringir } \\
\text { las posibles inferencias de } \\
\text { los enunciados. }\end{array}$ & Moeschler & Conectores. 22 & $\begin{array}{l}\text { Diferente } \\
\text { gramatical. }\end{array}$ & $\begin{array}{l}\text { No aparece. } \\
\text { Primero: instrucciones permarias y } \\
\text { secundarias, dificultad para su } \\
\text { clasificacion. } \\
\text { Despucs: traxos fuertes que no clasifice. } \\
\end{array}$ \\
\hline
\end{tabular}


Anejo 7a: Presentación general de Marcadores discursivos: diferentes nomenclaturas, distintos autores tratados en España

(Tomado de CORRAL, 2010: 23-34)

En España encontramos:

\begin{tabular}{|c|c|c|c|c|}
\hline TEORÍA & $\begin{array}{c}\text { AUTORES } \\
\text { DESTACADOS }\end{array}$ & TERMINOLOGÍA & $\begin{array}{c}\text { TIPO DE } \\
\text { ELEMENTOS }\end{array}$ & DIVISIÓN \\
\hline $\begin{array}{l}\text { LINGÜISTICA } \\
\text { TEXTUAL }\end{array}$ & Casado Velarde. & $\begin{array}{ll}\text { Operadores } & \text { discursivos } \\
\text { (1993). } & \text { Marcadores } \\
\text { (1998). } & \text { discursivos } \\
\end{array}$ & $\begin{array}{l}\text { Diferente naturaleza } \\
\text { gramatical. } \\
\end{array}$ & 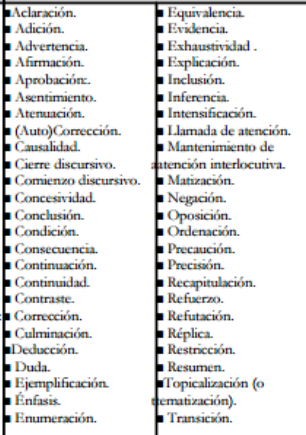 \\
\hline \multirow[t]{6}{*}{$\begin{array}{l}\text { Función: construyen } \\
\text { textos coherentes y } \\
\text { cohesionados. }\end{array}$} & Fucntes & $\begin{array}{l}\text { Enlaces extraoracionalcs } \\
\text { (1987). } \\
\text { Concctores pragmáticos } \\
\text { (1993). } \\
\text { Relacionantes } \\
\text { supraoracionalcs } \\
\text { (1996a]1998). } \\
\end{array}$ & $\begin{array}{l}\text { Diferente naturaleza } \\
\text { gramatical. }\end{array}$ & \begin{tabular}{|l} 
Aditivos. \\
- Opositivos. \\
- Causativos. \\
- Reformulativos. \\
- Temporales.
\end{tabular} \\
\hline & Mederos & Conctivos. & $\begin{array}{l}\text { Diferente naturaleza } \\
\text { gramatical.. }\end{array}$ & (2) \\
\hline & Cuartero & Concctores discursivos. & $\begin{array}{l}\text { Conjunciones } \\
\text { algunos adverbios. }\end{array}$ & (2) \\
\hline & Martínez Sánchez & Conctores. & $\begin{array}{l}\text { Diferente raturaleza } \\
\text { gramatical } \\
\text { conjunciones). }\end{array}$ & \begin{tabular}{|l|} 
Aditivos. \\
Opositivos \\
- Consecutivos. \\
- Temporalcs. \\
\end{tabular} \\
\hline & Cuenca & Conctores. & Diferente naturaleza. & $\begin{array}{l}\text { Composición oracional: } \\
\text { a) Coordinadas. } \\
\text { b) Subordinadas. } \\
\text { c) Interordenadas. }\end{array}$ \\
\hline & & & & \begin{tabular}{|c|c|} 
Conexión textual: \\
a) & Adición. \\
b) & Disyunción. \\
c) & Contrastc. \\
d) & Consccucncia. \\
\end{tabular} \\
\hline $\begin{array}{l}\text { TEORIA DE LA } \\
\text { ARGUMENTACIÓN }\end{array}$ & Briz & Conectores pragmáticos. & $\begin{array}{l}\text { Diferente naturaleza } \\
\text { gramatical. }\end{array}$ & $\begin{array}{l}\text { a.Concctores argumentativos (tres } \\
\text { valores): } \\
\text { a.1.) Monológico fustificación, concesión, } \\
\text { etc.). } \\
\text { a.1.i.) Introducen argumentos. } \\
\text {-Oricntados. } \\
\text { - Cooricntados. }\end{array}$ \\
\hline $\begin{array}{l}\text { Función: instauran } \\
\text { estructuras } \\
\text { argumentativas. }\end{array}$ & & & & 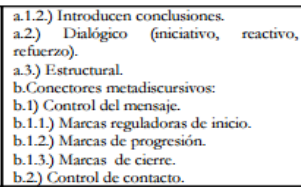 \\
\hline $\begin{array}{l}\text { ANÁLISIS DE LA } \\
\text { CONVERSACIÓN }\end{array}$ & \begin{tabular}{|l} 
Pons Borderia \\
\end{tabular} & Marcadores del discurso. & $\begin{array}{l}\text { Diferente naturaleza } \\
\text { gramatical. }\end{array}$ & \multirow{2}{*}{\begin{tabular}{|l|} 
Marcadores del discurso: \\
a)Conexión: \\
a.1.) Función argumentativa. \\
a.2.) Función metadiscursiva: \\
a.2.1)Estructuración. \\
- Demarcación. \\
- Formulación. \\
- Reguación: inicio, progresión y cierre. \\
a.2.2)Reformulación. \\
b)Modalidad. \\
c)Control de contacto.
\end{tabular}} \\
\hline $\begin{array}{lrr}\begin{array}{l}\text { Función: } \\
\text { fragmentos }\end{array} \text { de } & \text { dos } \\
\text { conversación } & & \\
\text { asegurando } & & \text { su } \\
\text { continuación } & & \\
\end{array}$ & & & & \\
\hline $\begin{array}{ll}\text { TEORÍA DE } & \text { LA } \\
\text { RELEVANCIA } & \end{array}$ & $\begin{array}{l}\text { Martín Zorraquino y } \\
\text { Portolés }\end{array}$ & Marcadores del discurso. & $\begin{array}{l}\text { Diferente naturaleza } \\
\text { gramatical. }\end{array}$ & \multirow{2}{*}{ 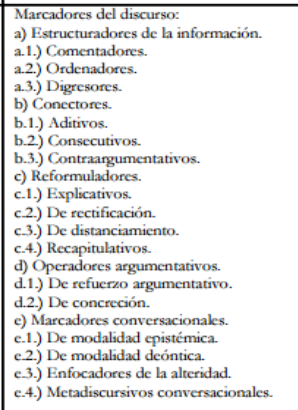 } \\
\hline $\begin{array}{ll}\text { Función: orientan } & \text { el } \\
\text { procesamiento } & \text { al } \\
\text { restringir las posibles } \\
\text { inferencias de los } \\
\text { enunciados. }\end{array}$ & & & & \\
\hline
\end{tabular}

